



\title{
TRATAMIENTO LAPAROSCÓPICO DE LOS DEFECTOS DE LA PARED ABDOMINAL
}

\author{
RELATO OFICIAL
}

$71^{\circ}$ CONGRESO URUGUAYO DE CIRUGÍA

Sociedad de Cirugía del Uruguay

Dr. Gonzalo Estapé Viana

Co-Relator Dr. Nicolás Ramos Serena 


\section{AUTORES}

Dr. Gonzalo Estapé Viana

Ex.Prof. Adj. Clínica Quirúrgica

Unidad Cirugía Endócrina y Pared Abdominal Hospital Pasteur

Dr. Nicolás Ramos Serena

Asist. Clínica Quirúrica 1 Hosp. Pasteur

Unidad Cirugía Endócrina y Pared Abdominal Hospital Pasteur

Dra. Claudia Barreiro Bonifacino

Ex.Prof. Adj. Clínica Quirúrgica

Unidad Cirugía Endócrina y Pared Abdominal Hospital Pasteur

Dra. Gabriela Rodríguez Calvete

Ex. Asist. Clínica Quirúrica

Unidad Cirugía Endócrina y Pared Abdominal Hospital Pasteur

Dr. Juan Sanguinetti

Unidad de Pared Abdominal

Centro Hospitalario Maldonado / San Carlos. ASSE

Dr. Alejandro Soumastre

Residente de Cirugía

Hospital Pasteur

\section{Dra. Isabel Gabito}

Residente de Cirugía

Hospital Pasteur

Dr. Ezequiel M. Palmisano (MAAC)

Rosario, Argentina.

Tutor y Comentador del Relato

Título: Tratamiento Laparoscópico de los Defectos de la Pared Abdominal

Relator: Dr. Gonzalo Estapé Viana

Co-Relator: Dr. Nicolás Ramos Serena

208 p.-; $21 \times 29,5 \mathrm{~cm}$.

Editoral: Grupo Elis

info@grupoelis.com.uy

www.grupoelis.com.uy

Impreso en Uruguay - Printed in Uruguay

Este libro se terminó de imprimir en Noviembre de 2021

Impresión y encuadernación: $\mathbf{0}$ msimpresos

www.msimpresos.com

Tiraje: 250 ejemplares

Depósito Legal Nº 380.312 


\section{INDICE}

PROLOGO

Dr. Daniel Montano Morgade 7

Dr. Ezequiel M. Palmisano (MAAC) 8

INTRODUCCIÓN

Dr. Gonzalo Estapé

¿POR QUÉ CAMBIAR? IMPORTANCIA DEL TEMA Y ASPECTOS HISTÓRICOS

Dr. Gonzalo Estapé

EVOLUCION Y SITUACION ACTUAL DE LA LAPAROSCOPIA EN PATOLOGIA PARIETAL

Dra. Caludia Barreiro

EXPERIENCIA Y EVOLUCIÓN EN URUGUAY

Dra. Claudia Barreiro

BIOMATERIALES PARA USO EN CIRUGÍA LAPAROSCÓPICA DE HERNIAS DE LA PARED ABDOMINAL

Dr. Gonzalo Estapé

CONCEPTOS ACTUALES EN EL DIAGNÓSTICO DE HERNIAS Y EVENTRACIONES

Dra. Gabriela Rodríguez 39

OPTIMIZACIÓN PREOPERATORIA DEL PACIENTE PARA CIRUGÍA PARIETAL

Dr. Gonzalo Estapé

CIRUGIA ROBOTICA EN EL TRATAMIENTO DE LAS HERNIAS DE LA PARED ABDOMINAL

Dra. Gabriela Rodríguez

TAPP VS LICHTENSTEIN EN LA RESIDENCIA: ¿EN QUÉ ESTAMOS?

Dras. Gabito I., Campos M., País C., Haro C.

DOCENCIA Y SIMULACION EN CIRUGIA LAPAROSCOPICA DE HERNIAS DE LA PARED

ABDOMINAL

Dr. Juan Sanguinetti, Dr. Ezequiel Palmisano, Dr. Gonzalo Estapé

TRATAMIENTO LAPAROSCÓPICO DE LAS HERNIAS DE LA REGIÓN INGUINO-FEMORAL

Dr. Nicolás Ramos

TRATAMIENTO LAPAROSCÓPICO DE LA HERNIA INCISIONAL

Conceptos generales e históricos. Dr. Gonzalo Estapé

TRATAMIENTO LAPAROSCÓPICO DE LA HERNIA INCISIONAL

Criterios diagnósticos. Dr. Gonzalo Estapé

TRATAMIENTO LAPAROSCÓPICO DE LA HERNIA INCISIONAL MEDIAL

Dr. Gonzalo Estapé

TRATAMIENTO LAPAROSCÓPICO DE LA HERNIA INCISIONAL LATERAL

Dr. Gonzalo Estapé

ROL DE LA LAPAROSCOPÍA EN LA HERNIA INCISIONAL COMPLICADA

Dr. Gonzalo Estapé

COMPLICACIONES DE LA EVENTROPLASTIA LAPAROSCÓPICA

Dr. Gonzalo Estapé 
TRATAMIENTO LAPAROSCÓPICO DE LAS HERNIAS VENTRALES PRIMARIAS MEDIALES

Dr. Nicolás Ramos

TRATAMIENTO ENDOSCÓPICO DE LA DIASTASIS DE LOS MÚSCULOS RECTOS

Dr. Nicolás Ramos

TRATAMIENTO ENDOSCÓPICO DE LAS HERNIAS VENTRALES LATERALES

Dr. Nicolás Ramos

EXPERIENCIA DE LA UNIDAD DE CIRUGÍA DE PARED ABDOMINAL DEL HOSPITAL PASTEUR

Dr. Gonzalo Estapé

RESULTADOS DE ENCUESTA: CIRUGÍA PARIETAL LAPAROSCÓPICA

Dr. Alejandro Soumastre, Dr. Gonzalo Estapé, Dr. Nicolás Ramos

EL FUTURO EN LA CIRUGÍA ENDOSCÓPICA DE LA PARED ABDOMINAL

Dr. Gonzalo Estapé

AGRADECIMIENTOS

Dr. Gonzalo Estapé Viana 207

Dr. Nicolás Ramos Serena 


\section{PRÓLOGO}

\section{Tratamiento Laparoscópico de los Defectos de la Pared Abdominal}

Cuando se nos confiere la responsabilidad de organizar el Congreso Uruguayo de Cirugía muchas son las decisiones difíciles a tomar, y una de las más importantes es definir que orientación queremos para el Relato Oficial.

El Relato, se ha convertido en un evento central del Congreso, pues en esta instancia se desarrolla el tema elegido y se pone al día el conocimiento sobre el mismo, convirtiéndose en una referencia nacional imprescindible.

Este año el Congreso Uruguayo, se realiza en conjunto con el Congreso Latinoamericano de Cirugía Endoscópica por lo que pensamos incluir un tema vinculado a la laparoscopía.

Dos aspectos debíamos definir para darle brillo al Relato y que resulte un esfuerzo exitoso, primero el tema y luego el relator.

Nos parece que nuestra Sociedad se beneficia en la revisión de temas sobre patologías frecuentes, de alto impacto, que resulten de interés tanto para cirujanos experimentados, como así los que se encuentran en su etapa formativa. Y en este sentido, que mejor que la patología parietal? quizá la de mayor incidencia y con un impacto fuerte en la calidad de vida de nuestros pacientes.

Surge así la idea de abordar el lugar del tratamiento laparoscópico en los defectos de la pared abdominal, como forma de desarrollar los aspectos innovadores de una patología tan frecuente.

En cuanto a la elección del relator no tuvimos ninguna duda, desde el primer momento pensamos en el Dr. Gonzalo Estapé Viana. Lo conocemos desde su etapa de residente, sabemos de la sólida formación que posee en el tema a tratar y en la cirugía en general. Hablar de Gonzalo es poner un ejemplo de cirujano, por su bajo perfil, siempre priorizando lo grupal sobre lo personal, cirujano de equipo, pero no obsecuente, sino todo lo contrario, firme en sus convicciones siempre las mantuvo desde la solidez de su conocimiento y basado en la evidencia de su estudio.

Coordinador de la Unidad Docente Asistencial de Cirugía Laparoscópica del Hospital Pasteur durante muchos años, enseñó esta cirugía a los residentes y cirujanos en formación siendo de los primeros en realizar abordaje laparoscópicos en los defectos parietales y por ello sabíamos que era un tema que conoce profundamente.

$\mathrm{El}$ autor expone las virtudes de este abordaje, y lo coloca en su justa expresión, con sus precisas indicaciones y técnicas. Agradecemos el esfuerzo y dedicación del autor, en especial conociendo dificultades familiares que debió afrontar y sobrellevar y aún así pudo completar la tarea. Sabíamos que no nos defraudaría y nos entrega esta monografía que habría disfrutado mucho su padre, nuestro Profesor el Dr. Gonzalo Estapé Carriquiry quien desafortunadamente no pudo disfrutar ver este éxito de su hijo.

Encontrarán en este trabajo un análisis serio y completo con participación de varios colaboradores que enriquecen el Relato.

Esperamos que sea de agrado de los Congresistas y encuentren un material de referencia donde acudir cuando se enfrenten a pacientes con patología parietal. 


\section{PRÓLOGO}

La cirugía laparoscópica de la pared abdominal se encuentra en un momento de máxima aceptación, cada día más cirujanos apuestan en su formación al desarrollo de habilidades y destrezas en técnicas por accesos mínimos de las hernias, como también vemos una mayor consulta de pacientes requiriendo para su tratamiento acceder a éstas alternativas basados en los reconocidos beneficios sobre su rápida recuperación.

En los últimos años hemos sido testigos de innumerables artículos científicos dedicados al reconocimiento de éstas modalidades terapéuticas con resultados concretos cada vez más alentadores, lo que ha motivado el desarrollo de modelos de entrenamiento y cursos especializados.

Los aportes tecnológicos y de materiales han contribuido al desarrollo de nuevos y seguros procedimientos, sin dejar de lado la cirugía abierta, pues el cirujano debe contar con una gama de alternativas terapéuticas y aplicarlas a la medida de cada paciente.

En definitiva, nuestra responsabilidad como educadores es brindar las herramientas para lograr una formación integral a las generaciones más jóvenes aportando nuestras experiencias en todos los aspectos de la practica quirúrgica, todo se encuentra en permanente evolución y por ello tenemos la obligación de adaptarnos a ella, tal cual como lo expresa aquel refrán que dice: "quienes estén abiertos al aprendizaje se adueñarán del futuro, mientras que aquellos que crean saberlo todo estarán preparados para un mundo que ya no existe".

En las próximas páginas tendrán la oportunidad de sumergirse en un manuscrito que condensa los conceptos más actualizados sobre la cirugía laparoscópica de la pared abdominal, créanme que tendrán resumidos los aspectos más relevantes que los motivarán para iniciarse o avanzar en las técnicas miniinvasivas para la reparación de las hernias, eventraciones y diástasis abdominal.

Por tal motivo felicito sinceramente a los autores por su gran dedicación y trabajo para la elaboración de éste Relato.

Dr. Ezequiel M. Palmisano (MAAC)

Rosario, Argentina. 


\section{INTRODUCCIÓN}

\section{Dr. Gonzalo Estapé}

No por ser una frase habitualmente usada en estas ocasiones, uno puede evitar transmitir el enorme honor, orgullo y satisfacción, que supone ser designado Relator de un Congreso Uruguayo de Cirugía. El reconocimiento de pacientes y colegas (principales motores y objetivos de la práctica médica), ante el desempeño profesional, son sin duda las circunstancias que más alegrías me ha dado mi vida como médico. Seguido a ello, confieso que en mi actividad profesional y académica, no tuve una distinción comparable con esta designación como Relator.

El Relato Oficial del Congreso Uruguayo de Cirugía, hoy incluído reglamentariamente en el programa oficial del congreso anual, comenzó en el 2001, con el brillante y recordado Relato: El Paciente Quirúrgico Crítico confeccionado por el Dr. Oscar Cluzet. A partir de ese año, reconocidos cirujanos nacionales fueron distinguidos con la misión de desarrollar el Relato Oficial, que desde 2009 no tuvo interrupciones y están publicados en la página web de la Sociedad de Cirugía del Uruguay. Esta distinción recae en muy pocos cirujanos de nuestra comunidad quirúrgica, lo que genera una enorme responsabilidad y obliga al desarrollo de cada tema con un nivel de excelencia. Hasta ahora esta premisa se cumplió sin fisuras y el estar a su altura es una de nuestras máximas motivaciones.

Desde ya el agradecimiento al Dr. Daniel Montano por el ofrecimiento de este relato, que hasta hoy recuerdo, se inició con la frase: "Lalo tengo una propuesta para hacerte, a la que no podes decir que NO". Seguramente el no se imagina las sensaciones que generó en mi, la noticia del deber asumir una responsabiliad de tal magnitud. Al orgullo inicial, que lo que asumí como un depósito de confianza extrema, con la implícita obligación del "no fallar", le sigue el temor de no lograr estar a la altura esperada por él y mis pares, y finalmente el agobio de una carrera contra-reloj, para lograr el mejor producto a mi alcance y que este sea de utilidad para la toda la comunidad quirúrgica nacional, desde el Residente al cirujano formado.

Asumo esta distinción personal, reconociendo que en ella están presentes todos los que colaboraron en mi formación personal, médica y quirúrgica; por lo que agradezco, participo y dedico este Relato a mi familia, amigos, colegas y docentes, que anónima y desinteresadamente me ayudaron en esta larga y sacrificada, pero maravillosa carrera.

El desafío de lograr un Relato a la altura del esperado y que se asemeje a los de mis antecesores, me llevó a planificar su desarrollo, de la manera en que sin duda he logrado los mejores resultados profesionales: trabajando en equipo. La extensión y complejidad actual del tema a desarrollar: Tratamiento Laparoscópico de los defectos de la pared abdominal, obliga a un análisis extenso y específico, que difícilmente pueda ser desarrollado por una sola persona.

Así, invité a participar en el Relato, a un grupo de amigos (más que colegas) con los que compartimos la Unidad de Cirugía Endócrina y Pared Abdominal del Departamento de Cirugía del Hospital Pasteur de Montevideo. Luego de años de trabajo en conjunto, cientos de cirugías, y diversidad de experiencias compartidas, era esperable su condicional apoyo y desinteresada colaboración, en este nuevo objetivo científico y académico planteado. Pedí al Dr. Nicolás Ramos, cirujano jóven, con especial y manifiesta dedicación a la patología parietal, que me acompañe como co-relator, función que cumplió en forma brillante. Las Dras. Claudia Barreiro y Gabriela Rodríguez Calvette, con quienes comparto la amistad y la cirugía desde hace muchos años, fueron pilares fundamentales en el apoyo, consejo y escritura de varios capítulos del Relato. Sus conocimientos técnicos y metodológicos, son garantes de la rigurosidad científica del tarbajo. Solicitamos al Dr. Juan Sanguinetti, impulsor de la simulación y el entrenamiento preoperatorio en Uruguay, escriba el capítulo sobre Docencia y Simulación en cirugía laparoscópica parietal. También pedimos la participación a Residentes de cirugía: el Dr. Alejandro Soumastre, colaboró en el desarrollo y análisis de la encuesta realizada; y la Dra. Isabel Gabito, junto con residentes de otros hospitales, analizaron la formación del Residente en Cirugía de la hernia inguinal. Considero de gran importancia la participación de los Residentes y cirujanos jóvenes, población objetivo principal de este Relato y seguros impulsores de estas técnicas. En ellos está centrada la esperanza del desarrollo de la cirugía endoscópica parietal en Uruguay, con manifiesto atraso en comparación con la región y el mundo. Finalmente el agradecimiento al Dr. Carlitos Arévalo, Jefe de Cirugía del Hospital Pasteur, por su incondicional apoyo en esta misión.

El efecto de la pandemia por SARS-COV2 influyó en forma diversa en el desarrollo de este Relato. Por un lado, influyó negativamente dada la disminución de la presencialidad en los centros de salud, y por ello la interacción personal con colegas y pacientes, de tanta importancia en nuestra prácticas clínica; la disminución casi a cero de las cirugías parietales de coordinación, y las que operamos fueron pacientes extremos o con patologías muy complejas; la suspensión de congresos, pasantías y cursos de especialización presenciales y hands on. Por otro lado, la pandemia influyó positivamente por el mayor tiempo disponible para la planificación, estudio y escritura del Relato. A su vez, a pocos meses de establecida la pandemia, se desarrollaron en el mundo, inumerables cursos on line a traves de Webinairs, que nos 
permitió una constante y profusa actualización a distancia y por los máximos exponentes de la cirugía parietal, con una accesibilidad muy amplia a sus trabajos y videos de cirugías. En nuestro caso, la pandemia nos aportó un gran número de conocimientos y experiencias teóricas; pero nos detuvo la experiencia quirúrgica, que habiamos iniciado recientemente con gran ímpetu en nuestro hospital.

En cuanto a mi formación en cirugía laparoscópica parietal, fue escasa en mi Residencia, y mínima durante el desempeño de los cargos docentes y la Jefatura de Residentes. A pesar del interés en la patología, y la participación en congresos y cursos específicos, la experiencia práctica estuvo en el debe. Dadas estas circunstancias, mi experiencia inicial y la curva de aprendizaje, la realicé en el medio privado, donde la cirugía laparoscópica parietal, considerada cirugía laparoscópica de avanzada, está aún gravada, en muchos centros, por un ticket regulador prepago. Por este motivo, la selección de pacientes fue influenciada por el acceso al prepago y alteró el criterio de selección por complejidad progresiva de los casos, situación lógicamente recomendada. En este escenario, solo el cuidado táctico y técnico extremo, con el obvio rechazo de algunos casos complejos que no estaba preparado a tratar, me permitió progresar y lograr una experiencia básica y sin complicaciones, que actualmente intento transmitir a los cirujanos jóvenes.

La experiencia quirúrgica en hernioplastia laparoscópica (solamente TAPP) en nuestra Unidad en el Hospital Pasteur, comenzó en el 2019, siendo hasta esa fecha, anecdóticas las hernioplastias laparoscópicas realizadas. Los motivos de este atraso fueron: falta de estímulo y apoyo por parte de las autoridades académicas, escasas horas de sala de operaciones como para iniciar una curva de aprendizaje, evitar la disminución de cirugías a los residentes más jóvenes, dificultad en acceder a los costosos medios de fijación de mallas, ausencia de tutores, descreimiento de la técnica laparoscópica y excelentes resultados con la hernioplastia de Lichtenstein. El análisis de estos motivos, que sabemos son discutibles y algunos muy difíciles de explicar, exceden a los objetivos de este Relato.

Recién en Julio de 2021, con la estabilización de la pandemia en Uruguay, se reinició la cirugía parietal electiva en nuestro Hospital, solo para pacientes que cumplieran los requisitos de la cirugía ambulatoria. Así se retomó el programa establecido de desarrollo de la hernioplastia laparoscópica, para la formación de cirujanos tutores y la experiencia inicial como cirujanos, de los Residentes mayores. En esta etapa, reconocemos el mayor apoyo institucional y académico, que se traduce en un proceso seguro, progresivo y sin interrupciones. Esta breve experiencia en número de pacientes y corto seguimiento, se expondá en el capítulo de Casuística.

\section{Definiciones y Delimitación del tema}

Dado lo amplio del tema de la patología parietal en su conjunto, por su diversidad y creciente estudio y avance del conocimiento en las mismas, limitaremos este relato al tratamiento mininvasivo/ laparoscópico/ endoscópico de las mismas. Incluímos en este Relato, bajo el título de Técnicas Laparoscópicas, que estrictamente contemplarían, solo las que abordan la cavidad peritoneal (TAPP, IPOM y sus variantes); a técnicas endoscópicas parietales que no traspasan el peritoneo (TEP, eTEP, separación endoscópica de componentes); y técnicas mini-invasivas abiertas o híbridas que cumplen los mismos preceptos y beneficios que las técnicas precedentes (MILOS, eMILOS). Si bien el término ideal sería agruparlos como Técnicas Endoscópicas o Video Asistidas, en nuestro medio son mejor conocidas con el término Laparoscópicas.

Analizaremos someramente los aspectos no terapéuticos, que consideramos de mayor interés por novedosos o por su implicancia fundamental en la decisión de los aspectos terapéuticos.

Desarrollaremos principalmente el tratamiento laparoscópico (endoscópico) de hernias y eventraciones abdominales, en los que la comunidad quirúrgica y la evidencia científica, concuerden en tener buenos resultados y con seguridad para el paciente.

Excluimos el manejo de los pacientes con una situación parietal o abdominal previa compleja, grandes hernias y eventraciones y las eventraciones paraostómicas. Aquí la cirugía laparoscópica es discutible, dificultosa y solo desarrollada en centros de alta especialización en el tema.

Analizaremos en forma muy resumida las recomendaciones actuales de las técnicas Robóticas en patología parietal, dado el nulo desarrollo local en estas técnicas y nuestra impresión de la lejanía en la incorporación de las mismas.

\section{Objetivos del Relato}

Este Relato no intenta, ni lograría, ser un tratado de terapéutica quirúrgica. Si pretende facilitar el abordaje del tema, con una presentación esquemática, práctica y actualizada, adecuada a la situación actual de la cirugía laparoscópica de la pared abdominal en Uruguay. 
Reconociendo el poco desarrollo y experiencia sobre el tema en nuestro medio, este Relato se basa en trabajos y experiencias internacionales, muy difundidas y accesibles en la actualidad. Los numerosos estudios científicos de calidad, consensos y guias clínicas, que reunen la mejor evidencia científica disponible y realizan recomendaciones prácticas, concretas y seguras, fueron la base de la organización, desarrollo y recomendaciones finales de este Relato.

Los objetivos generales son:

- presentar, a los cirujanos Uruguayos, el estado actual del abordaje laparoscópico en el tratamiento de los defectos de la pared abdominal.

- estimular el desarrollo de estas técnicas en Uruguay, basados en su reconocida efectividad y seguridad para el paciente.

Los objetivos específicos son:

- presentar los nuevos criterios de clasificación, optimización y estudio de los pacientes para cirugía parietal abdominal;

- definir las indicaciones actuales y específicas a cada patología, de las técnicas laparoscópicas;

- describir las técnicas endoscópicas y laparoscópicas para tratar hernias y eventraciones;

- analizar las complicaciones de cada técnica y los fundamentos para prevenirlas (formación, simulación, entrenamiento, detalles de técnica quirúrgica).

El público objetivo principal son los cirujanos en formación y residentes de cirugía. Como ya mencionamos, ellos serán los encargados de impulsar y desarrollar estas técnicas, intentado remedar el franco retraso en la utilización de las mismas en nuestro medio. El demostrar el amplio uso y seguro desarrollo de estas técnicas en otros medios, con el camino formativo trazado, seguramente les permitirá la deseada extensión de las mismas. Los cirujanos jóvenes, nacidos en la era digital y formados desde su inicio en el abordaje laparoscópico de la mayor parte de las patologías abdominales, están en inmejorable situación para lograr este avance terapéutico que generará un amplio beneficio para nuestros pacientes.

\section{Formato del relato}

Dentro de la agrupación habitual por patología, se jerarquizarán los puntos claves, novedades o topicos discutibles del tema, con analisis profundo del problema, evidencia científica disponible y recomendación actual. La Bibliografia será por capítulo. Se realizará un análisis breve y conceptual de cada trabajo seleccionado como valioso.

Se analizará toda la evidencia nacional accesible (Biblioteca de la Sociedad de Cirugía del Uruguay), trabajos internacionales de referencia, guías, consensos, con énfasis en trabajos recientes (2010 en adelante), latinoamericanos (por compartir realidad económica, social) o muy citados. Recurrimos a la valiosa ayuda de la Lic. Cecilia Valenzuela, quien nos aportó gran parte de la bibliografía que manejamos en este Relato, por lo que le estamos profundamente agradecidos.

\section{Encuesta Nacional y del grupo easy lap.}

La encuesta a distancia fue difundida a través de los diversos grupos quirúrgicos de WhatsApp locales e internacionales disponibles. Titulada como Cirugía Parietal Laparoscópica, el objetivo fue evaluar la situación de los cirujanos sobre su formación académica y práctica, experiencia asistencial, resultados y posibilidad de desarrollo en los medios donde actúan. Expondremos y analizaremos los resultados obtenidos.

Finalmente agradezco a través de sus presidentes: Dr. Daniel Montano y Dr. Gustavo Rodríguez, al Comité Organizador del 71 Congreso Uruguayo de Cirugía y del 14 Congreso de la Asociación Latinoamericana de Cirugía Endoscópica (ALACE), por la confianza depositada y el apoyo brindado en la realización de este Relato. Agradezco también a la Sra. Lourdes Alanís y demás integrantes del Grupo Elis, empresa organizadora del congreso, por su disposición, eficiencia y invalorable ayuda.

Especial reconocimiento y agradecimiento al Dr. Ezequiel Palmisano. Cirujano Argentino reconocido a nivel internacional por su especialización en la patología parietal y en sus abordajes endoscópicos, en los que realiza valiosos y frecuentes aportes. Amigo del Uruguay, donde concurrió en varias oportunidades a compartir su experiencia, dejando valiosas enseñanzas y fundamentalmente, estimulando al desarrollo y extensión de las técnicas endoscópicas para la hernia inguinal. Considerando estos antecedentes, le solicité su consejo para la confección del Relato, así como la invitación a comentarlo en nuesto Congreso, solicitudes a las que tuve su inmediata aceptación. Sé que invirtió muchas horas de su valioso tiempo en la tutorización del trabajo y soportando nuestras reiteradas consultas, aportando generosamente correcciones y sugernencias que sin duda enaltecen al Relato. Gracias Ezequiel!!! 


\title{
¿POR QUÉ CAMBIAR? \\ IMPORTANCIA DEL TEMAY ASPECTOS HISTÓRICOS
}

\author{
Dr. Gonzalo Estapé
}

Las defectos de la pared abdominal, hernias y eventraciones, constituyen unas de las patologías más frecuentes de la práctica quirúrgica y determinan un porcenteaje alto de los procedimientos quirúrgicos que realizamos. Así, toda propuesta de cambio en su manejo peri-operatorio, planteados para mejorar la calidad de la asistencia del paciente, determina importantes modificaciones asistenciales. Estos cambios afectan la disponibilidad de estudios, materiales y equipamiento quirúrgicos, formación del cirujano, aceptación y manejo de nuevas complicaciones y cambios en la ecuación de los costos asistenciales.

Es muy frecuente que se considere una hernia como un cirugía simple, sin complicaciones potenciales y de relleno en las coordinaciones quirúrgicas. Sin embargo su alta frecuencia y las múltiples variaciones clínico patlógicas y terapéuticas, sitúan esta patología en un sitial de alta preocupación de pacientes, cirujanos y gestores de salud. Además, la patología herniaria es realizada por un amplio número de cirujanos con diversa especialización, por lo que los resultados serán heterogéneos a igual patología.

El interés en la confección de este relato: Tratamiento laparoscópico de los defectos de la pared abdominal, acompaña el histórico y mantenido trabajo de la comiunidad sanitaria en su conjunto, de lograr el manejo ideal de la patología herniaria de la pared abdominal. Al término ideal, lo definimos como el procedimiento quirúrgico que demuestre los mejores resultados en: eficacia, seguridad para el paciente, complicaciones, calidad de vida y relación costo-beneficio.

\section{¿Por qué cambiar? ¿Qué aportan las técnicas endoscópicas?}

La cirugía parietal por vía anterior o abierta, que es "patron de oro" para la mayoría de los cirujanos (especialistas o no) y para la mayoría de las patologías parietales, se compara, como en casi todas las cirugías abdominales, con los resultados beneficiosos de las cirugías mini invasivas, en este caso: laparoscópicas y endoscópicas. Las técnicas abiertas, que también presentan constantes avances que mejoran sus resultados en todos los aspectos, presentan excelentes y comprobados resultados asistenciales, y son aceptadas universalmente por cirujanos, pacientes y prestadores de salud.

Existen múltiples interrogantes que deben responderse previo al desarrollo del Relato. Sin responder aquí estas interrogantes, es posible que para muchos cirujanos, no sea atractivo, ni encuentren la justificación para continuar su lectura.

Respondemos con la evidencia al 2021, plasmado en las guías clínicas internacionales y en las conclusiones de grandes series habitualmente de centros especializados (los trabajos serán analizados en cada capítulo específico).

1) Son mejorables los resultados quirúrgicos de la hernioplastia con técnica de Lichtenstein para la hernia inguinal primaria (facilidad, recidivas, complicaciones, dolor agudo y crónico)?

Puede mejorar los resultados quirúrgicos en situaciones específicas (hernias bilaterales, deportistas, obesos, recidivas de Lichtenstein) y será comparable en el resto de las hernias primarias. Las técnicas laparo-endoscópicas son más difíciles de aprender y reproducir, tienen igual tasa de recidivas, menor morbilidad global pero eventualmente de mayor gravedad, y menor dolor agudo y crónico.

2) Son mejorables los resultados socio-laborales y de costos de la hernioplastia con técnica de Lichtenstein para la hernia inguinal primaria (reintegro laboral y social, y costo total del procedimiento a corto y largo plazo)?

$\mathrm{Si}$. Las técnicas laparo-endoscópocas permiten más rápida reinserción social, laboral y sexual; los costos iniciales son algo mayores, lo que se invierte si se consideran los parámetros laborales y a largo plazo.

3) La curva de aprendizaje para las técnicas endoscopica y laparoscopicas, condicionan la extensión de las técnicas?

Si. La más larga y compleja curva de aprendizaje de estas técnicas condiciona su extension a mayor número de centros y cirujanos. Es esperable que la rápida inserción de los cirujanos jóvenes a estos procedimientos, las mejoras en las técnicas quirúrgicas y de accesibilidad (menores costos) de equipos e instrumental, la simulación y la experiencia acumulada, permitan a corto plazo superar este escollo actual. 
4) Cual es el lugar para la eventroplastia laparoscopica considerando la estricta selección de pacientes, mayores costos y grado entrenamiento que requiere?

El lugar es creciente dadas las claras ventajas de estas técnicas en situaciones cada vez más frecuentes en la actualidad: eventraciones menores de 5-6 cm (cirugía laparoscópica extendida en todas las especialidades quirúrgicas), pacientes obesos y/o con comorbilidades. Los costos y el entrenemiento, actualmente son un escollos con alta espectativas de ser superadas en los próximos años.

5) Los prestadores de salud aceptarán estas técnicas? Mantendrán el prepago?

La aceptación de las técnicas endoscópicas es un hecho, dada la evidencia de que, cuando la indicación es adecuada, los resultados globales son al menos iguales que los de las técnicas abiertas. Los tiempos operatorios, tasa de complicaciones y satisfacción del usuario, son los parámetros principales que consideran los prestadores, y que ya presentan números favorables.

A igual remuneración quirúrgica, los costos son similares entre ambos abordajes, siendo las mallas bilaminares y los sistemas de fijación de la malla los parámetros a considerar. La menor morbilidad y corta hospitalización de las técnicas endoscópicas, acortan esta brecha económica. Consideramos NO justificado el ticket prepago para el tratamiento de hernias inguinales y a estudiar con detalle y en forma individualizada, el tratamiento de las eventraciones que requieran mallas bilaminares y tackers como sistema de fijación.

6) Son extrapolables los resultados internacionales a nuestro medio?

Es probable que aún NO. Los resultados dependen de la curva de aprendizaje tutorizada y la experiencia en cirugía parietal y laparoscópica. En Uruguay recién se inicia la experiencia en algunos centros, hay pocos tutores y se crearon las primeras Unidades de Cirugía Parietal. En los próximos años estaremos en coindiciones de acercar nuestros resultados a los de los centros más especializados, al menos en el tratamiento de la hernia inguinal.

7) Que tipo de cirujano operará cirugía parietal laparoscópica?

Estas técnicas, a veces complejas y de avanzada, deben ser operadas por cirujanos entrenados tanto en cirugá parietal abierta como en laparoscopía de avanzada. La necesidad de la reconstrucción anatomo-funcional de la pared abdominal, estabilizando las presiones toraco abdominales, la mecánica respiratoria y el giro y flexión del abdomen, implica más que operar una simple hernia. El conocimiento de la anatomía, los biomateriales y las diferentes tácticas y técnicas operatorias, obligan a integrar Unidades de cirugía parietal para tratar muchos casos de defectos parietales.

\section{Importancia del tema}

La patología herniaria de la pared abdominal, constituye un tema central en la práctica médica habitual de los cirujanos. La especialización en esta patología en busca de resultados óptimos, estimuló la formación de cirujanos especialistas, grupos, seccionales, congresos, revistas, capítulos en sociedades científicas; con alta o exclusiva dedicación al tema, con valiosos avances en todas las áreas y su traducción en una gran producción cientifica. Existen numerosos cursos de anatomía endoscópica, videos en internet de alta calidad, grupos especializados en Redes Sociales, cursos Hands On, y un contacto estrecho con la industria que perfecciona y hace más accesibles los biomateriales necesarios para cirugía parietal. Hoy las Unidades de Cirugía Parietal son una realidad y están presentes el muchos de los Servicios de Cirugía.

La alta frecuencia de esta patología, en todas las etapas de la vida, y con una enrome variabilidad de: presentaciones, formas clínicas, riesgos de complicaciones, tácticas de manejo medico-quirúrgico, entre otras; supone una gran complejidad en encontrar la formula de estandarizar el tratamiento de estos pacientes.

El creciente y justificado interés de los pacientes, en pretender unas adecuada calidad de vida, aumentó el número de consultas y requerimiento de solución definitiva de su patología, cuando lo afectan: el dolor, miedo de complicaciones o motivos estéticos y funcionales.

El aumento global de la expectativa de vida, supone también incluir pacientes añosos y con mayor morbilidad en el universo a taratar, dado que los síntomas afectan la actividad física, de gran importancia en ellos, y es donde eventuales complicaciones agudas suponen mayor morbimortalidad anestésica y quirúrgica, así como intentar brindarles el tratameinto con menor morbilidad posible.

La presencia (causalidad o inicio de sintomas) de la patología herniaria en el período laboral activo, tambíen la impone como foco de interés en el área laboral: Compañías (o instituciones) de Seguros Médicos (Cajas auxilio y BPS), Certificadoras de salud (BPS/BSE), y equipos de medicina laboral, incorporados actualmente en forma obligatoria 
en gran número empresas. Estos, estudian minuciosamente y cuantifican las implicancias económicas y de jornales de trabajo afectados por esta patología, por lo que frecuente y sostenidamente, intentan influir en el manejo de la misma. Es conocido, que muchos de los estudios científicos para lograr avances en el desarrollo de técnicas, instrumental y materiales médicos, fueron estimulados y solventados económicamente por estas compañias, con el doble objetivo de mejorar los resultados terapéuticos de la patología herniaria, lo que supondrá menos costos asistenciales y más rápido reintegro laboral.

De esta manera, gran parte de la patología herniaria de la pared abdominal, se trata actualmente bajo dos conceptos que demostraron ampliamente sus beneficios para los pacientes, instituciones de salud y seguros médicos: tratamientos mediante técnicas mininvasivas y en sistema de cirugía ambulatoria. En estos, se busca: minimizar las complicaciones agudas (dolor, hemorragias) y alejadas (dolor crónico y recidivas), internación hospitalaria (implicancia social/familiar, costos en salud y riesgo de infecciones) y días de convalescencia postoperatoria hasta el reintegro laboral y social ad integrum.

\section{Epidemiología ${ }^{(1)}$}

La alta incidencia de hernias de la pared abdominal, hernias y eventraciones, convierte a esta patología en un importante problema de salud pública en todo el mundo.

En adultos se estima una prevalencia para la hernia inguinal primaria de entre 5-15\%, con una proporción de hombre/ mujer de 12/1. En los hombres la frecuencia aumenta con la edad, mientras que en la mujer se mantiene constante a partir de los 40.

Se estima que anualmente se reparan alrededor de 20 millones de hernias en todo el mundo, 700.000 en Estados Unidos y más de 100.000 en el Reino Unido. Esto implica unos gastos significativos y una importante carga de morbilidad. Según el Sistema de Información de Listas de Espera del Sistema Nacional de España, los pacientes en lista de espera de hernia inguino-crural, son el segundo proceso quirúrgico más frecuente, solo detrás de la catarata; por delante de artroscopia, hallux valgus, adeno amigdalectomía, varices o colecistectomía.

Recientes estudios epidemiológicos sobre la frecuencia relativa de las hernias ventrales han evidenciado el siguiente orden: inguinal (70-75\%), umbilical, epigástrica, incisional, paraumbilical, femoral, y finalmente otros tipos.

Se calcula que la frecuencia de la hernia incisional o eventración está entre el 12-15\% de todas las laparotomías efectuadas, aumentado su frecuencia hasta el $23-40 \%$ en caso de que exista infección añadida de la herida quirúrgica.

Se considera que en un Hospital General, el porcentaje de cirugía de pared abdominal es de un 12-15\%, correspondiendo aproximadamente el 7-10\% de ellas, a hernias incisionales, si bien este número cae en forma sostenida ante el deserrollo cada vez más extendido de la cirugía y procedimientos mininvasivos. En esta patología, la prevención es el objetivo primario, evitando así, defectos anatomo-funcionales crónicos, cirugías con morbilidad considerable y altos costos asistenciales.

\section{HISTORIA}

"La cirugía mínimamente invasiva, la siguiente revolución después de la asepsia y de la anestesia, surgió con la intención de disminuir o eliminar los lastres de la cirugía abierta (el dolor, la incapacidad, las hernias del sitio de la incisión, las adherencias y sus consecuencias, como la obstrucción intestinal e infertilidad, la respuesta metabólica al trauma, etc.). Sin embargo, para lograr su cometido se necesitan condiciones especiales de entrenamiento, como una tecnología adecuada, un equipo de trabajo eficiente y una predisposición personal. Nunca la cirugía abierta ha sido sometida al tipo de escrutinio al que lo ha sido la cirugía laparoscópica; no obstante, los resultados en centros especializados han sido excelentes". Jorge Daes ${ }^{(2)}$

Leonard S. Schultz en 1990 presenta la primera serie de reparaciones herniarias por vía laparoscópica con una prótesis de polipropileno en el espacio preperitoneal (TAPP). J. Barry McKernan en 1992, ha sido el impulsor del desarrollo y la utilización de la vía totalmente extraperitoneal (TEP) en el tratamiento laparoscópico de la hernia. En 1993, ${ }^{(3)}$ Le Blanc, Henniford, Park, Ranshaw y Voeller iniciaron la era de la reparación laparoscópica de la hernia ventral con la técnica intraperitoneal onlay mesh (IPOM). Los primeros accesos mediante la técnica eTEP para la reparación de hernias inguinales, se llevaron a cabo por Jorge Daes en el 2009.(4) Poco tiempo después, también Daes describe la utilidad del eTEP para reparar hernias ventrales primarias e incisionales y el acceso directo mediante el abordaje eTEP 
por fuera de la línea semilunar, para el reparo de las hernias lumbares. Daes describe luego el abordaje endoscópico para la separación anterior de componentes como adyuvante del cierre parietal ${ }^{(5)}$. Igor Belyansky $y^{(6)}$, describe la maniobra de cruce de la línea media (crossover), que permitió la implementación de la técnica eTEP Rives-Stoppa y de la eTEP-Transversus Abdominis Muscle Release, las cuales han sido aplicadas en varios centros hospitalarios del mundo para el tratamiento de hernias ventrales complejas.

A pesar de las ventajas del acceso laparoscópico, su implantación y consolidación no ha sido homogénea, especialmente en técnicas laparoscópicas avanzadas, siendo la cirugía de la pared abdominal un claro ejemplo de ello. Se han demostrado sus ventajas en el tratamiento de la hernia inguinal siendo, para muchos, el abordaje de elección para la hernia bilateral y recidivada. ${ }^{(7)(8)}$

Sin embargo, Moreno-Sanz et al. ${ }^{(9)}$ refieren con respecto a la hernia inguinal, que el 64\% de los cirujanos españoles nunca utiliza la cirugía endoscópica para la reparación de la hernia inguinal, el 30\% lo hace de manera ocasional y solo el 6\% la realiza habitualmente. Estas cifras contrastan notoriamente con las publicadas en EE.UU. y Europa, donde los registros realizados en Francia y Alemania refieren que la hernioplastia laparoscópica se lleva a cabo en un 25-28\%, mientras que en Dinamarca, Holanda, Reino Unido e Italia se sitúa entre el 15-18\%. Además, en algunos de estos países, la hernioplastia laparoscópica supone más del $40 \%$ de los procedimientos en hernia recidivada y bilateral.

En el caso de la hernia incisional, el mismo trabajo muestra que los resultados en España tampoco son alentadores: la utilización rutinaria asciende al 10\%, el 49\% selecciona su utilización y un $41 \%$ nunca la contempla. ${ }^{(9)}$

Cifras del Registro Nacional de Eventración de España, con casi 3.000 casos registrados, muestra que solo un 12,8\% de las reparaciones son laparoscópica; ${ }^{(7)}$ mientras que en EE.UU. son en un 26- $28 \%,{ }^{(10)}$ y el registro danés refiere un $54 \%$ de reparaciones laparoscópicas con un índice de recidiva menor que las reparaciones abiertas y, concluyen, que la vía laparoscópica aporta beneficios para los pacientes siendo, además, costo-efectiva. ${ }^{(11)}$

Hay diversos motivos que han contribuido en mayor o menor grado a esta anómala situación: la poca predisposición a iniciarnos en un procedimiento nuevo, con una exigente curva de aprendizaje; el desconocimiento por parte de la mayoría de cirujanos de la vía preperitoneal abierta en la hernia inguinal; y un costo económico superior, especialmente si se utiliza material de un solo uso. Frecuentemente, la hernia es una patología de relleno de programas quirúrgicos, incentivando únicamente la cantidad de procedimientos a realizar en vez de la calidad de estos. ${ }^{(7)}$ Estos conceptos definidos en la situación Española, son extrapolables al Uruguay.

En EE.UU. y Europa se insistie fundamentalmente formación laparoscópica en pared abdominal, donde se ha incluído en el currículum formativo del residente, haciéndose especial énfasis en que obtengan las habilidades técnicas laparoscópicas necesarias y un adecuado conocimiento anatómico de la pared desde este acceso, que es diferente al que estaban familiarizados por vía anterior. ${ }^{(12)}$

El uso de simuladores ha demostrado ser de utilidad, ya que permite la obtención de estas mejoras en técnicas laparoscópicas. Con ello se minimiza la curva de aprendizaje al no realizarse en pacientes, no precisan una supervisión permanente y optimizan el uso del quirófano.

\section{Cómo mejorar la situación de la hernioplastia laparoscópica: ${ }^{(7)}$}

Cursos teórico-prácticos y supervisión de los primeros casos por cirujanos expertos, como mejor manera de reducir la curva de aprendizaje y facilitar el dominio de la técnica

Entrenamiento adecuado: incluir la cirugía laparoscópica de la pared abdominal en la formación del residente y creación de centros de referencia formativos.

Cambiar el concepto de que la hernia es patología de relleno de programas quirúrgicos, incentivando la calidad de la reparación sobre la cantidad de estas y manejadas por unidades de pared abdominal especializadas.

\section{Dificultades y como mejorar la situación de la eventroplastia laparoscópica:(2)}

La falta de entrenamiento en laparoscopia avanzada, así como su mayor costo directo, son motivos por los que la eventroplastia laparoscopia no tenga una mayor implementación.

La deficiencia de la medicina basada en la evidencia en aportar respuestas definitivas a los problemas del reparo ventral, en gran parte debido al número inmenso de variables involucradas, hace que un aprendizaje global no tenga aplicación local. Son la experiencia, la evaluación de los procesos y la mejoría clínica continua las que tienen mayor influencia a 
nivel local y regional. Un factor como la destreza individual hace que un método sea mejor en un centro hospitalario específico, a pesar de que la evidencia no lo avale.

Faltan procesos de selección adecuada de pacientes para una técnica específica, a pesar de los esfuerzos en esta dirección por parte de los consensos internacionales. Existe un gran grupo de pacientes para los que no sabemos cuál es la mejor alternativa.

Falta la estandarización de las técnicas quirúrgicas de la reparación de hernias. En gran parte se debe a la rápida adopción de nuevas técnicas, insumos y tecnología a un ritmo tal que no nos permite su evaluación adecuada, la comparación de resultados con otros grupos o incluso el establecimiento de la causa exacta de la mejora en los resultados o de una complicación. No obstante, la estandarización se ha implementado con éxito en otras áreas de la cirugía.

El reparo laparoscópico de la hernia ventral ha evolucionado significativamente desde sus comienzos, lo que nos permite mejorar la morbilidad y la calidad de vida de nuestros pacientes, cuando se practica en las circunstancias y ambiente adecuados. Su futuro se presenta prometedor en la medida en que se mejore la enseñanza de destrezas, se desarrolle la tecnología que incluye la robótica (con la tendencia natural a que disminuya su costo y complejidad actuales), se refine la utilización de las redes sociales para la educación en cirugía de hernia, se continúe implementando la especialidad en este campo quirúrgico y se encuentren mejores alternativas para la evaluación científica de los resultados obtenidos. ${ }^{(2)}$

\section{BIBLIOGRAFÍA}

1) López Quindós P, García Ureña MA. Castellón Pavón C. Concepto, epidemiología y clasificación de las hernias inguino- crurales primarias y recidivadas 26:281-288 Guías Clínicas de la Asociación Española de Cirujanos Cirugía de la Pared Abdominal 2a Edición 2013

2) Evolución de la reparación laparoscópica de las hernias ventrales y del sitio de la incisión Jorge Daes rev hispanoam hernia. 2016;4(3):83-85 2255-2677/ http://dx.doi.org/10.1016/j.rehah.2016.05.001

3) LeBlancKA,BoothWV.Laparoscopicrepairofincisionalabdominalherniasusingexpanded polytetrafluoroethylene: Preliminary findings. Surg Laparosc Endosc. 1993;3:39-41.

4) Daes J Abordaje extraperitoneal de vista extendida (eTEP) para la reparación de hernias cir esp. 2020;98(5):249250

5) Daes J. Dennis RJ. Endoscopic subcutaneous component separation as an adjunct to abdominal wall reconstruction Surg Endosc 2017; 31:872-876 DOI 10.1007/s00464-016-5045-0

6) Belyansky I, Daes J, Radu VG, Balasubramanian R, Reza Zahiri H, Weltz AS, et al. A novel approach using the enhanced-view totally extraperitoneal (eTEP) technique for laparoscopic retromuscular hernia repair. Surg Endosc. 2018;32:1525-32.

7) Feliu PalaX.Cirugía laparoscópica de la pared abdominal: por qué no se ha implementado como otros procedimientos laparoscópicos? Editorial Cir Esp. 2015;93(2):65-67 http://dx.doi.org/10.1016/j.ciresp.2014.07.007 0009-739X/

8) Shaikh I, Olabi B, Wong VM, Nixon SJ, Kumar S. NICE guidance and current practise of recurrent and bilateral groin hernia repair by Scottish surgeons Hernia 2011;15:387-91.

9) Moreno-Sanz C, Tenías-Burillo JM, Morales-Conde S, Balague-Ponz C, Diaz-Luis H, et al. 25 años de cirugia laparoscopica en España. Cir Esp. 2014;92:232-9.

10) Colavita PD, Tsirline VB, Walters AL, Lincourt AE, Belyansky I, Heniford BT. Laparoscopic versus open hernia repair: Outcomes and sociodemographic utilization results from the nationwide in patient sample. Surg Endosc. 2012;27:109-17.

11) Helgstrand F, Rosenberg J, Kehlet H, Jorgensen LN. Nationwide prospective study of outcomes after elective incisional hernia repair. J Am Coll Surg. 2013;216:217-28.

12) McCoy AC, Gasevic E, Szlabick RE, Sahmoun AE, Sticca RP. Are open abdominal procedures a thing of the past? An analysis of graduating general surgery residents' case logs from 2000 to 2011.J Surg Educ. 2013;70:6839. 


\section{EVOLUCION Y SITUACION ACTUAL DE LA LAPAROSCOPIA EN PATOLOGIA PARIETAL}

\section{Dra. Caludia Barreiro}

La colecistectomía y la cirugía herniaria son los dos procedimientos quirúrgicos más frecuentes en la práctica diaria de un cirujano general de adultos. Por lo cual es imposible comenzar este capítulo sin hacer una comparación entre la disímil evolución en ambos procedimientos en las últimas décadas. La colecistectomía laparoscópica, desde su implementación 1987 por Phillipe Mouret, ${ }^{(1)}$ rápidamente se convirtió en el patrón de oro para la cirugía de la vía biliar, en virtud de tres grandes grupos de ventajas: para el paciente, para el cirujano y para las instituciones prestadoras de servicios de salud.

Para el paciente: la franca disminución del dolor postoperatorio, el rápido reintegro a sus tareas habituales y los excelentes resultados cosméticos junto con la menor tasa de complicaciones parietales.

Para el cirujano: la rápida curva de aprendizaje de la técnica, la cual está estandarizada, y en virtud de las dos anteriores la sencillez y rapidez del procedimiento cuando se logra el grado de entrenamiento adecuado.

Para las instituciones: lograr solucionar una de las patologías más frecuente de la consulta quirúrgica con una relación costo-beneficio excelente: amplia satisfacción del usuario, disminuyendo los costos directos e indirectos por su breve estadía hospitalaria junto con su baja tasa de complicaciones. Todo esto, con una razonable erogación monetaria inicial por la adquisición de equipamiento e instrumental, que rápidamente se amortiza.

Todas estas ventajas de la colecistectomía se han progresivamente extendido hacia otras técnicas como la cirugía del hiato, apendicetomía y cirugía colorrectal.

En la cirugía herniaria, en cambio, la situación ha favorecido la implementación de hernioplastias por vía anterior sin tensión tipo Lichtenstein. Este tipo de abordaje es hoy en día el patrón oro de la cirugía de las hernias inguinales, justamente, porque cumple con los tres grupos de ventajas anteriormente detalladas, para el paciente, para el cirujano y para la institución de salud. El primer trabajo sobre hernioplastia sin tensión se publicó en 1989; ${ }^{(2)}$ mostrando una tasa de recidiva menor al $1 \%$. Estos resultados fueron reproducibles en todos los centros y por todos los cirujanos, por lo que rápidamente fueron la técnica de elección recomendada en Europa y Norteamérica; ${ }^{(3)(4)(5)}$ así como también en nuestro medio. ${ }^{(6)}$

En este contexto, la difusión de técnicas video asistidas para la reparación de los defectos parietales se ha encontrado con varios obstáculos. Los pacientes no han percibido una dramática ventaja cosmética, un reintegro más rápido a su actividad habitual o una menor morbilidad respecto de las plastias por vía anterior. Los cirujanos han debido "aprender" una forma completamente diferente de reconocer la región miopectinea, debieron pasar por una curva de aprendizaje muchas veces ardua y en donde las posiciones para la cirugía no eran ergonómicas o cómodas; por lo cual las técnicas video asistidas de reparación herniaria aún representan un desafío para la amplia mayoría del colectivo quirúrgico. Finalmente, las instituciones prestadoras de salud, exceptuando tal vez las del ambiente académico y algunas privadas que atienden a una elite exclusiva; han sido reacias a realizar mayores erogaciones económicas (sobre todo en instrumental), para estimular el desarrollo de una técnica quirúrgica que aún no han visualizado como atractiva desde el punto de vista costo-beneficio.

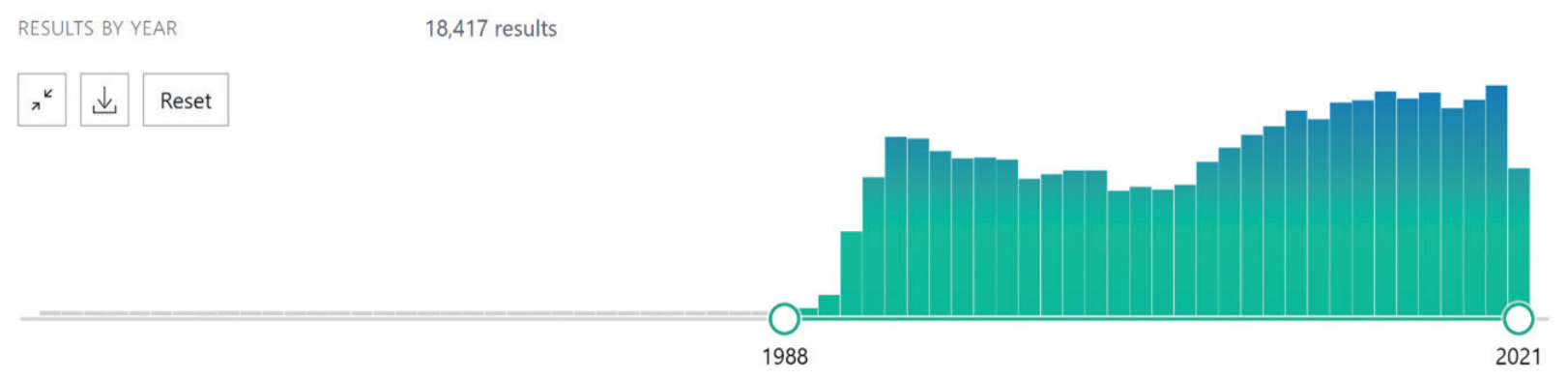

Figura 1. Cantidad de articulos publicados por año según PubMed para el término "laparoscopic cholecistectomy". PUBMED.

Búsqueda bibliográfica "Laparoscopic cholecystecomy" 1988-2021 [Consulta 21 de julio de 2021].

Disponible en: https://pubmed.ncbi.nlm.nih.gov/?term=laparoscopic+cholecystectomy\&filter=years.1988-2021 
Esta realidad ha sido similar en el mundo entero. Si analizamos la cantidad de artículos publicados por año, según PubMed; constatamos que desde 1988, la cantidad de artículos que versan sobre algún aspecto de la colecistectomía laparoscópica han sido más de 18.000 y la frecuencia de su publicación ha sido creciente desde el inicio (Figura 1). En cambio, la densidad de publicaciones encontradas por el mismo motor de búsqueda para las hernioplastias laparoscópicas es significativamente diferente (Figura 2). Arregui y colaboradores, ${ }^{(7)}$ publicaron el primer trabajo sobre hernioplastia preperitoneal transabdominal en 1992 (pocos años después de la $1^{a}$ colecistectomía laparoscópica), sin embargo, hubo que esperar hasta luego del 2010 para encontrar un verdadero "despegue" en el número de publicaciones sobre el tema. Durante casi 20 años, el interés mundial sobre esta vía de abordaje ha sido menor; a pesar de que la patología herniaria es igual de frecuente y rutinaria que la litiasis vesicular.

En nuestro país la evolución de las técnicas ha sido similar, en 1994 los Dres. Raul Morelli y Hector Geninazzi hicieron los primeros TAPP. ${ }^{(8)}$ Si bien el empuje inicial fue grande, tanto las dos grandes técnicas video asistidas TAPP y TEP han quedado relegadas a un papel totalmente secundario en el arsenal terapéutico de la patología herniaria.

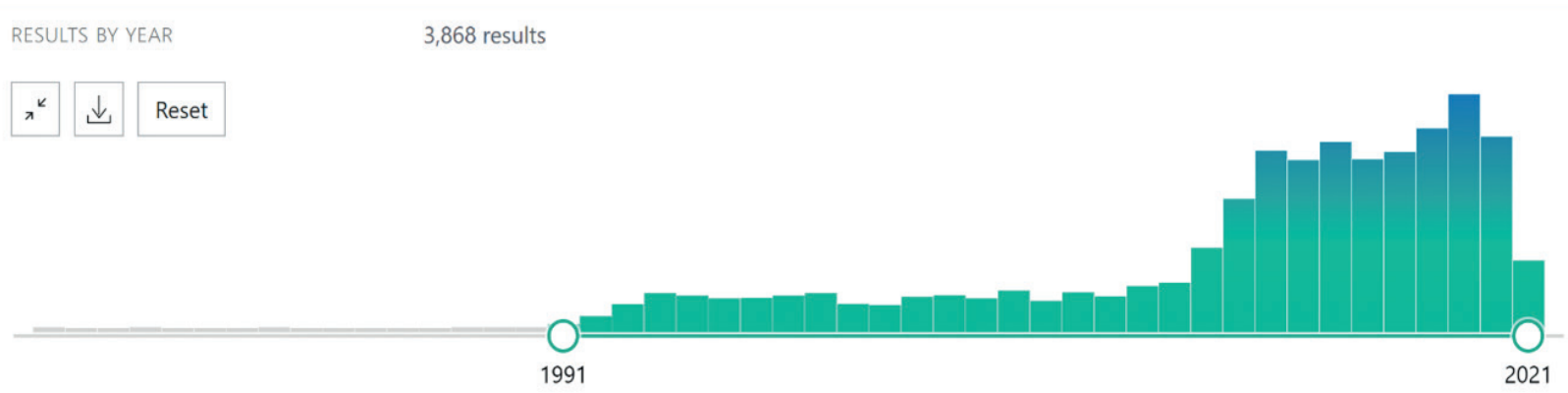

Figura 2. Cantidad de articulos publicados según Pubmed para el término "laparoscopic hernioplasty" PUBMED.

Búsqueda bibliográfica "Laparoscopic hernioplasty” 1991-2021 [Consulta 21 de julio de 2021].

Disponible en: https://pubmed.ncbi.nlm.nih.gov/?term=laparoscopic+hernioplasty\&filter=years.1991-2021

Las comunicaciones iniciales, mostraban una clara ventaja del TAPP, comparado con procedimientos de rafia por vía anterior, ${ }^{(9)(10)(11)}$ en cuanto al dolor postoperatorio, las tasas de recidivas y velocidad de reintegro a la actividad habitual. Sin embargo, los trabajos con plastias por vía anterior tipo Lichtenstein mostraron excelentes resultados en cuanto a dolor postoperatorio, estadía hospitalaria, velocidad de reintegro laboral, recidiva, resultado cosmético. ${ }^{(12)} \mathrm{Y}$ todo eso con un tiempo operatorio significativamente menor, la posibilidad de realizarla con anestesia regional o local, una ocurrencia de complicaciones graves menor, una menor curva de aprendizaje, y un costo directo e indirecto mucho menor. ${ }^{(13)(14)} \mathrm{El}$ riesgo de complicaciones graves como lesión vascular y perforación intestinal que conllevaba la hernioplastia trans abdominal preperitoneal hizo que muchos aconsejaran el uso sistemático del abordaje totalmente extraperitoneal (TEP), ${ }^{(14)(15)}$ y así evitar las complicaciones derivadas del abordaje de la cavidad peritoneal. En conclusión, hacia comienzo de este milenio no se recomendaba el uso sistemático de las técnicas video asistidas para la reparación herniaria, sino que se debía reservar para casos especiales: recidivas herniarias de la vía anterior, ante la concomitancia de otra patología intraabdominal que requiriera abordaje simultaneo, ante dudas de hernia inguinal en paciente con dolor a dicho nivel. ${ }^{(16)}$

¿A qué se debe entonces el renovado auge por las técnicas laparoscópicas para la reparación de los defectos de la pared abdominal que se está viendo en la última década? La respuesta a esta pregunta es compleja. Varios aspectos debemos considerar.

Por un lado, los cirujanos hemos acumulado a lo largo de los años gran experiencia en los procedimientos miniinvasivos; nos sentimos más "cómodos" realizando diversos procedimientos laparoscópicos. La laparoscopía es la primera opción en la que pensamos para el tratamiento de cirugía de la litiasis biliar, del hiato esofágico, de las suprarrenales, de los procesos apendiculares, en una buena parte de los cuadros agudos de abdomen, etc. Los cirujanos jóvenes y en formación desde hace varios años realizan su aprendizaje de técnicas laparoscópicas y laparotómicas por igual, y se desenvuelven con la misma fluidez en ambos tipos de abordajes (muchas veces superando ampliamente a los cirujanos ya formados). El entrenamiento en trainers y fantomas es parte de la formación inicial de los residentes, al inicio del postgrado de cirugía. Esto hace que las maniobras y movimientos básicos, así como la familiarización con el instrumental y la visión bidimensional sean destrezas que ya se adquieren al inicio de la formación quirúrgica. Se puede acceder a videos de cirugías, repasarlos, reiterarlos y aprender y tratar de emular a los expertos en cada una de las técnicas. Finalmente, la sistematización de la técnica quirúrgica en pasos básicos y la descripción de una "visión crítica de seguridad para el TAPP” (en analogía con la ya descripta para la colecistectomía), ha facilitado el aprendizaje de la técnica, ha aumentado la seguridad del procedimiento y, por ende, ha mejorado los resultados del mismo.(17)(18)(19) 
La tecnología ha avanzado en forma extraordinaria, estamos siendo testigos presenciales de una revolución tecnológica en casi todos los aspectos de la vida. Basta recordar cómo eran hace unos pocos años dispositivos de uso diario como teléfonos, televisiones, etc. En cirugía, estos avances han sido vertiginosos, fundamentalmente en tres aspectos: la miniaturización de los dispositivos, la mejoría en la calidad de las imágenes y abaratamiento de costos (y su obvia consecuencia que es la mayor democratización en el acceso a la tecnología). Cuando empezamos con nuestro aprendizaje en cirugía laparoscópica en el Hospital Pasteur al inicio de la década del '90, la realidad era muy diferente que en la actualidad: sólo contábamos con ópticas de $0^{\circ}$, los monitores eran de emisión catódica (CRT)(Imagen 1), con una definición inferior a la actual y con una distorsión angular de la imagen, los procesadores de imágenes eran analógicos, las ganancias de los colores eran regulares y muchas veces se saturaban en rojo; grabábamos los videos en casetes VHS; los insufladores de $\mathrm{CO} 2$ eran primitivos, el instrumental adolecía de defectos ergonómicos, no contábamos con sistema de grapas laparoscópicas adecuadas, por lo que muchas veces la fijación de la malla se hacía con puntos laparoscópicos, y cuando disponíamos de grapadoras estas eran metálicas (propiciando el dolor crónico). En esas condiciones la realización de cualquier procedimiento laparoscópico era mucho más difícil que en la actualidad.

A diferencia de esto, en la actualidad contamos con monitores FullHD 4K, incluso con posibilidad de procesador de fluorescencia, fuentes de luz fría LED, insufladores con aspiración de humo, hilos barbados que facilitan la confección de suturas, grapadoras de materiales absorbibles, selladores de cianacrilato y fibrina, instrumental ergonómico a precios más accesibles (Imagen 2). Todo lo cual logra que la visión sea óptima, y la propia manualidad quirúrgica sea el único límite del cirujano (Imagen 3).

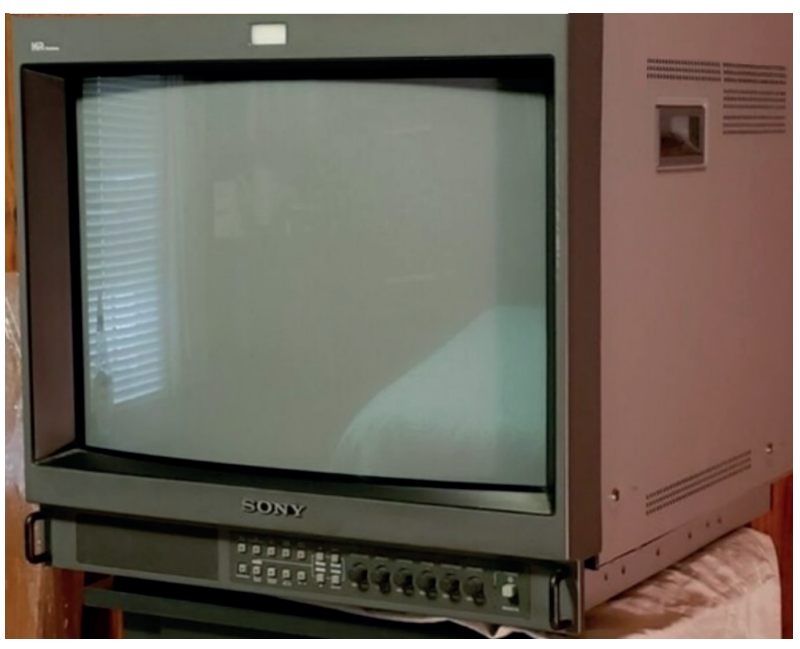

Imágen 1

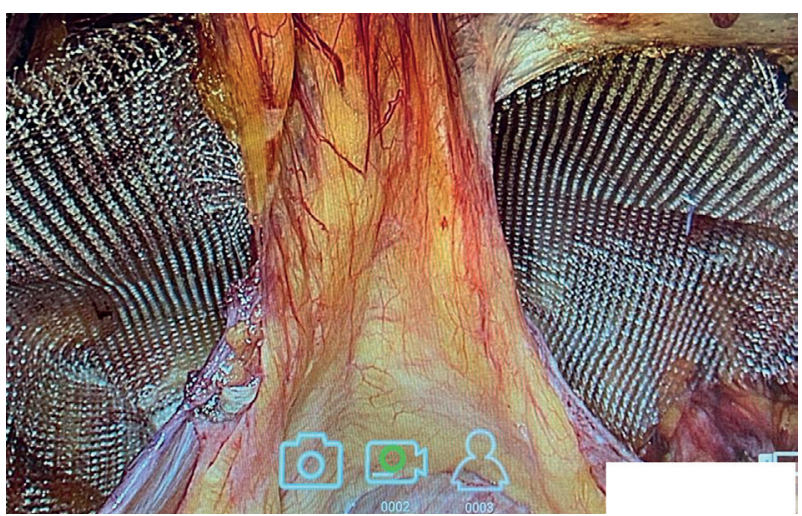

Imágen 3

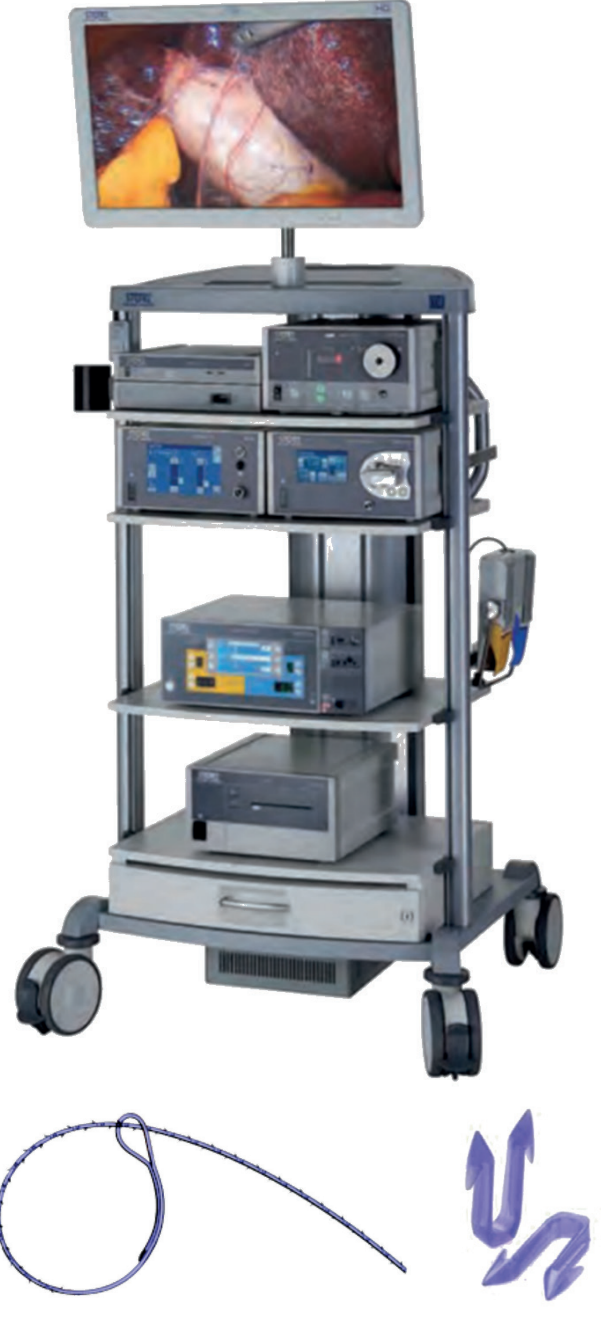

Imágen 2

Recursos actuales en cirugía 
Por otro lado, la sociedad en su conjunto de la mano de la postmodernidad y la globalización, ha evolucionado en cuanto a las expectativas que deposita en la medicina en general y en los cirujanos y los procedimientos quirúrgicos que realizamos, en particular. El infinito acceso que ofrece la internet, permite estar solo a un clic de distancia de toda la información. Cualquier persona aun no siendo profesional sanitario, puede recabar información detallada de diversas técnicas quirúrgicas, videos de cirugías y resultados de las mismas. De la misma manera que los usuarios del sistema sanitario exigen resultados en cuanto a dolor postoperatorio, tasas de curación, etc; también han aumentado sus expectativas en cuanto al resultado cosmético y el reintegro a sus actividades habituales. En la consulta diaria los usuarios del sistema de salud, se interesan, indagan e incluso exigen los abordajes miniinvasivos.

En el Uruguay del 2021, aún existe falta de interés de las instituciones prestadoras de salud en que se desarrollen estas técnicas. Aún encontramos obstáculos en la implementación de las mismas, ya sea por el cobro al usuario de aranceles desmedidos, por la falta de aggiornamiento en el equipamiento o en algunos lugares, directamente por la prohibición de realizar determinados procedimientos miniinvasivos. De todas maneras, este óbice, es cuestión de tiempo para que sea superado, ya sea por legislación (como ya pasó en 2016 donde por Decreto del Poder Ejecutivo se incorporó la colecistectomía laparoscópica al paquete de prestaciones obligatorias de las entidades del Sistema Nacional Integrado de Salud) o por la necesidad de prevalecer en un mercado cada vez más competitivo.

A nivel internacional, existe un renovado interés en la comparación de los procedimientos endoscópicos versus la hernioplastia tipo Lichtenstein. A continuación, analizamos algunas de las publicaciones más recientes y relevantes.

En 2017 se publicó una revisión sistemática con metaanálisis, comparando TAPP versus Lichtenstein en hernias inguinales primarias. ${ }^{(20)}$ Este metaanálisis mostró que el TAPP se asocia con un dolor inguinal crónico significativamente menor en comparación con la reparación de Lichtenstein. No se encontraron más diferencias significativas entre los dos métodos, pero calidad metodológica moderada y bajo número de pacientes de los estudios incluidos que hacían necesarios ensayos multicéntricos adicionales.

En 2018, Ielpo y colaboradores del Hospital Universitario Sanchinarro de Madrid, ${ }^{(21)}$ publicaron los resultados de un estudio prospectivo aleatorizado comparando los resultados de TAPP versus Lichtenstein en 134 pacientes con hernia inguinal bilateral (61TAPP/73 Lichtenstein). Los autores encontraron que el TAPP tenía significativamente menos dolor en la primera semana de postoperatorio, menor estadía hospitalaria, menor incidencia de complicaciones y menor frecuencia de dolor crónico que la hernioplastia abierta. Por lo que concluyen que el TAPP es un procedimiento seguro y que brinda mejor resultado en cuanto a calidad de vida para el paciente

En una serie prospectiva multicéntrica sobre el registro del Herniamed Study Group en 525 hospitales privados de Alemania, Austria y Suiza, se analizaron los resultados encontrados en 57.906 pacientes operados, por técnica del Lichtenstein (21.111), TEP (14.559) y TAPP (21.236). ${ }^{(22)} \mathrm{El}$ análisis demostró ventajas para las técnicas endoscópicas sobre el Lichtenstein. Con tasas significativamente menores de dolor postoperatorio, dolor crónico y complicaciones postoperatorias. Los resultados entre TEP y TAPP, fueron comparables. Los autores concluyen que los hallazgos de este análisis de registro confirman la validez de las recomendaciones realizadas en las guías internacionales.

Según las Guías EHS, ${ }^{(23)}$ tanto la hernioplastia abierta tipo Lichtenstein como los procedimientos video asistidos (TAPP y TEP), son recomendados, siempre y cuando el cirujano tenga suficiente experiencia en la técnica específica. En manos de un equipo experto, que trabaje en centros de alto volumen, la evidencia parece demostrar que las técnicas video-asistidas son mejores en cuanto a la incidencia de dolor postoperatorio, velocidad de recuperación y presencia de dolor crónico al mismo tiempo que la relación de costos es razonable. Además, si el equipo quirúrgico está entrenado, el tiempo operatorio es comparable al de la hernioplastia abierta y la incidencia de complicaciones es baja. Todo esto a expensas de una curva de aprendizaje más larga en los procedimientos endoscópicos (sobre todo en TEP). Sin embargo, el Grupo considera que aún la evidencia es débil ya que los estudios en que se basan no tienen criterios suficientemente objetivos de evaluación en los resultados. El grado de evidencia seria mayor y la recomendación más fuerte para las técnicas endoscópicas cuando la hernia es bilateral, para las hernias recidivadas por vía anterior, en pacientes jóvenes y con elevada actividad física, en pacientes con hernias crurales y en pacientes de sexo femenino. Mientras que, en pacientes con antecedentes de enfermedad o cirugía pélvica, radioterapia a dicho nivel, y en pacientes con muchas comorbilidades, se debe preferir la hernioplastia por vía anterior.

En 2019 se publicó un nuevo metaanálisis, ${ }^{(24)}$ de excelente calidad metodológica, que analizó 17 estudios clínicos controlados, comparando los resultados de TAPP versus TEP. Este trabajo mostró que ambas técnicas son valiosas en el arsenal terapéutico para el tratamiento de la patología herniaria; con una tasa de recidiva herniaria en ambas técnicas menor al 1\%, mostrando que el TEP tiene menor requerimientos de analgésicos en el postoperatorio inmediato, mientras que el TAPP tuvo menor tiempo operatorio sobre todo en recidivas herniarias. Este trabajo además evidenció que 
la experiencia de los cirujanos es un factor importante que afecta la duración de la cirugía. Los cirujanos con poca experiencia (menos de 20 procedimientos), demoran casi el doble que los cirujanos experimentados ( 30 a 100 reparaciones).

En el Manual de Cirugía de la Hernia de SAGES, ${ }^{(25)}$ se recomienda la realización de procedimientos miniinvasivos en hernias unilaterales no complicadas en centros de gran volumen, en hernias recidivadas cuando el procedimiento inicial se realizó por vía anterior, cuando se trata de hernias bilaterales, en hernias curales y en las hernias en mujeres. Mientras que se debe preferir la vía anterior ante hernias inguino-escrotales grandes o irreductibles, en aquellos pacientes que no sean candidatos a anestesia general, que no toleren la posición en Trendelembourg, cuando existen laparotomías previas infraumbilicales o cuando el paciente tenga alto riesgo de cáncer de próstata o sea candidato a una prostatectomía en el futuro.

Finalmente, en nuestro medio, luego de un periodo de escepticismo, ha habido un resurgimiento del interés en la técnica. Lentamente se está venciendo la resistencia del "establishment", que denostaba la técnica (años atrás, también nuestros maestros debieron dar "batalla" en defensa de la colecistectomía laparoscópica). Desde el 2018 ha habido múltiples presentaciones en la Sociedad de Cirugía, en el Congreso Uruguayo y en las diversas Jornadas de nuestra Sociedad. En el siguiente capítulo detallaremos la experiencia nacional.

Según los registros informáticos de ASSE, algo más del 6\% del total de hernias del adulto reparadas, lo han sido por técnica video asistida (Gráfica 1). Sin embargo, estos números entrañan una realidad muy heterogénea. En la encuesta realizada por Gabito y colaboradores en el Capítulo de Residentes del CUC 2019, ${ }^{(26)}$ más del 50\% de los residentes no realizaron ninguna hernioplastia laparoscópica, y de los que realizaron alguna, casi todos realizaron menos de 10 procedimientos.

\begin{tabular}{|c|c|c|c|c|c|c|}
\hline \multirow{2}{*}{ AÑO } & \multicolumn{3}{|c|}{ HOSPITAL PASTEUR } & \multicolumn{3}{c|}{ ASSE } \\
\cline { 2 - 7 } & VIDEO & ANTERIOR & TOTAL & VIDEO & ANTERIOR & TOTAL \\
\hline 2017 & 4 & 155 & 159 & 98 & 1511 & 1609 \\
\hline 2018 & 2 & 103 & 105 & 107 & 1470 & 1577 \\
\hline 2019 & 17 & 128 & 145 & 142 & 1477 & 2033 \\
\hline 2020 & 13 & 102 & 115 & 83 & 1020 & 1103 \\
\hline
\end{tabular}

Gráfica 1. Cantidad de pacientes operados por año, por abordaje video asistido (Video), y por via anterior (Anterior), en el Hospital Pasteur y en ASSE (todo el país). Datos gentileza Dr. Raúl Blanco

En el Hospital Pasteur, en el ámbito de la Unidad de Pared de Abdomen y Cirugía Endocrina, estamos desarrollando nuestra experiencia en la técnica. El 12\% de las hernioplastias las reparamos por vía endoscópica, y se incluye sistemáticamente la enseñanza de la técnica a los residentes que pasan por la Unidad. La selección de los pacientes es rigurosa, se ha sistematizado la técnica quirúrgica y el seguimiento postoperatorio es estrecho, todo lo cual está evidenciando que se trata de una técnica segura y que ofrece al paciente las ventajas referidas al inicio del capítulo. Así mismo, el trabajar en una unidad de pared de abdomen, con un plantel quirúrgico estable, abocado a la resolución de la patología parietal, genera un feed back positivo, acorta la curva de aprendizaje al sistematizar la técnica e integrar los "tips \& tricks", mejorando así la comodidad y la fluidez con que realizamos los procedimientos. El acortamiento de la curva de aprendizaje, genera además una difusión más amplia del método, ya que los cirujanos que la cumplieron pueden propagar sus conocimientos a otros colegas. Décadas atrás, pasó un proceso similar con los cirujanos que innovaron en la colecistectomía laparoscópica, que invirtieron en cursos en el extranjero, para luego traer la técnica a nuestro país, y así enseñársela a una primera generación de colegas; estos a la siguiente y así sucesivamente hasta nuestros días.

Hasta el momento de concluir este Relato, el gran paso limitante para el mayor desarrollo de las técnicas endoscópicas es el costo económico, sobre todo en lo que implican a los métodos de fijación de la malla. Pero confiamos en que ese límite en forma progresiva se va a ir traspasando, de la mano con el desarrollo tecnológico.

En conclusión, la cirugía video asistida tiene su sitial ganado en el arsenal terapéutico de la patología herniaria inguinal, en pacientes seleccionados, logrando excelentes resultados a corto, mediano y largo plazo. 


\section{BIBLIOGRAFIA}

1) Dubois F, Berthelot G, Leverth H. Cholecystectomie par celioscope. Prense Medicalle 1989;18: 980-2.

2) Lichtenstein IL, Shulman AG, Amid PK, Montllor MM. The Tension Free Hernioplasty. Am J Surg 1989; 157: 188.

3) EU Hernia Trialists Collaboration. Mesh compared with non-mesh methods of open groin hernia repair: systematic review of randomized controlled trials. Br J Surg 2000; 87: 854-9.

4) Schoots IG, Van Dijkman D, Butzelaar RMJM, Van Geldere D, Simons MP. Inguinal hernia repair in the Amsteridam Region 1994-1996. Hernia 2001; 5: 37-40.

5) Schulman AG, Amid PK, Lichtenstein IL. The safety of mesh repair for primary inguinal hernias: results of 3019 operations from diverse surgical sources. Am Surg 1992; 58: 255-7

6) Santandreu J, Vitancourt G, Figoli, y cols. Hernioplastia tipo Lichtenstein. Análisis preliminar. Cir Uruguay 1996; 66: $238-40$.

7) Arregui ME, Davis CJ, Yucel O, Nagan RF. Laparoscopic mesh repair of inguinal hernia using a preperitoneal approach: a preliminary report. Surg Laparosc Endosc. 1992; 2:53-8.

8) Morelli Brum R. Cirugía Laparoscópica de la hernia inguinal. Cir Uruguay 2005, 75: 48-54

9) Kozol R, Lange PM, Kosir M et al. A Prospective, Randomized Study of Open vs Laparoscopic Inguinal Hernia Repair. Arch Surg 1997; 132: 292-5.

10) Chung R S, Rowland D Y. Meta-analyses of randomized controlled trials of laparoscopic vs conventional inguinal hernia repairs. Surgical Endoscopy 1999, 13: 689-694.

11) McCormack K; Scott NW; Go PMNYH; Ross S. Laparoscopic techniques versus open techniques for inguinal hernia repair The Cochrane Library, 2002;2:no page \#.

12) Kurzer M, Belsham PA, Kark AE. The Lichtenstein repair. Surg Clin North Am 1998; 78:1025-46.

13) EU Hernia Trialists Collaboration Laparoscopic compared with open methods of groin hernia repair: systematic review of randomized trials Br J Surg 2000; 87:860-7

14) Bringman S, Ramel S, Heikkinen TJ, Englund T, Westman B, Anderberg B. Tension-Free Inguinal Hernia Repair: TEP Versus Mesh-Plug Versus Lichtenstein A Prospective Randomized Controlled Trial Ann Surg 2003; 237: $142-7$.

15) Praderi Gambardella LA, Estapé Viana G. Reparación laparoscópica de la hernia inguinal. En: Hernia inguinal (2004). Estapé G, Croci F, Eds. Academia Nacional de Medicina. Montevideo. p 89-97

16) Barreiro CH. Costo beneficio del tratamiento de la hernia inguinal. . En: Hernia inguinal (2004). Estapé G, Croci F, Eds. Academia Nacional de Medicina. Montevideo. p 159-64.

17) Daes J, Felix E. Critical view of of myopectineal orifice. Ann Surg 2017;266: e1-e2

18) Furtado M, Claus C, Cavazzola LT, Malcher F, Bakonyi-Neto A, Saad-Hossne R. Systemization Of Laparoscopic Inguinal Hernia Repair (TAPP) Based On A New Anatomical Concept: Inverted Y And Five Triangles. Arq Bras Cir Dig 2019;32(1):e1426

19) Palmisano EM, Brea Andrade A. Actualización de la nomenclatura del orificio miopectíneo en la reparación endoscópica de las hernias de la región inguinal. Rev Hispanoam Hernia. 2021; 9:46-9

20) Scheuermann U, Niebisch S, Lyros O, Jansen-Winkeln B, and Gockel I. Transabdominal Preperitoneal (TAPP) versus Lichtenstein operation for primary inguinal hernia repair - A systematic review and meta-analysis of randomized controlled trials. BMC Surgery. 2017; 17:55

21) Ielpo B, Duran H, Diaz E, et al. A prospective randomized study comparing laparoscopic transabdominal preperitoneal (TAPP) versus Lichtenstein repair for bilateral inguinal hernias. Am J Surg 2018; $216: 78$ - 83.

22) Köckerling F, Bittner R, Kofler M, et al. Lichtenstein Versus Total Extraperitoneal Patch Plasty Versus Transabdominal Patch Plasty Technique for Primary Unilateral Inguinal Hernia Repair A Registry-based, Propensity Score-matched Comparison of 57,906 Patients. Ann Surg 2019; 269:351-7.

23) International guidelines for groin hernia management. The HerniaSurge Group. Hernia 2018. DOI 10.1007/ s10029-017-1668-x

24) Chen LS, Chen WC, Kang YN, Wu CC, Tsai LW, Liu MZ. Effects of transabdominal preperitoneal and totally extraperitoneal inguinal hernia repair: an update systematic review and meta-analysis of randomized controlled trials. Surg Endosc. 2019; 33: 418-28.

25) Balla F and Patel AD. MIS vs. Open Inguinal Hernia for Uncomplicated Unilateral Hernia. En: Davis SSJr, Dakin G, Bates A. Editors. The SAGES Manual of Hernia Surgery. 2nd Edition. Switzerland: Springer; 2019 pp. 429-38.

26) Gabito I, Pais C, Haro C, Dardanelli S, Campos M. Capitulo de Residentes SCU. TAPP vs Lichtenstein en la residencia ¿en qué estamos? https://www.youtube.com/watch?v=31cvqHGUYks 


\section{EXPERIENCIAY EVOLUCIÓN EN URUGUAY}

\section{Dra. Claudia Barreiro}

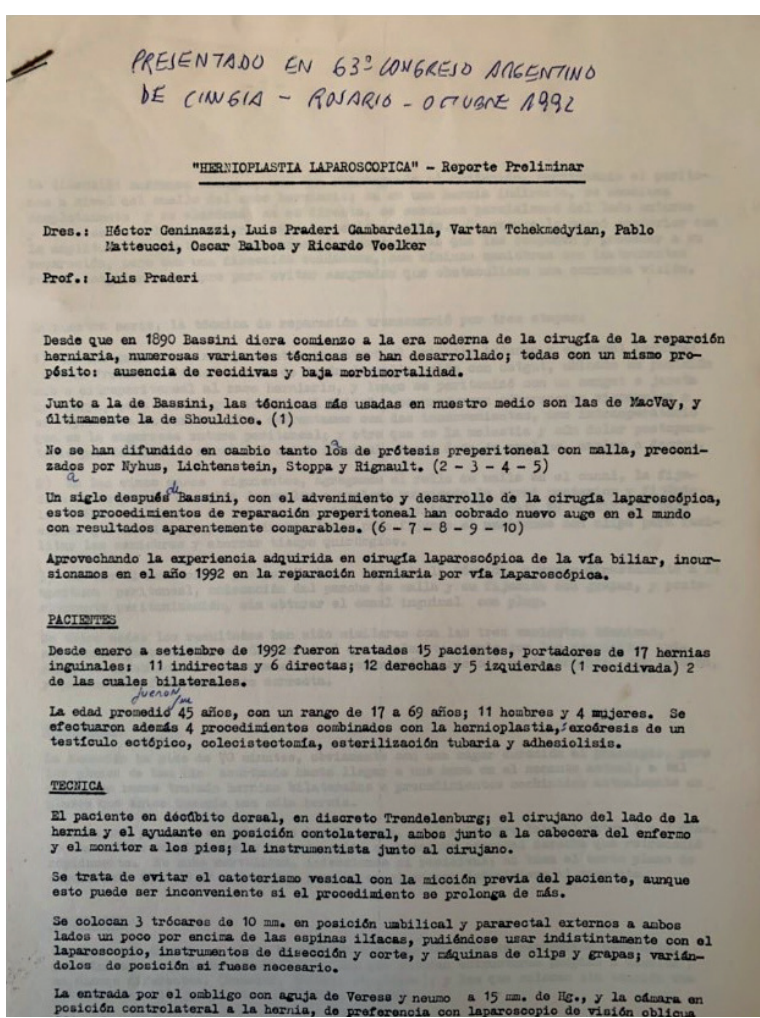

Ilustración 1. Gentileza Dr. Luis Praderi Gambardella

La primera experiencia reportada a nivel nacional data de 1992. En el 63 Congreso Argentino de Cirugía, uno de los equipos pioneros en el desarrollo de la video cirugía en el Uruguay, encabezado por el Profesor Luis Praderi; comunicaron su experiencia preliminar en hernioplastia transabdominal preperitoneal (TAPP) en 15 pacientes portadores de 17 hernias inguinales (Ilustración 1). De esta comunicación debemos realizar varios comentarios: en primer lugar, que los autores del trabajo desarrollaron principalmente su experiencia en un centro privado (CILAE - Hospital Italiano de Montevideo), y desde allí la difundieron hacia los centros universitarios. Todos los autores de este trabajo eran al momento de la presentación cirujanos formados, con alto rango académico. Todos formados en el exterior del país en Francia con Dubois y en EEUU con Mc Kernan, Reddick y Olsen. Como detalle: se colocaban tres trócares de 10mm.

En 1994, Delbene ${ }^{(1)}$ y colaboradores publican una serie de 52 pacientes operados con técnica de Schultz a través de 3 trocares de $10-12 \mathrm{~mm}$. No observaron complicaciones operatorias ni infecciones. Sin embargo, no hubo seguimiento por lo que los resultados a largo plazo no se informaron. Cabe destacar que la serie de pacientes fueron operados en Buenos Aires, República Argentina.

Más adelante el Profesor Raul Morelli ${ }^{(2)}$ (integrante del otro grupo pionero en cirugía laparoscópica: el del Hospital Británico), publicó su experiencia desde 1994 a 2003 en 108 procedimientos TAPP realizados en 99 pacientes. Si bien los resultados encontrados en ese momento fueron excelentes, y comparables a la bibliografía internacional de esa época, cabe destacar que hubo 3 recurrencias herniarias en la serie, dos de las cuales se solucionaron con hernioplastia anterior tipo Lichtenstein. Adicionalmente hubo dos eventraciones en el sitio de inserción del trócar de 10mm (se colocaban dos puertos de $10 \mathrm{~mm}$ y uno de $5 \mathrm{~mm}$ ). La conclusión del trabajo es el escepticismo sobre la indicación de la técnica. Solo se recomienda en recidiva de cirugía convencional, cuando se acompaña de otra cirugía laparoscópica, ante hernias bilaterales o cuando existen dudas sobre la presencia de hernia contralateral.

En el año $2003{ }^{(3)}$ se presentó en el CUC una mesa de controversia sobre el tratamiento de la hernia inguinal. En esta se concluyó que las técnicas video asistidas tienen similar tasa de recidiva, pero con menor tasa de dolor postoperatorio, lo que permite una recuperación más rápida. Como contrapartida son técnicas más difíciles, con curva de aprendizaje larga y riesgo potencial de complicaciones. Por todo esto se concluyó que con una adecuada selección de los pacientes comparten un lugar junto con las técnicas convencionales en el arsenal terapéutico de cirujano. 
En 2004, se editó y publicó el libro titulado "Hernia Inguinal" de los Dres. Gonzalo Estapé y Fabio Croci, ${ }^{(4)}$ el cual mereció premio de la Academia Nacional de Medicina. De los veintidós capítulos que componen el libro, solo dos se dedicaron a las técnicas video asistidas. Transcribimos las conclusiones:

La hernioplastia laparoscópica es un método que logra un minimo dolor postoperatorio; es posible realizarla con una breve estadía hospitalaria y posibilita un reintegro laboral rápido, con una minima tasa de recidivas, y baja tasa de complicaciones. Sin embargo, estos resultados son comparables a los de la hernioplastia por via anterior, y con costos directos significativamente superiores. Por lo tanto, no debe ser usada en forma sistemática como procedimiento de reparación herniaria, sino que debe reservarse para casos especiales:

- Recidivas herniarias en las que la vía anterior ha sido abordada varias veces haciendo engorroso y peligroso un nuevo abordaje por dicha vía

- Cuando existe otra patología concomitante intraabdominal y se pretende realizar el tratamiento simultáneo. Por ejemplo: litiasis biliar + hernia

- Cuando quedan dudas si existe o no una hernia en un paciente con dolor inguinal. El abordaje inicial se realiza con criterio diagnóstico y luego se prosigue con criterio terapéutico.

Esta fue la última comunicación nacional que cerró el primer período de desarrollo de las técnicas video asistidas en nuestro país. Si bien tanto la reparación tipo TAPP como TEP, se realizaron en forma esporádica; no hubo más comunicaciones formales.

Recién en 2017, se retoma el tema otra vez el tema en la 10ª sesión Científica de la SCU, se expone el tema: "Tratamiento de la hernia inguinal por laparoscopia. Lugar de la hernioplastia laparoscópica, evidencia actual”. ${ }^{(5)} \mathrm{El}$ autor realiza una revisión de la literatura disponible hasta ese momento.

En 2018, en la actividad del Capítulo Uruguayo del American College of Surgeons, se invita al Dr. Gustavo Castagneto (Hospital Austral, Bs As, Argentina) a disertar sobre "Manejo video asistido de la hernia inguinal: indicaciones y técnica, experiencia". Es probable que este haya sido el "puntapié inicial" para relanzar en forma oficial y académica la experiencia en manejo video asistido de las hernias inguinales y de los defectos de la pared abdominal.

A partir de ese momento (y a pesar de todas las limitaciones que ha determinado la pandemia SARS-CoV-2 en el país y en el mundo), se comienzan a presentar las diferentes experiencias en cirugía video asistida de la pared abdominal.

En 2019, Perdomo y cols publican un video científico: "Anatomía quirúrgica para hernioplastias inguinales transabdominales preperitoneales (TAPP)"(6)

En la 1a sesión científica de la SCU (mayo 2019) la Unidad de Pared Abdominal de la Clínica Quirúrgica "2 del Hospital Maciel, ${ }^{(7)}$ presenta su experiencia Inicial en Hernioplastia Transabdominal Preperitoneal (TAPP). Presentaron 23 procedimientos en pacientes seleccionados realizados entre 2018 y 2019, con 2 conversiones, 1 recidiva herniaria y 1 seroma.

El 21 de marzo de 2020, en la Sesión del Capítulo de Residentes de la SCU se presento una encuesta sobre la formación de los residentes en el tratamiento de las hernias inguinales. ${ }^{(8)}$ Esta evidenció gran disparidad en cuanto a la formación ya sea en hernioplastias por vía anterior como en procedimientos video asistidos. La tercera parte de los residentes nunca participó como ayudante en ninguna cirugía, un $40 \%$ en menos de 5 procedimientos y el resto entre 5 y 20 procedimientos a lo largo del transcurso de su residencia. Así mismo, más de la mitad de los residentes encuestados nunca realizó un procedimiento como cirujano, los que si actuaron como cirujanos lo hicieron en menos de 10 procedimientos (la mayoría menos de 5). Una buena parte de estos últimos no pudieron completar la cirugía. Interrogados si se sienten seguros en cuanto a los pasos técnicos del procedimiento, más del $80 \%$ respondieron en forma negativa. Por lo que podemos concluir que aún no estamos formando adecuadamente a los futuros cirujanos en técnicas video asistidas de reparación herniaria, los procedimientos se concentran en Hospital de Clínicas, Pasteur y Maciel, pero ningún residente completa el número mínimo de la curva de aprendizaje.

Los datos del Sistema Informático de Descripciones Operatorias de ASSE (1.361.467 usuarios según censo 2019), reafirman estos conceptos. El número de procedimientos realizados es relativamente bajo: 


\begin{tabular}{|c|c|c|c|c|}
\hline \multirow{2}{*}{ AÑO } & \multicolumn{2}{|c|}{ HOSPITAL PASTEUR } & \multicolumn{2}{c|}{ PAIS } \\
\cline { 2 - 5 } & ABIERTAS & LAPAROSCOPICAS & ABIERTAS & LAPAROSCOPICAS \\
\hline 2017 & 155 & 4 & 1511 & 98 \\
\hline 2018 & 103 & 2 & 1470 & 107 \\
\hline 2019 & 128 & 17 & 1477 & 142 \\
\hline 2020 & 102 & 13 & 1020 & 83 \\
\hline
\end{tabular}

Tabla 1: cantidad de pacientes intervenidos quirúrgicamente por hernias inguinales, usuarios de ASSE, por año. Gentileza Dr. Raul Banco

Alrededor del 10\% de los pacientes con hernias inguinales se resuelven por técnicas video asistidas. La cirugía video asistida en estos momentos se trata de una cirugía que está en desarrollo en nuestro país, por lo que el número de procedimientos es limitado por la estricta selección de los pacientes y por el aun escaso entrenamiento del colectivo quirúrgico en la técnica. En este sentido los registros del principal prestador de salud del país, lo atestigua.

Finalmente, la comunicación más reciente se realizó en la 2a Sesión Científica Miércoles 24 De marzo de 2021 de la SCU los Dres. Bonilla, Vieira Da Cunha y Sauto, ${ }^{(9)}$ presentaron su experiencia inicial en el Departamento de Rivera (ROU) durante 5 años, en hernioplastias tipo TAPP en 82 hernias operadas en 72 pacientes. En la serie no tuvieron conversiones, la duración promedio de la cirugía fue de 55 minutos; el promedio de internación fue de 22 horas, la tasa de complicaciones fue de 6,9\% todas leves (Clavien Dindo I y II) y la incidencia de recidiva fue nula en un seguimiento promedio de 2 años. Se destaca en este trabajo los excelentes resultados, a pesar del numero relativamente pequeño de casos. La clave de estos buenos resultados estaría en la creación de una unidad de pared de abdomen, con un plantel quirúrgico estable, donde un cirujano ya formado en la técnica comparte su experiencia con el resto del equipo, y con ello la curva de aprendizaje disminuye.

\section{BIBLIOGRAFÍA}

1) Delbene R, Bruni JE, Lentino D, Dominguez J. Cirugía por vía laparoscópica en la reparación de la hernia inguinal. Cir Uruguay 1994; 64: 299-300

2) Morelli Brum R. Cirugía laparoscópica de la hernia inguinal. Cir Uruguay 2005, 75: 48-54

3) Muller A, Salon A. Controversia sobre el tratamiento de la hernia inguinal: abierta o laparoscópica. Congreso Uruguayo de Cirugía. Colonia del Sacramento.26 al 29 de noviembre 2003.

4) Estapé G, Croci F. Hernia Inguinal. Academia Nacional de Medicina. Montevideo: El País S.A.; 2004.

5) Monge G. Tratamiento de la hernia inguinal por laparsocopia.lugar de la hernioplastia laparoscópica. Evidencia actual. 10a Sesión Cientifica SCU. 13 de setiembre de 2017. https://www.youtube.com/watch?v=Wka5fMBWtI8

6) Perdomo MA, Armand Ugon G, Sciuto P, Ferreira M, Gonzalez D. Anatomía quirúrgica para hernioplastias inguinales transabdominales preperitoneales (TAPP). Cir. Uruguay. 2019; 2: 37. ISSN 1688-1281 (en línea)

7) Perna R, Espinosa G, Martinez M, Ximenez V, Rodriguez G. Hernioplastia Transabdominal Preperitoneal (TAPP). Experiencia inicial de la Unidad de Pared Abdominal de la Clínica Quirúrgica 2 del Hospital Maciel. 1 ${ }^{\text {a }}$ Sesión Cientifica SCU. Mayo 2019. https://www.youtube.com/watch?v=FBWttrdnbDI\&t=8s

8) Gabito I, Pais C, Haro C, Dardanelli S, Campos M. Capitulo de Residentes SCU. TAPP vs Lichtenstein en la residencia ¿en qué estamos? https://www.youtube.com/watch?v=31cvqHGUYks

9) Bonilla S, Vieira da Cunha G, Sauto S. Hernioplastia inguinal Laparoscopica TAPP. Serie de casos en Rivera Uruguay.2a Sesion Cientifica SCU.24 de marzo de 2021. https://www.youtube.com/watch?v=xxiqNsnywtk 


\section{BIOMATERIALES PARA USO EN CIRUGÍA LAPAROSCÓPICA DE HERNIAS LA PARED ABDOMINAL}

\section{Dr. Gonzalo Estapé}

La práctica quirúrgica actual, basada en la mejor evidencia científica, sustenta el uso de una malla protésica permanente como mejor método para la reparación de las hernias de la pared abdominal. Este cambio en el tratamiento de los defectos herniarios en general, se sustentó en los buenos resultados obtenidos por el grupo de Lichstentein, con la reparación con malla, "sin tensión" de las hernias inguinales. ${ }^{(1)}$

En los últimos años se han desarrollado múltiples mallas protésicas con una amplia variedad de características. Aún así, ningún material ha ganado una preferencia de uso universal y numerosas complicaciones se han relacionado con estos materiales sintéticos permanentes. La mayoría de las mallas sintéticas hacen más fuerte la pared abdominal mediante una intensa respuesta fibroplástica, que da lugar a una densa interfaz cicatriz-malla. Aunque esto puede ser beneficioso si se analiza desde el objetivo de reparar el defecto, esa respuesta intensa incitada por el material sintético también puede dar lugar a complicaciones como: fístula intestinal, contracción de la malla, adherencias intraperitoneales, sensación de "presencia" de la malla y/o aumento de rigidez de la pared abdominal, con la consiguiente disminución de la distensibilidad de la misma.

La investigación y el desarrollo de nuevos biomateriales constituyen un área en continua y creciente expansión. La pared abdominal no ha permanecido ajena a las diferentes innovaciones sino que además ha contribuido al diseño de nuevos materiales, dándoles nuevas aplicaciones.

Para el cirujano que trata hernias abdominales, es necesario familiarizarse con los diferentes tipos existentes de materiales protésicos, y saber con qué fin y para qué se han diseñado, así como conocer cuál es su mejor ubicación tisular.

Las prótesis se clasifican en dos grandes grupos:(2)

1. Poliméricas o sintéticas: Reticulares. Laminares. Compuestas.

2. Biológicas o naturales: bioprótesis.

\section{Prótesis reticulares}

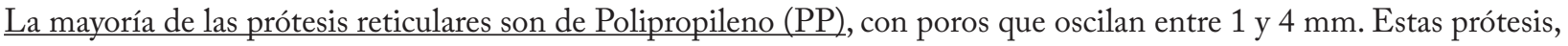
tienen una óptima integración tisular. El tejido conectivo rodea los filamentos, formando espirales sobre los mismos, existiendo una importante angiogénesis, siendo excelente el anclaje al tejido receptor. En estudios tensiométricos, la fuerza tensil obtenida es superior a la de otros materiales protésicos.

\begin{tabular}{|c|c|c|}
\hline \multicolumn{3}{|c|}{ POLIMÉRICAS O SINTÉTICAS } \\
\hline \multirow{3}{*}{$\begin{array}{l}\text { Prótesis } \\
\text { reticulares }\end{array}$} & No absorbibles & $\begin{array}{l}\text { Polopropileno (alta o baja densidad), } \\
\text { poliéster, politetraflouroetileno } \\
\text { no expandido (PTFE), PVDF }\end{array}$ \\
\hline & $\begin{array}{l}\text { Parcialmente } \\
\text { absorbibles }\end{array}$ & $\begin{array}{l}\text { Polopropileno /poliglactín } 910 \\
\text { Polopropileno/poliglecaprona }\end{array}$ \\
\hline & Absorbibles & Poliláctico, poliglactín 910 \\
\hline $\begin{array}{l}\text { Prótesis } \\
\text { laminares }\end{array}$ & No absorbibles & $\begin{array}{l}\text { Politetrafluroetileno expandido } \\
\text { (PTFEe), silicona, poliruetano }\end{array}$ \\
\hline \multirow[b]{2}{*}{$\begin{array}{l}\text { Prótesis } \\
\text { compuestas }\end{array}$} & $\begin{array}{l}\text { Componentes } \\
\text { no absorbibles } \\
\text { (barrera física) }\end{array}$ & $\begin{array}{l}\text { Polipropileno/PTFEe } \\
\text { Polipropileno/poliuretano }\end{array}$ \\
\hline & $\begin{array}{l}\text { Componentes } \\
\text { absorbibles } \\
\text { (barrera química) }\end{array}$ & $\begin{array}{l}\text { Poléster/polietilenglicol } \\
\text { Polipropileno/polietilenglicol } \\
\text { Polipropileno/ácido hialurónico } \\
\text { Polipropileno/polidioxanona/celulosa }\end{array}$ \\
\hline \multicolumn{3}{|c|}{ BIOLÓGICAS O NATURALES } \\
\hline \multirow[t]{2}{*}{ Bioprótesis } & $\begin{array}{l}\text { Sin enlaces } \\
\text { covalentes }\end{array}$ & $\begin{array}{l}\text { Dermis porcina } \\
\text { Pericardio bovino } \\
\text { Submucosa intestinal porcina }\end{array}$ \\
\hline & $\begin{array}{l}\text { Con enlaces } \\
\text { covalentes }\end{array}$ & Dermis porcina \\
\hline
\end{tabular}


Tomado de Eventraciones Otras hernias de pared y cavidad abdominal Fernando Carbonell Tatay Alfredo Moreno Egea Valencia, 2012

En los últimos años, las prótesis reticulares clásicas de poro pequeño, han sufrido modificaciones, teniendo en cuenta, como parámetro fundamental, el tamaño del poro, así como otros aspectos como el diámetro de los filamentos y la distribución espacial de los mismos.

Estos cambios han dado lugar a modificaciones en la clasificación de las prótesis reticulares, de tal forma que dependiendo del parámetro $\mathrm{g} / \mathrm{m} 2$ se han clasificado, en prótesis de alto peso (alta densidad) o bajo peso (baja densidad). Se consideran prótesis de alto peso, aquellas que se sitúan por encima de $80 \mathrm{~g} / \mathrm{m} 2$ y de bajo peso las que se encuentran por debajo de esta cifra. Recientemente se han incluido en la clasificación las prótesis de media densidad, cuyo peso estaría entre 50 y $80 \mathrm{~g} / \mathrm{m} 2$, situándose entonces las bajas densidades entre 35 y $50 \mathrm{~g} / \mathrm{m} 2$. En algunas clasificaciones recientes se incluye las de muy baja densidad, cuyo peso estaría por debajo de los $35 \mathrm{~g} / \mathrm{m}^{(2)}$

Algo que hay que tener en cuenta, es que a veces el peso protésico, es independiente del tamaño del poro. Ello es debido, a que hay prótesis con un diseño de poro pequeño, con una estructura espacial y un anudado o entrecruzamiento simple y a su vez un filamento fino, y que son de bajo peso, por tener en su conjunto un peso en $\mathrm{g} / \mathrm{m} 2$ bajo. Se considera que el tamaño del poro protésico, es el principal parámetro para considerar a una prótesis como de alta o baja densidad. De esta manera, las prótesis de alta densidad tendrían un diseño con poro pequeño y las de baja densidad tendrían un poro amplio. Los objetivos de los nuevos diseños de baja densidad son: reducir la cantidad de material extraño que queda ubicado en el huésped, y dejar una fibrosis menor en el tejido receptor. ${ }^{(3)}$

En las mallas de polipropileno con un tamaño de poro menor a 1,0 $\mathrm{mm}$ los poros suelen rellenarse de tejido cicatricial (lo que da lugar al fenómeno llamado «puente» o, en terminología anglosajona, bridging), esto se podría evitar en la mayoría de los casos con poros de un tamaño mayor a $1,0 \mathrm{~mm}$, con la incorporación de la malla al tejido y mejor respuesta mecánica. Por esto la preferencia actual por las mallas macroporosas, aunque haya otros factores determinantes de la biocompatibiliad y la fuerza tensil final, como el tipo de biomaterial, el tejido y el peso.
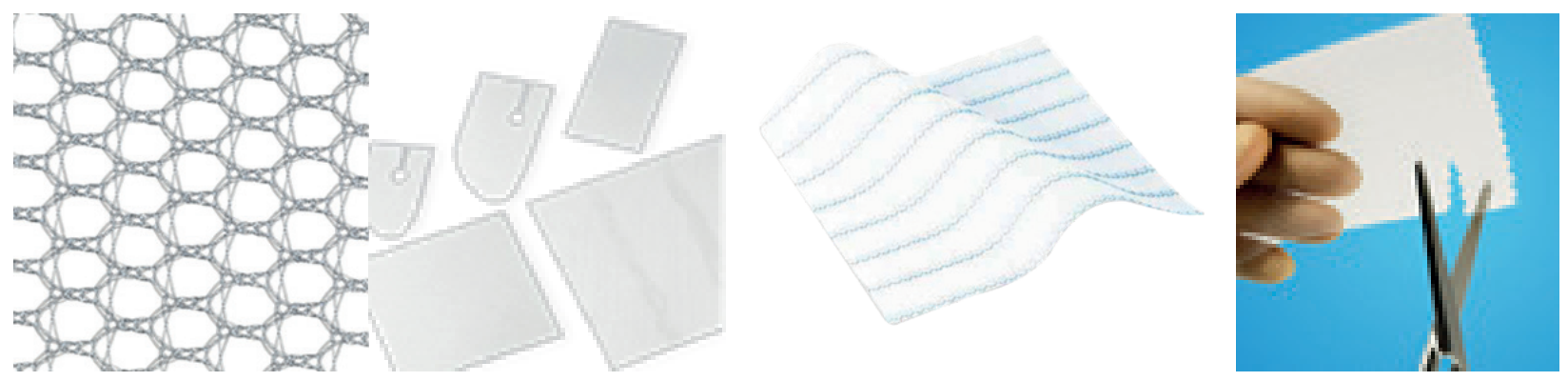

Mallas de Polipropileno

También se han diseñado prótesis reticulares con material absorbible. (UltraPro Ethicon) De esta forma se generan prótesis parcialmente absorbibles o de tipo híbrido, en las cuales hay componentes absorbibles (poligrecaprone 25) y no absorbibles (polipropileno). Estas prótesis, son de poro amplio $(4 \mathrm{~mm})$ y por tanto de baja densidad $28 \mathrm{~g} / \mathrm{m} 2$. El biomaterial ha de permanecer a veces largo tiempo incluido en los tejidos, y no se sabe todavía la reacción o los cambios alejados que pueden generar.
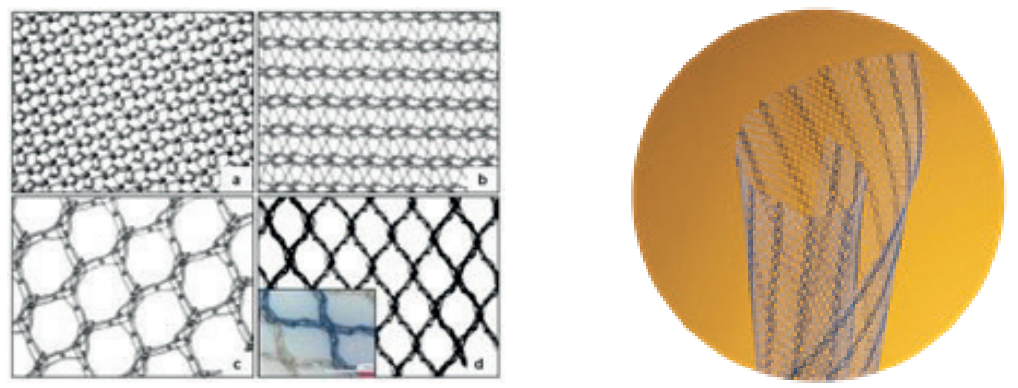

Bellon ${ }^{(4)}$, ha demostrado que la integración y la resistencia mecánica, tanto de las prótesis de bajo peso como parcialmente aborbibles, es similar a las prótesis reticulares convencionales de alto peso. Otra ventaja de estas prótesis es generar una cicatrización menos compacta y con una menor fibrosis. Ello permitiría que la pared abdominal no sufra "rigideces", que pueden observarse en algunos pacientes operados con prótesis de PP de alta densidad (poro pequeño). 
La prótesis reticular ideal, desde el punto de vista mecánico, sería aquella que mejor pudiera adaptarse a las propiedades fisiológicas de la pared abdominal. Las prótesis deberían soportar la tensión de forma simétrica en todas las direcciones y permitir una movilidad homogénea de toda la pared abdominal.

Una innovación importante, también en el campo de las prótesis reticulares, ha sido la creación de prótesis autofijables. (PROGRIP, Covidien) Estas prótesis tienen un sistema de adhesión, en forma de gancho que además es biodegradable, que permite la adherencia al tejido de forma casi inmediata. Están confeccionadas con polipropileno y ácido poliglicólico, siendo su estructura de poro amplio $(1.8 \mathrm{~mm})$ y peso liviano luego de la absorción de las anclas $(49 \mathrm{~g} / \mathrm{m} 2)$.

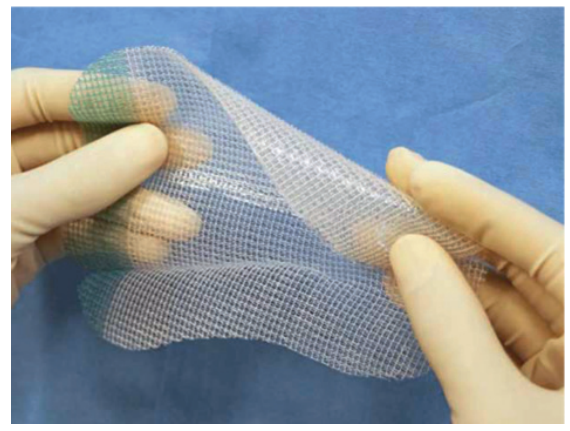

Malla Progrip (Covidien)

Las prótesis reticulares con polipropileno, generan un neoperitoneo con una estructura desorganizada, de textura rugosa, con algunas zonas de hemorragia y necrosis que facilitarían la aparición de adherencias. La estructura reticular de la prótesis, condiciona una inapropiada disposición sobre ella de las células mesoteliales, generando una superficie favorable para la formación de adherencias viscerales y sus complicaciones asociadas. ${ }^{(2)}$

También actualmente, disponemos de prótesis reticulares de politetrafluoroetileno no expandido. Son prótesis de mediana densidad $(70 \mathrm{~g} / \mathrm{m} 2)$.

\section{Prótesis laminares}

Las prótesis laminares están representadas fundamentalmente por el politetrafluoroetileno expandido (PTFEe), en todas sus variantes. Su integración es de tipo celular, invadiendo las mismas los tercios más externos de la prótesis. E1 tejido receptor encapsula con tejido conectivo al biomaterial. Los vasos no penetran en los intersticios del PTFEe, siendo la interfaz prótesis/tejido receptor no tan buena como en las prótesis reticulares, hecho que también se corrobora por los estudios tensiométricos.

Cuando esta prótesis se ha modificado, por ejemplo, perforando las mismas con pequeños orificios, es decir creando así una prótesis macro-microporosa, los resultados de resistencia a la tracción no mejoran. Otra modificación en la que se suprime la integración celular por la vertiente peritoneal del implante, y solamente dicha integración se efectúa por la vertiente superficial de la prótesis, provista de una superficie rugosa, tampoco mejora la resistencia mecánica de las prótesis convencionales de PTFE.

Las diferencias más interesantes, que poseen las prótesis laminares respecto a las reticulares, son aquellas que acontecen cuando el biomaterial se coloca en contacto directo con el peritoneo visceral. Las prótesis laminares permiten un buen desarrollo de neoperitoneo. En estudios experimentales se observa ya muy precozmente una red de fibras colágenas recubiertas de células mesoteliales típicas, colocadas de forma paralela a la superficie protésica. Con el tiempo, el neoperitoneo se remodela desapareciendo la mayoría de las células de reacción a cuerpo extraño (índice de la buena tolerancia de la prótesis), siendo los fibroblastos las dominantes. La génesis de este neoperitoneo perfectamente conformado, evita la formación de adherencias viscerales.

Entre las prótesis laminares existe actualmente materiales poliméricos, absorbibles, cuya estructura es un copolímero formado por ácido poliglicólico y carbonato de trimetileno. Estos materiales presentan una buena mesotelización e integración tisular, completando la reabsorción entre tres y seis meses. Son materiales diseñados para refuerzo y no para reparación tisular.

\section{Prótesis compuestas}

Para reunir en una sola prótesis la respuesta tisular de reticulares y laminares, han surgido las prótesis compuestas. De esta forma se podrían alcanzar las cualidades básicas ideales de un implante: a) buena integración tisular; b) buen comportamiento a nivel peritoneal y c) buena resistencia mecánica post-implante. 
Estas prótesis compuestas o bilaminares o de "doble capa", se crearon inicialmente para la reparación de grandes defectos herniarios, en los que básicamente hay que llevar a cabo una reconstrucción total de la pared abdominal y en los cuales no hay soporte prácticamente de tejido, teniendo que quedar ubicadas en contacto con el peritoneo visceral. Estas prótesis han abierto un amplio abanico de posibilidades, y su uso se extendió por la reparación intraperitoneal laparoscópica de los defectos abdominales. Por ello, el objetivo primordial de las mismas es mejorar el comportamiento en relación con la interfaz visceral y evitar la aparición de adherencias viscerales. Las prótesis compuestas tienen dos componentes: uno de ellos es el biomaterial principal (primer componente), al que se añade otro, que cumpla la función especifica que no puede llevar a cabo el primero (segundo componente), unidos mediante pegamentos acrílicos, termosellado e incluso sutura. El biomaterial del primer componente, asumirá el papel de integración tisular: prótesis reticular de polipropileno o poliester. El segundo componente estará en contacto directo con el peritoneo visceral y modula el comportamiento a nivel de esta interfaz, permitiendo la correcta mesotelización. Será de tipo laminar y puede ser absorbible (barrera química) o no absorbible (barrear física). Ambas barreras, no ofrecen diferencias significativas en la formación de un neoperitoneo. En el caso de las barreras químicas, ofrecen la ventaja de no dejar residuos en el organismo receptor al ser biodegradadas.

Estos materiales compuestos están permanentemente evolucionando en cuanto a su composición polimérica y especialmente en su estructura espacial. La realización de modelos de simulación electrónicos, permite recrear parámetros importantes, como fuerzas de presión (intracavitaria abdominal), tensión de los tejidos bajo esfuerzo, los cuales van a actuar directamente sobre el material protésico a implantar. De esta forma, pueden generarse materiales que se adapten de una forma más "fisiológica" a los requerimientos dinámicos de la pared abdominal.

Una malla ligera de polipropileno monofilamento o poliester, con una sola barrera de hidrogel absorbible tiene en cirugía de HI laparoscópica una tasa de complicación y de recurrencia baja. ${ }^{(5)}$

Covidien presenta: Parietex Composite y Symbotex Composite. Mallas bilaminares constituidas por una capa externa de polipropileno o poliester multifibra tridimensional con estructura hexagonal de $1,5 \mathrm{~mm}$ de espesor y tamaño del poro superior a $700 \mathrm{~m}$; y por la cara interna, una membrana antiadherente hidrofílica y reabsorbible de colágeno. Tejido macroporoso monofilamento tridimensional. Tamaño de los poros: $2.3 \times 3.3 \mathrm{~mm}$ Densidad: $66 \mathrm{~g} / \mathrm{m} 2$. Grosor $0.7 \mathrm{~mm}$.
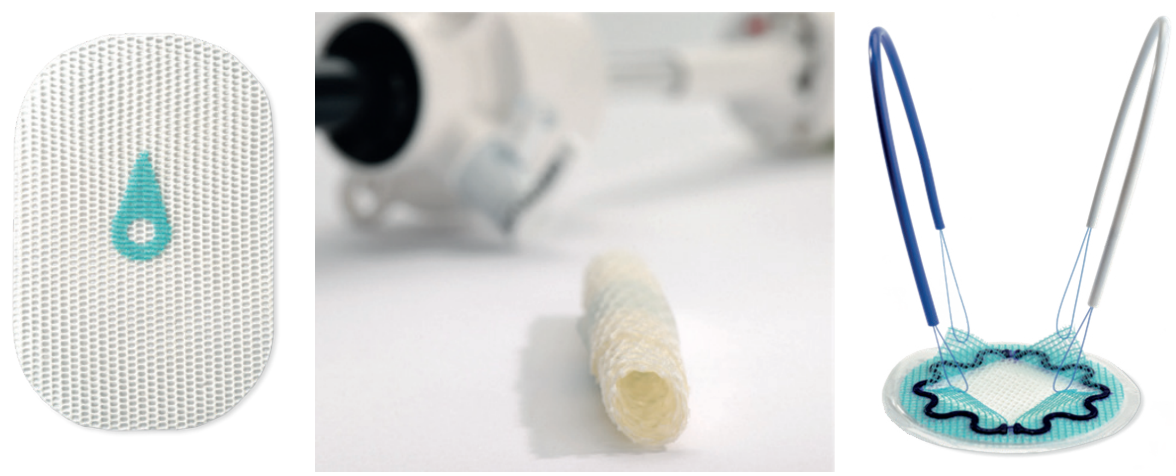

Parietex y Symbotex (covidien)

- Proceed ${ }^{\circledR}$ (Ethicon). Está formada por tres elementos: una malla de polipropileno con una densidad de $45 \mathrm{~g} / \mathrm{cm} 2 \mathrm{y}$ un tamaño de poro superior a $700 \mathrm{~m}$ encapsulada en polidioxanona (PDS); una capa de celulosa oxidada y regenerada absorbible, y una lámina de polímero de PDS reabsorbible, que une ambos elementos.
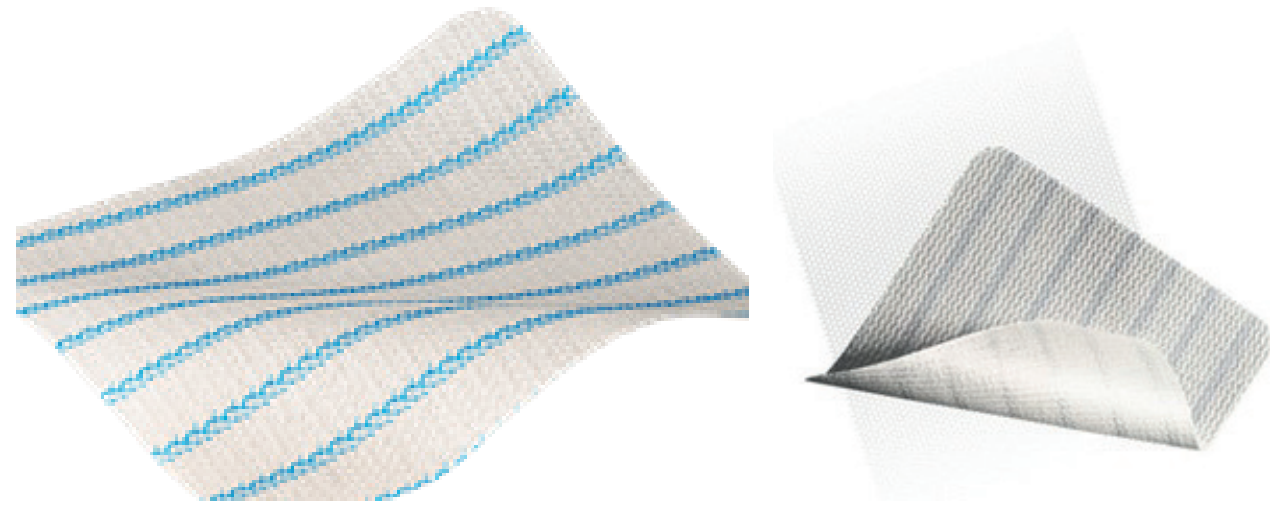

Proceed (Ethicon) 


\section{OTRAS NO DISPONIBLES EN URUGUAY}

Dynamesh IPOM ${ }^{\circledR}$. Formado por 2 estructuras -el fluoruro de polivinilideno (PVDF) y el polipropileno (PP). Presenta tres ventajas: 1) gran comodidad por su biocompatibilidad y propiedades dinamométricas; 2) gran seguridad por su durabilidad, ${ }^{(3)}$ y una óptima manipulación con buena transparencia, poca tendencia a enrollarse, y posibilidad de corte y de superposición.

Timesh $^{\circledR}$, prótesis bilaminar, base de la malla es un polipropileno de bajo peso molecular recubierta de titanio. Physiomesh $^{\circledR}$., malla compuesta, de bajo peso y parcialmente absorbible, formada por una malla macroporosa no absorbible de polipropileno, laminada entre dos capas de poliglecaprona-25, en desuso por mayor tasa de recidivas.

\section{Prótesis biológicas o bioprótesis}

Las prótesis biológicas forman parte de las nuevas herramientas disponibles dentro del arsenal terapéutico del cirujano, y podrían tener un papel importante en la reparación de las hernias ventrales, sobre todo en campos quirúrgicos contaminados, donde muestran mejor respuesta y resistencia a la infección que las mallas sintéticas. Son prótesis de origen natural, derivadas de colágeno, bien de procedencia animal o humana. El objetivo de estos biomateriales, es conseguir, además de la reparación, la regeneración tisular, de tal manera que, una vez implantados, estimulen elementos de la matriz extracelular del receptor, favorezcan la angiogénesis e incluso impliquen a los factores de crecimiento en la creación de una neopared abdominal. Para conseguir este último fin, es necesario que el proceso de degradación/ regeneración esté controlado.

Sus beneficios potenciales son muy atractivos: mejor biocompatibilidad (mínima respuesta inflamatoria), reducción de la formación de adherencias y disminución del riesgo de infección en ambientes contaminados, logrando así, evitar la infección aguda y/o crónica, la inflamación crónica, y la formación de tejido denso fibroso. ${ }^{(6)}$

El comportamiento de estas bioprótesis, desde el punto de vista reparativo (integración tisular) y en la formación de neoperitoneo, es muy similar a las prótesis poliméricas de tipo laminar.

Varias prótesis biológicas están en uso en en el mundo, pero no están disponibles en el mercado Uruguayo. Está en estudio la malla híbrida sintética/biológica. Su clasificación puede ser por: el origen (animal o humano), la procedencia del tipo de matriz tisular (dermis, pericardio, submucosa intestinal) y por la presencia de enlaces covalentes entre las moléculas de colágeno. El cirujano debe de saber, dependiendo del tipo de reparación que va a realizar, cuál es el material biodegradable o cuál es el que va a permanecer en los tejidos de forma definitiva.

El empleo de prótesis biológicas es todavía limitada, debido a varias causas: la existencia de otros materiales inertes (polipropileno, poliéster, PTFEe) con buenos resultados, las indicaciones precisas que tienen estas prótesis biológicas (pacientes inmunocomprometidos, zonas de reparación afectadas por contaminación bacteriana) y por su costo elevado. Su indicación en el abordaje laparoscópico es limitado, y compite con las prótesis lamimnares y doble faz.(7)

\section{Mallas Sintéticas Absorbibles}

La utilización de polímeros sintéticos absorbibles (poliglicólico, poliláctico) para la reparación de los defectos de la pared abdominal se ha asociado con el desarrollo de una hernia en virtualmente todos los casos. El uso de prótesis absorbibles en la cirugía de las hernias en situaciones electivas, limpias y no contaminadas está desaconsejado.

Su utilización se ha centrado sobre todo como recurso temporal en el cierre de una pared abdominal en "etapas" en contextos contaminados. En estas situaciones pueden tener la ventaja de mantener la resistencia del defecto de pared hasta que la piel lo ha cubierto y la infección se ha resuelto, momento en el que el paciente podrá beneficiarse de una segunda cirugía para reparar el defecto con un material sintético permanente.

Las mallas biológicas y las sintéticas absorbibles no han demostrado ninguna ventaja en campos contaminados. No se recomiendan en técnicas de puenteo por su alta tasa de recidiva. No deben recomendarse en la reconstrucción de la pared abdominal. ${ }^{(8)}$

Su uso en las plastias parietales laparoscópicas es excepcional.

\section{Clasificación e indicaciones de los pegamentos en la pared abdominal}

La técnica de reparación de la hernia abdominal ha evolucionado de la reparación con sutura primaria del orificio herniario a la reparación sin tensión por medio de una malla sintética o biosintética, resultando en un menor número de recidivas. El cirujano dispone de técnicas traumáticas y atraumáticas para la fijación de este tipo de mallas a la pared abdominal, entre las primeras las suturas, grapas y los tackers de titanio o reabsorbibles, sin embargo, la fijación atraumática con adhesivo ha representado una de las claves en la cirugía de la pared abdominal. 
Un adhesivo/pegamento se utiliza como hemostático, sellador de fístulas o anastomosis, y como adhesivas: unir órganos, tejidos o estructuras. El uso de este grupo de productos en la patología parietal herniaria, puede reducir la necesidad de emplear medios mecánicos de fijación. Usadados inicialmente en cirugía abierta de hernias y eventraciones, se encuentra ya difundido y adoptado, en numerosas técnicas de cirugía endoscópica parietal. ${ }^{(9)}$

El producto ideal debe tener ciertas características: seguridad, eficacia en unión de tejidos biologicos y sintéticos, facilidad de uso, relación costo-efectividad positiva y contar con la aprobación de los organismos reguladores.

El objetivo es evitar los efectos adversos asociados a los métodos mecánicos, tales como el dolor agudo y crónico por atrapamientos nerviosos u osteítis, hematomas, hemorragias y seromas parietales, formación de adherencias, pudiendo incluso reducir los tiempos quirúrgicos. Tienen además, mejor relación costo beneficio en la cirugía de la hernia inguinal laparoscóica, dependiendo del tipo y cantidad de grapas a usar en cada caso y su costo local. ${ }^{(10)}$

El beneficio es claro en hernias inguinales laparoscópicas y aún en estudio en las hernias ventrales.

Los adhesivos tisulares pueden ser clasificados en función de su composición en: naturales (fibrina), semisintéticos (albúmina bovina y glutaraldehído) y sintéticos (cianocrilatos).

\section{Adhesivos de Fibrina}

A nivel experimental, el uso de AF es una alternativa tan eficaz desde el punto de vista biomecánico (fuerza tensil, abombamiento de la malla con el aumento de la presión y desplazamiento de la malla) como el empleo de fijadores mecánicos. ${ }^{(11)}$ Los AF se reabsorben aproximadamente en unas tres semanas, dejando tejido conectivo endógeno, favoreciendo la integración de los materiales protésicos. Se considera con menor capacidad adhesiva que otros productos. $^{(11)(12)}$

\section{Adhesivos Semisintéticos (ALBÚMINA BOVINA Y GLUTARALDEHÍDO)}

Se han estudiado varios sistemas que incluyen enlaces de proteínas (gelatina o albúmina bovina) por medio de aldehídos (formaldehído, glutaraldehído) que son bien conocidos por sus propiedades de fijación de tejidos. (Bioglue $\left.{ }^{\circledR}\right)$ A nivel experimental, el Bioglue tiene exelentes propiedades adhesivas, pero muestra una baja biocompatibilidad, causando una integración e inflamación desfavorables, tanto en ubicación intra o extraperitoneal de la malla, no siendo recomendable su uso. ${ }^{(13)}$

\section{Adhesivos Sintéticos (CIANOCRILATOS)}

Los cianocrilatos son productos sintéticos, que por alteración del grupo alcoxicarbonilo de la molécula, podemos obtener diferentes tipos de sustancias, utilizadas como adhesivos y hemostáticos. Cuando son aplicadas y entran en contacto con tejido vivo, en el contexto de un ambiente húmedo, polimerizan rápidamente, creando una fina película elástica de elevada resistencia a la tensión, garantizando una sólida adhesión a los tejidos.

La fijación de las mallas con Cianocrilatos, durante la reparación de las hernias inguinales por vía laparoscópica, es segura, reduce el tiempo quirúrgico y el dolor postoperatorio. Es efectiva, costo-beneficio adecuada y por lo tanto recomendada actualmente. ${ }^{(14)(15)(16)}$ Exsisten dispositivos comerciales con piostola aplicadora, o bien se puede introducir mediante un sistema casero con un catéter de alimentación a través de un Abocath.

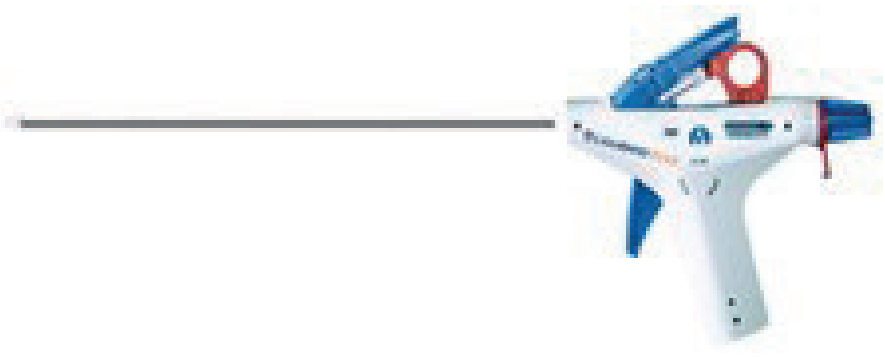



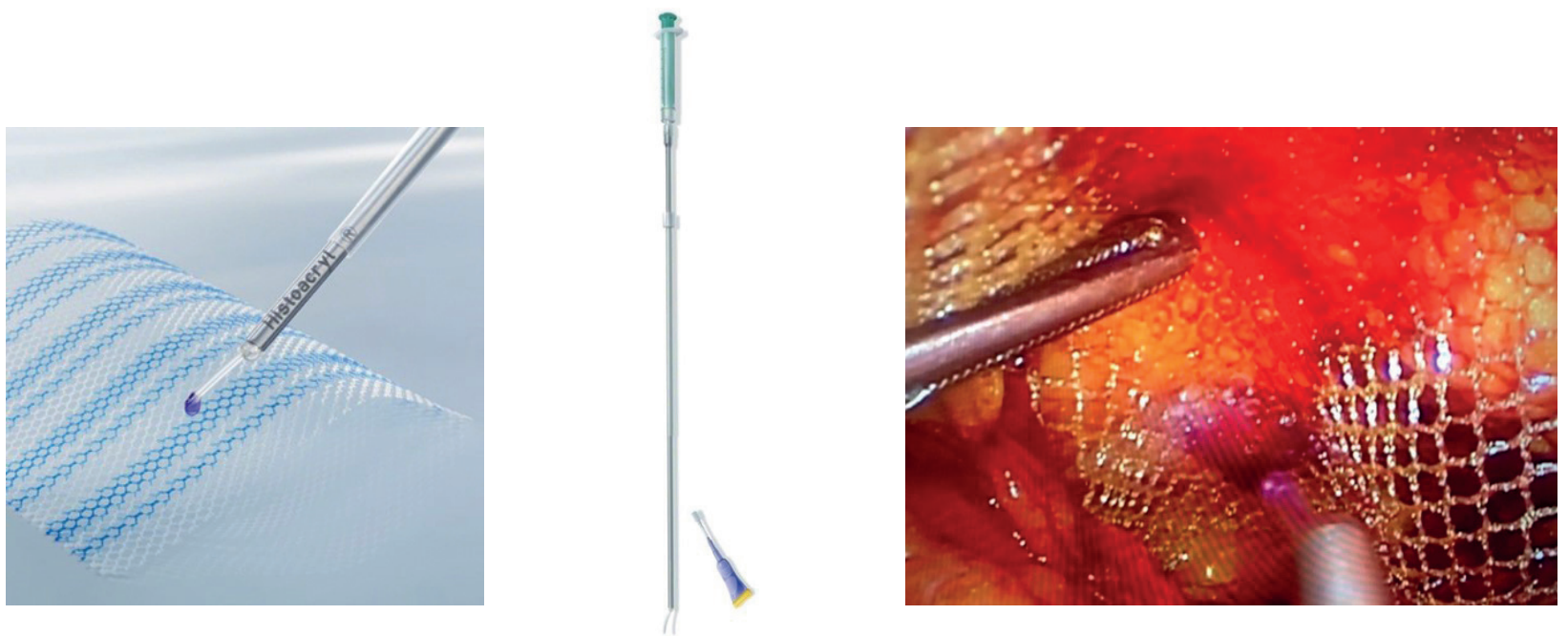

Histoacry ${ }^{\circledR}$ LapFix (Braun)

El efecto en la cirugía de las hernias ventrales, permanece en estudio. Se usa en forma segura y eficaz en técnicas de fijación combinada con fijación traumática en IPOM/IPOM plus, siendo de elección en las técnicas totalmente extraperitoneales, en ocasiones combinada con algún tipo de fijación invasiva. ${ }^{(5)(10)}$

\section{Sistemas mecánicos para la fijación de mallas}

La correcta fijación de las mallas sigue siendo hoy día objeto de debate. Históricamente se ha considerado indispensable un anclaje firme de las prótesis a las distintas referencias anatómicas de cada hernia en cuestión, pero la evolución de la cirugía de la hernia y la eventración es hacia una reparación cada vez más funcional, menos agresiva y, en definitiva, lo más fisiológica posible. ${ }^{(17)}$

Antiguamente, el debate era si fijar las mallas con suturas reabsorbible o irreabsorbibles; y con suturas contínuas o puntos separados. La llegada de los nuevos sistemas de fijación, amplía el espectro de posibilidades, surgiendo la posibilidad de su uso aislado o combinado con puntos o adhesivos, intentando que la malla no se mueva hasta lograr su integración a la pared abdominal. ${ }^{(10)}$

Tipos de agrafes: 1) Agrafes planos (grapas), más utilizados en cirugía abierta convencional; 2)Agrafes espirales (tackers), para uso abordaje laparoscópico, Irreabsorbibles o Reabsorbibles.

\section{Las Ventajas de los sistemas de fijación mecánicos son: ${ }^{(17)}$}

1. Tiempo operatorio: tanto en cirugía abierta como por vía laparoscópica, la colocación de estos agrafes es eficaz, sencilla y muy rápida, por consiguiente se reduce considerablemente la duración de la intervención, aún fijando la prótesis en varios puntos, más que si se realizara mediante sutura manual.

2. Acceso: los dispositivos dispensadores de estos tackers acceden a regiones anatómicas difíciles de alcanzar o bien riesgosas.

3. Penetrancia: tienen un espesor que asegura la fijación de la malla al plano aponeurótico, pero sin traspasar el total de la pared abdominal.

Las Desventajas de los sistemas de fijación mecánicos son: ${ }^{(5)(8)(16)}$

1. Dolor postoperatorio: las causas son el atrapamiento o lesión de fibras nerviosas sensitivas y a la reacción a cuerpo extraño, que inducen en los tejidos circundantes. La fijación con agrafes metálicos o absorbibles, no tienen diferencia en dolor postoperatorio, así como tampoco hay diferencia entre la fijación con suturas transfasciales o tackers.

2. Fuerza tensil: existen estudios que apuntan a una reducción de hasta el 50\% en la fuerza tensil de los tackers comparándola con suturas transfasciales, lo que en teoría, tendría una consecuencia negativa en el plegamiento o desplazamiento de la malla, defectos de cobertura y por último, recidiva. Se reconoce una tasa de recidivas creciente entre fijaciones con suturas transfasciales, tackers metálicos y tackers anbsorbibles. En grandes eventraciones, obesos, tabaquistas o EPOC, situaciones de máximo requerimiento de los fijadores, se proponen sistemas de fijación especial como se describirá oportunamente.

3. Retracción: los tackers son estáticos y la malla sufre una retracción variable (hasta 30\%) en los primeros meses, por esto la importancia de la cobertura amplia del defecto, con cierta elasticidad considerando este margen de retracción. 
4. Lesión de estructuras viscerales: se han descrito casos de lesión de vasos y de asas intestinales por horadación directa o por decúbito del agrafe sobre la estructura anatómica en cuestión, esto puede dar como resultado la creación de adherencias, fístulas, sangrado. Se ha propuesto la cobertura de la superficie cruenta de estos agrafes con sustancias protectoras como pudieran ser colas de fibrina u otros elementos de barrera similares.

\section{Sistemas de Tackers para Laparoscopía}

Diseñados para ofrecer una fijación mecánica en localizaciones a distancia y de difícil acceso, sobre todo en el abordaje laparoscópico.

Los tackers pueden ser irreabsorbibles de titanio (espiral o sacacorchos), o reabsorbibles (ácido poliláctico o polidioxanona). Existen sistemas helicoidales de punta fina y base ancha, macizos en su interior, otros cilíndricos huecos, de diámetro constante, que permiten el crecimiento del neotejido en su interior. Otro tipo de agrafes reabsorbibles, tienen conformación que asemeja a una punta de flecha. La versatilidad y eficacia de ambos sistemas es similar. ${ }^{(10)}$

Los agrafes reabsorbibles, tienen como ventaja, la eliminación de material residual con la consiguiente minimización de la reacción a cuerpo extraño. Esto mejoraría morbilidad a corto plazo y largo plazo: al desaparecer completamente el biopolímero aproximadamente al año de su colocación (dependiendo de la composición), se reducen el dolor (agudo y crónico), inflmación crónica; los riesgos de lesión visceral por decúbito y la formación de adherencias peritoneales. La degradación paulatina, permite la integración segura de la malla en los tejidos. ${ }^{(17)}$ Existe evidencia de la mayor tasa de recidivas con tackers reabsorbibles. ${ }^{(10)(18)}$
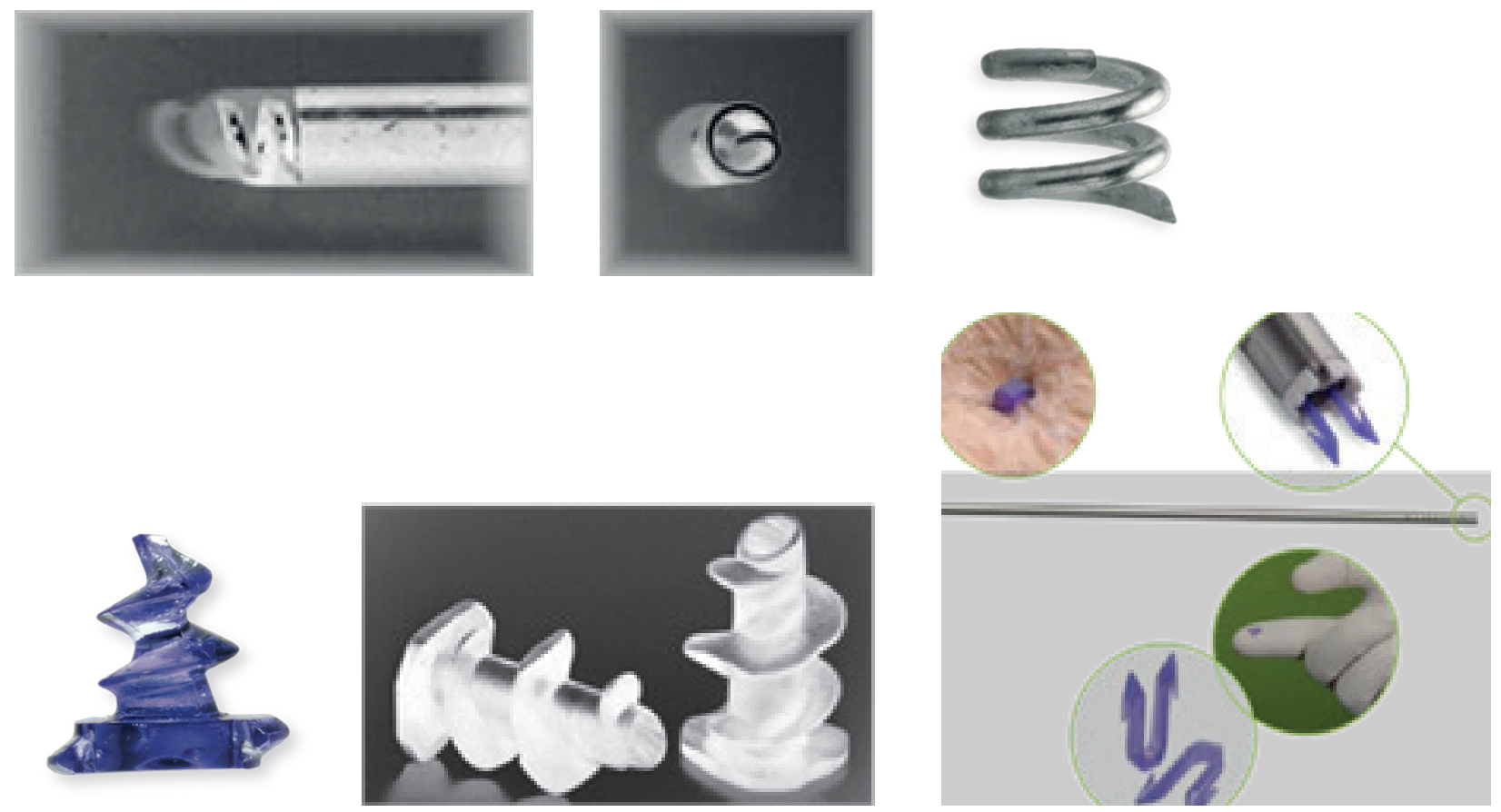

Es preciso elegir el tipo y tamaño de la grampa y la longitud del dispensador, según el caso a reparar. Una vez desplegada la malla se intenta orientar la máquina de tackers lo más perpendicular posible a la superficie de fijación, para la correcta penetración del dispositivo. La suave presión externa ayuda a dar sostén al disparo. Una presión excesiva aumeta el dolor y las lesiones nerviosas parietales. En caso de desprendimiento de uno de estos tackers es preciso encontrarlo y retirarlo, dado el riesgo de lesión visceral ulterior. El tipo de fijación y su correcta colocación, tiene incidencia en las recurrencias herniarias. ${ }^{(18)}$ 


\section{BIBLIOGRAFÍA}

1) Lichtenstein IL, Shulman AG, Amid PK, Montlor MM. The tension-free hernioplasty. Am J Surg 1989;157:18893.

2) Bellón Caneiro JM. Clasificación de los materiales protésicos; 7: 97-105 Guías Clínicas de la Asociación Española de Cirujanos Cirugía de la Pared Abdominal 2a Edición 2013

3) Orenstein SB. Permanent Prosthetics: Polypropylene, Polyester, ePTFE, and Hybrid Mesh 5:57-69 Society of American Gastrointestinal and Endoscopic Surgeons (SAGES) 2019; 5:57-69 S. S. Davis Jr. et al. (eds.), The SAGES Manual of Hernia Surgery, https://doi.org/10.1007/978-3-319-78411-3_5

4) Bellón JM, Rodríguez M, García-Honduvilla N, Pascual G, Buján J. Partially absorbable meshes for hernia repair offer advantages over nonabsorbable meshes. Am J Surg 2007;194:68-74.

5) González LG, Lora A, Varela E, Vergara G, Vega Peña V, Ayala JC, Martínez JD, Hanssen A, Gómez JP, Ruiz JP. Guía para el tratamiento laparoscópico de la hernia ventral e incisional. Rev Hispanoam Hernia. 2021;9(2):105117

6) Bellón JM, Rodriguez M, Gómez-Gil V, Sotomayor S, Pascual G. Postimplant intraperitoneal behaviour of collagen-based meshes followed by laparoscopy. Surg Endosc 2012;26:27-35.

7) López Cano M, Arbos Vía MA, Armengol Carrasco M. Mallas biológicas 8:107-114 Guías Clínicas de la Asociación Española de Cirujanos Cirugía de la Pared Abdominal 2a Edición 2013

8) Roca Domínguez B, Gutiérrez Ferreras AI, Mayagoitia JC. Guía para el manejo de la hernia ventral e incisional medial. Rev Hispanoam Hernia. 2021;9(2):80-87

9) Barranco Moreno A, Socas Macías M, Morales Conde S. Clasificación e indicaciones de los pegamentos en la pared abdominal 9:115-124 Guías Clínicas de la Asociación Española de Cirujanos Cirugía de la Pared Abdominal 2a Edición 2013

10) Stoikes N, Webb D, and Voeller G. Prosthetic Fixation Options 7: 85-96. Society of American Gastrointestinal and Endoscopic Surgeons (SAGES) 2019 S. S. Davis Jr. et al. (eds.), The SAGES Manual of Hernia Surgery, https://doi.org/10.1007/978-3-319-78411-3_5

11) Morales-Conde S, Barranco A, Socas M, Alarcón I, Grau M, Casado MA. Systematic review of the use of fibrin sealant in abdominal-wall repair surgery. Hernia. 2011 Mar 31.

12) Lovisetto $F, Z$ Znta $S$, Rota $E$, et al. Use of human fibrin glue (Tissucol) versus staples for mesh fixation in laparoscopic transabdominal preperitoneal hernioplasty: a prospective, randomized study. Ann Surg 2007;245:222-31.

13) Gruber-Blum S, Petter-Puchner AH, Mika K, Brand J, Redl H, Ohlinger W, et al. A comparison of a bovine albumin/glutaraldehyde glue versus fibrin sealant for hernia mesh fixation in experimental onlay and IPOM repair in rats. Surg Endosc. 2010 Dec;24(12):3086-94.

14) Fortelny RH, Petter-Puchner AH, Walder N, Mittermayr R, Ohlinger W, Heinze A, Redl H. Cyanoacrylate tissue sealant impairs tissue integration of macroporous mesh in experimental hernia repair. Surg Endosc. 2007 ;21(10):1781-5.

15) Kukleta J, Freytag C, Weber M. Efficiency and safety of mesh fixation in laparoscopic inguinal hernia repair using n-butyl cyanoacrylate: long term biocompatibility in over 1300 mesh fixations. Hernia. 2012;16:153-62.

16) The HerniaSurge Group International guidelines for groin hernia management Hernia.2018; 22(1): 1-165. Published online 2018 Jan 12. doi: 10.1007/s10029-017-1668-x

17) Bustos Jiménez M, Martín Cartes JA, Tamayo López MJ. Grapas y suturas espirales para la fijación de mallas 10: 125-132 Guías Clínicas de la Asociación Española de Cirujanos Cirugía de la Pared Abdominal 2a Edición 2013

18) Virinder R. Kumar B. Bansal F. et al. A prospective randomize study comparing suture mesh fixation versus tacker mesh fixation for laparoscopic repair of incisional and ventral hernias. Surg Endosc 2011;25(5):1431-8. 


\section{CONCEPTOS ACTUALES EN EL DIAGNÓSTICO DE HERNIAS Y EVENTRACIONES}

\section{Dra. Gabriela Rodríguez}

La cirugía parietal de las hernias inguino-femorales así como de las hernias ventrales primarias e incisionales (eventraciones) es de las más frecuentemente realizadas por los cirujanos en el mundo. Sin embargo continúa siendo un tema controversial; sobre todo actualmente con el advenimiento de nuevos procedimientos de reparación, nuevos materiales protésicos así como a la especialización de los equipos quirúrgicos en esta patología.

Estos cambios han llevado a la necesidad fundamental de unificar criterios tanto en el diagnóstico, la clasificación de los defectos parietales así como la necesidad de mayor y más precisa información de los componentes del defecto parietal y de la pared abdominal.

De esta manera se intenta lograr una estandarización de la valoración preoperatoria, la planificación de la reparación parietal y lograr desarrollar pautas de medicina basada en la evidencia mejorando de esta manera los resultados.

Con estos objetivos en mente, debemos tener en cuenta la necesidad de un registro estandarizado y detallado que se pueda reproducir fácilmente, Es por eso que se han desarrollado bases de datos para registros de hernias ${ }^{(1)} \mathrm{y}$ se han generado nuevas clasificaciones tanto para las hernias inguinales, ventrales primarias así como para las eventraciones ${ }^{(2)(3)}$

Todo lo planteado anteriormente ha obligado a la necesidad de recurrir a los estudios de imagen preoperatorios, sobretodo la tomografía, para evaluar de manera completa el defecto parietal y la pared abdominal en su conjunto.

Por tanto en este capítulo analizaremos:

- Anatomía de la pared antero lateral del abdomen. Fundamental para la reparación parietal y la correcta interpretación de los estudios de imagen.

- Las nuevas clasificación de las hernias primarias y las hernias incisionales.

- La valoración preoperatoria necesaria para lograr planificar de manera adecuada la reparación parietal, tomando en cuenta los factores más relevantes para lograr los mejores resultados.

\section{Anatomía de la pared antero lateral del abdomen ${ }^{(4)}$}

Es fundamental el conocimiento de la pared antero lateral del abdomen para la correcta interpretación de las imágenes así como para una correcta reparación de las hernias ventrales y eventraciones.

Tres músculos crean la masa lateral de la pared abdominal de adentro hacia afuera.

- Musculo transverso del abdomen

- Musculo oblicuo interno

- Musculo oblicuo externo

Comienzan en la parte posterior de la región paraespinosa y convergen en el borde lateral del musculo recto del abdomen creando la línea semilunar.

\section{Musculo transverso}

Sus fibras se orientan transversalmente y contribuyen a la vaina posterior del recto en el tercio superior del abdomen. En los dos tercios inferiores del abdomen, las fibras musculares se detienen lateralmente al recto y la fascia transversal por sí sola contribuye a la vaina del recto posterior.

\section{Oblicuo interno}

Las fibras del músculo oblicuo interno terminan en la línea semilunar. Su fascia anterior y posterior se convierten en la vaina del recto anterior y posterior en los dos tercios superiores del abdomen. En el tercio inferior del abdomen por debajo del nivel de la línea arcuata, ambas capas fasciales pasan por delante de los músculos rectos, dejando solo la capa fascial transversal como vaina del recto posterior.

\section{Oblicuo externo}

Las fibras de este musculo terminan en la línea semilunar y su fascia de revestimiento crea parte de la vaina del recto anterior. 


\section{Músculos rectos}

Los músculos rectos del abdomen crean el núcleo central del abdomen. Están limitados lateralmente por la línea semilunaris y separados medialmente por la línea alba. Por arriba se extienden desde el xifoides y las costillas llegando a la sínfisis pubiana. La vaina de estos músculos está formada por las fascias de los músculos anchos.

Los músculos piramidales son pequeños músculos triangulares que se originan en la cresta púbica y se insertan en la línea alba. Corren por delante del músculo recto, pero dentro de la vaina del recto. Están ausentes en más del 20\% de los individuos. (fig. 1)

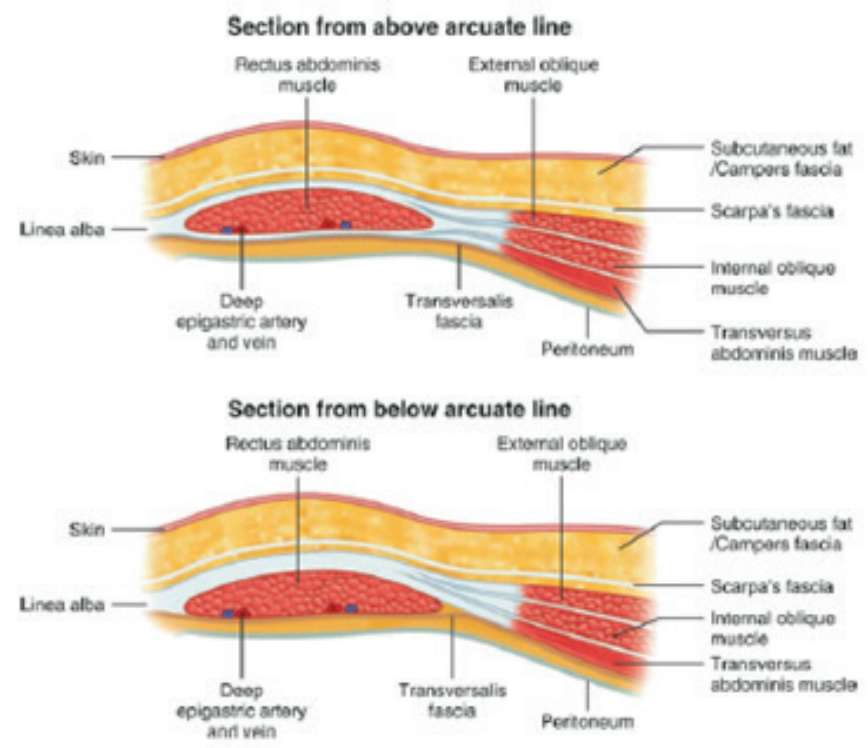

Figura 1: Estructuras fasciales por debajo y por arriba de la línea arcuata. Tomado de Sages Manual of Surgery

\section{Vascularización}

La vascularización de la pared abdominal se divide en tres zonas.

La zona 1 es el abdomen superior central. Irrigada superiormente por la arteria epigástrica superior rama de la mamaria interna. Inferiormente por la epigástrica inferior rama de la iliaca externa. Ambas convergen en la región supra umbilical. Transcurren por detrás del musculo recto dando los vasos perforantes

La zona 2 abarca el área supra púbica por debajo de la línea arqueada. El área está irrigada medialmente por las ramas superficial y profunda de la arteria epigástrica inferior. Lateralmente, el riego sanguíneo proviene de la arteria ilíaca circunfleja superficial como una rama de la ilíaca externa.

La zona 3 es el área superior a la línea arqueada y lateral a la línea semilunar. Está perfundido inferiormente por la arteria ilíaca circunfleja profunda y superiormente por la arteria musculofrénica como rama lateral de la arteria mamaria interna. (fig. 2)

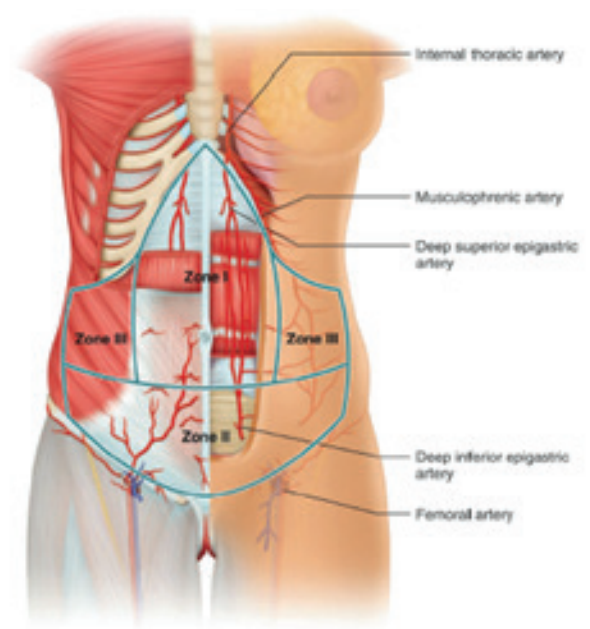

Fig 2. Vascualrizacion de la pared anterior del abdomen. Tomado del Sages Manual of Surgery 


\section{Nervios}

Los nervios que inervan la pared abdominal corren en el plano entre el transverso del abdomen y los músculos oblicuos internos. Superiormente, estos nervios provienen de las raíces espinales T6-T12. En la parte inferior, la raíz del nervio L1 proporciona inervación a través de los nervios ilioinguinal e iliohipogástrico (fig.3)

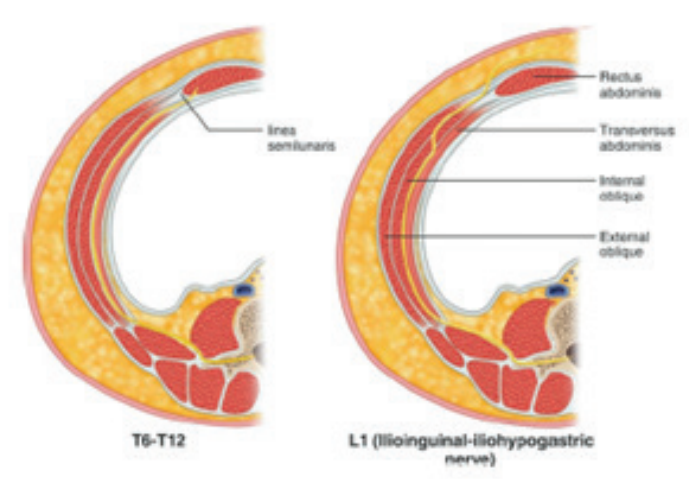

Fig 3: inervación pared anterior del abdomen. Tomado del Sages Manual of Surgery.

\section{Clasificación de hernias inguinales y hernias de la pared abdominal primarias e incisionales}

A lo largo de la historia han existido múltiples clasificaciones para las hernias inguinales, mientras que para las hernias ventrales primarias y secundarias los intentos de clasificación estandarizada han demoraron más en aparecer.

Las clasificaciones de las hernias inguinales más ampliamente utilizadas, como la de Nyhus por dar un ejemplo, han perdido validez. Esto se debe a la aparición de las reparaciones protésicas así como de la cirugía laparoscópica. Esto asociado a la necesidad de unificar criterios obliga a realizar nuevas clasificaciones estandarizadas, reproducibles, fáciles de recordar y que contemplen los datos relevantes para la reparación parietal.

Con estos objetivos en el 2007 la Sociedad Europea de la hernia (EHS) presento una clasificación de las hernias inguinales y en el 2009 de las hernias de la pared abdominal primarias y eventraciones. ${ }^{(3)}$

Estas clasificaciones son intraoperatorias pero con las técnicas actuales de imágenes obtenidas en el preoperatorio es posible obtener estos datos previamente a la cirugía.

\section{Clasificación hernias inguinales}

Las hernias inguinales se clasifican usando una combinación entre la localización y el tamaño

Según la localización:

L: lateral (indirecta), M: medial (directa), F: femoral

Según el tamaño:

Para el tamaño se utiliza en cirugía abierta el tamaño de la punta del dedo índice y en cirugía laparoscópica la longitud de las ramas de las pinzas. Ambos miden entre $1,5 \mathrm{a} 2 \mathrm{~cm}$.

1: hasta $2 \mathrm{~cm}$,

2: hasta $4 \mathrm{~cm}$,

3: más de $4 \mathrm{~cm}$

Para una hernia combinada se utilizan las letras correspondientes (L, M y/o F).

Si es una recidiva herniaria se le agrega la letra $\mathrm{R}$ y si es una primaria la letra $\mathrm{P}$. Se coloca la letra $\mathrm{X}$ en una situación poco clara o región herniaria no explorada. Se coloca 0 si se exploró la región y no presenta hernia (Tabla 1)

\begin{tabular}{|c|c|c|c|c|c|}
\hline Clasificación & & Primaria & Recurrente & & \\
\hline & 0 & 1 & 2 & 3 & $\mathrm{x}$ \\
\hline $\mathrm{L}$ & & & & & \\
\hline M & & & & & \\
\hline F & & & & & \\
\hline
\end{tabular}

Tabla 1: clasificación hernia inguinal 


\section{Clasificación de las hernias de la pared anterior del abdomen}

En el 2009 la EHS propuso una clasificación para las hernias primarias de la pared anterior del abdomen y las hernias incisionales o eventraciones utilizando los mismos criterios que para la hernia inguinal ${ }^{(2)}$

\section{Hernias primarias}

Se clasifican combinando la localización y el tamaño (tabla 2)

De esta manera tenemos las hernias:

- Mediales

- Laterales

Dentro de las mediales tenemos la epigástrica y la umbilical y dentro de las laterales tenemos la lumbar y la hernia de Spiegel.

Dado que estas hernias tienen una forma ovalada se utiliza su diámetro para clasificarlas.

Según diámetro:

- diámetro menor a $2 \mathrm{~cm}$ son pequeñas,

- mayores o iguales a 2 y menores de $4 \mathrm{~cm}$ son medianas

- iguales o mayores a $4 \mathrm{~cm}$ son grandes

\begin{tabular}{|l|l|l|l|l|}
\hline $\begin{array}{l}\text { Hernias } \\
\text { primarias } \\
\text { de la pared } \\
\text { abdominal }\end{array}$ & & $\begin{array}{c}\text { Pequeñas } \\
<2 \mathrm{~cm}\end{array}$ & $\begin{array}{c}\text { Medianas } \\
>=2 \mathrm{a} 4 \mathrm{~cm}\end{array}$ & $\begin{array}{c}\text { Grandes } \\
>4 \mathrm{~cm}\end{array}$ \\
\hline \multirow{2}{*}{ Mediales } & Epigástrica & & & \\
\cline { 2 - 5 } & umbilical & & & \\
\hline \multirow{2}{*}{ Laterales } & Spiegel & & & \\
\cline { 2 - 5 } & lumbar & & & \\
\hline
\end{tabular}

Tabla 2: Clasificación de las hernias primarias de la pared abdominal.

\section{Hernias incisionales o eventraciones}

A lo largo de los últimos 20 años se han intentado múltiples clasificaciones de las hernias incisionales, sin lograr llegar a un consenso que se reflejara en la utilización de manera generalizada de estas clasificaciones

Esto se debe fundamentalmente a que las hernias incisionales tienen una presentación y patogenia muy variada que influye en la calidad de su reparación y es imposible integrar en una única clasificación todos los factores que orienten a una técnica adecuada. Es así que en el año 2000 J.P. Chevrel1(5) ${ }^{(5) a l i z o ~ u n ~ e s t u d i o ~ r e t r o s p e c t i v o ~ e n ~ b u ́ s q u e d a ~ d e ~ f a c-~}$ tores de mayor valor predictivo para proponer una clasificación de las hernias incisionales. De esa manera propuso una clasificación tomando en cuenta la localización, el tamaño (más específicamente el ancho), y el número de reparaciones previas. Esta clasificación si bien también ha sufrido criticas como ser la falta de factores como el biotipo del paciente, o factores de riesgo de recurrencia ${ }^{(6)}$ es en la que se basa la clasificación de la EHS 2009.

Esta clasificación ha intentado simplificar las clasificaciones previas para que sea ampliamente aceptada y reproducible. Si bien no todos los puntos considerados han sido completamente consensuados se plantea como un punto inicial para la unificación de criterios.

La calificación toma en cuenta la localización, el tamaño y recurrencia o no.

Se divide el abdomen en medial y lateral

La región media es aquella que va desde el apéndice xifoides hasta el pubis. Lateralmente su límite es el margen lateral de la vaina de los músculos rectos. Esta región se divide 5 zonas mediales ${ }^{(2)}$ (fig.4):: 


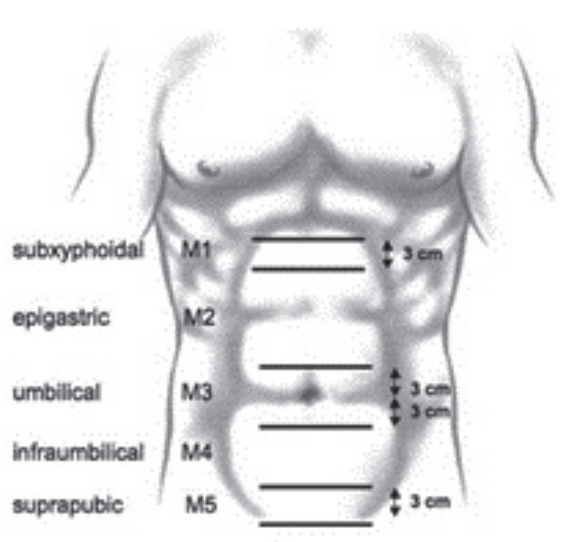

Fig 4: clasificación de las hernias incisionales mediales. Tomado de EHS

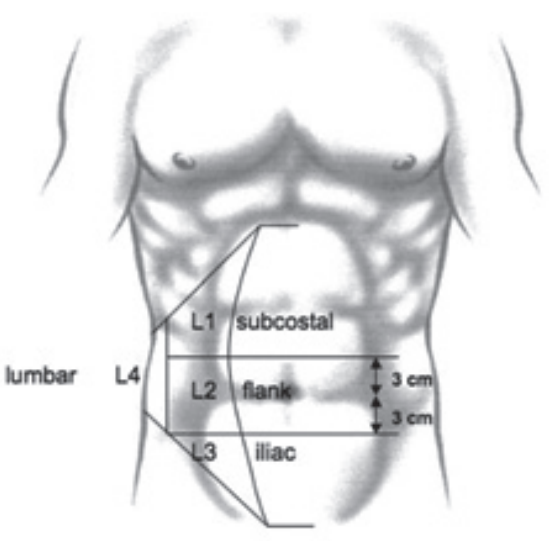

Fig 5: clasificación hernias incisionales laterales. Tomado EHS

M1: SUBXIFODEA desde el xifoides a $3 \mathrm{~cm}$ por debajo.

M2: EPIGASTRICA desde la región subxifoidea hasta $3 \mathrm{~cm}$ por encima del ombligo.

M3: UMBILICAL desde la región epigástrica a $3 \mathrm{~cm}$ por debajo del ombligo.

M4: SUBUMBILICAL desde la región umbilical a $3 \mathrm{~cm}$ por arriba del pubis.

M3: SUPRAPUBICA desde el pubis a $3 \mathrm{~cm}$ por arriba.

Si una eventración abarca más de una zona se debe colocar todas las zonas que abarca

Si son más de un defecto parietal pero solo provocado por una incisión se considera una eventración única pero si son varios defectos provocados por más de una incisión se consideran hernias incisionales diferentes.

Los límites de las regiones laterales son (Figura5):

- Superior: el margen costal,

- Inferior: la región inguinal

- Medial: el margen lateral de las vaina de los rectos

- externo: la región lumbar

Se divide entonces en 4 zonas:

- L1: SUBCOSTAL por debajo de las costillas y $3 \mathrm{~cm}$ por debajo del ombligo.

- L2: FLANCO: $3 \mathrm{~cm}$ por arriba y $3 \mathrm{~cm}$ por debajo del ombligo.

- L3: ILIACO: $3 \mathrm{~cm}$ por debajo del ombligo y la región inguinal.

- L4 LUMBAR: por fuera de la línea axilar anterior.

Tomando en cuenta su diámetro transversal: $\mathrm{W} 1: 4 \mathrm{~cm}$; W2: 4-10 cm; W3: C $10 \mathrm{~cm}$.

\begin{tabular}{|c|c|c|c|}
\hline \multicolumn{4}{|l|}{ Hernia insicional } \\
\hline \multirow{5}{*}{$\begin{array}{l}\text { LÍNEA } \\
\text { MEDIA }\end{array}$} & \multicolumn{2}{|c|}{ Subxifoidea } & \\
\hline & \multicolumn{2}{|c|}{ Epigastrica } & \\
\hline & \multicolumn{2}{|c|}{ umbilical } & \\
\hline & \multicolumn{2}{|c|}{ subumilical } & \\
\hline & \multicolumn{2}{|c|}{ Suprapubica } & \\
\hline \multirow{4}{*}{ LATERAL } & \multicolumn{2}{|c|}{ Subcostal } & \\
\hline & \multicolumn{2}{|c|}{ Flanco } & \\
\hline & \multicolumn{2}{|l|}{ Iliaca } & \\
\hline & \multicolumn{2}{|c|}{ Lumbar } & \\
\hline Recidiva & \multicolumn{2}{|l|}{ Sí } & No \\
\hline Ancho & Alto & $\mathrm{cm}$ & \\
\hline \multirow{2}{*}{ Tamaño } & W1 & W2 & W3 \\
\hline & & & \\
\hline
\end{tabular}

Tabla 3: clasificación de hernias incisionales 
El ancho del defecto herniario se definió como la mayor distancia horizontal en $\mathrm{cm}$ entre los márgenes laterales del defecto herniario en ambos lados. En caso de múltiples defectos, el ancho se mide entre los márgenes más laterales de todos los defectos juntos.(fig6)

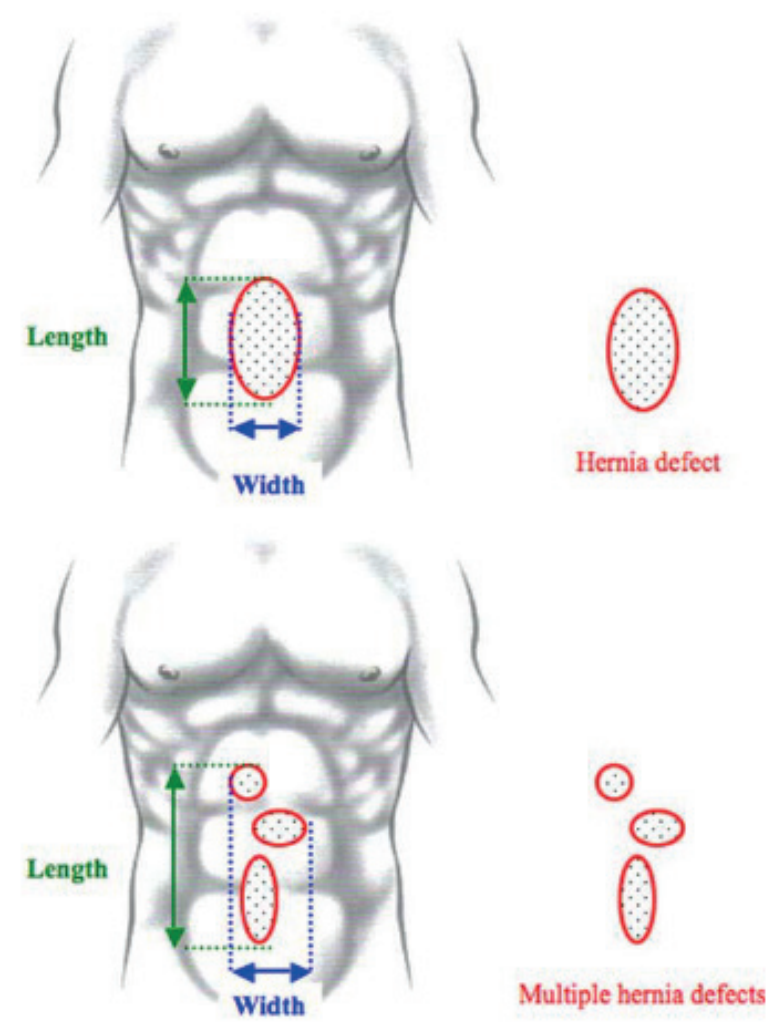

Figura 6: alta y ancho de las hernias incisionales. Tomado EHS

\section{Valoración preoperatoria}

Debemos obtener una historia clínica completa haciendo énfasis:

- antecedentes quirúrgicos como ser: incisiones quirúrgicas, complicaciones posoperatorias. Existencia de ostomas previos. En hernias incisionales es fundamental la historia de reparaciones previas, la técnica empleada y el tipo de malla utilizada, el plano donde se encuentra la malla.

- factores a corregir en el preoperatorio tabaquismo, obesidad, diabetes.

Todos estos datos son fundamentales para una adecuada planificación de la técnica de reparación, la necesidad o no de separación de componentes, tamaño y tipo de implante protésico así como el plano más adecuado para la colocación de la malla ${ }^{(4)}$

Si bien el diagnóstico de hernia y eventración es clínico, existen situaciones particulares en los cuales necesitamos realizar estudios de imagen, como pacientes obesos, multioperados, hernias de localización atípica, o frente a la sospecha de complicaciones. Incluso actualmente debido al mejor conocimiento de la anatomía y dinámica parietal así como la especialización de los equipos quirúrgicos y el desarrollo de técnicas de reparación más complejas y nuevos materiales protésicos se ha vuelto imprescindible la obtención de imágenes en las hernias y eventraciones más complejas ${ }^{(4)}$

\section{ECOGRAFÍA}

La ecografía siempre ha tenido su lugar en el diagnóstico de las hernia sobre todo de topografía inguinal y en su control posoperatorio. La exploración física por sí sola no detecta el 20-30\% de las hernias inguinales teniendo una sensibilidad $74,5 \%$ y especificidad del $96,3 \%$ para su diagnóstico, mientras que la ecografía tiene una sensibilidad de $92 \%$ y especificidad del $96,3 \%$ incluso superior en algunos trabajos. ${ }^{(7)(8)(9)}$ Pero en un meta análisis y revisión sistemática realizada en el 2013 se vio que la ecografía disminuye su sensibilidad a 86 \% y especificidad al 77\% en el diagnóstico de las hernias 
inguinales ocultas que es donde podría tener su mayor utilidad y que las altas sensibilidades de la ecografía se dan mayormente en pacientes con hernias clínicamente manifiestas. ${ }^{(10)}$

La ecografía es económico, no invasivo, fácil de realizar, disponible permite la obtención de imágenes en tiempo real, minimiza la exposición a radiaciones. Se debe realizar de manera dinámica con maniobra de Valsalva. Pero depende en gran medida del técnico, no es recomendada en obesidad móbida, no puede estimar tamaños, calcular volúmenes, valorar prótesis previas y en los casos en que podría ser más beneficiosa como en la hernia inguinal oculta su valor es discutido. ${ }^{(9)}$

Por lo que la ecografía mantiene sobre todo su valor en los diagnósticos diferenciales de tumoración a nivel inguinal como ser hidrocele, hematoma, aneurisma, varicocele, absceso, embarazo ectópico, fibromas, orquiepididimitis, linfadenopatía, etc. ${ }^{(9)}$

\section{TOMOGRAFÍA}

La tomografía ha tomado un lugar preponderante sobre todo en las hernias incisionales más complejas, en las hernias de topografías poco frecuentes, e incluso en aquellas hernias inguinales con pérdida de derecho a domicilio. Esto se debe a que proporciona información detallada que permite planificar adecuadamente la reparación parietal de manera individualizada. Muchas variables determinan la capacidad de cierre del defecto parietal por ejemplo: el hábito del paciente, la morfología y distensibilidad de la musculatura de la pared abdominal, el volumen de la cavidad abdominal, las dimensiones y volumen de las hernias y eventraciones, etc.

La utilización de la tomografía si bien presenta muchos beneficios también ha traído nuevos problemas. Uno de ellos es el diagnóstico de hernias y eventraciones ocultas no sintomáticas, con la incógnita si deben ser tratadas o no. ${ }^{(11)(12)} \mathrm{Y}$ por otro lado que en el diagnóstico de hernias ventral o su recurrencia al no existir consensos y protocolos de lectura se ha observado diferencias interobservador llegando en algunos estudios al $73 \%$ de los casos. ${ }^{(12)}$

Por lo tanto se intenta generar protocolos y estandarización de lectura de las tomografías. Se debe ser sobretodo sistemático en valorar los puntos de referencias anatómicos como la línea blanca, el apéndice xifoides, las espinas iliacas etc. Todos estos necesarios para topografiar los defectos parietales, valorar relaciones óseas así como para el cálculo de volúmenes ${ }^{(13)}$ (figura 7 )

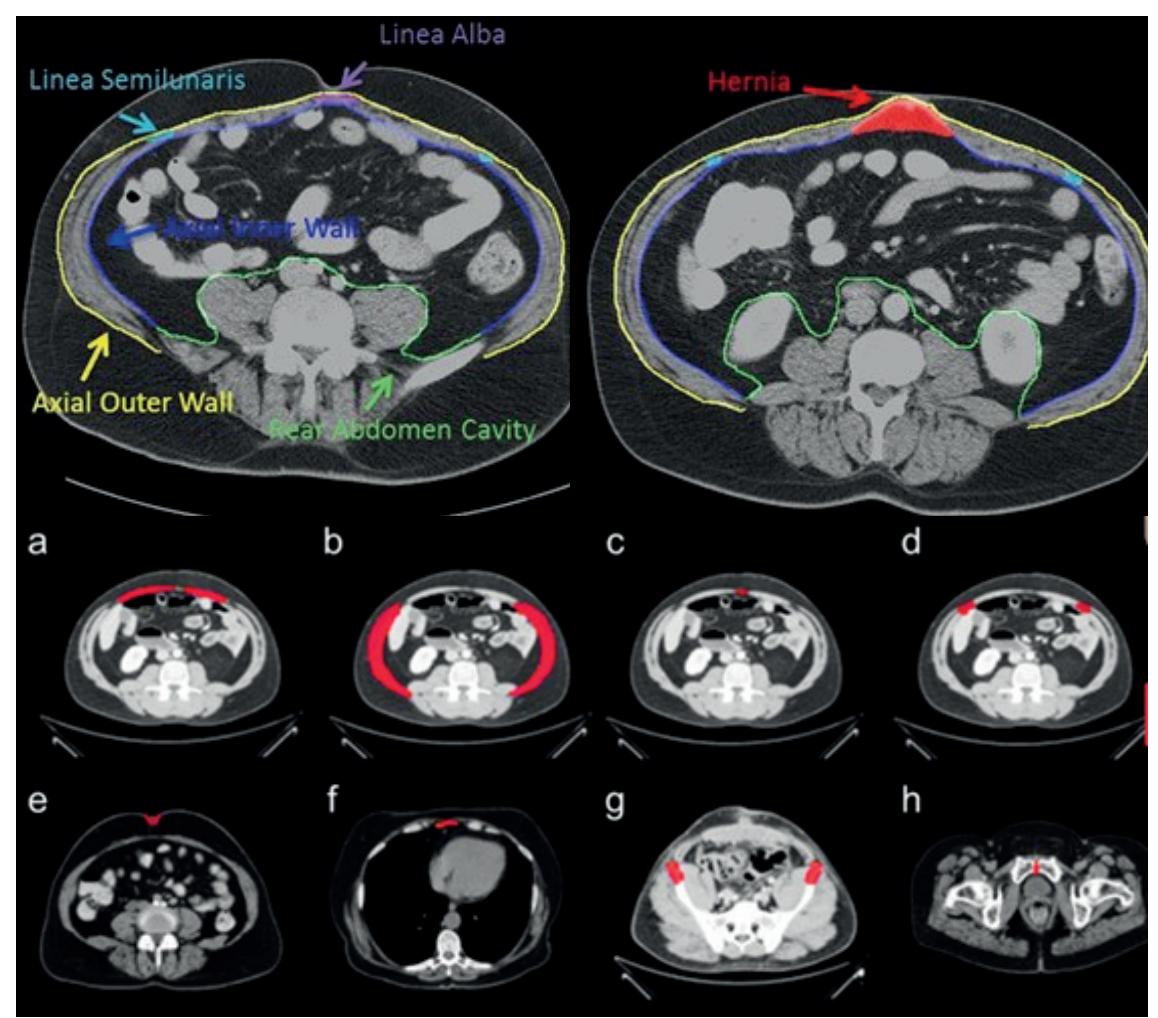

Figura 7(13): reperes anatómicos: en la primera imagen se marcan: la línea blanca, la línea semilunar la pared anterior y posterior del abdomen. En la segunda se marca la hernia ventral presente. En las imágenes inferiores se marca a: músculo recto, b: musculo oblicuo, c: línea blanca, d: línea semilunar, e: ombligo f: apéndice xifoides, g: espina iliaca anterosuperior, h: sínfisis pubiana 
La tomografía da información detallada de la situación anatómica (figura 8):

- Valora los sacos herniarios, determina el número de orificios pudiendo poner de manifiestos aquellos que pasaron desapercibidos al examen físico y de esta manera determinar la mejor técnica a emplear en la reparación parietal, pudiendo calcular de manera más exacta el tamaño del defecto parietal. ${ }^{(4)(14)}$

- Valora el estado y calibre de los músculos parietales pudiendo valorar denervaciones, roturas musculares o de sus inserciones.

- Permite clasificar las hernias tanto por su topografía como por sus dimensiones. Así como el cálculo de volúmenes el cual es necesario para valorar la posibilidad de reparación sin tensión, la necesidad o no de separación de componentes o incluso determinar la necesidad de preparación preoperatoria del volumen de la cavidad abdominal en las hernias con pérdida de derecho a domicilio
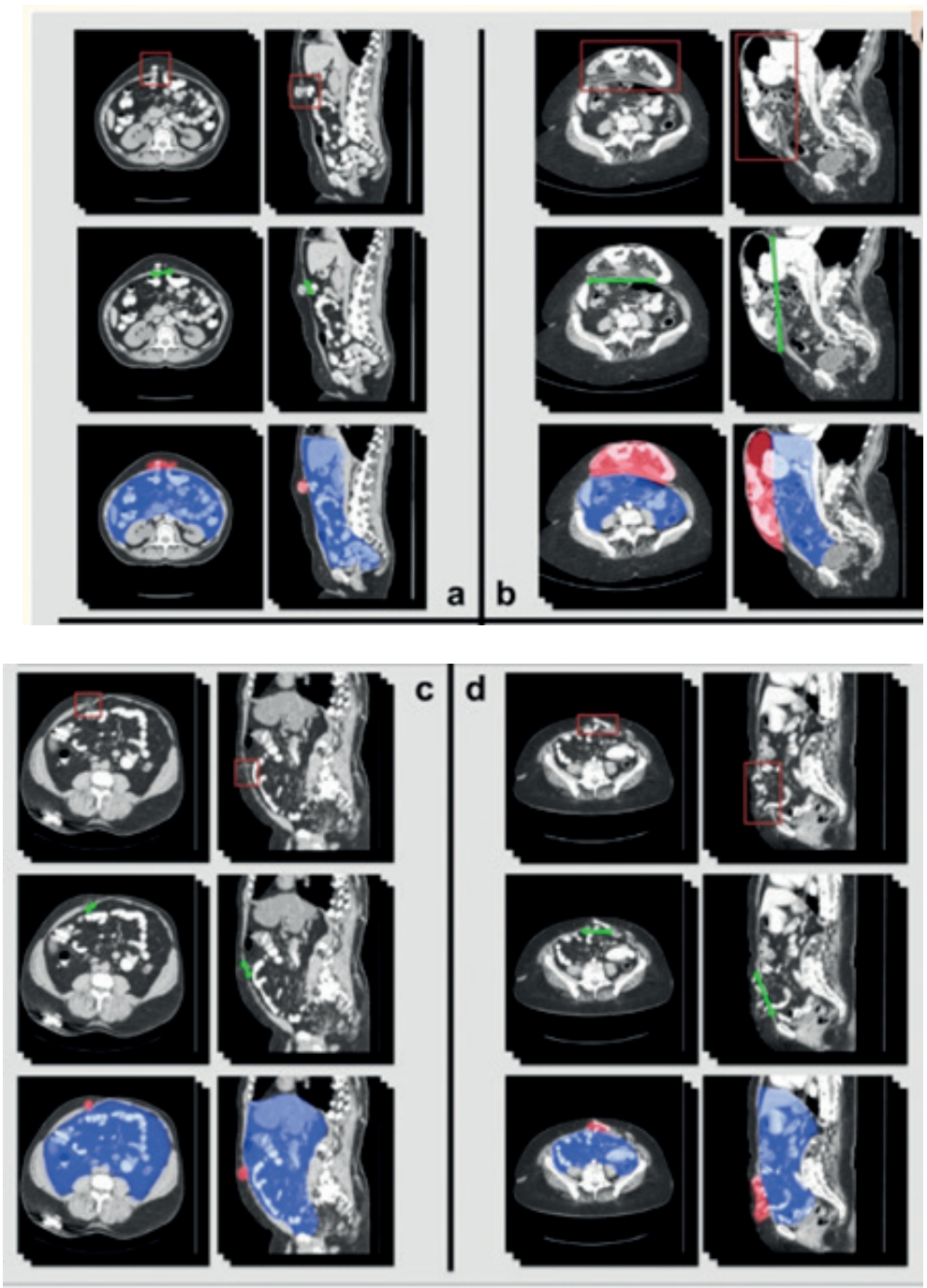

Figura 8(13): tomografías de 4 pacientes donde en la primer fila se identifica la hernia,

en la segunda el tamaño del orificio y en la ultima el volumen herniario y el volumen de la cavidad abdominal

- En las recidivas nos da la localización del implante protésico, el tipo de malla, y complicaciones de la misma (figura 9)

La visualización de las mallas en las tomografía es deficiente ya que va a depender: del material, el grosor e incluso del tipo de tejido que las rodeas. Las mallas son más visibles cuando tienen grasa a su alrededor o cuando tienen pliegues. Las mallas de PTFE se observan como una estructura lineal hiperreactiva con un tono brillante distintivo y es fácilmente visible. Las mallas de polipropileno y poliéster, son poco visibles a menos que haya contenido de grasa entre la malla y el músculo. Los productos de malla ligera son casi invisibles. También se pueden observar las grapas metálicas de fijación lo que permite determinar los límites de la malla. ${ }^{(4)(9)(15)}$ 

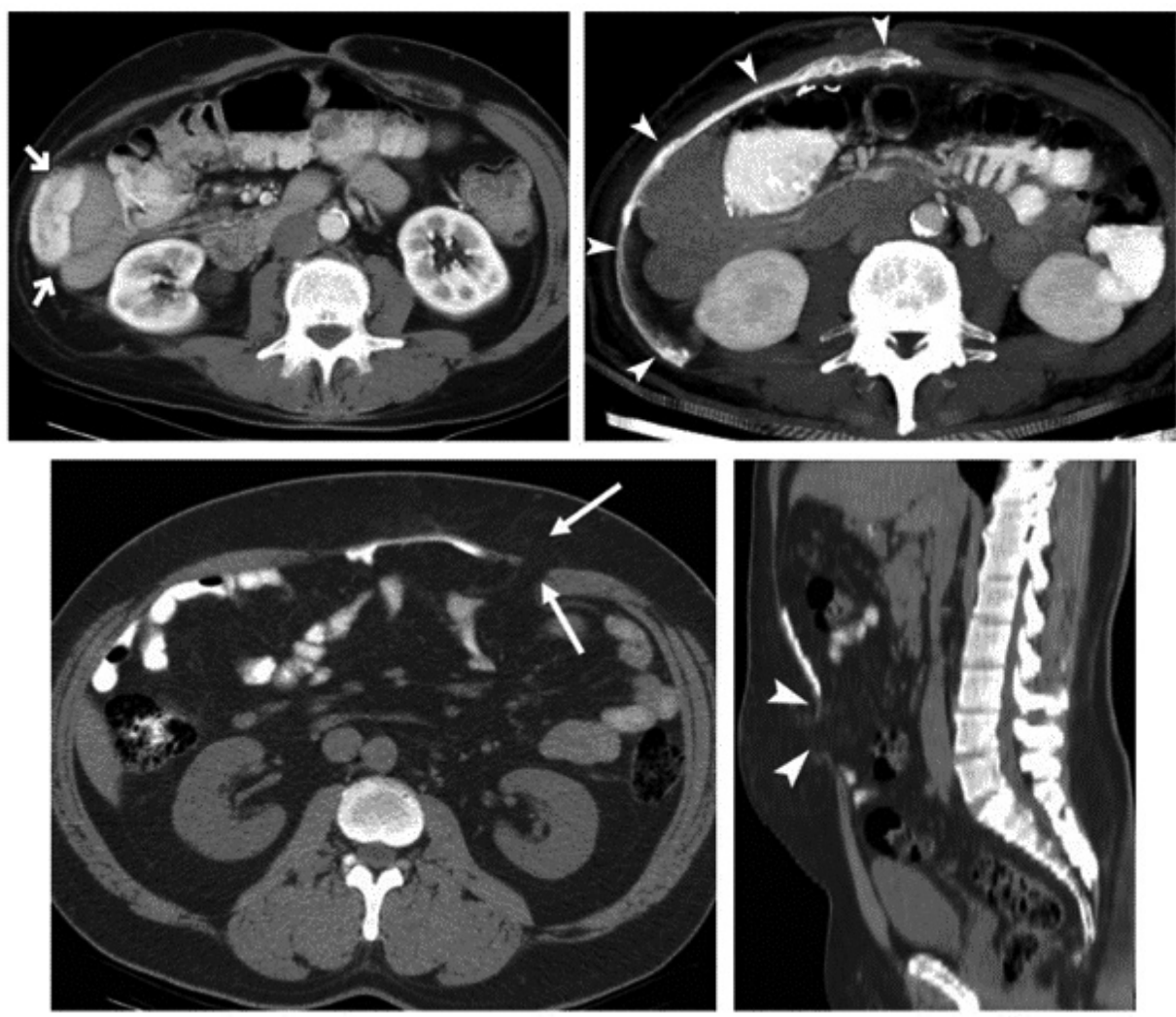

Figura 9 (15)en la imagen superior se muestra eventración lateral y su reparación con malla de PTFE.

En las inferiores se muestra corte axial y corte sagital de recidiva de eventración.(Flechas muestran defecto)

Un capitulo a parte son las grandes hernias/eventraciones.

Las grandes hernias o eventraciones con pérdida de derecho a domicilio son un desafío para el cirujano: tienen altos índices de recidiva, incluso realizando separación de componentes y además graves complicaciones posoperatorias relacionadas sobre todo a la hipertensión intraabdominal.

La tomografía es capaz de darnos información de los volúmenes herniarios, de la cavidad abdominal y de los músculos parietales. De esta manera permite predecir la posibilidad del cierre sin tensión del defecto parietal complejo o la necesidad de técnicas especiales como la separación de componente e incluso la necesidad de tratamiento preoperatorio para adaptación de la cavidad abdominal al contenido que será reintroducido como son el neumoperitoneo progresivo o toxina botulínica.

Pero el ancho, la altura así como el área de superficie de la hernia incisionales por sí solos son criterios insuficientes para predecir el cierre de la fascia sin tensión, la necesidad o no de técnicas de reparación complejas o la necesidad o no de preparación preoperatoria de la cavidad abdominal. Para tomar todas estas decisiones se debe de tener en cuenta también la topografía de la misma el volumen de la cavidad abdominal así como el ancho de los músculos rectos y la distensibilidad de la pared abdominal. Es por esto que se han desarrollado múltiples índices y cálculos preoperatorios-tomográficos para poder planificar la cirugía con los mejores resultados.

El método de Tanaka calcula la relación entre el volumen del saco herniario y el volumen de la cavidad abdominal. Calculando estas variables según las imágenes tomográficas y de esta manera predecir si es necesario realizar técnicas de expansión de la pared abdominal o por el contrario si se puede realizar la reparación parietal sin necesidad de estas. ${ }^{(16)}$

Tanaka considera la cavidad abdominal y el saco herniario como elipsoides lo que permite estimar su volumen (FIG.10). Se toma la medida craneocaudal de la pared abdominal desde el primer corte axial que muestra el diafragma, hasta es el último corte axial que muestra el cóccix. El límite anterior de la cavidad abdominal está determinado por una línea que une los grupos musculares de la pared sana, y el límite posterior por una línea que atraviesa la apófisis de las vértebras. Los límites transversales para la medición de la cavidad abdominal son el peritoneo parietal de cada lado. Para la medición del saco herniario, los límites son el peritoneo parietal del saco herniario superior, inferior y transversal mientras que el límite posterior es la línea que determina el límite anterior de la cavidad abdominal. ${ }^{(16)}$ (FIG 11) 


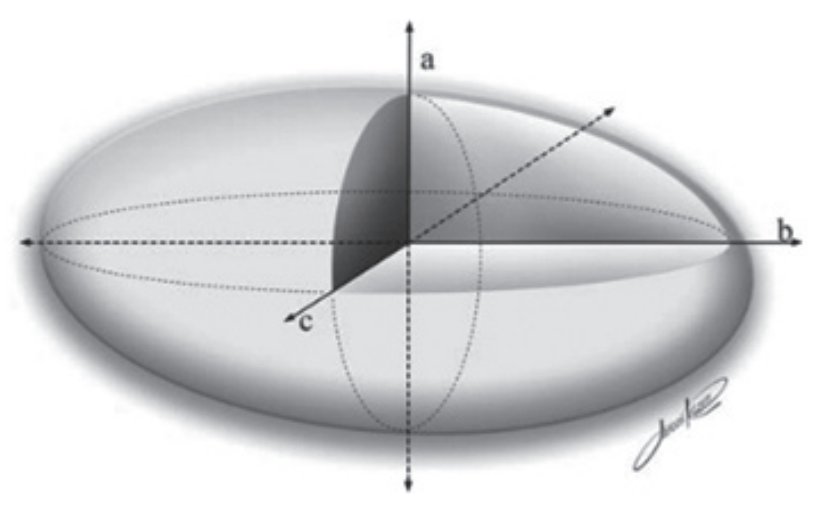

Figura 10 (16): elipsoides con sus diámetros a,b y c
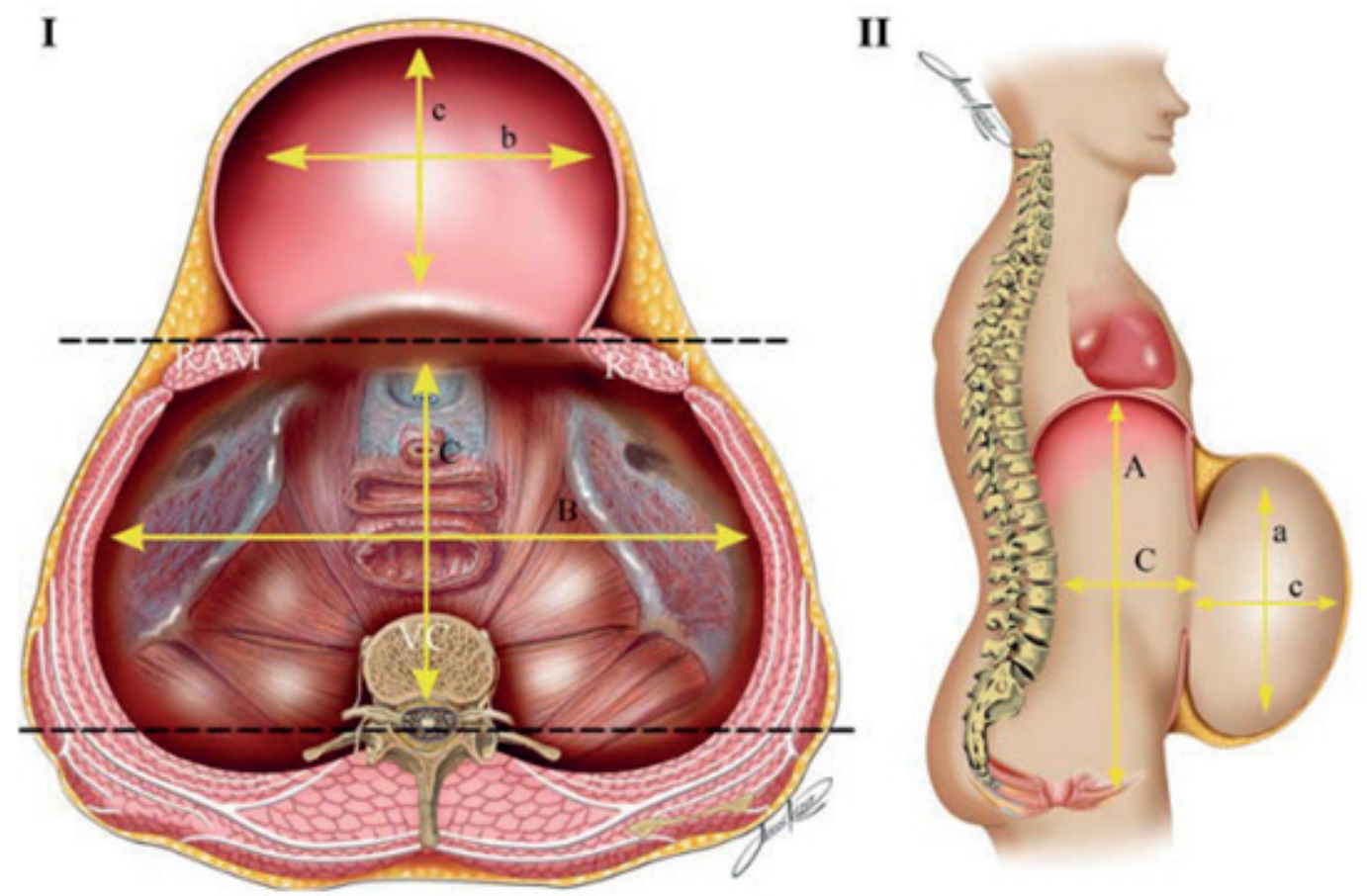

Figura 11(16) Dibujo transversal y sagital de la cavidad abdominal y la hernia A: medida longitudinal de la cavidad abdominal, B: medida transversal de la cavidad abdominal y $\mathrm{C}$ : medida anteroposterior de la cavidad abdominal.

Con minúscula se representan las mismas medidas pero del caso herniario

Obteniendo estos valores se puede calcular el volumen de la hernia o de la cavidad abdominal con la fórmula de cálculo de volumen del elipsoide

Una relación de estos dos volumenes superior al $25 \%$ se considera que el paciente es candidato a las técnicas de expansión de la pared abdominal. Si bien es un método simple el problema que presenta es que el valor de $25 \%$ se decidió de manera $\operatorname{arbitraria}^{(16)(17)}$

En el 2011 Sabbagh demostró en un estudio prospectivo que la relación volumen de la hernia/ volumen peritoneal $<20 \%$ era un factor predictivo para el cierre de la fascia sin tensión, después de realizar neumoperitoneo progresivo. El volumen peritoneal que es una combinación entre el volumen del saco y el volumen de la cavidad abdominal se considera un mejor denominador que el volumen de la cavidad abdominal que utiliza Tanaka. El problema que presenta este método es la necesidad de software especializado. ${ }^{(17)(18)}$ Aunque actualmente existe un software gratuito y sencillo para poder calcular el volumen. ${ }^{(19)}$

Por otro lado Carbonell informo otra medida relacionando el ancho del defecto y el ancho del musculo recto que fue modificado y validado por Love encontrando que la relación entre el ancho del defecto y la suma del ancho de los dos músculos rectos con una relación mayor de 2:1 es un predictor confiable en el 90\% de los casos para el cierre sin tensión con la separación retro rectal sin liberación miofacial lateral. ${ }^{(20)}$ 


\section{Resonancia nuclear magnética}

La resonancia a diferencia de la tomografía permite variedad de secuencias para valorar los diferentes tipos de tejidos. Esto le proporciona una mejor visualización en los pacientes operados ya que permite diferenciar mejor la malla de la cicatriz y del musculo o la presencia de colecciones. Esto le da cierta ventaja en los pacientes ya intervenidos en busca de complicaciones o recidivas. Pero en la mayoría de los casos es suficiente con una tomografía que es un estudio más barato y ampliamente disponible. ${ }^{(9)}$

\section{BIBLIOGRAFIA}

1) Muysoms F, Campanelli G, Champault GG, DeBeaux AC, Dietz UA, Jeekel J, et al. EuraHS: The Development of an international online platform for registration and outcome measurement of ventral abdominal wall Hernia repair [Internet]. Vol. 16, Hernia. 2012. p. 239-50. Available from: www.eurahs.eu

2) Muysoms FE, Miserez M, Berrevoet F, Campanelli G, Champault GG, Chelala E, et al. Classification of primary and incisional abdominal wall hernias. Hernia [Internet]. 2009;13(4):407. Available from: /pmc/articles/ PMC2719726/

3) Miserez M, Alexandre JH, Campanelli G, Corcione F, Cuccurullo D, Pascual MH, et al. The European hernia society groin hernia classication: Simple and easy to remember. Hernia. 2007;11(2):113-6.

4) Davis Scott, Dakin Gregory BA. The Sages Manual of Hernia Surgery. 2 eD. SPRINGER, editor. New York. USA; 2019. 109-120 p.

5) Chevrel JP, Rath AM. Classification of incisional hernias of the abdominal wall. Hernia. 2000;4(1):7-11.

6.) Dietz UA, Hamelmann W, Winkler MS, Debus ES, Malafaia O, Czeczko NG, et al. An alternative classification of incisional hernias enlisting morphology, body type and risk factors in the assessment of prognosis and tailoring of surgical technique. J Plast Reconstr Aesthetic Surg. 2007;60(4):383-8.

7) Van Den Berg JC, De Valois JC, Go PMNYH, Rosenbusch G. Detection of groin hernia with physical examination, ultrasound, and MRI compared with laparoscopic findings. Invest Radiol. 1999;34(12):739-43.

8) Bradley M, Morgan D, Pentlow B, Roe A. The groin hernia - An ultrasound diagnosis? Ann R Coll Surg Engl. 2003;85(3):178-80.

9) Hope WW, Cobb WS, Adrales GL. Textbook of Hernia. Textbook of Hernia. 2017.

10) Robinson A, Light D, Kasim A, Nice C. A systematic review and meta-analysis of the role of radiology in the diagnosis of occult inguinal hernia. Vol. 27, Surgical Endoscopy. 2013. p. 11-8.

11) Cherla D V, Viso CP, Moses ML, Holihan JL, Ko TC, Kao LS, et al. Clinical assessment, radiographic imaging, and patient self-report for abdominal wall hernias.J Surg Res [Internet]. 2018;227:28-34. Available from: https:// doi.org/10.1016/j.jss.2017.11.014

12) Holihan JL, Karanjawala B, Ko A, Askenasy EP, Matta EJ, Gharbaoui L, et al. Use of Computed Tomography in Diagnosing Ventral Hernia Recurrence A Blinded, Prospective, Multispecialty Evaluation. JAMA Surg [Internet]. 2016;151(1):7-13. Available from: https://jamanetwork.com/

13) Xu Z, Asman AJ, Baucom RB, Abramson RG, Poulose BK, Landman BA. Quantitative CT imaging of ventral hernias: Preliminary validation of an anatomical labeling protocol. PLoS One. 2015 Oct 28;10(10).

14) Pamiés Guilabert J, Aboud Llopis C, Navarro Aguilar V. Qualitative and quantitative assessment of abdominal hernia with multidetector computed tomography. Rev Hispanoam Hernia. 2013;1(4):149-58.

15.) Aguirre DA, Santosa AC, Casola G, Sirlin CB. Abdominal wall hernias: Imaging features, complications, and diagnostic pitfalls at multi-detector row CT. In: Radiographics [Internet]. Radiological Society of North America; 2005. p. 1501-20. Available from: https://pubs.rsna.org/doi/abs/10.1148/rg.256055018

16) Tanaka EY, Yoo JH, Rodrigues AJ, Utiyama EM, Birolini D, Rasslan S. A computerized tomography scan method for calculating the hernia sac and abdominal cavity volume in complex large incisional hernia with loss of domain. Hernia [Internet]. $2010 \mathrm{Feb}$ 12;14(1):63-9. Available from: https://link.springer.com/article/10.1007/s10029009-0560-8

17) Afaque MY. Assessing the complexity of ventral hernia by methods of Tanaka, Sabbagh, Carbonell, and Love [Internet]. Vol. 25, Hernia. Springer; 2021. p. 557-8. Available from: https://link-springer-com.proxy.timbo.org. uy/article/10.1007/s10029-020-02267-7

18) Sabbagh C, Dumont F, Robert B, Badaoui R, Verhaeghe P, Regimbeau JM. Peritoneal volume is predictive of tension-free fascia closure of large incisional hernias with loss of domain: A prospective study. Hernia [Internet]. 2011 May 17;15(5):559-65. Available from: https://link-springer-com.proxy.timbo.org.uy/article/10.1007/ s10029-011-0832-y 
19) Martre P, Sarsam M, Tuech JJ, Coget J, Schwarz L, Khalil H. New, simple and reliable volumetric calculation technique in incisional hernias with loss of domain. Hernia [Internet]. 2020;24(2):403-9. Available from: https:// doi.org/10.1007/s10029-019-01990-0

20) Love MW, Warren JA, Davis S, Ewing JA, Hall AM, Cobb WS, et al. Computed tomography imaging in ventral hernia repair: can we predict the need for myofascial release? Hernia [Internet]. 2021 Apr 10. 


\title{
OPTIMIZACIÓN PREOPERATORIA DEL PACIENTE PARA CIRUGÍA PARIETAL
}

\author{
Dr. Gonzalo Estapé
}

\section{INTRODUCCIÓN}

La cirugía de las hernias de la pared abdominal se acompaña de una morbilidad no despreciable, fundamentalmente en complicaciones sistémicas (respiratorias y cardiovasculares), y locales como infecciones, sangrados, necrosis cutánea. El índice de reitervenciones, la estadía hospitalaria y finalmente la recidiva herniaria, con aún mayor morbilidad en su tratamiento, son indicadores de resultados de gran jerarquia en la evaluación de los resultados globales de esta patología..$^{(1)(2)}$

Asi, la optimización preoperatoria del paciente, cumple un rol fundamental en el tratamiento de esta patología y sus resultados médicos y quirúrgicos postoperatorios, con afectación directa en el status biológico, satisfacción del paciente y en los costos asistenciales.

Con los avances en el estudio y tratamiento de las comorbilidades, la seguridad de las diferentes técnicas anestésicas, y sobre todo el desarrollo de las técnicas miniinvasivas, con mejor tolerancia a la cirugía y menor morbilidad parietal, ha aumentado de manera significativa el número de pacientes, con alto riesgo anestésico, pasibles de cirugía de manera segura. $^{(3)}$

La optimización perioperatoria de las hernias ventrales y/o incisionales, a veces verdadero reto para el cirujano, abarca desde su diagnóstico, indicación quirúrgica, via de abordaje y del procedimiento quirúrgico a realizar, hasta el manejo del paciente en block quirúrgico antes y durante la cirugía.

No consideraremos la optimización para la cirugía laparoscópica de hernias inguinales. En esta patología, al poder ser operada por técnica abierta y anestesia regional, local potenciada o incluso local pura, su valoración general y preparación preoperatoria son de menor complejidad y compromenten en menor término la evolución postoperatoria. Estos puntos serán analizados en otro capítulo de este relato.

Tampoco abordaremos la preparación de pacientes con grandes o complejos defectos parietales, en los que los abordajes laparoscópicos son discutibles o no sugeridos fuera de centros muy especializados. Estos pacientes, en que se debe manejar técnicas de readecuación del volúmen abdominal y preparación específica de la pared abdominal con técnicas como expansores parietales, inyección de Toxina Botulínica o la realización de neumoperitoneo progresivo preoperatorio, escapan al abordaje de este Relato.

\section{EVALUACIÓN CLÍNICA}

Valoraremos edad, sexo, hábitos tóxicos, sobre todo el tabaquismo por su afectación de la microcirculación. Antecedentes patológicos: respiratorios, cardíacos, circulatorios. Antecedentes quirúrgicos: reparaciones previas de la misma hernia, con o sin malla, plano de la malla, separación de componentes. Enfermedades intercurrentes, neoplasias, (conocer estadificación actual, pronóstico y venetual plan de QT o RT próximos), inmunodeprimidos (transplantados, renal o hepático, diálisis peritoneal actual o previa) y que recibieron radioterapia abdominal. La perspectiva y calidad de vida actual del paciente, puede condicionar la indicación quirúrgica. ${ }^{(4)}$

En las hernias incisionales y en las recidivas, valorar las complicaciones postoperatorias que presentó el paciente, como infección, fístulas, hematomas, evisceración, y que nos pueden orientar sobre el estado actual de la pared abdominal. En la exploración clínica se jerarquiza: la reductibilidad total o parcial, el tamaño del anillo herniario y el saco y su contenido, la distancia a estructuras óseas y el trofismo de la pared abdominal. El estado de la piel sobreyacente, alteraciones tróficas, ulceraciones, sobreinfección y la existencia o no de delantales dermograsos, pueden determinar la asociación procedimientos de dermolipectomía. ${ }^{(5)(6)}$ La importancia de la imagenología, en algunos casos imprescindible, y la clasificación del defecto pariertal en estudio, se analizan en otros capítulos de este Relato. 


\section{VALORACIÓN ANESTÉSICA}

Los criterios generales de valoración y preparación preoperatoria, de pacientes con patología herniaria de la pared abdominal, difieren poco de otras cirugías mayores. De la relación entre el estado biológico del paciente y su estabilidad, la patología en curso y el tratamiento quirúrgico planificado, se determinará la operabilidad, oportunidad y riesgos del mismo. ${ }^{(7)}$

La valoración anestésica se basa en una buena historia clínica. En función de esta, de la patología, del tipo de procedimiento a realizar y de los protocolos institucionales, se solicitarán las pruebas complementarias necesarias. Son imprescidibles a optimización de la función respiratoria, cardiológica, renal y la valoración nutricional y metabólica. También se definirá si el procedimiento planificado se puede realizar bajo programas de cirugía mayor ambulatoria o requiere ingreso hospitalario, y la posibilidad de cirugía laparoscópica, considerando la fisiopatología del neumoperitoneo.

\section{PREPARACIÓN PREOPERATORIA}

Es conocido que desde la creación de Unidades de Cirugía de Pared Abdominal, se ha logrado disminuir la morbimortalidad y aumentar el bienestar físico y psicológico del paciente. El seguimiento de protocolos consensuados y basados en la mejor evidencia disponible, logra los mejores resultados. Habitualmente integran estas unidades: enfermeras, internistas, anestesistas, cirujanos plásticos, especialistas en nutrición, fisioterapeutas, radiólogos (protocolización de la TAC) y cirujanos. Deben desarrollarse reuniones conjuntas periódicas y eventualmente con otros especialistas implicados, personalizando la preparación a cada paciente.

El objetivo es que el paciente se encuentre en condiciones óptimas o las más favorables posibles, para el procedimiento quirúrgico, tanto en el aspecto sistémico como local.

El paciente recibirá preparación bajo tres conceptos: preparación sistémica, local y del contenido de la cavidad abdominal (estas últimas no se analizan en este Relato).

\section{Se reconocen a la obesidad, el tabaquismo, la diabetes y las enfermedades con inmunodepresión, como factores} principales de la morbilidad postoperatoria y recurrencia herniaria.

La estabilización de la diabetes y otras enfermedades metabólicas, será de al menos 4-6 semanas antes de la cirugía. Se recomienda no operar pacientes con hemoglobina glicosilada mayor a $8 \% .{ }^{(8)}$

Las pruebas funcionales respiratorias y cardiovasculares, solicitadas selectivamente y a veces reiteradas para valorar el éxito del tratamiento instaurado, valoran el estado funcional actual y la eventual repercusión del reintegro del contenido herniario a la cavidad abdominal. Aquí se determina la operabilidad, la indicación del neumoperitoneo preoperatorio (o toxina botulínica) o la aplicación de respiración asistida en el postoperatorio inmediato. Asimismo, después de la cirugía debe solicitarse una nueva valoración para comprobar la nueva situación fisiológica respiratoria y hemodinámica, $\mathrm{y}$ adecuar sus tratamientos.

La supresión del tabaco y la compensación prolongada del asma y EPOC, son los objetivos principales en esta etapa. ${ }^{(9)}$

Es necesaria la fisioterapia respiratoria, para conseguir una mejor función en pacientes con eventraciones importantes. Se indicarán ejercicios de superación de la capacidad respiratoria, que en ocasiones el paciente los practicará con una faja de contención en el abdomen para simular el estado de reparación final. En el postoperatorio inmediato, la fisioterapia respiratoria ayudará a prevenir complicaciones pulmonares, atelectasias, neumonías, y es necesaria en todos los pacientes

$\mathrm{El}$ tabaquismo fue identificado como un factor independiente de aumento de la morbimortalidad luego de reparaciones herniarias, sobre todo infecciones superficiales, profundas, de las malla y reoperaciones precoces ${ }^{(1)(11)}$ Los fumadores activos tienen 2.5 más riesgo de complicaciones parietales. ${ }^{(12)}$ Tambien predispone las re hospitalizaciones ${ }^{(13)(14)}$ y la tasa de recurrencias. ${ }^{(15)}$

El cese total del tabaquismo, al menos 4-8 semanas antes de la cirugía, ${ }^{(16)}$ debería ser obligatorio, al ser un factor modificable. La nicotina y otros mútiples agentes presentes en el tabaco, causan hipoxemia y hipoxia tisular, generando 
la reducción de los depósitos de colageno, del proceso inflamatorio y de los factores de crecimiento. Estos factores predisponen a la infección e isquemia tisular, con una cicatrización defectuosa de los tejidos, objetivo principal en esta patología. La combinación de medicación con terapia de conductas (grupos de apoyo) y consejo médico, logran los mejores resultados. ${ }^{(17)}$

La valoración nutricional tiene enorme jerarquía en la definición de la oportunidad del procedimiento quirúrgico. Tanto la desnutrición como la obesidad (más frecuente), generan una situación parietal y sistémica desfavorable para la reparación de defectos parietales, al ser acompañados de mayor morbilidad general postoperatoria y un franco aumento en la tasa de infecciones y recurrencia herniaria. Dada su jerarquía, a la obesidad no referiremos por separado.

Obtener un grado de mejor trofismo muscular, es otra de las condiciones importantes para prevenir complicaciones y conseguir mejores resultados técnicos. No es raro observar disminución del tono muscular, ya que suelen ser de edades superiores a los 50 años, con poco ejercicio físico. Los ejercicios de fisioterapia general son aconsejables y en casos imprescindible. La actividad física programada y controlada, adecuada a la patología herniaria y a cada paciente, mejora el trofismo muscular parietal, disminuye el exceso adiposo abdominal y colabora en el tratamiento de la obesidad.

Respecto a la profilaxis tromboembólica, en la cirugía de hernia incisional pequeña no se recomienda de manera rutinaria, por estar en el grupo de bajo riesgo para tromboembolismo venoso. Sin embargo, siempre deben tenerse en cuenta los factores de riesgo perioperatorios, hernias grandes y las condiciones predisponentes individuales para establecer la indicación. De igual manera, se decidirá la indicación de este tratamiento luego del alta hospitalaria.

La preparación local, es importante en los casos de ulceraciones de la piel por isquemia, traumatismos, sobreinfecciones o micosis en pliegues cutáneos cercano: ${ }^{(18)}$

- Indicamos lavados con jabón quirúrgico, antisépticos y tratamientos con cremas o apósitos hidratantes, pomadas antifúngicas y antibioterapia específicas, en casos de lesiones sobreinfectadas.

- Evitar la tensión en la piel sobre la eventración, necesaria para la cicatrización de estas lesiones, por lo que el reposo físico, evitar situaciones de hipertensión abdominal y el uso casi permanante de faja elástica amplia abdominal son ampliamnete recomendados.

- Las nuevas preparaciones: geles coloides, con agregados vitamínicos y cicatrizantes, abren esperanza en tratamientos más eficaces.

- Las terapias con vacío y las sesiones de cámara de oxígeno hiperbárico, se utilizan en casos seleccionados y con resultados inciertos aún. Excepcionalmente, procedimientos de cirugía plástica (injertos), deben ser utilizados para recubrir la lesion, controlar la infección y evolutivamente tratar el defecto parietal.

- En todos los pacientes, con o sin alteraciones cutáneas, indicamos baño antiséptico (Clorhexidina jabonosa) en el preoperatorio inmediato.

La preparación mecánica colónica, se sugiere en grandes eventraciones o grandes sacos, megacolon, constipados habituales, eventraciones paracolostómicas, o que asociarán una cirugía intestinal (resección, cierre de ostomía), junto con la eventroplastia.

\section{PREPARACIÓN EN BLOCK QUIRÚRGICO}

El cateterismo vesical tiene indicación en: grandes hernias, para medición de la presión intrabdominal (PIA) controlando los valores pre, intra y postoperatorios, debiendo ser siempre inferiores a $12 \mathrm{mmHg}$., necesidad de balance hídrico en las intervenciones de larga duración, eventraciones con componente infraumbilical, donde una distensión vesical puede dificultar el procedimiento quirúrgico. Colocación de sonda nasogástrica en pacientes con hernias supraumbilicales, distensión gástrica confirmada o dificultades técnicas en liberación de adherencias. Se retira en postoperatorio inmediato.

Lavado con Clorhexidina jabonosa de la región operatoria, después de que el paciente esté anestesiado, haciendo hincapié en el ombligo y en los pliegues intertriginosos. Posterior aplicación de Yodopovidona o Clorhexidina Alcoholica (de nuestra preferencia) según preferencia y/o normativas institucionales. ${ }^{(19)}$ 
La tasa de infección del sitio quirúrgico de las reparaciones laparoscópicas de las HV es usualmente baja, con un intervalo que varía de 0.5 a $4 \%$, y no existe evidencia sólida que apoye la profilaxis antibiótica de rutina, siendo el S. Aureus meticilino sensible el gérmen mas frecuente. Se debe indicar selectivamente según el protocolo de profilaxis específico de cada centro hospitalario. Nosotros utilizamos Cefazolina 2 gr. intravenoso, luego de la inducción anestésica, y lo prolongamos por $24-48 \mathrm{hs}$ en caso de infecciones superficiales concomitantes inadvertidas o accidentes intraoperatorios. ${ }^{(20)}$

Compresión elástica o sistema de compresión intermitente de las extremidades inferiores como profilaxis del tromboembolismo, en: obesos, neoplásicos, insuficiencia venosa crónica de miembros inferiores, cirugías prolongadas o que requieran posicón ginecológica prolongada o cambios forzados de posición de la mesa operatoria (Trendelemburg invertido).

Fijación adecuada del paciente, que sufrirá cambios posicionales durante la cirugía y prevención de la hipotermia.

\section{Obesidad y Cirugía Parietal Abdominal}

La obesidad se define como un exceso de tejido adiposo, y la diferencia entre normalidad y obesidad es arbitraria. Para la OMS, el parámetro de medida recomendado es el índice de masa corporal (IMC) [IMC = peso $(\mathrm{kg}) /$ altura $(\mathrm{m} 2)$ ]. Se considera normal un IMC menor de 25; sobrepeso, entre 25 y 29,9; obesidad grado 1, entre 30 y 34,9; grado 2, entre 35 y 39,9, y grado 3 o mórbida, si es mayor de 40. Diversos estudios epidemiológicos dan cuenta del incremento acelerado de la obesidad en el mundo, especialmente en los países occidentales y tambien en nuestro medio. ${ }^{(21)}$

La acumulación excesiva de tejido adiposo, afecta la salud física y mental y reduce las expectativas de vida del sujeto y por ello, se considera una condición patológica. Es aceptado que la obesidad se asocia con una mayor morbilidad y mortalidad en general, por el propio estado y la asociación de otras patologías en diversa gravedad, así como tambien aumenta la morbimortalidad quirúrgica. ${ }^{(22)}$

\section{Morbilidad y obesidad}

La obesidad se asocia con aumento de dislipemias, diabetes, hipertensión pulmonar, enfermedades tromboembólicas, cardiopatía isquémica, hipertensión y accidentes vasculares encefálicos. Afecciones cardiacas como insuficiencia cardíaca y arritmias, se asocian a una alta tasa de muerte súbita. Otras enfermedades prevalentes en obesos son: reflujo gastroesofágico patológico, esteatosis y esteatohepatitis no alcohólica, colelitiasis, osteoartopatías, entre otras. ${ }^{(23)}$

De gran trascendencia quirúrgica son las alteraciones respiratorias propias del obeso: disminución del volumen de reserva espiratorio, desequilibrios de ventilación/ perfusión y disminución de la capacidad residual funcional. Dos síndromes respiratorios han sido descritos en obesos: el síndrome de hipoventilacion-obesidad y el de apnea del sueño, ambos con afectación directa del perioperatorio en cirugía parietal, donde sobre todo en la reducción de hernias grandes, afectan variablemente los parametros ventilo respiratorios. ${ }^{(21)}$

Estas eventuales comorbilidades, justifican la aprehensión de cirujanos y anestesistas para definir la indicación y oportunidad quirúrgica, con un estudio más extenso y costoso en el preoperatorio. Son comprensibles, entonces, los esfuerzos para inducir una reducción del peso corporal ante una intervención quirúrgica, aunque ello rara vez se logra.

\section{Anestesia en el paciente obeso}

Los procedimientos de cirugía mayor, con excepción de aquellos susceptibles de ser realizados con anestesia local, exigirán una exhaustiva evaluación preoperatoria del riesgo opertorio. En las obesidades mayores destacamos: la eventualidad de una intubación difícil (requerir endoscopista), prolongación de la intubación en el postoperatorio y de la eventualidad de una traqueostomía. Tanto la anestesia raquídea como la peridural son de difícil realización por la dificultad de identificar los reperes óseos y por alteraciones anatómicas del canal medular, y por ello con una elevada tasa de fracaso. ${ }^{(21)}$

La posición supina, de litotomía o la de Trendelenburg acentúan la dificultad respiratoria del obeso. Las maniobras de inducción acentúan la hipoxia e hipercapnia y favorece el reflujo del contenido gástrico y aspiración traqueal. Las complicaciones pulmonares, frecuentes en el postoperatorio del paciente obeso, se explica por una mayor sensibilidad a las drogas sedantes, analgésicos opioides y drogas anestésicas, lo que contribuye a deprimir la función ventilatoria. La extubación del obeso debe realizarse con el paciente completamente vigil.

En los casos de procedimientos que determinarán dolor postoperatorio intenso, planificar tanto de la técnica intraoperatoria más adecuacda así como la analgesia postoperatoria, pudiendo combinarse diversas técnicas y vias de administración, para lograr el mejor control posible del dolor y recuperación postoperatoria. Aquí las técnicas peridurales, bloqueos regionales ecoguiados y las bombas de analgesia intravenosa, tienen indicación formal. 


\section{Cirugía parietal en el paciente obeso}

La relación entre obesidad y alta morbilidad luego de una eventroplastia, fue demostrada en un análisis retrospectivo de 78.348 pacientes, que mostró mayores complicaciones pulmonares graves como neumonia distress respiratorio y embolia pulmonar, al igual que mayor internación, complicaciones inmediatas y recurrencias. ${ }^{(23)(24)(25)}$ Pernar identificó al IMC como indicador de complicaciones parietales postoperatorias de hernias ventrales: $16.5 \%$ en pacientes con $>40$ vs $5.6 \%$ en pacientes con IMC <25. También encuentra complicaciones médicas 3.4 veces más frecuentes en pacientes con IMC $>40 .{ }^{(26)(27)}$

El trastorno ventilatorio del paciente con eventraciones se debe a la disfunción de los músculos abdominales y del diafragma, que será más evidente en las eventraciones de gran tamaño y más aún en las supraumbilicales. Aquí se compromete además a las vísceras abdominales y los grandes vasos. El saco herniario y la piel, constituyen un tipo de «volet abdominal», determinando una respiración abdominal paradojal. Esta respiración alterada determina la ineficiencia del diafragma y una mala ventilación de las bases pulmonares. ${ }^{(21)}$

El trastorno respiratorio propio de la obesidad se compensa y enmascara ante una gran eventración, así el obeso con una eventración puede ventilar sus pulmones de mejor manera que el obeso sin eventración. La corrección de la eventración, termina con esta compensación y expone al paciente a serias complicaciones ventilatorias difícilmente previsibles en el estudio preoperatorio.

El primer factor patogénico de recurrencia herniaria, es la tensión generada sobre las líneas de sutura fasciales. Esta tensión producirá los primeros defectos de la sutura, pero será la hipertensión abdominal (habitual en obesos), la que determinará el aumento de amplitud de los anillos eventrales y el tamaño de los sacos.

Es de gran importancia el apoyo psicológico al paciente obeso. Este disminuyela ansiedad y aumenta la confianza en el equipo multidisciplinario. Los grupos de apoyo, siempre presentes en estos casos, pueden compartir experiencias similares y positivas en otros pacientes y estimulan el a veces largo proceso de preparación general y las diferentes técnicas de adelgazamiento. Es de gran ayuda que el cirujano mantenga cierto plazo para la eventual cirugía, aunque esté condicionado por el cumplimiento de las metas nutricionales mencionadas.

Basados en las tasas de infecciones y de recurrencias, la eventroplastia con malla laparoscópica, favorece a los pacientes obesos por ser menos invasiva y disminuir drásticamente las complicaciones de la herida operatoria. Esta técnica no logra disminuir las recidivas, que son más frecuentes en los pacientes hiperobesos. ${ }^{(28)(29)}$

\section{Se recomienda NO operar obesos con IMC mayor a 40, abierto ni laparoscópico.}

El tratamiento dietético programado y la actividad física personalizada, con el objetivo de lograr un IMC menor a 30, se indica desde la consulta inicial. Los pacientes son citados y controlados periódicamente, para eventuales modificaciones de la dieta, medicación y nuevas evaluaciones. El incentivo es primordial, aún ante el fracaso o enlentecimiento del objetivo trazado, no suspendiendo ni posponiendo excesivamente la oportunidad de la cirugía previamente planteada, que será tomada como un "premio". Las complicaciones mecánicas con obstrucción y estrangulación, son más frecuentes en pacientes con obesidad, por lo que la no pérdida de peso, no debe retrasar la cirugía en pacientes muy sintomáticos.

La participación del equipo bariátrico puede optimizar al obeso para una cirugía parietal menos mórbida. Los procedimeintos miniinvasivos como los balones gástricos oclusivos, las gastroplastia en manga endoscópica y finalmente la manga gastrica o by pass gastrico laparoscópicos, integran las opciones actuales a considerar. El proceso se inicia con tratamiento dietético y medicamentoso, dirigido y controlado por un equipo multidisciplinario especializado. Los resultados se analizan en un plazo de 12-18 meses, cuando se podrá planificar la cirugía en caso de evolución favorable. (30) Ante el fracaso del tratamiento medico, se optará por técnicas quirurgicas o endoscópicas de cirugía bariátrica. Se evaluará cada caso en particular, para definir si se realizará la eventroplastia en el mismo acto que la cirugía bariátrica o en otro procedimiento alejado. Cuando el defecto parietal es pasible de repararse por métodos endoscópicos, puede considerarse la realización de procedimientos de cirugía bariátrica en la misma intervención. Cuando la reparación endoscópica del defecto herniario no esté indicada o no sea posible, puede considerarse un tratamiento en dos etapas: procedimiento de cirugía bariátrica en primer lugar y reparación parietal en un segundo tiempo. Aunque varios estudios muestran que la cirugía bariátrica y la eventroplastia abdominal concomitante es posible y segura, la preferencia global es a separar los procedimientos. El estado deficitario nutricional, comorbiliades presentes y habitualmente mal compensadas y la precaria situación anatomofuncional parietal en el obeso grave, desalientan la plastia parietal simultánea con la cirugía bariátrica, que implica mayores complicaciones infecciosas y tiene su propia y considerable morbilidad. ${ }^{(31)(32)(33)}$ 
La discusión y frecuentes diferencias, (entre los diferentes médicos, cirujanos y el paciente), sobre la indiciación, oportunidad y táctica terapéutica, entre ellas el abordaje laparoscópico, están simpre presentes en el paciente obeso. La obesidad dificulta el procedimiento quirúrgico, sencillamente porque la acumulación de tejido adiposo constituye un obstáculo mecánico a la acción del cirujano. La dificultad en pacientes con un IMC inferior a 35 será leve, y se resolverá con una incisión cutánea algo mayor y con separadores adecuados, agravándose en índices mayores. Un manejo descuidado de los tejidos, el uso excesivo del bisturí eléctrico y la prolongación del acto quirúrgico, contribuirán a una mayor cantidad de tejido desvitalizado, lo que facilitará la frecuente complicación de la infección de la herida.

\section{BIBLIOGRAFÍA}

1) LeBlanc Karl A. Current considerations in laparoscopic incisional and ventral herniorrhaphy.jsls 2000;4(2):131-9.

2) Horne C., Prabhu A Recurrent Ventral Hernia Repair. Society of American Gastrointestinal and Endoscopic Surgeons (SAGES) 2019; 26:359-372 S. S. Davis Jr. et al. The SAGES Manual of Hernia Surgery, https://doi. org/10.1007/978-3-319-78411-3_26

3) HuynhD.T.K, Ghanem O.M. Patient Comorbidities Complicating a Hernia Repair: The PreoperativeWorkup and Postoperative Planning. Society of American Gastrointestinal and Endoscopic Surgeons (SAGES) 2019; 9:109-123 S. S. Davis Jr. et al. (eds.), The SAGES Manual of Hernia Surgery, https://doi.org/10.1007/978-3-31978411-3_9

4) Carbonell Tatay F. Estudio preoperatorio en la eventración. Protocolos de preparación a la cirugía 26:357-363 En Eventraciones Otras hernias de pared y cavidad abdominal Fernando Carbonell Tatay Alfredo Moreno Egea Valencia, 2012

5) Picazo-Yeste J, Moreno-Sanz C, Sedano Vizcaino C, Morandeira-Rivas A, Sanchez-De Pedro F. Outcomes after laparoscopic ventral hernia: does the number of previous recurrences matter? A prospective study. Surg Endosc. 2017;17:5510-4.

6) Hauters P, Desmet J, Gherardi D, Dewaele S, Poilvache H, Malvaux P. Assessment of predictive factors for recurrence in laparoscopic ventral hernia repair using a bridging technique. Surg Endosc. 2017;1:1-8.

7) Roca Domínguez B, Gutiérrez Ferreras AI, Mayagoitia JC. Guía para el manejo de la hernia ventral e incisional medial. Rev Hispanoam Hernia. 2021;9(2):80-87

8) Liang MK, Holihan JL, Itani K, Alawadi ZM, Gonzalez JRF, Askenasy EP, Ballecer C, et al. Ventral hernia management: expert consensus guided by systematic review. Ann Surg. 2017;265(1):80-89.

9) Landin M, Kubasiak JC, Schimpke S, Poirier J, Myers JA, Millikan KW, Luu MB. The effect of tobacco use on outcomes of laparoscopic and open inguinal hernia repairs: a review of the NSQIP dataset. Surg Endosc. 2017;31(2):917-21.

10) Sorensen LT, Karlsmark T, Gottrup F. Abstinence from smoking reduces incisional wound infection: a randomized controlled trial. Ann Surg. 2003;238(1):1-5.

11) Fischer JP, Wink JD, Nelson JA, Kovach SJ. Among 1,706 cases of abdominal wall recon- struction, what factors influence the occurrence of major operative complications? Surgery. 2014;155(2):311-9.

12) Gronkjaer M, Eliasen M, Skov-Etrrup LS. Preoperative smoking status and postoperative complications: a systematic review and meta-analysis. Ann Surg. 2014;259:52-71.

13) Lovecchio F, Farmer R, Souza J, Khavanin N, Dumanian GA, Kim JY. Risk factors for 30-day readmission in patients undergoing ventral hernia repair. Surgery. 2014;155(4):702-10.

14) Nelson JA, Fischer J, Chung CC, Wink J, Wes A, Serletti JM, Kovach S. Readmission following ventral hernia repair: a model derived from the ACS-NSQIP datasets. Hernia. 2015;19(1):125-33

15) Huerta S, Patel PM, Mokdad AA, Chang J. Predictors of inguinodynia, recurrence, and metachronous hernias after inguinal herniorrhaphy in veteran patients. Am J Surg. 2016;212(3):391-8

16) Sørensen LT, Hemmingsen UB, Kirkeby LT, Kallehave F, Jørgensen LN. Smoking is a risk factor for incisional hernia. Arch Surg. 2005;140(2):119-23.

17) Lindström D, Azodi OS, Wladis $A$, Tønnesen $H$, Linder $S$, Nåsell $H$, et al. Effects of a peri- operative smoking cessation intervention on postoperative complications: a randomized trial. Ann Surg. 2008;248(5):739-45

18) Robres Puig J, Subirana Magdaleno H. Manejo preoperatorio de las hernias ventrales. 14:161-167 Cirugía de la Pared Abdominal 2a Edición Guías Clínicas de la Asociación Española de Cirujanos Copyright 2013.

19) Zhang D, Wang XC, Yang ZX, Gan JX, Pan JB, Yin LN. Preoperative chlorhexidine versus povidone-iodine antisepsis for preventing surgical site infection: a meta-analysis and trial sequential analysis of randomized controlled trials. Int J Surg. 2017;44:176-84.

20) Baucom RB, Ousley J, Oyefule OO, Stewart MK, Phillips SE, Browman KK, et al. Evaluation of long-term surgical site occurrences in ventral hernia repair: implications of preoperative site independent MRSA infection. Hernia. 2016;20(5):701-10. 
21) Acevedo Fagalde A. Martín A. Obesidad y cirugía de las eventraciones 20: 309-316 En Eventraciones Otras hernias de pared y cavidad abdominal Fernando Carbonell Tatay Alfredo Moreno Egea Valencia, 2012

22) Liang MK, Holihan JL, Itani K, Alawadi MD, et al. Ventral hernia management: expert consensus guided by systematic review. Ann Surg. 2017;265:80-9.

23) Novitsky YW, Orenstein SB. Effect of patient and hospital characteristics on outcomes of elective ventral hernia repair in the United States. Hernia. 2013;17(5):639-45.

24) Heniford BT, Park A, Ramshaw BJ, Voeller G. Laparoscopic repair of ventral hernias: nine years' experience with 850 consecutive hernias. Ann Surg. 2003;238(3):391-9.

25) Sauerland S, Korenkov M, Kleinen T, Arndt M, Paul A. Obesity is a risk factor for recurrence after incisional hernia repair. Hernia. 2004;8(1):42-6.

26) Pernar LI, Pernar CH, Dieffenbach BV, Brooks DC, Smink DS, Tavakkoli A. What is the BMI threshold for open ventral hernia repair? Surg Endosc. 2017;31(3):1311-7.

27) Giordano SA, Garvey PB, Baumann DP, Liu J, Butler CE. The impact of body mass index on abdominal wall reconstruction outcomes: a comparative study. Plast Reconstr Surg. 2017;139:1234-44.

28) Tsereteli Z, Pryor BA, Heniford BT, Park A, Voeller G, Ramshaw BJ. Laparoscopic ventral hernia repair (LVHR) in morbidly obese patients. Hernia. 2008;12(3):233-8.

29) González LG, Lora A, Varela E, Vergara G, Vega Peña V, Ayala JC, Martínez JD, Hanssen A, Gómez JP, Ruiz JP. Guía para el tratamiento laparoscópico de la hernia ventral e incisional. Rev Hispanoam Hernia. 2021;9(2):105117

30) Rosen MJ, Aydogdu K, Grafmiller K, Petro CC, Faiman GH, Prabhu A. A multidisciplinary approach to medical weight loss prior to complex abdominal wall reconstruction: is it feasible? J Gastrointest Surg. 2015;19(8):1399406.

31) Newcomb WL, Polhill JL, Chen AY, Kuwada TS, Gersin KS, Getz SB, et al. Staged hernia repair preceded by gastric bypass for the treatment of morbidly obese patients with complex ventral hernias. Hernia. 2008;12:465-9.

32) Khorgami Z, Haskins IN, Aminian A, Andalib A, Rosen MJ, Brethauer SA, Schauer PR. Concurrent ventral hernia repair in patients undergoing bariatric surgery: a case-matched study using the National Surgical Quality Improvement Program Database. Surg Obes Relat Dis. 2017;13:997-1002.

33) Blatnik JA, Krpata DM, Jacobs MR, Gao Y, Novitsky YW, Rosen MJ. In vivo analysis of the morphologic characteristics of synthetic mesh to resist MRSA adherence. J Gastrointest Surg. 2012;16:2139-44. 


\title{
CIRUGIA ROBOTICA EN EL TRATAMIENTO DE LAS HERNIAS DE LA PARED ABDOMINAL
}

\author{
Dra. Gabriela Rodríguez
}

\section{HERNIOPLASTIA INGUINAL ROBOTICA}

La reparación de las hernias y eventraciones ha ido evolucionando con el tiempo. En los años noventa se introduce la reparación laparoscópica de la hernia inguinal y en el 2007 se realiza la primera reparación robótica.

Pero la reparación de la hernia inguinal continua realizándose mayormente por cirugía abierta a nivel mundial. Al inicio de la cirugía laparoscópica la tasa de recurrencia era elevada, cercana al 10\%, pero con el paso del tiempo y la mayor experiencia de los cirujanos estas tasas disminuyeron hasta ser comprables a la cirugía abierta. Según las guías de la Sociedad Europea de hernia el Linchestein y las técnicas mínimamente invasivas se recomienda como las mejores opciones para la reparación.

Hasta la fecha los resultados son contradictorios y aún faltan estudios que ofrezcan una evidencia sólida que favorezca un tratamiento sobre otro. Uno de los factores más relevantes a favor de la cirugía abierta es la larga curva de aprendizaje de la cirugía laparoscópica de 240 operaciones en comparación a 100 de la cirugía abierta. ${ }^{(1)}$

La cirugía robótica ofrece ciertos beneficios como ser una visión tridimensional, mayor amplitud de movimiento de los instrumentos y una ergonomía mejorada para el cirujano. Varios estudios han demostrado que las suturas y los nudos se realizan significativamente más rápido que en la laparoscopia. ${ }^{(2)(3)(4)}$ Sin embargo, existen algunas preocupaciones con la cirugía robótica como el tiempo operatorio, la curva de aprendizaje del cirujano, y los costos económicos.

$\mathrm{Al}$ igual que con la laparoscopia, con la cirugía robótica se está realizando tanto abordaje totalmente extraperitoneal (rTEP) como una reparación transabdominal preperitoneal (rTAPP). Siendo más frecuente la realización de rTAPP ${ }^{(4)}$

En el 2019 se realizó un metaanalisis y una revisión sistémica que incluyeron 16 estudios donde se comparó la cirugía abierta, el TAPP, TEP y el TAPP robótico. Se observó que presentan resultados similares en términos de hematoma y seroma postoperatorios. Encontrándose que en la cirugía robótica la tasa de conversión y complicaciones intraoperatorias era del $0,03 \%$ y del $0,14 \%$, siendo valores similares a la cirugía laparoscópica. ${ }^{(1)}$ Pero la cirugía robótica fue la que presento un tiempo quirúrgico estimado más largo y mayores costos debido al mantenimiento de los equipos y los costos de los mismos. Ninguno de los estudios analizados valoro la cirugía robótica en cuanto al dolor crónico siendo la cirugía abierta la de mayor incidencia de esta complicación. ${ }^{(1)(3)}$

También en el 2019 se publicó otro estudio en el que se analizaron los pacientes operados en una base nacional de datos en Nebraska en donde se comparó cirugía abierta, laparoscópica y robótica incluyendo 3547 pacientes. En este estudio la cirugía robótica se asoció con los mejores resultados en todos los grupos. Presento la menor tasa de complicaciones generales, sin infecciones posoperatorias, con la tasa de readmisión más baja, menor estadía intrahospitalaria, el menor uso de analgésicos en comparación con la cirugía abierta. Estas tres últimas variables (readmisión, estadía hospitalaria y uso de analgésicos) no tuvieron diferencia con la cirugía laparoscópica. Pero la cirugía robótica presento los mayores costos. ${ }^{(5)}$

Con respecto a la curva de aprendizaje para el dominio de rTAPP y el tiempo operatorio aún no se ha determinado. En un 2018, Muysoms y sus colaboradores encontraron que el tiempo operatorio para rTAPP se reducía drásticamente en una curva de aprendizaje de 50 casos (número de pacientes tomados de manera arbitraria) para cirujanos experimentados en cirugía inguinal laparoscópica, mientras que en un trabajo publicado en 2019 donde se operaron 300 pacientes por cirugía robótica la curva de aprendizaje de un cirujano era de 11 a 12 casos. ${ }^{(4)(6)}$ Como fue señalado al inicio, la curva de aprendizaje para pasar a la cirugía laparoscópica se plantea como un problema y este problema se está superando con éxito, situación creemos que sucederá con la cirugía robótica. La literatura actual sugiere que la transición de la reparación abierta a la robótica es más difícil que cambiar de una plataforma principalmente laparoscópica a una robótica. ${ }^{(5)}$

Si bien todos estos datos son alentadores se requieren más estudios para encontrar un beneficio categórico de la cirugía robótica sobre las técnicas ya adoptadas, sobre todo, tomando en cuenta los costos, factor limitante para el uso de la plataforma robótica. 


\section{HERNIAS VENTRALES y EVENTRACIONES}

En los últimos años la cirugía de las hernias abdominales ventrales primarias y las eventraciones ha evolucionado de gran manera.

La reparación inicial por técnica abierta con sutura simple presentaba una alta tasa de recurrencia (en algunas series hasta 63\%) y alta tasa de complicaciones de la herida por los grandes colgajos. Luego la reparación con malla libre de tensión ha disminuido el índice de recurrencia pero continúa teniendo complicaciones de la herida y asociando ahora la infección de la malla.

En 1992 la reparación laparoscópica de las eventraciones se introduce con un menor tiempo de recuperación, disminuyendo también la estadía hospitalaria, la tasa de complicaciones y las recurrencias. Pero persiste con complicaciones como ser el dolor posoperatorio, los seromas, el hematoma entre otros. ${ }^{(7)}$

Desde su introducción en el año 2000 la cirugía robótica presenta ventajas potenciales sobre la cirugía laparoscópica, al igual que para la hernia inguinal (mayor libertad de movimiento, imágenes tridimensionales y una ergonomía superior). Estos beneficios planteados parecen tener más relevancia en la reparación de las hernias ventrales y las eventraciones que en la hernia inguinal. La sutura intracorpórea más fácil y precisa, favorece el cierre del defecto parietal, permitiendo la colocación de la malla pre o intra peritoneal de manera más sencilla. La fijación con suturas disminuye la utilización de tackers. Esto permite disminuir la producción de seromas, "abombamiento" de la malla y las recidivas. ${ }^{(7)(8)(9)(10)(11)(12)}$ (13)

$\mathrm{Al}$ evitar mecanismo de fijación que no sea una sutura intracorpóreo y ya que las fuerzas no se ejercen sobre la entrada de los trocares sino en los propios instrumentos se reduce el traumatismo parietal y el atrapamiento nervioso lo que puede disminuir el dolor posoperatorio. ${ }^{(7)(8)(13)}$

Persisten los problemas de los costos y la curva de aprendizaje que como ya analizamos con las hernias inguinales creemos que con el tiempo, se irán superando. ${ }^{(8)}$

Las sociedad hispanoamericana de hernia en sus guías recomienda la utilización de la cirugía robótica en centros especializados para la reparación de defectos herniarios complejos que requieran cierre del defecto con sutura y/o separación de componentes. ${ }^{(14)}$

En conclusión, la cirugía robótica de la hernia inguinal parece tener ciertos beneficios como mejor movimiento, técnica más precisa, así como desaparición de los temblores y una ergonomía más favorable para el cirujano. Estos beneficios son mayores en la reparación de las hernias ventrales y las eventraciones. Se necesitan más estudios para evaluar los resultados a largo plazo y valorar hasta qué punto la selección de cirujanos o pacientes contribuye a esos resultados. También se necesita más tiempo para poder observar disminución en las curvas de aprendizaje así como en los costos de los equipos. 


\section{BIBLIOGRAFÍA}

1) Aiolfi A, Cavalli M, Micheletto G, Lombardo F, Bonitta G, Morlacchi A, et al. Primary inguinal hernia: systematic review and Bayesian network meta-analysis comparing open, laparoscopic transabdominal preperitoneal, totally extraperitoneal, and robotic preperitoneal repair [Internet]. Vol. 23, Hernia. 2019. p. 473-84. Available from: https://doi.org/10.1007/s10029-019-01964-2

2) Kudsi OY, McCarty JC, Paluvoi N, Mabardy AS. Transition from Laparoscopic Totally Extraperitoneal Inguinal Hernia Repair to Robotic Transabdominal Preperitoneal Inguinal Hernia Repair: A Retrospective Review of a Single Surgeon's Experience. World J Surg. 2017 Sep 1;41(9):2251-7.

3) Aiolfi A, Cavalli M, Micheletto G, Bruni PG, Lombardo F, Perali C, et al. Robotic inguinal hernia repair: is technology taking over? Systematic review and meta-analysis [Internet]. Vol. 23, Hernia. 2019. p. 509-19. Available from: https://doi.org/10.1007/s10029-019-01965-1

4) Podolsky D, Novitsky Y. Robotic Inguinal Hernia Repair [Internet]. Vol. 100, Surgical Clinics of North America. 2020 [cited 2021 Aug 26]. p. 409-15. Available from: https://doi.org/10.1016/j.suc.2019.12.010

5) Pokala B, Armijo PR, Flores L, Hennings D, Oleynikov D. Minimally invasive inguinal hernia repair is superior to open: a national database review. Hernia [Internet]. 2019;23(3):593-9. Available from: https://doi.org/10.1007/ s10029-019-01934-8

6) Muysoms F, Van Cleven S, Kyle-Leinhase I, Ballecer C, Ramaswamy A. Robotic-assisted laparoscopic groin hernia repair: observational case-control study on the operative time during the learning curve. Surg Endosc [Internet]. 2018;32(12):4850-9. Available from: https://doi.org/10.1007/s00464-018-6236-7

7) Allison N, Tieu K, Snyder B, Pigazzi A, Wilson E. Technical feasibility of robot-assisted ventral hernia repair [Internet]. Vol. 36, World Journal of Surgery. Springer; 2012 [cited 2021 Sep 16]. p. 447-52. Available from: https://link-springer-com.proxy.timbo.org.uy/article/10.1007/s00268-011-1389-8

8) Kennedy M, Barrera K, Akelik A, Constable Y, Smith M, Chung P, et al. Robotic TAPP ventral hernia repair: Early lessons learned at an inner city safety net hospital.J Soc Laparoendosc Surg [Internet].2018;22(1). Available from: www.SLS.org

9) Oviedo RJ, Robertson JC, Desai AS. Robotic Ventral Hernia Repair and Endoscopic Component Separation: Outcomes. JSLS J Soc Laparoendosc Surg [Internet]. 2017;21(3). Available from: www.SLS.org

10) Gonzalez A, Escobar E, Romero R, Walker G, Mejias J, Gallas M, et al. Robotic-assisted ventral hernia repair: a multicenter evaluation of clinical outcomes. Surg Endosc. 2017;31(3):1342-9.

11) Sugiyama G, Chivukula S, Chung PJ, Alfonso A. Robot-assisted transabdominal preperitoneal ventral hernia repair.J Soc Laparoendosc Surg [Internet]. 2015;19(4). Available from: www.SLS.org

12) Rodrigues V, López-Cano M. TARUP technique. Advantages of minimally invasive robot-assisted abdominal Wall surgery. Cir Esp [Internet]. 2021 [cited 2021 Sep 10];99(4):302-5. Available from: https://doi.org/10.1016/j. ciresp.2020.10.008

13) Bittner R, Bain K, Bansal VK, Berrevoet F, Bingener-Casey J, Chen D, et al. Update of Guidelines for laparoscopic treatment of ventral and incisional abdominal wall hernias (International Endohernia Society (IEHS))-Part A. Surg Endosc [Internet]. 2019 Oct 15 [cited 2021 Oct 12];33(10):3069-139. Available from: /pmc/articles/ PMC6722153/

14) González LG, Lora A, Varela E, Vergara G, Peña VV, Ayala JC, et al. Laparoscopic treatment guide for ventral and incisional hernia. Vol. 9, Revista Hispanoamericana de Hernia. ARAN Ediciones S.A.; 2021. p. 105-17. 


\title{
TAPP VS LICHTENSTEIN EN LA RESIDENCIA: ¿EN QUÉ ESTAMOS?
}

\author{
Dras. Gabito I., Campos M., País C., Haro C.
}

La cirugía de la hernia inguinal es uno de los procedimientos más frecuentemente realizados a nivel mundial. Desde 1990, la reparación inguinal laparoscópica ha ganado cada vez mayor aceptación debido a sus múltiples ventajas. A pesar de esto, es un procedimiento técnicamente más demandante que la clásicamente utilizada técnica de Lichtenstein, por lo que requiere una curva de aprendizaje mayor. ${ }^{(1)}$

La evolución en la reparación herniaria ha sido bastante variable y data desde el siglo XVI en que se realizó la primera reparación mediante aproximación de componentes musculares y fasciales. Ya en el siglo XX, en la década de los sesenta se incorporó el uso de material protésico que se ha mantenido hasta la actualidad como "gold standard" en la reparación parietal. En la década de los ochenta, surgieron los primeros reportes de técnicas mini invasivas como el TAPP (TransAbdominal Pre Peritoneal) y TEP (Totalmente Extra Peritoneal). Hoy en día, la técnica de Lichtenstein sigue siendo la más usada a nivel mundial. Sin embargo, la reparación mediante abordaje laparoscópico tiene un índice bastante variable dependiendo de los recursos de cada país, yendo desde un 0-55\% de los procedimientos de reparación de la hernia inguinal en el mundo. ${ }^{(1)}$

Actualmente, la patología parietal ha experimentado un aumento en su complejidad debido al desarrollo de estas nuevas técnicas quirúrgicas para su resolución. Debido a este aumento en la complejidad técnica, y a la demanda de la mejor resolución que se le pueda brindar al paciente, el número de procedimientos realizados por los residentes en formación no parece ser el adecuado. ${ }^{(1)}$

La curva de aprendizaje se define como el tiempo y esfuerzo requerido para adquirir una nueva habilidad. Tomando en cuenta diversos estudios realizados a nivel mundial, se llegó a la conclusión que la reparación herniaria por abordaje abierto en manos de aprendices no supervisados está directamente asociado a un mayor índice de recurrencia. (Calificando a dichos aprendices como aquellos residentes que poseen menos de 60 procedimientos realizados o menos de 3 años de experiencia). Evaluando el índice de complicaciones, no encontraron diferencias entre consultantes o residentes supervisados, independientemente del año de residencia, si bien el tiempo operatorio es globalmente más prolongado. Por otro lado, habiéndose comparado la curva de aprendizaje del TAPP versus Litchtenstein se observó que es superior a favor del primero, requiriéndose más procedimientos laparoscópicos que abiertos para adquirir una destreza aceptable y de seguridad. Como consenso general, se aceptó además, que los residentes en formación deben ser supervisados hasta alcanzar un nivel de destreza de seguridad. ${ }^{(1)(2)(3)(4)(5)}$

Para averiguar en qué situación se encontraban los residentes del Uruguay desde el primer hasta el cuarto año, diseñamos una encuesta web que incluye a todos los residentes que se encuentren en actividad durante el año 2020 tanto de instituciones públicas como privadas.

El objetivo principal de la encuesta es valorar si al término del cuarto año de la residencia, los residentes cumplen con el número estipulado de cirugías para alcanzar la curva de aprendizaje tanto en la técnica de TAPP como Lichtenstein para realizar cirugías sin supervisión; así como valorar de forma subjetiva la destreza técnica alcanzada por vía laparoscópica.

Se tomaron en cuenta Residentes de primero a cuarto año de Hospitales Públicos (H. de Clínicas, H. Maciel, H. Pasteur), HCFFAA (Hospital Central de las Fuerzas Armadas), Hospital Policial, y del área Mutual de Montevideo (ASESP, Círculo Católico, Casa de Galicia) y del Interior del País (Hospital Regional Salto y Hospital Departamental Paysandú). Se encuestaron un total de 57 residentes. De estos, un 33,3\% pertenecían a primer año, 22, 8 \% a segundo y a tercer año, y un $21 \%$ a residentes de cuarto. La mayor proporción de los residentes $(66,67 \%)$ corresponden al ámbito público. (Figura 1 y 2 ). 


\section{P1 Año de residencia que cursa}

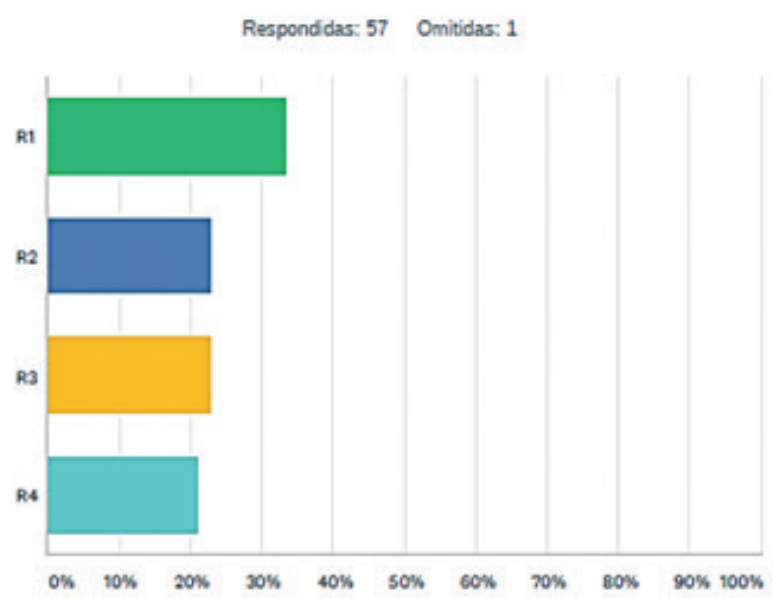

\begin{tabular}{l|l}
\hline OPCIONES DE RESPUESTA & RESPUESTAS \\
\hline R1 & $33.33 \% 6$ \\
\hline R2 & $22.81 \%$ \\
\hline R3 & 22.8196 \\
\hline R4 & $21.05 \%$
\end{tabular}

Figura 1

\section{P2 Centro al que pertenece}

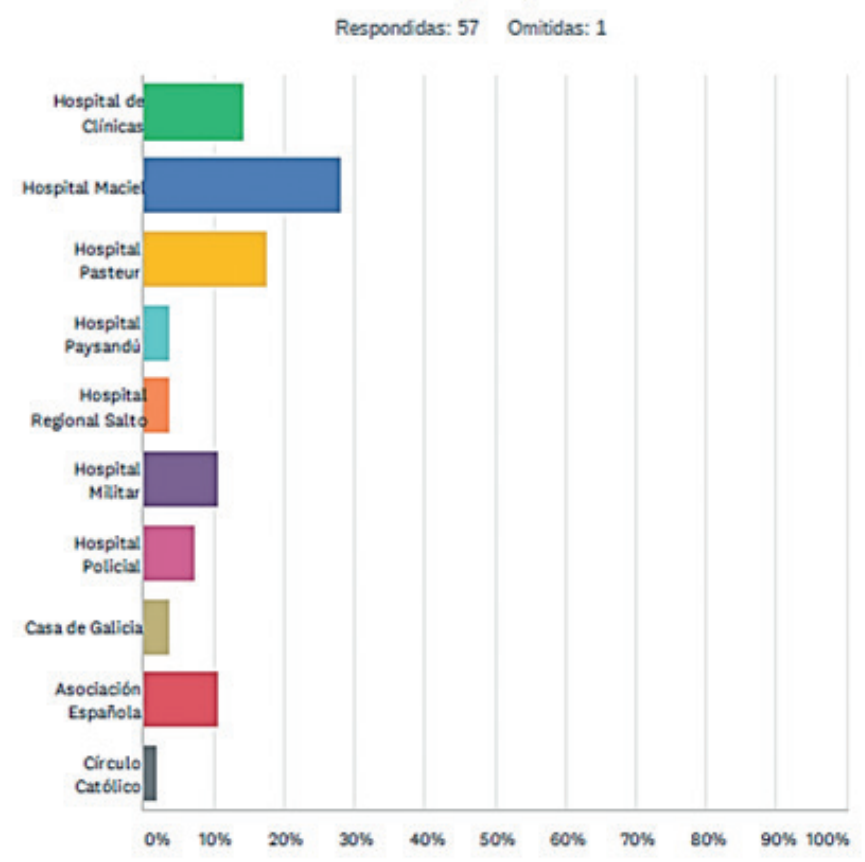

Figura 2

En cuanto a las hernioplastias inguinales convencionales que se realizaron como cirujano, el 28\% (16 residentes) habían realizado menos de 10 procedimientos, 17,54\% (10 residentes) realizaron entre 20 y 30 hernioplastias. Destacamos que sólo un 7\% (4 residentes) realizaron entre 50-60 hernioplastias y el 10,53\% (6 residentes) realizaron más de 60 cirugías. (Figura 3).

Si analizamos las respuestas de los residentes del último año y el lugar donde realizan la residencia, se desprende que los residentes de Centros Mutuales son los que realizaron el mayor número de hernioplastias convencionales (40 a 60 procedimientos), y los residentes de centros públicos realizaron entre 10 a 40 hernioplastias. 


\section{P3 Número de hernioplastias inguinales convencionales que realizo como cirujano}

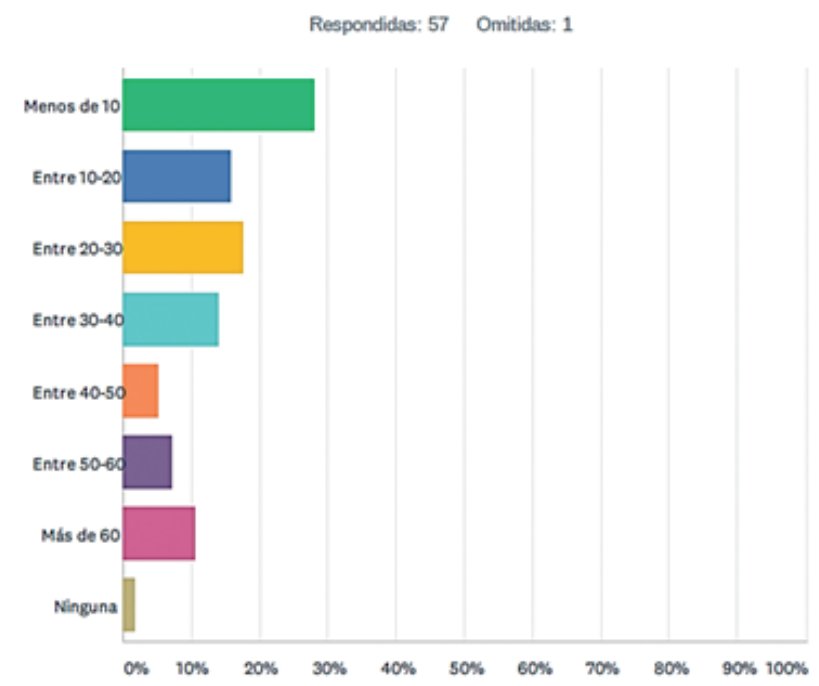

Figura 3

Tomando en cuenta estos números, se destaca la gran disparidad (prácticamente el doble) entre procedimientos realizados por residentes del mismo año en diferentes centros, sobretodo comparando hospitales públicos y privados, a favor de estos últimos.

El programa de formación de especialistas en Cirugía General de la Universidad de la República, aprobado por la Escuela de Graduados en el año 2014, ${ }^{(6)}$ especifica que el residente deberá realizar como cirujano tutorizado durante el primer año, 80-100 intervenciones entre menores y corrientes, incluyendo urgencia y coordinación. Dentro de estos procedimientos se incluye la patología parietal (hernias, eventraciones), tumores supraaponeuróticos (incluidas adenomegalias), nódulos mamarios benignos, apendicectomías y amputaciones mayores y menores, siempre tutorizados por un docente autorizado.

En 2017, en un Hospital Universitario de Gales, Reino Unido, se realizó un estudio analítico retrospectivo, ${ }^{(4)}$ para analizar el número de procedimientos realizados por residentes necesarios para alcanzar la curva de aprendizaje de algunas cirugías, incluyendo la reparación herniaria. Analizaron los registros de cirugías realizadas por residentes, haciendo un análisis estadístico mediante evaluaciones de los procedimientos. Como resultados obtuvieron, que la media de procedimientos necesarios para alcanzar la curva de aprendizaje es de 64 (rango de 18-110).

Por otro lado, en 2019 se publicó un estudio prospectivo, multicéntrico que incluía 3 diferentes Hospitales de Italia, ${ }^{(5)}$ donde el objetivo fue analizar cuántos procedimientos se requieren para lograr la curva de aprendizaje de la técnica de Lichtenstein. Se realizó un análisis retrospectivo de los primeros 100 procedimientos de Lichtenstein realizados por 4 aprendices de tres instituciones diferentes y se los comparó con el mismo número de procedimientos realizados por 3 cirujanos senior de las mismas instituciones. Tomaron en cuenta el tiempo operatorio y las complicaciones intra y postoperatorias.

Como resultado, se dedujo que los aprendices logran la curva de aprendizaje después de 37 a 42 procedimientos, alcanzando un tiempo operatorio similar al de los cirujanos senior.

De nuestra encuesta se desprende que el 50\% de los residentes de cuarto año (R4) de nuestro medio, no cuentan con el número mínimo de procedimientos realizados requeridos como curva de aprendizaje, si extrapolamos los números a los estudios previamente mencionados.

- Más de 60: 5 r4 (Centro mutual)

- 50-60: $1 \mathrm{r} 4$ (Centro mutual)

- 30-40: 2 r4 (H. Público)

- 20-30: 3 r4 (H.Público)

- 10-20: 1 r4 (H.Público) 
En suma, del total de $\mathrm{R} 4$, seis residentes realizaron más de 50 procedimientos, todos ellos corresponden a centros mutuales y seis residentes realizaron menos de 40 procedimientos siendo los residentes de centros públicos.

Por otro lado, también nos preguntamos si la formación laparoscópica en nuestro medio es igual para todos los residentes, de lo cual surgió que el 70\% no había recibido curso de formación en laparoscopía tomando en cuenta los cuatro años de residencia, y del 30\% restante que si recibió, la mayoría lo obtuvo en el primer año en su hospital o centro de formación y otros en congresos o cursos pagos de forma extracurricular. Destacándose de esto una clara desigualdad en la formación laparoscópica recibida dependiendo del centro donde se cursa la residencia.

Cuando encuestamos sobre la participación como ayudantes en TAPP, el $40 \%$ de los residentes ${ }^{(23)}$ ayudaron en menos de 5 procedimientos de este tipo, y casi un 33\% ${ }^{(19)}$ no participó en ninguno. Siendo aún menor el porcentaje en cuanto a la participación en TAPP como cirujanos, ya que más del $50 \%$ de los residentes no participó en ninguno, y menos del $30 \%$ tiene menos de 5 realizados. (Figuras 4 y 5 )

\section{P7 ¿Cuántos TAPP ha realizado como ayudante?}

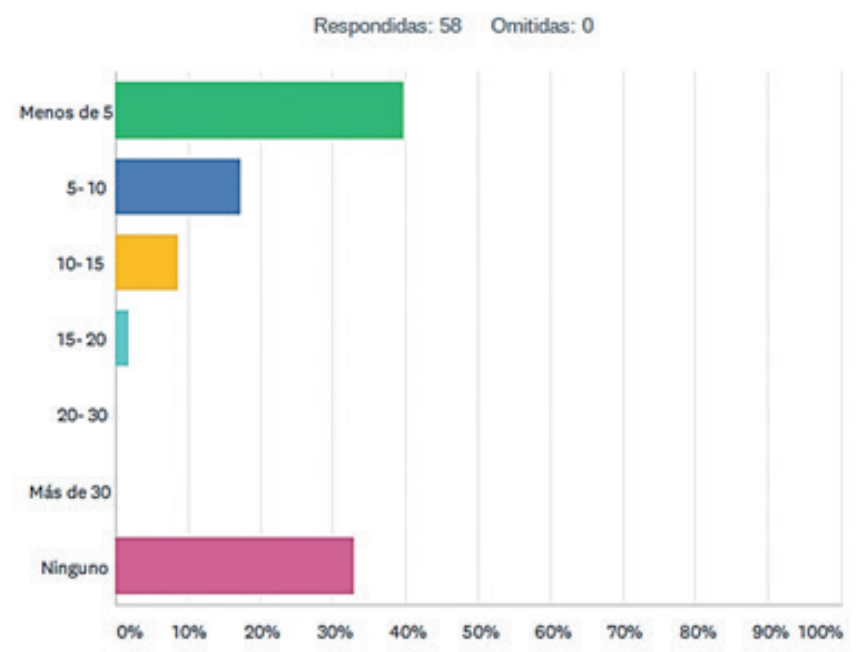

Figura 4

\section{P8 ¿Cuántos TAPP ha realizado como cirujano?}

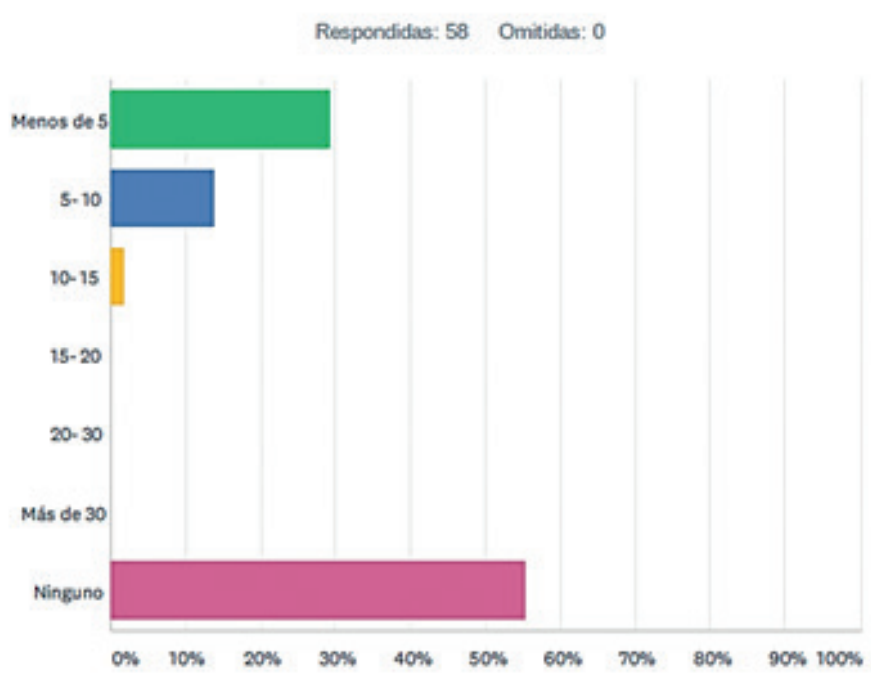

Figura 5

No existe consenso en cuántos TAPP se requieren para alcanzar la curva de aprendizaje. Dentro de la búsqueda bibliográfica para definirlo, en $\wedge^{\prime}$ Achieving the Learning Curve in Laparoscopic Inguinal Hernia Repair by Tapp: A Quality Improvement Study" se realizó la prueba demostrando que se necesitan de 60 a 65 procedimientos para alcanzar el nivel de cirujano experto. ${ }^{(2)(3)}$

Destacando además la disparidad entre el sector público y privado una vez más, debido a que no hay ningún residente del sector privado que haya participado como cirujano del abordaje laparoscópico mencionado; ningún residente de 
cuarto año alcanza los 60 procedimientos realizados, requeridos como número mínimo para la curva de aprendizaje según la bibliografía. ${ }^{(2)}$

Al consultar si al realizar el TAPP lograban finalizar el procedimiento en todos los pasos o algún paso debía de ser finalizado por un docente, el 60\% refiere culminar el procedimiento mientras que el $40 \%$ requiere la ayuda de un docente para finalizarlo. (Figura 6). Sin embargo, el $80 \%$ de los residentes refieren no sentirse seguros respecto a los pasos técnicos a realizar. Del total de los encuestados que realizó la técnica como cirujano, solo el $47 \%$ se siente seguro para realizar los pasos técnicos y el 53\% refiere no sentirse seguro. (Figura 7)

\section{P9 De la respuesta anterior, ¿usted realizó todos los pasos de la técnica o ha tenido que finalizar un docente?}

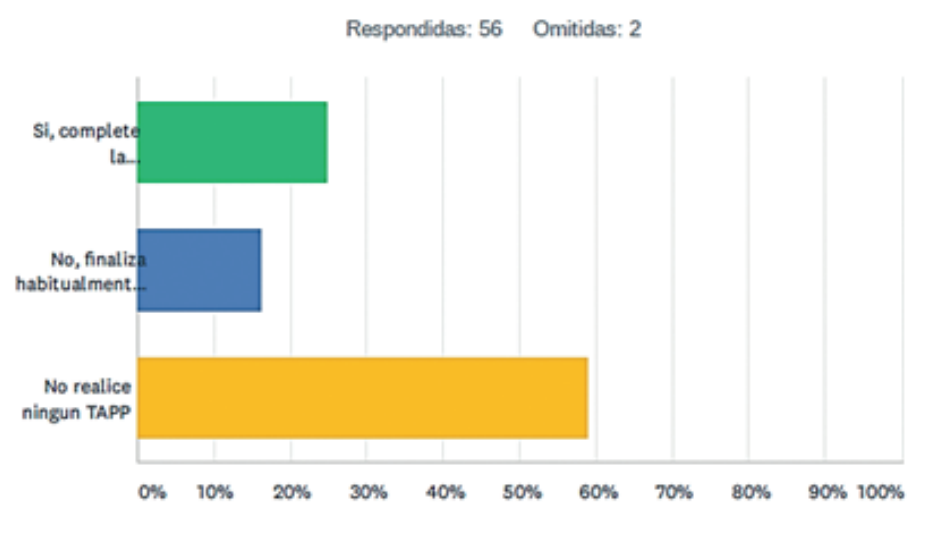

Figura 6

\section{$\mathrm{P} 10$ ¿Se siente seguro respecto a los pasos técnicos a realizar?}

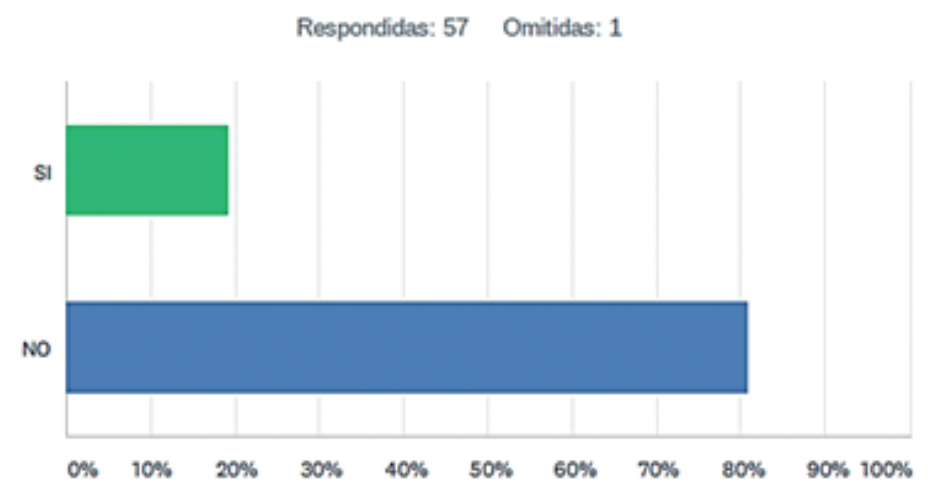

Figura 7

Lo antedicho se refleja a nivel internacional, donde se destaca que con la llegada de la técnica laparoscópica los residentes no acceden a realizar ayudantías como si lo hacen con la cirugía laparotómica. Hay un cambio en la formación del residente donde el mismo transcurre más tiempo fuera del block quirúrgico. ${ }^{(7)}$ Esto genera que al finalizar la residencia los residentes no se sienten seguros en realizar cirugías de forma completa, necesitando la ayuda de cirujanos expertos para concluir las mismas. Una de las estrategias propuestas por la American College of Surgeons es realizar un programa llamado "Transition to Practice", siendo un fellowship que permite al residente del último año realizar cirugías de forma supervisada logrando paulatinamente mayor independencia en la toma de decisiones. ${ }^{(8)}$

Como conclusiones de este trabajo, resaltamos la marcada diferencia dependiendo del centro donde se realiza la residencia, destacando que en centros privados no se realiza TAPP por parte de los residentes y refieren haber ayudado en menos de 5 procedimientos, sumado a esto, también hay una gran diferencia según el centro del número de Lichtenstein, el 50\% de los R4 no cuentan con el mínimo de curva de aprendizaje según los trabajos internacionales. Existe una clara concentración de TAPP en Hospital Maciel, Pasteur y Clínicas, con alguna diferencia en cuanto al número de cirugías que varían de acuerdo a la etapa formativa en la que se encuentren, sabiendo que los residentes de cuarto año de dichas instituciones realizaron por lo menos 5 cirugías de TAPP tanto como ayudante y cirujano. De estos más del $70 \%$ termina la cirugía pero la mayoría no se siente seguro para completar las maniobras.Es de destacar finalmente que ningún residente cumple con la curva de aprendizaje mínima estipulada de 60-65 procedimientos TAPP. 


\section{BIBLIOGRAFÍA}

1) HerniaSurge Group. International guidelines for groin hernia management. Hernia. 2018 Feb;22(1):1-165. doi: 10.1007/s10029-017-1668-x. Epub 2018 Jan 12. PMID: 29330835 ; PMCID: PMC5809582.

2) Bracale U, Merola G, Sciuto A, Cavallaro G, Andreuccetti J, Pignata G. Achieving the Learning Curve in Laparoscopic Inguinal Hernia Repair by Tapp: A Quality Improvement Study.J Invest Surg. 2019 Dec;32 (8):738745. doi: 10.1080/08941939.2018.1468944. Epub 2018 Jun 14. PMID: 29902096.

3) Köckerling F, Sheen AJ, Berrevoet F, Campanelli G, Cuccurullo D, Fortelny R, et al. The reality of general surgery training and increased complexity of abdominal wall hernia surgery. Hernia. 2019 Dec;23(6):1081-1091. doi: 10.1007/s10029-019-02062-z. Epub 2019 Nov 21. PMID: 31754953; PMCID: PMC6938469.

4) Brown C, Abdelrahman T, Patel N, Thomas C, Pollitt MJ, Lewis WG. Operative learning curve trajectory in a cohort of surgicaltrainees. Br J Surg. 2017 Sep;104(10):1405-1411

5) Merola G, et al. Learning curve in open inguinal hernia repair: a quality improvement multicentre study about Lichtenstein technique. Hernia. 2020 Jun;24(3):651-659

6) Clínicas Quirúrgicas A, B, F, 1, 2 y 3, Departamento Básico de Cirugía, Departamento de Emergencia del Hospital de Clínicas. Programa de Formación de Especialistas en Cirugía General. Universidad de la República, Facultad de Medicina. Aprobado por la Escuela de Graduados el 3/10/2014.

7) Huber T, Richardsen I, Klinger C, Mille M, Roeth AA, Dörner J, et al. See One, Do One, Teach One: Reality of Surgical Resident Training in Germany. World J Surg. 2020;44(8):2501-10.

8) Mullen MG, Salerno EP, Michaels AD, Hedrick TL, Sohn MW, Smith PW, et al. Declining operative experience for junior-level residents: Is this an unintended consequence of minimally invasive surgery? J SurgEduc. 2016;73(4):609-15. 


\title{
DOCENCIA Y SIMULACION EN CIRUGIA LAPAROSCOPICA DE HERNIAS DE LA PARED ABDOMINAL
}

\author{
Dr. Juan Sanguinetti \\ Dr. Ezequiel Palmisano \\ Dr. Gonzalo Estapé
}

La patología herniaria de la pared abdominal es muy frecuente y con elevada prevalencia en la clínica quirúrgica. Por eso la formación adecuada y el conocimiento anatómico de la región es imprescindible para lograr los mejores resultados en los pacientes con esta patología de alta incidencia y cuya morbilidad puede no ser menor en caso de complicaciones o errores técnicos. Hoy en día se debe solucionar la patología herniaria de pared abdominal con la menor morbilidad posible y con técnicas de menor agresión, siempre que esto sea factible. ${ }^{(1)(2)}$

En los últimos años, la cirugía de las hernias tiene una mayor presencia, un crecimiento extraordinario dentro de la Cirugía General; se ha hecho notar en forma clara, de modo para considerarla como una especialidad propia, tal y como ha sucedido con la cirugía coloproctológica, la hepatobiliopancreática y trasplantes, la de mama o la endocrinometabólica, que ya estaban antes afianzadas, respetadas y reconocidas en los Servicios de Cirugía, desde hace tiempo. Hoy, las Unidades de Cirugía de Pared, están presentes en los grandes hospitales internacionales. (18; prologo del Dr. Carbonell; Palmisano, Ezequiel Mariano. Manual Práctico de Cirugía Endoscópica de la Pared Abdominal.)

Las nuevas técnicas para resolución de la patología herniaria se han beneficiado del avance de la tecnología, mejores materiales laparoendoscopicos, prótesis de mejor calidad, puertos laparoscópicos de avanzada y menos invasivos ademas la aparición de cirugía robótica en la patología herniaria la ha potenciado y expuesto a otro nivel, Todos estos avances deben tener un principal objetivo, reconstruir la biomecánica primitiva de esta pared abdominal, la restitutio ad integrum para normalizar sus funciones alteradas por un defecto, entre las que se encuentran: el equilibrio de presiones toracoabdominales, la mecánica respiratoria, el movimiento giratorio y de flexión de nuestro abdomen junto a la protección de las delicadas vísceras que contiene. Los cirujanos que se acerquen al tratamiento, deben estar formados, primero en las técnicas de cirugía abierta, de reconstrucción anatómica, con el conocimiento suficiente para valorar si reparan el defecto de esta forma o con accesos laparoendoscópicos. Nunca un cirujano de los que llamamos "laparoscopistas" debe tratar a estos pacientes, sin haber pasado por el previo aprendizaje anatómico. Así lo ha entendido y descripto el Dr. E. Palmisano (Argentina) en su reciente manual sobre esta patología. Y de ahí citamos en forma casi textual las palabras antes nombradas, dado que creemos no apropiado que un cirujano sin experiencia previa en cirugía abierta de la región inguinal o de la patología de pared abdominal pueda abordar en forma integral casos complejos de esta especialidad e incluso pudiendo tener complicaciones innecesarias por el no reconocimiento anatómico de las estructuras por esta nueva vía. Recordamos que las estructuras anatómicas con las que tenemos relación por vía laparoscópica no son menores y su lesión podría terminar en complicaciones severas o en morbilidad no despreciable para nuestros pacientes.

Los cirujanos que están comenzando a practicar la cirugía mínimamente invasiva de la pared abdominal, no tienen porque volver a emprender el camino de aprendizaje ya recorrido por los innovadores. Actualmente, disponemos de mejores cursos de anatomía, de innumerables videos en internet, de redes sociales con grupos cerrados especializados como la International Hernia Collaboration, de cursos de inmersión, de mejores tecnologías e insumos, y de un mayor número de cirujanos expertos que podrían servir de tutores. ${ }^{(18)}$

Tradicionalmente los cirujanos aprenden las técnicas quirúrgicas siguiendo la metodología clásica diseñada en el siglo XIX por William Steward Halsted. Esta metodología se basa en la asunción progresiva de responsabilidades por parte del cirujano en formación, tutorizado por un cirujano con mayor experiencia y entrenando las técnicas directamente en el paciente. Antes de esto, la enseñanza médica era, con algunas excepciones, errática, no estandarizada, y escasamente regulada. ${ }^{(18)}$ Este tipo de enseñanza quirúrgica si bien todavía tiene su valor para ciertas actividades de la docencia quirúrgica viene cambiando por el nuevo paradigma que trajo la simulación en cirugía, donde ahora según los autores de este texto, los pasos serian; primero ver cirugías o videos en la basta red de internet, ayudar en una cirugía, simular-entrenar y luego proceder a realizar el procedimiento en forma segura y tutorizada luego de varios ciclos de ver-ayudar y simular. 
El rol del instructor es fundamental debe ser un mentor presente en forma física y o virtual este será un guía pudiendo dejar varios pasos del entrenamiento al estudiante e incluso con docencia a distancia como lo ha demostrado el Dr. Julian Varas y colaboradores con su aplicación móvil "LAPP” donde ya a validado este tipo de entrenamiento a distancia. Hoy en dia tenemos instructores expertos en la técnica por lo que no deberíamos repetir los errores que cometieron nuestros predecesores al inicio d e la cirugía laparoscópica, nos debemos apoyar en la tecnología no solo durante el acto quirúrgico sino que también durante la etapa formativa, explorando en la red de internet manuales, foros, grupos online,trabajos,videos y cursos para llegar al momento o clímax quirúrgico con el máximo de entrenamiento, esto también es parte de la llamada simulación quirúrgica, que no solo involucra el entrenamiento motor o manual sino el entrenamiento cognitivo y de enfrentamiento a complicaciones para las diferentes eventualidades durante los procedimientos.

Será fundamental que los instructores estén formados para la docencia y la simulación en la área especifica,mas aun en esta especialidad que trata una patología benigna donde los pacientes y los cirujanos en general no esperan complicaciones mayores, se debe profesionalizar la docencia, no alcanza con tener un cirujano experto debemos tener un instructor experto y esto es uno de los pilares del modelo de formación que nombra Donald kirkpatric donde en general los programas de entrenamiento fallan. Y esto es por debemos tomar el entrenamiento y formación en simulación como una nueva especialidad básica para ser instructor o docente..$^{(19)}$

Dado que en nuestro medio y menos en nuestra especialidad, se conoce poco sobre el Profesor Kirkpatrick y sus métodos para evaluar entrenamiento creemos oportuno nombrarlo en este capitulo para generar posteriormente la búsqueda bibliográfica sobre el referente, nombramos sus 4 niveles de aprendizaje y un modelo de entrenamiento con evaluación para llegar al objetivo del desempeño deseado. Los cuatro niveles son 1: reacción, el grado que los estudiantes encuentran el entrenamiento favorable, 2: aprendizaje, el grado de conocimiento o habilidades que se adquieren asi como la actitud y confianza durante el entrenamiento, 3: comportamiento; el grado que se aplican los conocimientos adquiridos en el entrenamiento cuando deben realizar la tarea dada, 4: Resultados, el grado de efectividad que ocurre como resultado del entrenamiento empleado.

De todo esto podemos definir que se puede ser un excelente profesional o técnico y un no tan buen instructor quizás dada la falta de estimulo por enseñar, el estimulo o pasión por la docencia será base y pilar del instructor para poder generar la confianza del estudiante durante la trasferencia de conocimientos. El Profesor Dr. Juan Azagra (Luxemburgo) relata en su charla sobre Innovación en cirugía ${ }^{(20)}$ que todos los cirujanos somos "pilotos o conductores de automóviles" pero no todos correremos en la "formula uno", creemos que tampoco todos tendriamos la capacidad o pasión docente necesaria la excelencia como instructores.

El estudiante o residente que se comienza a formar en cirugía laparoscópica de pared abodminal debe tener un programa claro, objetivos definidos y un mentor o instructor que lo acompañe. Sus errores no deberían corregirse inicialmente en el paciente sino en un ambiente simulado estandarizado como ya lo demostró en forma costo efectiva F. Jacob Seagull y colaboradores en su publicación en "Surgical Education and Training" del 2009 donde describen los modelos de bajo costo de la Universidad de Maryland, EEUU.estos fácilmente podrían extrapolarse a nuestro medio
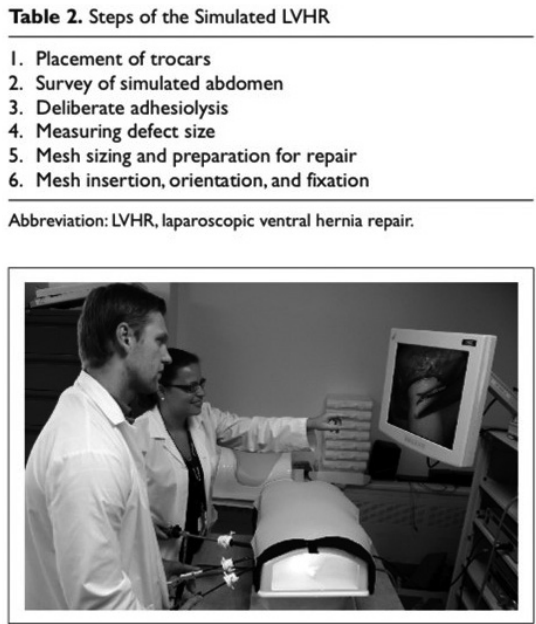

Figure 4. Note the 3 trocars in the lateral wall of the "abdomen" of the model; as in an actual procedure, the trocars have been placed contralateral to the defects, and the monitor is on the opposite side of the patient from the surgeons

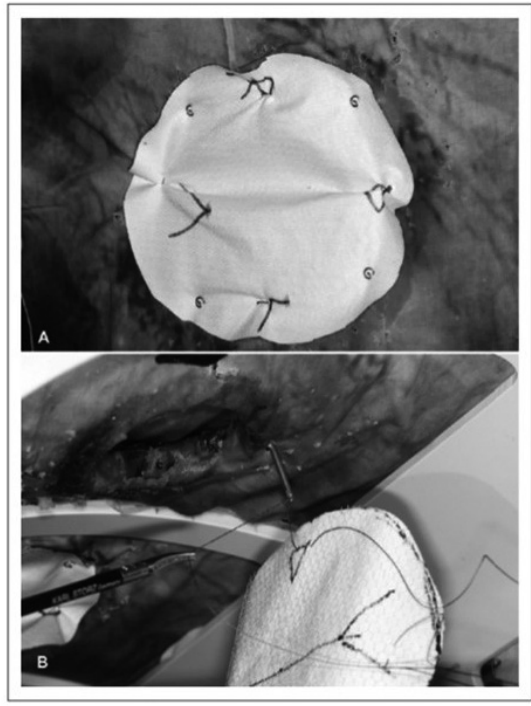

Figure 5. The hernia repair: A. view of the repair inside the simulator; B. fixation of the mesh with the sutures and suture passer

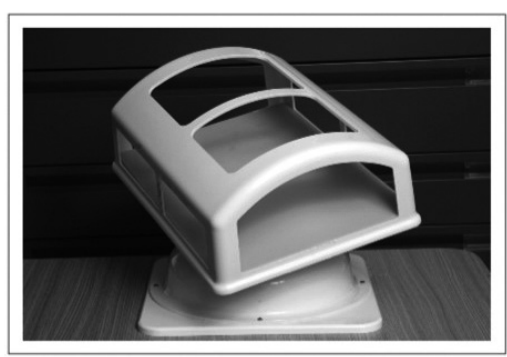

Figure I. The trainer box from Stryker Endoscopy can be tilted in different axes; it possesses 2 working spaces, each measuring $18 \times 20 \mathrm{~cm}^{2}$

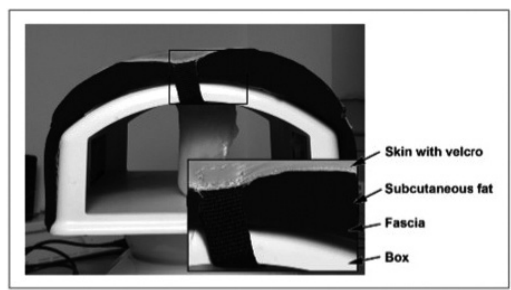

Figure 2. The surgical abdominal wall (SAW) model covers 3 sides of the box (left, top, and right); note that the SAW model is affixed to the box with a series of Velcro straps 
El error inicial del estudiante es querer operar rápidamente así lo nombra el Dr. Mario Secchi en el manual del Dr. Palmisano, para evitar esto otra vez la simulación es una herramienta para que el estudiante llegue con la actitud necesaria y juicio suficiente de sus habilidades para enfrentarse en forma segura al paciente. No solo en técnica debe formarse sino en valoración preoperatoria indicaciones y tácticas adecuadas para cada paciente, sino incurriríamos en el segundo error operar sin elegir la táctica adecuada.

El tercer error que nombra el colega es operar sin el entrenamiento adecuado, hay que recordar que las suturas y disecciones que se realizan por vía laparoscópica en cirugía parietal son de difícil adquisición y seguramente muchos de los cirujanos con años de experiencia colecistectomías laparoscópicas les seria muy complejo e incluso imposible para algunos de ellos cerrar el flap peritoneal en forma optima en una simple hernioplastia tapp sino tienen el entrenamiento especifico adecuado. ${ }^{(18)(20)(21)}$

El rol de los simuladores en cirugía ya están bien establecidos; acortan la curva de aprendizaje y nos enfrentan a un entrenamiento mas estandarizado; han surgido por esto muchos modelos de endotrainers de bajo costo que incluso los alumnos podrían fabricarse para entrenar. Creemos que la cirugía experimental ha sido una gran herramienta que ha quedado en desuso en la simulación moderna de la patología de pared salvo para casos muy particulares de entrenamiento, pero nunca en principio para un nivel incial de formación.En patología de pared con los simuladores de bajo costo han mejorado el entrenamiento en suturas tan necesarias para esta técnica ${ }^{(20)(21)(22)}$ tal es así que se han creado a nivel local con Easylap ${ }^{\circledR}$ desarrollo nacional de nuestro equipo de cirujanos de Maldonado Uruguay con apoyo de la Fundación Favaloro de Argentina modelos que hemos podido acercar de forma accesible y reproducible a nivel regional.

El residente de cirugía gral y especialista quirúrgico en aparato digestivo debe familiarizarse con la resolución de la patología de pared abdominal.

Si bien es poco probable que el residente se pueda enfrentar en su formación a todas las posibles eventualidades de la patología parietal se deben establecer objetivos básicos y avanzados de la formación en esta especialidad. ${ }^{(1)(3)}$

Es muy discutido el numero de cirugías que debe realizar el cirujano en formación, y mas aun si tomamos en cuenta la variable de abordaje por vía laparoscópica o mínimamente invasiva. Simmons et al. en la guía de la Sociedad Europea de Hernias refiere que el residente debe haber realizado 50 abordajes por vía anterior, 7 abordajes TEP y 7 abordajes TAPP durante su formación. Probablemente en nuestro medio la formación en vía anterior supera ampliamente este numero pero los otros abordajes no siempre estarán tan accesibles para la formación de los residentes ya que requieren de una curva de aprendizaje diferente con instructores formados y material no siempre accesible. Por esto,en estos abordajes seguramente la simulación y el entrenamiento ex vivo y en cadáveres tome importancia. ${ }^{(3)(4)(5)(6)}$

Las técnicas no contempladas en la formación según cada centro académico se deberían complementar con rotaciones en centros de referencia y simulación en las técnicas de bajo volumen. ${ }^{(1)(2)(6)}$

Se debería evaluar el proceso formativo con un sistema de feedback para poder mejorar los aspectos técnicos y conocimiento teórico de la patología caso a caso.

También incluir en la formación la revisión de videos de técnicas como varias escuelas europeas han implementado. ${ }^{(4)(5)}$

La simulación ex vivo así como la revisión de videos y el tele-mentorship debería ser parte fundamental de la enseñanza de la técnica laparoscópica de patología herniaria.

A nivel nacional el Dr. Raul Morelli presentó en el 2005 en la revista de Cirugía del Uruguay una importante experiencia en 99 pacientes en hernias laparoscópicas pero no encontramos indexado a nivel nacional publicaciones sobre modelos originales de entrenamiento en hernias laparoscópicas. ${ }^{(7)(8)}$

A nivel local en el Jornada de Cirujanos del interior del año 2018 organizado por el Dr. Daniel Pignanesi se coordino con un equipo de cirujanos de la Asistencial Medica de Maldonado un Hands On orientado a la patología laparoscópica de la pared Abdominal invitando al Dr. Ezequiel Palmisano cirujano Argentino referente en la especialidad, evento que quedo registrado en la actividades de nuestra Sociedad. En esa oportunidad que genero un modelo para sutura vertical y simular el cierre del flap peritoneal con los simuladores de Easylap ${ }^{\circledR}$.

A nivel latinoamericano existen varias publicaciones de referentes en la especialidad, desde simuladores para diastasis de los rectos y hernias laparoscópicas por el Dr Derlin Suarez y también modelos presentados en SAGES por el Dr. Andrés Hansen (Venezuela 2017, https://www.youtube.com/watch?v=44FbIRviq4M\&t=108s) con una chuleta de cerdo y un preservativo para simular la región inguinal y hernias a este nivel muy costo efectivo y atractivo para el entrenamiento. 
A nivel nacional el Dr. Gustavo Arman Ugon-Bigi y Cols. a presentado un trabajo en cadáveres como modelo de simulación en la técnica y el Dr. Mauro Perdomo y cols. han presentado en el 2019 en una actividad de la Sociedad de Cirugía del Uruguay interesante video docente (https://www.youtube.com/watch?v=MLNblLXRun4\&t=56s) que creemos relevante nombrarlo por su importancia docente y describir el posible entrenamiento en la técnica con material cadavérico. ${ }^{(17)}$

Los Dres. Julián Varas y Pablo Achurra de la Universidad Católica de Chile, se han convertido en el equipo con mas publicaciones en docencia en Latinoamérica tienen una gran experiencia y han presentados diferentes modelos de simulación en cirugía entre ellos en cirugía laparoscópica de hernias en material ex vivo y cadavérico.

E1 Dr. Achurra ha comentado en el Congreso Chileno de Cirugía 2020 (https://www.youtube.com/watch?v=EcipxyxtO_0\&t=1606s) que las complicaciones que se comentaban en la técnica laparoscópica de hernias; recurrencia de hasta $20 \%$ y dolor neuropático por uso indiscriminado de tackers (Voitk,CJS 1998) ha disminuido gracias a la mejora en la curva de aprendizaje en la técnica, (Gao,C IJS 2020). ${ }^{(16)}$ Comentando también que luego de 20 procedimientos, actualmente se llega a un nivel aceptable en la curva de aprendizaje, dado que hoy en día aprendemos de expertos y en gral. se llega a un nivel de seguridad mas rápido y con menos errores. Sugiriendo recomendaciones para que los cirujanos comiencen por la técnica TAPP antes de comenzar por técnica TEP dado su mayor complejidad. Es de destacar que no encontramos modelos de entrenamiento en técnica TEP en nuestra revisión.

E1 Sanatorio Rivadavia de BsAs. Argentina recientemente (2020) ha publicado un video con su modelo usado desde el año 2005 en su residencia de simulación en técnica TAPP utilizando piel de pollo. Por su originalidad y fácil realización nos pareció oportuno nombrarlos: D.Zeballos JL. Kameyha y R. Vega https://www.youtube.com/watch?v=eJNVndopVtc\&t $=349 s$

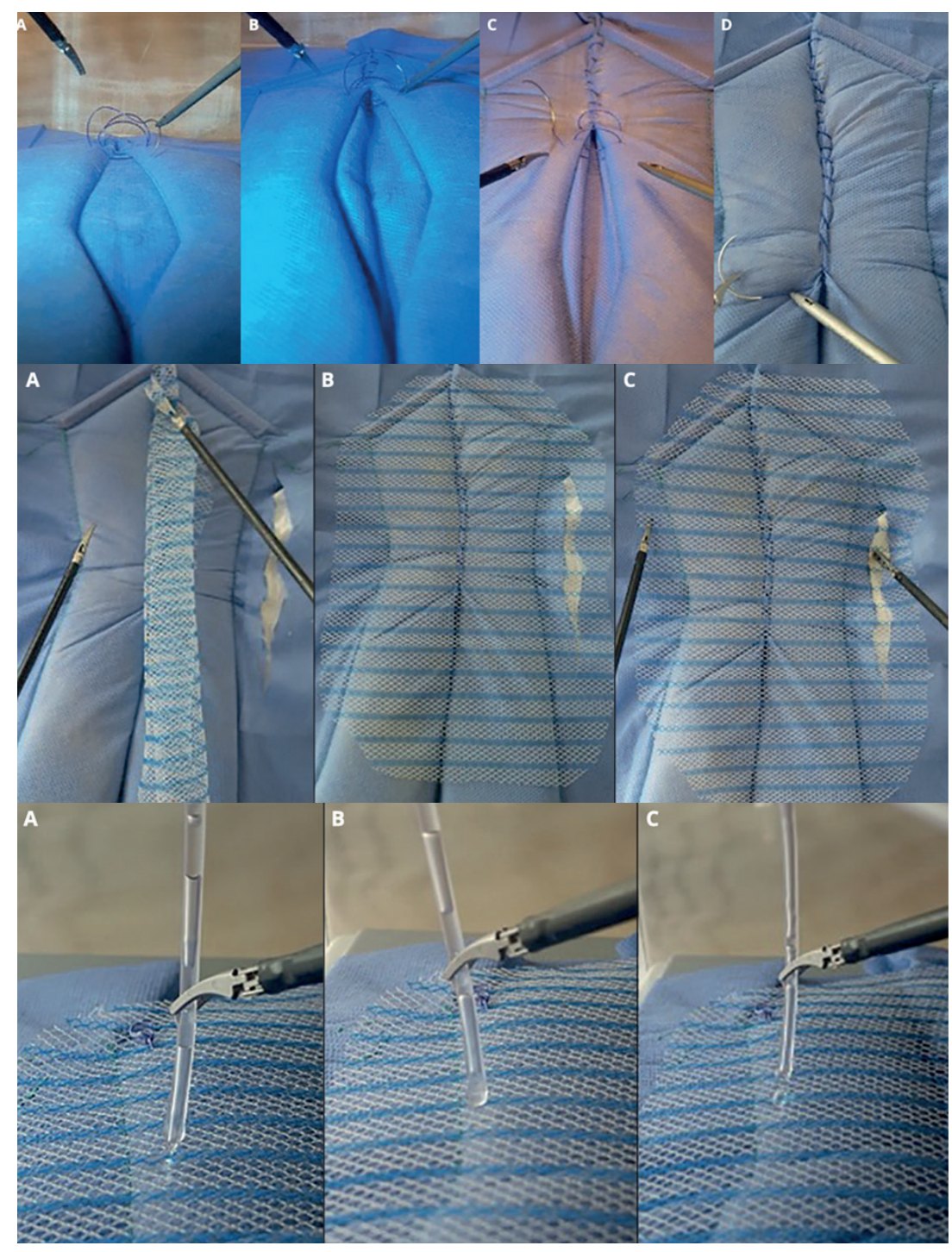

Modelo Dr. Derlin Suarez. Entrenamiento en Diastasis de los rectos. 

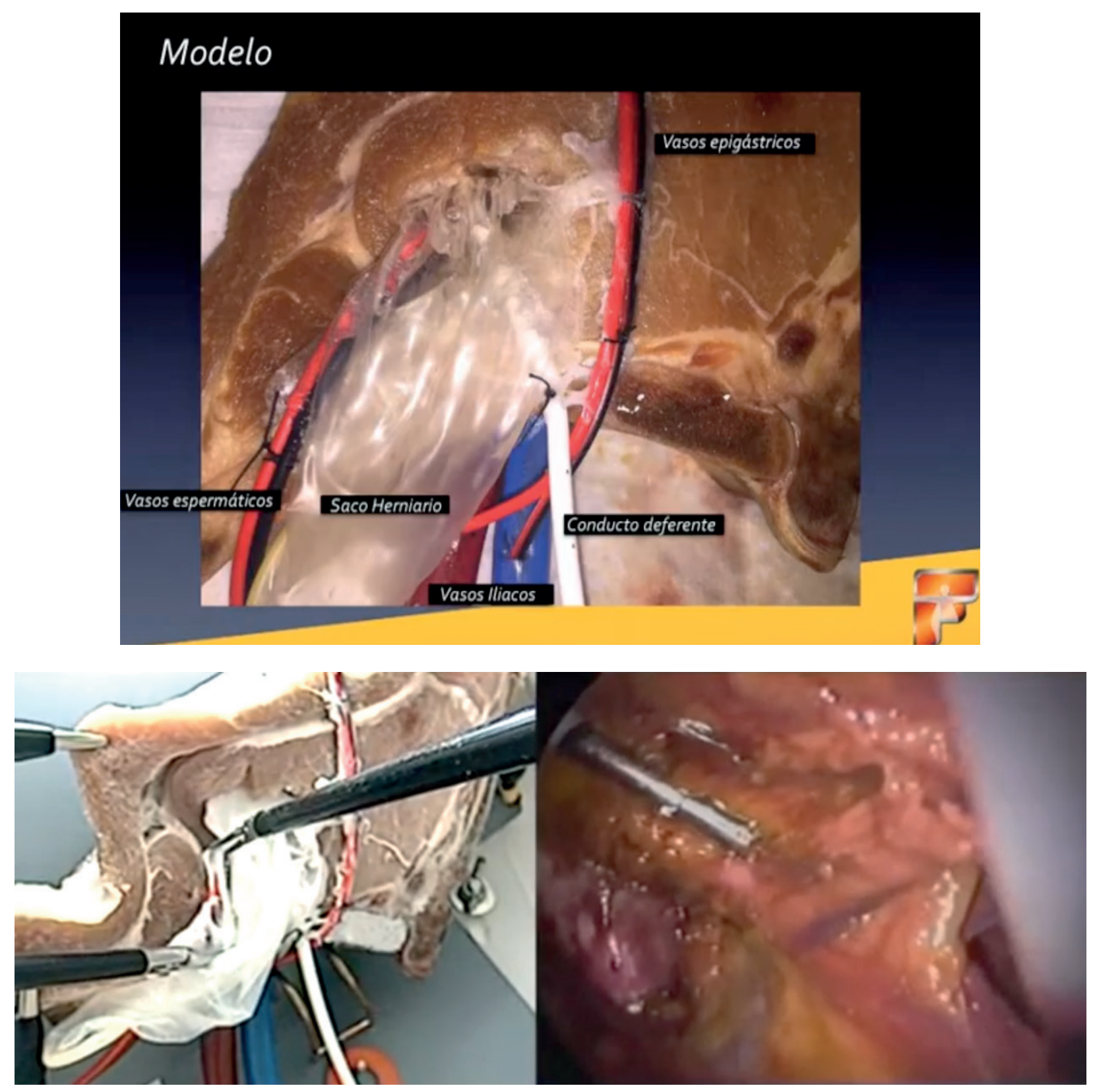

Modelo del DR.ANDRES HANSSEN (Venezuela) 2017.Utiliza Chuleta de cerdo como base de la estructura, un preservativo como saco y cables electricos para simular estructuras tubulares de los vasos sanguineos y deferente. https://www.youtube.com/watch?v=44FbIRviq4M\&t=108s

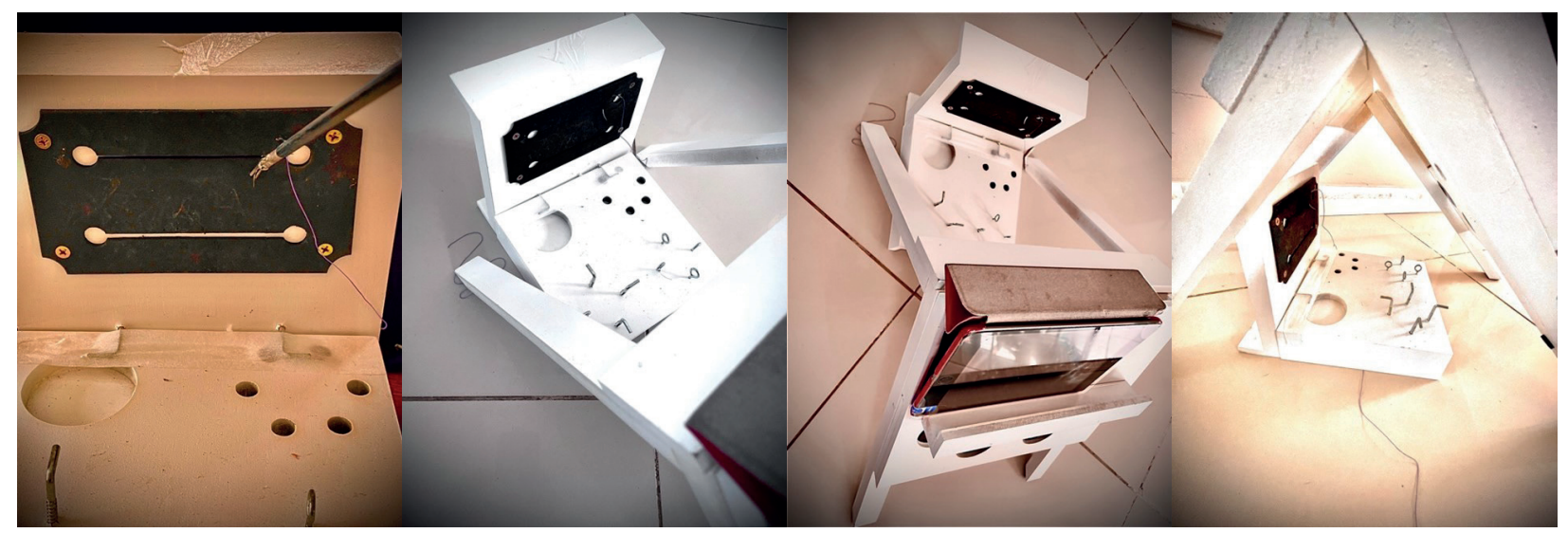

Modelo en endotrainer para sutura vertical y practica de cierre de flap peritoneal en cirugía de hernia laparoscópica, modelo Easylap ${ }^{\circledR}$ ( Dr. Juan Sanguinetti, Uruguay), Jornadas de Cirugía del interior 2018, Capitulo de Cirujanos del Interior SCU. 

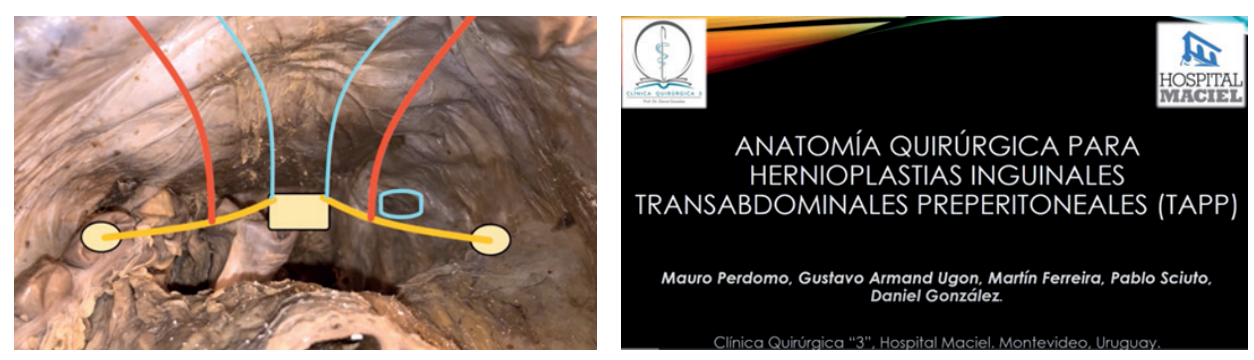

Entrenamiento y Docencia en Cadaveres para técnica TAPP. Dr. Mauro Perdomo, Hospital Maciel; Uruguay. https://www.youtube.com/watch?v=MLNblLXRun4\&t=56s

El Hospital Central Sur de Alta Especialidad PEMEX. Ciudad de México (México), ha presnetado tambien un modelo interesante de suimualcion con base en una pelvis plastica utlizando materiales reciclable plsticos de uso diario pudieron reproducir la region inguiinal derecha para tecnica TAPP con materiales plasticos en forma costo efectiva en un trabajo publicado por la Dra. Ana Paula Ruiz Funes Molina y cols. ${ }^{(15)}$

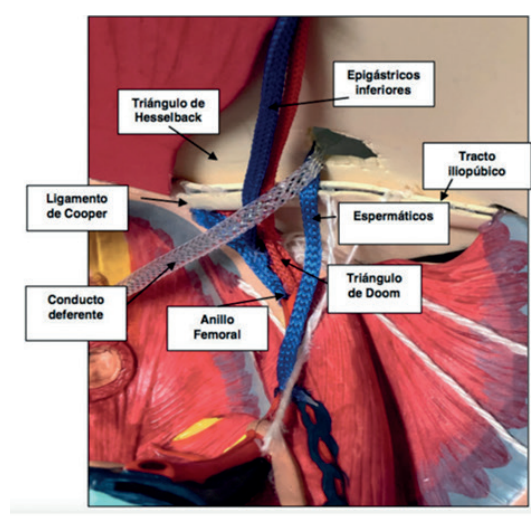

Figura 3. Modelo de región inguinal derecha antes de la colocación del peritoneo.

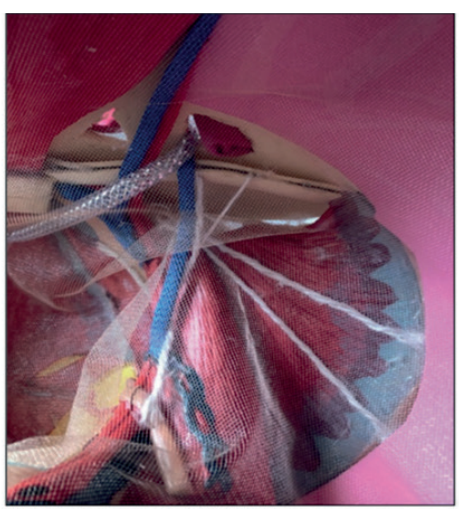

Figura 4. Modelo de región inguinal derecha después de la colocación del peritoneo.

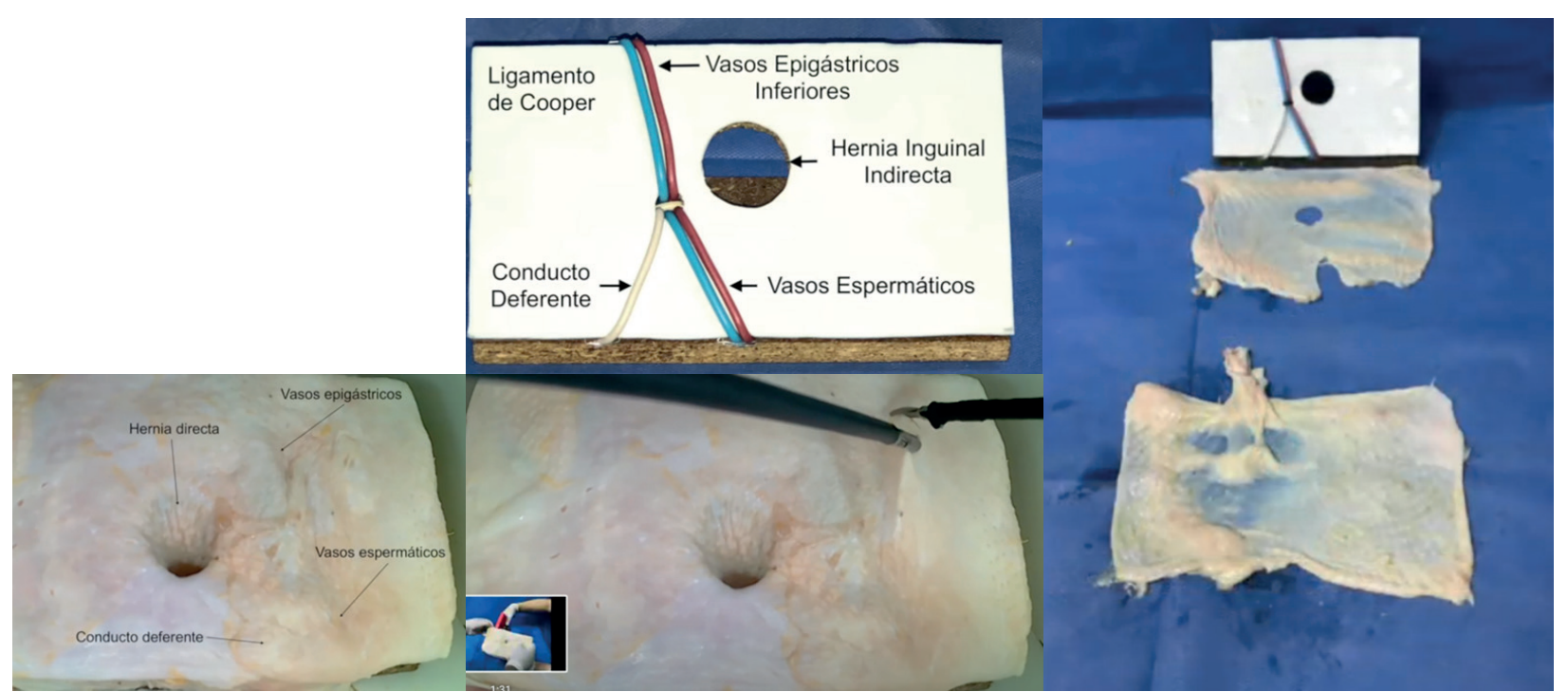

Modelo de simulación cirugía TAAP, sanatorio Rivadavia Argentina, Dres.D.Zeballos,JL. Kameyha y R. Vega.

Existen estudios que demuestran que la incidencia de la recidiva de hernia por vía laparoscópica disminuye significativamente con la experiencia del cirujano por ello es fundamental el entrenamiento previo, antes de llegar al paciente, como los músicos se entrenan antes de un concierto así deben entrenarse los cirujanos antes de reparar una hernia por vía laparoscópica y en la base de este entrenamiento esta la simulación. ${ }^{(8)(9)}$ 
Mas aun cuando sabemos que estamos frente a una técnica mas compleja que la resolución por vía anterior, mas difícil de reproducir y enseñar con una curva de aprendizaje diferente, que es mas larga y que obliga a realizar una de las suturas mas incomodas dentro de la cavidad peritoneal para el cirujano y el ayudante (camarógrafo) por la disposición y verticalidad del flap peritoneal para su cierre. ${ }^{(1)(11)}$ Pensamos que los residentes no deberían intentar reproducir esta técnica sin tener por lo menos un basto entrenamiento en disección y suturas en endotrainer en modelos simulados.

En las guías de la Asociación Internacional de Endohernia (IEHS) no se establecen cuántos procedimientos TAPP deberían realizarse en la formación quirúrgica, pero diferentes publicaciones que describen rangos tan amplios como de 13 a 80 operaciones. ${ }^{(11)(12)}$ En una revisión sobre curvas de aprendizaje, Ramsay y cols. describen que hay dos tipos de variables que se pueden utilizar para medir el aprendizaje: 1) medidas sobre los resultados del paciente y 2) medidas sobre el procedimiento o la eficiencia de las tareas realizadas. ${ }^{(13)}$ Esto definiría que el uso de la simulación antes de enfrentarse a una cirugía in vivo TAPP ayudaría al cirujano a obtener mejores resultados y al paciente a sufrir menos complicaciones. ${ }^{(11)(13)(14)}$

\section{BIBLIOGRAFÍA}

1) Brebbia G, Carcano G, Boni L, Dionigi GL, Rovera F, Diurni M, et al. "To teach and to learn in day surgery. The role of residents". Int J Surg. 2008;6 Supl 1:S56-8.

2) Docobo F. "Objetivos de la rotación de los médicos residentes de cirugía en la unidad clínica de cirugía mayor ambulatoria". Cir May Amb 2008; 13: 78-82.

3) Docobo F, Bernal C, Durán I, Mena J, Blanco JL, Tamayo MJ. "Participación de los residentes en cirugía mayor ambulatoria. Programación docente”. Rev And Pat Digest 1999; 22: 97-98.

4) Herrera FA, Docobo F, Jiménez JA, Marin J, Plata J, Sarmiento C, et al. "Proceso asistencial integrado. Hernias de pared abdominal". Edita Servicio Andaluz de Salud.Sevilla 2003.

5) Hope W, ÖDwyer B, Adams A, Hooks III W.B, Kotwall C, Clancy T "An evaluation of hernia education in surgical recidency programs" Hernia 2014;18,4:535-342

6) Simons MP, Aufenacker T, Bay-Nielsen M, Bouillot JL, Campanelli G, Conze J, de Lange D, et al " European Hernia Society guidelines on the treatment of inguinal hernia in adult patients". Hernia. 2009 August; 13(4): 343-403.

7) Dr. Raúl Morelli Brum; Cirugía Laparoscópica de la hernia inguinal,CIR Uruguay 2005, 75 (1): 48-54

8) Lanzarini E. Simulación: una herramienta útil en la formación quirúrgica moderna. Rev Chil Cirug. 2008;60:167-9.

9) Cawich SO, Mohanty SK, Bonadie KO, et al. Laparoscopic Inguinal Hernia Repair in a Developing Nation: Shortterm Outcomes in 103 Consecutive Procedures. J of Surg Tech and Case Report. 2013;5(1):13-7.

10) Bökeler U, Schwarz J, Bittner R, et al. Teaching and training in laparoscopic inguinal hernia repair (TAPP): impact of the learning curve on patient outcome. Surg Endosc. 2013;27(8):2886-93.

11) Edwards CC, Bailey RW. Laparoscopic hernia repair: the learning curve. Surg Laparosc Endosc \& Percutan Tech. 2000;10(3):149-53

12) Yang XF, Liu JL. Anatomy essentials for laparoscopic inguinal hernia repair. Ann of Translational Med. 2016;4(19):1-7.

13) Bansal VK, Krishna A, Misra MC, et al. Learning curve in laparoscopic inguinal hernia repair: experience at a tertiary care centre. Indian J Surg. 2016;78(3):197-202.

14) Hernández-Irizarry R, Zendejas $B$, Ali SM, et al. Optimizing training cost-effectiveness of simulation-based laparoscopic inguinal hernia repairs. Am J Surg. 2016;211(2):326-35.

15) Ruiz Funes Molina AP, Cruz Zárate A, Barbosa Villarreal F, Sosa López AJ, Farell Rivas J, Cuevas Osorio VJ. Mejora de la curva de aprendizaje en la hernioplastia inguinal laparoscópica tipo transabdominal (TAPP) con la utilización de un nuevo modelo de simulación. Rev Hispanoam Hernia. 2020;8(4):156-161

16) Voitk AJ.The learning curve in laparoscopic inguinal hernia repair for the community general surgeon. Can J Surg 1998; 41: 446-50.

17) Ugon-Bigi GA y cols. Entrenamiento quirúrgico en hemorrafias y hernioplastias en cadáveres humanos Simulación Clínica 2020; 2 (2): 65-70

18) Palmisano, Ezequiel Mariano. Manual Práctico de Cirugía Endoscópica de la Pared Abdominal (Spanish Edition) (p. 7). Editorial Autores de Argentina.

19) kirkpatric D.L, Kirkpatrick J.D (1994) Evaluating trainig Programs,Berrett-Koehler Publishers.

20) https://www.youtube.com/watch?v=DRCbaesrz4I FEMI, Dr Juan Azagra. Innovacion como Puente para Mejorar en Cirugia.

21) Porras Hernández JD. Enseñanza y aprendizaje de la cirugía. Inv Ed Med. 2016: 5(20):261-267

22) Ruiz Gómez JL, Martin Parra JI, González Noriega M y cols. La simulación como modelo de enseñanza en cirugía. Cir Esp 2018; 96(1):12-17 


\title{
TRATAMIENTO LAPAROSCÓPICO DE LAS HERNIAS DE LA REGIÓN INGUINO-FEMORAL
}

\author{
Dr. Nicolás Ramos
}

\section{INTRODUCCIÓN}

La cirugía de la hernia inguinal se conoce desde la antigüedad. Es por el año 1885 que Bassini describe la reparación que lleva su nombre, utilizando tejidos propios de la zona para efectuar la reparación. Sucesivamente se le suman las técnicas de Halsted, Shouldice y Mc Vay. Todas ellas realizaban una reparación con tensión y llegaban a tasas de recidiva que iban del 5 al 75\% de los casos. Es por la década del 60 que Usher introduce el concepto de reparación libre de tensión, popularizando el uso de mallas protésicas logrando excelentes resultados en términos de recidiva. En 1984 Lichtestein describe la técnica de hernioplastia inguinal por abordaje anterior que utilizamos hasta el día de hoy y que muchos consideran como el "gold stándard" para la reparación herniaria. En la década del 90 con el avance de la cirugía laparoscópica comienzan a desarrollarse las primeras técnicas de cirugía mini invasiva, las que, aun hoy continúan en pleno desarrollo siendo actualmente la cirugía robótica la punta de lanza del desarrollo tecnológico.

Actualmente se estima que se efectúan alrededor de 20 millones de cirugías de hernia inguinal a nivel mundial, lo que la hace una de las cirugías mas frecuentes en cirugía general. Si bien la cirugía muestra altas tasas de éxito, un $10 \%$ de los casos requerirá de una reintervención, un 12\% presentará algún tipo de dolor en los 3 meses siguientes a la intervención y entre un 1-3\% presentará dolor invalidante a largo plazo. ${ }^{(6)}$ Estos números nada despreciables pueden representar una carga económica brutal hacia los sistemas de salud, y de seguridad social, debido al alto numero de certificaciones por dolor o incapacidad que esta patología determina. Esto nos lleva a pensar que todo aquello que intente modificar algún aspecto del tratamiento de esta patología, tendrá repercusión notoria sobre estos sistemas tan sobrecargados en las ultimas décadas

En este capítulo describiremos las principales técnicas de abordaje laparo/endoscópico (L/E) para el tratamiento integral de la patología herniaria de la región inguinofemoral, como son la técnica trans abdomino preperitoneal (TAPP) y la técnica totalmente extraperitoneal (TEP, TEP).

No realizaremos el análisis comparativo entre estas técnicas con las de abordaje abierto, que fue expuesto con anterioridad. Como se ha demostrado, las técnicas $\mathrm{L} / \mathrm{E}$ presentan cierta ventaja en términos de menor dolor postoperatorio inmediato, menor tasa de complicaciones locales, estancia hospitalaria mas corta y reintegro laboral mas rápido.

EL uso de las técnicas $\mathrm{L} / \mathrm{E}$ varia desde 0 a un máximo del 55\% en países desarrollados. Hacia el año 2015 las técnicas abiertas, fundamentalmente la de Lichtenstein representaban el 64\%, mientras que las $\mathrm{L} / \mathrm{E}$ en conjunto el $28 \%$ de los procedimientos de reparación herniaria. ${ }^{(6)}$ Actualmente en EEUU, los números han cambiado siendo un $42 \%$ para las abiertas, un $40 \%$ para las $\mathrm{L} / \mathrm{E}$ y un $18 \%$ para las robóticas ${ }^{(1)}$ lo que muestra claramente el cambio en la concepción y el modelo en el tratamiento actual de las hernias inguinales.

La mayoría de las hernias inguinales del adulto son operadas de forma electiva. Muchas veces esta decisión se basa en el supuesto que una cirugía temprana pone a reparo de la probable aparición de complicaciones como puede ser la estrangulación. En una revisión sistemática ${ }^{(2)}$ se demostró un $8 \%$ de morbilidad y $0.5 \%$ de mortalidad en 85.000 pacientes en un periodo de seguimiento de 50 años. El riesgo de atascamiento y estrangulación de las hernias inguinales fue de 3.6/100.000 en hombres y de 5.4/100.000 en mujeres por año.

Las hernias inguinales sufren de atascamiento con menos frecuencia que las femorales aumentando el riesgo con la edad y la duración de los síntomas. Esta diferencia se hace notoria en hombres mayores de 65 años, presentando síntomas en el 79\% de los casos en comparación a los jóvenes (62\%). ${ }^{(1)}$ Con la evidencia actual se puede considerar el manejo conservador (watch and wait) como seguro y efectivo. En aquellos pacientes que sean sintomáticos, la evidencia demostró que los síntomas irán progresando con el tiempo, por lo que se les debe aconsejar la cirugía.

Haremos una breve reseña de las principales recomendaciones en cuanto a las indicaciones de cirugía L/E, establecidas en las guías internacionales mas importantes y de referencia. Estas incluyen las guías de la European Hernia Society (EHS), la International Endohernia Society, el Hernia Surge Group así como las guías de la Sociedad Hispanoamericana de Hernia. ${ }^{(4)(5)(6)(15)(26)}$ 
En las guías tanto el abordaje abierto (Lichtenstein) como el mini invasivo, laparoendoscópico (TAPP, TEP, eTEP) son recomendados como las opciones con mejor nivel de evidencia para el tratamiento de la hernia primaria unilateral.

El tratamiento $\mathrm{L} / \mathrm{E}$ es una opción tanto para hernias inguinales o femorales, unilaterales o bilaterales, primarias o recurrentes, en cirugía electiva o de urgencia.

Las posibilidades de manejo deberán ser adecuadas a la curva de aprendizaje lograda y experiencia acumulada por parte del equipo quirúrgico tratante.

Como fuera mencionado previamente, menor tasa de infección, el menor trauma quirúrgico, menor estancia hospitalaria y retorno mas rápido a las actividades diarias, son algunas de las ventajas que hacen preferir y recomendar los abordajes $\mathrm{L} / \mathrm{E} .{ }^{(2)} \mathrm{La}$ tasa de dolor postoperatorio, guarda relación con la técnica de disección realizada y con mecanismo de fijación invasivo de la malla, tópicos de frecuente avance.

Para las hernias bilaterales, las guías europeas ${ }^{(24)(4)(6)}$ recomiendan el abordaje laparoscópico ya que mediante tres trocares se puede lograr una reparación exitosa de ambas hernias, evitando dos incisiones inguinales de mayor tamaño. También si durante la reparación L/E de una hernia sintomática, se descubre una hernia oculta contralateral, ambas podrían ser tratadas en el mismo procedimiento. Por el contrario, si durante la exploración L/E no se evidencia hernia contralateral, no se recomienda la colocación de malla profiláctica en el lado asintomático, sin importar el diagnóstico de bilateralidad previo.

$\mathrm{El}$ abordaje L/E se recomienda en casos de recidiva herniaria, sobre todo luego de un primer abordaje abierto. Estas técnicas presentan menor tasa de dolor postoperatorio y convalecencia mas rápida comparadas con la técnica del Lichtenstein.

De acuerdo a las guías internacionales, las mujeres tienen mayor riesgo de recurrencia (inguinal o femoral) que los hombres luego de una reparación abierta de una hernia inguinal, debido a la mayor incidencia de hernias femorales (45\%). Un abordaje L/E permite el tratamiento integral de la patología herniaria del orificio miopectíneo (OMP) por lo que debe ser considerado en la reparación herniaria en la mujer.

Por el contrario, no se recomienda el abordaje $\mathrm{L} / \mathrm{E}$ en casos de hernias inguino escrotales grandes o gigantes, con anillos mayores a $4.5 \mathrm{~cm}$, recurrencia luego de abordajes abiertos en los que se hayan utilizado plugs (técnica de Rutkow) o dispositivos 3D, recurrencia luego de TAPP o TEP, ni en hernias luego de procedimientos urológicos complejos. Si bien éstas no son contraindicaciones absolutas, los abordajes $\mathrm{L} / \mathrm{E}$ no han demostrado ventajas y dependerá del grado de experiencia del cirujano en estas técnicas. Son situaciones en las que un abordaje abierto puede resultar mas seguro y efectivo.

\section{DIAGNÓSTICO}

La historia clínica y el examen físico son suficientes para confirmar el diagnostico de hernia inguinal en el 95\% de los casos. Este diagnóstico se basa en la presencia de una tumoración a nivel inguino crural que pulsa con maniobras de Valsalva. En estos casos en los que la hernia es evidente no son necesarios mas estudios diagnósticos. Estos pueden resultar útiles en casos de dudas, frente a la presencia de síntomas sin clara tumoración palpable, o la presencia de una tumoración intermitente o que no es evidente durante el examen físico (hernia oculta). La ecografía de la región inguinal es un estudio ampliamente distribuido, fácilmente accesible, inocuo y barato con una especificidad del $81 \%$ y una sensibilidad del $100 \%$ en caso de hernia clínica. ${ }^{(5)}$ Se reconoce como el estudio imagenológico de primera línea que puede aumentar la sensibilidad de lo hallado durante el examen físico. ${ }^{(6)}$ Cuando la ecografía es negativa o no diagnóstica, se debe considerar la TC dinámica y la RNM dinámica. El termino dinámica en este contexto refiere a la realización de estos estudios durante maniobra de Valsalva, en un intento de hacer que hernias pequeñas se vean forzadas a ocupar los canales inguinales y se hagan evidentes.

La TC dinámica tiene una sensibilidad del 83\% y una especificidad del 67-83\%, mientras que la RNM dinámica tiene una sensibilidad del 94,5\% y especificidad del $96 \%$. Tienen la ventaja que son estudios útiles para evaluar los planos musculoaponeuróticos, valoran el defecto, su tamaño, así como volumen y contenido del saco herniario. Permiten además el diagnostico de otras patologías diferenciales sobre todo la RNM, como son: osteítis del pubis, tendinitis del musculo aductor, bursitis ileopectínea, endometriosis.

A modo de resumen, en el caso de dudas diagnósticas clínicas, la ecografía debe ser considerada en primer lugar. Luego, si persiste la duda, podremos solicitar RNM y TC dinámicas, que permiten identificar hernias y/o diagnósticos diferenciales. De todas maneras, ninguna de estas modalidades de imagen se considera como gold standard. 
La ecografía, TC y RNM son útiles en el postoperatorio en la identificación de causas no neuropáticas de dolor inguinal crónico, identificando causas vinculadas a la malla (meshomas), hernias recurrentes y seromas. ${ }^{(4)(26)(6)}$

Las hernias ocultas se describen generalmente como asintomáticas y se descubren de forma incidental en estudios radiológicos de imagen o durante la exploración laparoscópica durante la cirugía de una hernia contralateral sintomática hasta en el $33 \%$ de los casos.

Se utiliza el termino hernia inguinal sintomática, clínicamente oculta, radiológicamente evidente (SCORE del inglés) para describir las hernias ocultas sintomáticas. Estas carecen de una definición exacta y consensuada. Su etiopatogenia no es del todo conocida, así como tampoco su incidencia real. Se reportó una incidencia del 9,5\% en pacientes con dolor inguinal que fueron estudiados con ecografía. ${ }^{(14)}$ No deben confundirse con otras causas de dolor inguinal en los que aparezcan hernias de forma incidental, como pueden ser el desgarro del tendón conjunto, de los músculos oblicuos o de la arcada inguinocrural, muchas veces interpretadas como hernias del deportista. En muchos casos, el solo hecho de identificar una hernia lleva a tomar una conducta quirúrgica activa a pesar de la poca evidencia que soporte esto. Por el contrario, tampoco existen ensayos clínicos aleatorios y controlados que comparen el manejo conservador y fisioterapia en contraposición al tratamiento quirúrgico en el caso de hernias SCORE.

\section{CLASIFICACION}

A lo largo del tiempo se han desarrollado múltiples clasificaciones para las hernias inguinales. La mayoría de ellas son complejas y difíciles de recordar, lo que da como resultado que su uso sea poco sistematizado en la practica quirúrgica diaria. Actualmente las de mayor uso son las de Nyhus (1991) (tabla 1), Gilbert modificada por Rutkow y Robins (1993) (tabla 2) y la de la EHS.

\begin{tabular}{ll} 
Tabla 1. & Clasificacion de Nyus \\
\hline TIPO I & $\begin{array}{l}\text { HII indirecta con anillo inguinal profundo de diametro normal, pared posterior } \\
\text { y saco herniario que alcanza la porcion medial del conducto inguinal }\end{array}$ \\
\hline TIPO II & $\begin{array}{l}\text { HII indirecta con anillo inguinal profundo dilatado, pared posterior normal } \\
\text { y vasos epigástricos no desplazados. }\end{array}$ \\
\hline TIPO III & $\begin{array}{l}\text { Defectos de la pared posterior. } \\
\text { III a. HI directa, pequeña o grande. } \\
\text { III b. HI indirecta con dilatación importante del anillo inguinal profundo, } \\
\text { pared posterior involucrada, hernia inguinoescrotal y hernia mixta en pantalón. }\end{array}$ \\
III c. Hernia femoral.
\end{tabular}

En 2007 la EHS (tabla 3), publica una nueva clasificación "simple y fácil de recordar", ${ }^{7}$ dirigida inicialmente a Europa, después adoptada por el resto del mundo, con el fin de utilizar una clasificación única y común a todos los cirujanos. El cometido de esta es intentar de que toda la comunidad medico/ quirúrgica describa las hernias inguinales objetivamente pudiendo así unificar criterios y comparar resultados. Es una modificación de la clasificación de Aachen, en la cual la hernia se denomina con la letra L, M y F según sea lateral (indirecta), medial (directa) o femoral y los números 
1,2 o 3, según sea el tamaño del defecto herniario. En la cirugía abierta se toma como referencia el tamaño del dedo índice y en la cirugía $\mathrm{L} / \mathrm{E}$ el tamaño de las pinzas de agarre abiertas. Es así que se adjudica como 1 cuando el tamaño del defecto es menor que un dedo índice o que la abertura de las pinzas de agarre, 2 cuando el tamaño esta entre uno y dos dedos índice o pinzas, y 3 cuando supera los dos dedos y dos veces el tamaño de las pinzas. Adicionalmente se añade la letra $\mathrm{P}$ si la hernia es primaria o la letra $\mathrm{R}$ si es una recurrencia.

Cuando no se evidencia orificio, pero si una debilidad de la pared posterior se considera como una hernia medial y se le adjudica la letra $\mathrm{X}$ en vez de un numero $(\mathrm{Mx})$. Los lipomas preperitoneales o del cordón son catalogados como L1 así como las hernias inguinoescrotales como L3. Esta clasificación es ampliamente recomendada en todas las guías clínicas consultadas. ${ }^{(4)(5)(6)(26)}$

Tabla 3. Clasificacion de la EHS

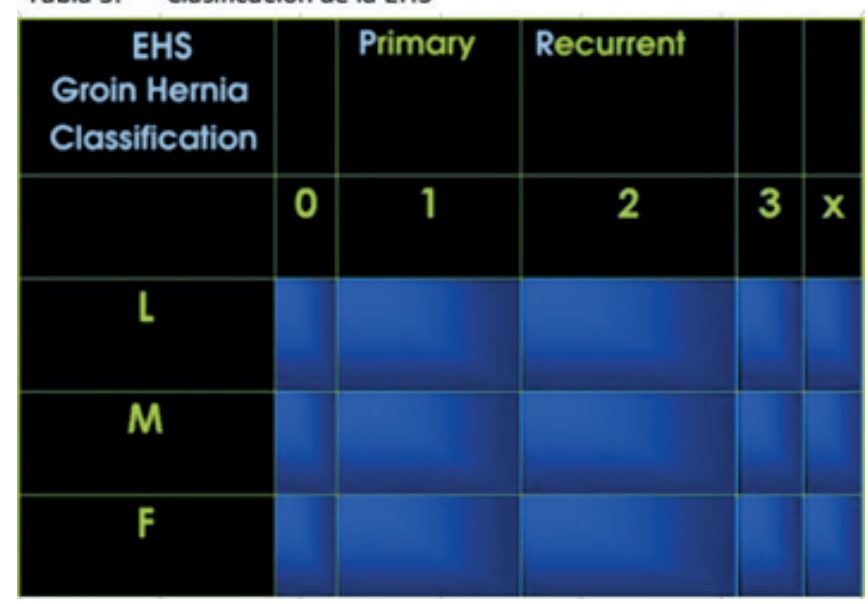

\section{CONCEPTO ANATÓMICO}

Durante la formación como residentes la mayoría de nosotros estudiamos y aprendimos a ver la anatomía del canal inguinal desde la perspectiva del abordaje anterior, al entrenarnos fundamentalmente con la técnica de Lichtenstein.

La incorporación de las técnicas L/E nos lleva a un cambio en modelo quirúrgico al que estábamos acostumbrados. Nos obliga a un cambio en la visión y perspectiva anatómica de la región inguinofemoral que ahora es vista desde su cara posterior.

Esta nueva visión anatómica de la pared abdominal, denominada orificio miopectíneo (OMP) fue descrita por Fruchaud en 1956 (fig1) y corresponde al lugar común en el que surgen las hernias en la región inguino- crural. Se encuentra delimitado medialmente por el musculo recto, inferiormente por el ligamento pectíneo (Cooper), lateralmente por el musculo Psoas y superiormente por los músculos transverso abdominal y oblicuo menor (tendón conjunto).

Uno de los argumentos en contra del desarrollo de la cirugía L/E de las hernias inguinales, además de los costos materiales, era la dificultad que generaba la comprensión y reconocimiento de estas estructuras anatómicas, desanimando así a muchos cirujanos a adoptar estas técnicas.

En 2019, Furtado y col. publican su trabajo sobre la sistematización de la reparación endoscópica, en base a un nuevo concepto anatómico: la Y invertida y los cinco triángulos. ${ }^{(10)}$ Este trabajo, referencia a nivel mundial, intenta sistematizar y facilitar la comprensión anatómica del OMP durante la técnica del TAPP y que como veremos mas adelante, podremos también extender a la técnica TEP.

En este concepto se reconoce la presencia de reperes anatómicos que terminarán por formar una $Y$ invertida: los vasos epigástricos superiormente, los vasos espermáticos lateralmente y el conducto deferente medialmente (fig 2).

Una vez reconocidas estas estructuras veremos que los vasos epigástricos dividen la región inguinal en un sector lateral, externo a ellos, lugar de proyección del orificio inguinal profundo y por donde emergen las hernias inguinales indirectas (L). Un sector medial, representado por la proyección del triangulo de Hesselbach, por donde emergen las hernias directas (M). 
Otra estructura anatómica de importancia es la cintilla ilio-pubiana, que representa la visión interna de la arcada crural (fig 2). Esta se extiende como una línea desde la espina iliaca anterosuperior al ligamento de Cooper. Divide así la región inguinal en un sector anterior, donde emergen las hernias inguinales (laterales y mediales) y otro posterior algo mas inferior a la cintilla por donde aparecerán las hernias femorales y obturatrices.

SI vemos estas líneas en su conjunto, veremos que el OMP aparece dividido en cinco triángulos (Fig.3), el triangulo de las hernias indirectas (L), el de las hernias directas (D), el de las hernias femorales (F) y dos triángulos mas, de suma importancia. El denominado triangulo del desastre (Doom triangle), situado entre el conducto deferente medialmente y los vasos espermáticos lateralmente, en este se topografían los vasos ilíacos externos. Lateral a este, el triangulo del dolor (pain) entre los vasos espermáticos medialmente y la citilla ilio-pubiana superiormente, proyección de las estructuras nerviosas: femorocutáneo, génitofemoral y crural. W. Reinpold, demostró en estudios de disección cadavérica que estas ramas pueden pasar hasta $2 \mathrm{~cm}$ por encima de la cintilla ilio- pubiana, por lo que se recomienda tener esto presente al momento de realizar la fijación de la malla.

En la actualidad, algunos autores (Palmisano, Brea Andrade) ${ }^{(27)}$ postulan una actualización en la nomenclatura de los cinco triángulos. Por un lado, reconocen que el concepto de la $\mathrm{Y}$ invertida y sus cinco triángulos se basan en la anatomía del varón, sobre todo en el sector inferior. En la mujer, por debajo de la cintilla ilio-pubiana, la única referencia anatómica es el ligamento redondo, por lo que lateralmente, los triángulos del desastre y del dolor no tendrían estructura anatómica que los divida y estarían formando un espacio único, que postulan se denomine como trapezoide del desastre y así poder generalizar la descripción anatómica. Otro concepto que se busca actualizar es la nomenclatura del triangulo femoral, por triangulo femoro- obturatriz, basado en el hecho que la exploración sistemática y completa del OMP que permiten las técnicas $\mathrm{L} / \mathrm{E}$ puede poner de manifiesto hernias ocultas dentro de las que están las obturatrices.

Felix y Daes introducen el concepto de "visión critica de seguridad" del $\mathrm{OMP}^{(8)}$ en analogía al utilizado en la colecistectomía laparoscópica introducido por Strasberg en 1995. En su trabajo, la visión critica de seguridad (VCS) del OMP se define como los nueve pasos técnicos que llevan a la adecuada exposición del OMP antes de poder colocar la malla con seguridad durante la reparación L/E y robótica de las hernias inguino- crurales. El objetivo es enseñar y sistematizar la reparación mini invasiva de las hernias, reducir las recurrencias, prevenir complicaciones y mejorar el cuidado del paciente.

Este concepto es tomado por Furtado en su trabajo sobre la sistematización de la técnica TAPP, ${ }^{(10)}$ donde una vez reconocidos los landmarks y los cinco triángulos, describe tres zonas de disección (fig. 4).

ZONA 1: es aquella que aparece lateral a los vasos epigástricos y a los espermáticos. Corresponde a la disección de la grasa preperitoneal del espacio de Bogros, zona que como vimos incluye el triangulo del dolor. El límite de la disección de esta zona corresponde a la visualización de la espina ilíaca anterosuperior en el sector superolateral y del músculo Psoas en el sector inferior.

ZONA 2: es aquella medial a los vasos epigástricos y corresponde al sito de las hernias directas. La disección de la zona 2 debe de extenderse sobre el espacio prevesical (Retzius) $1-2 \mathrm{~cm}$ por debajo del ligamento de Cooper, y medialmente 1-2 $\mathrm{cm}$ sobre la sínfisis pubiana.

ZONA 3: es la zona "problema" y la que nos demandara mas atención durante la reparación herniaria, fundamentalmente en las hernias indirectas. En esta zona realizaremos la parietalización de los elementos del cordón, separando el peritoneo o saco herniario, de los vasos y conducto espermático. Esta zona incluye los vasos ilíacos externos, o triángulo del desastre. El limite inferior de disección corresponde al entrecruzamiento del conducto deferente y la vena iliaca. El orden en las zonas de disección puede variar, en la técnica TAPP habitualmente se inicia por la zona 1, seguida de la zona 2 y la 3. En el la técnica TEP, como veremos mas adelante, debido al abordaje y creación del espacio preperitoneal, se inicia por la zona 2 , seguida de la 1 y luego la 3.

En 2019 Claus y col terminan por publicar su trabajo denominado "las 10 reglas de oro para la reparación segura y mini invasiva de la hernia", ${ }^{(9)}$ articulo de referencia mundial y que surge de combinar en uno solo modelo, los conceptos de la VCS del OMP descrita por Felix y Daes, con la sistematización anatómica y por zonas del trabajo de Furtado. Es basados en este modelo que nosotros describiremos a continuación las técnicas L/E TAPP y TEP.

Veremos que, en estas técnicas, los conceptos sobre la sistematización de la disección del OMP, el tamaño de la prótesis, modo de fijación son casi idénticos, diferenciándose fundamentalmente en la forma de abordaje del espacio preperitoneal. 
No existe una técnica estándar. Si bien pueden existir determinadas situaciones en las que estará recomendada alguna de ellas, en la mayoría de los casos de hernias inguinales primitivas, la elección de la técnica dependerá de las características del paciente y de la hernia, del tipo de anestesia, de los recursos logísticos y de la preferencia del cirujano.

En general los cirujanos dedicados a la pared abdominal manejan ambas técnicas, pero de acuerdo al grado de formación y experiencia adquirida siempre tendrán una de ellas como preferida.

Estudios que comparan ambos abordajes muestran tasas de complicaciones similares para el seroma, edema de escroto, inflamación del cordón espermático, atrofia testicular, lesión de vejiga, lesión de nervios, dolor crónico y recurrencia. ${ }^{(6)(26)(15)}$

\section{TECNICATRANS ABDOMINO PREPERITONEAL:TAPP}

EL abordaje TAPP es la técnica que implica la disección del OMP a través de un primer abordaje laparoscópico de la cavidad peritoneal. Esta forma de abordaje le confiere cierta ventaja teórica comparándola al bordaje TEP. La anatomía y el tipo de hernia es mas fácil de reconocer, así como también el identificar otras hernias del lado opuesto. ${ }^{\left({ }^{6}\right)}$ Tiene la desventaja de que, por un lado, implica la apertura y cierre del peritoneo, lo que la hace una técnica mas compleja de aprender y de mayor tiempo operatorio, y por el otro que se ve incrementado el riesgo de lesión visceral.

Previo al a inducción anestésica, insistimos en el vaciamiento de la vejiga urinaria. En dialogo con el paciente confirmamos y marcamos el lado a tatar, así como los principales reperes anatómicos que puedan resultarnos de utilidad, espina iliaca anterosuperior (EIAS), línea semilunar, espina del pubis).

Se indica antibioticoterapia profiláctica en base a Cefazolina 1 gr i i $/ v$ en dosis única.

Estas son cirugías que pueden resultar físicamente desafiantes, largas y ergonómicamente muy incomodas, es por esto que lograr una adecuada posición de trabajo es fundamental.

El paciente se coloca en decúbito dorsal, con ambos MMSS en aducción y ligero Trendelemburg (15 grados).

El monitor se coloca del lado de la hernia (puede estar a los pies en caso de hernias bilaterales) y el cirujano se coloca del lado contralateral. El ayudante, habitualmente uno solo, puede ubicarse del mismo lado que el cirujano o en el contralateral a este según su preferencia.

Los materiales que utilizaremos son los habituales para cualquier cirugía laparoscópica, óptica de 30 grados, un trocar óptico de $10 \mathrm{~mm}$, dos trocares de trabajo de 5mm, pinza de agarre tipo Endoclich o Marylan, Tijera, Hook, aspirador/ irrigador.

Podremos utilizar trocares de trabajo de $3 \mathrm{~mm}$ (mini Lap), pinzas de uso percutáneo e incluso dispositivos electromagnéticos (cirugía sin cicatrices), buscando un resultado mas bien estético.

Nosotros en todos los casos realizamos infiltración con anestesia local (Bupivacaina al 0.25\% y lidocaína al 1\%) en el lugar donde se colocarán los trocares.

Se realiza una incisión supraumbilical y neumoperitoneo cerrado con aguja de Veress a una presión de 14 o $15 \mathrm{mmHg}$. Una vez efectuado en neumoperitoneo colocamos el trocar de $10 \mathrm{~mm}$ con la fibra óptica. El resto de los trocares se colocan a cada lado, sobre la line medio clavicular, dependiendo un poco del biotipo y tejido graso del paciente. En caso de hernia unilateral, el trocar izquierdo algo mas abajo, para poder lograr mejor triangulación. En caso de hernias bilaterales pueden quedar a la misma altura (fig5).

Inicialmente realizamos la exploración de la cavidad abdominal para luego centrarnos en la región inguinal, procediendo a la identificación de los landmarks y de a Y invertida descrita por Furtado (fig6). Esto puede verse facilitado por la presencia del propio defecto herniario. Recordemos que estos son: los vasos epigástricos, el conducto deferente y los vasos espermáticos en el hombre, vasos epigástricos y ligamento redondo en la mujer.

La incisión peritoneal debe pasar al menos a unos $4 \mathrm{~cm}$ por encima del borde superior del orificio inguinal profundo y siguiendo una línea algo curva, que va desdela espina iliaca anterosuperior, al ligamento umbilical en el sector medial. En caso de ser necesario crear un flap peritoneal de mayor tamaño, la incisión se puede extender en sentido cefálico paralela al ligamento umbilical. ${ }^{(28)}$ 
La disección debe de seguir el plano peritoneal, mediante tracción y contra tracción, aprovechando la disección que realiza en neumoperitoneo, cuidando en todo momento de no dañar el flap peritoneal.

Trataremos de dejar todo el tejido graso del espacio preperitoneal hacia el plano muscular, evitando exponer las fibras musculares previniendo así la lesión de vasos epigástricos inferiores y estructuras nerviosas.

En nuestro caso la disección inicia en la zona 1, para seguir a la zona 2 y terminar por último en la zona 3 que como vimos representa la zona con disección mas laboriosa.

Zona 1: disección lateral, en esta la disección se extiende superiormente hasta un plano y poco mas arriba de la EIAS, inferiormente el limite es la exposición del musculo Psoas. Como ya fue comentado, debemos de mantenernos siempre contra el plano peritoneal, minimizando así el trauma sobre las estructuras nerviosas.

Zona 2: disección medial, en esta zona continuaremos la disección hacia adelante, buscando exponer el tubérculo del pubis y el ligamento de Cooper. Una vez identificadas estas estructuras realizamos la exposición del triangulo de Hesselbach y del espacio prevesical (Retzius).

Esta disección se debe de extender 1-2 cm por debajo del ligamento de Cooper y 1-2 cm hacia el lado contralateral sobre la sínfisis pubiana que podrá extenderse a $3-4 \mathrm{~cm}$ de presentar defecto medial (fig.7) cuidando de no lesionar estructuras vasculares (Corona Mortis).

En caso de encontrar una hernia directa realizaremos la reducción del saco y su contenido quedando una fascia transversalis holgada. Las guías recomiendan la plicatura de la fascia transversalis sobre la cara posterior del musculo recto o a nivel del ligamento de Cooper. ${ }^{(5)(6)(15)}$ Esto tiene como fin disminuir la tasa de seroma y dar mas superficie de contacto a la malla para lograr mejor integración a los tejidos.

Visualizaremos la vena iliaca externa y paquete obturatriz, pesquisando así defectos femorales u obturatrices asociados. A lo largo de la vena iliaca podemos identificar ganglios linfáticos en general son pardos, granulares y diferenciarlos de la grasa del canal femoral que es de color amarillo claro y lisa. Los ganglios dan sensación de brincar y sangran al tomarlo con las pinzas.

ZONA 3: la zona de mayor demanda técnica en la que realizamos la disección del saco herniario (hernia indirecta). Durante este paso el peritoneo debe ser movilizado medial y lateralmente para facilitar la identificación y separación del mismo de los elementos nobles del cordón (parietalización) cuidando de no lesionar los vasos iliacos ubicados justo por debajo (triangulo del desastre).

En casos de sacos inguino escrotales, o de difícil disección secundario a fibrosis, se recomienda la sección del mismo y abandono del sector distal a nivel de la bolsa escrotal, sola y únicamente una vez identificados los elementos nobles del cordón.

Si bien esto puede tener como consecuencia la formación de seroma, que en general es transitorio, evita la posibilidad de lesionar la rama genital el nervio genitocrural y la posibilidad de orquitis isquémica.

En caso de hernia en mujeres, no hay consenso en cuanto a la recomendación de la sección sistemática del ligamento redondo. En general se recomienda la conservación en mujeres nulíparas, ya que este es un agente estabilizador del útero grávido. ${ }^{(21)}$ En caso de mujeres de edad avanzada o multíparas puede seccionarse, $1 \mathrm{~cm}$ proximal al orificio inguinal profundo, evitando así lesionar la rama genital del nervio genitocrural. ${ }^{(10)}$

La disección del peritoneo debe extenderse hasta por lo menos sobrepasar la zona donde el conducto deferente cruza los vasos iliacos externos

Una vez reducido completamente el saco, debemos explorar sistemáticamente el orificio inguinal profundo en búsqueda del lipoma del cordón. Esta es una prolongación de la grasa preperitoneal, si existe no es necesaria su resección, bastara solamente con reducirlo, luego podremos utilizarlo sobre la malla para evitar que esta se arrolle hacia arriba. Un lipoma no tratado puede se causa mayor de recidiva clínica luego de la reparación L/E.

Una vez que completamos la disección de estas 3 zonas, ya sea por técnica TAPP o TEP, lograremos la visión critica de seguridad del OMP (fig.8). Podremos identificar y clasificar adecuadamente el defecto parietal, en nuestro caso según la clasificación de la EHS ya expuesta (tabla 3). 
Es entonces que procederemos a la colocación de la prótesis. Los tipos y características mecánicas de las mallas existentes para la reparación herniaria ya fueron expuestas en el capitulo correspondiente.

En nuestro medio son pocas las veces que podemos elegir que tipo de malla utilizar, y debemos conformarnos con la que nos ofrecen las instituciones. Lo mas habitual que estas sean de polipropileno microporosas (pesadas).

Esta malla debe de tener idealmente $15 \times 12 \mathrm{~cm}$, siendo el mínimo aceptable de $12 \times 10 \mathrm{~cm}$. Recordemos que las mallas pueden contraerse hasta en un $30 \%$ una vez que se complete el proceso de integración por lo que cualquier medida mas pequeña puede resultar insuficiente y ser causa de recurrencia. ${ }^{(19)(33)}$ Se pueden hacer una serie de cortes, como es en nuestro caso (fig. 9), para que se adopte mejor al espacio prevesical medialmente y al musculo Psoas lateralmente. Esta se introduce arrollada x el trocar óptico de $10 \mathrm{~mm}$ y se debe de desplegar de forma que cubra completamente el OMP. Este paso es fundamental, la malla debe de quedar correctamente desplegada, sin pliegues y sobrepasando el defecto con margen (overlap) adecuado. A nivel medial debería de ser de $1-2 \mathrm{~cm}$ en caso de hernias indirectas y de $3-4 \mathrm{~cm}$ en caso de hernias femorales o directas, por debajo de la sínfisis pubiana debe de extenderse $1-2 \mathrm{~cm}$ y de 3 o $4 \mathrm{~cm}$ por encima del orifico inguinal profundo (fig 10).

Debemos evitar quela malla se arrolle en el sector inferior de la disección, para ver esto podemos levantar el flap peritoneal y ver a su través como se comporta, si vemos que con esta maniobra la malla se arrolla, deberemos extender la disección del flap peritoneal.

Una vez correctamente colocada y extendida la prótesis, se deberá proceder a la fijación de la misma siguiendo las recomendaciones de las guías internacionales. ${ }^{(24)(4)(6)(15)}$ En caso de realizarla, utilizamos tackers de material reabsorbible, colocando habitualmente dos sobre el ligamento de Cooper, uno sobre la cara posterior del musculo recto alto y otro, lateral a los vasos epigástricos, $3 \mathrm{~cm}$ por encima de la cintilla ileo- pectinea sobre el musculo transverso.

El cierre del flap peritoneal se debe de hacer con sutura continua, de hilo reabsorbible en el calibre $2 / 0$ o 3/0 intentando de no dejar ojales, que expongan la malla al contacto visceral. EL uso de hilos barbados facilita esta tarea ya que la sutura se mantiene en su lugar con cada pasada. Si contamos con la suficiente practica podremos utilizar hilos de poliglactina, que son de uso frecuente y de menor costo.

Se desaconseja el uso de medios de fijación en este paso de la técnica, ya que no solo encarece los costos, sino que al realizarse a ciegas aumenta el riesgo de aparición de complicaciones mayores totalmente evitables. ${ }^{(28)}$

Por ultimo, procederemos a la desinsuflación bajo visión directa, en este paso realizaremos el aspirado del Co2 del espacio preperitoneal. De esta manera comprobaremos la correcta posición de la malla, cerciorándonos que la misma no haya quedado arrollada ni con pliegues excesivos. Esta maniobra también sirve para disminuir el enfisema subcutáneo del escroto que se produce durante la disección y que puede resultar incómodo para el paciente.

Se retiran los trocares bajo visión, se aspira el resto del neumoperitoneo y se procede a la sutura de piel.

\section{HERNIAS BILATERALES: MALLA UNICA}

En caso de hernias bilaterales nosotros optamos por la realización de un TAPP bilateral con colocación de malla única (BTOM). Como vimos el monitor se pone a los pies, los trocares de trabajo a ambos lados de la cicatriz umbilical con diferencia que el de la mano derecha es de $10 \mathrm{~mm}$, esto va a facilitar la entrada de la malla.

Se realiza la disección de cada OMP por separado, iniciando por el lado sintomático, y comunicando totalmente el espacio prevesical (Retzius), esto deja un puente de peritoneo, entre ambos ligamentos umbilicales (fig. 11).

La prótesis que utilizamos es una malla de polipropileno de alta densidad de 28 x $12 \mathrm{~cm}$ (fig. 12) y que introducimos en forma de cigarro por el trocar de la mano derecha.

En todos los casos de BTOM realizamos la fijación de la prótesis con suturas o tackers a nivel de los ligamentos de Cooper (no sínfisis pubiana), cara posterior de músculos rectos y dos mas a cada lado, laterales a los vasos epigástricos, $3 \mathrm{~cm}$ por encima de la cintilla ilio - pectínea (fig. 13). El cierre del flap peritoneal se realiza con sutura continua de hilo reabsorbible como ya fue comentado, cada flap por separado. Debido al peso del flap, que es de mayor tamaño que en el unilateral, puede ser de ayuda el descenso del neumoperitoneo a $7 \mathrm{mmHg}$. 


\section{TECNICA TOTALMENTE EXTRAPERITONEAL:TEP}

Como ya fue mencionado con anterioridad, técnica de abordaje totalmente extraperitoneal (TEP) difiere del TAPP fundamentalmente en la forma en que se accede al espacio preperitoneal. El abordaje TEP se basa en la clásica técnica de Rives- Stoppa y resulta en el abordaje casi ideal. Dentro de las ventajas principales se destacan, se evita el ingreso a la cavidad peritoneal minimizando con ello el riesgo de lesión visceral y de formacion de adherencias. Se reduce el riesgo de eventración en el sitio de trocares, y se evita además la apertura y cierre del flap peritoneal lo que podría resultar en tiempo operatorio mas corto. El resto de las ventajas se resumen en la tabla 4.

\begin{tabular}{|l|}
\hline Tabla 4. Principales ventajas del abordaje extraperitoneal. \\
\hline Disminuye el riesgo de lesion visceral \\
\hline Disminuye la necesidad de retraccion visceral \\
\hline Menos ileo posotperatorio \\
\hline Se forman menos adherencias intraperitoneales \\
\hline Hay menos efectos hemodinamicos \\
\hline
\end{tabular}

En la técnica TEP clásica se describen varios inconvenientes, un espacio limitado para la disección y colocación de la malla, sobre todo en pacientes portadores de hernias inguino escrotales, obesos, con distancia corta entre el ombligo y el pubis; ${ }^{(30)}$ restricción para la colocación de los trocares, poca ergonomía y dificultad para enseñar y aprender la técnica. Estas desventajas podrían explicar la baja implementación de la técnica clásica fuera del circulo de expertos en cirugía parietal.

En 2011, el cirujano colombiano J. Daes, publica su trabajo e introduce el concepto de abordaje extraperitoneal en visión extendida (eTEP), y que consiste en la serie de maniobras y estrategias operatorias que tienen como fin ampliar el campo de trabajo extraperitoneal, aplicable tanto el la reparación mini invasiva de las hernias inguinales como en otros procedimientos. ${ }^{(30)(31)}$

Estas maniobras incluyen:

- El acceso alejado del defecto herniario, a nivel del ombligo o sobre la musculo recto anterior homolateral.

- Creación de un gran espacio de trabajo extraperitoneal.

- Colocación flexible de los trocares de trabajo.

- Ampliación de los márgenes naturales del OMP, seccionando el arco del musculo transverso, el borde medial de la lamina posterior de la vaina del musculo recto y la fascia posterior de los músculos oblicuo menor y transverso.

Si bien este abordaje se puede aplicar a la mayoría de los pacientes con hernias inguinales, esta especialmente indicado en pacientes con distancia ombligo- pubis corta, obesos o posbariátrico, cuando existen cirugías previas en la pelvis y en hernias inguino escrotales. ${ }^{(24)}$ Dependiendo de la experiencia del cirujano, las indicaciones del eTEP pueden extenderse a las hernias con deslizamiento e incluso al estrangulamiento. Estos casos pueden requerir la combinación con una exploración laparoscópica para valorar la viabilidad intestinal y eventualmente la colocación de trocares accesorios para facilitar la reducción del contenido. ${ }^{(31)}$

Debemos mencionar que la experiencia en este abordaje tanto a nivel nacional como en nuestro hospital es muy limitada, por lo que comentaremos la técnica según la describe el autor.

La preparación inicial del paciente, la colocación del equipo quirúrgico, así como la posición del paciente son idénticas que las descritas para el abordaje TAPP.

Los materiales a utilizar básicamente son idénticos, a excepción del balón disector como veremos a continuación.

Se realiza una incisión de 10-12 $\mathrm{mm}$ aproximadamente $4 \mathrm{~cm}$ por fuera y $5 \mathrm{~cm}$ encima a la cicatriz umbilical sobre el estuche del musculo recto, del lado de la hernia si es unilateral o en cualquiera si se trata de hernias bilaterales.

Se realiza la disección del tejido celular hasta llegar a la vaina anterior del músculo recto, se incide la misma y se divulsionan las fibras del músculo recto hasta lograr visualizar la vaina posterior del músculo que en este lugar es lo suficientemente gruesa. De esta manera alcanzaremos el espacio retromuscular.

Se introduce el dedo índice hasta contactar con la vaina posterior del musculo recto y mediante maniobras suaves se amplia el área de disección hacia el pubis, para dar lugar a la colocación del trocar balón (fig. 14).

Este se introduce primero de forma vertical, hasta contactar la vaina posterior del recto, para luego inclinarlo y dirigirlo hacia el pubis, una vez en contacto con este se insufla hasta lograr desplegar el espacio de trabajo (fig. 15). 
Existen algunas variantes técnicas a esta primera etapa del abordaje eTEP, como son el uso de trocares ópticos para abordar el espacio retromuscular, que de esta forma se hace bajo visión directa, siempre cuidando de no penetrar mas allá de la vaina posterior del recto. La otra, y principal variante es la de poder prescindir del uso del trocar balón y sustituirlo por la disección roma con la propia óptica de $30^{\circ}$. Si bien esto resulta algo mas laboriosa, permite reducir costos y hacer el procedimiento mucho mas accesible (fig. 16).

En esta etapa se debe de tener cuidado de lograr dejar los vasos epigástricos contra el vientre muscular, es decir en el sector superior de la imagen, y evitar lesionarlos.

Una de las ventajas del abordaje eTEP es la versatilidad en la que se pueden colocar los trocares de trabajo. Estos se pueden colocar de forma individualizada de acuerdo al biotipo del paciente y la preferencia del cirujano. En términos generales para hernias unilaterales se coloca un trocar de $5 \mathrm{~mm}$ para la mano derecha a nivel del pliegue umbilical y el otro, para la mano izquierda sobre la misma línea algo mas inferior o ligeramente lateralizado hacia el lado contralateral (fig. 17 A).

En caso de hernias inguinales bilaterales, la cámara se suele colocar algo mas lateral, para que la cicatriz umbilical no interfiera en la visión de la hernia contralateral. Los trocares se pueden colocar a cada lado del ombligo como en el TAPP, algunos colocan un tercer trocar a nivel del pliegue umbilical inferior (fig. $17 \mathrm{~B}$ ).

En muchas ocasiones la aponeurosis posterior del musculo recto desciende los suficiente como para limitar la visibilidad del espacio preperitoneal. En estos casos la vaina posterior puede dividirse a nivel de la línea arqueada de Douglas. Esta maniobra puede realizarse con tijeras, desde el trocar colocado mas inferior. Para esto a línea de Douglas se separa del peritoneo en el sector inferior de la vaina posterior y esta se secciona de forma vertical hacia arriba.

Al seccionar la aponeurosis posterior del musculo recto se logra una visión amplia del campo operatorio, incluso mayor que en el TAPP.

Después de completar los pasos iniciales se prosigue con la disección del OMP de forma sistematizada como ya fuera comentado y de acuerdo a trabajo del Claus de las 10 reglas de oro $^{(9)}$ hasta lograr la visión critica de seguridad del OMP. Debemos recordar que a diferencia del TAPP, en el abordaje eTEP la disección se inicia por la zona 2 seguida de la zona 1 y zona 3 (fig 4.).

El tipo, tamaño y colocación de la malla protésica es idéntica al TAPP, esta se introduce a través del trocar de la cámara $(10 \mathrm{~mm})$.

En lo referente a la fijación, la mayoría de los que realizan esta técnica no fijan la malla, lo hacen cuando se trata de hernias grandes o directas M3 como recomiendan las guías internacionales. ${ }^{(4)(26)(6)(15)}$ Como veremos a continuación existen diferentes métodos de fijación, debiendo tener presentes las mallas autofijantes y los adhesivos en estos casos. ${ }^{(21)}$

Durante la desinsuflación bajo visión directa, una pinza Grasper es utilizada para mantener en posición el borde inferior de la prótesis de esta manera podremos evitar que el peritoneo se doble y enrolle la malla. ${ }^{(9)}$

\section{FIJACION DE LA MALLA: ¿es necesario?}

Desde la introducción de las técnicas mini invasivas para la hernioplastia la fijación de la malla se ha vuelto tema frecuente de discusión. El tipo de fijación esta íntimamente relacionado con la aparición de dolor postoperatorio y malos resultados funcionales.

Existen numerosos métodos de fijación, los invasivos dentro de los que encontramos los diferentes dispositivos comerciales de grampas (fig. 18) y no los invasivos, como son las mallas autofijantes y los adhesivos.

Los métodos de fijación invasivos se utilizan desde el inicio, sobre todo en la técnica del TAPP y se pueden asociar mas frecuentemente a lesiones vásculo nerviosas y dolor postoperatorio. ${ }^{(29)}$

Desde el estudio anatómico de Reinpold, ${ }^{(30)}$ sabemos que el punto de entrada de las ramas genital y crural del nervio genitofemoral en el OMP puede ser variable, incluso pueden correr por encima de la cintilla ilio -pubiana. Esto da como resultado un ensanchamiento de las áreas anatómicas de riesgo (triángulos del DOOM y PAIN) que debemos de tener presentes al momento de realizar la fijación. 
El uso de grampas confeccionadas en materiales reabsorbibles no ha demostrado una reducción en la aparición de dolor crónico ${ }^{(29)}$ por lo que son los detalles técnicos y no el material los que tendrán influencia en los resultados.

La probabilidad de lesión nerviosa puede verse incrementada en caso de mallas microporosas (ya que no permiten reconocer las estructuras anatómicas a su través) y al mayor grado de penetración de la grampa en la pared abdominal. Muchas veces durante la fijación el mismo cirujano empuja la pared desde el exterior, en un intento de lograr mayor estabilidad del dispositivo, maniobra que debemos de evitar de acuerdo a lo expresado.

En las ultimas décadas, nuevos métodos de fijación han estado en fase de investigación y desarrollo. Nuevos dispositivos autofijantes y mas recientemente, el desarrollo de pegamentos, han demostrado suficiente evidencia como para su recomendación en las diferentes guías consultadas. ${ }^{(4)(6)(15)}$

En cuanto a las mallas autofijantes, son pocos los trabajos que se han publicado al respecto, Denham et al, en su ensayo clínico randomizado establecen la comparativa entre el uso de malla autofijante y la fijación invasiva con tackers. La mediana de tiempo operatorio y de estancia hospitalaria fue similar. Se describió una tasa de dolor postoperatorio algo menor en los primeros 3 días, par luego no ser diferentes a los 3 meses y al año. En el seguimiento al año, no se describen recurrencias en ninguno de los grupos. Los autores terminan concluyendo que las mallas autofijantes no parecen tener impacto positivo en la calidad de vida luego de una reparación TEP.

La cola de fibrina, conocida como "Tissel o Tissucol”, es un agente hemostático biológico formado por fibrina humana y trombina. En estudios de biomecánica (Shawb et al) la fijación con cola biológica demostró tener mayor fuerza tensil comparándola con la no fijación y la fijación con sutura. Se recomienda la aplicación en forma de spray a 1,5 bar de presión y en una dosis de $0.014 \mathrm{ml} / \mathrm{cm} 2$ para lograr una adecuada cobertura de la malla la que deberá de ser de poro amplio (macroporosa) con el fin de que el sellador entre en contacto con los tejidos blandos. En diversos ensayos clínicos (Langreh et al. 2005) que comparaban la fijación con fibrina vrs la fijación invasiva con tackers en las técnicas TAPP y TEP y han demostrado tasas de dolor postoperatorio significativamente menor en aquellos con fibrina y sin cambios en las tasas de recurrencia. Es por esto que el uso de fibrina como agente de fijación atraumática parece ser seguro y es recomendado tanto el TAAP y TEP.

La contra que tiene es que es un producto de costo elevado en nuestro medio y la oferta en aplicadores es baja, lo que lo hace poco disponible.

El cianocrilato, es una alternativa sintética al adhesivo de fibrina. Uno de sus mas serios inconvenientes implica la degradación del material y la toxicidad potencial del compuesto. Otra contra asociada con el cianocrilato es la escasa flexibilidad de sus moléculas, una vez polimerizadas, se tornan duras y quebradizas lo que puede resultar improductivo en los tejidos vivos.

Los cianocrilatos aprobados para uso en medicina son n-hexyl (Ifabond ${ }^{\mathrm{TM}}$ ), n-butyl, (Glubran ${ }^{\mathrm{TM}}$ ) y el n-octyl. (OCA $\left.{ }^{\mathrm{TM}}\right)$. La técnica recomendada para la fijación de la malla con cianocrilato consiste en la aplicación de algunas gotas en cada uno de los cuatro cuadrantes de la malla (fig. 19). Las tasas de dolor agudo y crónico se demostraron inferiores cuando se compararon con la fijación invasiva con tackers.

En resumen, los adhesivos sintéticos, en especial el n-octyl, demostraron ser seguros como método de fijación no invasiva tanto en el TAPP como en el TEP. Se debe de tener mucho cuidado con no dejar caer gotas, sobre todo en contacto con las vísceras ya que además de su efecto adhesivo, se le describe cierta forma de reacción exotérmica, lo que podría producir una perforación intestinal en la evolución.

Una vez expuesto lo anterior, y a forma de resumen podemos decir que las recomendaciones de la mayoría de las guías internacionales son las de no fijar las mallas tanto en el abordaje TEP y TAPP. Fijar las mallas únicamente cuando se trate de grandes hernias inguinales, especialmente en hernias directas M3 de la clasificación de la EHS.(9)(15) De los métodos de fijación, de acuerdo a la disponibilidad de cada centro, se recomienda optar por los no invasivos, cianocrilatos, mallas autofijantes y como ultima alternativa el uso de métodos invasivos.

En caso de utilizarlos debemos seguir las siguientes recomendaciones: ${ }^{(9)}$

- Evitar estructuras óseas: la fijación debe efectuarse por encima del hueso del pubis, en el ligamento de Cooper, para evitar el riesgo de osteítis crónica.

- Prestar atención y evitar los vasos epigástricos inferiores.

- La fijación traumática no debe ser colocada jamás por debajo de la cintilla ilio-pubiana. Evitaremos así la lesión de los triángulos del dolor y del desastre. Considerar $3 \mathrm{~cm}$ por encima de la cintilla para mayor seguridad. 
- 5 o 6 puntos de fijación resultan suficientes, mayor numero de tackers se acompañan de un incremento en el desarrollo de dolor crónico.

- Evitar la presión excesiva del dispositivo desde afuera, ya que esto hace que el tacker penetre mas en la pared de lo que debería.

\section{COMPLICACIONES}

Las técnicas L/E TAPP y eTEP han demostrado ser seguras y con bajas tasas de complicaciones, pero se tratan de técnicas complejas que requieren entrenamiento y destreza quirúrgica lo que igual no evita la aparición de complicaciones, estas se resumen en la tabla 5.

Una primera clasificación las diferencia de aquellas que ocurren durante la cirugía, inmediatamente después y luego de forma mas alejada. A continuación, haremos una breve descripción de cada una, sugiriendo alguna estrategia para evitarlas.

Las lesiones a los grandes vasos (aorta, arteria y vena iliacas externas) son por fortuna muy poco frecuentes, $0.09 \% .{ }^{(16)}$ Estas se vinculan a la técnica de neumoperitoneo y colocación brusca de trocares y pueden resultar en desastre. La lesión de los vasos epigástricos inferiores puede producirse durante la apertura o cierre del flap peritoneal durante la técnica TAPP o durante la disección del espacio retromuscular en el TEP. Generalmente son sangrados que no amenazan la vida y pueden ser controlados con electobisturí o clipado.

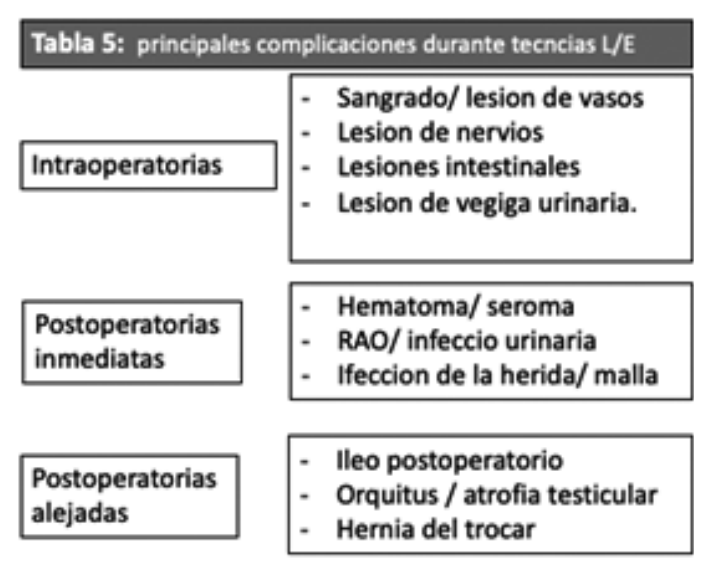

El reporte sobre las lesiones de las estructuras nerviosas varia desde el 0.8 al 3.8\% en la literatura. El nervio femoro cutáneo lateral es el mas frecuentemente dañado, viéndose hasta en el $60 \%$ de los casos. El daño puede producirse directamente sobre el nervio durante la disección o al realizar coagulación con electobisturí. De ahí la recomendación de efectuar la disección de forma roma, utilizando al mínimo las fuentes de energía, y nunca colocar tackers sobre el traingulo del dolor e idealmante $3 \mathrm{~cm}$ por encima de la cintilla ilio-pubiana.

Las lesiones sobre el intestino delgado se reportan entre el 0 y $0,1 \%$ de los casos. La forma mas común es provocar este tipo de lesión potencialmente mortal, es durante la realización del neumoperitoneo cerrado con la guja de Veress, durante la colocación brusca de los trocares y de forma inadvertida con el uso del electobisturí. La presencia de adherencias a nivel inguinal o por cirugías previas, puede resultar en lesiones intestinales durante su liberación. De echo, no se recomienda la liberación de estructuras adheridas al saco, solamente emplazar la incisión peritoneal por encima de ellas. ${ }^{(16)}$ Para minimizar esta complicación, deberemos tener los instrumentos a la vista en todo momento.

Las lesiones sobre la vejiga urinaria se reportan en el 0.07 y $0.1 \%$ de los casos, la mayoría de las veces en pacientes con antecedentes de cirugía del espacio preperitoneal previa, por ejemplo, en pacientes con prostatectomia trans abdominal, o con antecedentes de reparación herniaria con malla (TAPP o TEP). En estos casos la disección del espacio prevesical de Retzius (zona2) es muy dificultosa por lo que la misma dependerá del grado de experiencia del cirujano, debiendo tal vez, optar por un abordaje anterior.

Otro factor a tener en cuenta es que los cuernos vesicales pueden ascender sobre el limite medial del OMP o estar formado parte del contenido del saco, es por esto que no se recomienda la sección sistemática de los ligamentos umbilicales. 
Los hematomas y seromas son de las complicaciones mas frecuentes en la cirugía L/E de la hernia. Se describen una frecuencia del 4.4 al 13.1\% para los primeros y del 4.4 al 12.2\% para los segundos., La aparición de estos dependerá tanto del tamaño del defecto herniario, así como una correcta disección y hemostasis. En pacientes anticoagulados, se deberá suprimir la terapéutica entre 5 y 7 días antes de realizar la reparación. En caso de hernias mediales grandes, la plicatura de la fascia transversalis redundante demostró disminuir la incidencia del seroma. Generalmente de manejo conservador estos tienden a reabsorberse en un plazo de 6 a 8 semanas.

La retención aguda de orina se produce como consecuencia del trauma sobre la vejiga durante la disección del espacio prevesical (Retzius). Esta compilación se reporta el 3.5 al 3.8\% de los casos. El vaciamiento vesical previo y la disección cuidadosa de este espacio la minimizan. No esta indicada la colocación de sonda vesical de rutina en el preoperatorio.

La infección de la herida operatoria (ISQ) se reporta con una frecuencia del 0.5 y $1 \%$ de los casos que desciende al $0.04 \%$ en los pacientes que reciben una dosis profilactica e antibiótico. La infección en la malla aparece en e $0.1 \%$ de los casos, generalmente secundaria a la punción y evacuación de un seroma. Es por esto que se recomienda educar y explicar al paciente en cuanto a la duración de los seromas, y evitar puncionarlos. En las guías existe consenso en el uso de antibióticos profilácticos en aquellos pacientes con indicación, edad avanzada, terapia con corticoides, inmuno suprimidos y obesos. Nosotros en nuestro servicio realizamos la profilaxis antibiótica de forma sistemática previo a la inducción anestésica.

La orquitis y atrofia testicular, son complicaciones alejadas poco comunes, con una frecuencia del 0.15 al $0.6 \%$. Estas complicaciones suelen aparecer cuando se insiste en la disección completa de sacos herniarios grandes que se encuentran muy cerca del testículo. Para evitar este riesgo, en caso de sacos herniarios grandes, una vez identificados las estructuras nobles del cordón, se recomienda la sección del mismo abandonando el remanente. Otra estrategia recientemente introducida por A. Morrel ${ }^{(34)}$ en casos de sacos herniarios grandes o gigantes, es realizar la técnica del abandono primario del saco (PAS) (fig. 20). Esta técnica es una variante al momento de realizar la sección peritoneal durante el abordaje TAPP en pacientes con hernias inguino escrotales y tiene la base de abandonar el saco de forma primaria para evitar las lesiones de los elementos nobles del cordón.

Una vez realizado el neumoperitoneo y colocados los trocares de forma habitual para el TAPP se procede a la reducción completa del contenido herniario, esto permitirá visualizar completamente la circunferencia del orificio inguinal profundo.

Entonces se realiza una sección del flap peritoneal bordeando por delante y detrás el orificio inguinal profundo, lo que los autores denominan "en forma de parche de pirata" (fig. 21) dejando así el saco herniario en el canal inguinal. Luego se continua la sección del flap medial y lateralmente como ya fuera descrito. Con esta acción evitaremos realizar la disección del saco de las estructuras del cordón en e canal inguinal. Luego se prosigue con la disección completa del OMP hasta llegar a la visión critica de seguridad (Felix y Daes). La colocación de la prótesis sigue los mismos principios ya expuestos y el cierre peritoneal se realiza de la misma forma.

Las hernias en los sitios de trocar (eventración del puerto) pueden ocurrir hasta en el 7.7\% de los casos. Estas guardan clara relación con el diámetro del trocar, el lugar donde se coloca y con el tipo de punta del introductor. En aquellos pacientes que desarrollaron hernias en el $90 \%$ de los casos se demostró que habían sido utilizados trocares de 10 o mas milímetros. ${ }^{(16)}$ También se observo la disminución en la frecuencia de estas cuando se utilizaban trocares con punzón de forma cónica que actúan separando las fibras musculares y no cortándolas (0.01 vrs 12\%). El riesgo también aumenta cuando los trocares se emplazan a nivel de la línea media.

¿Como podemos evitarlas entonces? Utilizaremos trocares lo mas pequeños como sea posible de $3 \mathrm{~mm}$ o incluso instrumental percutáneo $(1.5 \mathrm{~mm})$. Desde que se disponen de ópticas de $5 \mathrm{~mm}$ no habría mayor necesidad de colocar trocares umbilicales de $10 \mathrm{~mm}$, para el pasaje de la malla es suficiente un puerto de trabajo $7 \mathrm{~mm}$. Debemos de utilizar trocares con punta de expansión roma.

\section{SITUACIONES ESPECIALES}

A continuación, expondremos brevemente dos situaciones que consideramos debemos conocer cuando pensamos en el abordaje laparoscópico del tratamietno de las hernias. Estas son la utilidad de la laparoscopia en la urgencia herniaria y las hernias del deportista. 


\section{LAPAROSCOPIA EN LA URGENCIA.}

A pesar en la frecuencia del desarrollo y aparición de las hernias, el riesgo de estrangulación intestinal es relativamente bajo. Las hernias inguinales se reparan de urgencia solo en el 3.8\% de los casos, con una incidencia de 0.0076 cada 100 personas/ año, comparándolo con la incidencia de la cirugía electiva, que es del 0.2 cada 100/año es baja. ${ }^{(35)}$ Por lo expuesto, y como fuera comentado previamente, es que se postula el manejo conservador como opción válida y segura. EL aspecto mas importante del manejo de la hernia estrangulada, es el de minimizar el tiempo desde el inicio de los síntomas al momento de la cirugía, sabiendo que la necrosis puede aparecer desde las 6 horas del inicio de los síntomas. Hay múltiples opciones para el abordaje quirúrgico de las hernias inguinales estranguladas, la elección del mas apropiado dependerá de la situación clínica general del paciente, de la existencia o no de cirugías previas, así como de la preferencia y seguridad del cirujano. Es así que las técnicas L/E constituyen una opción válida.

En el caso del abordaje TEP, es necesario realizar una exploración laparoscópica de la cavidad peritoneal, a fin de evaluar la viabilidad del asa involucrada, incluso puede ser necesario la colocación de mas trocares de trabajo para lograr la reducción completa del contenido del saco. Una vez evaluado el contenido se procede con la creación del espacio preperitoneal como se hace de forma habitual. La recomendación es intentar realizar los abordajes separados entre si, a fin de no contaminar el plano preperitoneal que se utilizara para la plastia. ${ }^{(37)}$ En caso de realizar un abordaje TAPP, el mismo se realiza de la forma habitual, iniciando por una laparoscopia exploradora e inspeccionando la viabilidad del contenido del saco. Una vez reducido y descartada la isquemia o necrosis se procede con la técnica habitual.

Como sabemos, la reducción del saco y su contenido durante la reparación herniaria de urgencia no siempre es sencilla. Se describe que hasta en un $45 \%$ de los casos la reducción se produce de forma espontanea durante la relajación muscular. ${ }^{(36)}$

En el resto de estos, deberemos de considerar una serie de estrategias para poder liberar el contenido, seccionando el anillo estrangulante (fig.22).

Para las hernias laterales, los vasos epigastrios pueden ser ligados y así poder emplazar una incisión vertical, hora 12 a nivel del orificio inguinal profundo. Para las hernias mediales o directas, se puede realizar una incisión sobre el sector anteromedial del defecto, lo que seria la cara posterior del musculo recto, para así evitar lesionar estructuras vasculares. Para la hernia femoral, la incisión puede ser efectuada medial al anillo femoral (Gimbernat) en el lugar de inserción de la cintilla ilio- pubiana y el ligamento de Cooper.

Otra opción es realizar el tratamiento de la hernia estrangulada en dos etapas. ${ }^{(35)}$ Como primer primer paso, se efectúa la laparoscopia exploradora con el fin de explorar y reducir en contenido herniario, si es necesario se realiza la resección intestinal. En este momento no se realiza el tratamiento de la hernia con la intención de realizarla en el futuro cercano, cuando las condiciones generales del paciente sean favorables. En este caso la reparación se debería de efectuar mediante abordaje TEP, la teoría detrás de esta postura es que de esta manera se reduce el riesgo de infección de la malla, al diferir la colocación de la misma tal vez en un ambiente local no del todo favorable.

Las ventajas de los abordajes $\mathrm{L} / \mathrm{E}$ incluyen la capacidad de evaluar la viabilidad intestinal sin necesidad de laparotomía, detectar hernias ocultas, poseen menores tasas de infección de la herida operatoria y de menor dolor postoperatorio, tienen una recuperación mas rápida. Sin embargo, la cirugía de la hernia estrangulada es técnicamente mas demandante, requiere de destreza y experiencia por parte del cirujano. El intestino se encuentra edematoso, distendido lo que limita el campo operatorio y su manipulación debe de ser muy cuidadosa. La reparación L/E debe evitarse en pacientes hemodinámicamente inestables, con abdómenes hostiles y cuando hay poca experiencia por parte del cirujano.

En la actualidad los datos existentes sugieren que la colocación de la malla sigue siendo beneficiosa, incluso existiendo resección intestinal si consideramos términos de recurrencia. Sin embargo, la información es limitada sobre la seguridad de reparar con malla en esta situación y el potencial riesgo de infección por lo que más investigaciones deben de llevarse a cabo (36). Por lo expuesto pensar en un abordaje abierto y en una reparación anatómica en esta situación, todavía sigue siendo totalmente válido.

\section{HERNIA DEL DEPORTISTA}

La incidencia del dolor inguinal en atletas es estimada en alrededor del 2 al 20\%, sin embargo, la incidencia en la población general sigue siendo desconocida. 
Las hernias inguinales y los hallazgos patológicos en la articulación de la cadera son frecuentes, pero una vez que se descartan estos diagnósticos diferenciales, sea mediante examen físico o estudios por imagen, la evaluación del dolor inguinal continúa siendo confusa para la mayoría de los médicos.

La mayoría de la literatura existente refiere a atletas de alta competencia por lo que la evidencia existente es de baja calidad y no aplicable a la población en general.

En las ultimas décadas, especialistas en el tema han unido esfuerzos para agrupar síntomas, hallazgos en examen físico e imagen, en un intento de lograr una uniformidad en la evaluación y atención de estos pacientes.

Varios términos son utilizados para referirse al dolor inguinal no vinculado a hernias o cadera: pubalgia del atleta, hernia del deportista, Hernia de Gilmore, ingle del deportista y muchos otros, lo actualmente aceptado es referirse como síndrome de dolor inguinal.

El conocimiento anatómico del canal inguinal y las relaciones de estas estructuras con los huesos de la pelvis es esencial. Se deben de considerar la magnitud de fuerzas que este conjunto de partes blandas, aplican sobre el hueso y sínfisis del pubis, lo que Meyers y col denominan como articulación del pubis. ${ }^{(39)}$

Durante la actividad física, los músculos, tendones y ligamentos son sometidos a un gran nivel de tensión y a su vez estos transmiten elevado estrés mecánico y torque al hueso y articulación del pubis. Una teoría en la patogenia de este dolor postula un disbalance entre fuerzas opuestas, desde arriba (musculo recto) y desde abajo (músculos aductores) ${ }^{(38)}$

La aparición de síntomas puede ser aguda, y responder a una lesión muscular o tendinosa especifica o por el contrario, tener una evolución mas insidiosa en el tiempo vinculado a tensión excesiva o desgarros crónicos.

El síntoma principal es el dolor inguinal, centrado fundamentalmente a nivel del tubérculo del pubis. Este dolor puede irradiar desde la caja de los aductores hacia el pubis o desde arriba, en la inserción del musculo recto abdominal. Menos frecuentemente los pacientes pueden desarrollar dolor y contractura a nivel de la inserción del ligamento inguinal en la espina del pubis.

Este dolor puede verse exacerbado en aquellas actividades que involucren los músculos aductores del muslo y la musculatura abdominal baja como movimientos de elevación y rotación lateral del muslo. También pueden experimentar sensación de quemazón o de pinchazos secundarios a neuralgias inguinales.

Los hallazgos físicos mas frecuentes son el dolor a la palpación del anillo inguinal superficial, dolor a la palpación de la espina del pubis o en la inserción del tendón del musculo aductor largo o recto abdominal sobre el pubis.

El examen clínico debe de ser completo, buscando sobre todo la presencia de hernias inguinales o femorales y valorando correctamente la funcionalidad de la articulación de la cadera. Se debe de prestar principal atención a la evaluación de la marcha y la posición en la que el paciente refiere el dolor.

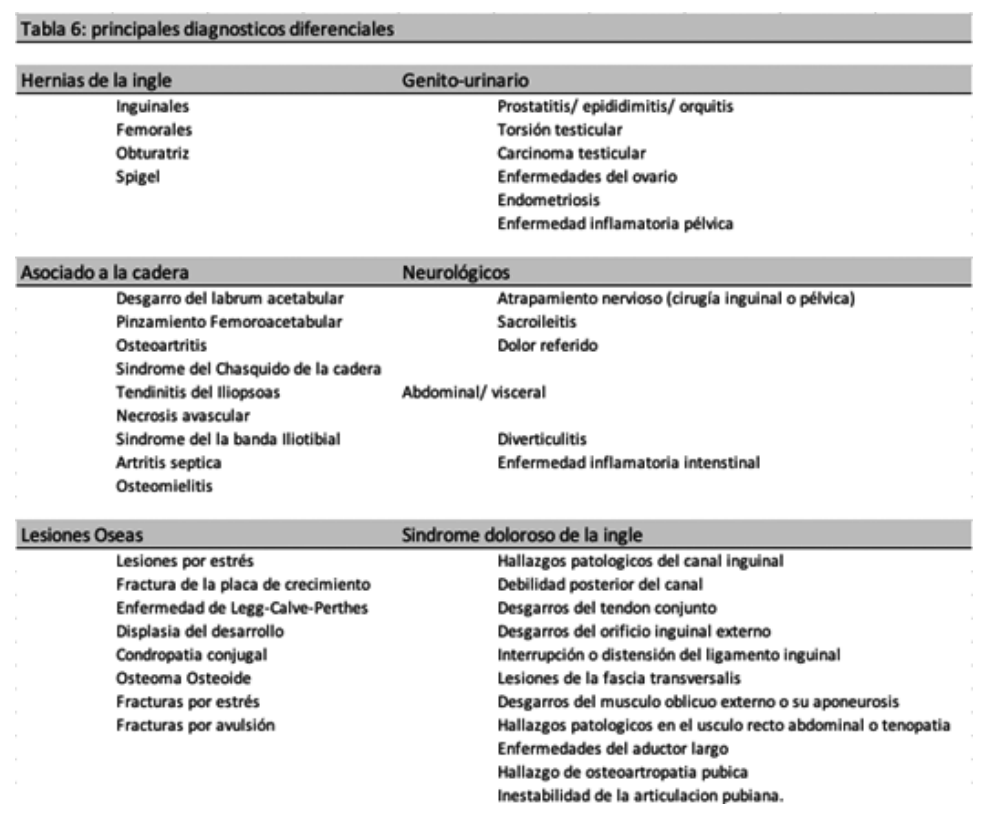


Los diagnósticos diferenciales son numerosos (tabla 6) y la dificultad radica en que muchos de estos pacientes con dolor inguinal tienen una combinación de hallazgos patológicos a nivel de la cadera y coexistir con otras causas de dolor inguinal. ${ }^{(38)}$

Los hallazgos patológicos que contribuyen al desarrollo el síndrome pueden agruparse en diferentes categorías, incluyendo hallazgos patológicos a nivel del canal inguinal, desgarros o distensiones de los músculos recto abdominal o aductor largo, neuralgia inguinal o hallazgos propios del hueso y sínfisis pubiana.

Canal inguinal: estos hallazgos son frecuentes durante la exploración, de ahí que se usara el termino hernia del deportista. Los hallazgos patológicos a este nivel pueden estar vinculados a la existencia de una debilidad o abultamiento de la fascia transversalis, sin existir una hernia directa; puede existir daño a nivel de las fibras del musculo oblicuo interno o tendón conjunto o existir roturas de las fibras del oblicuo externo que involucren el orificio inguinal externo.

Músculos y tendones del recto abdominal y aductor largo: la inserción de los músculos rectos del abdomen es anterior respecto al pubis. Estos se fusionan con el tendón del musculo aductor largo, para continuar hacia la parte alta del muslo. Pueden ocurrir diversos grados de distención o rotura de estos. Pueden aparecer signos inflamatorios de uno a ambos tendones en la RNM y en los casos mas severos puede haber rotura total del mismo o incuso de la espina del pubis.

Sínfisis pubiana: los hallazgos patológicos en la sínfisis del pubis no son menos frecuentes, son mas bien vinculados a mujeres en el postparto que a atletas. Los síntomas suelen describirse como sensación de inestabilidad centrada en la sínfisis.

Neuralgia inguinal: irritación o compresión de los nervios sensitivos de la región (ilio inguinal, ilio hipogasrico, rama genital de del genitofemoral) podría colaborar con la aparición del síndrome de dolor inguinal. Pueden aparecer como hallazgos únicos o como consecuencia de las alteraciones del canal inguinal ya expuestas. En pacientes con cicatrices a nivel inguinal, se debe de considerar el atrapamiento nervioso como posible causa de dolor.

Cuando la historia clínica y el examen físico son suficientes para el diagnostico, no son necesarios otros estudios complementarios. En los casos de dudas diagnosticas, la ecografía dinámica y la resonancia magnética (RNM) son los estudios de elección.

LA RNM puede estar indicada cuando el síndrome de dolor inguinal no puede distinguirse de hallazgos patológicos sobre la articulación de la cadera y se resumen en la tabla 7 .

El enfoque terapéutico de los pacientes con síndrome doloroso de la ingle debe ser multidisciplinario, incluyendo médicos especialistas en deporte, fisioterapeutas, traumatólogos y cirujano general con conocimiento y experiencia en la patología del canal inguinal.

El la etapa aguda, el dolor es tratado de forma conservadora, no operatoria, en base al reposo (2-8 semanas) y la indicación de analgésicos del tipo AINES. Si el dolor continua, el tratamiento se basara en la rehabilitación física, efectiva del 40al 100\% de los casos según la bibliografía consultada. ${ }^{(38)(39)}$ Esta rehabilitación también es fundamental para la recuperación postoperatoria.

\begin{tabular}{|l|}
\hline Tabla 7: hallazgos patológicos en la RNM \\
\hline Edema subcortical o de medula ósea a nivel del pubis \\
\hline Inflamación a nivel de la placa Recto - aductor \\
\hline Desgarro o distensión en el musculo recto o aductor largo \\
\hline Osteítis a nivel del pubis \\
\hline Edema de la sínfisis pubiana. \\
\hline
\end{tabular}

Se describen otras alternativas terapéuticas, con resultados variados, como son le tratamiento con corticoides tanto por vía oral, sistémica o local, la infiltración de la placa recto- aductor con y plasma enriquecido en plaquetas.

La ablación de las ramas nerviosas por radiofrecuencia perece tener muy buenos resultados, con altas tasas de alivio del dolor a 6 meses de seguimiento, tanto en pacientes con hallazgos en la RNM o no. 
El tratamiento quirúrgico tiene como objetivo liberar la tensión y torsión ejercida sobre la articulación del pubis mientras se reduce la compresión sobre de los nervios sensitivos llegando a realizar la neurectomia si es necesario. Muchos de estos procedimientos tienen en común la reparación o refuerzo del canal inguinal.

Se describen procedimientos con y sin colocación de malla, tano por vía abierta como por vía $\mathrm{L} / \mathrm{E}$.

En la tabla 8 se resumen las principales características de estos, los esquemas se muestran en la fig.23.

\begin{tabular}{|c|c|c|}
\hline Procedimiento & Ventajas & Comentario \\
\hline $\begin{array}{l}\text { Reparacion abierta } \\
\text { sin malla }\end{array}$ & $\begin{array}{l}\text { Resultan en cambios variables en } \\
\text { la tension y torsion apllicada a la } \\
\text { articulcaion del pubis. } \\
\text { Realizan la decompresion o neurectomia. } \\
\text { Se enfocan en reparar el defecto, reforzando el piso del } \\
\text { canal inguinal y/o lateralmente el musculo recto } \\
\text { abdominal a al ligamento inguinal }\end{array}$ & $\begin{array}{l}\text { Evitan posibles complicaciones vinculadas al } \\
\text { uso de mallas y mantienen la elasticidad y } \\
\text { flaxibilidad de los planos. }\end{array}$ \\
\hline $\begin{array}{l}\text { Reparacion con } \\
\text { malla }\end{array}$ & $\begin{array}{l}\text { Utilizan malla para reforzar lel piso del canal inguinal } \\
\text { y realizan la decompresion nerviosa. } \\
\text { Disminuyen notoriamente el grado de tension a nivel de } \\
\text { la articulacion del pubis } \\
\text { Pueden realizarse mediante abordaje abierto o laparoscopico }\end{array}$ & $\begin{array}{l}\text { Exponen posible complicaciones por el uso de mallas } \\
\text { Los procedimientos laparoscopicos si bien tienen la } \\
\text { ventaja de que el paciente retome su actividad mas } \\
\text { rapido, estos son menos efectivos en la decompresion nerviosa. }\end{array}$ \\
\hline $\begin{array}{l}\text { Tendectomia del } \\
\text { musculo aductor largo }\end{array}$ & $\begin{array}{l}\text { Actua cambiando el vector de las fuerras aplicadas sobre el } \\
\text { hueso del pubis. Libera presion sobre la logiade los aductores y } \\
\text { puede realizar la decompresion del nervio obturador. }\end{array}$ & $\begin{array}{l}\text { La tendectomia por si sola no atiende niguna lesion del piso o } \\
\text { canal inguinal. }\end{array}$ \\
\hline
\end{tabular}

$\mathrm{El}$ abordaje $\mathrm{L} / \mathrm{E}$ tiene las mismas consideraciones que para el tratamiento de las hernias inguinales y pueden realizarse por vía trans abdominal (TAPP) o totalmente extraperitoneal (TEP). Las ventajas en general ya fueron comentadas en este trabajo por lo que no las reiteraremos. En lo específico del tratamiento de este síndrome, si bien la disección completa del OMP puede revelar alguna anormalidad muscular, fundamentalmente a nivel del tendón conjunto o cara posterior del musculo recto, no valora correctamente lo vinculado a la placa recto - aductora ni al orificio inguinal superficial y compresión nerviosa asociada.

Independientemente del enfoque, la mayoría de los autores reportan tasa de éxito del 80 al 100\%(39) tomando como resultado positivo el alivio de los síntomas y el regreso a la actividad deportiva. En esta etapa es fundamental la terapia de rehabilitación postoperatoria, a fin de evitar la recaída.

\section{IMÁGENES}

Fig. 1: orificio miopectineo de Fruchaud

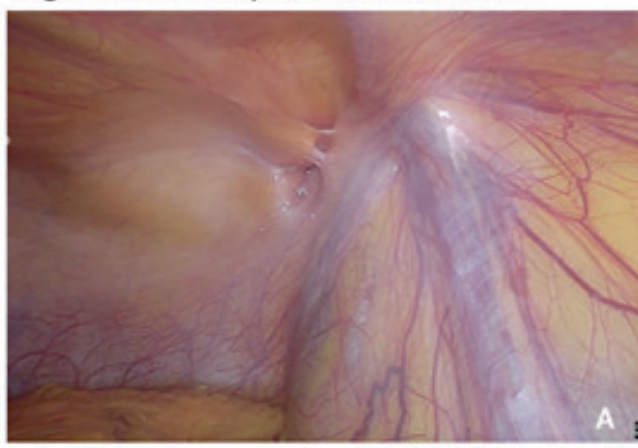

A - Vision laparoscopica del OMP de Fruchaud.

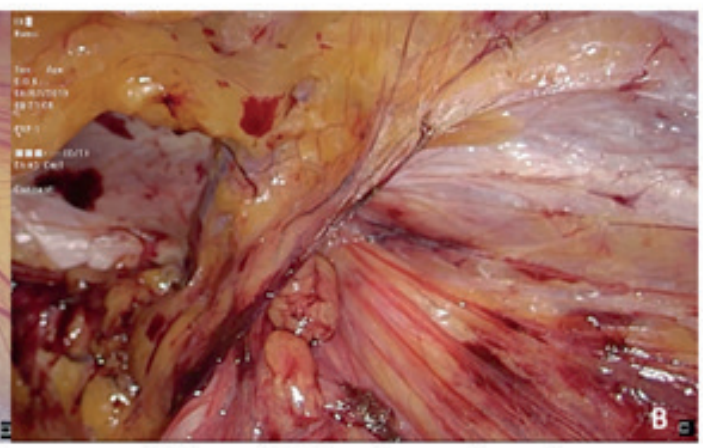

B luego de diseccion peritoneal. 
Fig 2. Y invertida y cintilla ilio-pubiana (azul), vision laparocopica

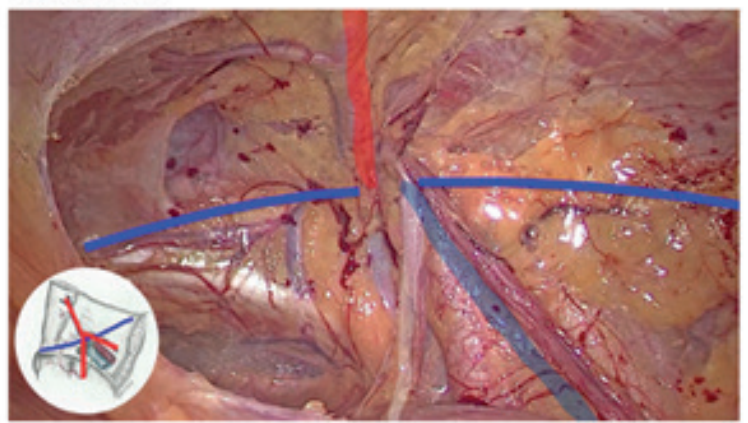

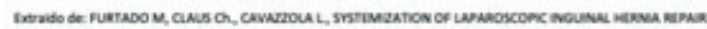
then asion ond

Fig.4: Zonas de diseccion

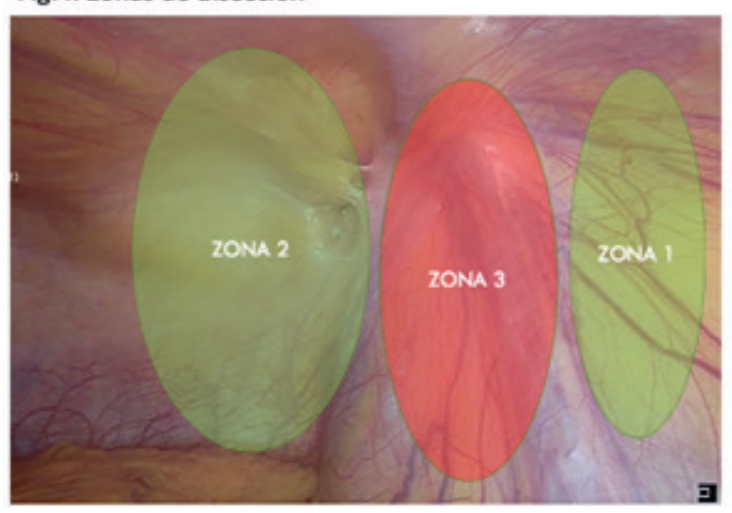

Fig.6: Hernia inguinal lateral izq. Vista laparosopica

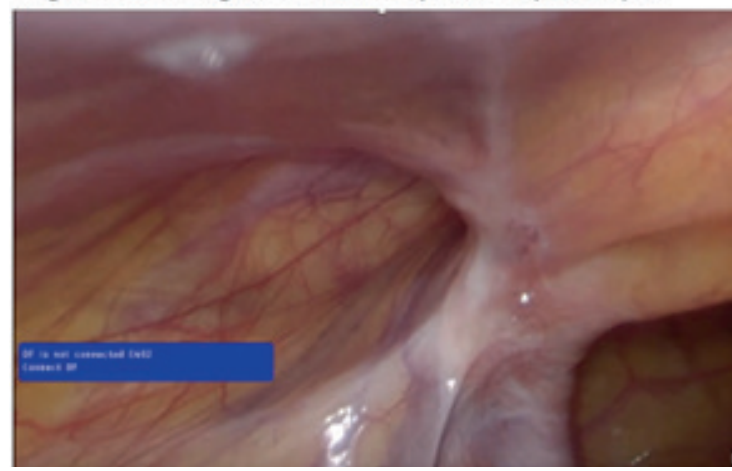

Fig. 8: diseccion completa del OMP. Vision critica de seguridad

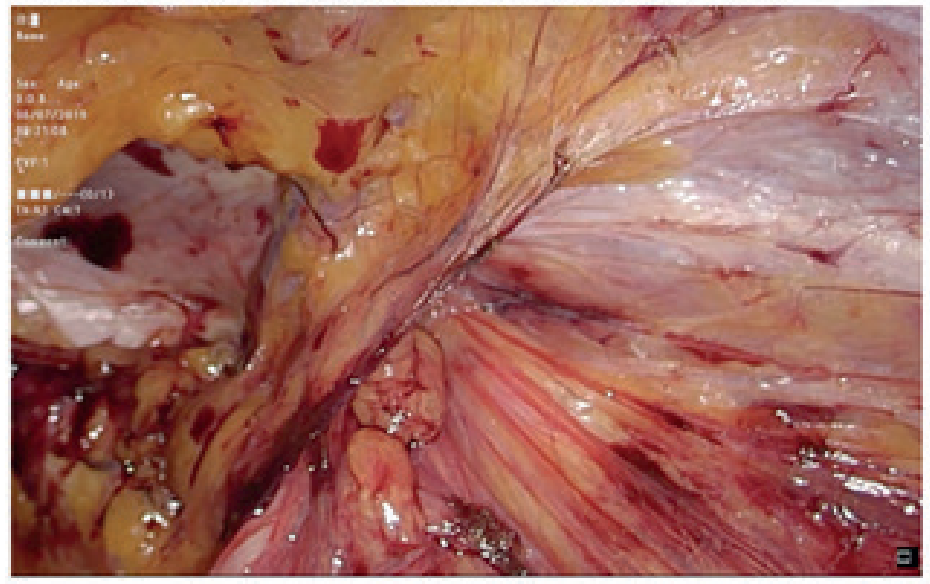

Fig. 3. Esquema de la $Y$ invertida y los cinco triangulos.

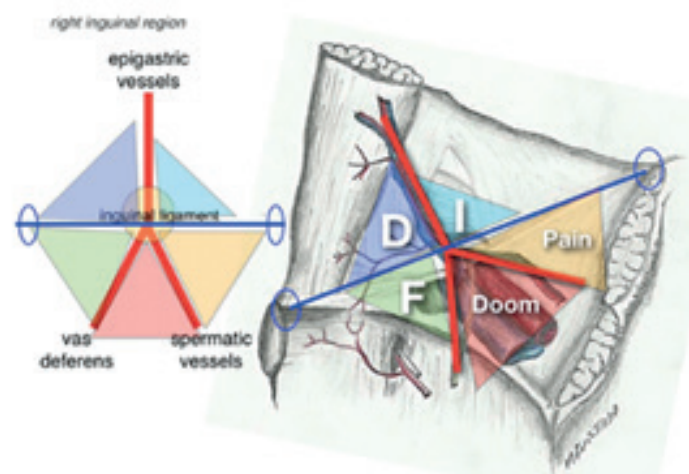

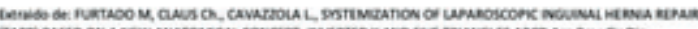
Ton:

Fig. 5: esquema colocacion de trocares TAPP

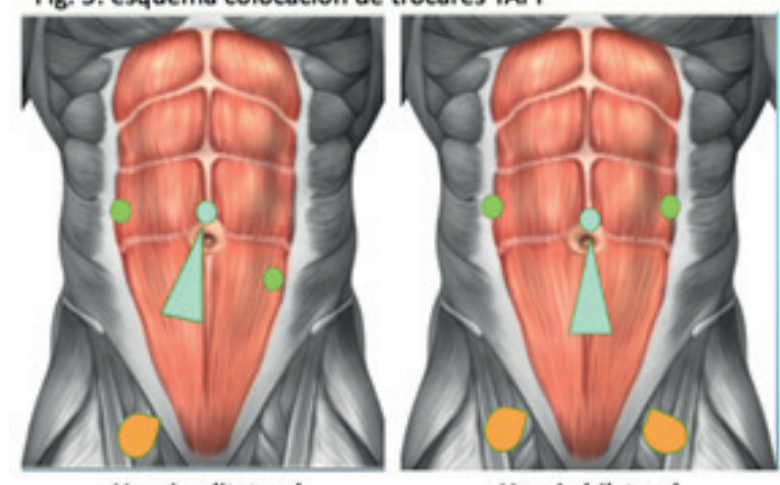

Hernia bilateral

Fig. 7: margenes de diseccion del OMP.

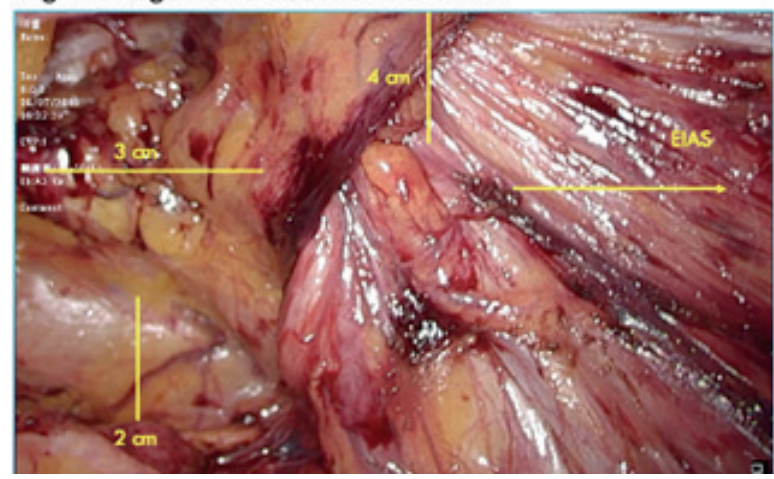

Fig.9: Esquema corte de malla.

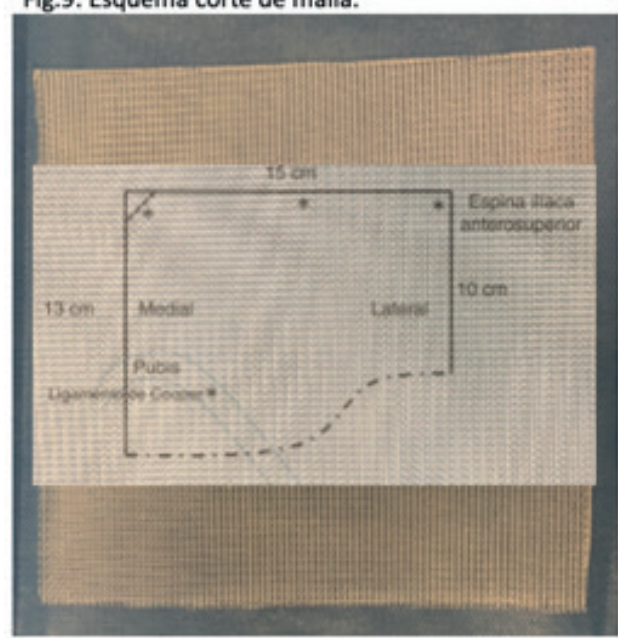


Fig 10: Esquema de colcacion de malla con margenes adecuados.

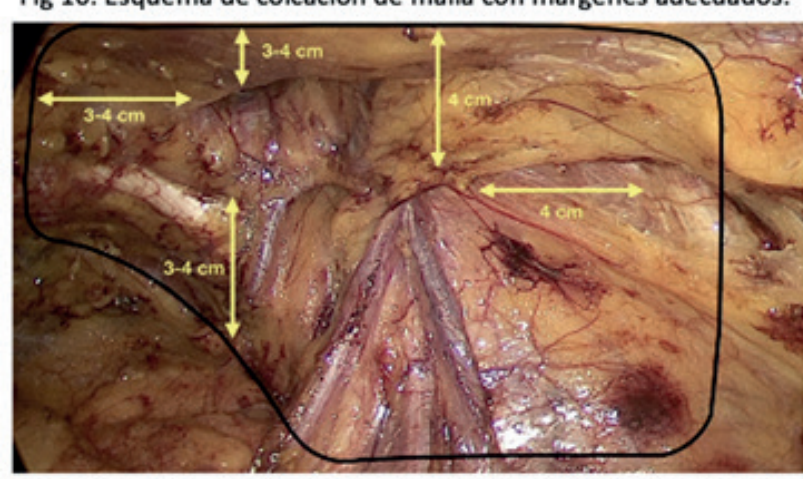

Extraido de: Clas Ch, Furtado M, Malcher F, Totti L, Felix $E$. Ten golden nules for a sate Mas inguinal hernia repair using a new anatomical concept as a guide Surgical fndoscopy (2020) 34-145a-1464

Fig. 12: malla de polipropileno a utilizar en el BTOM

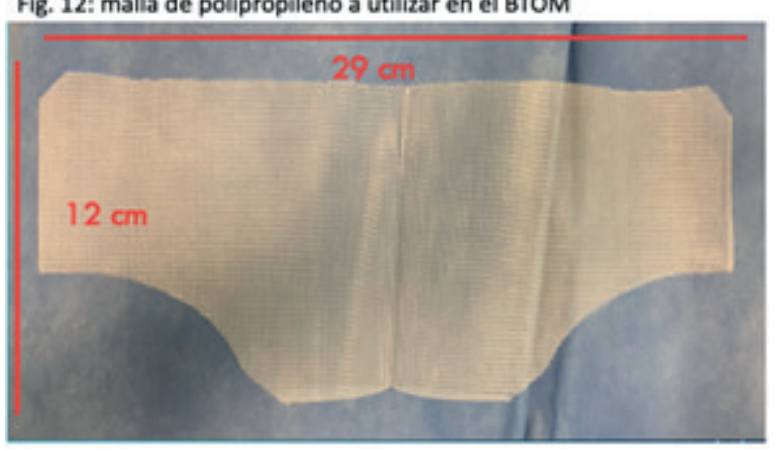

Fig.11: diseccion OMP en hernia bilateral. Se observa puente de peritoneal entre ambos ligamentos umbilicales.

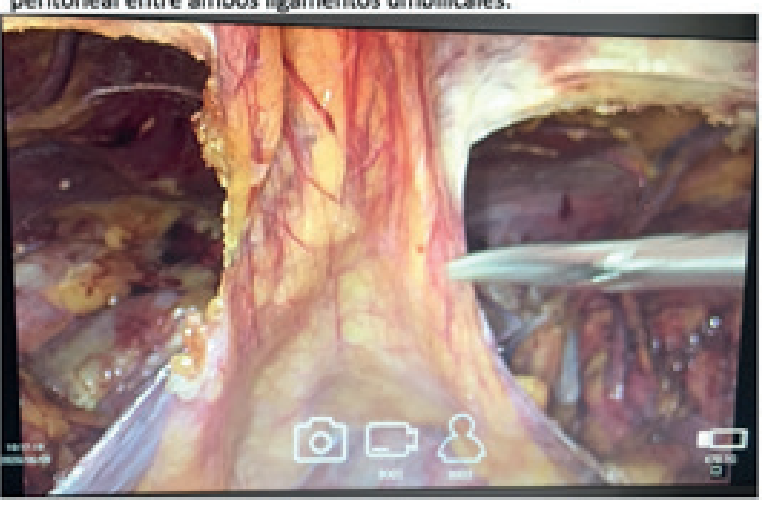

Fig 13: BTOM Hernioplastia bilateral con malla unica desplegada

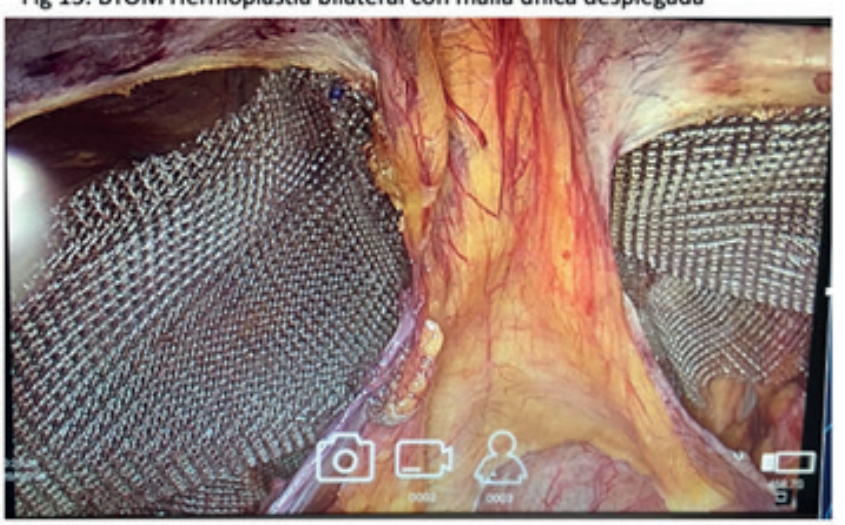

Fig.14: Trocar balon y esquema de introduccion.

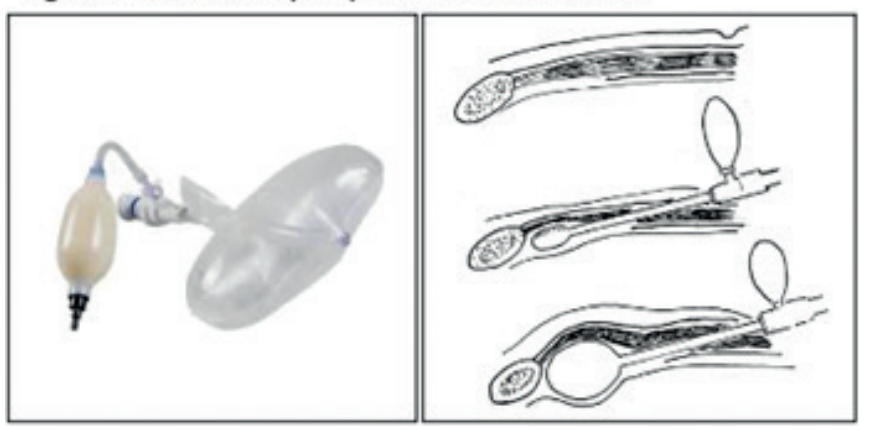

Fig. 15: visión a través de trocar balón

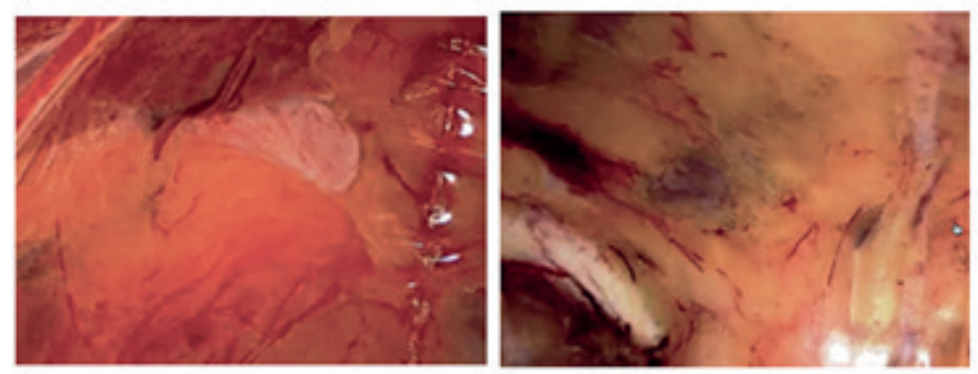

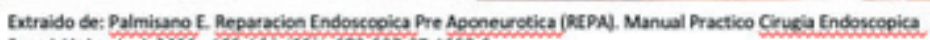

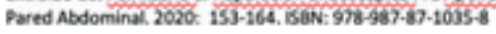


Fig 16: visión endoscópica del espacio retromuscular. Vista cefalo caudal

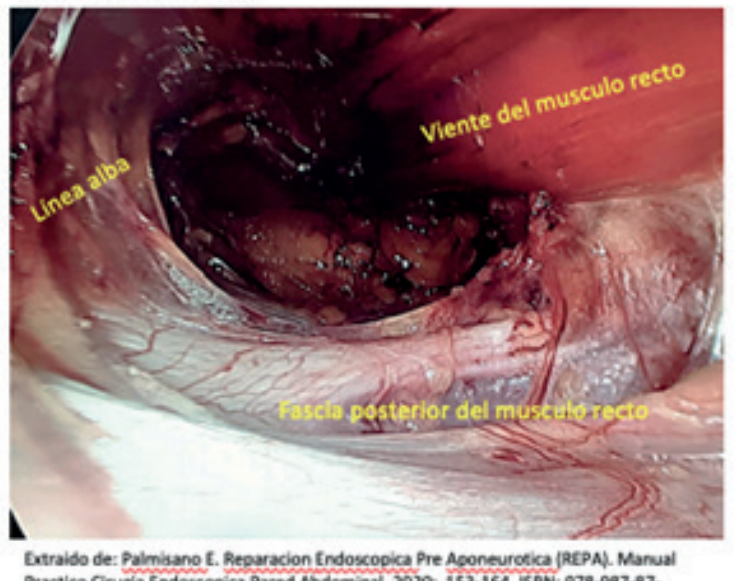
prectico Cinipa fond $1035-8$

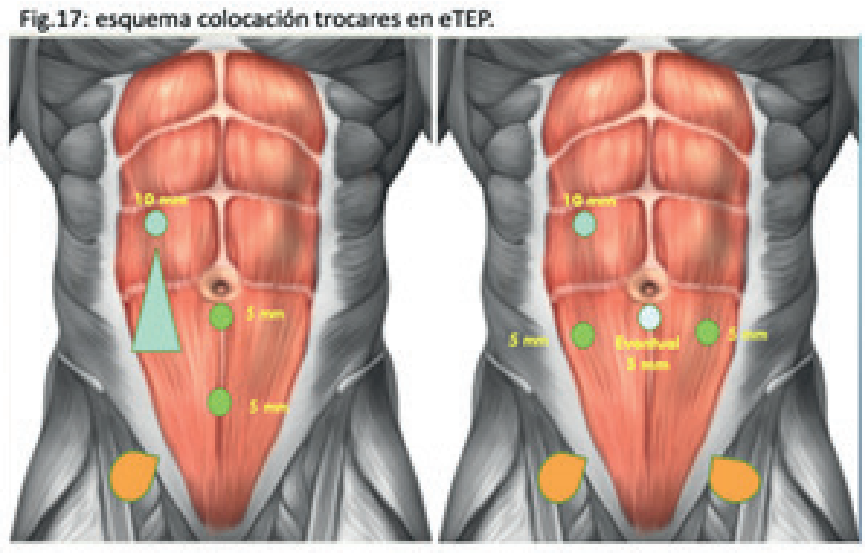

A

B

Fig 18: principales dispositivos de fijación invasiva.

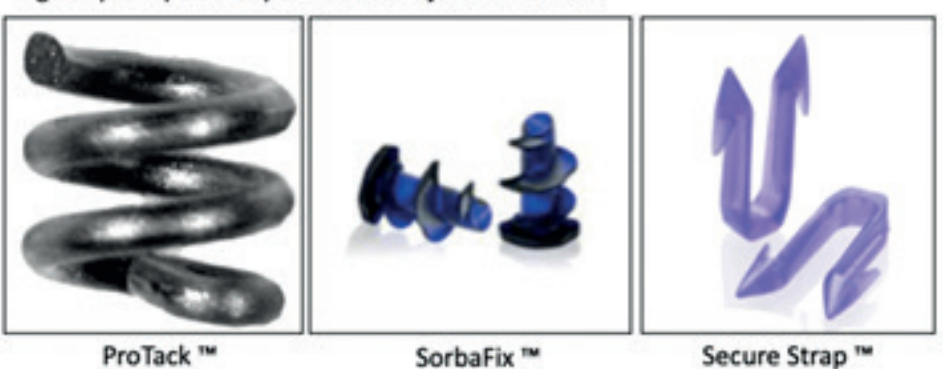

Fig. 19 Aplicación de cianocrilato (Histoacrylim).

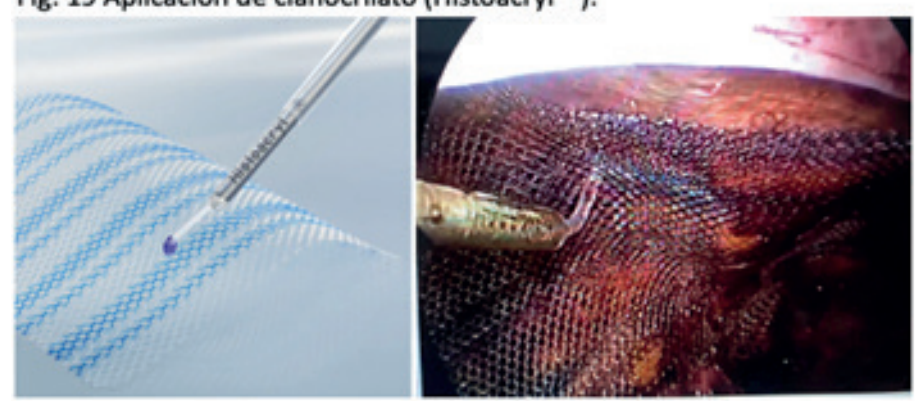

Fig. 20: Técnica de abandono primario del saco (PAS) "en parche de ojo de pirata".

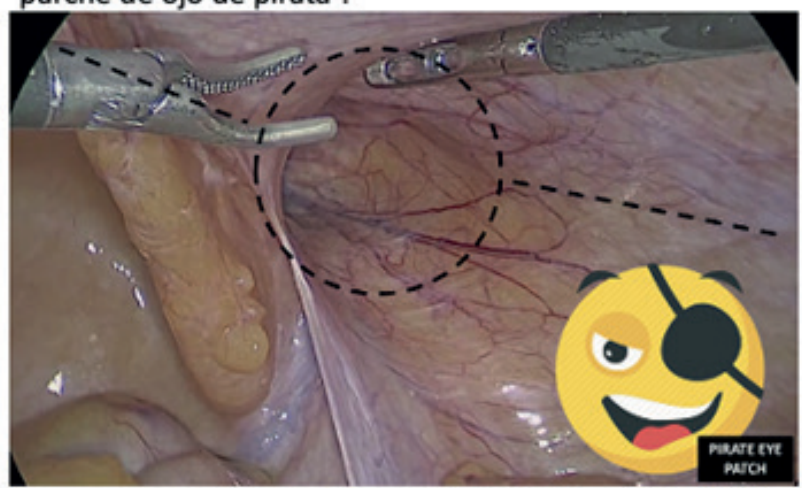

Extraido de: Morrel A.Ch, Morrel A.L, Malcher F, Morrel AL, Morrel - Junior A. Ch. Primany

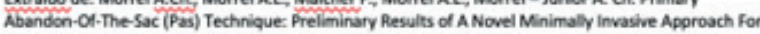
Inguinoscrotal Hernia Repair. Arg Bras Or Dig 2020:33(2): E1519 
Fig 21: seccion peritoneal rodeando anillo inguinal profundo en recnica de PAS.

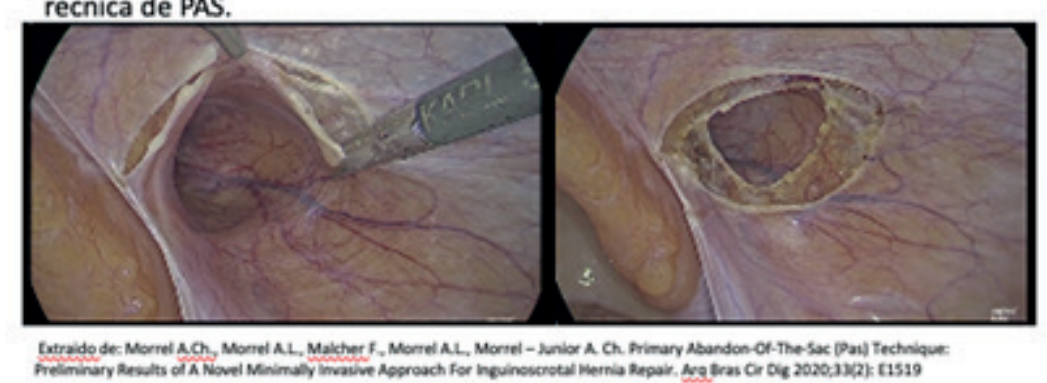

Fig 22: esquema sobre emplazamiento de incision de descarga sobre anillo de estrangulacion: A hernia inguinal indirecta, $\mathrm{B}$ hernia inguinal directa, $\mathrm{C}$ hernia femoral. The SAGES Book of Hernia Surgery. Spriger 20019; 503- 514.

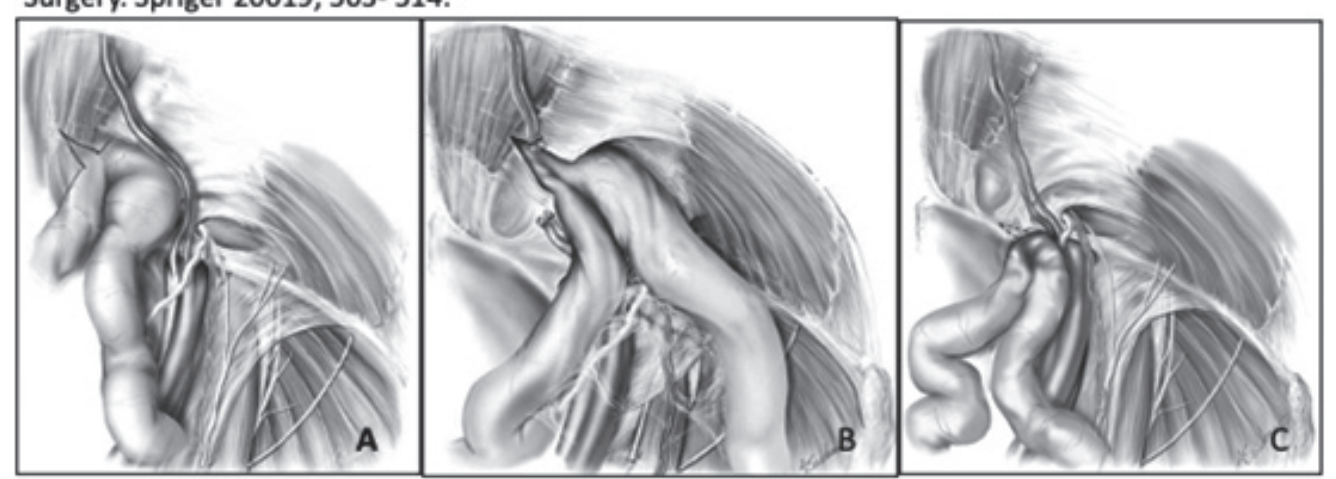

Fig. 23: esquemas de principales tecnicas sin malla para el tatamiento del sindrome doloroso de la ingle. Zuckerbraun B.; Cyr A; Mouro C. Groin Pain Syndrome Known as Sports Hernia A Review. IAMA Surgery Published online February 5, 2020.

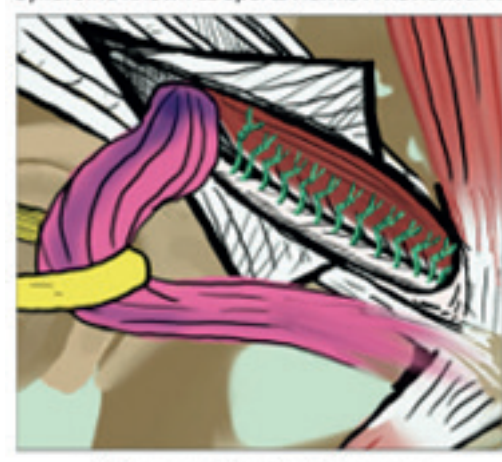

Reparación de Gilmore.

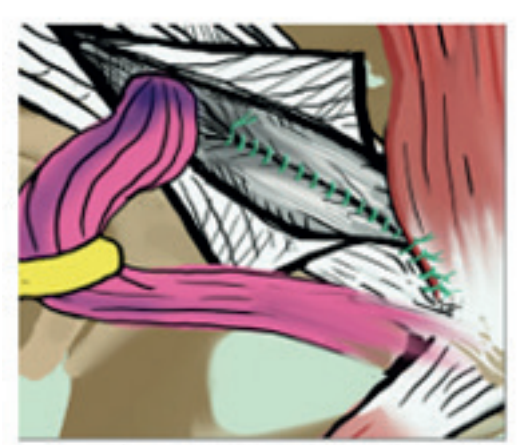

Reparación mínima de Muschaweck.

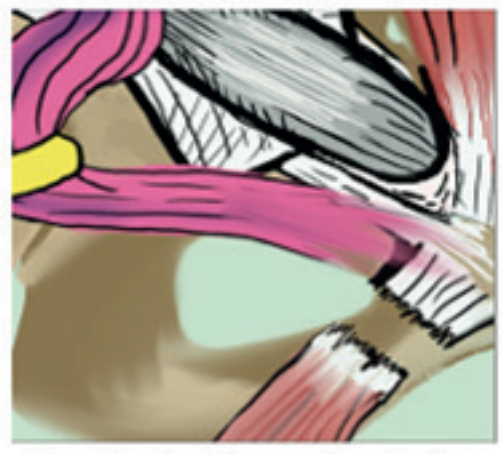

Tenotomia del musculo aductor largo.

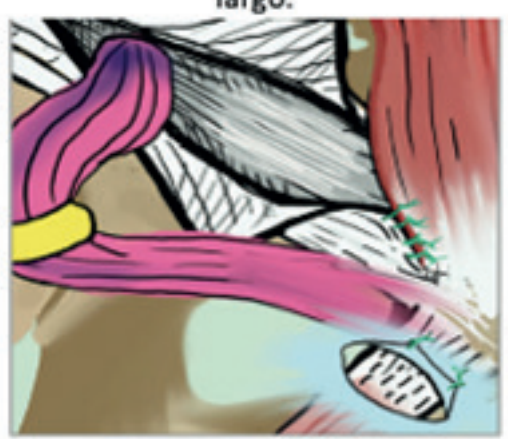

Reparación de Meyer. 


\section{BIBLIOGRAFIA}

1) Almarzooqi R.; Tish S.; Huang L-C.;Prabhu A.; Rosen M; Review of inguinal hernia repair techniques within the Americas Hernia Society Quality Collaborative. Hernia (2019) 23:429-438

2) Kukleta J.; Köckerling F.; George Ferzli G. Indication for Surgery: Open or Laparoendoscopic Techniques in Groin Hernias. R. Bittner et al. (eds.), Laparo-endoscopic Hernia Surgery, https://doi.org/10.1007/978-3-66255493-7_5

3) Nadine van Veenendaal N.; Maarten Simons M.; William Hope W.; Tumtavitikul S.; Bonjer J.; on behalf of the HerniaSurge Group Consensus on international guidelines for management of groin hernias. Surgical Endoscopy (2020) 34:2359-2377

4) Bittner R.; Arregui M. E.; Bisgaard T.; Dudai M.; Ferzli G.S.; Fitzgibbons R.J.; Fortelny R.H.; Klinge U.: Kockerling F.; Kuhry E.; Kukleta J. Lomanto D.; Misra M.C.; Montgomery A.; Morales-Conde S.; Reinpold W.; Rosenberg J.; Sauerland S.; Schug-Paß C.; Singh K.; Timoney M.; Weyhe D.; Chowbey P. Guidelines for laparoscopic (TAPP) and endoscopic (TEP) treatment of inguinal Hernia [International Endohernia Society (IEHS)]. Surg Endosc (2011) 25:2773-2843

5) Cisneros Muñoz H.C.; Mayagoitia J.C. Guía de práctica clínica y manejo de la hernia inguinal. Rev Hispanoam Hernia. 2021;9(2):61-70

6) The HerniaSurge Group. International guidelines for groin hernia management. Hernia (2018) 22:1-165 https:// doi.org/10.1007/s10029-017-1668-x

7) Miserez M.; Alexandre J.H.; Campanelli G.; Corcione F.; Cuccurullo D.; Hidalgo Pascual M.; Hoeferlin A.; Kingsnorth A.N; Mandala V.; Palot J.P.; V. Schumpelick V; Simmermacher R.K.J.;Stoppa R.; Flament J.B. The European hernia society groin hernia classication: simple and easy to remember. Hernia (2007) 11:113-116. DOI 10.1007/s10029-007-0198-3

8) Daes J.; Felix E. Critical View of the Myopectineal Orifice. Ann Surg 2017;266:e1-e2 . DOI: 10.1097/ SLA.0000000000002104

9) Claus CMP.; Furtado M.; Malcher F.;Cavazzola L.T.; Felix E. Ten golden rules for a safe MIS inguinal hernia repair using a new anatomical concept as a guide. Surgical Endoscopy (2020) 34:1458-1464 https://doi.org/10.1007/ s00464-020-07449-z

10) Furtado M.; Claus Cmp.; Cavazzola L.T; Malcher F.; Alexandre Bakonyi-Neto A.; Saad-Hossne R. Systemization of laparoscopic inguinal hernia repair (TAPP) based on a new anatomical concept: inverted y and five triangles. ABCD Arq Bras Cir Dig 2019;32(1):e1426. DOI: /10.1590/0102-672020180001e1426

11) Marenco de la Cuadra B.; Guadalajara Jurado J. F.; García Moreno J.; Moreno Romero R. Tipos De Hernias. Clasificaciones Actuales. Clasificación Actual EHS. Cir. Andal. 2013; 24: 225-227

12) Daoud I.M.; Dunn K. Groin Pain Etiology: The Inguinal Hernia, the Occult Inguinal Hernia, and the Lipoma. B.P. Jacob et al. (eds.), The SAGES Manual of Groin Pain. Springer International Publishing Switzerland 2016; 6: 49-58. DOI 10.1007/978-3-319-21587-7_6

13) Kwee R.M.;Kwee T.C. Ultrasonography in diagnosing clinically occult groin hernia: systematic review and metaanalysis. European Radiology. Published on line: 14 May 2018. https://doi.org/10.1007/s00330-018-5489-9

14) Aly M.; Farquharson B.M.; Clarke O.; Atkin G.K. Should surgeons repair symptomatic, clinically occult, radiologically evident, inguinal hernias? A case-control study of patient-reported outcomes. Hernia; plublished on line 11 January 2021. https://doi.org/10.1007/s10029-020-02346-9

15) Bittner R.; Montgomery M.A.; Arregui E.; Bansal V.; Bingener J.; Bisgaard T.; Buhck H.; Dudai M.; Ferzli G.S.; Fitzgibbons R.J.;Fortelny R.H.; Grimes K.L.; Klinge U.; Koeckerling F.; Kumar S.; Kukleta J.; Lomanto D.; Misra M.C.; Morales-Conde S.; Reinpold W.; Rosenberg J.; Singh K.; Timoney M.; Weyhe D.; Chowbey P. Update of guidelines on laparoscopic (TAPP) and endoscopic (TEP) treatment of inguinal hernia (International Endohernia Society). Surg Endosc (2015) 29:289-321 DOI 10.1007/s00464-014-3917-8

16) Bittner R.; Kukleta J.F.; Chen D. TAPP: Complications, Prevention, Education, and Preferences. R. Bittner et al. (eds.), Laparo-endoscopic Hernia Surgery. Springer-Verlag GmbH Germany, part of Springer Nature 2018:10; 101-118. https://doi.org/10.1007/978-3-662-55493-7_10

17) Palmisano EM. Brea Andrade A. Actualización de la nomenclatura del orificio miopectíneo en la reparación endoscópica de las hernias de la región inguinal Rev Hispanoam Hernia. 2021;9(1):46-49

18) Wilson P.; Hickey L.; Laparoscopic transabdominal preperitoneal (TAPP) groin hernia repair using n-butyl2-cyanoacrylate (Liquiband ${ }^{\circledR}$ Fix8TM) for mesh fixation and peritoneal closure: learning experience during introduction into clinical practice. Hernia (2019) 23:601-613 https://doi.org/10.1007/s10029-018-1861-6

19) Hiratsuka T.; Shigemitsu Y.; Etoh T.; Kono Y.; Suzuki K.; Zeze K.; Inomata M.; Appropriate mesh size in the totally extraperitoneal repair of groin hernias based on the intraoperative measurement of the myopectineal orifice. Surgical Endoscopy. Published online 11 May 2020. https://doi.org/10.1007/s00464-020-07616-2 
20) Legnani G.L.; Rasini M.; Pastori S.; Sarli D.; Laparoscopic trans-peritoneal hernioplasty (TAPP) for the acute management of strangulated inguino-crural hernias: a report of nine cases. Hernia (2008) 12:185-188 DOI $10.1007 / \mathrm{s} 10029-007-0305-5$

21) Palmisano E.M.; Martínez J.D.; Magdaleno Garcia M.; Gonzalez L.G.; Maniobras claves y trucos en eTEP. Rev Hispanoam Hernia. 2018;6(2):86-90

22) Lydeking L.; Johansen N.; Oehlenschläger J.M.; Bay-Nielsen M.; Bisgaard T. Re-recurrence and pain 12 years after laparoscopic transabdominal preperitoneal (TAPP) or Lichtenstein's repair for a recurrent inguinal hernia: a multi-centre single-blinded randomised clinical trial. Hernia (2020) 24:787-792 https://doi.org/10.1007/s10029020-02139-0

23) Roos M.M.;Jan E.; Verleisdonk M.M.; Sanders FBM.; Hoes A.W.; Stellato R.K.; Frederix GWJ.; Simmermacher RKJ.; Burgmans JPJ. and EFFECT study group. Effectiveness of endoscopic totally extraperitoneal (TEP) hernia correction for clinically occult inguinal hernia (EFFECT): study protocol for a randomized controlled trial. Roos et al. Trials (2018) 19:322 https://doi.org/10.1186/s13063-018-2711-7

24) Daes J.; Abordaje extraperitoneal de vista extendida (eTEP) para la reparación de hernias. Cir Esp. 2019. https:// doi.org/ 10.1016/j.ciresp.2019.09.001

25) Mancini G.J. Groin Pain Etiology: Athletic Pubalgia Evaluation and Management. B.P. Jacob et al. (eds.), The SAGES Manual of Groin Pain. Springer International Publishing Switzerland 2016; 7:59-72. DOI 10.1007/9783-319-21587-7_7

26) Simons M. P.; Aufenacker T.; Bay-Nielsen M.; Bouillot J.L.; Campanelli G.; Conze J.; D. de Lange D.; Fortelny R.; Heikkinen T.; Kingsnorth A.; Kukleta J.; Morales-Conde S.; Nordin P.; Schumpelick V.; Smedberg S.; Smietanski M.; Weber G.; Miserez M. European Hernia Society guidelines on the treatment of inguinal hernia in adult patients. Hernia (2009) 13:343-403 DOI 10.1007/s10029-009-0529-7

27) Tofigh A.M.; Ghadim M.K.; Bohlooli M. Comparing suture with N-Hexyl Cyanoacrylate glue for meshfixation in inguinal hernia repair, a randomised clinical trial. The American Journal of Surgery, https://doi.org/10.1016/ j.amjsurg.2020.10.029

28) Palmisano E.: M. Manual práctico de cirugía endoscópica de la pared abdominal. - 1ª ed . - Ciudad Autónoma de Buenos Aires: Autores de Argentina, 2020. Edición de Kindle.

29) Fortelny R.H. Is mesh fixation in TAPP and TEP still necessary?. Fortelny. Mini-invasive Surg 2021;5:16 DOI: 10.20517/2574-1225.2021.21

30) Daes J. Reparo laparoscopico de la hernia inguinal: presentacion de la tecncia totalmente extraperitoneal con vision extendida. Rev Colomb Cir. 2011; 26: 89-92

31) Daes J. The Extended-View Totally Extraperitoneal (eTEP) Technique for Inguinal Hernia Repair. Springer International Publishing Switzerland 2016 Y.W. Novitsky (ed.), Hernia Surgery, DOI 10.1007/978-3-31927470-6_45

32) The SAGES Manual of Hernia Surgery. Second Edition. Society of American Gastrointestinal and Endoscopic Surgeons (SAGES) 2019. Minimally Invasive Surgical Techniques for Inguinal Hernia Repair: The ExtendedView Totally Extraperitoneal Approach (eTEP). 33: 449-460.

33) Claus CMP.; Rocha G.M.; Ligocki Campos A.C.; Paulin JAN.; Coelho JCU. Mesh Displacement After Bilateral Inguinal Hernia Repair With No Fixation. Journal of the Society of Laparoendoscopic Surgeons. Volume 21 Issue 3 e2017.00033

34) Morrell A.C.; Morrell ALG.; Malcher F.; Morrell A.G.; Morrell-Junior ACh. Primary Abandon-Of-The-Sac (PAS) Technique: Preliminary Results Of A Novel Minimally Invasive Approach For Inguinoscrotal Hernia Repair. Arq Bras Cir Dig 2020;33(2):e1519 DOI: https://doi.org/10.1590/0102-672020200002e1519

35- The SAGES Manual of Hernia Surgery. Second Edition. Society of American Gastrointestinal and Endoscopic Surgeons (SAGES) 2019. Minimally Invasive Surgical Techniques for Inguinal Hernia Repair. Strangulated Inguinal Hernia: Options and Strategies. 37: 503-514.

36) Lin Y.T.; Weng T.Y.; Tam KW.; Effectiveness and Safety of Mesh Repair for Incarceratedor Strangulated Hernias: A Systematic Review and Meta-Analysis. World J Surg . Published online February 2020.

37) Liu J.; Zhai Z.; Chen J. The Use of Prosthetic Mesh in the Emergency Management of Acute Incarcerated Inguinal Hernias. Surgical Innovation.2019:0; DOI: 10.1177/1553350619828900

38) Zuckerbraun B.S.; Cyr A.R.: Mauro C.S.; Groin Pain Syndrome Known as Sports Hernia A Review. JAMA Surg. doi:10.1001/jamasurg.2019.5863 Published online February 5, 2020.

39) The SAGES Manual of Hernia Surgery. Second Edition. Society of American Gastrointestinal and Endoscopic Surgeons (SAGES) 2019. Minimally Invasive Surgical Techniques for Inguinal Hernia Repair. Groin Pain Syndromes in Athletes: "Sports Hernia". 38: 515-532. 


\title{
TRATAMIENTO LAPAROSCÓPICO DE LA HERNIA INCISIONAL
}

\author{
Dr. Gonzalo Estapé
}

\section{Conceptos Generales}

\section{INTRODUCCIÓN}

\begin{abstract}
Los objetivos de la reparación de una eventración, son proteger el contenido visceral abdominopélvico, restaurar la función respiratoria (y eventualmente cardiovascular) y reestablecer la situación anatomo funcional de la pared abdominal con capacidad de flexión abdominal.
\end{abstract}

La eventroplastia abierta con técnica de Rives - Stoppa, es el Glod Standard en la Henria Incisional (HI) medial, con bajas recurrencias pero con morbilidad parietal considerable. ${ }^{(1)}$

La eventroplastia laparoscópica (EL) surge como un nuevo abordaje para tratar las hernias de pared abdominal, mediales y no mediales, en un intento por mejorar los resultados del «abordaje tradicional o abierto». Recién con publicaciones a pertir del año 2000 de Heniford, Park, Ramshaw, and Voeller con series de EL que demostraban bajas complicaciones parietales, recurrencia (3.4\%) y menor hospitalización, es que la EL se adopta globalmente como posible y segura para tratar $\mathrm{HI}$ inicialmente seleccionadas. ${ }^{(2)}$ Así, en los últimos 10 años, las técnicas de Rives Stoppa abierta y la EL (IPOM) se reparten el 65\% de las reparaciones de HI en EEUU y Eurupa.

Para lograr el desarrollo seguro de la EL, se necesitan condiciones especiales de entrenamiento, una tecnología adecua$\mathrm{da}$, un equipo de trabajo eficiente y una predisposición personal especial. ${ }^{(3)}$

La adopción de la EL raramente supera el 20\% del total de la eventraciones a pesar de sus demostrados beneficios. Solo en centro especializados, alcanza el 30-35\% de las HI operadas. Las razones son: mayor incidencias de lesiones viscerales, las complicaciones derivadas de la malla intraperitoneal (adherencias, fístulas, obstrucción), el desplazamintos de la malla, el bulging a mediano plazo, los mayores costos y la dificultosa curva de aprendizaje. Por los mencionados problemas de la EL (IPOM), se desarrollaron técnicas que manteniendo los beneficios del abordaje mini invasivo, evitan los problemas de la situación intraperitoneal de la malla. Así se exporaron otras técnicas mini invasivas con la malla extraperitoneal como el TAPP ventral, el Rives-Stoppa laparoscópico, y las técnicas endoscópicas o hibridas: eTEP, MILOS/eMILOS, SCOLA; tanto por vía laparo/endoscópica como por cirugía robótica. ${ }^{(4)}$

Según una encuesta de 450 hospitales seleccionados de EE.UU., se calcula que el $22 \%$ de las reparaciones ventrales se llevan a cabo por laparoscopia, cifra que no es extrapolable a un contexto más global en donde este porcentaje es mucho menor. ${ }^{(5)}$

En España, sobre $4501 \mathrm{HI}$, la laparoscopia, que solo fue empleada en un 11,7\% de los casos. ${ }^{(6)}$

En nuestro medio, el abordaje laparoscópico de las eventraciones es aún excepcional, y en casos muy seleccionados. En los últimos años, se crearon las primeras Unidades de Patologóa Parietal en los centros académicos, con cirujanos dedicados a la patología parietal. Estos, completando su curva de aprendizaje, serán los encargados de tutorizar el progreso de estas unidades y la formación de los cirujanos jóvenes. La creciente experiencia en hernioplastias inguinales (TAPP), la mayor accesibilidad en costos y disponibilidad de mallas y tackers, así como la mayor experiencia en otras cirugías laparoscópicas de avanzada, permiten avisorar un importante progreso en estas técnicas.

El abordaje miniinvasivo, ofrece las siguientes ventajas: elimina la incisión, disminuye la perdida sanguínea, previene la reacción a cuerpo extraño superficiales, disminuye el riesgo de contaminación, evita la cirugía sobre la zona reparada, explora toda la incisión previa, permite una disección más precisa con magnificación. También se puede realizar cirugía asociada en el mismo acto quirúrgico y diagnósticos complementarios de otros procesos intraabdominales. ${ }^{(7)}$

Así, logra la reducción de la estancia hospitalaria, de la tasa de recurrencia de algunas hernias, de la tasa de complicaciones del sitio operatorio - en especial, las infecciones- y un retorno más rápido a las labores cotidianas, en comparación con la cirugía abierta. ${ }^{(8)(9)}$ 
Como desventajas se mencionan: 1) frecuentemente implica la colocación de una malla intraabdominal en contacto directo con las vísceras; 2 ) a veces no logra reestablecer la continuidad de la pared abdominal desde un punto de vista anatómico ni fisiológico en defectos grandes; 3 ) tiene mayor riesgo de lesiones viscerales intraperitoneales; 4) no trata la piel redundante ni grandes sacos, con morbilidad propia. ${ }^{(7)}$ Además, se informan neuralgias ocasionales en los sitios de la fijación de la malla, el frecuente seroma, la eventración de la malla, la recurrencia en hernias grandes o compejas, la insatisfacción del paciente por el pobre resultado cosmético y la pérdida de la función de la pared abdominal. ${ }^{(3)}$

Hoy no se discute la necesidad e indicación de colocar una malla en toda reparación de HI, independiente de su tamaño, ponderando la restitución anatomofuncional parietal y la reparación sin tensión. El uso de malla es el Estándar de Oro de las eventroplastias, salvo situaciones especiales como las infecciones en curso. Considerando el abordaje laparoscópico, no se describirán por no ser considerado un tratamiento adecuado, la reparación sin malla de las HI.(10) La EL debe debe desarrollarse dentro de una Unidad de Cirugía de Pared Abdominal por cirujanos de pared abdominal, que además tengan formación adecuada en ciruía laparoscópica avanzada. Tiene igual importancia la técnica quirúrgica, el adecuado estudio preoperatorio, un riguroso y programado control postoperatorio, lo que solo se puede conseguir con eficiencia trabajando en un equipo multidisciplinario. ${ }^{(7)}$

\section{ANTECEDENTES HISTÓRICOS Y EVOLUCIÓN DE LA EL}

Nos basamos en el excelente editorial del Dr. Jorge Daes publicado en la Revista de la Sociedad Hispanoamericana de Hernia en 2016. ${ }^{(3)}$

Hasta 1993, la reparación de la pared abdominal se hacía exclusivamente por cirugía abierta convencional, con los conocidos problemas de recurrencia, dolor, incapacidad laboral y morbilidad del sitio operatorio, sobre todo las infecciones. Pioneros como Le Blanc, Henniford, Park, Ranshaw y Voeller iniciaron la era de la reparación laparoscópica de la hernia ventral con la técnica intraperitoneal onlay mesh (IPOM), que consiste en la simple cobertura amplia del defecto con una malla fijada a la pared abdominal posterior. ${ }^{(11)(12)}$

A partir del 2000, se publican los primeros estudios comparativos entre los abordajes laparoscópico y abierto y, desde entonces, se ha trabajado y publicado, sobre los aspectos pre, intra y postoperatorios de la eventroplastia laparoscópica, con numerosas variaciones técnicas y progresos en las mismas. La técnica ha conseguido ya una relativa madurez y ha ido apropiándose de muchos principios, sustentados en la experiencia histórica acumulada con la cirugía convencional, que también siguie evolucionando y tiene su lugar en múltiples situaciones clínicas de la HI. ${ }^{(13)(14)}$

En el 2007, el desarrollo de mejores destrezas quirúrgicas, avances tecnológicos y nuevos materiales permitió implementar el cierre primario de los defectos con diversas técnicas a través de la fascia, endoscópicas e incluso híbridas, que combinaban el acceso abierto con el laparoscópico. El cierre primario se refuerza con una malla con barrera protectora sobre el lado visceral. Es posible adicionar una separación endoscópica de componentes que permite el cierre primario, sin tensión, de defectos más grandes. A este tipo de reparación se le ha denominado IPOM plus. ${ }^{(15)(16)(17)}$ El IPOM plus lograría la disminución de la tasa de recurrencia de las hernias, de seromas y de la eventración de la malla, un mejor resultado cosmético y una mejor función de la pared abdominal. ${ }^{(18)(19)}$

En 2018 se comunica la técnica LIRA (Laparoscopic intracorporeal rectus aponeuroplasty), es una alternativa al IPOM plus, para cerrar el defecto de la línea media sin tensión en eventraciones madianas o grandes $(4-10 \mathrm{~cm})$, e intentar evitar la separación de componentes de más compleja realización. Consiste en abrir (alrededor del defecto herniario) y rebatir medialmente la hoja posterior de ambas vainas rectales, suturándolas medialmente sin tensión. Luego de coloca una malla compuesta intraperitoneal, sobrepasando el defecto fascial, con la fijación habitual. Se obtuvo un cierre sin tensión adecuado, con escaso dolor postoperatorio, sin recurrencias ni bulging en corto seguimiento, por lo que se considera una técnica segura, eficaz y reproducible. ${ }^{(20)}$

El desafío actual es el estudio de la rección adherencial visceral a la malla intraperitoneal y sus potencialmente graves complicaciones. Las mallas biológicas y actualmente las mallas con doble faz, han logrado la menor incidencia de adherencias viscerales, con bajas complicaciones. Se han descrito técnicas como la trans-abdominal pre-peritoneal (TAPP) ventral, que implica la elevación de un colgajo peritoneal que permite el cierre del defecto y la colocación directamente sobre el músculo de una malla no protegida, facilitado con el uso del robot. Sin embargo, persiste el potencial problema del abordaje intraperitoneal y la dificultad para generar el colgajo peritoneal y su posterior cierre.

En el esfuerzo de reconstruir la pared abdominal y colocar una malla retromuscular con las ventajas que ello implica (disminución del costo de la malla, del riesgo de fístulas y obstrucción intestinal y mejor integración de la malla colo- 
cada sobre una plataforma muscular mejor irrigada) han surgido otras técnicas, como la técnica de Rives por vía laparoscópica o robótica transabdominal, y su posible extensión lateral como una separación posterior de componentes que incluye la liberación del músculo transverso del abdomen (transversus abdominis muscle release: TAR). Estas técnicas tienen tal grado de dificultad que, por ahora, han sido relegadas a grupos expertos. ${ }^{(3)(21)}$

Daes propone y desarrola la reparación ventral (y algunas hernias lumbares) con cierre endoscópico primario y separación de componentes, con la técnica totalmente extraperitoneal de vista extendida (eTEP). Reporta baja morbilidad, tiempo hospitalario, sin recurrencia herniaria ni nuevas hernias en el sitio de la separación de los componentes. ${ }^{(3)}$

Igor Belyasky ha revolucionado el campo de la reparación laparoscópica de la hernia ventral con su descripción de la reparación extendida totalmente extraperitoneal de las hernias ventrales, incluso complejas, con su técnica eTEP Rives y eTEP TAR. Teóricamente, reúne todas las ventajas del IPOM plus con las ventajas de un abordaje que evita el acceso intraperitoneal y coloca la malla por fuera de la cavidad abdominal, siendo técnicamente muy demandante. ${ }^{(22)(23)}$

La deficiencia de la medicina basada en la evidencia en aportar respuestas definitivas a los problemas del reparo ventral, en parte debido al alto número de variables involucradas, hace que el aprendizaje global no tenga aplicación local. Son la experiencia, la evaluación de los procesos y la mejoría clínica continua las que tienen mayor influencia a nivel local y regional. Existe un gran grupo de pacientes para los que aún no sabemos cuál es la mejor técnica a plantear, pesar de los esfuerzos de los consensos internacionales. ${ }^{(24)}$

Falta también la estandarización de las técnicas quirúrgicas. En gran parte se debe a la rápida adopción de nuevas técnicas, insumos y tecnología, no permitiendo su evaluación adecuada, la comparación de resultados ni establecer la causa exacta de la mejora en los resultados o de una complicación. ${ }^{(3)(25)}$ Así, detalles técnicos de gran jerarquía en toda reparción herniaria, están en estudio y permanente evolución: 1) Como evitar la tensión en la reparación fascial 2) La Malla como puente o refuerzo 3) Fijación invasiva mediante doble corona de puntos o tackers (metálicos o absorbibles) o suturas, 4) Grado de Solapamiento de la malla y cobertura de toda la cicatriz

El reparo laparoscópico de la hernia ventral ha evolucionado significativamente desde sus comienzos, lo que nos permite mejorar la morbilidad y la calidad de vida de nuestros pacientes, cuando se practica en las circunstancias y ambiente adecuados. Su futuro se presenta prometedor en la medida en que se mejore la enseñanza de destrezas, se desarrolle la tecnología que incluye la robótica (con la tendencia natural a que disminuya su costo y complejidad actuales), se refine la utilización de las redes sociales para la educación en cirugía de hernia, se continúe implementando la especialidad en este campo quirúrgico y se encuentren mejores alternativas para la evaluación científica de los resultados obtenidos. ${ }^{(3)}$

\section{INDICACIÓN DE TRATAMIENTO QUIRÚRGICO DE HI}

El paciente debe conocer previamente a iniciar su preparación preoperatoria y consentir la cirugía planteada, que la eventración es una secuela definitiva en su abdomen y que la funcionalidad completa puede no recuperarse a pesar de la cirugía. Esta tiene limitaciones y generará nuevas situaciones fisiopatológicas en su pared abdominal debido a que: la malla es un cuerpo extraño que puede generar dolor e infección, las suturas y tackers generan tensión y dolor, la separación de componentes compromenten la integridad de la pared abdominal, todas las técnicas planteadas para su reparación tiene morbilidad considerable. Además, el pronóstico funcional para los pacientes con HI es incierto.

La selección de pacientes es el aspecto clínico más importante para obtener el máximo rendimiento de una técnica. Actualmente la mejor preparación preoperatoria del paciente y los avances en las técnicas anestésicas y quirúrgicas mini invasivas, han permitido ampliar las indicaciones quirúrgicas.

Considerando un criterio clínico patológico, todas las eventraciones tendrían indicación de tratamiento quirúrgico, ya que su evolución natural es el aumento de tamaño, con pérdida de domicilio y retracción progresiva de los músculos lateralmente, incrementándose tanto la dificultad de reparación como la posibilidad de desarrollar complicaciones. ${ }^{(26)}$

Las eventraciones pequeñas y asintomáticas pueden observarse de forma segura con un riesgo bajo de complicaciones: $2,6 \%$ anual. Se recomienda en pacientes con alto riesgo anestésico quirúrgico. ${ }^{(27)}$

Para una adecuada indicación del tratamiento quirúrgico de las eventraciones debemos tener en cuenta la clasificación, manifestaciones clínicas (disfunciones respiratorias, intestinales o urinarias, dolor), crecimiento evidente de la hernia (puede llegar a establecer "la pérdida del derecho a domicilio"), y complicaciones de las mismas, así como las condiciones generales (comorbilidades, calidad de vida, Incapacidad laboral) del paciente, aunque con frecuencia estos criterios resultan relativos. ${ }^{(26)}$ 
Otros factores a considerar en la indicación de cirugía, son : alteraciones tróficas de la piel con ulceración e incluso exteriorización de las vísceras abdominales, razones estéticas, grandes delantales dermograsos: en estos casos se plantea cirugía plástica conjunta. Las alteraciones en la estabilidad y dinámica de la columna y aparato locomotor, y la respiración paradójica abdominal, se consideran en la indicación quirúrgica. ${ }^{(26)(28)}$

Se vincula habitualmente el riesgo de incarceración o estrangulación como motivo de reparación quirúrgica de la eventración. Aún así el verdadero riesgo de esta complicación en la población general no esta claro. ${ }^{(28)}$

No existe consenso sobre el momento más adecuado para reparar una HI, pero se recomienda dejar pasar un período de 8 a 12 meses desde la cirugía original. Luego de este período las adherencias son más laxas y menos sangrantes, además la cicatriz está en su etapa final de maduración y es improbable que progrese la debilidad o aparezcan orificios alejados originando pseudorecidivas. ${ }^{(29)}$

Existe beneficio en incorporar las preferencias y las expectativas del paciente en relación con el tipo de abordajes (laparoscópico vs abierto), así como la pertinencia y aceptación de la preparación preoperatoria en defectos de gran tamaño. Si el paciente no elimina los factores de riesgo modificables, las tasas de morbilidad y recidiva son altas. ${ }^{(10)}$

Se recomienda individualizar cada caso: estudiar las características de cada hernia y analizar la comorbilidad asociada del paciente. Por un lado debemos tener en cuenta los riesgos de morbilidad y mortalidad operatoria del paciente y, por otro, los riesgos propios de la evolución natural de la eventración.

\section{CONTRAINDICACIONES DE TRATAMIENTO QUIRÚRGICO DE HI}

La decisión de no intervenir una hernia ventral ocurre normalmente cuando el riesgo de complicaciones postoperatorias, derivadas del acto anestésico quirúrgico, es mayor que el derivado de la evolución de la propia eventración.

Actualmente la escala más utilizada para establecer el riesgo anestésico y pronóstico postoperatorio es la escala ASA (American Society of Anesthesiologists). Un valor elevado en la escala ASA, que define al paciente como no operable, SÍ puede considerarse una contraindicación absoluta.

La edad tiene relación directa con las comorbilidades y la mayor posibilidad de complicaciones en los pacientes con HI; sin embargo, per se no representa un impedimento para la ejecución de procedimientos complejos de reconstrucción de la pared abdominal. Se aplicarán las escalas de riesgo perioperatorio utilizadas en la cirugía de la pared abdominal. ${ }^{(10)}$

El riesgo de infección también suponía una causa de contraindicación (riesgo de infección de sitio quirúrgico, sepsis y aumento de recidivas parietales), siendo ahora prevenibles, corregibles o tratables en el perioperatorio. ${ }^{(10)(28)}$

El tamaño del defecto herniario importa fundamentalmente, en pacientes con alto riesgo anestésico-quirúrgico. En hernias de pequeño tamaño poco sintomáticas se plantea hacer solo seguimiento, al igual que en los grandes defectos parietales o con "pérdida de derecho a domicilio" poco sintomáticos, por su alta morbimortalidad quirúrgica. ${ }^{(28)}$

\section{ELECCIÓN DE ABORDAJE ABIERTO O ENDOSCÓPICO}

Las técnicas y el abordaje deben adaptarse al paciente y a las características de la hernia. No existe un abordaje quirúrgico ideal, al no demostrarse diferencias significativas entre ellos en cuanto a tasa de recidivas, dolor posoperatorio ni calidad de vida a largo plazo. Los abordajes miniinvasivos, preferidos siempre que sea posible y seguro, se asocian con menor hospitalización, menos complicaciones parietales y infecciones, en comparación con el abordaje abierto, pero con mayor tiempo operatorio y mayores costos, por lo que la diferencia entre ambos abordajes, es a veces marginal. ${ }^{(30)(31)}$

La evaluación de los factores clínicos y comorbidos implicados ya mencionados (síntomas, urgencia, morfología del orificio herniario, tamaño del defecto, calidad del tejido conectivo, tabaquismo, diabetes mellitus, obesidad y edad), orientarán la elección del abordaje abierto o laparoscópico. ${ }^{(32)}$

Hernia con indicación ideal para ser reparada por vía laparoscópica y que sería el caso ideal para comenzar con el desarrollo de técnica: ${ }^{(10)(21)(33)(34)}$

- Paciente sano, de edad media, moderadamente obeso, sin lesiones de piel. 
- Etiología: hernia primaria o una recidiva de una hernia primaria en la que no se ha colocado malla, ya que el número de adherencias será escaso.

- Localización: umbilical o supraperiumbilical, incisión pararrectal (menos dificultades de disección y fijación de la malla), al menos $5 \mathrm{~cm}$ alejadas del pubis y xifoides.

- Tamaño del defecto: no mayor de $5 \mathrm{~cm}$ en diámetro transversal y que precise una malla de tamaño inferior a $15 \mathrm{x}$ $20 \mathrm{~cm}$, más fácil de manejar y fijar. En HI de 5-10 cm, tanto el abordaje como la elección de la malla varían según el escenario clínico y la preferencia del cirujano, siendo el miniinvasivo el de preferencia actual. Las $\mathrm{HI}>10 \mathrm{~cm}$ o con pérdida de domicilio, precisan técnicas avanzadas para lograr el cierre del defecto fascial, preferentemente se indica el abordaje abierto.
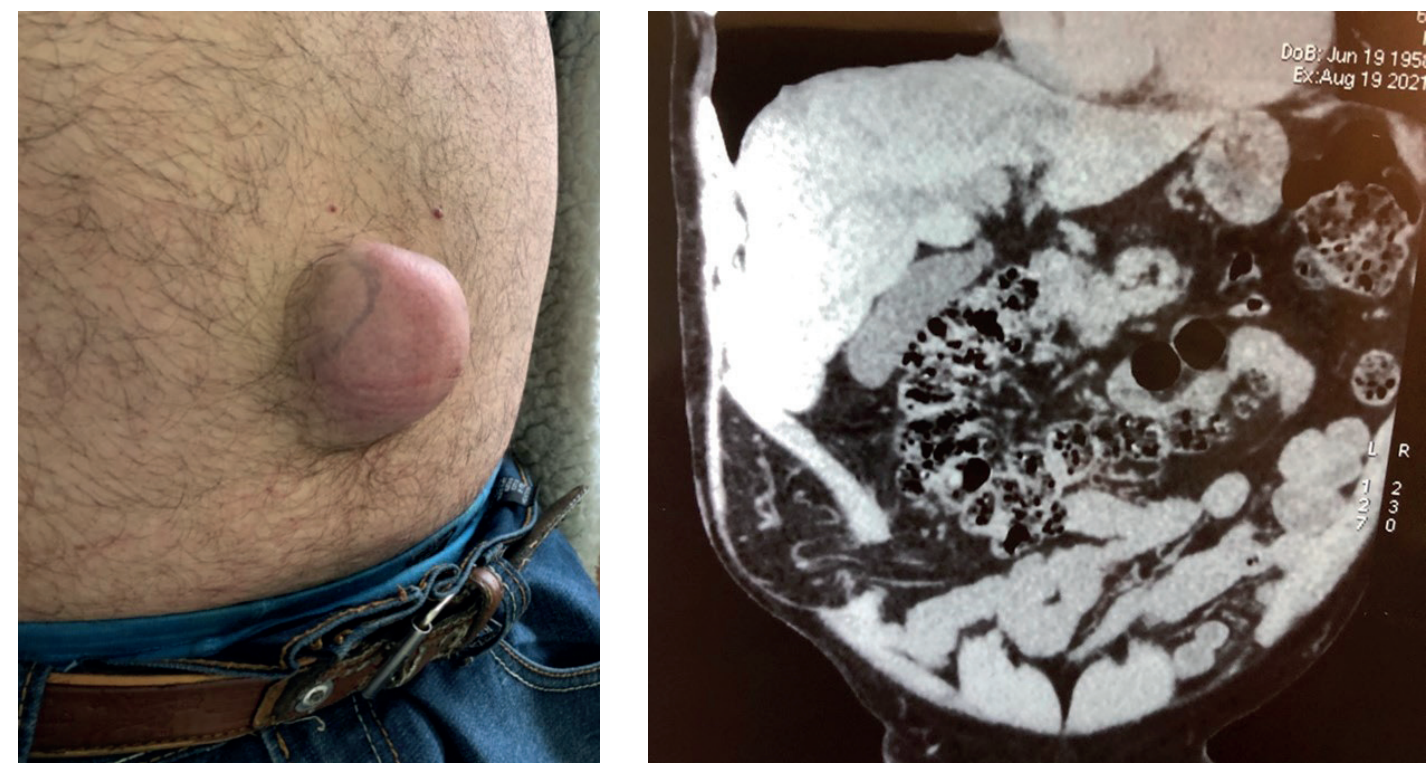

Ejemplos de casos favorables: HI umbilical y lateral chicas

- Características del saco: los unisaculares, sin contenido intestinal y más chicos serán más fáciles de resecar y presentarán menos seroma. Las hernias encarceladas, en situación de urgencias deberán ser operadas solo por expertos.

- Patologías asociadas: que no requiera otro procedimiento asociado ni tenga diástasis de rectos.

Hernia con indicación dudosa para ser reparada por vía laparoscópica, debe ser individualizada. Su indicación será discutida con el paciente:

- Cirugía concomitante potencialmente contaminada: aquí la implantación de mallas podría resultar controvertida; aunque la sugerencia actual es intentar la plastia parietal simultánea en colecistectomías y resecciones intestinales.

- Pacientes obesos mórbidos: la reparación laparoscópica minimiza la tasa de complicaciones y de recurrencia a largo plazo. Pueden ser necesarios pasos técnicos adicionales para disminuir recidivas (mayor fijación de la malla, más superposición, cierre con sutura del defecto). En la obesidad mórbida, si la HI puede repararse por métodos endoscópicos, puede considerarse la realización de procedimientos de cirugía bariátrica en la misma intervención; de lo contrario, puede considerarse un tratamiento en etapas con procedimientos para pérdida de peso (incluyendo cirugía bariátrica) en primer lugar, y reparación del defecto, con eventual dermolipectomía, en un segundo tiempo.

- Pacientes cirróticos: si está descompensada, con hipertensión portal o ascitis, se evitará la malla intraperitoneal.

Hernia técnicamente compleja para ser reparada por vía laparoscópica, debe ser adecuada a la experiencia del equipo quirúrgico y a cada paciente:

- Según la etiología del proceso previo: cuando se prevee un mayor número de adherencias que dificultan el abordaje laparoscópico, y cuya adhesiolisis requiere una gran experiencia. Se incluyen pacientes que tuvieron: peritonitis generalizada, fístulas intestinales, radioterapia, diálisis peritoneal, cirugía oncológica o multioperados.

- Según el tipo de reparación previa: la presencia de una eventración multirrecidivada supone una indicación adecuada para el abordaje laparoscópico en grupos experientes, siendo también compleja por vía abierta. En una recidiva de una EL, igualmente existirán adherencias aunque habitualmente laxas a la parte central de la malla y más firmes en relación a los bordes y a las suturas helicoidales o transfasciales utilizadas.

- Según su tamaño: compleja debido al difícil cierre fascial, al tamaño de la malla que precisa, siendo necesario en la mayoría de los casos un abordaje bilateral para su correcto anclaje y en ocasiones separación de componentes. 
- Según la localización: entre ellas se encuentran:

- Suprapúbicas, Subxifoideas, subcostales y postesternotomía: el anclaje en estructuras óseas es difícil y peligrosa, hay atrofia y retracción muscular.

- Lumbares: conlleva la movilización del colon para poder colocar la malla correctamente.

- Infraumbilicales: mayor complejidad por adherencias viscerales

- Paraestomales: son hernias complejas de reparar por vía abierta y por vía laparoscópica, tanto por la liberación de las adherencias, sin dañar el colon y su meso y comprometer su vascularización, como por la forma específica de colocación de la malla.

- Según el contenido del saco: las hernias irreductibles con saco con contenido intestinal, pueden resultar complejas, especialmente si existen asas comprometidas.

- Según su presentación: las hernias atendidas de forma urgente suponen un reto para los cirujanos, y tanto la incarceración aguda como la estrangulación deben ser tratadas por cirujanos con mucha experiencia y con gran humildad para convertir a cirugía abierta, especialmente en los casos de imposibilidad técnica o de necrosis intestinal.

\section{CONTRAINDICACIONES DE LA EVENTROPLASTIA LAPAROSCÓPICA $(10,33,34)$}

En principio, toda eventración en un paciente sano y estable podría ser reparada por laparoscopia si se tiene experiencia en la técnica, excepto en los casos considerados como contraindicación formal.

Las Contraindicaciones formales son: (a) las derivadas de la anestesia; (b) oclusión intestinal evolucionada o hernias estranguladas con sospecha de necrosis intestinal o perforación de asa, aunque en estos casos la realización de una laparoscopia exploradora previa puede ayudar a determinar el estado del asa y determinar la actitud a seguir; (c) las mujeres embarazadas o con embarazo próximo planificado; (d) antecedente cercano o infección intraabdominal actual, riesgo de sepsis; (e) en diálisis peritoneal; (f) cirróticos con hipertensión portal evolucionada; (g) pacientes muy ancianos o debilitados; (h) con poca expectativa de vida; (i) con múltiples enfermedades crónicas asociadas (enfermedad pulmonar), (j) las eventraciones de gran tamaño y/o «con pérdida del derecho a domicilio», y (k) necesidad de cirugía oncológica mayor simultánea.
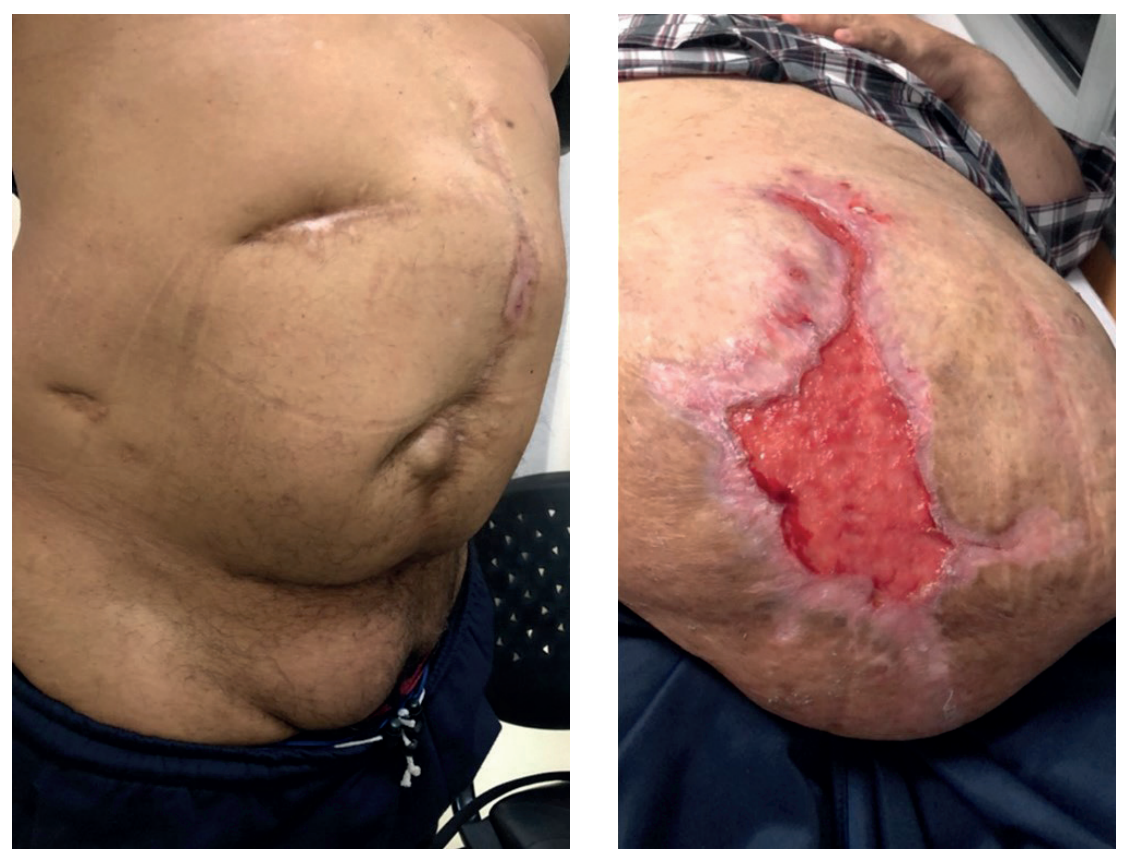

Contraindicaciones relativas de EL: Eventracion multirecidivada con varios defectos. Pérdida de dominio, delantal adiposo y cierre por segunda en curso

Contraindicaciones relativas o indicaciones inadecuadas son: (a) los pacientes con lesiones cutáneas asociadas celulitis, úlceras, necrosis, fístulas u onfalitis; (b) defecto estético importante que precise la extirpación de cicatrices previas o de piel redundante; (c) eventraciones infraumbilicales complejas; (d) los que precisen una dermolipectomia para reducir volumen abdominal; (e) los defectos de tamaño superior a $10 \mathrm{~cm}$ por su alto riesgo de recurrencia, (f) el riesgo alto de adherencias por múltiples cirugías intraabdominales por procesos inflamatorios; $(\mathrm{g})$ eventraciones multirrecidivadas y/o multisaculares que suelen precisar movilizaciones viscerales y liberación parietal extensa y $(h)$ pacientes obesos mórbidos 


\section{MBE (CBE) EN EVENTROPLASTIA LAPAROSCÓPICA $(25,31)$}

La Cirugía Basada en la Evidencia (CBE) es en la actualidad una herramienta muy útil para la práctica de la especialidad. Sin embargo, la competencia y el juicio que el cirujano adquiere a través de la experiencia y la práctica clínica nunca debe pasar a segundo plano. Para la cirugía de la HI, en la actualidad no hay una contestación basada en la evidencia que ofrezca una única solución. Como resúmen de los puntos estudiados, destacamos:

Se han de utilizar mallas para la reparación de la HI.

Las HI deben operarse (salvo excepciones), y el debate respecto a si utilizar un abordaje abierto o laparoscópico sigue abierto. Algunos criterios serán afines a la definición de CBE (contexto clínico, nivel de experiencia con las diferentes técnicas, preferencias del paciente tras la información del estado de los diferentes abordajes) y otros no (tipo de hospital, recursos disponibles).

En términos de recurrencia, no es posible recomendar un procedimiento estándar para todos los pacientes, y sí ajustar cada procedimiento bien estandarizado a cada paciente individual.

El desarrollo de las técnicas de EL, así como las habilidades necesarias para llevarlas a cabo, debe de realizarse en el contexto de unidades especializadas en cirugía de la pared abdominal y cirugía laparoscópica de avanzada.

\section{ESTUDIOS EVENTROPLASTIA LAPAROSCÓPICA VS ABIERTA}

Analizamos brevemente algunos estudios actuales de tipo metanálisis y revisiones sistemáticas, que intentan comparar las indicaciones y/o beneficios entre la eventroplastia laparoscópica y la vía abierta.

Sauerland, ${ }^{(36)}$ analiza diez ECAs con un número total de 880 pacientes. La tasa de recurrencia no difirió entre la cirugía laparoscópica y la cirugía abierta (seguimiento inferior a dos años en 5 ensayos). El tiempo operatorio tuvo datos demasiado heterogéneos como para ser agrupados. El riesgo de enterotomía intraoperatoria fue mayor en la vía laparoscópica (siete casos con lesión intestinal: 5 versus 2). El resultado más claro y consistente fue que la cirugía laparoscópica redujo el riesgo de infección de la herida. La cirugía laparoscópica significativamente la estancia hospitalaria en seis de nueve ensayos, pero los datos fueron heterogéneos. No fue posible detectar diferencias en la intensidad del dolor, tanto en la evaluación a corto plazo como a largo plazo. La reparación laparoscópica dio lugar a mayores costos hospitalarios. Los resultados a corto plazo de la reparación laparoscópica en la hernia ventral son alentadores. A pesar de los riesgos de enterotomía, la técnica es segura. Se necesita seguimiento a largo plazo para dilucidar si la reparación laparoscópica de la hernia ventral/incisional es eficaz.

Awaiz y cols.. ${ }^{(37)}$ analizan 6 estudios prospectivos randomizados y controlados (751 pacientes), con abordaje laparoscópico o abierto para tratamiento de HI, publicados entre 1993-2013. Encontraron: mayor lesion intestinal en EL; similares resultados en diámetro herniario, tiempo operatorio, complicaciones alejadas, infecciones de herida, al igual que hematomas y seromas. Tampoco demostraron diferencias significativas en tasa de reoperaciones, hospitalización, retorno al trabajo, tasa de recurrencias y neuralgias. Concluyen en la necesidad de estudios con criterios de inclusión y exclusión más estrictos y estandarización de las técnicas quirúrgicas empleadas.

Asencio, ${ }^{(38)}$ propone seguimiento a 10 años de 85 pacientes randomizados en EL vs EA. Las tasas globales fueron: recurrencia $(21 \%)$, reoperaciones(11.92\%), muerte $(24 \%)$, complicaciones vinculadas a la malla $(6.15 \%)$, y score de calidad de vida, sin encontrar diferencias significativas entre ambos brazos. Concluyen que la EL es tan segura y eficaz como la EA.

Fernández Lobato, ${ }^{(39)}$ en un estudio prospectivo de cohortes sobre 140 pacientes consecutivos con hernias ventrales, evalúa el costo de ambas técnicas. La vía laparoscópica presentó menor estancia media ( $p<0,001)$, menor morbilidad postoperatoria y complicaciones $(\mathrm{p}<0,001)$ y reducción en la tasa de reingresos. El costo del material laparoscópico fue más alto, aunque el costo total del procedimiento por paciente fue menor que la reparación abierta. Concluye que la reparación laparoscópica de las HV aporta beneficios para los pacientes con un coste final del procedimiento menor: la EL es una técnica eficiente con mejor costo-efectividad.

Bernal ${ }^{(40)}$ en estudio de cohortes, comparó los resultados para reparar Hernia Ventral: IPOM (sin cierre fascial, sobrepasa $5 \mathrm{~cm}$, fijacion mecanica)(EL) y abierto tipo Rives-Stoppa (EA). Resultados: Promedio de tiempo quirúrgico: 60 (EL) vs 80 minutos (EA). Tamaño del defecto fue de 6-10 cm, 10-15 cm y mayor de $15 \mathrm{~cm}$ en el $79 \%$ y $74 \%$, en el $18 \%$ y $24 \%$ y $2 \%$ y $1 \%$ para los grupos A y B. La estancia hospitalaria predio fue de 24 horas en el $60 \%$ de EL y de 
5 a 7 días en el 60\% de 1(EA). Se utilizó analgésicos por 48 horas y 7 días para los grupos EL y EA y B. Hubo en EL seroma (8.3\%) y dolor persistente (4.1\%) vs EA: seroma (9.2\%), hematoma (3.7\%), infección de herida (1.8\%) y dolor persistente (1.8\%). Hubo dos recidivas en cada grupo. Conclusiones: La reparación laparoscópica de hernia ventral es un abordaje seguro y eficaz y puede llevarse a cabo con una morbilidad e índice de recurrencias similar a la cirugía abierta con las ventajas de una cirugía mínimamente invasiva.

Henriksen, ${ }^{(41)}$ compara la evolucion de la EL vs EA, usando la información de Danish Hernia Database and the National Patient Registry. Analiza 3090 (57.5 \%) EL y 2288 (42.5\%) EA. El cierre fascial se realizó en 865 de las 3090 (28.0 \%) EL. La media de seguimiento fue de 4 años. La tasa de readmisión fue 16\% para EL y $19.3 \%$ para EA. Las reoperaciones por complicaciones fueron $7 \% \mathrm{EL}$ vs $12.5 \% \mathrm{EA}$ (diferencia significativa). Las reoperaciones por complicaciones intestinales fueron $0.6 \% \mathrm{EL}$ vs $0.3 \% \mathrm{EA}$ (diferencia significativa). Las reoperaciones por recurrencias fueron menores en EL en defectos entre 2-6cm (diferencia significativa) A pesar de que la EL reduce las complicaciones parietales de la EA, tiene los problemas de la malla intrapeitoneal y las complicaciones viscerales.

Aly y cols. ${ }^{(42)}$ analizó 49.349 pacientes mayores de 65 años sometidos a plasias por hernias ventrales electivas según datos obtenidos de la base de datos del American College of Surgeons National Surgical Quality Improvement Project (NSQIP). Se compararon según scores creados para evitar sezgo según datos demográficos, comorbilidades, tipo de defecto y cirugía. Se estudiaron los resultados a 30 días. Analizaron 35,079 (71.1\%) y 14,270 (28.9\%) pacientes operados por cirugía abierta $(\mathrm{CA})$ o laparoscópica $(\mathrm{CL})$ respectivamente. La CL presenta menor morbilidad general (5.9\% vs $9.1 \%)$, menos infecciones parietales (1.1\% vs $3.5 \%$ ) y menos reoperaciones $(1.7 \%$ vs $2.1 \%)$. No hubo diferencias en otras variables evolutivas ni mortalidad. Concluyen que la CL es segura y con baja morbilidad en adultos mayores.

Hoffmann y cols ${ }^{(43)}$ estudiaron las reurrencias luego de plastias de hernias incisionales, considerada con una incidencia del 25\% y como un factor pronóstico aislado desfavorable en la clasificación de la European Hernia Society (EHS). Realiza un estudio de cohorte analizando factores pronósticos para la evolución de la enfermadad, según el Multicenter Internet-based Herniamed registry, entre 2009-2018, enrolando 4015 pacientes de 712 centros. No encuentra diferencia significativa en la morbilidad entre IPOM y cirugía abierta, si bien hubo mayor índice de reoperaciones en IPOM.

Asti y cols, ${ }^{(44)}$ en estudio de cohorte de un centro con 124 pacientes, comparó la calidad de vida a un año de cirugías electivas abiertas y laparoscópicas de HI, no recidivadas; no encontraron diferencias entre ambos abordajes

Olmi y cols ${ }^{(45)}$ conducen un estudio multicéntrico retrospectivo observacional que incluye 4 centros especializados en tratamiento laparoscópico en patología parietal, y enrolaron 1777 pacientes operados de hernia ventral primaria e incisional por via laparoscópica (IPOM). Usaron la misma malla bilaminar y varios sistemas de fijación. Concluyen que es una técnica segura y efectiva. Los pasos cruciales para los buenos resulatdos son el solapamiento mayor a $4 \mathrm{~cm}$, el uso de fijación invasiva no reabsorbibles. Las hernias laterales y grandes tienen mayor tasa de recurrencias y hospitalización prolongada. Los tackers no absorbibles tuvieron mayor dolor postoperatorio pero menos recurrencias (3\% vs $11 \%$ ).

Köckerling F. y cols. ${ }^{(46)}$ analiza 61.627 HI operadas de coordinación, incluídas en la base de datos Herniamed, que reúne 737 centros de Alemania, Austria y Suiza, entre 2010-2019. Es un estudio prospectivo, no randomizado. La técnicas de Rives Stoppa abierta fue la más frecuentemente utilizada, y con cifras en ascenso en ese período: $32.1 \%$ en 2013 a 41.4\% ( p < 0.001) en 2019 . En el mismo período la variación descendente del IPOM laparoscópico fue del $33.8 \%$ al 21.0\% ( $\mathrm{p}<0.001)$. Las técnicas con separación de componentes varió del 1.9\% en 2013 vs. 3.1\% en 2019; p < 0.001). A partir del 2015, se introducen los abordajes eTEP y EMILOS con cifras en claro aumento (4.5\% en 2013 vs. 10.0\% en 2019: $\mathrm{v}<0.001$ ). El análisis del tamaño sęún la clasificación de la EHS mostró un aumento de las HI

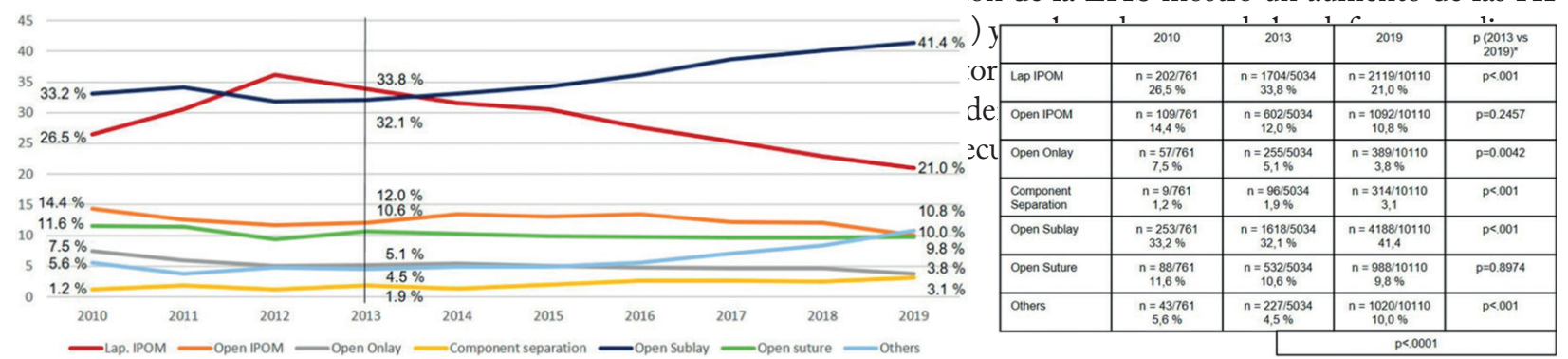




\section{BIBLIOGRAFIA}

1) G. L. Adrales GL. Coker AM. Society of American Gastrointestinal and Endoscopic Surgeons (SAGES) 2019; 2:11-22 S. S. Davis Jr. et al. (eds.), The SAGES Manual of Hernia Surgery, https://doi.org/10.1007/978-3-31978411-3_2

2) Heniford BT, Park A, Ramshaw BJ, Voeller G. Laparoscopic ventral and incisional hernia repair in 407 patients. J Am Coll Surg. 2000;190(6):645-50.

3) Daes J. Evolución de la reparación laparoscópica de las hernias ventrales y del sitio de la incisión. Rev hispanoam hernia. 2016;4(3):83-85 2255-2677

4) de Oliveira FM, Cavazzola LT, Weltz AS, Belyansky I, Ventral Abdominal Hernia Repair: MIS Extraperitoneal Repair Techniques: eTEP Rives, MILOS/EMILOS, and Onlay MIS Repair Endoscopic Surgeons (SAGES) 2019; 20:271-290 S. S. Davis Jr. et al. (eds.), The SAGES Manual of Hernia Surgery, https://doi.org/10.1007/9783-319-78411-3_20

5) Savitch S, Shah P. Closing the gap between the laparoscopic and open approaches to abdominal wall hernia repair: A trend and outcomes analysis of the ACS-NSQIP database. Surg Endosc. doi 10.1007/s00464-015-4650-7.

6) Pereira JA, Lopez-Cano M,Hernandez-Granados P y Feliu X, (grupo EVEREG) Resultados iniciales del Registro Español de Hernia Incisional Cir Esp. 2016;94(10):595-602

7) Moreno Egea A. Reparación laparoscópica de la eventración de línea media (42) 521-532 En Eventraciones y Otras hernias de pared y cavidad abdominal Fernando Carbonell Tatay Alfredo Moreno Egea Valencia, 2012

8) Lomanto D, Iyer SG, Shabbir A, Cheah WK. Laparoscopic versus open ventral hernia mesh repair: A prospective study. Surg Endosc. 2006;20:1030-5.

9) Olmi S, Scaini A, Cesana GC, Erba L, Croce E. Laparoscopic versus open incisional hernia repair: An open randomized controlled study Surg Endosc. 2007;21:555-9

10) Roca Domínguez B, Gutiérrez Ferreras AI, Mayagoitia JC. Guía para el manejo de la hernia ventral e incisional medial. Rev Hispanoam Hernia. 2021;9(2):80-87

11) LeBlancKA,BoothWV.Laparoscopicrepairofincisionalabdominalherniasusingexpanded polytetrafluoroethylene: Preliminary findings. Surg Laparosc Endosc. 1993;3:39-41.

12) Heniford BT, Park A, Ramshaw BJ, Voeller G. Laparoscopic repair of ventral hernias: Nine years' experience with 850 consecutive hernias. Ann Surg. 2003;238:391-400

13) Heniford BT, Park A, Ramshaw B, et al. Laparoscopic ventral hernia repair in 407 patients. J Am Coll Surg 2000;190:645-650.

14) LeBlanc KA, Booth WV, Whitaker JM, et al. Laparoscopic incisional and ventral herniorraphy in 100 patients. Am J Surg 2000;180:193-197.

15) Franklin ME Jr, González JJ Jr, Glass JL, Manjarrez A. Laparoscopic ventral and incisional hernia repair: An 11year experience. Hernia. 2004;8:23-7.

16) Daes J. Endoscopic subcutaneous approach to component separation.J Am Coll Surg. 2014;218:e1-4.

17) Hamby PM, Hernández MA, FranklinJr ME, Bridging Versus Closing the Defect During MIS Ventral Hernia Repair: Pros and Cons Society of American Gastrointestinal and Endoscopic Surgeons (SAGES) 2019; 13: 173-182 S. S. Davis Jr. et al. (eds.), The SAGES Manual of Hernia Surgery, https://doi.org/10.1007/978-3-31978411-3_13

18) Clapp ML, Hicks SC, Awad SS, Liang MK. Trans-cutaneous closure of central defects (TCCD) in laparoscopic ventral hernia repairs (LVHR). World J Surg. 2013;37:42-51.

19) Nguyen DH, Nguyen MT, Askenasy EP, Kao LS, Liang MK. Primary fascial closure with laparoscopic ventral hernia repair: Systematic review. World J Surg. 2014;38:3097-104.

20) Gómez-Menchero J, Guadalajara Jurado JF, Suárez Grau JM, Bellido Luque JA, García Moreno JL, Alarcón del Agua S, Morales-Conde S, Laparoscopic intracorporeal rectus aponeuroplasty (LIRA technique): a step forward in minimally invasive abdominal wall reconstruction for ventral hernia repair (LVHR) Surgical Endoscopy 2018; 32:3502-3508 https://doi.org/10.1007/s00464-018-6070

21) González LG, Lora A, Varela E, Vergara G, Vega Peña V, Ayala JC, Martínez JD, Hanssen A, Gómez JP, Ruiz JP. Guía para el tratamiento laparoscópico de la hernia ventral e incisional. Rev Hispanoam Hernia. 2021;9(2):105117

22) Belyansky I, Radu VG, Balasubra-manian R, Zahiri HR, Weltz AS. A novel approach using the enhancedview totally extraperitoneal (eTEP) technique for laparoscopic retromuscular hernia repair. Surg Endosc. 2018;32(3):1525-32. Houston, Texas.

23) Belyansky I, Zahiri HR, Park A. Laparoscopic transversus abdominis release, a novel minimally invasive approach to complex abdominal wall reconstruction. Surg Innov. 2016;23(2):134-41.

24) Bittner R, Bingener-Casey J, Dietz U, Fabian M, Ferzli GS, Fortelny RH, et al. International Endohernia Society (IEHS) guidelines for laparoscopic treatment of ventral and incisional abdominal wall hernias (International Endohernia Society (IEHS). Surg Endosc. 2014;28:2-29. 
25) Daes J. Standardization in hernia surgery. Hernia. 2015; 19:1039-40

26) González FJ, Pellón Daben R, Revuelta Álvarez S, Diagnóstico y métodos de imagen en las hernias ventrales (12)143-153 Guías Clínicas de la Asociación Española de Cirujanos Cirugía de la Pared Abdominal 2a Edición 2013

27) Liang MK, Holihan JL, Itani K, et al. Ventral Hernia Management Expert Consensus Guided by systematic Review. Ann Surg. 2017;265(1):80-9.

28) Utrera A, Perea MJ, Martín R, Indicaciones y contraindicaciones de cirugía en las hernias ventrales (13) 155-160 Guías Clínicas de la Asociación Española de Cirujanos Cirugía de la Pared Abdominal 2a Edición 2013

29) Brandi CD Hernias incisionales o eventraciones. En Tratamiento de los Defectos de la Pared Abdominal Relato Oficial CAC (2). 62-105. Buenos Aires Octubre 2009

30) Zhang Y, Zhou H, Chai Y, Cao C, Jin K, Hu Z. Laparoscopic versus open incisional and ventral hernia repair: a systematic review and meta-analysis. World J Surg. 2014;38(9):2233-40.

31) Al Chalabi $\mathrm{H}$ et a. A systematic review of laparoscopic versus open abdominal incisional hernia repair, with metaanalysis of randomized controlled trials. Int J Surg2015, 20:65-74

32) Barreiro Morandeira F, Fernández Pérez JA, Blanco Freire MN, Clasificaciones de técnicas quirúrgicas para el tratamiento de hernias ventrales (15)169-175 Guías Clínicas de la Asociación Española de Cirujanos Cirugía de la Pared Abdominal 2a Edición 2013

33) Socas Macías M, Barranco Moreno A, Morales- Conde S, Indicaciones y contraindicaciones del abordaje laparoscópico (19) 209-216 Guías Clínicas de la Asociación Española de Cirujanos Cirugía de la Pared Abdominal 2a Edición 2013

34) Morales Conde S, Barranco Moreno A, Socas Macías M, Cirugía laparoscópica para el tratamiento de las hernias ventrales (20) 217-228 Guías Clínicas de la Asociación Española de Cirujanos Cirugía de la Pared Abdominal 2a Edición 2013

35) López-Cano M. Cirugía basada en la evidencia y hernia incisional Rev Hispanoam Hernia 2013;1(1):18-26

36) Sauerland S, Walgenbach M, Habermalz B, Seiler CM, Miserez M, Técnicas de cirugía laparoscópica versus técnicas abiertas para la reparación de la hernia ventral o incisional Cochrane Database of Systematic Reviews Review, Intervention Version. published: 16March2011 https://doi.org/10.1002/ 14651858.CD007781.pub2

37) Awaiz A, Rahman F, Hossain MB, Yunus RM, Khan S, Memon B, Memon MA Meta-analysis and systematic review of laparoscopic versus open mesh repair for elective incisional hernia Hernia. 2015 Jun;19(3):449-63. doi: 10.1007/s10029-015-1351-z.

38) Asencio F, Carbó J, Ramon Ferri J, et al. Laparoscopic Versus Open Incisional Hernia Repair: Long-Term Followup Results of a Randomized Clinical Trial. World J Surg https://doi.org/10.1007/s 00268-021-06164-7

39) Fernandez Lobato R, Ruiz de Adana Belbel JC, Angulo Morales F, et al. Estudio de coste-beneficio comparando la reparación de la hernia ventral abierta y laparoscópica Cir esp. 2014 ;92(8):553-560

40) Bernal Gómez R, Sagüi de la Fuente L, Olivares Ontiveros O, et al. Hernia ventral: abordaje laparoscópico vs abierto Cir Gen. 2014;3(2):68-75

41) Henriksen NA, Friis-Andersen H, Jorgensen LN and Helgstrand F, On behalf of the Danish Hernia Database Open versus laparoscopic incisional hernia repair: nationwide database study BJS Open, 2021, 5(1), zraa010 DOI: 10.1093/bjsopen/zraa010

42) Aly S.W. de Geus WL. Carter OD. Hess TJ. Tseng JF Pernar LI Laparoscopic versus open ventral hernia repair in the elderly: a propensity score-matched analysis Hernia https://doi.org/10.1007/s10029-020-02243-1 Accepted: 27 May 2020

43) Hoffmann H. Köckerling F. Adolf D. Mayer F. Weyhe DW. Reinpold W. Fortelny R . Kirchhoff P Analysis of 4,015 recurrent incisional hernia repairs from the Herniamed registry: risk factors and outcomes Hernia https:// doi.org/10.1007/s10029-020-02263 Accepted: 9 July 2020

44) Asti E. Sironi A. Lovece A. Bonitta G.Bonavina L. Open Versus Laparoscopic Management of Incisional Abdominal Hernia: Cohort Study Comparing Quality of Life Outcomes Journal of Laparoendoscopic \& Advanced Surgical Techniques 2016;26 (4) DOI: 10.1089/lap.2016.0060

45) Olmi S, Millo P, Piccoli M, et al. Laparoscopic Treatment of Incisional and Ventral Hernia JSLS, Research Article 2021;(25):2 e2021.00007 DOI: 10.4293/JSLS.2021.00007 2021 by SLS, Society of Laparoscopic \& Robotic Surgeons.

46) Köckerling F. Hoffmann H. Mayer F. Zarras K. Reinpold W. Fortelny R. et al. What are the trends in incisional hernia repair? Real-world data over 10 years from the Herniamed registry Hernia (2021) 25:255-265 https://doi. org/10.1007/s10029-020-02319-y 


\section{TRATAMIENTO LAPAROSCÓPICO DE LA HERNIA INCISIONAL}

\section{Dr. Gonzalo Estapé GENERALIDADES Y CRITERIOS DIAGNÓSTICOS}

\section{Definiciones}

Si bien este Relato está dirigido a criterios terapéuticos de las eventraciones abdominales y específicamente a su tratamiento por abordajes minimamente invasivos, realizamos un breve análisis de los criterios patogénicos y diagnósticos, sobre los que basamos la terapéutica.

Los términos que tomamos como sinónimos de eventración, que varían según la procedencia de las publicaciones, son: hernia traumática, hernia postoperatoria, hernia ventral secundaria, hernia incisional (HI), laparocele. ${ }^{(1)}$ Nosotros utilizaremos solo e indistintamente los términos eventración y hernia incisional.

La hernia incisional o eventración se define como un defecto en la pared abdominal, medial o lateral, con o sin protusión, en el área de una cicatriz operatoria, perceptible o palpable mediante un examen clínico o visible por estudios de imágen.

Hay diferencias marcadas en criterios diagnósticos y terapéuticos entre una hernia ventral primaria respecto a una HI y recurrente, por lo que se analizan en capítulos separados.

Estrictamente, el término eventración implicaría la cicatrización previa de la herida quirúrgica, por lo que algunos autores excluyen a la evisceración como etapa evolutiva precoz de la eventración. La evisceración posterior a una laparotomía tiene una incidencia del $2.5-3 \%$, con una mortalidad de hasta el $45 \%$ y una morbilidad del $75 \%{ }^{(1)(2)}$

\section{Consideraciones generales}

La alta incidencia de las HI, las convierte en un importante problema de salud pública en todo el mundo. Se considera que en un hospital general, entre 5-7\% de la cirugías, corresponden al tratamiento de hernias incisionales. ${ }^{(1)}$

La hernia incisional ocurre en un $12-20 \%$ de las laparotomías, ${ }^{(2)}$ en el 25-40\% en caso de que exista infección de la herida quirúrgica y puede llegar al $50 \%$ en casos de cirugía urgente o grupos de alto riesgo.

En los últimos 30 años, con el gran desarrollo de los procedimientos mininvasivios, laparoscópicos y endoscópicos en todas las especialidades quirúrgicas que abordan la cavidad abdominal, sumado a la profilaxis de infecciones parietales, principal factor predisponente de la hernia incisional, la incidencia de esta disminuyó sensiblemente, y cuando suceden, son de menor tamaño, lo que permite reparaciones más simples y por abordajes también mini invasivos. Aquí es que surgen y se desarrollan los procedimientos laparo endoscópicos (mini invasivos) para tratar las hernias incisionales de la pared abdominal.

\section{Clasificaciones}

Ya fue analizada en detalle previamente en este Relato, por lo que solo jerarquizaremos la importancia clínica y terapéutica de cada tipo de eventración.

Usamos criterios clínicos y imagenológicos para clasificar cada eventración, basados en la localización del defecto, su tamaño y si es o no una recurrencia. Seguiremos la clasificación propuesta por la Sociedad Europea de la Hernia, por ser la más empleada en la actualidad, permitiendo unificar criterios diagnósticos, terapéutucos y evolutivos, con el objetivo de lograr el tratamiento ideal de la patología. ${ }^{(3)(4)}$

\section{Localización}

El abdomen se divide en región medial y lateral.

- Medial (80\% de las eventraciones). Localizada entre los márgenes laterales de los músculos rectos del abdomen, y entre el xifoides y el pubis.

Las hernias incisionales que abarcan más de una zona, se clasificarían en función de la complejidad, siendo de mayor a menor. 
Las hernias con múltiples defectos en una única incisión se consideran una única hernia, mientras que las originadas a partir de varias incisiones, se clasifican como hernias diferentes.

- Lateral (12\%). Localizada entre los márgenes laterales de los músculos rectos del abdomen y la región lumbar, y entre el margen costal y la región inguinal.

\section{Tamaño}

- Ancho: máxima distancia en cm entre los márgenes laterales del defecto. En los casos de múltiples defectos, se toma el margen del defecto más lateral a cada lado. Por la jerarquía terapéutica, con este parámetro se clasifican las eventraciones: tomando la ancho como medida: W1: cuando $<4 \mathrm{~cm}$. - W2: cuando $4-10 \mathrm{~cm}$. - W3: cuando $>10 \mathrm{~cm}$.

- Longitud: máxima distancia vertical en cm entre los márgenes craneales y caudales del defecto herniario. En los casos de múltiples defectos herniarios, se toma como referencia el margen más craneal o caudal del defecto más craneal o caudal, respectivamente.

\section{Reparaciones}

Se considera si se han realizado intentos de reparación previa de las hernias incisionales, con independencia del número de procedimientos realizados.

\begin{tabular}{|c|c|c|c|c|}
\hline \multicolumn{5}{|l|}{$\begin{array}{l}\text { EHS } \\
\text { Incisional hernia classification }\end{array}$} \\
\hline \multirow{5}{*}{ Midline } & Subxiphoidal & \multicolumn{2}{|c|}{ M1 } & \\
\hline & Epigastric & \multicolumn{2}{|c|}{ M2 } & \\
\hline & Umbilical & \multicolumn{2}{|c|}{ M3 } & \\
\hline & Infraumbilical & \multicolumn{2}{|c|}{ M4 } & \\
\hline & Suprapubic & \multicolumn{2}{|c|}{ M5 } & \\
\hline Recurrent incisional hernia? & Yes & 0 & No & 0 \\
\hline Length: & \multicolumn{2}{|l|}{ Width: } & $\mathrm{cm}$ & \\
\hline \multirow{2}{*}{ Tamaño } & W1 & \multicolumn{2}{|c|}{ W2 } & W3 \\
\hline & $<4 \mathrm{~cm} \mathrm{O}$ & \multicolumn{2}{|c|}{$\geq 4-10 \mathrm{~cm} \mathrm{O}$} & $\geq 10 \mathrm{~cm} \mathrm{O}$ \\
\hline
\end{tabular}

Esquema de localización de las hernias de acuerdo con la EHS. ${ }^{(3)}$

\section{¿EXISTE ALGUNA CLASIFICACIÓN PARA LOS PACIENTES SUSCEPTIBLES DE LAPAROSCOPIA?}

Petro y cols. describieron una clasificación por etapas en la que se involucran el ancho (en $\mathrm{cm}$ ) de la eventración y la clasificación de las heridas del Centro para el Control de Enfermedades (CDC) y establecieron un modelo de estratificación del riesgo para eventos relacionados con la herida quirúrgica y la recurrencia: ${ }^{(5)}$

- Grado I: ancho de la hernia < $10 \mathrm{~cm}$ y limpia (asociada con baja ocurrencia de eventos relacionados con la herida quirúrgica y el riesgo de recurrencia).

- Grado II: ancho de la hernia de $10-20 \mathrm{~cm}$ y limpia o $<10 \mathrm{~cm}$ y contaminada (asociada con un riesgo intermedio de ocurrencia de eventos relacionados con la herida quirúrgica y riesgo de recurrencia).

- Grado III: cualquier hernia con un ancho $>20 \mathrm{~cm}$ o $\geq 10 \mathrm{~cm}$ y contaminada (asociada con un riesgo alta de ocurrencia de eventos relacionados con la herida quirúrgica y riesgo de recurrencia).

\section{ETIOLOGÍA}

Mencionaremos por su jerarquía clínico patológica, las causas y factores predisponentes para la formación de una eventración. Consideramos que la prevención de la misma debe ser un factor primordial a considear en cada cirugía abdominal. El cirujano debe pensar en esta complicación durante el pre, intra y postoperatorio, minimizando el riesgo de que su paciente desarrolle una eventración.

La HI se desarrolla a las pocas semanas de la cirugía, aunque se manifieste en años, debido probablemente a la expansión de una o más hernias pequeñas ocultas. ${ }^{(6)(7)}$ Se ha sugerido que la aparición temprana de las HI estaría relacionada 
con defectos técnicos o infección de la herida, mientras que su formación tardía dependería de fallas en la síntesis del tejido colágeno.

\section{Factores relacionados con el paciente}

Impiden la cicatrización adecuada y afectan a la resistencia del tejido, su manejo adecuado y compensación preoperatorio, influyen en el índice de recidiva:

- Edad y Sexo: a mayor edad, disminuye la cantidad y la calidad de colágeno, se pierde la relación ente colágeno I/III y hay mayor frecuencia de otros factores de riesgo como neoplasias, diabetes. Sexo 3 a 1 a favor del sexo masculino.

- Enfermedades crónicas: diabetes mellitus, insuficiencia renal, hepatopatía, ascitis, tabaquismo y desnutrición.

- Obesidad, factor independiente de gran jerarquía. La HI se produciría por: incremento de la presión intraabdominal, incremento de las infecciones de herida debido al gran panículo adiposo y descenso de la resistencia y calidad de los músculos abdominales.

- Tratamientos sistémicos a largo plazo con esteroides, inmunosupresores, citostáticos (hay que postergar su uso por lo menos hasta dos semanas después de la intervención quirúrgica). Irradiación regional.

Las complicaciones postoperatorias son un factor determinante de la recurencia post EL. Siempre que sea posible, la preparación preoperatoria adecuada, permitirá romper el círculo vicioso de reparación herniaria - complicaciones recidiva herniaria. ${ }^{(8)}$

\section{Factores relacionados con la enfermedad}

- Motivo de la cirugía: cirugía vascular (aneurisma de aorta), cirugía abdominal intestinal, cirugía oncológica o cirugía urgente: oclusiva, traumática o séptica. Reoperaciones con reincisión y paraincisión. ${ }^{(9)}$

\section{Factores relacionados con la técnica quirúrgica}

- Tipo de incisión: más frecuente en las verticales medianas que en las transversas o paramedianas.

- Longitud de la incisión. Más frecuente en las de más de $15 \mathrm{~cm}$ de longitud.

- Forma de apertura: es aconsejable la apertura de la pared con el electrocauterio en la posición de corte, ya que en coagulación provoca un aumento de la necrosis tisular local y de la reacción inflamatoria.

- Técnica de cierre. Para prevenir una HI, cuyo mecanismo principal de formación es la separación temprana de los bordes aponeuróticos, debemos perfeccionar la técnica de cierre, manteniendo una aposición correcta de los bordes aponeuróticos durante el tiempo suficiente para que la cicatrización dé lugar a un aumento correcto de la resistencia a la tracción. Las recomendaciones actuales son (guías de EHS y Israelsson): cierre de la laparotomía media con sutura continua utilizando la técnica de puntos pequeños, solo en la aponeurosis, sin cerrar el peritoneo, a 5-8 $\mathrm{mm}$ desde el borde de la herida y con separación de 4-5 $\mathrm{mm}$. Respetar la relación de Jenkins: longitud de sutura y longitud de incisión de al menos de 4:1. Usar material monofilamento de absorción lenta o irreabsorbible. Bastaría con polidioxanona de 2/0.(2)(10)

Prevención con malla profiláctica: Única medida que ha demostrado eficacia, en pacientes con o sin factores de riesgo. Aún falta evidencia para determinar cuándo, a quiénes y que tipo de malla y en qué espacio debe colocarse. La colocación de la malla supraaponeurótica es más rápida y fácil de reproducir, pero produce mayor tasa de dolor crónico y seromas. Podrían emplearse en cirugía limpia y limpia-contaminada, su uso no está exento de riesgos. ${ }^{(11)(12)(14)}$

Las recomendaciones actuales son: el uso profiláctico de refuerzo con malla supraaponeurótica en pacientes con factores de riesgo (grado B); no hay diferencia en cuanto a incidencia de hernia entre incisión longitudinal frente a transversal, su uso queda a criterio del médico tratante (grado B); se recomienda usar malla como profilaxis en el cierre de una laparotomía media traumática en pacientes de alto riesgo (grado C); las colostomías extraperitoneales son más eficientes y seguras que las transperitoneales (grado B); la malla sintética absorbible no tiene ventaja durante la creación de ostomías emergentes, por lo que no se emite recomendación al respecto (grado B); se recomienda el uso de malla profiláctica en pacientes con factores de riesgo como: obesidad, tabaquismo, cáncer, alteraciones del tejido conectivo, desnutrición, inmunosupresión, tratamiento con corticoides y diabetes mellitus; hasta no tener nueva evidencia no puede emitirse una recomendación definitiva para usar malla profiláctica en la creación de estomas. ${ }^{(14)}$

Se publicaron otras (numerosas) técnicas de refuerzo de la sutura de cierre parietal para prevención de la HI, que no lograron aún la evidencia necesaria para su uso estandarizado. ${ }^{(2)(15)(16)}$

Experiencia del cirujano y relajación correcta del paciente durante el cierre. 


\section{Factores posoperatorios}

- Distensión abdominal y factores que generan aumento de la presión intrabdominal: patología pulmonar, íleo prolongado, retención de orina, vómitos y tos persistente. La medición de la circunferencia abdominal y de la distancia puboxifoidea antes y después de presentarse la distensión, muestra que la herida operatoria se alarga un $30 \%$.

- Infección de la herida operatoria: es el factor de riesgo más determinante para la formación de HI. Favorece la producción de colagenasa, con degradación del colágeno y disminución de la actividad fibroblástica y necrosis tisular.

\section{CRITERIOS DIAGNÓSTICOS}

Siempre que la exploración física sea inconcluyente o se trate de una hernia compleja: atípica, sospecha de hernias múltiples, de gran tamaño o pacientes multioperados u obesos, se debe evaluar mediante una técnica de imagen, siendo la tomografía axial computarizada (TAC) el método más sensible. ${ }^{(17)}$

La TAC, además permite clasificar la $\mathrm{HI}$ al proporcionar la topografía exacta, distancia de los reperes óseos y las dimensiones del defecto. Identifica el contenido y la relación entre el volúmen del saco y la cavidad abdominal, evalúa los diferentes planos musculares abdominales, su discontinuidad y grosor (técnicas de separtación de componentes previa?). Su rol es fundamental en la planificación de intervención, vía de abordaje y necesidad de técnicas adyuvantes pre o transoperatorias (neumoperitoneo, Toxina Botulínica, separación de componentes).

Ante complicaciones en hernias conocidas o debut con hernia complicada, la TAC tiene la mayor sensibilidad diagnóstica y debe solicitarse. ${ }^{(18)}$

La RNM supera a la TAC solo en casos de recidivas, siendo más sensible en la definicion de los planos musculares y topografía de la malla previa.

La ecografía de alta frecuencia, con maniobras dinámicas y cambios de posición, puede ser útil para diagnosticar HI de tamaño limitado y para la detección prequirúrgica de adherencias intestinales (y su fijeza), de gran valor en planificación de técnicas laparoscópicas.

Es necesario definir la nomenclatura y datos necesarios de incluir en la imagenología de la patología herniaria, estandarizando y protocolizando los informes. Así permitirá planificar el tratamiento adecuado a cada caso. Se debe fomentar la participación de radiólogos en futuros estudios, para definir criterios exactos de recurrencia para la HI y poder protocolizar su uso en el postoperatorio.

\section{HERNIAS EN LOS ORIFICIOS DETRÓCARES DE LAPAROSCOPÍA}

Las hernias en los orificios de los trocares de laparoscopia (HOT) constituyen una complicación potencialmente seria de la cirugía mínimamente invasiva y es considarada una "nueva etilología"de las eventraciones. La disparidad existente en la incidencia de HOT (0.65-2.8\%), se atribuye a factores como el tipo de procedimiento, cirugía urgente, presencia de casos de HOT con poca o nula expresividad clínica, la tendencia a subestimar o no comunicar este problema y la falta de estudios prospectivos a largo plazo. ${ }^{(19)}$

El desarrollo industrial de nuevos trocares (expansión radial, sin cuchilla, ópticos) con menor agresión a la pared abdominal, la tendencia a usar cada vez tócares de menor calibe por la minilaparoscopía (instrumentos de $3 \mathrm{~mm}$ y suturas mecánicas, clipadoras, selladoras de vasos y máquinas de tackers de $5 \mathrm{~mm}$ ) y las medidas preventivas que luego mencionaremos, explican a curva en descenso de esta patología.

Puede aparecer precozmente (primer mes postoperatorio), cuando existe una dehiscencia de todos los planos aponeuróticos y del peritoneo (no existe saco herniario) y con frecuencia se presenta como un cuadro de obstrucción intestinal. En la aparición tardía, existe un saco herniario formado por peritoneo, junto con un defecto parietal. Puede manifestarse clínicamente muchos meses después de la cirugía, y en ocasiones es asintomática, siendo en estos casos detectada mediante estudios radiológicos. Se palntea que las HOT precoces sean debidas a complicaciones en la inserción y/o 
cierre del trocar, mientras que en las tardías podrían influir además otros factores, dependientes del paciente y del proceso de cicatrización. ${ }^{(19)}$

De hecho, algunos estudios apuntan a una mayor incidencia de HOT después de determinados procedimientos, como cirugía bariátrica $(14,2 \%)$ o eventroplastia laparoscópica (22\%).

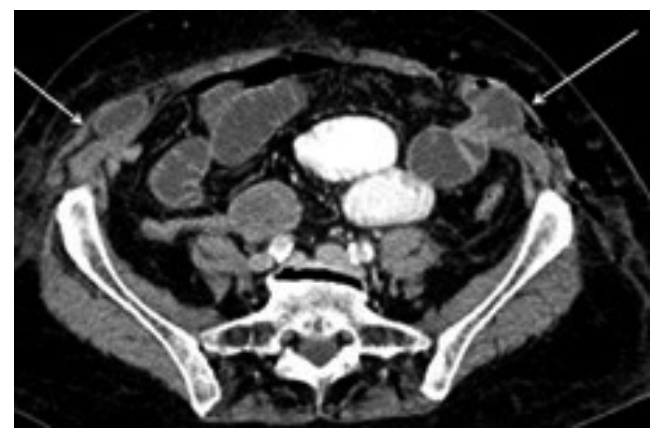

En la etipatogenia de las HOT, base para establecer la prevensión de la misma, se consideran: ${ }^{(20)(21)}$

Factores técnicos: predominantes en el desarrollo de la HOT, más que debidos a condiciones clínicas de los pacientes, entre ellos:

Diámetro del trocar, hay una relación directa entre el diámetro del trocar y el riesgo de herniación. E1 85\% de las HOT aparecen en orificios por trócares iguales o mayores de $10 \mathrm{~mm}$, y menos del $2 \%$ en trocares menores de $5 \mathrm{~mm}$.

Tipo de cierre, el cierre insuficiente o la ausencia del mismo aumenta el riesgo de HOT, sin diferencias significativas entre el cierre con material de reabsorción lenta o irreabsorbible.

Localización, hay mayor frecuencia de HOT en el trocar umbilical (82\%) frente a otras localizaciones (18\%), si bien no se acuerda si es por la existencia de varios planos musculares en las zonas laterales del abdomen o a la alta frecuencia de colocación umbilical de trocares de $10 \mathrm{~mm}$.

Factores dependientes del paciente: Edad (mayores de 60 años); Obesidad, por ella misma (mala calidad tisular, tensión en cierre y presión intraabdominal) o por la dificultad en el cierre del orificio; Infección; Diabetes y tabaco.

Las recomendoaciones de prevención de las HOT, incluyen: colocación de trócares del menor calibre posible, ingreso biselado y en cuadrantes laterales; el cierre adecuado con sutura externa o aguja pasahilos de todas las incisiones de trocares (o incisiones ampliadas) iguales o mayores a $10 \mathrm{~mm}$; incluso en trocares de 5-7 mm situaciones especiales (cirugía contaminada, pared hipotónica, o factores de riesgo propios del paciente). Si bien la colocación profiláctica de mallas o plugs puede disminuir el riesgo de HOT, aún no hay evidencia como para recomendar esta práctica en forma sistemática. ${ }^{(22)}$ Debe aplicarse selectivamente en incisiones ampliadas, contaminadas y pacientes con factores propios de riesgo. ${ }^{(20)(21)}$

\section{BIBLIOGRAFÍA}

1) León Ledesma R, Guillén Morales C, Limones Esteban M. Hernia ventral: concepto, epidemiología y clasificación (11) 135-141 Guías Clínicas de la Asociación Española de Cirujanos Cirugía de la Pared Abdominal 2a Edición 2013

2) Roca Domínguez B, Gutiérrez Ferreras AI, Mayagoitia JC. Guía para el manejo de la hernia ventral e incisional medial. Rev Hispanoam Hernia. 2021;9(2):80-87

3) Muysoms F, Campanelli G, Champault GG, DeBeaux AC, Dietz UA, Jeekel J, et al. EuraHS: The Development of an international online platform for registration and outcome measurement of ventral abdominal wall Hernia repair. Hernia 2012;212:239-50.

4) Muysoms FE, Miserez M, Berrevoet F, Campanelli G, Champault GG, Chelala E, et al. Classification of primary and incisional abdominal wall hernias. Hernia 2009;13(4):407.

5) Petro CC, Zolin S, Krpata D, et al. Patient-Reported Outcomes of Robotic vs Laparoscopic Ventral Hernia Repair With Intraperitoneal Mesh: The PROVE-IT Randomized Clinical Trial. JAMA Surg. 2021;156:22-9. 
6) Fekkes JF, Velanovich V. Amelioration of the effects of obesity on short- term postoperative complications of laparoscopic and open ventral hernia repair. Surg Laparos Endos Percutan Tech. 2015;25(2):151-7.

7) Fischer JP, Basta MN, Mirzabeigi MN, et al. A risk model and cost analy- sis of incisional hernia after elective, abdominal surgery based upon 12,373 cases. The case for targeted prophylactic intervention. Ann Surg. 2016;263:1010-7.

8) Huynh DTK. Ghanem OM. Patient Comorbidities Complicating a Hernia Repair: The Preoperative Workup and Postoperative Planning 9:109-120 Society of American Gastrointestinal and Endoscopic Surgeons (SAGES) 2019109 S. S. Davis Jr. et al. (eds.), The SAGES Manual of Hernia Surgery, https://doi.org/10.1007/978-3-31978411-3_9

9) Goodenough CJ, Ko TC, Kao LS, et al. Development and validation of a risk stratification score for ventral incisional hernia after abdominal surgery: Hernia expectation rates in intraabdominal surgery (The HERNIA project). J Am Coll Surg. 2015;220:405-13.

10) Israelsson LA, Millbourn D. Prevention of incisional hernias: How to close a midline incision. Surg Clin North Am. 2013;93:1027-40.

11) Caro-Tarragó $A$, Olona Casas $C$, Jiménez Salido $A$, et al. Prevention of incisional hernia in midline laparotomy with an onlay mesh: A randomized clinical trial. World J Surg. 2014;38:2223-30.

12) Gómez Díaz CJ, Rebasa Cladera $P$, Navarro Soto $S$, et al. Validación de un modelo de riesgo de evisceración. Cir Esp. 2014;92:114-9.

13) Jairam $P$, Timmermans $L$, Hasan $H$, et al. Prevention of incisional hernia with prophylactic onlay and sublay mesh reinforcement versus primary suture only in midline laparotomies (PRIMA): 2-year follow-up of a multicentre, double-blind, randomised controlled trial. Lancet. 2017;390(10094):567-76.

14) González LG, Lora A, Varela E, Vergara G, Vega Peña V, Ayala JC, Martínez JD, Hanssen A, Gómez JP, Ruiz JP. Guía para el tratamiento laparoscópico de la hernia ventral e incisional. Rev Hispanoam Hernia. 2021;9(2):105117

15) Breuing $\mathrm{K}$, et al. Incisional ventral hernias: review of the literature and recommendations regarding the grading and technique of repair. The ventral hernia Working group. Surgery 2010;148:544-58.

16) Liang MK, Holihan JL, Itani K, et al. Ventral Hernia Management Expert Consensus Guided by systematic Review. Ann Surg. 2017;265(1):80-9.

17) Bittner R, Bingener-Casey J, Dietz U, et al. Update of Guidelines for lapa- roscopic treatment of ventral and incisional abdominal wall hernias International Endohernia Society(EHS). Surg Endosc. 2019;33(10):3140-2.

18) Holihan JL, Karanjawala B, Ko A, Askenasy EP, Matta EJ, Gharbaoui L, et al. Use of Computed Tomography in Diagnosing Ventral Hernia Recurrence A Blinded, Prospective, Multispecialty Evaluation. JAMA Surg. 2016;151(1):7-13.

19) Picazo-Yeste JS, Moreno-Sanz C, Tenías Burill JM. Hernias en los orificios de trocares de laparoscopia (24); 261270 En Guías Clínicas de la Asociación Española de Cirujanos Cirugía de la Pared Abdominal 2a Edición 2013

20) Taylor GW, Jayne DG, Brown SR, et al. Adhesions and incisional hernias following laparoscopic versus open surgery for colorectal cancer in the CLASICC trial. Br J Surg 2010;97:70-78.

21) Helgstrand F, Rosenberg J, Bisgaard T. Trocar site hernia after laparoscopic surgery; a qualitative systematic review. Hernia 2011;15:113-21.

22) Moreno-Sanz, Picazo-Yeste JS, Manzanera-Díaz M, et al. Prevention of trocar site hernias: Description of the safe port plug technique and preliminary results. Surg Innov 2008;15:100-4. 


\section{TRATAMIENTO LAPAROSCÓPICO DE LA HERNIA INCISIONAL MEDIAL}

\section{Dr. Gonzalo Estapé TÉCNICA QUIRÚRGICA}

Se describirán los puntos fundamentales del proceso quirúrgico de una eventroplastia laparoscópica (EL). Incluiremos los diferentes pasos pre, intra y postoperatoriso inmediatos suegeridos para una EL exitosa y segura. Basaremos este análisis en las recomendaciones y guías internacionales, cuyo análisis abarca la mas valiosa y reciente evidencia científica en cada tema.

\section{PREOPERATORIO INMEDIATO}

La reparación se realiza habitualmente mediante anestesia general. Es recomendada la profilaxis antibiótica con una única dosis de cefalosporina de primera generación (Cefazolina 2 grs i $/ v$ ) en la inducción anestésica. La colocación de sonda nasogástrica o vesical no se indica de forma rutinaria, la indicamos cuando la vacuidad gástrica y/o vesical, faciliten la técnica quirúrgica y permitna evitar lesiones, dependiendo de la topografía de la hernia a tratar. En el caso de hernias grandes, recurrentes o parcialmente reductibles, se aconseja realizar preparación colónica mecánica. La antisepsia de la piel la realizamos con Clorhexidina alcohólica, que mostró menores tasas de infección de sitio quirúrgico que otros antisépticos. ${ }^{(1)}$ Se asegurará la fijación del paciente a la mesa y se seguirán las recomendaciones mecánicas habituales de profilaxis antitrombótica.

Es útil cubrir toda la piel del abdomen con un campo autoadhesivo, para evitar el contacto de la flora de la piel con los guantes y la malla y permitir dibujar los reperes anatómicos y del defecto herniario.

El equipo quirúrgico se colocará inicialmente lateral, debiendo estar previsto el posible cambio de lado, incluyendo entre las pirenas del paciente, para momentos específicos de la cirugía o hernias M1-2. Los movimientos de la mesa operatoria, son necesarios en técnicas intraperitoneales. La ergonomía del cirujano debe contemplarse para facilitar las maniobras de adhesiolisis, disección, suturas y grampados de la malla.

Es necesario contar además del instrumenal habitual de laparoscopía avanzada, con pinzas de agarre atraumático, portagujas, selladores de vasos, pasahilos de pared (tipo Reverdin) y hilos de sutura barbados irreabsorbibles o de reabsorción lenta, calibres 2-0 y 0. Debe asegurarse la presencia de o las mallas posiblemente requeridas para la reparación, así como los medios de fijación necesarios.

\section{CREACIÓN DEL NEUMOPERITONEO y COLOCACIÓN DETROCARES}

No hay diferencia en complicaciones entre el acceso sin neumoperitoneo previo usando trocar óptico, frente al neumoperitoneo previo con aguja de Veress, siendo este el método más frecuentemente utilizado. En casos de múltiples cirugías o cercanía del defecto herniario, se elige la entrada con trocar óptico o con técnica abierta. Recomendamos trabajar con ópticas de $30^{\circ}$, dado el amplico campo a explorar. Trabajamos con presión de neumoperitoneo de $12 \mathrm{mmHg}$, suficiente para operar y disminuyendo el dolor postoperatorio y la reabsorción de $\mathrm{CO} 2 .^{(1)}$

El sitio anatómico más seguro es el cuadrante superior derecho o izquierdo (punto de Palmer) al nivel de la línea media clavicular con el reborde costal izquierdo en casos de hernia en abdomen medio o inferior, alejados de posibles adherencias tanto como sea posible. La relajación muscular y vacuidad gástrica minimizan complicaciones del acceso. ${ }^{(2)}$

Se recomienda que la inserción de los trocares secundarios se realice bajo visión directa y se localicen en función del tamaño, localización y número de los defectos existente, en puntos lo más alejado posibles del defecto herniario y de posibles adherencias y que, además, permita al cirujano realizar adhesiolisis y fijación de la malla de manera ergonómica (triangulación). Serán 3 o 4 trocares de $5 \mathrm{~mm}$ operativos, habitualmente del lado izquierdo, línea axilar anterior, para 
defectos mediales y laterales derechos. En algunas técnicas se requiere la colocación de trocares en ambos lados del paciente, y también en los cuadrantes mediales (suprapubico o epigástrico). Todos los puntos de acceso deben de ser infiltrados con anestésico local (usamos Bupivacaína al $0.25 \%$ ), previamente a su colocación, lo que retrasa y disminuye la aparición del dolor postoperatorio.

Solo se recomienda el uso de técnicas de reparación de defectos herniarios de la pared abdominal por técnicas de puerto único o a través de orificios naturales en el contexto de protocolos de investigación, centros altamente especializados y programas de entrenamiento o enseñanza de cirugía de mínima invasión. Se requiere de estudios aleatorizados controlados para evaluar apropiadamente el posible papel de estos abordajes en las reparaciones de defectos herniarios. ${ }^{(2)}$

\section{TÉCNICAS MÁS SEGURAS PARA LA ADHESIOLISIS, PREVENCIÓN Y MANEJO DE LA LESIÓN INTESTINAL}

La adhesiólisis es necesaria en la mayoría de los pacientes que requieren corrección de una hernia incisional (HI) laparoscopica (70-95\%), siendo el epiplón y el intestino delgado los órganos frecuentemente involucrados. Esta complicación, casi exclusiva del abordaje laparoscópico de la eventración, es poco frecuente y de aparecer genera morbilidad postoperatoria inmediata, sin cambios en la evolución a largo plazo. ${ }^{(3)}$

La las enterotomías son las complicaciones más frecuentes (92\%) y peligrosas en la corrección de HI vía laparoscópica. La mitad de estas ocurre durante la adhesiólisis, por lo que prevenir esta complicación es de vital importancia. La hemorragia por lesiones mesiales o del epiplón, la siguen en frecuencia.

La adhesiólisis extensa es un factor predictor de aumento de la morbilidad, de la estancia hospitalaria, de la enterotomía y de la infección del sitio quirúrgico. ${ }^{(4)}$

El tiempo prolongado de adhesiólisis y la presencia de malla previa son factores de riesgo independientes para una enterotomía. Se deben evitar maniobras innecesarias, la exploración intestinal con pinzas traumáticas que puede dejar zonas denudadas de peritoneo o lesionadas por microtraumatismos que inician la formación de adherencias y pueden favorecer el íleo y aumentar el dolor postoperatorio. En caso de adherencias múltiples y firmes, la conversión a cirugía abierta evitará complicaciones mayores innecesarias. ${ }^{(5)}$

El remover una malla previa, sería ideal para lograr el major contacto y incorporación parietal de la nueva malla, pero esto no siempre es posible. De requerir una gran movilización y daño parietal o ante adherencias intestinales firmes, la malla se mantendrá en su lugar, incluso dejandu una zona adherida al asa intestinal. ${ }^{(6)}$

Se recomienda para la adhesiolisis intestinal: evitar tracción excesiva, limitar la adhesiólisis (tiempo y extensión) y el uso de tijera sin energía mono ni bipolar, para reducir el riesgo de enterotomías o lesiones térmicas inadvertidas. La compresión manual externa puede mejorar la exposición visceral. Si no existe un plano definido entre intestino y peritoneo, se inicia la disección a $1 \mathrm{~cm}$ del peritoneo adyacente al asa. ${ }^{(5)}$
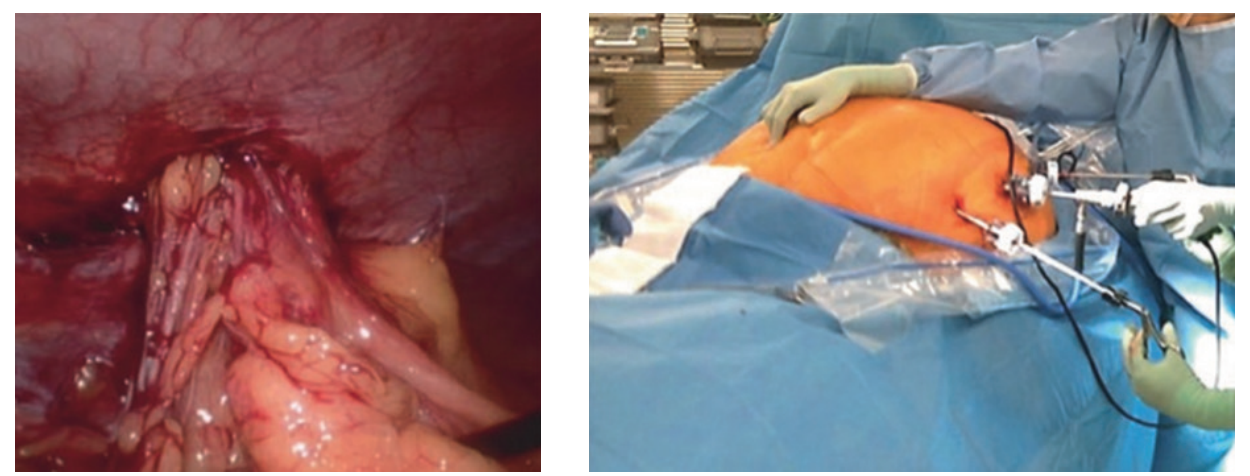

Reducción del contenido herniario. Tomado de Adrales GL. y Coker AM. The SAGES Manual of Hernia Surgery. 


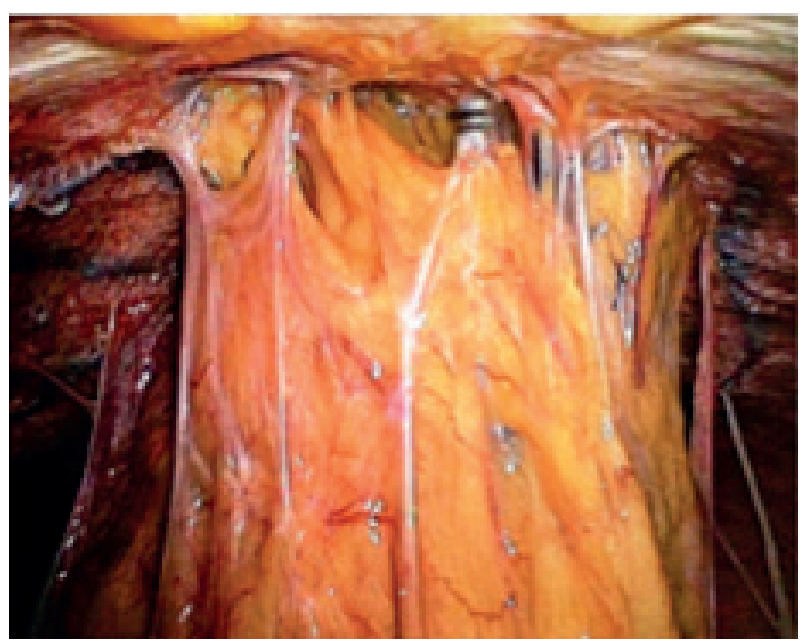

Adherencias a reparación previa

Para adhesiolisis del epiplón recomendamos la fulguración con energía mono o bipolar, Ligasure o Bisturí Armónico. Antes de la finalización de cirugía deben inspeccionarse las asas para identificar enterotomías o lesiones térmicas inadvertidas. La lesión visceral puede ocurrir entre un 2-4\% y es más común durante el periodo de aprendizaje. La documentación de este paso de la cirugía es vital , en vista de analizar las complicaciones viscerales. ${ }^{(5)}$

El diagnóstico tardío postoperatorio por lesión inadvertida o por caída de éscara, con peritonitis y eventual sepsis tiene una mortalidad del $40 \%$. $^{(2)(7)}$

\section{El manejo de la lesión intestinal es aún controvertido. Las opciones son:}

1. conversión inmediata a cirugía abierta, realizado la enterorrafia y la eventroplastia en mismo acto.

2. corrección de la enterotomía y culminar la herniorrafía usando o no la prótesis. Si la contaminación es escasa y el cirujano está capacitado para realizar la sutura intracorpórea, esta puede repararse y la hernioplastia puede realizarse inmediatamente usando prótesis sintética irreabsorbible. (Recomendada)

El manejo está determinado por el grado de contaminación, la extensión de la lesión, la habilidad y la experiencia del cirujano.

3. enterorrafía, antibioticoterapia IV y posponer la cirugía de reparación herniaria. Si hay o no conversión a cirugía abierta para la corrección de la enterotomía, puede diferirse la eventroplastia y realizarla por vía laparoscópica 5-7 días después, siempre y cuando no haya signos de infección o de falla de sutura.

En cuanto al uso de mallas biológicas, también ha sido descrito para la corrección de $\mathrm{HI}$ en presencia de contaminación. Hay reportes de infección de malla biológica hasta del $50 \%$, retiro de malla biológica en el 25\% y recurrencia herniaria del $66 \%$. No hay evidencia suficiente para recomendar el uso de mallas biológicas sobre mallas sintéticas. Hay algunos reportes que incluso las desaconsejan. ${ }^{(2)(7)}$

\section{DEFINICIÓN DE LOS MÁRGENES Y DEL TAMAÑO DE}

\section{LA HERNIA ANTES Y DURANTE LA CIRUGÍA}

Las mediciones dinámicas preoperatorias y la TAC, proveen al cirujano una buena aproximación del tamaño del defecto y escoger la medida de la malla. Entre los diferentes métodos que existen para medir el defecto herniario hay una correlación de leve a moderada (clínica, TAC, intraoperatorio).. ${ }^{(2)}$

Cuando se definen en el intraoperatorio, con seguridad, los límites del defecto y la pared sana, se dibuja el defecto en la pared anterior presionando con unas pinzas desde dentro, introducción de cintas calibradas, hilos o punción con agujas externas, reduciendo el neumoperitoneo $(6-8 \mathrm{mmHg})$ y bajo visión directa. ${ }^{(1)}$

La recurrencia post EL puede aparecer si se ignora el principio de que debe repararse toda la incisión y no solo la hernia, además la obligatoria exploración de toda la incisión puede mostrar defectos inadvertidos en el preoperatorio. Se 
considera que más del $50 \%$ de los pacientes tendrán más de un defecto herniario en la herida operatoria. El tamaño de la malla se define con las medidas iniciales del defecto, previo al cierre, de esta manera si el cierre fascial falla, la cobertura herniaria será igual adecuada. ${ }^{(6)}$
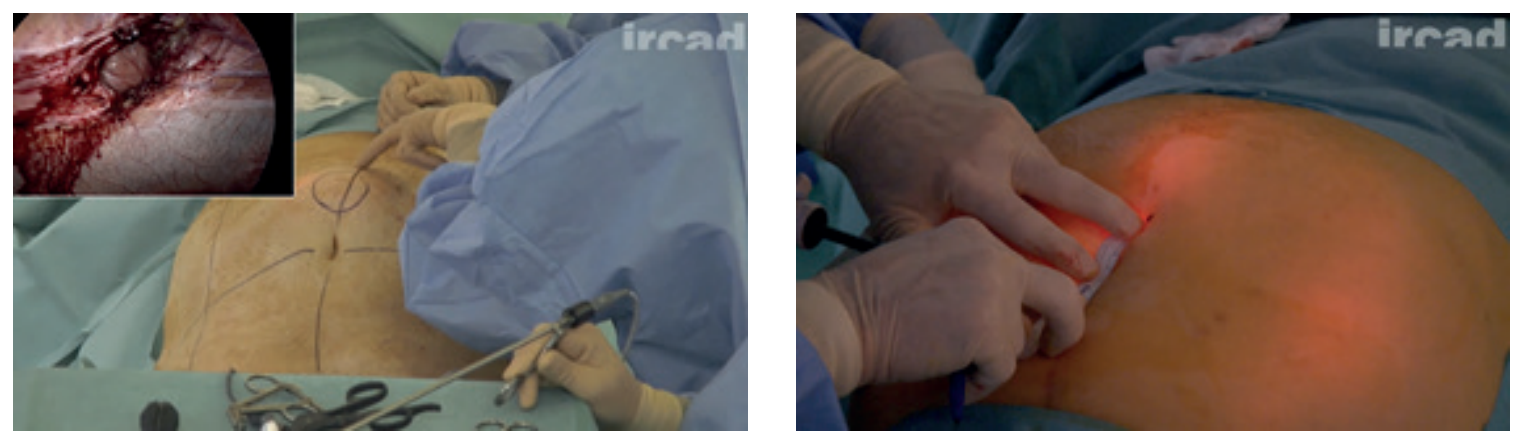

Es ideal que la malla sobrepase de 3 a $5 \mathrm{~cm}$ el borde de la hernia y que cuanto mayor sea el defecto, mayor sea el solapamiento de la malla. ${ }^{(7)} \mathrm{El}$ tamaño del defecto y la escasa superposición de la malla, entre otros factores, se relacionaron con el riesgo de recurrencia de la HI.

La relación entre el área de la malla y el área del defecto parece ser más importante para minimizar la recurrencia, que una longitud fija de superposición. Esta relación debe ser de 16:1; es decir, el radio de la malla utilizada debe ser al menos cuatro veces el radio del defecto. ${ }^{(7)(8)(9)}$ Este es el criterio aceptado actualmente y sustituye al margen en centímetros hasta ahora utilizdo.

Una malla excesivamente grande, aumenta el riesgo de adherencias viscerales, lesiones nerviosas y dolor por los métodos de fijación, aumenta significativamentelos costos y es más difícil técnicamente de colocar y fijar. Además, en caso de requerir el explante por infección crónica, esta es más dificultosa. ${ }^{(7)}$

El saco se podrá resecar si se decola sin dificultad ni sangrado ni riesgo de lesión cutánea. Puede abandonarse ante dificultades, asumiendo una tasa mayor de seroma postoperatorio y peor estética. ${ }^{(1)(5)}$ También deben disecarse todos los cojinetes grasos para dar el correcto contacto de la malla a la pared para una adecuada integración.

\section{REPARACIÓN DE HI CON O SIN MALLA}

La evidencia mantiene la recomendación con respecto al uso de malla en defectos, en campo limpio, > $1 \mathrm{~cm}$.

En la EL no se considera nunca la reparación sin malla, fuera de un cuadro séptico. ${ }^{(6)}$

La reparación con sutura simple se asocia a tasas de recidiva entre 25-50\%. Así, exceptuando la eventración estrangulada con peritonitis acompañante, todas las $\mathrm{HI}$ deben ser reparadas con prótesis (recidiva de $10 \%$ vs $25-50 \%$ ). ${ }^{(9)}$

El uso de malla por sí mismo no aumenta la posibilidad de infección, aunque de presentarse, en presencia de malla, su resolución es más compleja, por lo que su uso en un campo contaminado debe evaluarse caso por caso. ${ }^{(2)}$

\section{RECONSTRUCCIÓN DE LA LÍNEA ALBA:}

\section{IPOM vs. IPOM PLUS}

En la última década se ha sugerido la aproximación de la línea media en HI mediales y del cierre del defecto en defectos laterales debido a las grandes ventajas que se obtienen, y se recomienda de ser posible, el uso de técnicas que permitan el cierre sin tensión del defecto (posible en defectos menores de 6-7cm). Este puede efectuarse por acceso abierto o endoscópicamente.

Inicialmente el defecto herniario no se aproximaba y la eventroplastia era escencialmente un puente de malla (Intra peritoneal onlay mesh: IPOM). Actualmente el cierre del defecto herniario (IPOM Plus) debe considerarse siempre 
dada la robusta evidencia de menor morbilidad parietal postoperatoria y menor recurrencia, sindo una pastia de refuerzo parietal y no el simple puente (sustitución parietal) del IPOM. Luego describiremos otras variantes de cierre fascial (Laparoscopic intracorporeal rectus aponeuroplasty: LIRA)

Hasta la fecha, la evidencia marca que el cierre del defecto es favorable, ${ }^{(6)(7)(10)}$ al provocar:

- Más del $12 \%$ de reducción de la formación de seroma en el posoperatorio.

- Reducción de la recurrencia en un $25 \%$ aproximadamente.

- Reducción de la tasa de abombamiento o pseudorecurrencia (bulging).

Los pacientes con cierre del defecto tienen marcada mejoría de la calidad de vida, especialmente en aspectos relacionados con la actividad física, explicado por restituir la anatomía y la fisiología de la pared abdominal. Al minimizar el espacio muerto, disminuye la aparición de seromas y hematomas en el saco herniario o subcutáneo. El mayor área de contacto de la malla con el tejido músculo-aponeurótico, aumenta la efectividad de la plastia con menor índice de recurrencias. El cierre fascial mejora efecto de abombamiento o expulsiones de mallas ligeras a través del defecto por su distensibilidad aumentada (compliance).

En los casos de que el cierre sea bajo alta tensión fascial, se recomienda asociar alguna técnica de separación de componentes, evitando dolor o disrrupción del cierre. En hernias grandes pueden considerarse técnicas preoperatorias como la inyección de toxina Botulínica, neumoperitoneo progresivo o expansores intramusculares. ${ }^{(7)}$

A favor de no hacerlo se aduce: el cierre del defecto no necesariamente restituye la funcionalidad y la fisiología de la pared abdominal, ya que son estructuras dañadas y cicatriciales. Deberá evitarse cuando exista demasiada tensión en los bordes al hacerlo, con aumento innecesario de la presión intraabdominal con restricción ventilatoria y desgarro consecuente de la pared suturada. Se produce además, aumento del dolor posoperatorio. La tasa de seromas y infecciones no es significativamente mayor, al igual que las recurrencias. En esta postura encontramos al Texas Endosurgery Institute, ${ }^{(11)(12)}$ con Morris Franklin, uno de los pioneros de esta técnica, con 25 años de experiencia y largo seguimiento de su serie. Actualmnete comunica 699 IPOM por HI y HV primarias, con seguimiento medio de 52 meses: recurrencia $1.6 \%, 1.5 \%$ de seromas todos tratados conservadoramente. Argumenta que es una técnica más reproducible, con menos dolor postoperatorio y corta hospitalización que IPOM PLUS, reconociendo la presencia de seromas con mayor eventualidad de infecciones superficiales y de la malla y la afectación cosmética por el bulging, por lo que realiza ahora el cierre fascial. ${ }^{(13)(14)(15)}$

En 2011, Orenstein y Novitsky publica en cierre fascial medio con la técnica de "shoelacing" (atado de calzado). Comunica en 47 pacientes operados en 32 meses sin complicaciones parietales (seromas ni infecciones) ni recurrencias, en un seguimiento de 16 meses. ${ }^{(16)}$ Otros estudios no logran reproducer los resultados, no encontrando diferencias en recurrencias, dolor postoperatorio ni infecciones parietales, en comparación con IPOM clásico. ${ }^{(15)}$

Las técnicas de cierre más difundidas son: sutura extracorporea continua en forma de 8, usando pasa hilos, tipo "atado de calzado", ${ }^{(17)}$ puntos separados extracorpóreos, surget intracorporeo con sutura barbada, o técnicas combinadas intra y extracorpóreas. ${ }^{(10)} \mathrm{El}$ intento de aproximación se sugiere, aunque no se logre el cierre completo, Franklin propone puntos separados de polidioxanona 1 , con aguja pasa hilos, cada $2 \mathrm{~cm}$, anudados extracorpóreo (neumoperitoneo se deciende a $6 \mathrm{mmHg}$ ) y mantenidos en postoperatorio. ${ }^{(11)(12)}$
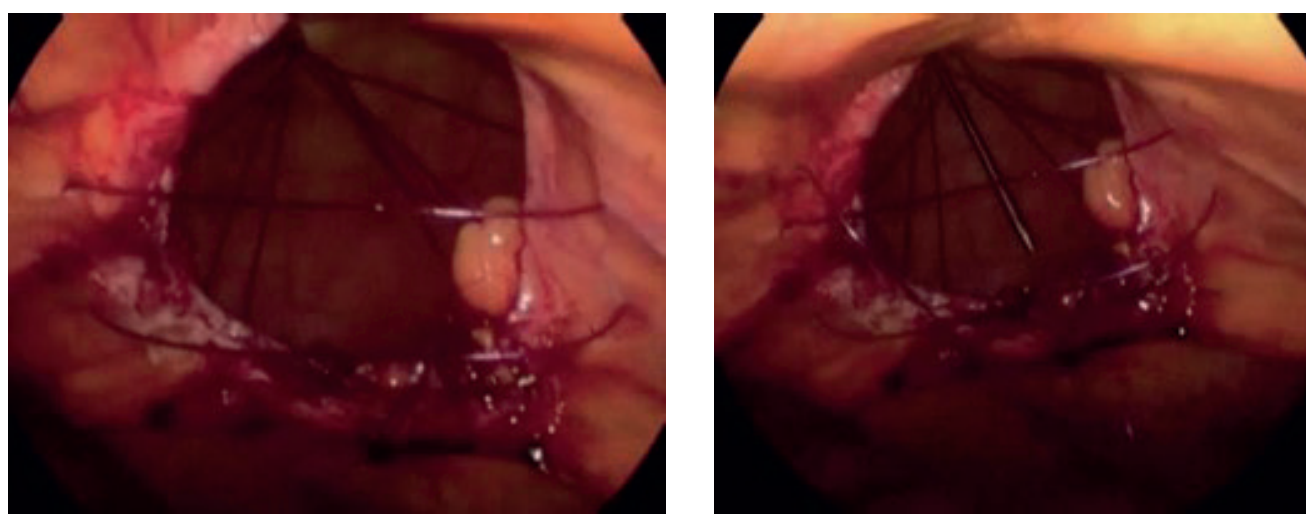

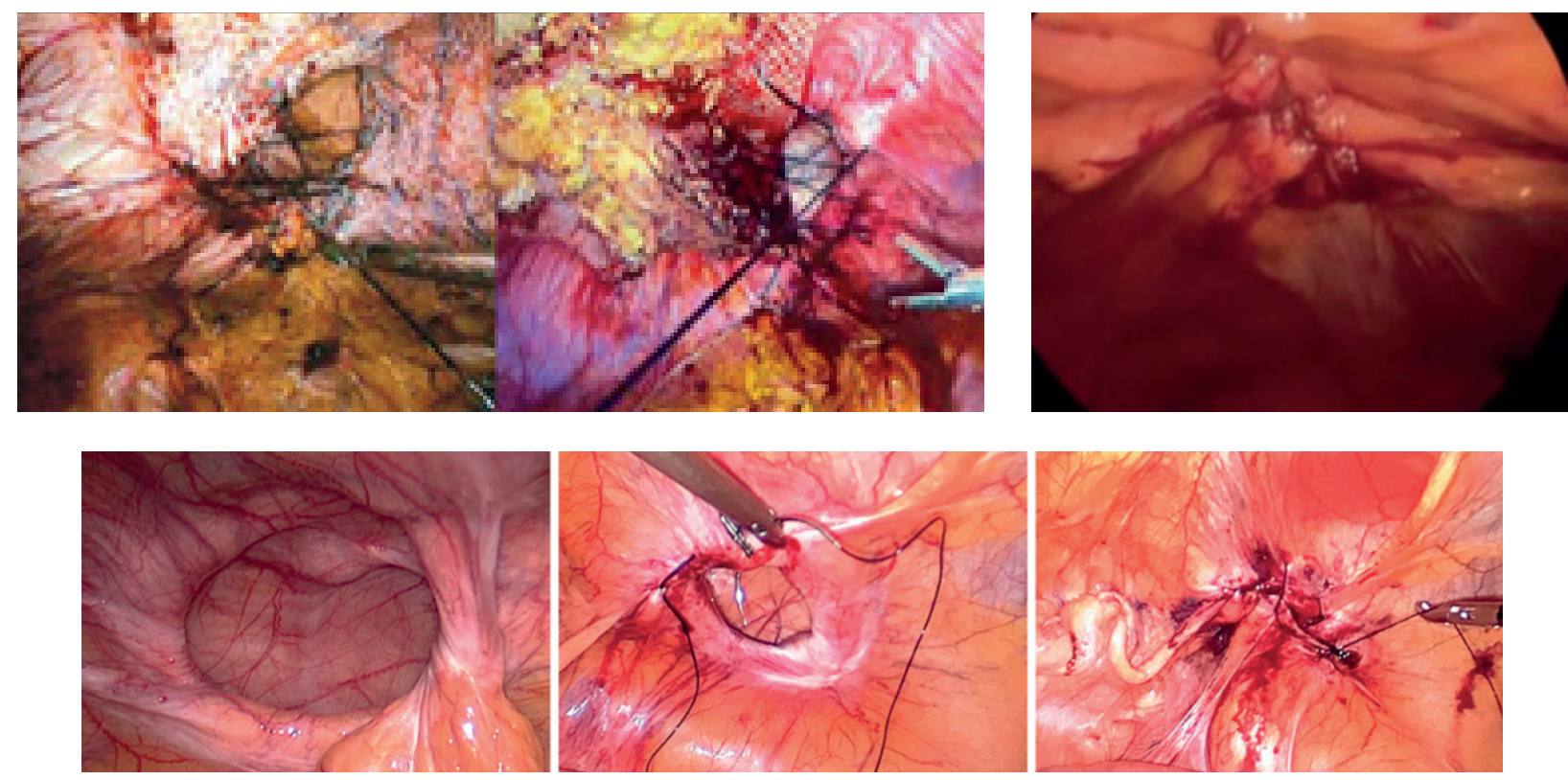

Técnicas de cierre de la linea alba ${ }^{(5)(6)}$

Ahonen ${ }^{(18)}$ propone un abordaje híbrido para la $\mathrm{HI}$ primarias con anillos entre $2-7 \mathrm{~cm}$, estudia 193 pacientes randomizados. Compara el IPOM clásico con el Abordaje Hibrido: resección del saco y cierre fascial (PDS 0), por una mini laparotomía y luego IPOM laparoscópico. Estudia: dolor crónico, seromas, recurrencias, calidad de vida y bulging . El seguimiento fue solamente a un año y no demostró diferencias significativas en los parámetros estudiados, requiriendo mayor tiempo de seguimiento.

Tandon ${ }^{(19)}$ realizó un studio sistemático analizando 16 estudios con 3638, comparando en cierre fascial (menos seromas y bulging) vs no cierre fascial (más fácil y menos dolor postoperatorio).

Las únicas diferencias estadísticamente significativas fueron a favor del cierre fascial: la menor ocurrencia de seromas y otras complicaciones parietales, y una menor estancia hospitalaria.

\section{ELECCIÓN DE LA MALLA}

En el tratamiento de la hernia incisional, «la malla lo es todo»; es la verdadera reparación del defecto, sobre todo cunado no es posible el cierre del anillo herniario; por lo que su elección es fundamental. La descripción de los tipos de mallas con las que contamos actualmente en Uruguay, se detallan en otro capítulo del Relato.

En cada paciente y situación clínica debe considerarse que tipo de malla será el aecuado, permanente o absorbible; malla simple o compuesta; sintético, biológico o híbrido. También se consideraré el diseño de la malla en base al caso clínico, su función final como refuerzo o sustitución parietal y la ubicación final de la misma. Así cada malla se diferencia no solo por tamaño y elasticidad, sino que la porosidad, el calibre de las fibras, y tipo de barrera saparadora; cada una con indicaciones específicas. Se recomienda contar en sala de operaciónes con los tipos de mallas que podrían necesitarse según las eventualizades de la exploración (adherencias, tamaño del defecto y definición de sitio de colocación de la malla), tanto en tipo como en tamaño de las mallas.

Para hernias no complejas, se intentará la ubicación preperitoneal o retromuscular de la malla. Aquí la sugerencia es la malla de Polipropileno, dado que no habrá contacto visceral. No es aconsejable la situación intraperitoneal de esta malla, aunque algunos autores la utilicen, considerándose inadecuada e imprudente por las graves complicaciones viscerales que puede presentar. ${ }^{(5)}$ Las de peso medio serían las ideales, aunque depende de las características de la hernia. El uso de mallas de muy baja densidad/peso, de baja densidad/peso o alta densidad/peso tienen más complicaciones que las mallas de mediana densidad/peso, recomendadas en la técnica de Rives. ${ }^{(6)(20)}$

Las mallas ligeras o asociadas a material absorbible, como polidioxanona o poliglecaprone, se asocian con menos dolor posoperatorio, pero tienen mayores tasas de recidiva. ${ }^{(7)(9)}$ 
La malla ideal para uso intraabdominal con contacto visceral (IPOM, IPOM PLUS, LIRA), debería ser aquella que estimulara el crecimiento de tejido fibroso sobre la pared abdominal posterior (cara parietal de Polipropileno) y evitara por el otro lado la adherencia de las vísceras (cara visceral:componente hidrofílico reabsorbible). Esta dualidad solo se puede obtener con una malla compuesta o bilaminar. Además, es importante su composición para minimizar el riesgo de infecciones, seromas, adherencias, contracción de la malla y el dolor excesivo. ${ }^{(1)}$ Alternativamente las placas de polytetrafluoroethyleno expandido (ePTFE) (sintética y laminar) es menos adhesiogénico que el polipropileno, aunque no presenta una barrera antiadherente especial. ${ }^{(21)}$ Estas mallas NO deben colocarse en campos contaminados.

Las mallas biológicas y las sintéticas absorbibles no han demostrado ninguna ventaja en campos contaminados. No se recomiendan en la reconstrucción parietal definitiva ni en técnicas de puenteo por su alta tasa de recidiva. ${ }^{(20)}$

Si bien es un tema aún en discusión, algunos estudios ponen de manifiesto que el uso de prótesis irreabsorbibles, en tejidos contaminados, se asocia a persistencia de la infección con eventual necesidad de retirada de la prótesis para su resolución, provocando un defecto herniario mayor que el de la primera cirugía, por lo que su uso no está indicado en medios sépticos. Por ello, ante pacientes de alto riesgo para desarrollar infecciones o en tejidos contaminados debemos considerar el uso de prótesis biológicas o sintéticas absorbibles, que se mantienen intactas incluso en tejidos con infección activa, aunque la recurrencia será segura. ${ }^{(7)(20)(22)}$

\section{Reacción del organismo luego de la inserción de una malla}

Las mallas sufren cambios físico-químicos como resultado de la defensa del huesped contra objetos extraños. Se reconoce que las mallas irreabsorbibles, se "contraen" entre 20-30\% de su área en el primer año por la reacción del huesped. La malla sintética utilizada para la reparación de la hernia no es inerte cuando se inplanta en el paciente. Esta interacción biológica es compleja y los efectos pueden ser variables. ${ }^{(23)}$

Las complicaciones relacionadas con la interacción de la malla con el cuerpo incluyen: la recurrencia debido a la contracción o el encogimiento de la malla, el desplazamiento, la migración, la erosión sobre vísceras o piel (grado máximo: extrusión de la malla), dolor crónico, problemas funcionales por pérdida de la elasticidad de la malla (fibrosis intensa, «acartonamiento»), infección aguda o tardía, reacciones inflamatorias agudas y crónicas, incluyendo seromas activos crónicos, y síntomas sistémicos inflamatorios y autoinmunes potencialmente relacionados con la malla sintética. La tasa de complicaciones relacionadas con la malla después de una reparación laparoscópica de $\mathrm{HI}$ no es mayor que la de la eventroplastia abierta.

Estos conceptos jerarquizan la correcta elección de la malla dentro del proceso terapéutico de una HI. Si bien en parte la reacción del huesped y las características biomecánicas de cada paciente, son factores determinantes y defíciles de cuantificar con precisón, la precisa elección del tipo de malla, su ubicación en los planos de la pared abdominal, su tamaño con relación al defecto y su cotrrecta fijación, condicionarán las complicaciones postoperatorias y la calidad de vida del paciente en el futuro.

\section{Características y beneficios de cada tipo de malla ${ }^{(2)}$}

La elección de la malla adecuada para cada paciente, es a veces un desafío para el cirujano.

La fuerza tensil requerida en cada caso en particular y la biocompatibilidad son las variables más importantes, pero también difíciles de determinar con exactitud en el preoperatorio: ${ }^{(23)}$

La biocompatibilidad general es establecida por los organismos sanitarios que aprueban el uso del producto, pero la reacción personal al mismo es imprerdecible.

La fuerza tensil, que se mide in vitro, depende de múltiples factores: tipo de material, tipo y grosor de la fibra, tipo y densidad de tejido de la malla. En forma práctica, se clasifican en macro/microporosas; liviana/pesada (en g/m2), densidad alta/media/baja. No hay posibilidad de medir la fuerza tensil ideal de cada malla para cada paciente (actividad física, BMI, comorbilidades) y situación clínica (hernias mediales , laterales, cercanía osea, tamaño). El / los sentidos de la tracción principal, variable e impredecible en cada hernia/técnica/paciente, es difícil de evaluar in vitro como para lograr una recomendación fiable del tipo de malla para cada caso.

Respecto al tipo de prótesis ideal para utilizar en la EL con situación extraperitoneal o retromuscular de la malla, no existen estudios que evalúen y comparen resultados frente a diferentes tipos de prótesis en términos de dolor crónico, recurrencia, reacción a cuerpo extraño o calidad de vida. 
En la reparación laparoscópica de HI, las mallas compuestas consistentes en un compuesto de polipropileno intercalado entre dos capas separadoras de tejidos con un recubrimiento bioabsorbible tienen un riesgo significativamente mayor de recurrencia y de dolor crónico en comparación con las otras mallas recomendadas, por lo que su uso se desaconseja. La malla híbrida sintética/biológica, útil en la reparación de HI, no están disponibles en nuestro medio.

La malla recomendada en la técnica IPOM/IPOM PLUS, sería una malla bilaminar de polipropileno monofilamento liviana/mediana, con una sola barrera de hidrogel absorbible en su fase visceral. Esta tiene una tasa de complicación y de recurrencia baja. En defectos grandes o pacientes obesos, o si no se logra cerrar la línea media, se sugiere una malla de mayor densidad. En técnicas extraperitoneales con cierre del defecto herniario adecuado, se optaría por malla de polipropileno liviana macroporosa.

\section{INTRODUCCCIÓN DE LA MALLA EN LA CAVIDAD}

\section{ABDOMINAL/PREPERITONEAL}

Debemos estar familiarizados con la malla a utilizar, con los reperes de las superficies visceral y parietal en las mallas combinadas y la ubicación espacial en los defectos asimétricos, que son la mayoría. Aquí, las marcas con tinta, suturas cardinales o las que vienen de fábrica en algunas mallas, ayudan a evitar errores y facilitan las maniobras intraabdominales.
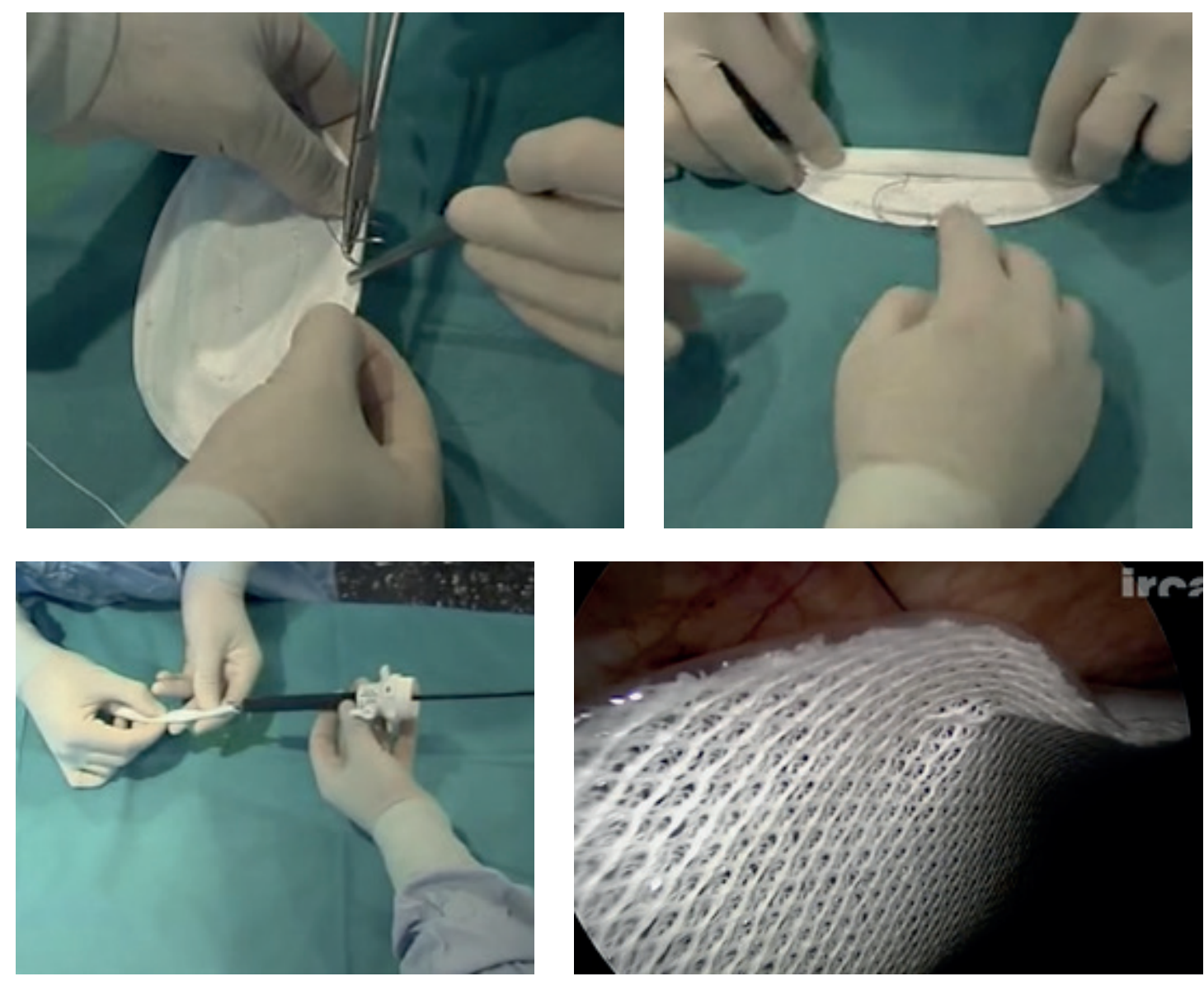

La inserción de mallas (hasta de 30 x $30 \mathrm{~cm}$ ) a través de un puerto de 10 a $12 \mathrm{~mm}$ es posible en la mayoría de las reparaciones laparoscópicas de hernias incisionales. La $\mathrm{m}$ alla se se dobla y se introduce, extendiéndola cerca del defecto. Con una aguja atrapa suturas se punciona la pared abdominal en las localizaciones predeterminadas, se atrapan los hilos y se extraen de la pared, tensándolos. La maniobra es repetida según se necesite hasta situar correctamente la malla (cuatro puntos cardinales). ${ }^{(5)}$ Se debe evitar el desplazamineto de la malla al lado opuesto de los puerto de trabajo, error frecuente que ubicaría la malla en forma asimétrica. 
La inserción de la malla a través de una incisión de 2 a $3 \mathrm{~cm}$ en el centro del defecto (dentro de una funda plástica) o por un puerto de $15 \mathrm{~mm}$ son alternativas viables para defectos que requieren mallas más grandes de $30 \mathrm{~cm} .{ }^{(2)} \mathrm{E} 1$ contacto de la malla con la piel puede contaminar la malla y no se recomienda.

\section{SITIO DE IMPLANTACIÓN DE LA MALLA}

La facilidad de la técnica quirúrgica puede determinar la elección del procedimiento por parte del cirujano, así como a los riesgos de complicaciones posoperatorias. La expereiencia y entrenamiento del cirujano, el manejo de todas las opciones técnicas posibles, la disponibilidad de equipos y materiales adecuados, puedene modificar la ubicación "ideal" de la malla .

La posición de la malla puede ser:

- Supraaponeurótica, (abierta)

- Suturada a los bordes del defecto, (abierta)

- Retromuscular con/sin separación de componentes, (abierta, lap, robótica)

- Preperitoneal, (lap, robótica)

- Intraperitoneal (lap, malla compuesta)

La colocación ideal debe tener una cobertura anterior de tejido para minimizar la exposición a las infecciones del sitio quirúrgico, así como posterior, que lo aisle del contenido visceral intraperitoneal.

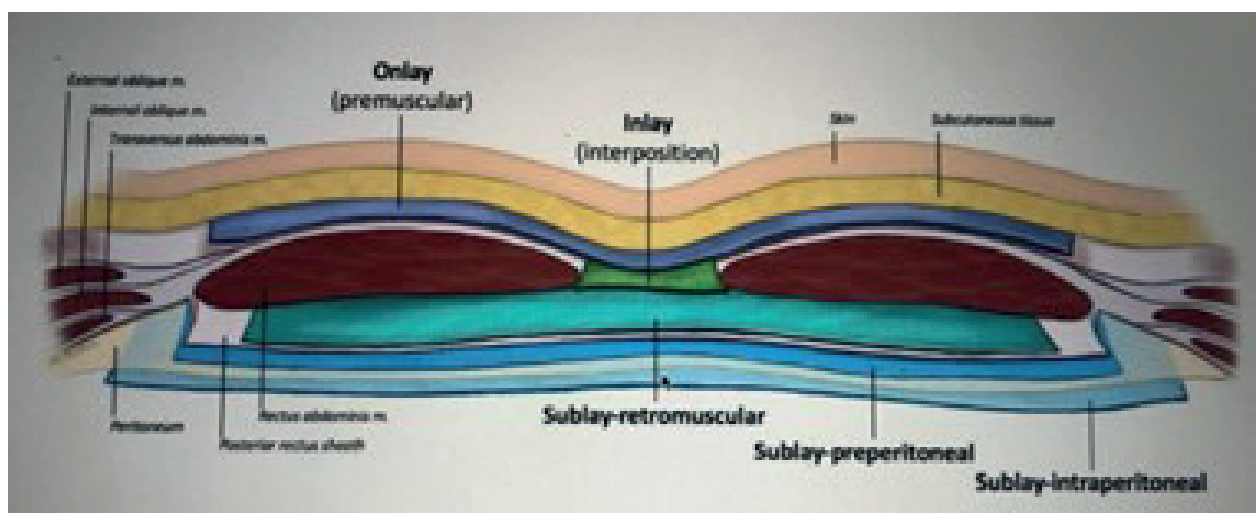

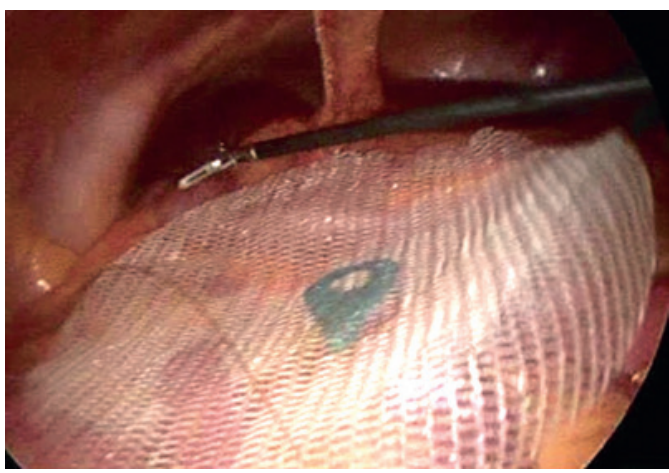

Malla bilaminar intraperitoneal

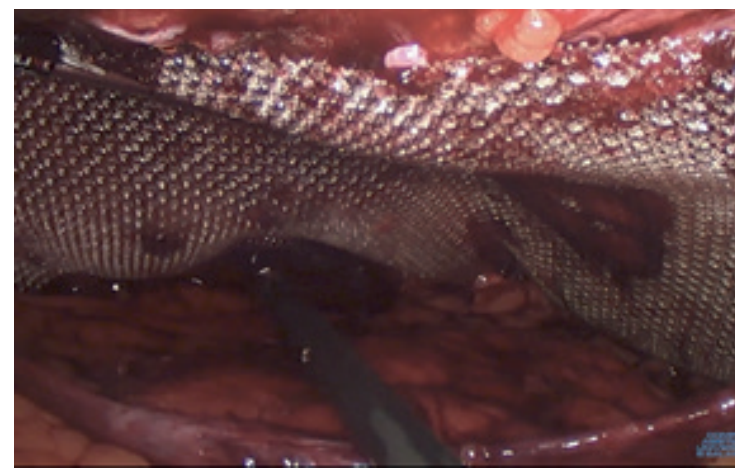

Malla PPL preperitoneal

Las tasas de recidiva son: $16.5 \%$ en posición supraaponeurótica; del $30.2 \%$ fijada a los bordes del defecto; del 7 \%, retromuscular y del $14.7 \%$ para la intraabdominal. ${ }^{(20)}$

Las tasas de infección del sitio quirúrgico: $16.9 \%$ supraaponeurótica; $31.3 \%$ fijada a los bordes del defecto; $3.7 \%$ retromuscular y $16.7 \%$ para la intraperitoneal. ${ }^{(20)}$

La colocación de la malla supraaponeurótica y la suturada a los bordes del defecto, son los dos sitios con peores tasas de recidiva y de infección del sitio quirúrgico. La malla intraperitoneal sin cierre fascial presenta pobres resultados globales en defectos grandes, riesgo de enterotomías y mayores costos. 
Como recomendación basada en la evidencia, se sugiere la situación retromuscular prefacial de la malla, tanto por técnica abierta o endoscópica (técnica de Rives- Stoppa). Esta presenta el riesgo más bajo de recidiva fundamentalmente por aprovechar el mecanismo fisiológico de la presión intraabdominal como procedimiento fijador de la malla en aposición con las capas de la pared suprayacentes a la misma y de infección del sitio quirúrgico al estar la malla alejada de la piel y tener menor contacto con la misma. Puede definirse como una exelente técnica reconstructiva morfológica y funcional. La evidencia muestra la mejor integración y menor posibilidad de migración y de complicaciones parietales. Sin embargo, el mayor despegamiento de las capas, con posibilidad de lesión de vasos perforantes, hace que estén gravadas con una mayor incidencia de hematomas. Es de más difícil ejecución, exigen una mayor experiencia y destreza técnica y consumen mayor tiempo quirúrgico.

La implantación preperitoneal (técnica de Stoppa), se utiliza más frecuentemente en eventraciones infraumbilicales y subarcuatas, en las que se puede separar con facilidad el peritoneo. En ocasiones se necesita despegar la vejiga y anclar la prótesis a los ligamentos de Cooper.

\section{MÉTODOS DE FIJACIÓN DE LA MALLA}

Numerosos trabajos actuales se han centrado en el estudio y comparación de los métodos de fijación de las malla durante la eventroplastia laparoscópica. Estos se clasifican en: MÉTODOS INVASIVOS: tackers (reabsorbibles e irreabsorbibles), puntos de sutura (absorbibles y no absorbibles), puntos transmurales; MÉTODOS NO INVASIVOS: mallas autoadherentes y pegamentos. También se considera en casos: la NO FIJACIÓN DE LA MALLA.

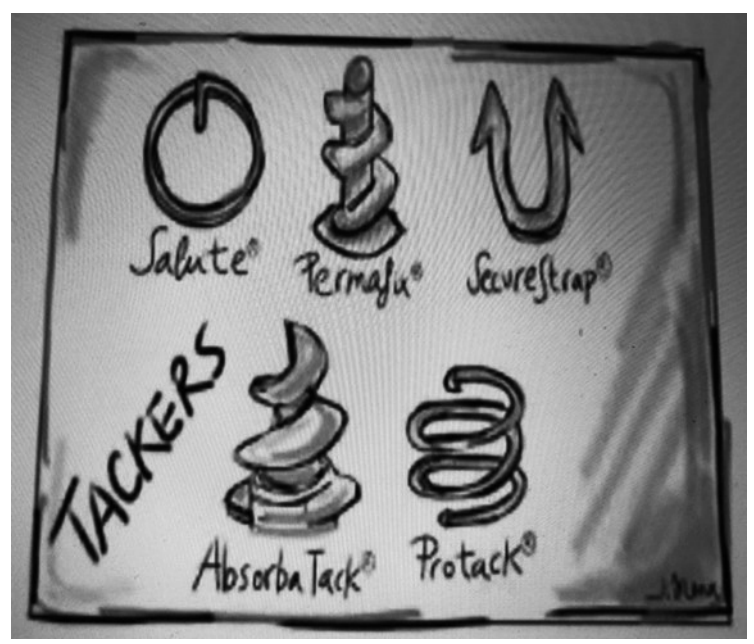

Es frecuente la combinación de varios de estos métodos de fijación, adecuado a cada paciente, intentando el equilibio justo entre la fijación más segura y menos invasiva posible. Dado que el riesgo de recurrencia para los pacientes obesos es mayor, pueden ser necesarios pasos técnicos adicionales (mayor fijación de la malla, más superposición, cierre con sutura del defecto) cuando el abordaje laparoscópico está indicado. Similares recomiendaciones se plantean en pacientes con defectos grandes o que realizarán una actividad física importante en el postoperatorio (tareas de esfuerzo, deportistas).

La tendencia natural de la cirugía de pared abdominal es sustituir la fijación invasiva por una forma de fijación reabsorbible y atraumática (suturas, adhesivos y pegamentos), aunque todavía no hay suficiente evidencia científica para generalizarlo. En la actualidad, a pesar de que el uso de pegamentos en la cirugía abierta o laparoscópica de la hernia inguinal pueda ser un hecho viable y muy atractivo, en el abordaje laparoscópico de la eventración parece muy difícil de aceptar, ya que se trabaja en una bóveda, bajo el efecto de la gravedad y sin control manual directo. El neumoperitoneo impide que se produzca un contacto suficiente entre la pared abdominal posterior y la malla lo que hace que el pegamento aplicado sobre esta no llegue a contactar con la pared abdominal el tiempo necesario (15-30 seg) como para ser eficaz (si no ejercemos una presión directa con una pinza) y por la gravedad el material sobrante puede caer directamente sobre las asas intestinales pudiendo ser origen de complicaciones no conocidas todavía (obstrucciones, fístulas, perforaciones). ${ }^{(24)}$ 

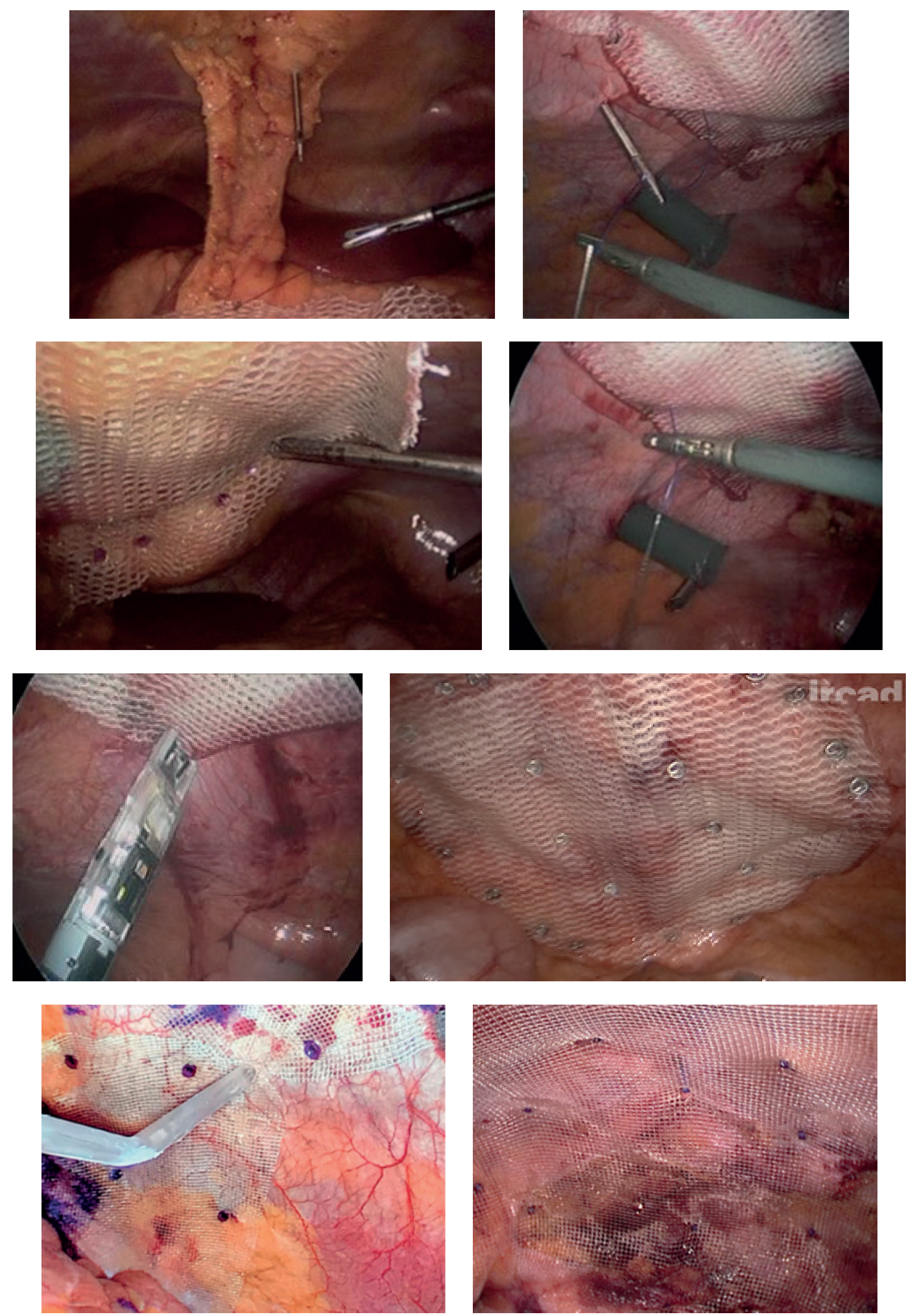

Diferentes técnicas de fijación de la malla. Tomado de Hamby PM.

Society of American Gastrointestinal and Endoscopic Surgeons (SAGES) 2019 y Moreno Egea A. ${ }^{(4)}$ y WebSurg. 
Transcribimos las recomendaciones actuales de algunas de las guías, que se sustentan en el estudio de la mejor evidencia disponible al momento. ${ }^{(2)(7)(25)}$

\section{Sobre la Recurrencia:}

Nivel 1A El riesgo de recurrencia luego de fijación cona tacker o suturas es similar

Nivel 1B El uso de adhesivos se asocial con mayor recurrencia

Nivel 2C El uso de tackers absorbibles se asocial con mayor recurrencia que con irreabsorbibles.

Grado A La fijación con sutura sola o combinada, o la doble corona de tackers es recomandada para minimizar el riesgo de recurrencia.

\section{Sobre el Dolor:}

Nivel 1B La fijación combinada con tackers y suturas transfasciales causa más dolor en los primeros 3 meses, en comparación con la doble corona de tackers. No hay diferencia en dolor postoperatorio entre la fijación con tackers absorbibles o irreabsorbibles.

Grado B El uso de tackers absorbibles o irrabsorbibles se recomiendan indistintamente en términos de dolor postoperatorio.

\section{Sobre los Costos:}

Nivel 1B/ Grado B : La fijación con tackers irreabsorbibles es mas barata que con absorbibles por lo que se recomienda en término de costos.

\section{Sobre la Calidad de Vida:}

Grado B El uso de tackers absorbibles o irrabsorbibles se recomiendan indistintamente en términos de calidad de vida.

\section{Sobre Estadía Hospitalaria:}

Grado A: El uso de tackers absorbibles o irrabsorbibles, o la fijación con suturas, se recomiendan indistintamente en términos de estadía hospitalaria.

En los defectos cercanos a rebordes óseos, se recomineda la fijación invasiva para disminuir el riesgo de recurrencias, aunque genera mayor dolor postoperatorio a corto y largo plazo y no se recomienda pos encima del reborde costal por el riesgo de lesiones pleuropulmonares o pericárdicas. ${ }^{(7)}$

Alfredo Moreno-Egea, ${ }^{(24)}$ presenta una técnica de fijación combinada (sutura mecánica y pegamento), abaratando el proceso y mejorando el bienestar postoperatorio del paciente. Para la aplicación segura del pegamento, la malla siempre es tensada y mantenida con los habituales 4 puntos de tracción en los vértices; luego se fija en 4-6 puntos equidistantes periféricos con tackers reabsorbibles y después, con ayuda de un retractor hepático, se mantiene la malla en contacto con la pared abdominal posterior y entre las hojas metálicas apoyadas se aplica una fina película de pegamento. Antes del proceso hay que asegurarse de contar con un epiplón adecuado que cubra las asas intestinales durante la aplicación del producto, que se polimeriza en segundos y se reabsorbe de forma completa a los 3 meses sin dejar residuos ni inflamación peritoneal. Esta técnica fue usada en 10 casos en eventraciones medianas de línea media con buenos resultados y sin complicaciones intra o postoperatorias en un seguimiento ahora completado de 6 meses: no íleo postoperatorio, obstrucciones, seromas ni recidivas. La satisfacción en el postoperatorio fue muy buena con alta hospitalaria entre 1 y 3 días. Están endientes los resultados futuros para verificar si mejora la calidad de vida y las recidivas a largo plazo.

Tim Mathes y cols ${ }^{(26)}$ publica en Cochrane Database of Systematic Reviews un estudio sobreTécnicas de fijación de mallas en la reparación de las hernias ventrales primarias o incisionales. Se incluyeron diez ensayos con 787 participantes. Tachuelas absorbibles comparadas con tachuelas no absorbibles: Las tasas de recurrencia en los grupos fueron similares. Tachuelas no absorbibles comparadas con suturas no absorbibles: sin diferencias en posoperatorio temprano, el seguimiento tardío, recurrencias y el dolor crónico. Tachuelas absorbibles comparadas con suturas absorbibles: no se observaron recurrencias al año (evidencia de certeza muy baja). El dolor posoperatorio temprano fue mayor en el grupo de las tachuelas. Combinación de diferentes tipos de fijación (tachuelas y suturas) o materiales (absorbibles y no absorbibles): no hubo diferencias importantes entre las combinaciones en comparación con una sola técnica, así como las combinaciones en comparación con otras combinaciones. Tachuelas no absorbibles o absorbibles en comparación con el sellador de fibrina: Resultados similares en recurrencia y dolor temprano o crónico 


\section{RECOMENDACIONES POSTOPERATORIAS}

Reposo en cama lo más breve posible y deambulación precoz según tipo de cirugía y condciones del paciente, dieta rica en frutas y verduras para evitar el estreñimiento. Se recomienda llevar faja tubular durante dos meses (hasta alcanzar la herida el $80 \%$ de su resistencia final), lo que mejora la respiración y alivia el dolor al toser o caminar. También previene la formación de seromas. A la semana del alta se cita en policlínica, para control general, abdominal y de la herida y retirada de puntos. Durante 10 días se deben evitar ejercicios violentos o cargar pesos. ${ }^{(1)}$

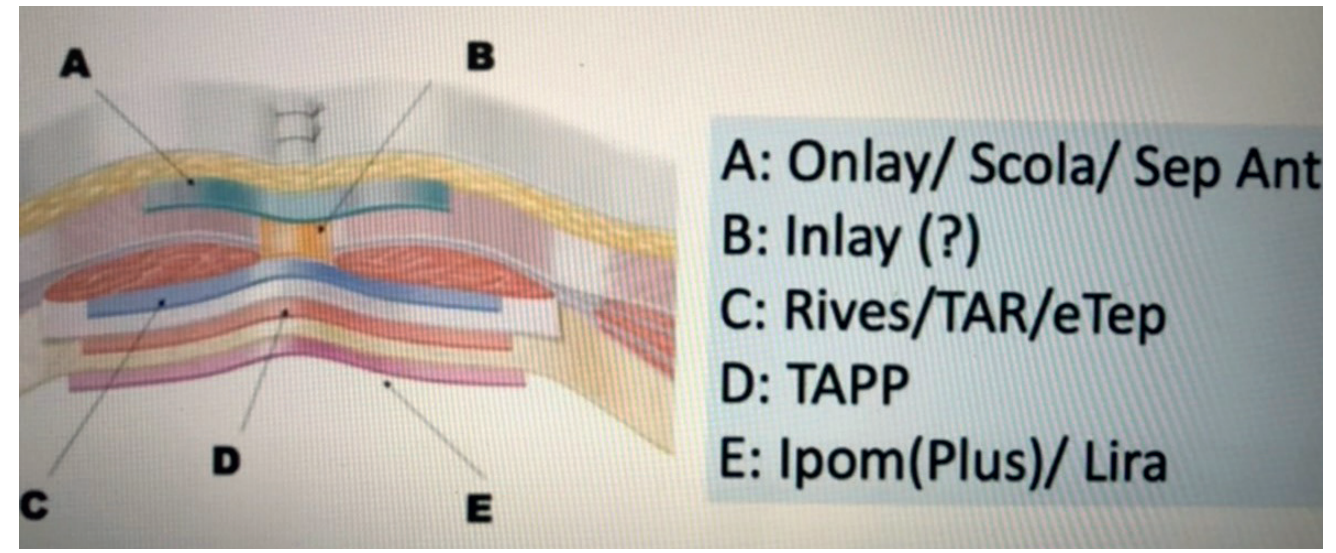

\section{TÉCNICAS QUIRÚRGICAS DE EL}

Aunque la evidencia sigue construyéndose, la mayor información se ha centrado en estudios realizados para la técnica IPOM. Sin embargo, la cirugía mínimamente invasiva ha tenido un gran desarrollo, con técnicas extraperitoneales, endoscópicas y robóticas, lo que necesariamente ha cambiado la forma en que se ubican y fijan las prótesis.

\section{Técnicas con malla intraperitoneal}

Con la malla (compuesta o bilaminar) en el campo operatorio, se colocará en posición intraperitoneal:

1) como puente sobre el defecto sin cerrarlo (malla de sustitución parietal, IPOM),

2) como refuerzo sobre el defecto herniario cerrado o aproximado (malla de refuerzo: IPOM Plus),

3) como refuerzo sobre el defecto cerrado por sección y sutura medial de vainas rectales posteriores (LIRA)

Los diferentes tipos de fijación son requisitos indispensables, a disponer en sala de operaciones, para evitar una inadecuada posición o desplazamiento de la malla.

La fijación invasiva con suturas y fijadores laparoscópicos absorbibles y no absorbibles, o la combinación de estos, disminuye el riesgo de recurrencia herniaria, pero están relacionados con mayor tasa de dolor agudo y crónico. ${ }^{(2)}$

Para posicionar la malla, sobre todo en las de gran tamaño, contamos con los hilos que trae de fábrica la malla o colocados selectivamente por el cirujano previo a introducirla al campo operatorio. El uso de agujas pasahilo, permite extraer el hilo y usarlo solo como reper y retirarlo luego de la fijación intraperitoneal o anudarlo sobre la aponeurosis y mantenerlo como puntos de fijación permanente. ${ }^{(6)}$

El número de tackers debe ser el suficiente para asegurar la malla mientras se integra, sabiendo que serán posible causa de dolor y neuralgias postoperatorio, eventualmente crónicos, con riesgo agregado de lesion vascular parietal y hematomas. Es aconsejable usar suturas reabsorbibles en sustitución de tackers. Estas, según el caso y destreza técnica del cirujano, pueden ser suturas intracorpóreas (preferida) o transmulares (ayudados con aguja pasahilos), a través de una incisión de unos $2 \mathrm{~mm}$ cada 3-5 cm, siendo anudados en el subcutáneo.

La técnica más difundida de fijación, y que presenta menor indice de recidiva herniaria, es la colocación de una DOBLE CORONA de tackers o puntos. Primero una periférica a $1 \mathrm{~cm}$ del borde de la malla (y separados no más de $2 \mathrm{~cm}$ para evitar la introducción de asas intestinales y generar cuadros oclusivos o fístulas por contacto con la cara parietal de la malla) y luego otra interna a 2-3 cm del anillo herniario (todavía hay fibrosis del anillo con tejido más resistente para 
la fijación).(1)(6)(9)(27) En un estudio randomizado Wassenaar compara la fijación con doble corona de tackers con o sin suturas transfaciales, no mostró diferencias en dolor postoperstorio, tiempo quirúrgico ni calidad de vida. ${ }^{(28)}$ Durante la colocación de esta corona es importante presionar levemente desde el exterior contra el aplicador de suturas para garantizar la fijación de la malla a la pared, aunque la presión excesiva en algunos sectores de la pared puede provocar atrapaminetos o lesiones nerviosas o vasculares, generando morbilidad postoperatoria. ${ }^{(29)}$

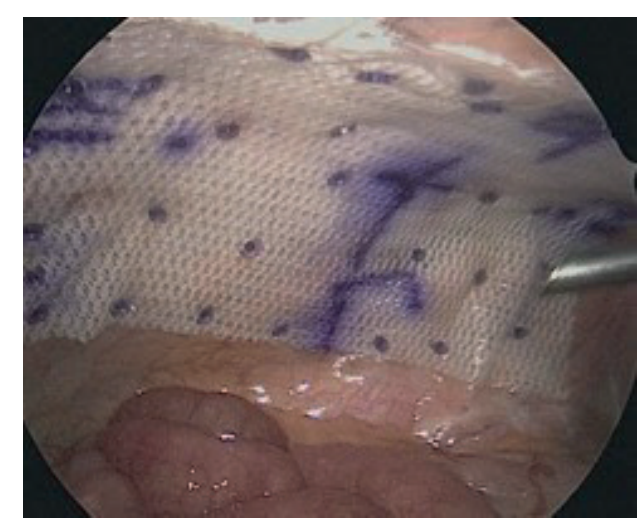

Fijación con Doble corona de tackers

Moreno Egea ${ }^{(5)(24)}$ propone la técnica de fijación combinada con tackers periféricos y adhesivos en corona central, modificando la proporcón de los mismos según el tamaño del defecto, a mayor tamaño, mayor cantidad de tackers y menos adhesivos, y a la inversa. No se aconseja el uso de métodos de fijación traumáticos en zonas anatómicas como los rebordes óseos y áreas en zonas donde transcurren ramos nerviosos. En estos casos, se sugiere usar alternativas como los pegamentos.

El epiplón, si está libre, puede colocarse por delante de las asas intestinales. Se retiran los trocares bajo visión directa para comprobar la hemostasia, se cortan los hilos-guía por debajo de la piel, se evacúa completamente el neumoperitoneo bajo visión.

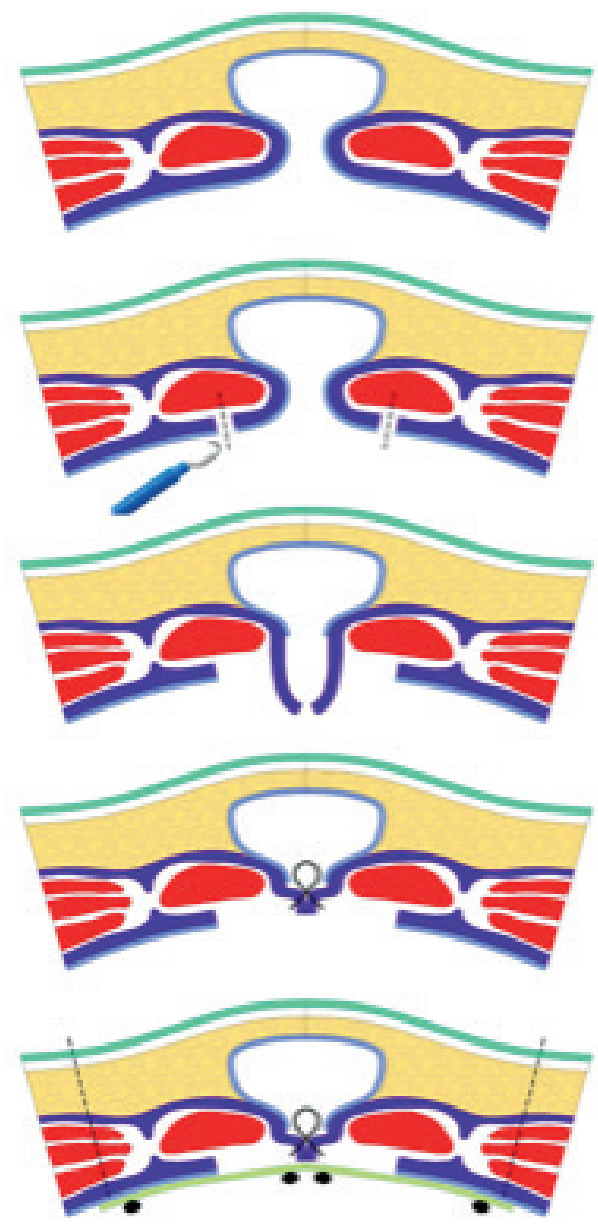

Técnica de Lira ${ }^{(30)}$ 
LIRA (Laparoscopic intracorporeal rectus aponeuroplasty), es una alternativa al IPOM Plus, para cerrar el defecto de la línea media sin tensión en eventraciones madianas o grandes $(4-10 \mathrm{~cm})$, e intentar evitar la separación de componentes de más compleja realización. Consiste en, madiante abordaje laparoscópico, abrir la hoja posterior de las vainas rectales, bilateralmente, alrededor del defecto herniario; se crean dos flaps (de tamaño medido y estimado previamente) que se reabaten y suturan medialmente sin tensión. Luego de coloca una malla compuesta intraperitoneal, sobrepasando el defecto fascial, con la fijación habitual. Se evalúa recurrencia (clinica y TAC 1 y 12 meses), distancia entre los rectos y seromas. Se obtuvo un cierre sin tensión adecuado, con escaso dolor postoperatorio, sin recurrencias ni bulging en corto seguimiento, por lo que se considera una técnica segura, eficaz y reproducible. ${ }^{(30)}$

\section{Técnicas con malla extraperitoneal}

El desarrollo de las técnicas con ubicación de la malla extraperitoneal, es un recurso importante en las reparaciones de la pared abdominal. Tiene las ventajas, con respecto al IPOM, de evitar el contacto de la malla con las vísceras abdominales, mejor incorporación de la malla al plano parietal por contacto directo muscular, requiere menos o ningúna fijación según la técnica (con menor dolor postoperatorio), mínima movilidad de la malla y es menos costosa por poder utilizarse malla de polipropileno en vez de las costosas mallas compuestas.

Para acceder al espacio preperitoneal/retromuscular, pueden usarse técnicas laparoscópicas (TAPP ventral, Rives laparoscópico, endoscópicas puras (eTEP), o combinadas (MILOS y EMilos). Todas estas técnicas, si incluyen el cierre del defecto de la línea media, hace que el resultado sea más prometedor.

\section{1) ABORDAJE TRANSABDOMINAL (LAPAROSCÓPICO) TAPP ventral y Rives-Stoppa laparoscópico}

Existe un vacío en el campo de la fijación de prótesis en cirugía de hernia ventral mínimamente invasiva extraperitoneal o retromuscular, pues la información en este campo se ha extrapolado de técnicas diferentes, por lo que no existe evidencia sólida suficiente para emitir una recomendación concreta.

Con el auge de la cirugía extraperitoneal y retromuscular laparoscópica, han cobrado importante valor las técnicas de fijación atraumática de las prótesis, o incluso la no fijación en casos seleccionados, lo que representa una menor incidencia de dolor agudo y crónico, con mejor calidad de vida y menores gastos en atención en salud.

Actualmente se recomienda evitar técnicas de fijación invasiva y evaluar de manera individual qué casos se benefician de la no fijación.

\section{TAPP Ventral ${ }^{(31)}$}

Luego del acceso igual al mencionado para IPOM (ubicación de trócares, adhesiolisis, reducción del contenido herniario y exposición del defecto herniario), se creará un bolsillo de peritoneo (flap o colgajo peritoneal) donde se colocará la malla de polipropileno que quedará cubierta, evitando el contacto visceral. Se creará el colgajo peritoneal comenzando a $5-6 \mathrm{~cm}$ a la izquierda del anillo herniario, planificando el solapamiento de malla necesario. Se decolará todo el saco sin uso de energía para evitar la retracción del peritoneo y la eventual lesión de la piel. Se determinará el tamaño de la malla según los diámetros del anillo, con los criterios ya mencionados. Se cierra el defecto herniario con sutura extracorpórea (puntos separados en 8, con aguja pasa hilos ) o intracorpórea (surget de sutura barbada calibre 0), hilos de absorción lenta y neumoperitoneo de $8 \mathrm{mmHg}$. Se introduce la malla de Polipropileno, ubicándola extendida y sin arrugas, por delante del flap peritoneal. Se fija con tackers absorbibles y pegamentos en proporción variable según el tamaño del defecto. Finalmente se cierra el flap peritoneal con surget de sutura absorbible o barbada.

\section{Rives- Stoppa ventral laparoscópico ${ }^{(32)}$}

Luego de liberar las adherencia y reducir el contenido herniario, se incide la hoja posterior de la vaina rectal contralateral, lateral al defecto herniario o de la linea alba. Se libera el espacio retro rectal bilateral para lo que se require el cambio de posición del los trocares y equipo quirúrgico al lado opuesto. Se procede a la disección cefálica y caudal retrorrectal, sobrepasando al menos 5-6cm el defecto herniario. El saco se resecará según la facilidad del procedimiento. La malla se ubicará retromuscular preaponeurótica. La fijación será con tackers o combinada con adhesivos. La fascia posterior rectal se cerrará con surget de sutura barbada, siendo el paso crítico y más difícil de la técnica, por lo que no se 
recomienda en defectos grandes. En estos casos, el cierre fascial posterior puede ser imposible o con alta tensión en la sutura. Aquí estaría indicada una técnica de separación posterior de componentes, medinate la liberación del músculo transverso abdominal (TAR), uni o bilateral de necesidad. Se abordan bilateralmente el espacio retromuscular como se describió antes, y se libera el musculo transverso, accediendo al espacio preperitoneal lateralmente, permitiendo el desplazamiento medial de la vaina rectal posterior. Cierre de la línea media anterior con polydioxanona 1, colocación de la malla de polipropileno retromuscular y finalmente el cierre sin tensión de la hoja posterior de la vaina rectal. Presenta exelentes resultados postoperatorio, similares al Rives Stoppa abierto: conversiones 3.4\%, recidivas 5.6 \% y ISQ 1.1\%. Esta técnica es altamente demandante para el cirujano que debe tener gran experiencia en cirugía parietal y laparoscópica. La cirugías robótica muestra ventajas en esta técnica. ${ }^{(33)}$

\section{2) eTEP (eTEP Rives-Stoppa)}

El abordaje totalmente extraperitoneal con vision extendida (eTEP) fue descrito por Daes inicialmente para el tratamiento de la hernia inguinal en 2012 [34], inspirado por las limitaciones del TEP clásico: un espacio quirúrgico reducido, la restricción para colocar los trócares de trabajo, la escasa tolerancia al neumoperitoneo accidental, la poca ergonomía y la dificultad para enseñr y aprender la técnica. Con este abordaje de la pared abdominal, queda la noción de lo ilimitado del espacio preperitoneal luego que se sobrepasa la confluencia de las lineas arcuata y semilunar. Según Daes (35): "El abordaje eTEP consiste en la serie de maniobras y estrategias operatorias destinadas a potenciar un espacio extraperitoneal de trabajo, para la reparación mínimamente invasiva de las hernias abdominales y la realización de otros procedimientos. Estas maniobras incluyen el acceso remoto al defecto, la creación de un gran espacio extraperitoneal y la colocación flexible de los trócares de trabajo; complementadas con la escisión de los límites naturales del espacio, como el arco del músculo transverso, el borde medial de la lámina posterior del músculo recto abdominal y la fascia posterior del músculo oblicuo menor y el músculo transverso del abdomen. La mayoría de estas maniobras se inician en posición medial a la línea semilunar, aunque es posible acceder al espacio extraperitoneal directamente en posición lateral a la línea semilunar (eTEP lateral), para reparar una hernia lumbar lateral o para practicar una triple neurotomía alta."

Este abordaje, ahora estandarizado y golbalizado, permite acceder y tratar diversas patologías: hernias inguinales, mediales primarias e incisionales, hernias laterales. Puede realizarse por técnicas endoscópicas clásicas, robóticas o híbridas. ${ }^{(35)}$

Igor Belyansky, ${ }^{(36)}$ describe la maniobra de cruce de la línea media (crossover), permitiendo la implementación de la técnica eTEP Rives-Stoppa y de la eTEP-TAR (Transversus Abdominis Muscle Release). La disección comienza en uno de los espacios retrorrectales, cruzando luego la linea media en lugar variable según la topografía de la eventración, llegando al espacio retrorrectal contralateral, generando así un amplio espacio único retrorrectal o preperitoneal según el sector del abdomen.

Las ventajas del abordaje extraperitonea sonl:disminuye el riesgo de lesión intestinal, disminuye la necesidad de retracción visceral, hace menos frecuente el íleo postoperatorio, se forman menos adherencias intraperitoneales, con sus complicaciones, hay menos efectos hemodinámicos adversos que con el abordaje intraperitoneal. Permite aplicar todos los principios actuales para la reconstrucción de la pared abdominal: el cierre primario del defecto, reconstrucción de la línea alba bajo tensión fisiológica; el refuerzo protésico extenso del saco visceral (Stoppa); la colocación de una malla convencional (polipropileno), en posición retromuscular (disminuyendo las complicaciones de la exposición visceral, mejor integración, con menos necesidad de fijación y a un costo más reducido). Permite una rápida rehabilitación y la aplicación del protocolo ERAS.

Algunas de sus desventajas son: su dominio requiere una curva de aprendizaje larga, la orientación en el espacio es difícil, el riesgo de ruptura accidental del peritoneo puede comprometer el espacio quirúrgico, la obesidad aumenta el grado de dificultad de este abordaje y no es recomendable en pacientes con cirugías extraperitoneales previas.

Es razonable iniciar la experiencia con pacientes y hernias seleccionadas (pequeñas, mediales).

Aunque raras, se han descrito complicaciones inherentes a este abordaje, como la hernia interna por dehiscencia del cierre posterior, la lesión de la línea alba durante el crossover y los grandes hematomas.

Los resultados de estudios realizados en varios países demuestran que la ténica es segura, efectiva y con grandes ventajas sobre la calidad de vida de los pacientes. No obstante, es una técnica laboriosa, que requiere un conocimiento detallado de la anatomía del espacio extraperitoneal, incluyendo sus divisiones naturales y sus estructuras neurovascu- 
lares, el amplio conocimiento teórico y de videos de cirugías realizadas por expertos, y un entrenamiento formal, que idealmente debe incluir prácticas en cadáer fresco, cursos hands on, pasantías específicas, tener un mentor en la técnica, y iniciarse en el manejo de la cirugía robótica. ${ }^{(35)(37)}$

Quedan como tareas pendientes afinar las indicaciones del procedimiento, evaluar su reproducibilidad, sus resultados estéticos y el posible sobreuso de la separación posterior de componentes-TAR. ${ }^{(35)}$

\section{A) Creación del espacio preperitoneal}

Para DFECTOS SUPRAUMBILICALES, la primera incision se realiza $2 \mathrm{~cm}$ debajo en nivel de la linea umbilical, justo por dentro de la linea semilunar derecha. Se identifica y separa en forma roma el musculo recto anterior derecho, llegando hasta la hoja posterior de su vaina y así al espacio retrorrectal, usando un balón disector, pinzas atraumáticas, o usando el efectos del $\mathrm{CO} 2$ y presionando con la ópitca. Esta maniobra debe evitar lesionar el músculo recto, la linea semilunar, los vasos epigástricos y el peritoneo. Luego de liberar hacia caudal el espacio de Retzius se colocan los siguientes trocares bajo vision, en el hemiabdomen inferior. El balón disector puede cambiarse a uno de los puertos inferiores y así avanzar hacia el sector cefálico y también abordar el espacio retrotrrectal izquierdo que se diseca en sentido de caudal a cefálico hasta la línea alba. De esta manera queda disecado todo el espacio preperitoneal y retromuscular alrededor de la eventración, que aún no se abordó. En el sector alto, se aborda el espacio preperitoneal delante de los ligamentos falciforme y umbilical, comunicando así ambos espacios retrorrectales luego de seccionar ambas vainas rectales (crossover). ${ }^{(32)}$

Se recomienda realizar el crossover inicialmente, a nivel infraumbilical, abordando un espacio virgen. Este es uno de los pasos más importantes y dificultosos de la técnica. La apertura peritoneal no debe limitar el progresos de la cirugía, si esta eventualidad dificulta la disección, se cierra la brecha transitoriamente con pinzas o se coloca una aguja de Veres para evacuar el neumoperitoneo. Cuanto más amplio es el espacio preperitoneal, estas brechas y el neumoperitoneo generan menos dificultades. ${ }^{(38)}$

Seguidamente se aborda el cuello del saco herniario, que en las eventraciones suele ser fibroso y difícil de liberar. De no reducirse fácilmente, por el plano perisacular, se abre cuidadosamente el saco cerca del cuello, se reduce el contenido visceral herniario bajo visión directa, con viscerolisis limitada de ser necesario y luego se cierre la fascia posterior del recto con sutura contínua hasta el apéndice xifoides.
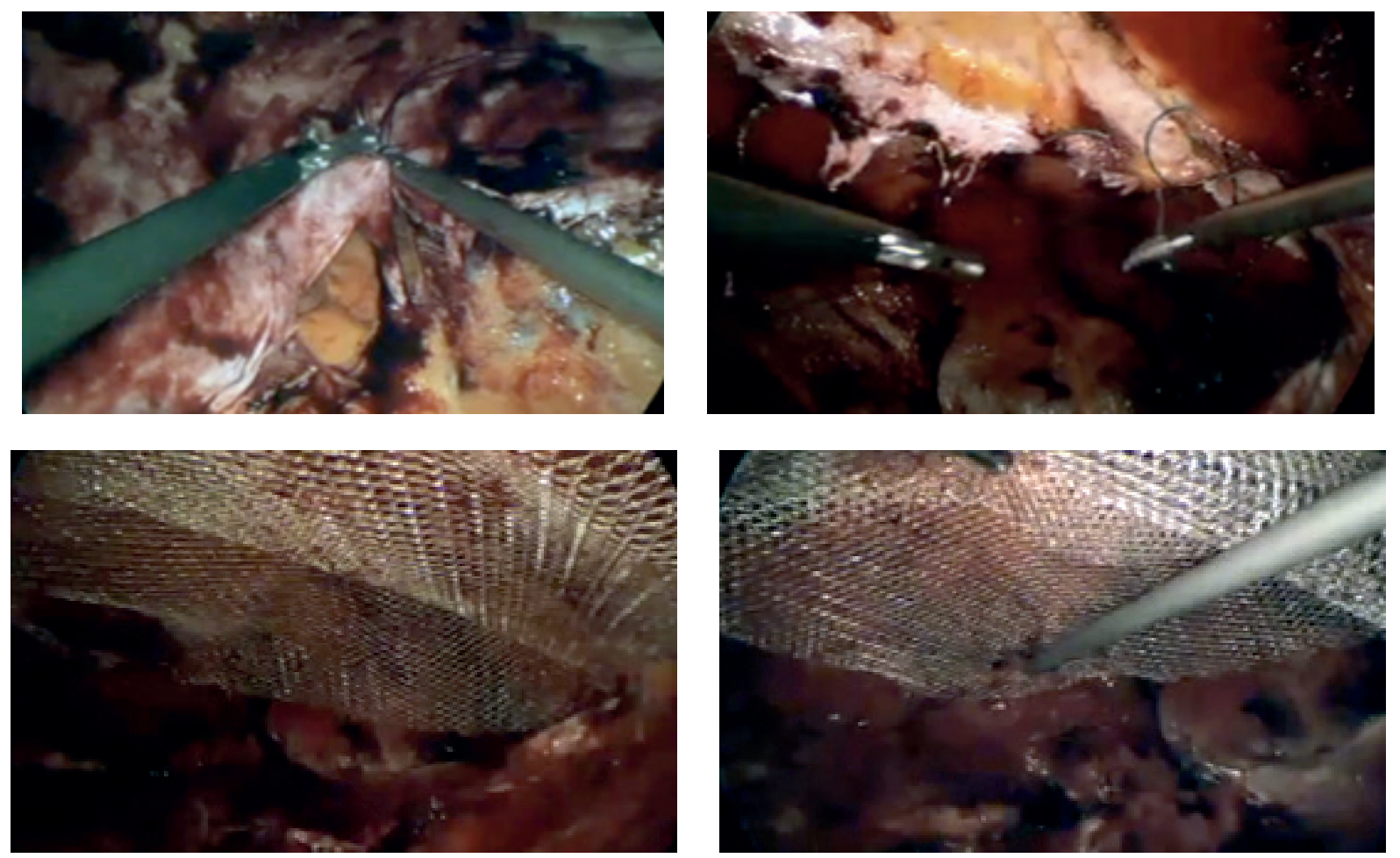

HI Medial, eTEP: cierre fascial posterior, anterior, colocación y fijación de malla de PPL (J.Daes) 
Para DEFECTOS INFRAUMBILICALES, para cirujanos diestros se aconseja el abordaje por el espacio retrorrectal izquierdo alto. Con el avance del balón disector se llega al pubis y se colocan los puertos accesorios en el espacio retrorrectal izquierdo. Como el sector supraumbilical está sano, se secciona el sector medial de la vaina del recto izquierdo, se pasa al espacio preperitoneal a nivel del ligamento falciforme y luego a traves de la vaina rectal derecha se accede al espacio retrorrectal derecho, liberandolo en sentido cefálico a caudal. Se aborda luego el saco con las mismas consideraciones descritas para $\mathrm{HI}$ supraumbilicales.

\section{B) Liberación del Transverso Abdominal (TAR)}

La tasa de recurrencia es significativamente menor cuando puede evitarse un puente del defecto con malla. La restauración de la línea media es benéfica tanto en términos de resultados funcionales como de tasa de recurrencia.

En algunos casos de defectos complejos, puede no lograrse un cierre adecuado de la fascia rectal o se realiza con tensión. En ellos, se puede asociar una liberación posterior de componentes: TAR. Se considera que el TAR es beneficioso en defectos mayores a $10 \mathrm{~cm}$ de ancho, espacios retrorrectales estrechos (menores a $5 \mathrm{~cm}$ ) o escasa compliance de la pared muscular. La TAR es eficaz en la reconstrucción parietal en las hernias de línea media amplias (M1-5, W3), así como en las hernias laterales (L1-4).

Para el TAR, se retrae la hoja posterior de la vaina rectal medialmente, se identifica la delgada lámina que recubre al músculo transverso y se corta con Hoock, medial a la linea semilunar y a la emergencia de los pedículos neurovasculares perforantes para el musculo recto anterior que se conservan. ${ }^{(39)}$ Se continua la sección con Hoock de las fibras musculares del transverso, manteniéndose por delante del peritoneo y la fascia trasversalis, en sentido caudal y cefálico. Con disección roma se separa el transverso de la fascia transversalis, permitiendo medialización fascial y el factible cierre medial de la vaina posterior del recto. El decolamiento puede extenderse hasta la línea axilar media, permitiendo una medialización de hasta $7 \mathrm{~cm}$ de la vaina rectal posterior con un TAR unilateral, realizandolo bilateralmente solo de necesidad. El cierre fascial, ahora sin tensión, se realiza con surget de sutura barbada calibre 0, bajando el neumoperitoneo a $8 \mathrm{mmHg}$. El TAR facilita también el cierre facial anterior o de la linea alba. ${ }^{(33)}$

Zolin ${ }^{(40)}$ comunica su experiencia sobre TAR en un centro de hernia de alto volúmen, recomendando una estricta selección de pacientes, tutorización inicial y optimización de la técnica, ya que a pesar de lograr buenos resultados globales iniciales, reconoce las posibilidad de graves complicaciones intra y postoperatorias.

\section{C) Cierre fascial anterior y posterior}

La vaina rectal posterior se sutura con surget de sutura reabsorbible 0 o 2-0 o barbada, desde el xifoides hasta el pubis de ser necesario, bajando el neumoperitoneo a $8 \mathrm{mmHg}$. Este paso se considera el Tendón de Aquiles de esta técnica, y su disrrupción es la principal complicación. Solamente en los casos descriptos precedentemente, se realizará el TAR uni o bilateral, para lograr la medialización de las vainas rectales y el cierre fascial sin tension. ${ }^{(32)}$

La vaina rectal anterior se sutura bajando el neumoperitoneo a $8 \mathrm{mmHg}$, facilitando un cierre sin tension. Es técnicamente difícil por quedar el plano anterior en el campo quirúrgico, sugiriéndos surget de sutura barbada con la aguja en reversa de abajo hacia arriba. Si queda un saco subcutaneo remanente, se puede incluir en la sutura de cierre para disminuir el espacio muerto y evitar el seroma postoperatorio.

\section{D) Colocación de la malla}

Luego que ambas vainas rectales están cerradas, se colocará la malla en el espacio retromuscular, previamente medido. Se prefiere una malla de Polipropileno macroporosa de mediana densidad, que se introduce por un trocar de $12 \mathrm{~mm}$. En esta ubicación, la malla permanece inmóvil y no require fijación invasiva con puntos o tackers. Las opciones son la no fijación, o la fijación con adhesivos o colas de fibrina, sin demostrarse mayores recurrencias. El neumo extraperitoneal se evacúa lentamente, controlando que la malla permanezca en posicón y sin arrugas entre ambas fascias rectales. Se colocan drenajes aspirativos en forma selectiva, premalla para prevenir seroma y hematoma.

\section{E) Separación Anterior de Componentes Subcutánea Endoscópica}

Jorge Daes ${ }^{(41)}$ en 2017, describe la separación anterior de componentes por vía subcutánea edoscópica, como adyuvante a la reparación miniinvasiva de los defectos mediales. Inicialmente 20 pacientes consecutivos, estrictamente seleccionados (defectos menores a $15 \mathrm{~cm}$ de ancho, no multioperados, entre otros) con seguimiento medio de 21 meses. Consiste en abordar el espacio subcutáneo lateral con trocares subcostales y luego el espacio entre el oblicuo mayor y menor, se llega hasta el pubis por este espacio y finalmente sección de la vaina del oblicuo mayor, 2-3 cm lateral a la línea semilunar, desde el pubis hasta reborde costal, permitiendo la medialización del anillo herniario y facilitando el cierre fascial sin tensión. No comunica recidivas, escasas complicaciones superficiales (hematoma y seroma) y buena satisfacción del paciente, concluyendo que es una técnica segura, efectiva y reproducible, que permite el mejor cierre de defectos herniarios en pacientes seleccionados. 


\section{F) Estudios publicados sobre eTEP}

Hay numerosos estudios sobre la técnica, con series cortas en opacientes y seguimiento, y similares resulatdos. Sergio Salido, ${ }^{(42)}$ intervino 40 pacientes con hernias ventrales, en 16 se asoció TAR y seguimineto de 10 meses. Publica resultados iniciales con dolor leve postoperatorio, internación promedio de un día, un caso de recidiva y 2 reintervenciones.

Belyansky y Daes ${ }^{(36)}$ en 2018, publican la experiencia sobre 79 pacientes de 5 centros, operados por hernias ventrales primarias o incisionales con técnica eTEP, logrando un óptmo cierre fascial, colocación de amplias mallas retromusculares y escasa necesidad de fijación transfascial. Concluyen que es una técnica segura y efectiva, y aguardan por estudios más extensos y a largo plazo
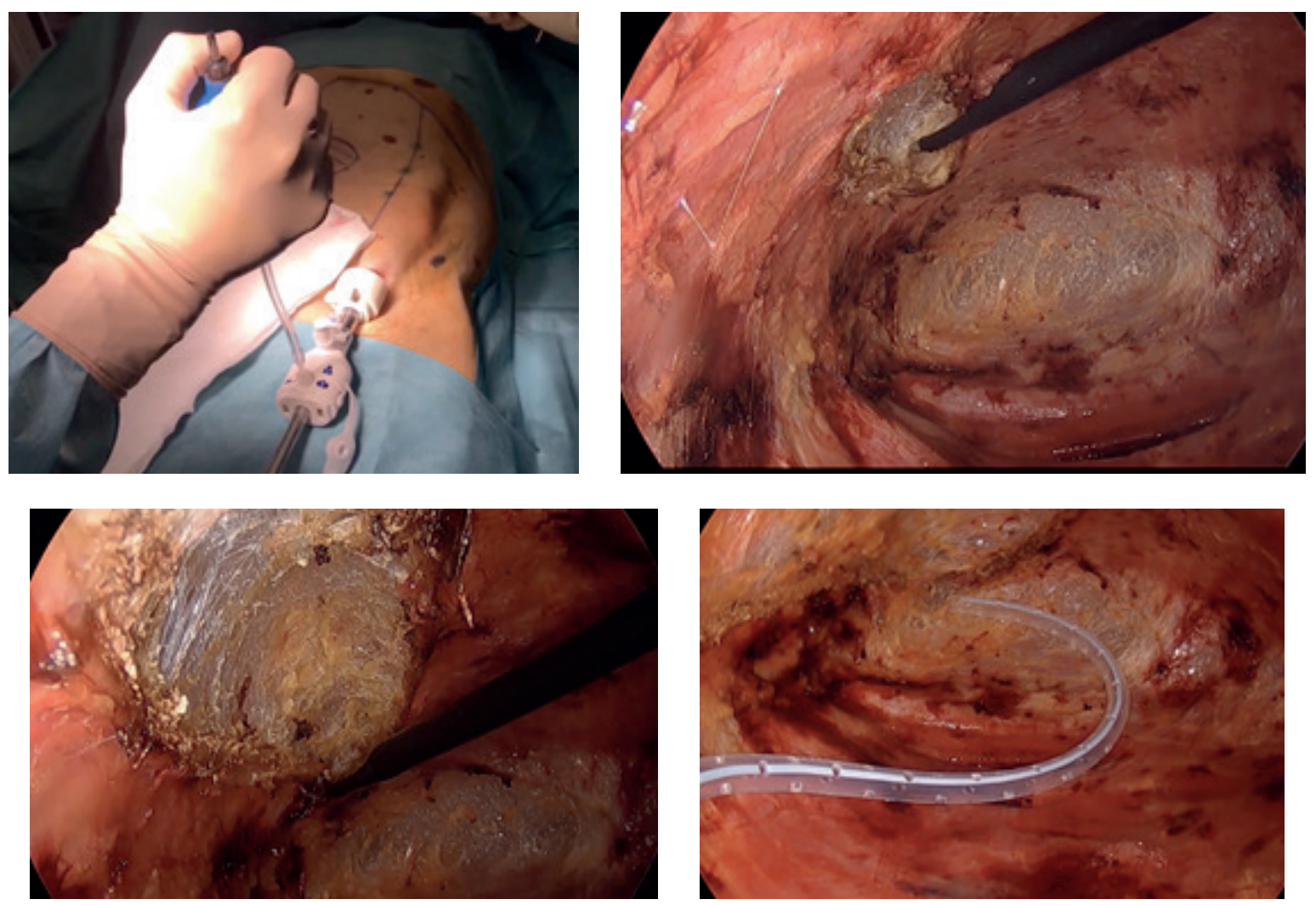

SAC endoscópica: creación del espacio entre ambos oblicuos, inicio de sección de aponeurosis de oblicuo mayor, liberación completa y drenaje aspirativo. J Molina

\section{3) Abordajes MILOS (MIni and Less Open Sublay) y EMILOS (Endoscopic MILOS)}

Consiste en una cirugía abierta con minima incisión y los criterios de miniinvasiva en la disección, colocacion de malla y fijación. Las contraindicaciones para MILOS son las mismas que para eTEP al compartir el espacio preperitoneal de tranajo.

MILOS inicia con una incision de 2-6 cm sobre el saco herniario, cuyo cuello guía al abordaje del espacio preperitoneal. Se libera y habitualmente abre el saco para tartar su contenido, que puede realizarse por vía abierta o laproscopica de ser necesario. Se cierra el saco y se aborda el espacio preperitoneal, según el tamaño del defecto herniario se definen los decolamientos necesarios y el tamaño de la malla a colocar. Se prosigue por la mini incisión, si el defecto es pequeño o en hernias medianas mediante la colocación de trocares convencionales con los criterios de eTEP descrito o inclusio un single port. Es importante preservar la linea blanca, ya que luego será cerrada cubriendo la malla. ${ }^{(32)}$

Se abre la vaina de ambos rectos bajo vision directa, labrando un amplio bolsillo retrorrectal que recibirá la malla. Esto puede realizarse también con intrumentos de laparoscopía básicos y con la ayuda de la endocamara con luz, facilitando las maniobras. Plataformas novedosas (EndoTORCH) estan en evaluación, orientadas a facilitar esta técnica. Se coloca la malla de polipropileno retromuscular, sin requerir fijación invasiva. ${ }^{(43)}$

La introdución del laparoscopio transhernario (EMILOS) en el espacio preperitoneal, fue propuesta por Reinpold, para liberar bajo vision directa los espacios retrorrectales. ${ }^{(44)} \mathrm{El}$ objetivo del abordaje y el procedimiento son los mismos 
que en MILOS, solo que utiliza instrumentos de laparoscopía y el endoscopio, logrando maniobras mas seguras y lejanas, alcanzando todo el espacio retromuscular. Pinzas tipo Foerster o incluso el balón disector, son ideales para disecar este espacio. El insuflado con $\mathrm{CO} 2$, aumenta este espacio y lo mantiene real para poder medirlo y luego extender la malla. Se realiza la misma maniobra en la vaina rectal contralateral. Pueden colocarse trocares accesorios, facilitando la disección y colocación de la malla.

\section{4) Técnicas Miniinvasivas Preaponeuróticas (Onlay): Subcutaneous Onlay Laparoscopic Approach (SCOLA)(REPA) y Endoscopic-Assisted Linea Alba Reconstruction (ELAR)}

Esta técnica, es descrita y analizada en este Relato para tartar hernias umbilicales y/o ventrales primarias con diastasis de los rectos anteriores, puede adaptarse a la resolución de eventraciones mediales pequeñas, también asociadas a diastasis de los rectos. Este mismo concepto puede adoptarse para cirugía abierta con mini incisiones y por cirugía robótica. El tratamiento simultáneo de la diastasis en estos casos es de gran importancia, dado que por la afectación anatómica y funcional de la línea media, se asocia a un alto índice de recidivas en caso de reparación aislada de la eventración. Como ya fue descrito, brevemente, esta técnica consiste en el abordaje endoscópico subcutáneo del espacio preaponeurótico, utilizando trócares en hemiabdomen inferior, con el cirujano entre las piernas del paciente. Decolamiento desde el infraumbilical hasta el apéndice xifoides, y lateral 3-4 cm cada lado (ancho total de decolamiento $15-16 \mathrm{~cm}$ ), exponiendo ambas hojas anteriores de las vainas rectales. Liberación y reducción del saco, cierre de defecto herniario con puntos separados o surget de hilo irreabsorbible o sutura barbada calibre 0 , previa decisión si se reralizará solamente la plicatura de la linea media, o su apertura y cierre borde a borde, como corrección de la diastasis de los rectos. ${ }^{(32)}$ Este cierre se extiende desde el xifoides hasta 2-3 cm subumbilical, y determina una aproximación de los rectos anteriores y la confección de una "nueva"linea alba, reforzada y mas estrecha. ${ }^{(45)(46)}$ Sobre los rectos y linea alba se coloca una malla de Polipropileno macroporosa de densidad mediana, previamente medida para adaptarla al espacio subcutaneo creado y se fija con varios puntos o surget de hilo reabsorbible $2 / 3-0$, adhesivos, tackers absorbibles o combinación de ellos. ${ }^{(47)}$ Se colocan 2 drenajes aspirativos subcutaneos y se indica el uso de faja elástica por 6 semanas.

El abordaje endoscópico para la corrección de la diástasis de rectos asociado a hernias de la línea media con colocación de una prótesis de refuerzo preaponeurótico aumenta la seguridad de la plastia y, además, provee buenos resultados cosméticos. ${ }^{(2)(48)}$

\section{INTERVENCIONES COMPLEMENTARIAS PREOPERATORIAS}

\section{EN LA REPARACIÓN DE LA HI}

Técnicas como el neumoperitoneo progresivo (PPP), el expansor tisular (TE) y, más recientemente, la toxina botulínica A (TBA) han ganado interés como complemento del abordaje quirúrgico de las grandes $\mathrm{HI}$ para lograr el cierre fascial primario (CFP). Estas se realizan en el preoperatorio y pueden permitir un abordaje mini invasivo de una $\mathrm{HI}$ que primariamente sería para cirugía abierta por sus dimensiones y riesgos de reintroducción del contenido del saco herniario. Resumimos las recomendaciones de la Sociedad Hispanoamericana de Hernia en su reciente guía. ${ }^{(2)}$

La aplicación de toxina botulínica A (TBA) antes de la reparación de la HV se asocia con un uso menor de analgesia opioide y menos dolor, es segura, sin complicaciones ni eventos adversos relacionados con la TBA. Esta disminuye el diámetro transversal de la hernia, reduce el grosor y alarga significativamente los músculos laterales de la pared abdominal. Se aplica en tres o cinco sitios de inyección en cada lado de la pared abdominal bajo guía ecográfica, demostrando la efectividad entre cuatro a seis semanas antes de la cirugía. En la mayoría de los pacientes con grandes HV la sola aplicación de TBA permite el cierre fascial directo sin técnicas de separación de componentes adicionales.

El neumoperitoneo preoperatorio progresivo (PPP) puede aumentar el volumen de la cavidad abdominal, incrementando la longitud de los músculos de la pared abdominal lateral, lo que permite un potencial cierre fascial primario sin tensión. Los eventos adversos relacionados con el PPP son: dolor de hombro, enfisema, neumotórax e infección del catéter.

El expansor tisular tiene potencial como complemento en la reconstrucción de la pared abdominal. No hay consenso sobre indicaciones, técnica óptima y riesgos asociados a los expansores de tejidos (ET). 


\section{INDICACIONES DE LAS TÉCNICAS DE SEPARACIÓN ANATÓMICA DE COMPONENTES (SAC)}

Las técnicas de separación de componentes son herramientas quirúrgicas para la reconstrucción (cierre fascial) de la hernia incisional compleja (grandes o escasa elasticidad parietal), y han ganado gran difusión en los últimos años, surgiendo como alternativa al las técnicas preoperatorias antes mencionadas.

Una técnica de separación de componentes (SAC) está indicada cuando no sea posible cerrar la línea alba sin tensión en la reparación de la hernia incisional ventral y se recomienda combinarla con el uso de malla, de elección retromuscular, para reducir recurrencias. ${ }^{(2)}$

Tienen complicaciones que involucran a la piel y al tejido celular subcutáneo: isquemia (interrupción de los vasos perforantes por disección excesiva o no controlada de los colgajos), seroma, hematoma y la hipotonía parietal (por denervación de los músculos anchos del abdomen). El conocer bien la anatomía de la pared abdominal permite evitar daños indeseables en la pared abdominal que aumentan su morbilidad.

Las técnicas de separación de componentes más comunes son:

- Separación anterior abierta de componentes (SAAC).

- Liberación del transverso del abdomen (TAR).

- Separación anterior endoscópica (SAE).

- Separación abierta con preservación anterior de perforantes (SAPP).

La SAAC tiene la mayor morbilidad de la herida, por lo que se recomiendan las técnicas miniinvasivas, que además tienen menor estadía hospitalaria. No hay diferencias de tasas de cierre fascial, recurrencia ni en costos entre las diferentes técnicas aneriores ni comparadas con el TAR.

En campos contaminados se recomienda considerar la SAC para obtener el cierre fascial cuando no se usará malla. En hernias laterales y en las recurrentes, después de realizar una separación de componentes anterior (SAAC), la TAR es una opción para la reconstrucción de la pared abdominal.

Se desaconseja la realización simultánea de SAC y TAR en el mismo lado. Esto provoca denervación y desestabilza funcionalmente la pared, generando hipotonía y una hernia de flanco a corto plazo. ${ }^{(2)}$

Dada la complejidad técnica del TAR, la cirugía robótica aparece como un abordaje ideal. No se han publicado ensayos controlados aleatorios que comparen TAR abierta y laparoscópica o robótica, solo estudios retrospectivos que comparan los resultados de TAR abierto y rTAR. Algunos estudios han mostrado que rTAR tiene un mayor tiempo operatorio que TAR abierto; sin embargo, hay menor pérdida de sangre, menos complicaciones sistémicas y estancia hospitalaria más corta. Tanto la TAR abierta como la mínimamente invasiva son procedimientos seguros y con la misma incidencia de morbilidad de la herida posoperatoria.

\section{EDUCACIÓNY ENTRENAMIENTO EN EL}

La educación y el entrenamiento requieren de especial atención, ya que la complejidad de la EL, genera una curva de aprendizaje prolongada.

\section{Educación ${ }^{(2)(46)}$}

El reparo laparoscópico de la hernia ventral ha evolucionado significativamente desde sus comienzos, lo que nos permite mejorar la morbilidad y la calidad de vida de nuestros pacientes, cuando se practica en las circunstancias y ambiente adecuados. Su futuro se presenta prometedor en la medida en que se mejore la enseñanza de destrezas, se desarrolle la tecnología que incluye la robótica (con la tendencia natural a que disminuya su costo y complejidad actuales), se refine la utilización de las redes sociales para la educación en cirugía de hernia, se continúe implementando la especialidad en este campo quirúrgico y se encuentren mejores alternativas para la evaluación científica de los resultados obtenidos. ${ }^{(46)}$

La deficiencia de la medicina basada en la evidencia en aportar respuestas definitivas a los problemas del reparo ventral, en gran parte debido al número inmenso de variables involucradas, hace que un aprendizaje global no tenga aplicación local. Son la experiencia, la evaluación de los procesos y la mejoría clínica continua las que tienen mayor influencia a 
nivel local y regional. La destreza individual hace que un método sea mejor en un centro hospitalario específico, a pesar de que la evidencia no lo avale.

La falta de procesos de selección adecuada de pacientes para una técnica específica, y la falta la estandarización de las técnicas quirúrgicas, conspira con el avance científico el este tema. En gran parte se debe a la rápida adopción de nuevas técnicas, insumos y tecnología a un ritmo tal que no nos permite su evaluación adecuada, la comparación de resultados con otros grupos o incluso el establecimiento de la causa exacta de la mejora en los resultados o de una complicación.

\section{Entrenamiento $^{(2)(46)}$}

Es necesaria la implementación de programas específicos de entrenamiento en cirugía de pared abdominal en centros de referencia o de alto volumen de estas operaciones, con personal docente con amplia experiencia en ellas y que ofrezcan la posibilidad de participar en un número «suficiente» de intervenciones de este tipo.

Es difícil establecer un número específico de procedimientos para considerar que se ha superado la curva de aprendizaje, y esta definición probablemente deba hacerse en función de la evaluación de competencias.

La simulación y el empleo de recursos tecnológicos, como la realidad virtual o los sistemas computarizados de entrenamiento virtual, podrían contribuir al acortamiento de las curvas de aprendizaje en las reparaciones de defectos herniarios de la pared abdominal, especialmente en los abordajes de mínima invasión.

La tutoría a distancia (tele-mentoring o tele-proctoring) podría ser una opción para introducir en la cirugía de hernia ventral endoscópica a cirujanos con experiencia en técnicas avanzadas de mínima invasión.

Se recomienda implementar programas de residencia o de ampliación de conocimientos específicamente en cirugía de pared abdominal, con especial orientación al manejo de casos complejos, que salen del campo habitual de competencia por «cirujanos generales». (46)

\section{CIRUGÍA ROBÓTICA EN LA REPARACIÓN DE LAS HI}

En centros especializados, la eventroplastia robótica, ha ganado su lugar inicialmente en casos complejos y actualmente con indicaciones en expansión.

La cirugía robótica mejora aspectos ergonómicos, ofrece visión en 3D y facilita maniobras complejas como la sutura y el anudado. Las desventajas principales son el costo de estos sistemas y los tiempos quirúrgicos más prolongados.

Los estudios que comparan la técnica IPOM laparoscópica contra la cirugía robótica no han logrado demostrar las ventajas de la robótica en términos de costos, tiempos quirúrgicos, pérdidas sanguíneas o estancia hospitalaria, por lo que $\mathrm{NO}$ se recomienda actualmente para su uso rutinario. ${ }^{(49)}$
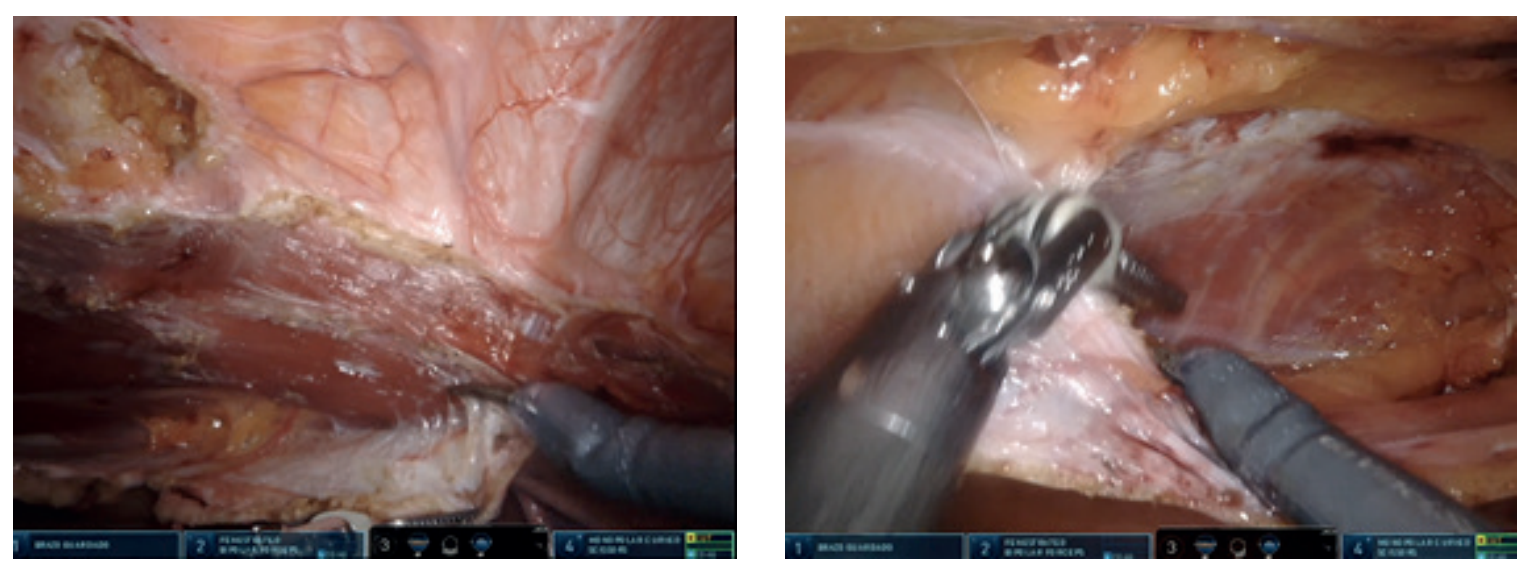

Abordaje espacio retro rectal. TAR derecho 

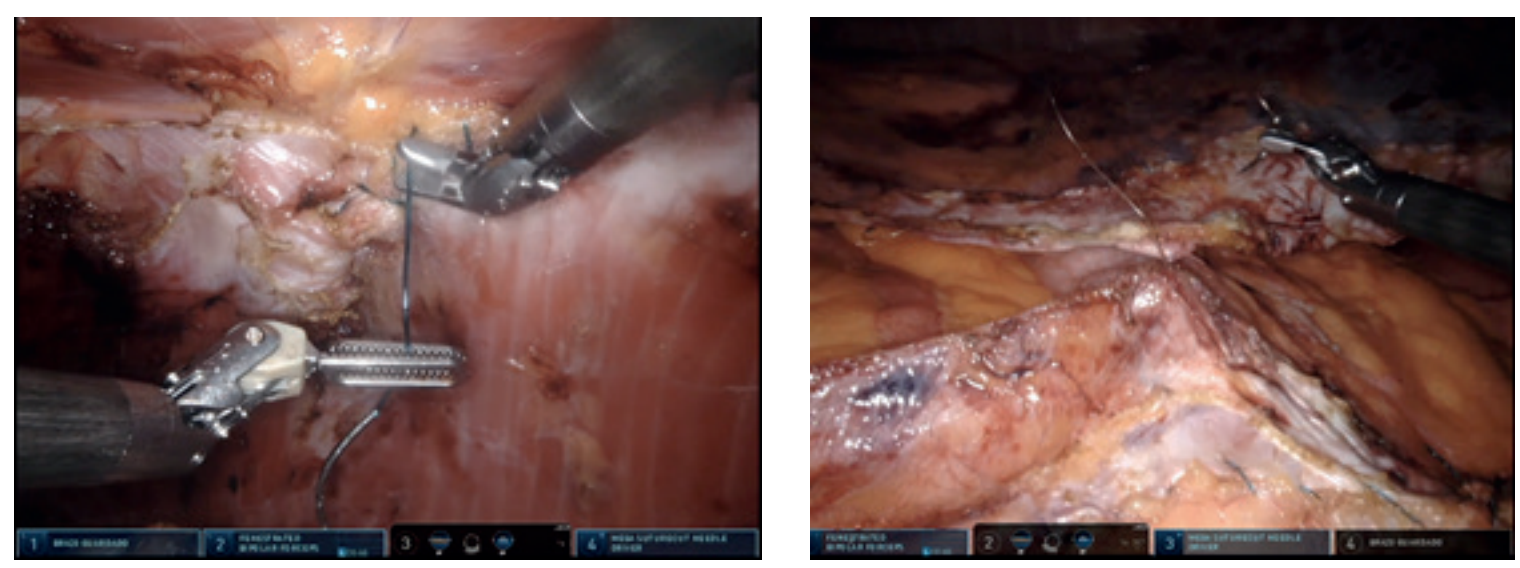

Cierre de fascial anterior y posterior

Hay pocos estudios que comparen en procedimientos más complejos, como: cierre de defectos grandes, reparaciones retromusculares (Rives-Stoppa) o separación posterior de componentes con sección del transverso abdominal (TAR), en los que las ventajas potenciales de los sistemas de cirugía robótica podrían mostrar su valor, haciendo estas técnicas mas accesibles a todos los cirujanos. Su desarrollo persiste en la órbita de centros altamente especializados en cirugía parietal y robótica. ${ }^{(2)}$

\section{MANEJO DE LA RECIDIVA DE UNA HI}

Esta patología es altamente costosa para los sistemas de saludo, estimándose que en EEUU una reducción del 1\% en el ínidice de re eventraciones, permitiría un ahorro de 3.2 millones de dólares. Los esfuerzos por prevenir esta complicación son constantes. A pesar de ello, las recurrencias mantienen una alta incidencia, siendo más alta (hasta 44\%), en cuanto aumenta el numero de reparaciones parietales del paciente. ${ }^{(50)(51)}$

El tamaño del anillo (mayor a 7-8 cm), la infección de herida, el embarazo luego de una reparación parietal y el número de reparaciones previas, son los factores más importantes en la recurrecia de la HI..$^{(2)(7)(9)(52)}$

La incidencia reportada de recidiva CON el uso de malla en hernia incisional es del 10\% a 1 año, $25 \%$ a 5 años y del $32 \%$ después de 10 años. ${ }^{(20)}$

Los factores que hacen dificultosa esta cirugía, son: anatomía de la pared alterada por reparaciones previas; malla/s colocada en diferentes planos, a veces infectada, con variable componente inflamatorio cronico; variables e impredecibles adherencias viscerales intraperitoneales o a la malla. ${ }^{(50)}$ Las infecciones superficiales o profundas, si es posible, deben tratarse y estabilizarse perviemante a la definición del abordaje y táctica terapéutica, no siendo una contraindicación formal de abordaje laparoscópico. El plazo ideal para realizar la eventroplastia, sería de 4-6 semanas sin infección local o sistémica. Situaciones como pérdida de derecho a domicilio o afectación severa de la piel, ya fueron mencionados y su tratamiento no es objetivo de este Relato.

Es imperioso analizar la causa del fracaso previo, intentando evitar la falla cometida en el pre (selección, preparación del paciente), intra (táctica o técnica inadecuada) o postoperatorio (seguimiento y recomendaciones), que motivó o motivaronla recurencia. El énfasis en este concepto preventivo, lo consideramos de mayor jerarquía que la planificación y ejecución de la nueva reparación.

El estudio completo y preparación (general y local) del paciente así como la calidad y corecta interpretación de la TAC/ RNM solicitada, son factores guías en la planificacíon del abordaje quirúrgico. La recidiva puede tratarse por abordaje abierto o abordaje endoscópico, ya sea después de cirugía abierta o endoscópica previa. Se aconseja derivar a un cirujano experto.

Los argumentos a favor del abordaje laparoscópico/endoscópico tras una recidiva por vía abierta, son que las reoperaciones se realizan en una zona anatómica diferente, puede cubrirse todo el defecto con una malla, se evita la disección extensa de la pared abdominal al no tener que retirar la malla previa y permite diagnosticar hernias ocultas. Se asocia a menor morbilidad parietal, dolor y tasa de recurrencias (3.5-5.8\% a 3 años), aún luego de varias cirugias previas. ${ }^{(52)}$ 

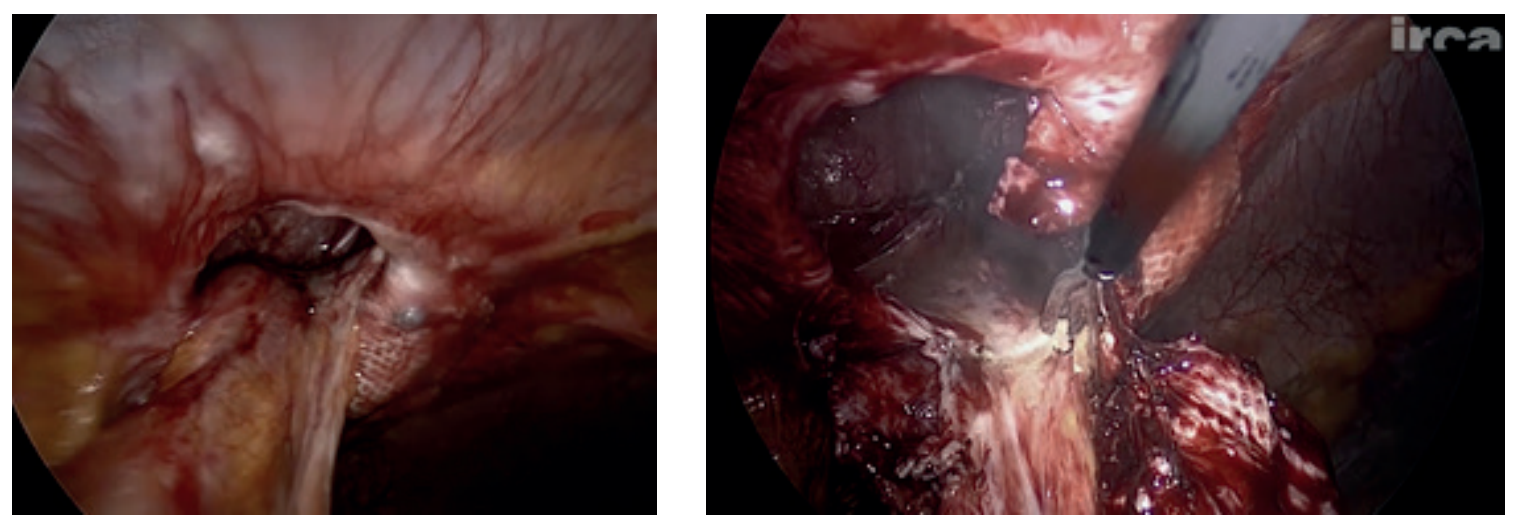

Recidiva de IPOM. Tomado de WebSurg

Hay descripciones de cirugía híbrida (o laparoscópica asistida) en estos complejos pacientes: 1) tratamiento de la piel, el saco y el contenido por vía abierta anterior, con viscerolisis segura y exploración de adherencia parietales para una correcta colocación de trócares y fácil cierre fascial posterior; 2) eventroplastia laparoscópica intraperitoneal, con trócares insertados bajo control visual o manual, y colocación de amplia malla combinada, con los criterios de técnica IPOM PLUS. ${ }^{(53)}$

Los estudios disponibles sobre la reparación endoscópica de las HI recidivadas después de una reparación abierta o sin malla demuestran un riesgo mayor de complicaciones intraoperatorias (lesiones intestinales) y posoperatorias (infección, seroma) que ante una cirugía primaria. Varían en función de las características de la hernia y del tipo y número de reparaciones previas. No se recomienda retirar las mallas previas si están bien integradas. ${ }^{(20)}$

\section{Recomendaciones:}

1) Se recomienda abordaje abierto en pacientes con comorbilidades, defectos grandes $(>8 \mathrm{~cm})$, con técnica IPOM laparoscópica previa, con síndrome adherencial intraabdominal, malla infectada, fistula intestinal o piel comprometida.

2) Se recomienda abordaje laparoscópico en: defectos $<8 \mathrm{~cm}$, reparaciones previas por vía abierta con o sin malla y por un cirujano experto en reparición laparoscópica.

Se considera la laparoscopia una excelente opción para la corrección de recidivas cuando está bien indicada.

\section{EVENTROPLASTIA EN CAMPO CONTAMINADO}

La infección del sitio quirúrgico, es un factor determinante en la morbilidad general del paciente, selección de oportunidad y táctica terapéutica, entre ellas, la eventual vía laparoscópica. El reconocido mayor índice de recidivas y posibilidad de nuevas complicaciones sépticas postoperatorias, jerarquizan este problema. ${ }^{(54)(55)}$

Decidida la indicación de la eventroplastia a pesar de estar con una ISQ, la vía de abordaje, y el sitio y tipo de malla a colocar pasan a ser las preocupaciones del cirujano.

Para la elección del tipo de malla se considera la resistencia a la infección y la recurrencia. Las mallas biológicas tienen buena resistencia a la infección (15-36\%) pero alta tasa de recidiva herniaria (12\%) ${ }^{(56)}$ y no requiere su extracción ante su propia infección. ${ }^{(57)}$

Lopez et al. compara el uso de malla biológica y sintética en campo contaminado, obteniendo igual tasa de infección parietal con una recurrencia de para malla biológica (35\%) vs (8.3\%) en malla sintética. ${ }^{(58)}$ Están en estudio las mallas "biosintéticas" con $28 \%$ de infecciones y $17 \%$ de recurrencias a 2 años, ${ }^{(59)}$ aún se requiere mayor evidencia para su recomendación.

Actualmente se considera de elección, la reparación con máximas medidas de asepsia, por equipo especializado y malla sintetica irreabsorbible, para la reparación de eventraciónes en campo contaminado. ${ }^{(50)}$ 


\section{BIBLIOGRAFIA}

1) Moreno Egea A. Reparación laparoscópica de la eventración de línea media En Eventraciones. Otras hernias de la pared y cavidad abdominal Fernando CarbonelTatay Alfredo Moreno Egea (42) 521-532 Valencia, 2012

2) González LG, Lora A, Varela E, Vergara G, Vega Peña V, Ayala JC, Martínez JD, Hanssen A, Gómez JP, Ruiz JP. Guía para el tratamiento laparoscópico de la hernia ventral e incisional. Rev Hispanoam Hernia. 2021;9(2):105117

3) Sharma A. Berger D The current role of laparoscopic IPOM repair in abdominal wall reconstruction Hernia 2018 (22); 739-741

4) LeBlanc KA, Elieson MJ, Corder JM III. Enterotomy and mortality rates of laparoscopic incisional and ventral hernia repair: a review of the literature. JSLS. 2007;11(4):408-14.

5) Moreno Egea A. Intra Peritoneal Onlay Mesh Plus (IPOM Plus) (11) 125-132 En Manual práctico de cirugía endoscópica de la pared abdominal Ezequiel Mariano Palmisano 1a ed. Ciudad Autónoma de Buenos Aires: Autores de Argentina, 2020 Libro Digital : online ISBN 978-987-87-1035-8

6) Adrales GL. Coker AM. Society of American Gastrointestinal and Endoscopic Surgeons (SAGES) 201911 S. S. Davis Jr. et al. (eds.), The SAGES Manual of Hernia Surgery, https://doi.org/10.1007/978-3-319-78411-3_2

7) Bittner R, Bain K, Bansal VK, et al. Update of Guidelines for Laparoscopic Treatment of Ventral and Incisional Abdominal Wall Hernias (International Endohernia Society (IEHS))-Part A y B. Surg Endosc. 2019;33:30693139. DOI:10.1007/s00464-019-06907-

8) Tulloh B, de Beaux A. Defects and donuts:the importance of the mesh:defect area ratio. Hernia 2016; 20:893- 5. https://doi.org/10.1007/s10029-016-1524-4 (4)

9) Morales Conde S, Barranco Moreno A, Socas Macías M. Cirugía laparoscópica para el tratamiento de las hernias ventrales (20) 217-228 Guías Clínicas de la Asociación Española de Cirujanos Cirugía de la Pared Abdominal 2a Edición 2013

10) Suwa K, Okamoto T, Yanaga K. Closure versus non-closure of fascial defects in laparoscopic ventral and incisional hernia repairs: a review of the literature. Surg Today. 2016;46:764-73

11) Franklin ME, Gonzalez JJ, Glass JL, Manjarrez A. Laparoscopic ventral and incisional hernia repair: 11-year experience. Hernia. 2004;8:23-7.

12) Hamby PM. Hernández MA. FranklinJr ME. Bridging Versus Closing the Defect During MIS Ventral Hernia Repair: Pros and Cons (C) Society of American Gastrointestinal and Endoscopic Surgeons (SAGES) 2019173 S. S. Davis Jr. et al. (eds.), The SAGES Manual of Hernia Surgery, https://doi.org/10.1007/978-3-319-78411-3

13) Chelala E, Thoma M, Tatete B, Lemye AC, Dessily M, Alle JL. The suturing concept for laparoscopic mesh fixation in ventral and incisional hernia repair: mid-term analysis of 400 cases. Surg Endosc. 2007;21:391-5.

14) Papageorge CM, Funk LM, Poulose BK, Philips S, Rosen MJ, Greenberg JA. Primary fascial closure during laparoscopic ventral hernia repair does not reduce 30-day wound complica- tions. Surg Endosc. 2017;31(11):45517. https://doi.org/10.1007/s00464-017-5515-z.

15) Wennergren JE, Askenasy EP, Greenberg JA. Laparoscopic ventral hernia repair with primary fascial closure versus bridged repair: a risk adjusted, comparative study. Surg Endosc. 2016;30:3231-8.

16) Orenstein SB, Dummer JL, Monteagudo J, Poi MJ, Novitsky W. Outcomes of laparoscopic ventral hernia repair with routine defect closure using "shoelacing" technique. Surg Endosc. 2011;25:1452-7

17) Clapp ML, Hicks SC, Awad SS, Liang MK. Trans-cutaneous Closure of Central Defects (TCCD) in laparoscopic ventral hernia repairs (LVHR) World J Surg. 2013;37:42-51. doi: 10.1007/s00268-012-1810-y. [PubMed] [CrossRef] [Google Scholar]

18) Ahonen-Siirtola M, Nevala T, Vironen J, Kössi J, et al Laparoscopic versus hybrid approach for treatment of incisional ventral hernia: a prospective randomised multicentre study, 1-year results Surgical Endoscopy 2020; 34:88-95 https://doi.org/10.1007/s00464-019-06735-9

19) A Tandon, S Pathak, N J R Lyons, QM Nunes, I R Daniels, N J Smart Meta-analysis of closure of the fascial defect during laparoscopic incisional and ventral hernia repair British Journal of Surgery, Volume 103, Issue 12, November 2016, Pages 1598-1607, https://doi.org/10.1002/bjs.10268

20) Roca Domínguez B, Gutiérrez Ferreras AI, Mayagoitia JC. Guía para el manejo de la hernia ventral e incisional medial. Rev Hispanoam Hernia. 2021;9(2):80-87

21) Rastegarpour A, Cheung M, Vardhan M, et al. Surgical mesh for ventral incisional hernia repairs: Understanding mesh design. Plast Surg. 2016;24(1):41-50.

22) Majumder A, Winder JS, Wen Y, Pauli EM, Belyansky I, Novitsky YW. Comparative analysis of biologic versus synthetic mesh outcomes in contaminated hernia repairs Surgery 2016; 160:828-838

23) Earle D. How to Choose a Mesh in Hernia Repair (8), 97-108 Society of American Gastrointestinal and Endoscopic Surgeons (SAGES) 201997 S. S. Davis Jr. et al. (eds.), The SAGES Manual of Hernia Surgery, https://doi.org/10.1007/978-3-319-78411-3_8 
24) Moreno-Egea A. Sobre el uso de pegamento en la cirugía de las hernias. Técnica de fijación combinada en la eventroplastia laparoscópica Cir esp. 2014;92(1):53-57

25) Stoikes N,Webb D, Voeller G.Prosthetic Fixation (7);85-96 Society of American Gastrointestinal and Endoscopic Surgeons (SAGES) 2019173 S. S. Davis Jr. et al. (eds.), The SAGES Manual of Hernia Surgery, https://doi. org/10.1007/978-3-319-78411-3

26) Mathes T, Prediger B, Walgenbach M, Siegel R. Técnicas de fijación de mallas en la reparación de las hernias ventrales primarias o incisionales Cochrane Database of Systematic Reviews Version published: May $2021 \mathrm{https} / / /$ doi.org /10.1002/14651858.CD011563.pub2

27) Bansal V, Asuri K, Panaiyadiyan S, Kumar S, Subramaniam R, Ramachandran R, et al. Comparison of absorbable versus nonabsorbable tackers in terms of long-term outcomes, chronic pain, and quality of life after laparoscopic incisional hernia repair: a randomized study. Surg Laparosc EndoscPercutan Tech. 2016;26(6):476-83.

28) Wassenaar E, Schoenmaeckers E, Raymakers J, van der Palen J, Rakic S. Mesh-fixation method and pain and quality of life after laparoscopic ventral or incisional hernia repair: a randomized trial ofthree fixation techniques. Surg Endosc. 2010;24(6):1296-302.

29) Beldi G, Wagner M, Bruegger L, Kurmann A, Candinas D. Mesh shrinkage and pain in laparoscopic ventral hernia repair: a randomized clinical trial comparing suture versus tack mesh fixation. Surg Endosc. 2011;25(3):749-55.

30) Gómez-Menchero J. Guadalajara Jurado JF. Suárez Grau JM. Bellido Luque JA. García Moreno JL. Alarcón del Agua S. Morales-Conde S. Laparoscopic intracorporeal rectus aponeuroplasty (LIRA technique): a step forward in minimally invasive abdominal wall reconstruction for ventral hernia repair (LVHR) Surgical Endoscopy (2018) 32:3502-3508 https://doi.org/10.1007/s00464-018-6070

31) Aguirre M.Trans Abdominal Pre Peritoneal Ventral (TAPP Ventral) (12); 133-142 En Manual práctico de cirugía endoscópica de la pared abdominal Ezequiel Mariano Palmisano 1a ed. Ciudad Autónoma de Buenos Aires: Autores de Argentina, 2020 Libro Digital : online ISBN 978-987-87-1035-8

32) de Oliveira FMM. Cavazzola LT. Weltz AS. Belyansky I. Ventral Abdominal Hernia Repair: MIS Extraperitoneal Repair Techniques: eTEP Rives, MILOS/EMILOS, and Onlay MIS Repair (20);271-290 Endoscopic Surgeons (SAGES) 2019271 S. S. Davis Jr. et al.(eds.), The SAGES Manual of Hernia Surgery, https://doi.org/10.1007/9783-319-78411-3_20

33) Ashwin A. Masurkar A.A. Laparoscopic Trans-Abdominal Retromuscular (TARM) Repair for Ventral Hernia: A Novel, Low-Cost Technique for Sublay and Posterior Component Separation 2019 World J Surg https://doi. org/10.1007/s00268-019-05298-z

34) Daes J. The enhanced view-totally extraperitoneal technique for repair of inguinal hernia. Surg Endosc. 2012;26(4):1187-9.

35) Daes J Abordaje extraperitoneal de vista extendida (eTEP) para la reparación de hernias cir esp. 2020;98(5):249250

36) Belyansky I, Daes J, Radu VG, Balasubra-manian R, Zahiri HR, Weltz AS. A novel approach using the enhancedview totally extraperitoneal (eTEP) technique for laparoscopic retromuscular hernia repair. Surg Endosc. 2018;32(3):1525-32.

37) Daes J, Telem D. The principled approach to ventral hernia repair. Revista Colombiana de Cirugia. 2019;34:25-8.

38) Lora A. Totalmente extraperitoneal de vision extendida Rives (eTEP Rives) (13);143-152 En Manual práctico de cirugía endoscópica de la pared abdominal Ezequiel Mariano Palmisano $1^{\mathrm{a}}$ ed. Ciudad Autónoma de Buenos Aires: Autores de Argentina, 2020 Libro Digital : online ISBN 978-987-87-1035-8

39) Ramana B. E. Arora E. Belyansky I. Signs and landmarks in eTEP Rives-Stoppa repair of ventral hernias Hernia https://doi.org/10.1007/s10029-020-02216-4

40) Zolic SJ. Fafaj A. Krpata DM. Transversus abdominis release (TAR): what are the real indications and where is the limit? Hernia https://doi.org/10.1007/s10029-020-02150-Accepted: 19 February 2020 Springer

41) DaesJ. Dennis RJ. Endoscopic subcutaneous component separation as an adjunct to abdominal wall reconstruction Surg Endosc (2017) 31:872-876 DOI 10.1007/s00464-016-5045-0

42) Salido Fernandez S. Vía totalmente extraperitoneal extendida (eTEP) para la correccion de hernias ventrales: resultados preliminares Cir Esp. 2020;98(5):260-266

43) Reinpold W, Schröder M, Schröder A, Berger C, Nehls J, Stoltenberg W, Köckerling F. Minimally invasive sublay mesh repair of incisional and primary abdominal wall hernias using the MILOS technique. Eur Surg. 2017;49:5964.

44) Schwarz J, Reinpold W, Bittner R. Endoscopic mini/less open sublay technique (EMILOS)—a new technique for ventral hernia repair. Langenbeck's Arch Surg. 2017;402:173-80.

45) Juares Muas D. Reparación Endoscópica Pre Aponeuóticas (REPA) (14);153-162 En Manual práctico de cirugía endoscópica de la pared abdominal Ezequiel Mariano Palmisano 1a ed. Ciudad Autónoma de Buenos Aires: Autores de Argentina,2020 Libro Digital : online ISBN 978-987-87-1035-8 
46) Belyansky I, Zahiri HR, Park A. Laparoscopic transversus abdominis release, a novel minimally invasive approach to complex abdominal wall reconstruction. Surg Innov. 2016;23(2):134-41

47) Köckerling F, Botsinis MD, Rohde C, Reinpold W, Schug-Pass C. Endoscopic-assisted linea alba reconstruction. New technique for treatment of symptomatic umbilical, trocar, and/or epigastrichernias with concomitant rectus abdominis diastasis. Eur Surg. 2017;49:71-5.

48) Daes J. Evolución de la reparación laparoscópica de las hernias ventrales y del sitio de la incisión. Rev hispanoam hernia. 2016;4(3):83-85 2255-2677/(C 2016 Sociedad Hispanoamericana de Hernia. Elsevier España

49) Petro $C$ Zolin $S$ Patient reported outcomes of robotic vs laparoscopic ventral hernia repair The prove it randomized clinical trial Jama Surg 2021; (156), 1:22-29

50) Horne C, A. Prabhu Recurrent Ventral Hernia Repair (26);359-372 Society of American Gastrointestinal and Endoscopic Surgeons (SAGES) 2019 S. S. Davis Jr. et al. (eds.), The SAGES Manual of Hernia Surgery, https:// doi.org/10.1007/978-3-319-78411 3_26

51) Cox TC, Blair LJ, Huntington CR, Colavita PD, Prasad T, Lincourt AE, Heniford TB, Augenstein VA. The cost of preventable comorbidities on wound complication in open ventral hernia repair. J Surg Res. 2016;206:214-22.

52) Hauters P, Desmet J, Gherardi D, Dewaele S, Poilvache H, Malvaux P. Assessment of predicive factors for recurrence in laparoscopic ventral hernia repair using a bridging technique. Surg Endosc. 2017;1:1-8.

53) Stoikes N, Quasebarth M, Brunt LM. Hybrid ventral hernia repair: technique and results. Hernia.2013;17:627-32.

54) Kaoutzanis C, Leichtle SW, Mouawa NJ, et al. Risk factors for postoperative wound infections and prolonged hospitalization after ventral/incisional hernia repair. Hernia. 2015;19:113-23.

55) Heniford BT, Park A, Ramshaw BJ, Voeller G. Laparoscopic repair of ventral hernias: Nine years' experience with 850 consecutive hernias. Ann Surg. 2003;238:391-400

56) Atema JJ, Furnee EJ, Maeda Y, Warusavitarne J, Tanis PJ, et al. Major complex abdominal wall repair in contaminated fields with use of non-cross-linked biologic mesh: a dual institution experience. World J Surg. 2017;14:1993-9.

57) The Ventral Hernia Working Group. Incisional ventral hernias: review of the literature and recommendations regarding the grading and technique of repair. Surgery. 2010;148:544-8.

58) Lopez-Cano M, Quiles MT, Pereira JA, Armengol-Carrasco M, Via MAA. Complex abdomi- nal wall hernia repair in contaminated surgical fields: factors affecting the choice of prosthesis. Am Surg. 2017;83:583-9.

59) Rosen MJ, Bauer JJ, Harmaty MD, et al. Multicenter, prospective longitudinal study of the recurrence, surgical site infection and quality of life after contaminated ventral hernia repair using biosynthetic absorbable mesh. The COBRA study. Ann Surg. 2017;265:205-11. 


\title{
TRATAMIENTO LAPAROSCÓPICO DE LA HERNIA INCISIONAL LATERAL
}

\author{
Dr. Gonzalo Estapé
}

\section{Definición Incidencia}

Se entiende por hernia incisional no medial o lateral, a todo defecto secundario de pared abdominal localizado por fuera de la línea alba y originado a través de una incisión previa. Por tanto, incluye en un mismo grupo todos los defectos laterales (paramedianos, subcostales, ilíacos e inguinales) y los posteriores (lumbares). Se clasifican en defectos tipo L (1-4) de la EHS.

Su frecuencia es entre el 6 y el $17 \%$ de las HI. ${ }^{(1)}$

El estudio peroperatorio de cada paciente con eventración no medial y su clasificación ya fueron tratados.

Como características particulares, destacamos:

La eventración ilíaca se asocia con mayor frecuencia a hematomas, posiblemente por la necesidad de ampliar la disección hacia el retroperitoneo pélvico, buscando una fijación sólida en el pubis y en el ligamento de Cooper. ${ }^{(2)}$

La lumbar, frecuentemente grande, con gran atrofia y debilidad muscular, puede presentarse como una debilidad parietal extensa sin anillo herniario claro y cercanía de rebordes óseos. Precisa de una gran disección retroperitoneal y puede asociarse con frecuencia a seromas, hematomas y dolor persistente. Se proponen varias técnicas, ninguna ideal, abiertas, endoscópicas, laparoscópicas y híbridas. ${ }^{(3)}$

La subcostal comparte la existencia de un borde óseo y un tamaño del defecto con frecuencia difuso, lo que se asocia con recidivas precoces en relación con la necesidad de una fijación más dificultosa.

El tipo paramediano comprende los defectos con mayor similitud a los de la línea media en cuanto a tratamiento y complicaciones, siendo las más favorables del las HI laterales.

El continuo crecimiento y daño progresivo de los tejidos, a veces con gran hipotonía, dificultará aún más poder obtener un buen resultado funcional y estético final en HI laterales, además de tener mayor índice de recidivas.

La tasa de recidivas global en las eventraciones no mediales es del 8,2\%, siendo más frecuentes y precoces en las subcostales $(25 \%) \cdot{ }^{(1)}$ Todas las recidivas aparecen durante el primer año, lo que indica que la causa del fracaso de este abordaje es siempre un error técnico, hecho que se confirma durante las reoperaciones: deficiente fijación de la malla que no consigue una «adecuada tensión» al ser fijada en condiciones no fisiológicas (neumoperitoneo), en una pared dañada y laxa, con rebordes óseos cercanos.

Las limitaciones conocidas y consensuadas sobre el uso de la vía laparoscopica son: Anatómica: incapacidad para restablecer la anatomía funcional y fisiológica de la pared abdominal; Estética: incapacidad para reparar problemas dérmicos (piel redundante)y frecuente bulging; Técnica: imposibilidad de conseguir una adecuada tensión en una pared laxa o debilitada (atrófica), por un problema de fijación de la malla en una situación forzada (neumoperitoneo) y con cercanía extrema de rebordes óseos.

Las variables que mejor se relacionan con la recurrencia a largo plazo son: el tamaño del defecto mayor de $15 \mathrm{~cm}$; las complicaciones locales y la obesidad con IMC mayor de $30 \mathrm{~kg} / \mathrm{m} 2$ Estos pacientes son considerados desfavorable para el abordaje laparoscópico. 

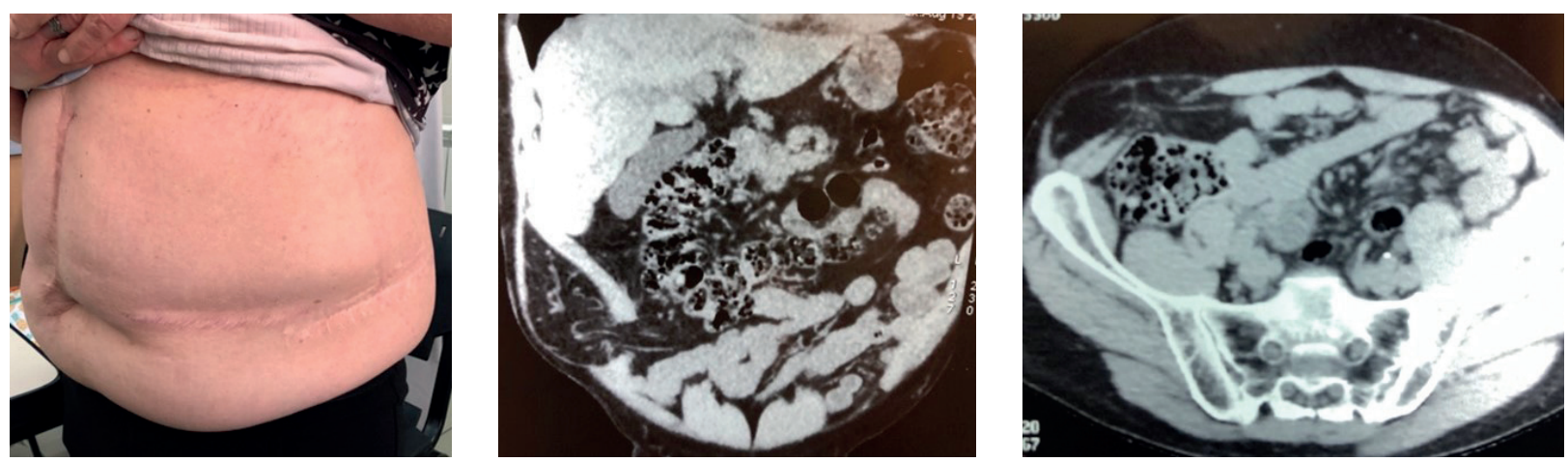

Ejemplo de HI ilíaca/lumbar izquierda(L3-4) y ilíaca derecha (L3)

\section{Eventroplastia laparoscopica en HI Lateral}

$\mathrm{El}$ abordaje laparoscópico ofrece las ventajas conocidas de una cirugía poco agresiva, y por el contrario, tiene las desventajas de que trabaja siempre en un campo intraabdominal y no modifica ni repara la solidez de la pared abdominal posterolateral. ${ }^{(3)}$

El uso de una técnica sin tensión con malla es mandatario, y la posición que ofrece mejores resultados es la profunda (tanto en defectos laterales como en los posteriores).

El uso de una doble malla es aconsejable cuando se asocia atrofia muscular por denervación, para conseguir una mayor rigidez de la pared.

La laparoscopia en los defectos no mediales se asocia a menores lesiones intestinales que en la de línea media, por trabajar parcialmente en un campo lateral o retroperitoneal.

\section{Técnica Quirúrgica}

Si consideramos las múltiples variables que afectan a estas hernias (etiología, tamaño, topografía, tiempo de la hernia, atrofia muscular, enfermedades asociadas, tipo de cirujano, experiencia), es imposible sistematizar el tratamiento de las HI laterales. Se debe tratar a cada paciente de una forma personalizada.

\section{a) Grupo ilíaco}

Se coloca la óptica supraumbilical y los trocares de trabajo laterales. Se busca un plano $2-4 \mathrm{~cm}$ por encima del defecto y se abre el peritoneo anterolateral para entrar en el sub o retroperitoneo. Se baja toda la hoja de peritoneo desde el ligamento triangular del uraco hasta la cresta ilíaca, sobrepasando el defecto ampliamente. Se reduce el contenido de la hernia y se buscan las referencias óseas (pubis, Cooper y cresta ilíaca), vasculares (vasos epigástricos inferiores, obturatriz, femoral y nervio femorocutáneo) y las musculares (recto anterior, psoas, transverso y oblicuo interno). Este paso precisa disecar el espacio inguinal de igual forma que si realizáramos un TAPP para hernia inguinal. Los defectos ilíacos precisan una mayor disección, se asocian a más complicaciones locales (hematoma, seroma) y los resultados clínicos son buenos, pero los estéticos no son del todo satisfactorios. ${ }^{(4)}$
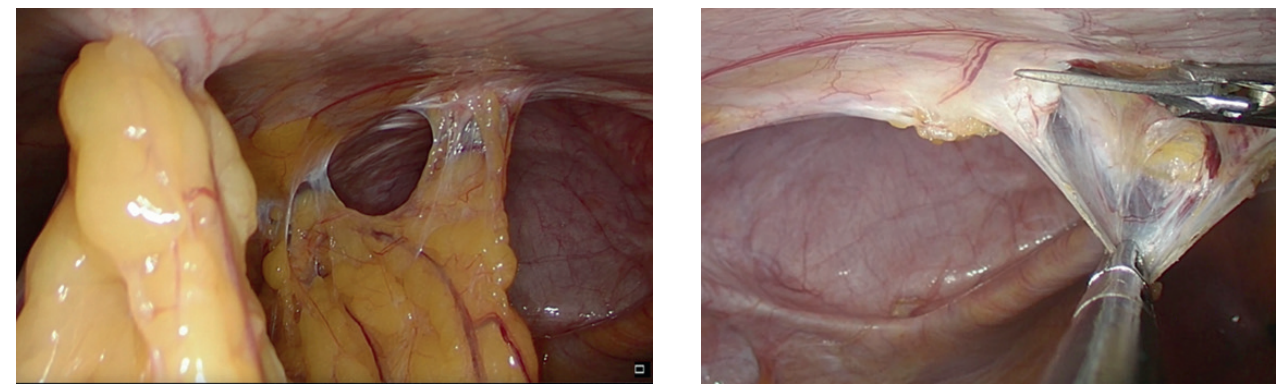

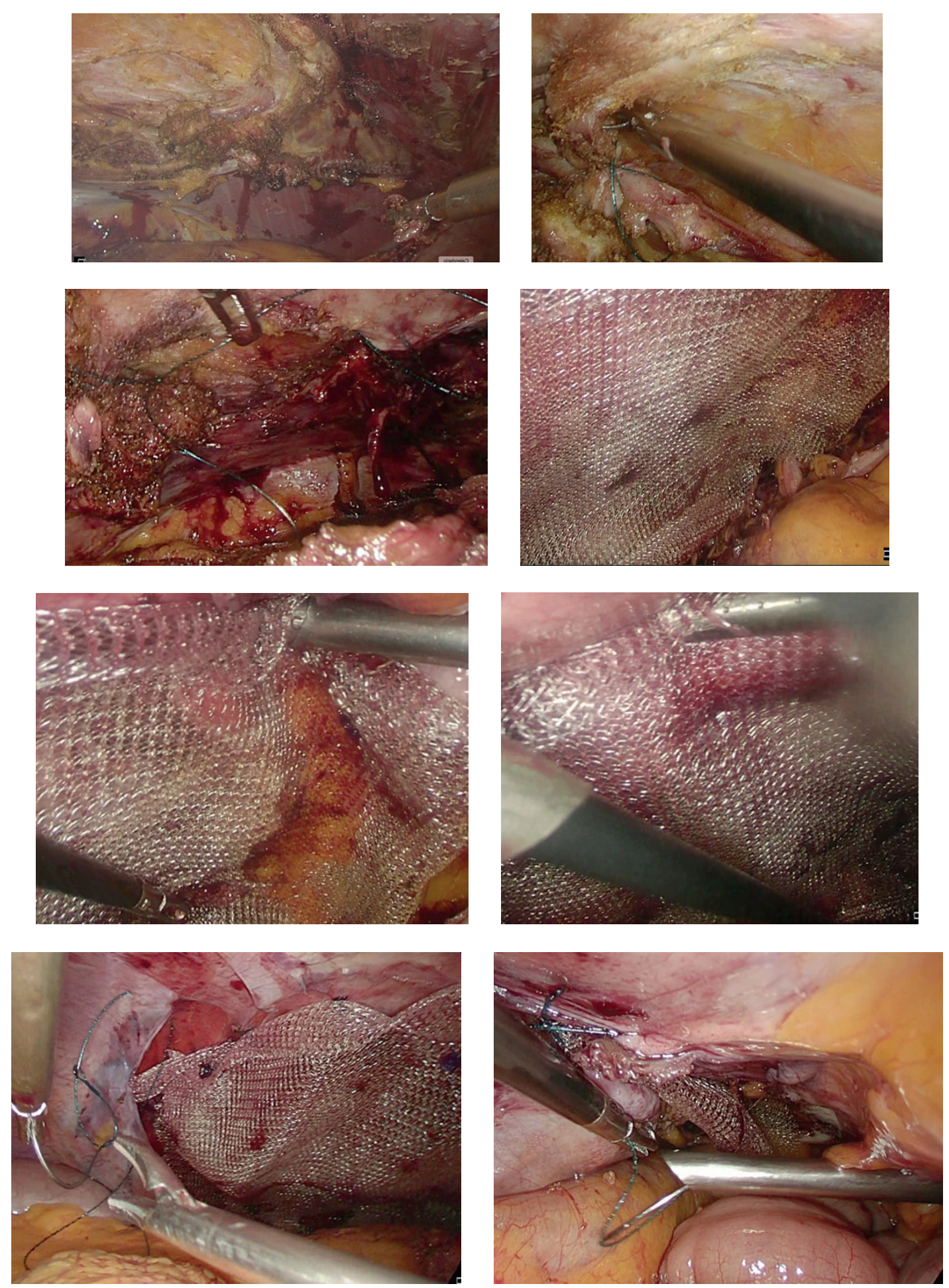

TAPP ventral en HI L2-3 W2

\section{b) Grupo lumbar (45\%)}

El paciente debe estar en decúbito lateral y con «pille» a nivel renal para abrir el espacio lumbar. Se coloca la óptica y los trocares de trabajo en la línea media o axilar anterior, según el tamaño de la hernia. Se visualiza el defecto y se liberan las adherencias viscerales. Se busca un plano 2-4 cm por encima del defecto (y del colon) y se abre la fascia de Told para trabajar siempre a nivel retroperitoneal. Se baja toda la hoja de peritoneo desde el diafragma costal hasta la cresta ilíaca, sobrepasando el defecto ampliamente. Una vez reducido el contenido de la hernia, se visualiza todo el espacio lumbo- dorsal libre, y se reconocen las referencias óseas (arco costal inferior 120 y cresta ilíaca) y los musculares (inferior, el cuadrado lumbar/fascia lumbar; superior, el oblicuo interno/transverso; por arriba, los intercostales; y abajo, el psoas-ilíaco con el utéter). Es necesario visualizar los nervios ilioinguinales para no dañarlos durante la fijación de la malla. Las eventraciones lumbares chicas y medianas son accesibles al tratamiento por laparoscopia, con buenos resultados y pocas complicaciones menores (dolor, seromas). Se debe conocer bien la anatomía y evitar defectos grandes. 
Es difícil poder cerrar el anillo herniario, por tamaño y relaciones óseas, puede en cambio plicarse la pared para una mejor aposición de la malla. ${ }^{(3)}$ Dada la relación habitual con estructuras óseas y retroperitoneo, el decolamiento debe ser amplio para la colocación de una malla amplia con el solapamiento adecuado. La malla puede quedar preperitoneal (TAPP ventral) en caso de fcectos chicos. Otra posibilidad de reparación retro - extraperitoneal, es por vía endoscópica con el concepto eTEP. El abordaje laparoscópico es una opción con menor morbilidad, menor estancia hospitalaria, menor consumo de analgésicos y un más precoz retorno a la actividad laboral sin aumentar los costes del proceso. Las ventajas de este abordaje son: facilita la visión anatómica, identifica la localización exacta del defecto, permite una reparación sin tensión en un plano muscular profundo, evita grandes incisiones y disecciones de la pared lumbar. ${ }^{(2)(4)}$

\section{c) Grupo subcostal}

Se realiza el neumoperitoneo a nivel subcostal izquierdo, y los trocares de trabajo en en flanco. El defecto suele estar libre. Se puede movilizar el hígado para aumentar el solapamiento craneal. Es aconsejable ampliar la disección hasta comprender desde la cresta ilíaca hasta la bóveda costal suprahepática, pero habitualmente siempre se trabaja en un campo intraperitoneal. El tipo subcostal es una mala opción para el abordaje laparoscópico, al ser defectos grandes y mal definidos muscularmente. Es recomendable la aproximación del defecto herniario, aunque no siempre es posible. Se sugiere un solapamineto amplio y fijación con suturas reabsorbibles, no transcostales y evitar al máximo el uso de tackers por encima del reborde oseo. Tienen mayor tasa de recurrencias y con pobre satisfacción por parte del paciente. Limitar las indicaciones a defectos chicos, bien definidos muscularmente, sin atrofia muscular y con IMC $<30 \mathrm{~kg} / \mathrm{m} 2$. Las frecuentes recidivas, nos llevan a aconsejar el uso de suturas transmurales, en todas las hernias subcostales y en pacientes obesos.

En los tres casos la reconstrucción se realiza habitualmente con una malla bilaminar, al quedar total parcialmente expuesta en la cavidad abdominal. La malla debe sobrepasar todos los márgenes del defecto al menos $5 \mathrm{~cm}$., usando la regla de radio 4/1. La malla se prepara, introduce y presenta (puntos cardinales extracorpóreos) inicialmente de la misma manera ya descripta para IPOM. Las dferencias en la fijación dependen de la topografía herniaria, siguiendo los principios de: evitar la fijación con tackers en zonas de riesgo de lesión vascular y/o nerviosa (retroperitoneo, Bogros), no colocar tackers por encima del reborde costal evitando lesiones de pared torácica, pleurales y pericárdicas, intentar siempre que sea posible técnicamente la fijación con suturas intracorpóreas con hilo reabsorbible, al igual que el uso de mallas autoadherentes y fijación con adhesivos, efectivos y seguros en el retroperitoneo y topografías de riesgo para fijación invasiva. Habitualmente se requiere un sistema combinado de fijación, con tackers, suturas extra e intracorpóreas y pegamentos. En defectos cercanos a rebordes óseos y con imposibilidad de fijación invasiva, las tasas de recurrencias son mayores y más precoces. El peritoneo abierto y decolado, puede levantarse y pegarse (suturarse) al otro borde peritoneal o a la malla, cerrando el espacio de trabajo creado y disminuyendo las complicaciones adherenciales. En los casos de defectos pequeños, que se colocó una malla de Polipropileno para reparar el defecto, TAPP ventral, este último paso es obligatorio, peritonizando el defecto, quedando la malla parte pre y parte retroperitoneal. Se realiza con sutura barbado intracorpórea. ${ }^{(5)(6)(7)}$

$\underline{\text { Reinpold y cols }},{ }^{(8)}$ en las guías de la IEHS publicadas en 2019, analiza los 4 trabajos más significativos sobre tratamiento laparoscópico de HI laterales entre $2012-2018{ }^{(9)(12)}$ con un total de 188 pacientes. No se registraron infecciones del sitio quirúrgico, lesiones viscerales intraoperatorias 0-15\%, Un estudio ${ }^{(9)}$ con 73 pacientes y un seguimiento de 62 meses, reporta recurrencias globales del $8 \%$ y del $25 \%$ para las HI subcostales, desaconsejando la reparación laparoscópica de defectos mayores de $15 \mathrm{~cm}$. No hubo diferencias en la tasa de dolor crónico, comparadas con series históricas de reparaciones abiertas.

Recomendación actual en eventraciones laterales: ${ }^{(2)(8)(9)(13)}$

- defectos pequeños con contenido extraperitoneal: hernioplastia vía anterior

- defectos medianos con hernias intraperitoneales: vía laparoscópica transabdominal

- casos recidivados o hernias difusas con tamaño superior a $10 \mathrm{~cm}$ : plastia anterior con doble malla

- casos con atrofia muscular asociada o con gran deformidad, es necesaria una reparación bajo cierta tensión para garantizar un resultado estético y funcional adecuado, objetivo que no se puede alcanzar por laparoscopia, por lo que se aconseja una técnica de doble reparación protésica preperitoneal 

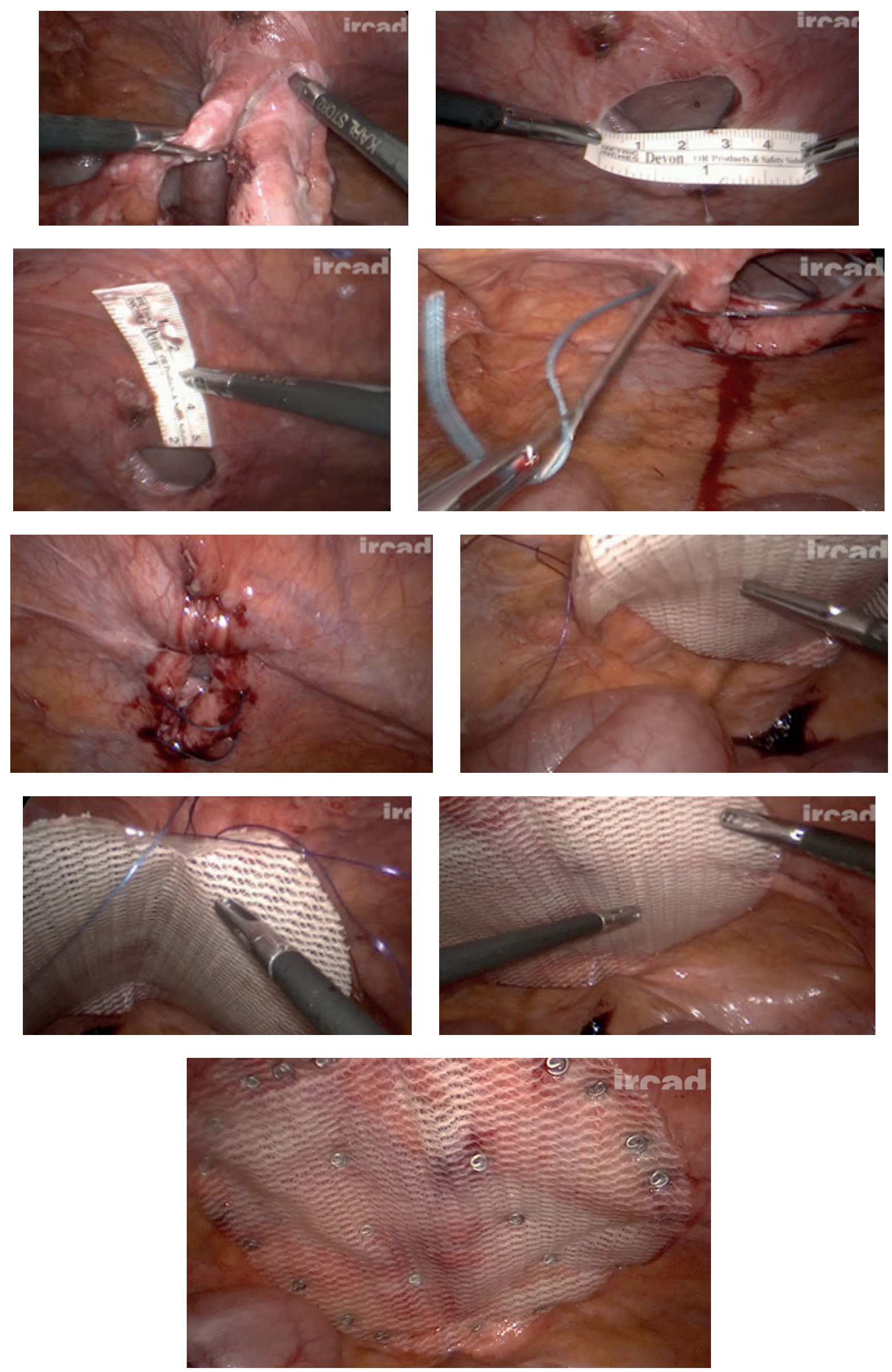

Ipom Plus HI L2-W1 (Tomado de Web Surg) 


\section{BIBLIOGRAFÍA}

1) Moreno Egea A. Eventroplastia por Laparoscopia de los defectos posterolaterales (43) 533-550. En Eventraciones. Otras hernias de la pared y cavidad abdominal Fernando CarbonelTatay Valencia, 2012

2) A. Moreno-Egea Hernias lumbares. Hernias de Spiegel. Hernia obturatriz (22); 241-252 Guías Clínicas de la Asociación Española de Cirujanos Cirugía de la Pared Abdominal 2a Edición 2013

3) Sánchez Ramírez M, Alarcón del Agua I, Morales-Conde S. Reparación de hernias especiales por vía laparoscópica (25);271-277 Guías Clínicas de la Asociación Española de Cirujanos Cirugía de la Pared Abdominal 2a Edición 2013

4) Moreno Egea A, Torralba JA, Morales G, et al. Open vs laparoscopic repair of secondary lumbar hernias: a prospective nonrandomized study. Surg Endosc 2005;19:184-7.

5) Moreno Egea A, Bustos JA, Girela E, et al. Long- term results of laparoscopic repair of incisional hernias using an intraperitoneal composite mesh. Surg Endosc 2010;24(2):359-65.

6) Moreno-Egea A, Carrillo A, Aguayo JL. Midline versus nonmidline laparoscopic incisional hernioplasty: a comparative study. Surg Endosc. 2008;22(3):744-9.

7) Moreno-Egea A, Baena EG, Calle MC, et al. Controversies in the current management of lumbar hernias. Arch Surg. 2007;142:82-8.

8) Reinpold W., Sutedja B. Key question: treatment of lateral primary or incisional hernias: Which technique should be preferred? 7:3542-46 En: Update of Guidelines for laparoscopic treatment of ventral and incisional abdominal wall hernias (International Endohernia Society (IEHS)): Part B Bittner R. et al. Surgical Endoscopy 2019; 33:3511-3549 https://doi.org/10.1007/s00464-019-06908-6

9) Moreno-Egea A, Carrillo-Alcaraz A. Management of non-midline incisional hernia by the laparoscopic approach: results of a long-term follow-up prospective study. Surg Endosc 2012; 26(4):1069-78.

10) Lal R, Sharma D, Hazrah P, Kumar P, Borgharia S, Agarwal A. Laparoscopic management of non- midline ventral hernia. J Laparoendosc Adv Surg Tech 2014 A 24(7):445-450.

11) Farrarese A, Enrico S, Solej M, Surace A, et al. Laparoscopic management of non-midline incisional hernia: A multicentric study. Int J Surg 2016; 33 Suppl 1:S108-113.

12) Novitsky YW Laparoscopic repair of traumatic flank hernias. Hernia 2018; 22(2):363-369. https://doi. org/10.1007/s10029-017-1707-7. Epub 2017 Dec 15. (4)

13) Asencio F, Aguiló J, Peiró S, et al. Open randomized clinical trial of laparoscopic versus open incisional hernia repair. Surgical Endoscopy 2009;23(7):1441-8. 


\section{ROL DE LA LAPAROSCOPÍA EN LA HERNIA INCISIONAL COMPLICADA}

\section{Dr. Gonzalo Estapé}

La indicación de cirugía de urgencia en la hernia incisional (HI) está bien establecida. Son la hernia encarcelada, la obstrucción intestinal y la estrangulación, etapas con ritmo evolutivo variable, de la complicación mecánica en patología herniaria.

La vía de abordaje para la HI complicada (abierta o laparoscópica), contiúa en estudio. Las ventajas de la EL son: 1) intraoperatorios: mejor exposición del defecto de pared, especialmente en hernias con múltiples orificios, el reconocer la vitalidad de la viscera atascada en caso de reducción espontánea de la hernia; 2) postoperatorios: menos dolor, morbilidad parietal (infecciones) y estancia hospitalaria, y más rápido retorno al trabajo, con similar tasa de recurrencias (menos de 5\%). ${ }^{(1)(2)}$ Las desventajas de la EL serían la necesidad de un cirujano experimentado en esta técnica, el riesgo de lesión intestinal por la distensión de asas y la dificultad de la adhesiolisis. La disponibilidad en la urgencia del equipamineto y materiales necesarios para una EL, no siempre se logra. A pesar de estos beneficios, su utilización, tanto en los casos de coordinación o en la urgencia, son significativamente menores que para otras cirugías complejas. ${ }^{(3)(4)}$

En 2005, la Conferencia de Consenso de la EAES (European Association for Endoscopic Surgery) expuso la recomendación de que la reparación abierta es el tratamiento estándar y que la laparoscopia puede ser considerada en el caso de pacientes seleccionados y supeditada a cirujanos experimentados. En una revisión Cochrane del año 2011, ${ }^{(5)}$ que compara las técnicas de cirugía laparoscópica frente a las técnicas abiertas en la reparación de la hernia ventral o incisional. Encuentran deficiencias del metaanálisis por la breve duración del seguimiento y por el número relativamente escaso de pacientes incluidos. No logró demostrar la superioridad ni inferioridad en cuanto a tasas de recurrencia, calidad de vida, dolor postoperatorio o incluso resultados económicos entre ambas técnicas. Por tanto, no disponemos de suficiente evidencia científica en los casos de reparaciones urgentes de las hernias ventrales. En las guías más recientes para la reparación urgente de las hernias de la pared abdominal, ${ }^{(6)}$ el World Society of Emergency Surgery Consensus group también reconoce la necesidad de mayor evidencia que soporte la superioridad del abordaje abierto o laparoscópico para estas patologías.

Se han publicado pocos estudios evaluando el tratamiento quirúrgico urgente por vía laparoscópica. Mason et al. sobre 71,054 de eventroplastias (2005-2009), encontraron que el 17\% se realizaron por laparoscopía. ${ }^{(7)}$ Aher et al. sobre 117,007 eventroplastias (2009-2012), encontraron que el 22\% fueron por laparoscopía. ${ }^{(4)}$ Kao et al, sobre 11,075 eventroplastias de urgencia (2009-2016), encontraror que el 14.5\% fueron por laparoscopía. ${ }^{(8)}$

Esta situación está relacionada con la experiencia y especialización de cada cirujano con la técnica. Considerando que en los casos de eventraciones complicadas, la tasa de complicaciones es 15 veces mayor y presentan mayor tasa de reoperaciones y re internaciones que en casos no complicados, la incidencia de eventroplastias laparoscópicas de urgencia es globalmente aún menor (10\%). ${ }^{(9)(10)}$ En estos pacientes, la valoración preoperatorioa de la eventración, así como la corrección de las comorbilidades personales modificables, habitulamente son inferiores a las logradas en el paciente no complicado. ${ }^{(1)}$

Hay publicaciones de centros independientes, que muestran algunos veneficios de la EL en la urgencia. Shah et al, ${ }^{(12)}$ evaluó 103 pacientes: sin mortalidad, 20\% de complicaciones postoperatorias y menor internación. Landau and Kyzer, ${ }^{(10)}$ analizan 25 pacientes con $4 \%$ de conversiones y sin complicaciones mayores. Olmi et al, ${ }^{(13)}$ en 48 pacientes, concluye en la seguridad de esta técnica, no tuvo complicaciones mayores y tuvo una menor hospitalización. Huntington et al, ${ }^{(14)}$ obtienen mejoría en las tasas de complicaciones de la herida, recurrencias, infecciones de la malla y calidad de vida del paciente.

Pechman ${ }^{(15)}$ en un studio retrospectivo, sobre 13,126 pacientes obtenidos de la base de datos ACS-NSQIP en Estadios Unidos, sin criterios uniformes de inclusion, tipo de hernia, tamaño de defectos e irregular seguimineto, encuentra que solo el 8,6\% de las eventraciones operadas de urgencia se realizaron por abordaje laparoscópico. Los resultados obtenidos fueron: mayor tiempo operatorio, menor internación hospitalaria, menor infección de sitio quirúrgico (superficial y profundo) y menos mortalidad a 30 días. Concluye, a pesar de las limitaciones del estudio, que la EL en casos complicados seleccionados, puede resultar en beneficioso para los pacientes. 
Kao et al, ${ }^{(8)}$ analiza la serie en que presentó mayor incidencia de pecientes jóvenes con menos comorbilidades en abordaje laparoscópico. Luego de eliminar las variables de confusion de la serie, encuentra que los abordajes abierto y laparoscópico en hernias ventrales complicadas son similares en cuantos a complicaciones mayores, recidivas, reoperaciones, y mortalidad a 30 días. La EL presenta menores complicaciones parietales infecciosas (5\% vs $1.8 \%$ ) y menor internación hospitalaria (6.7\% vs 4.0\%). Sugiere considerar el abordaje laparoscópico en pacientes seleccionados, estables, con comorbilidades corregidas, que toleren neumoperitoneo y equipo con experiencia, especielmente en pacientes con alto riesgo de morbilidad parietal.

Como recomedaciones actuales, siguiendo la evidencia científica disponible, surge que la EL en situación de urgencia, es posible, segura y efectiva en casos seleccionados y cirujanos experimentadaos. Presenta los beneficios operatorios de una exploración de toda la herida operatoria y de la vitalidad del asa en la reducción espontánea; y postoperatorias de menos infecciones parietales y más corta internación.

\section{BIBLIOGRAFÍA}

1) Arita NA et al. Laparoscopic repair reduces incidence of surgical site infections for all ventral hernias. Surg Endosc 2015; 29(7):1769-1780

2) Al Chalabi $\mathrm{H}$ et a. A systematic review of laparoscopic versus open abdominal incisional hernia repair, with metaanalysis of randomized controlled trials. Int J Surg2015, 20:65-74

3) Buia A, Stockhausen F, Hanisch E. Laparoscopic surgery: a qualified systematic review. World J Methodol 2015, 5(4):238-254

4) Aher CV et al. The utilization of laparoscopy in ventral hernia repair: an update of outcomes analysis using ACSNSQIP data. Surg Endosc 2015, 29(5):1099-1104

5) Sauerland S, Walgenbach M, Habermalz B, et al. Técnicas de cirugía laparoscópica versus técnicas abiertas para la reparación de la hernia ventral o incisional (Revisión Cochrane tra- ducida). Cochrane database of Systematic Reviews 2011;3:Cd007781.

6) Sartelli M, Coccolini F, van Ramshorst GH, et al.WSES guidelines for emergency repair of complicated abdominal wall hernias. World J Emerg Surg. 2013;8:50.

7) Mason RJ et al. Laparoscopic versus open anterior abdominal wall hernia repair: 30-day morbidity and mortality using the ACS-NSQIP database. Ann Surg 2011, 254(4):641-652

8) Kao A. Huntington C. Otero J, et al. Emergent laparoscopic ventral hernia repairs journal of surgical research 2018; 232: 497-502

9) Savitch SL, Shah PC. Closing the gap between the laparoscopic and open approaches to abdominal wall hernia repair: a trend and outcomes analysis of the ACS-NSQIP database. Surg Endosc Other Interv Tech. 2016;30:3267e3278.

10) Landau O, Kyzer S. Emergent laparoscopic repair of incarcerated incisional and ventral hernia. Surg Endosc Other Interv Tech. 2004;18:1374-1376

11) García Ureña MA. López Monclús J. Eventración de urgencias (18): 298-302 En Eventraciones. Otras hernias de la pared y cavidad abdominal Fernando CarbonelTatay Alfredo Moreno Egea Valencia, 2012

12) Shah RH, Sharma A, Khullar R, Soni V, Baijal M, Chowbey PK. Laparoscopic repair of incarcerated ventral abdominal wall hernias. Hernia. 2008;12:457-463.

13) Olmi S, Cesana G, Erba L, Croce E. Emergency laparoscopic treatment of acute incarcerated incisional hernia. Hernia. 2009;13:605e608.

14) Huntington CR, Cox TC, Blair LJ, et al. Biologic mesh in ventral hernia repair: outcomes, recurrence, and charge analysis. Surgery. 2016;160:1517e1527

15) Pechman D. Cao L. Fong C. Thodiyi Pl. Suric B. Laparoscopic versus open emergent ventral hernia repair: utilization and outcomes analysis using the ACSNSQIP database 2018 SAGES Oral Surgical Endoscopy https:// doi.org/10.1007/s00464-018-6312-z

16) Pueyo Rabana A. Blázquez Hernando A, García Ureña MA. Manejo y técnicas quirúrgicas en el tratamiento de las hernias ventrales en situación de urgencias (41);455-461 Guías Clínicas de la Asociación Española de Cirujanos Cirugía de la Pared Abdominal 2a Edición 2013 


\section{COMPLICACIONES DE LA EVENTROPLASTIA LAPAROSCÓPICA}

\section{Dr. Gonzalo Estapé}

Históricamente, las complicaciones postoperatorias en la cirugía laparoscópica de la hernia incisional (HI) se repor-

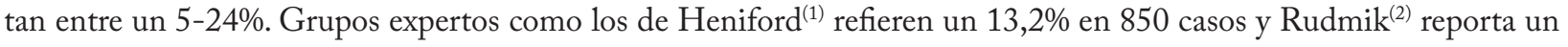
$14,3 \%$.

Al igual que otros procedimientos laparoscópicos, el éxito de esta técnica se basa en dos pilares fundamentales: la correcta indicación del acceso laparoscópico (o selección de casos) y la experiencia del equipo quirúrgico en la reparación laparoscópica de la HI, criterios también relacionados al índice de complicaciones postoperatorias. ${ }^{(3)}$

La eventroplastia laparoscópica (EL) es una nueva alternativa que ofrece ventajas sobre la cirugía convencional, al evitar las grandes incisiones y disecciones parietales y colocación de drenajes. Todo ello disminuye la destrucción tisular y la posterior aparición de seromas, hematomas e infección. Permite la exploración de otros eventuales defectos de la incisión, anillos secundarios y del resto de la pared abdominal, que podrían pasar desapercibidos con el abordaje anterior, permitiendo la colocación correcta de la malla. Si bien se publica la disminución del índice de recidivas y complicaciones postoperatorias, algunas series todavía recogen cifras elevadas de recidiva (hasta de 20-34 \%), con diferencias según el tipo de malla, sitio de colocación y fijación de la misma, ${ }^{(3)}$ lo que ha retrazado la extensión y globalización de la técnica.

Los metaanálisis publicados por Forbes y $\mathrm{Pham}^{(4)(5)}$ que comparan cirugía abierta y laparoscópica, tópico de extenso estudio científico, confirman que esta vía es segura y presenta menos complicaciones postoperatorias (16,4\% vs. $29,4 \%)$, estancia hospitalaria y recidivas, cuando es realizada por cirujanos expertos en esta técnica.

Las complicaciones pueden dividirse en los relacionadas con el acceso laparoscópico y los derivadas de la reparación del defecto herniario.

\section{Relacionadas al acceso laparoscópico}

\section{a) Realización del neumoperitoneo}

La colocación incorrecta de la aguja de Veress puede causar complicaciones leves como el enfisema preperitoneal, subcutáneo o del mesenterio, o bien lesiones más graves, como la hipercapnia severa, enfisema mediastinal, neumotórax, lesión visceral o vascular. Por ello es aconsejable siempre, el control de los parámetros el CO2 y la laparoscopia exploradora de toda la cavidad abdominal y la pared abdominal antes de proceder a la reparación de la eventración.

\section{b) Introducción de los trocares}

El primer trócar es el que puede determinar complicaciones ("trócar ciego"). Si bien los trócares actuales disponen de mecanismos de protección frente a la lesión intrabdominal, este es un momento peligroso, ya que en estos pacientes con cirugía abdominal previa puede haber adherencias intestinales a la pared. Por ello algunos cirujanos optan por de utilizar el primer trocar con visión directa (óptico), colocación alejada de incisiones o posibles adherencias o realizar el neumoperitoneo abierto, a fin de minimizar el riesgo de lesiones. ${ }^{(6)}$

La lesión de los vasos epigástricos o alguna de sus ramas es otra complicación que debemos tener presente, ya que la mayoría de grupos utilizan un acceso de tres trocares en flanco izquierdo cercano al trayecto de estos vasos. La lesión vascular mesenterica puede provocar hemorragias o hematomas de entidad y resolución diversa. Si se detecta sangrado durante la cirugía, es conveniente solucionarlo con suturas o compresión. Las lesiones vasculares mayores o de organos sólidos son muy raros en este momento.

\section{Derivadas de la reparación del defecto herniario}

\section{a) Hemorragia}

El sangrado intraoperatorio es una complicación habitualmente no reportada en la mayoría de series y, por ello, su incidencia real es desconocida. Puede ocurrir durante la adhesiolisis, al lesionar algún vaso del epiplón mayor, del meso intestinal o un órgano sólido (bazo, hígado). El control se realiza con compresión, puntos de sutura, electrocoagulación mono o bipolar o selladores de vasos. 
También puede ocurrir durante la fijación de la malla si se lesionan los vasos epigástricos al fijarla con helicosutura. Es aconsejable retirar el tacker y valorar el hematoma producido, ya que puede disecar el peritoneo y la fijación de la malla puede ser incorrecta al no anclarse en el plano musculoaponeurótico.

\section{b) Lesión intestinal}

Es una de las complicaciones más graves y es casi propia de la técnica laparoscópica. En las revisiones de LeBlanc, ${ }^{(8)(9)}$ reporta un 0-6 \% de casos. Se produce por lesión de un asa intestinal durante la disección, pero también puede deberse a maniobras bruscas de tracción, presa traumática de las pinzas laparoscópicas o por lesión térmica a distancia.

En la enterotomía inadvertida (2-4 \%), puede existir un periodo ventana donde el paciente permanece asintomático y con exploración abdominal normal. Se provoca por una lesión directa no advertida, o indirecta durante la disección con alguna fuente de energía y formación de una escara o tejido isquémico que posteriormente se necrosa y desprende causando la perforación. También la reducción en bloque del contenido visceral dentro del saco herniario, puede provocar el desgarro intestinal. ${ }^{(10)} \mathrm{La}$ aparición del dolor abdominal, peritonitis y sepsis no siempre es florida y a veces tan solo existen síntomas inespecíficos. La sospecha clínica cuando el paciente no evoluciona con la rapidez de los postoperatorios tras cirugía laparoscópica, demandará estudios de urgencia.

Diferentes estudios publican cerca del 2\% de lesiones intestinales ( $92 \%$ delgado, $8 \%$ colon), con $80 \%$ identificadas y reparadas en la misma cirugía. Esta complicación aumenta la mortalidad de la técnica de 0.05 al 3\% y sigue siendo significativamente mayor que en la eventroplastia abierta. ${ }^{(1)(12)}$

El riesgo de lesión intestinal no es predecible ni exclusivo de grandes defectos o de pacientes considerados, a priori, de alto riesgo. Cualquier paciente es susceptible de padecer una lesión visceral, por lo que debe garantizarse un seguimiento postoperatorio adecuado.

El manejo de esta complicación es controvertido y ya fue analizado previamente.

\section{c) Íleo prolongado}

Se ha referido en un 1-8\% de los casos, usualmente tras amplias o dificultosas adhesiolisis o hemoperitoneo residual. Puede encubrir una lesión intestinal inadvertida, por lo que si se prolonga o existen otros signos de alarma, demandará estudios complementarios. Su manejo es conservador: hidratación, antieméticos y control del dolor.

Junto al dolor postoperatorio, es la causa más común de retraso del alta hospitalaria. ${ }^{(13)}$

\section{d) Seroma}

Es la complicación más frecuentemente tras cirugía laparoscópica de la eventración. En la revisión de Rudmik ${ }^{(5)}$ se refiere entre el 17-24 \%, si bien, en mayor o menor grado, ocurre en casi todos los casos y para muchos autores no se considera una complicación como tal. Por tanto, debemos explicar siempre al paciente, antes de la intervención, que puede aparecer y que ello no conlleva problemas, ya que habitualmente desaparecerá espontáneamente. De todas maneras, el seroma postoperatorio tiene un impacto negativo en la calidad de vida de los pacientes, aumenta la tasa de recurrencia e incrementa la tasa de infección del sitio operatorio.

En las colecciones líquidas (hematomas, seromas), la ecografía con trasductor de partes blandas, tiene la mejor relación costo - beneficio, en caso de requerir estudio. Debe informar: tamaño , tabiques, topografía, relación con la malla, presencia de gas y accesibilidad para el eventual drenaje percutáneo.

Como factores de riesgo para la formación del seroma, se reconocen: obesidad, no cierre fascial primario, ${ }^{(14)}$ grandes sacos persistentes o decolamiento subcutaneo. El IPOM clásico es el que tiene mayor tasa de seroma. Las disecciones extensas retromusculares o por técnica TAPP tienen mayores tasas de seroma que el IPOM PLUS.

Al colocar la malla intraperitoneal el seroma se forma en el saco herniario, independientemente del tipo de material protésico utilizado. La resección del saco herniario si es posible disminuye el seroma, aunque aún sin evidencia firme. Existe evidencia escasa sobre el impacto y el costo-efectividad de la cauterización del saco herniario para prevenir seromas. Los diferentes sistemas de fijación de la malla, no tienen diferencias en la formación de seromas. ${ }^{(14)}$

Las medidas de compresión externas postoperatorias descritas por LeBlanc, ${ }^{(8)}$ son el mejor medio de minimizarlo. Se aconseja una curación compresiva durante 2 semanas y posteriormente, una faja elástica durante, al menos, 4 semanas. Se ha reportado que el uso de pegamentos (en especial los biológicos) es efectivo para la prevención de la formación de seroma; sin embargo, tiene un alto costo y hace falta una evidencia fuerte para recomendar su uso. ${ }^{(15)}$ 


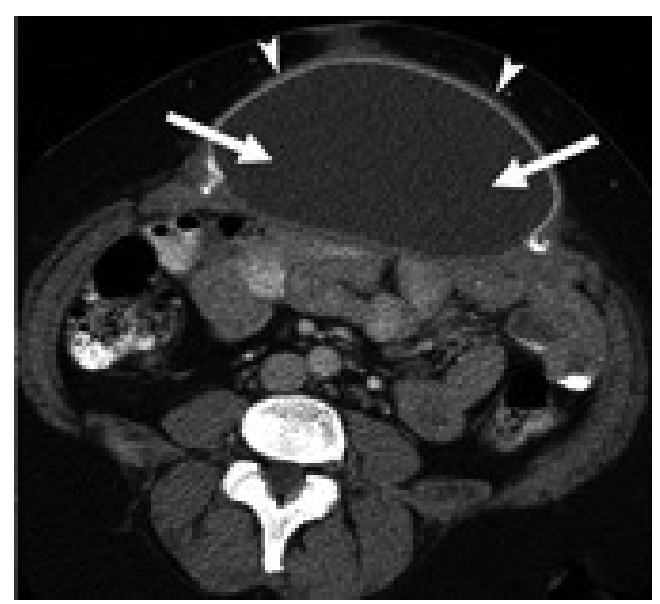

Seroma post eventroplastia. Tomado de En Eventraciones Otras hernias de pared y cavidad abdominal Fernando Carbonell Tatay Alfredo Moreno Egea Valencia, 2012

En la mayoría de casos el seroma se resuelve por sí solo en pocas semanas. Solo hay que aspirarlo cuando por la tensión o tamaño es sintomático, o pasados 3 meses, afectando la calidad de vida. Deben extremarse las medidas antisépticas para evitar la infección de la prótesis. También se evacúan aquellos seromas de gran tamaño que pueden modificar la correcta situación de la prótesis y favorecer la infección y recidiva. ${ }^{(16)}$

\section{e) Necrosis grasa}

El epiplón puede reaccionar con la malla y formar una masa inflamatoria compacta. No tiene repercusión clínica y $\tan$ solo puede ser un hallazgo imagenológico. También puede ocurrir cuando al reducir la hernia, se deja gran cantidad de epiplón atascado dentro del saco.

\section{f) Dolor agudo y persistente postoperatorio}

El dolor es la complicación más frecuente tras la EL y es en la actualidad un gran reto para anestesiólogos y cirujanos. La ausencia de una analgesia efectiva puede ocasionar una hospitalización más prolongada, aumentando la morbilidad y el costo económico del procedimiento. ${ }^{(10)(17)}$

La mayor eficacia en el tratamiento del dolor agudo postoperatorio se obtiene actuando sobre los tres tiempos del proceso: en el preoperatorio realizar una valoración de la actitud del paciente ante la cirugía y el dolor, informarlo del procedimiento al que se va a someter, motivación para afrontar la situación y administración de ansiolíticos de ser necesario; en el intraoperatorio, aplicar la técnica con la mayor eficacia analgésica para cada situación, la analgesia profiláctica puede ser con bloqueos nerviosos, anestésicos locales en sitios de trócares, analgesia intrarraquídea o endovenosa, previos a la producción del daño tisular quirúrgico; en el postoperatorio, combinación de AINE y opiáceos, en bomba o programados, intravenoso y/o vía oral

Un 2-5 \% de los pacientes refieren dolor pasadas 6 semanas, si bien hay reportes hasta de un $25 \%$. Se relaciona con los mecanismos de fijación de la prótesis, bien sean tackers, sutura helicoidal periférica o puntos transfasciales. Los grandes defectos tienen un mayor periodo de dolor y limitación de la actividad. ${ }^{(18)}$ Es aconsejable realizar la TAC abdominal para descartar complicaciones precoces (recidiva, seroma o infección profunda).

Las grampas absorbibles no están asociadas con menos dolor crónico, ${ }^{(19)}$ aunque si este disminuye con las suturas con hilo reabsorbible, la fijación no invasiva (pegamentos o mallas autoadhesivas), y en las técnicas sin fijación de la malla. ${ }^{(20)}$

El tratamiento médico se realiza con AINES y corticoides. Si es un punto selectivo puede ser exitosa la infiltración local; si es de gran intensidad y no responde con estas medidas en 3-6 meses, se plantea la retirada selectiva del tacker o punto responsable del atrapamiento nervioso.

\section{g) Infección}

Una de las ventajas de la EL es la disminución de la infección del sitio quirúrgica (ISQ) respecto al abordaje anterior, por la menor destrucción tisular y la ausencia de drenajes postoperatorios. ${ }^{(21)} \mathrm{El}$ hecho de que la prótesis no esté en contacto con la herida quirúrgica hace que la infección de la prótesis en la cirugía laparoscópica sea una complicación infrecuente (1-2\%). ${ }^{(22)}$ La infección del sitio del los trocares es infrecuente (1-2 \%), y responden al tratamiento local. 
Se reconocen factores de riesgo para la ISQ: índice de masa corporal $>30 \mathrm{~kg} / \mathrm{m} 2$, tabaquismo, ASA 3, parte de la técnica abierta, tiempo operatorio prolongado y readmisión hospitalaria. La institución en la que se realiza la cirugía y el número de cirugías abdominales previas, también son factores asociados a la ISQ. ${ }^{(23)(26)}$

El diagnóstico se suele basar en criterios clínicos y analíticos. Los métodos de imágen confirman la presencia de la colección, su localización y sirven de guía para su diagnóstico (aspiración y cultivo), tratamiento (drenaje percutáneo) y seguimiento

El tratamiento de la infección de la prótesis es idéntico al aconsejado en cirugía abierta. Si no mejoran con medidas locales de drenaje, curaciones, terapias basadas en el cierre asistido por vacío de presión negativa y antibióticos dirigidos, puede ser aconsejable su retiro, excepcional en el momento actual, ya que las prótesis de polipropileno soportan bien la infección. Aquí, el remplazo con una malla sintética absorbible o una prótesis biológica, parece funcionar para lograr el cierre facial. Se usa en reparos «puente», a pesar de que tiene una elevada tasa de recurrencia. El explante vía laparoscópica de la malla intraperitoneal infectada, puede realizarse en forma segura y eficaz, evitando la lesión innecesaria de las capas sanas de la pared abdominal y la eventual infección superficial. ${ }^{(7)}$

La prevención es el objetivo principal en la Infección de Sitio Quirúrgico. Se recomienda: 1) evaluar y tratar en el preoperatorio de manera individualizada los factores de riesgo modificables del paciente para desarrollar ISQ; 2) elegir la técnica laparoscópica en aquellos casos en los que sea posible; 3) los cirujanos, durante la cirugía, deben seguir las guías basadas en la evidencia o en la experiencia; 4) profilaxis antibiótica perioperatoria; y 5) los pacientes deben ser operados en instituciones con la experiencia adecuada.

\section{h) Hematoma}

Al igual que otras complicaciones a nivel de herida quirúrgica, su presencia es inferior al de la cirugía abierta, donde las grandes disecciones de planos musculares y subcutáneos favorecen su aparición. La mayoría de series laparoscópicas no la refieren. Aparecen en el saco herniario, en las entradas de los trocares o bien en los rectos abdominales por fijación de la malla con los tackers. El tratamiento conservador suele ser exitoso.

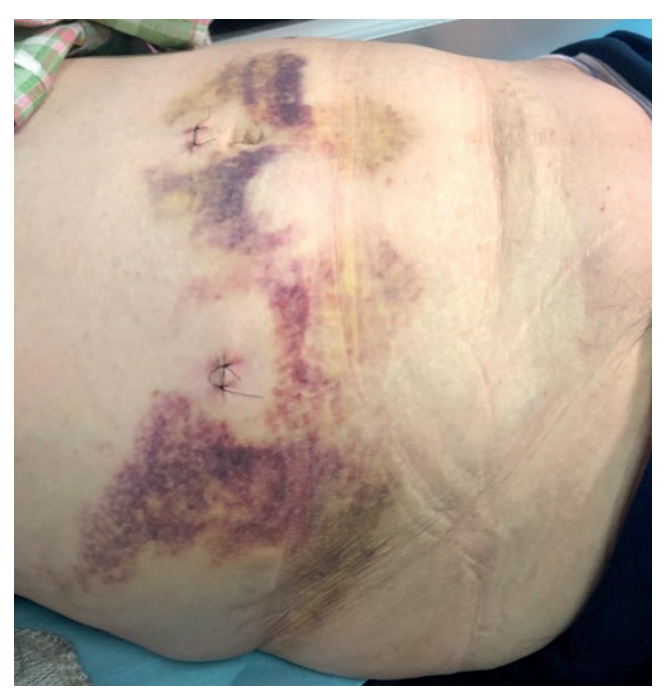

\section{i) Adherencias a la prótesis}

Las mallas utilizadas en IPOM y sus variantes, al colocarse en situación intraperitoneal, deben ser antiadherentes y se reperitonizan. Se han descrito complicaciones adherenciales relacionadas a la malla, los tackers de fijación o cuando se utilizó prótesis de polipropileno, lo que desaconsejamos. Son poco frecuentes, pero potencialmente graves.

Adherencias a la malla y tackers. Tomado de Eventraciones Otras hernias de pared y cavidad abdominal Fernando Carbonell Tatay Alfredo Moreno Egea Valencia, 2012

Se han publicado oclusiones intestinales, debidas a adherencias a la malla o defectos en su fijación, fístulas intestinales y migraciones de mallas y tackers a intestino o vejiga. 

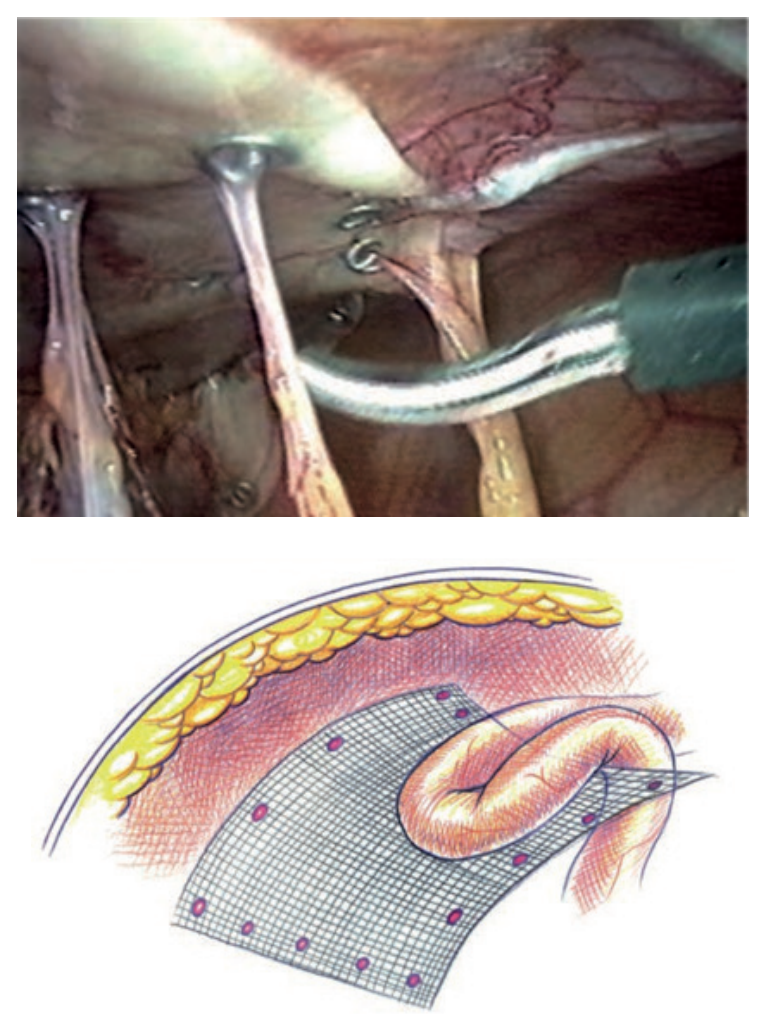

Deslizamiento de asa intestinal por defecto de fijación de la malla. Tomado de Eventraciones Otras hernias de pared y cavidad abdominal Fernando Carbonell Tatay Alfredo Moreno Egea Valencia, 2012

\section{j) Hernia por trocar de entrada}

Es una complicación más fercuente luego de EL (2-4\%) que leuego de otras cirugías laparoscópoicas (1-2\%). Se presentan cuando se utilizan trócares mayores de $10 \mathrm{~mm}$, especialmente en obesos. Se recomienda el uso de trócares atraumáticos, del menor calibre posible, ubicación lateral, introducción oblicua y el cierre parietal en trócares de $10 \mathrm{~mm}$ o de calibre superior.

\section{k) Conversión}

No debe considerarse una complicación ni un fracaso quirúrgico, sino un cambio táctico. Es preferible una conversión a tiempo, que una complicación grave. Se produce alrededor de un $4 \%$ de los casos, dependiendo de la experiencia del equipo quirúrgico y su consiguiente selección de casos. La causa habitual es por complicación intraoperatoria no controlable por laparoscopia (hemorragia o lesión intestinal); por imposibilidad de proseguir la disección en eventraciones complejas con cuadro adherencial severo, o por la situación clínica del paciente.

\section{1) Recidiva}

Es un parámetro importante para valorar el éxito de la técnica. Se ha referido entre un 3-17 \% y depende, en gran medida, de una correcta indicación (localización y tamaño de la eventración, número de intervenciones previas), técnica empleada y la experiencia del equipo quirúrgico.

Como factores de riesgo de recidiva se reconocen: tamaño grande, el embarazo después de EL, complicaciones infecciosas y hipertensión abdominal postoperatorias. ${ }^{(27)}$ 


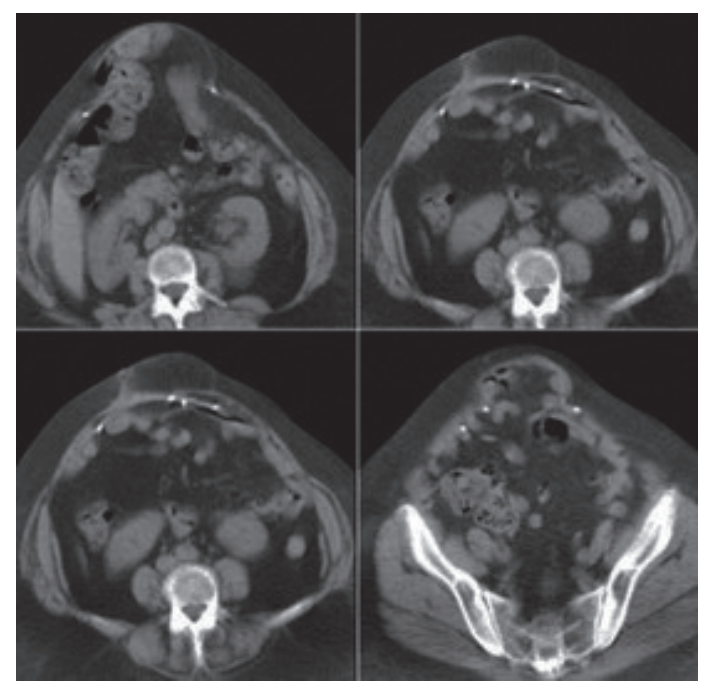

Recidiva de eventroplastia laparoscópica medial. Tomado de Eventraciones Otras hernias de pared y cavidad abdominal Fernando Carbonell Tatay Alfredo Moreno Egea Valencia, 2012

Se deben evitar los errores técnicos, que son la principal causa de recidiva:

- El no cierre fascial posterior o el cierre con tension excesiva, no genera la reconstrucción anatomofuncional parietal adecuada, lo que favorece la recidiva, así como la formación de seromas, infección superficial y bulging. ${ }^{(28)(29)}$ La no corrección concomitante de una diástasis de los rectos se asocia a cifras mayores de recurrencia.

- Error en la elección de la malla: composición, densidad, porosidad, fuerza tensil, tamaño en relación al defecto.

- La malla debe estar bien centrada en el defecto herniario, evitando un error común en esta técnica, que consiste en desplazar la prótesis contralateralmente a los trocares.

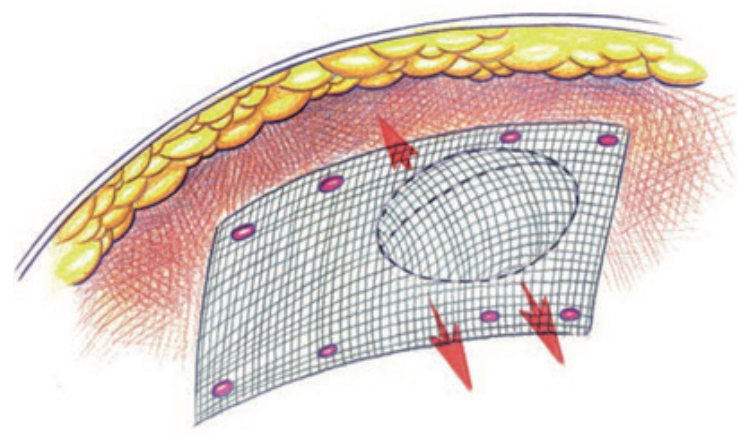

Situación desplazada de la malla. Tomado de Eventraciones Otras hernias de pared y cavidad abdominal

Fernando Carbonell Tatay Alfredo Moreno Egea Valencia, 2012

- La malla debe sobrepasar ampliamente el defecto herniario. Al inicio se utilizaban prótesis pequeñas que sobrepasaban poco el defecto herniario y la posterior retracción de la prótesis causaba la recidiva por el borde del foramen herniario. Actualmente, la mayoría de grupos son partidarios de sobrepasar ampliamente la hernia, con un overlap superior a los 4-5 cm o la relación 4/1 (radio de la malla vs radio del defecto), cubriendo toda la incisión previa. La evidencia demuestra que distancia del overlap de la malla sobre el defecrto herniario, es el factor más determinante de las recurrencias. ${ }^{(30)}$

- La malla situada en posición retromuscular presenta menos recurrencias. ${ }^{(31)}$

- Los tackers periféricos deben situarse en el borde de la prótesis, cada $2 \mathrm{~cm}$, evitando dejar demasiado espacio entre estos y que un asa intestinal pueda deslizarse entre ellos, asegurando que los tackers sujeten la malla adecuadamente. Para ello, es recomendable colocarlos en 90 o y con suave compresión manual externa. ${ }^{(32)}$

- Una segunda corona de tackers o suturas, es recomendada en las plastias de defectos mayores a $5 \mathrm{~cm}$, demostrando menor recidiva postoperatoria. La corona interna se ubica a $2-4 \mathrm{~cm}$ del orificio herniario.

- Las suturas transfaciales cardinales tiene más valor para la ubicación de la malla, que como medio de fijación. ${ }^{(33)}$ Rudmik,,$^{(2)}$ al comparar la recidiva de la técnica de fijación solo con tackers frente al uso tackers y suturas transfasciales, no comunica diferencias en recidivas. 
La RNM y la TC permiten valorar la recurrencia, al visualizar algunas de las mallas empleadas y su continencia, evaluar el tamaño del defecto y el contenido del saco. La realización de una fase dinámica, identifica defectos ocultos. Se visualizan mejor las prótesis de PTFEe, en desuso. Las mallas de polipropileno son casi indistinguibles de la aponeurosis normal y pueden valorarse si se usaron grapas metálicas de fijación. Estas sería una guía útil para establecer los límites de la malla y evaluar así su tensión, localización exacta y continencia.

Luego del tratamiento quirúrgico, las re-recidivas se calculan en el $50 \%$ cuando no se usa malla. Con el uso de mallas, se reportan un 5-10 \% a un año, un $25 \%$ a 5 años y hasta un $32 \%$ a 10 años. En pacientes con recidivas de HI, se valora individualmente el nuevo abordaje, la técnica y el tipo de malla según las características del defecto herniario, las preferencias del cirujano y las expectativas del paciente. A mayor número de recidivas, mayor tasa de complicaciones posoperatorias. ${ }^{(6)(34)}$

\section{1) Abultamiento postoperatorio o Seudorecidiva}

E1 96\% de los pacientes mantienen una pared abdominal simétrica y tensa a los 5 años del postoperatorio. Algunos pacientes no recuperaran con esta técnica una pared estéticamente aceptable, precisando llevar una faja abdominal. La seudorecidiva o "bulgging", es la protrusión clinica de la prótesis, intacta y bien colocada y fijada, ante maniobras dinámicas de la pared abdominal. Diferenciar el abultamiento de la recurrencia es clínicamente difícil, por lo que una TAC o RNM deben ser solicitadas.

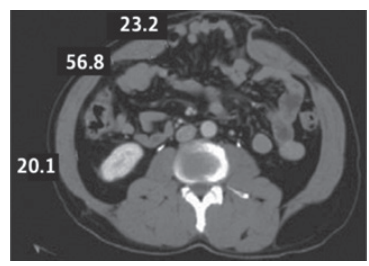

Diferencia entre:

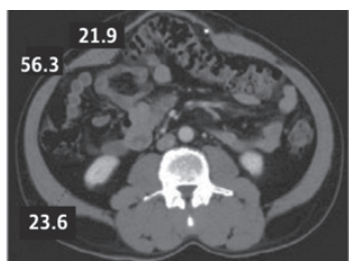

IPOM (Bulging)
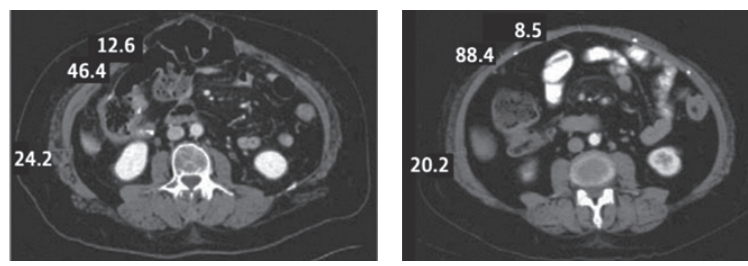

IPOM Plus (Sin Bulging)

Se reconocen como factores determinantes:(35) 1 ) Sobretraslape de la prótesis inferior a $5 \mathrm{~cm}$, o relación de radios menor a 4/1.2) No cierre del defecto herniario. 3) Fijación de la malla muy floja o con arrugas. 4) No corrección de diastasis de los rectos concomitante. 5) Defectos herniarios superiores a $20 \mathrm{~cm} 2$ (área elipsoide).

Se recomienda tratarlo solo cuando es sintomático o evoluciona a la progresión

\section{m) Mortalidad}

La EL tiene una mortalidad entre 1-3\% y aunque sea igual o menor que la de la eventroplastia abierta, significa un hecho especialmente grave, tanto desde un punto de vista social como legal. Habitualmente, ni los pacientes ni familiares están preparados para la aparición de un evento negativo en una cirugía laparoscopica. Con frecuencia se minimiza su enfermedad y el tratamiento propuesto con su morbilidad. Estos hechos hacen que cuando aparece una evolución inesperada, esta no pueda ser comprendida ni asimilada fácilmente. ${ }^{(10)}$

\section{COMPARACIÓN ENTRE LA TÉCNICA LAPAROSCÓPICA (EL) FRENTE A LA ABIERTA (EA) ${ }^{(36)(38)}$}

Tiempo operatorio. Inicialmente mayor en EL. Después de alcanzada la curva de aprendizaje (50 casos), no hay evidencia estadísticamente significativa en el tiempo operatorio.

Infección postoperatoria. La EL tiene significativamente menor riesgo para la infección de la herida quirúrgica, aún en hernias encarceladas o estranguladas.

Las lesiones intestinales inadvertidas son más comunes en la EL y pueden conllevar complicaciones graves.

La estancia hospitalaria es menor para la vía laparoscópica, aún en pacientes con enfermedad hepática crónica y obesidad.

El regreso a la actividad es más temprano con la EL; sin embargo, se requieren más estudios. 
La relación costo-efictividad es mejor el EL, con mayor impacto en pacientes obesos. Es menor aún costo con técnica e-tep comparada con técnica IPOM plus debido al uso de mallas convencionales. ${ }^{(39)}$

La calidad de vida en el corto plazo, es mejor con la EL.

La calidad de vida a largo plazo, no es diferente entre vía laparoscópica y vía abierta.

El dolor agudo y crónico, no hay diferencia significativa entre ambos abordajes.

\section{Conclusiones}

Si bien las técnicas de eventroplastia laparoscópica están aún en desarrollo, los resultados de grupos especializados, demuestran la seguridad de la técnica y su idoneidad en situaciones concretas (pacientes obesos, multirrecidivados, multisaculares), reportando un índice de complicaciones postoperatorias inferior a las obtenidas con cirugía abierta, con una estancia hospitalaria menor y una más rápida recuperación postoperatoria.

Enfatizamos la importancia de un correcto aprendizaje y sistematización de la técnica como factor más importante en la disminución de errores y complicaciones, así como el poder resolverlas adecuadamente si aparecieran. Es necesaria la formación tutelada por un cirujano experto, durante la curva de aprendizaje, momento de mayores complicaciones. Es recomendable seleccionar los pacientes durante el periodo de aprendizaje: en los primeros 30 casos, varones menores de 65 años, con defectos inferiores a 6-8cm y de localización medial no infraumbilical. ${ }^{(40)}$

\section{BIBLIOGRAFÍA}

1) Heniford BT, Park A, Ramshaw BJ, Voeller G. Laparoscopic repair of ventral hernias . Nine years' Experience with 850 consecutive hernias. Ann Surg 2003;238:391-400.

2) Rudmik LR, Schieman C, Dixon E, Debru E. Laparoscopic incisional hernia repair: a review of the literature. Hernia 2006;10:110-119.

3) Feliu Pala X. Camps Puigantell J. Complicaciones y errores en cirugía laparoscópica de la eventración. 64:763- 766 En Eventraciones Otras hernias de pared y cavidad abdominal Fernando Carbonell Tatay Alfredo Moreno Egea Valencia, 2012

4) Forbes SS, Eskicioglu C, McLeod RS, Okrainec A.Meta-analysis of randomized controlled trials comparing open and laparoscopic ventral and incisional hernia repair with mesh. Br J Surg 2009;96(8):851-8

5) Pham CT, Perera CL, Watkin DS, Maddern GJ. Laparoscopic ventral hernia repair: a systematic review. Surg Endosc 2009;23:4-15.)

6) Roca Domínguez B, Gutiérrez Ferreras AI, Mayagoitia JC. Guía para el manejo de la hernia ventral e incisional medial. Rev Hispanoam Hernia. 2021;9(2):80-87

7) González LG, Lora A, Varela E, Vergara G, Vega Peña V, Ayala JC, Martínez JD, Hanssen A, Gómez JP, Ruiz JP. Guía para el tratamiento laparoscópico de la hernia ventral e incisional. Rev Hispanoam Hernia. 2021;9(2):105117

8) LeBlanc KA. Laparoscopic incisional and ventral hernia repair: Complications. How to avoid and handle. Hernia 2004;8:323-31.

9) LeBlanc KA, Elieson MJ, Corder JM. Enterotomy and mortality rates of laparoscopic incisional and ventral hernia repair: A review of the literature. JSLS 2007;11(4):408-14.

10) Moreno Egea A. Reparación laparoscópica de la eventración de línea media 42:521-532 En Eventraciones Otras hernias de pared y cavidad abdominal Fernando Carbonell Tatay Alfredo Moreno Egea Valencia, 2012

11) Adrales G.L.A., Coker M. Society of American Gastrointestinal and Endoscopic Surgeons (SAGES) 2019; 2:1122 S. S. Davis Jr. et al. (eds.), The SAGES Manual of Hernia Surgery, https://doi.org/10.1007/978-3-319-78411$3 \_2$

12) Zhang $Y$, Zhou $\mathrm{H}$, Chai $\mathrm{Y}$, Cao $\mathrm{C}$, Jin $\mathrm{K}, \mathrm{Hu} Z$. Laparoscopic versus open incisional and ventral hernia repair: a systematic review and meta-analysis. World J Surg 2014;38 (9):2233-40.

13) Lovecchio F, Farmer R, Souza J, Khavanin N, Dumanian GA, Kim JY. Risk factors for 30-day readmission in patients undergoing ventral hernia repair. Surgery. 2014;155(4):702-10.

14) Suwa K, Okamoto T, Yanaga K. Closure versus non-closure of fascial defects in laparoscopic ventral and incisional hernia repairs: a review of the literature. Surg Today. 2016;46(7):764-73

15) Kukleta JF. Estado actual de los adhesivos en la cirugía de la hernia. Revista Hispanoam Hernia. 2020;8:1-2.

16) Morales-Conde S, Suarez-Artacho G, Socas-Macias M, Barranco-Moreno A. Retroprosthetic seroma after laparoscopic ventral hernia repair: incidence, risk factors and clinical significance. Hernia. 2015;19(6):943-7.

17) Bittner R, Bain K, Bansal VK, et al. Update of Guidelines for Laparoscopic Treatment of Ventral and Incisional Abdominal Wall Hernias (International Endohernia Society (IEHS))-Part A y B. Surg Endosc. 2019;33:3069549. DOI: $10.1007 / \mathrm{s} 00464-019-06907-7$ 
18) Bansal V, Asuri K, Panaiyadiyan S, Kumar S, Subramaniam R, Ramachandran R, et al. Comparison of absorbable versus nonabsorbable tackers in terms of long-term outcomes, chronic pain, and quality of life after laparoscopic incisional hernia repair: a randomized study. Surg Laparosc Endosc Percutan Tech. 2016;26(6):476-83.

19) Wassenaar E, Schoenmaeckers E, Raymakers J, van der Palen J, Rakic S. Mesh-fixation method and pain and quality of life after laparoscopic ventral or incisional hernia repair: a randomized trial of three fixation techniques. Surg Endosc. 2010;24(6):1296302.

20) Beldi G, Wagner M, Bruegger L, Kurmann A, Candinas D. Mesh shrinkage and pain in laparoscopic ventral hernia repair: a randomized clinical trial comparing suture versus tack mesh fixation. Surg Endosc. 2011;25(3):749-55.

21) Sauerland S, Walgenbach M, Habermalz B, Seiler CM, Miserez M. Laparoscopic versus open surgical techniques for ventral or incisional hernia repair. Cochrane Database Syst Rev. 2011;3:CD007781.

22) Bernal Agudo E Complicaciones específicasde la cirugía de las hernias ventrales por vía laparoscópica 49:530-538 Guías Clínicas de la Asociación Española de Cirujanos Cirugía de la Pared Abdominal 2a Edición 2013

23) Holihan JL, Alawadi Z, Martindale RG, Roth JS, Wray CJ, Ko TC, Kao LS, Liang MK. Adverse events after ventral hernia repair: the vicious cycle of complications. J Am Coll Surg. 2015;221(2):478-85.

24) Arita NA, Nguyen MT, Nguyen DH, Berger RL, Lew DF, Suliburk JT, Askenasy EP, Kao LS, Liang MK. Laparoscopic repair reduces incidence of surgical site infections for all ventral hernias. Surg Endosc. 2015;29(7):1769-80.

25) Moreno Egea A, Bustos JA, Girela E, Aguayo Alba- sini JL. Long-term results of laparoscopic repair of incisional hernias using an intraperitoneal composite mesh. Surg Endosc 2010 24(2):359-65.

26) Ousley J, Baucom RB, Stewart MK, Phillips SE, Holzman MD, Ehrenfeld JM, Sharp KW, Nealon WH, Poulose BK. Previous methicillin-resistant Staphylococcus aureus infection independent of body site increases odds of surgical site infection after ventral hernia repair. J Am Coll Surg. 2015;221(2):470-7.

27) Mercoli H,Tzedakis S, Antonio D’U, Nedelcu M, Memeo R, Meyer N, Vix M, Perreta S, Mutter D. Postoperative complications as an independent risk factor for recurrence after laparoscopic ventral hernia repair: a prospective study of 417 patients with long-term follow-up. Surg Endosc. 2017;31:1469-77.

28) BakerJJ. ÖbergS. AndresenK. Rosenberg J.Decreased re-operation rate for recurrence after defect closure in laparoscopic ventral hernia repair with a permanent tack fixated mesh: a nationwide cohort study Hernia https:// doi.org/10.1007/s10029-018-1776-2 Published online: 10 May 2018

29) Tandon A, Pathak S, Lyons NJR, Nunes QM, Daniels IR, Smart NJ. Meta-analysis of closure of the fascial defect during laparoscopic incisional and ventral hernia repair Br J Surg, 2016; 103(12):1598-1607 https://doi. org/10.1002/bjs.10268

30) LeBlanc K. Proper mesh overlap is a key determinant in hernia recurrence following laparoscopic ventral and incisional hernia repair. Hernia. 2016;20(1):85-99.

31) Bittner R, Bingener-Casey J, Dietz U, Fabian M, Ferzli G, Fortelny R, et al. Guidelines for laparoscopic treatment of ventral and incisional abdominal wall hernias (International Endohernia Society (IEHS)) - part 1. Surg Endosc. 2014;28(1):2-29.

32) Wassenaar E, Schoenmaeckers E, Raymakers J, Rakic S. Recurrences after laparoscopic repair of ventral and incisional hernia: lessons learned from 505 repairs. Surg Endosc 2009;23(4):825-32.

33) Chelala E, Barake H, Estievenart J, Dessily M, Charara F, Alle JL. Long-term outcomes of 1326 laparoscopic incisional and ventral hernia repair with the routine suturing concept: a single institution experience. Hernia 2016; 20: 101-110.

34) Lund S. FarleyD. A decade of experience with laparoscopic ventral hernia repairs The American Journal of Surgery 2019;217: 546-549

35) Bernardi K, Olavarria OA, Holihan JL, et al. Primary Fascial Closure during Laparoscopic Ventral Hernia Repair Improves Patient Quality of Life: A Multicenter, Blinded Randomized Controlled Trial. Ann Surg. 2020;271(3):434-9. DOI: 10.1097/SLA.0000000000003505

36) Jin J, Rosen MJ. Laparoscopic versus open ventral hernia repair. Surg Clin N Am 2008;88:1083-1100.

37) Sajid MS, Bokhari SA, Mallick AS, Cheek E, Baig MK. Laparoscopic versus open repair of incisional/ventral hernia: a meta-analysis. Am J Surg 2009;197:64-72.

38) Turner PL, Park AE. Laparoscopic repair of ventral incisional hernias: Pros and Cons. Surg Clin N Am 2008;88:85100.

39) Ruíz J, Barrios A, Vega N, et al. Técnica extraperitoneal comparada con IPOM plus: Análisis de costos evitados para optimizar el manejo de la hernia ventral por laparoscopia. Rev Colomb Cir. 2020;35(3):422-8. DOI: 10.30944/20117582.778

40) Gamón Giner R. Influencia de la selección de los pacientes en la implementación de la vía laparoscópica para el tratamiento de la hernia incisional. Rev Hispanoam Hernia. 2021;9:25-9. 


\section{TRATAMIENTO LAPAROSCÓPICO DE LAS HERNIAS VENTRALES PRIMARIAS MEDIALES}

\section{Dr. Nicolás Ramos}

La hernia ventral (HV) se define como el defecto de la pared abdominal anterior, con o sin tumoración perceptible o palpable, o que se evidencia mediante el uso de imágenes. La European Hernia Society (EHS) las divide en hernias ventrales primarias (HVP) y hernias incisionales (HVI). El primer grupo comprende las hernias de la línea media (epigástricas, umbilicales) y las laterales (lumbares, Spigel). La Hernia incisional (HI) es el defecto que aparece sobre una cicatriz operatoria y suele categorizarse según su topografía. Vale hacer esta diferencia, ya que si bien el abordaje quirúrgico puede ser similar, hay diferencias en cuanto a la tasa de complicaciones y recurrencia.

En este capítulo nos dedicaremos al análisis de algunos factores relevantes en la planificación y al tratamiento laparoscópico de las HVP del adulto.

Todavía se sigue debatiendo cual es el mejor abordaje para la cirugía de las HVP, abierto o laparoscópico. Se estima que aproximadamente $3 / 4$ partes de las reparaciones abdominales se efectúan de forma abierta. Sin embargo, estudios recientes demuestran mejores resultados con el abordaje mini invasivo (laparo/endoscópico) en la población en general. La reparación laparoscópica de la HVP esta asociada con una menor incidencia de complicaciones, menor estancia hospitalaria y menor tasa de reingresos en comparación con los abordajes abiertos. ${ }^{(1)}$ También se ha demostrado claros beneficios en cuanto a las complicaciones relacionadas con la herida operatoria (infección, sangrado, necrosis) incluso en pacientes obesos. ${ }^{(4)}$

Las hernias umbilicales (HU) aparecen sobre todo en la infancia, afectando entre el 10 a 20\% de los recién nacidos, sobre todo en niñas. Estas suelen ser menores a $1 \mathrm{~cm}$ y tienden a cerrar de forma espontánea hacia los 4 años de edad. En los adultos, sin embargo, 9 de $10 \mathrm{HU}$ no son congénitas y no tienden a cerrar. Aparecen hacia la $3^{\text {a }}$ década de vida y se consideran factores de riesgo sexo femenino (embarazo) y toda situación que aumente la presión intraabdominal. ${ }^{(5)}$ Las HU suelen tener un anillo estrecho y fibroso, ya que la línea alba por encima y debajo es muy resistente a la tensión. Esto hace que el anillo permanezca pequeño en relación al desarrollo del saco, convirtiéndolo en agente de estrangulación.

Las hernias epigástricas (HE) son aquellas que aparecen entre el apéndice xifoides y la cicatriz umbilical. Afectan al $10 \%$ de la población general entre la $3^{\mathrm{a}}$ y $5^{\mathrm{a}}$ década sin diferencia de géneros. Si bien la etiopatogenia no esta del todo aclarada, estas se producen como consecuencia del exceso de tensión aplicado sobre la línea alba. Las causas vinculadas son: un exceso en la tensión indirecta de fibras diafragmáticas, la presencia de los vasos perforantes de la pared abdominal, déficit en la síntesis de colágeno y características especificas del paciente, como pueden ser la obesidad y el tabaquismo.

\section{DIAGNOSTICO}

El diagnostico es fundamentalmente clínico siendo mas difícil en los pacientes obesos y con defectos pequeños.

La ecografía de partes blandas tiene su rol fundamental en el diagnostico inicial de toda tumoración o masa inmersa en la pared abdominal. Es un estudio accesible, de bajo costo y no ionizante. Combinada con el estudio de elastografia permite hacer diagnostico de hernia en la mayoría de los casos. ${ }^{(10)}$

La tomografía computada (TC) es el método mas confiable y coste - efectivo para diagnosticar los casos de dudas, hernias ocultas, pequeñas o en pacietnes obesos (3). La TC puede ser hecha con o sin contraste. Permite identificar, topografiar y medir con exactitud el tamaño del defecto. Valora el saco y el contenido así como el resto de la línea blanca y otras zonas herniarias de la pared abdominal.

En el caso de hernias complejas o de gran tamaño, la TC es fundamental para predecir las posibles complicaciones de la herida, la posible necesidad de aplicar terapias adyuvantes (neumoperitoneo progresivo) o la necesidad de efectuar alguna técnica de separación de componentes. Como fue descrito en otro capitulo, se han descrito múltiples métodos de calculo de proporción y volumen para anticipar estas situaciones. El método de Tanaka, relaciona la mediad estimada del volumen del contenido del saco herniario (VSH) y lo compara con el volumen de la cavidad abdominal (VCA), una 
relación VSH/VCA mayor al 25\%, predice una perdida de derecho a domicilio y hace al paciente candidato a técnicas de liberación miofascial.

Sabbagh describe una formula que evalúa la relación entre el volumen de la hernia incisional (VHI) sobre el volumen peritoneal (VP), una relación VHI/VP menor al 20\% podría ser indicador de un cierre de la fascia libre de tensión. Carbonell describe otra formula preoperatoria, en el que el cierre directo de la fascia no seria posible si el ancho del defecto supera al doble del ancho del recto. Esta formula es fácil de aplicar y utilizada, pero carece de validez científica. ${ }^{(8)}$

Frente a este hecho, Love et al ${ }^{(9)}$ comparan la relación entre el ancho de los músculos rectos y el ancho máximo del defecto (RDR), con la hipótesis de que una relación 2:1, predicen un cierre fascial sin tensión y no seria necesario aplicar otras técnicas de liberación parietal (TAR o SAC). Esta formula fue validada en 342 pacientes y tiene la ventaja, frente a la de Sabbagh, en la que no se requiere de software especializado para el calculo volumétrico ya que con la simple medida de los cuerpos de los rectos y el defecto es suficiente (Figura 1.)
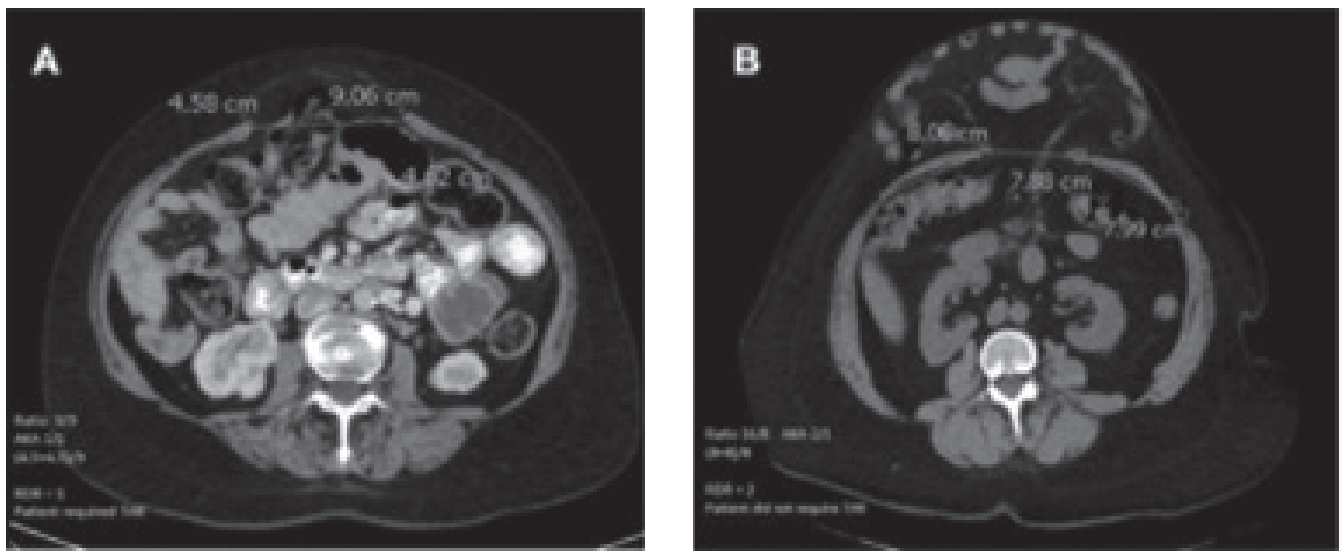

Fig 1. Tc en la que se evidencia la relación entre la medida de los rectos y el defecto (RDR) A: paciente con necesidad de realizar TAR. $\mathrm{RDR}<2$. B: paciente con $\mathrm{RDR}>$ a 2 no requiere TAR Extraido de: doi.org/10.1007/s10029-020-02181-y

Si bien estos métodos de calculo de volúmenes y radios son de gran ayuda en la planificación del tratamiento quirúrgico, existe un factor vinculado a la expansibilidad o compliance parietal, que determina que hasta un $10 \%$ de los pacientes requieran técnicas de liberación miofascial a pesar de tener cálculos que determinarían lo contrario ${ }^{(9)}$ y es de resorte intraoperatorio. La medida subjetiva de la tensión parietal luego del cierre del defecto, asi como la medida de presión en vía aérea, se describen como variables a tener en cuenta durante la cirugía. Si luego del cierre de la línea blanca, la sutura parece tensa y/o existe aumento en la presión en la vía aérea, se requerirá de una técnica de liberación miofascial.

\section{CLASIFICACION}

Actualmente la clasificación aceptada es la de la EHS (Fig 2.), descrita en 2007, tiene como fin lograr una uniformidad en la nomenclatura de estos defectos dentro de la comunidad quirúrgica especializada y de esta manera poder comparar resultados. ${ }^{(3)}$ Esta es sencilla, fácil de recordar y de aplicar por la mayoría de los cirujanos. Esta toma en cuenta la localización anatómica del defecto en la pared abdominal y el ancho del defecto (TABLA 1).

Todavía son necesarias algunas puntualizaciones en la clasificación de la EHS, como son la de incluir información sobre la recidiva, así como de defectos ventrales mixtos que incluyan tanto la línea media como la pared lateral.

En las actualizaciones de las guías del tratamiento para las hernias ventrales (IEHS-2019)(10) se deja ver que existe una brecha entre la aplicación de esta clasificación y el impacto clínico en el tratamiento de los pacientes. Se requieren además de estudios adicionales de validación para optimizar los puntos de corte en cuanto a la media del ancho de los defectos ventrales. ${ }^{(2)}$ 


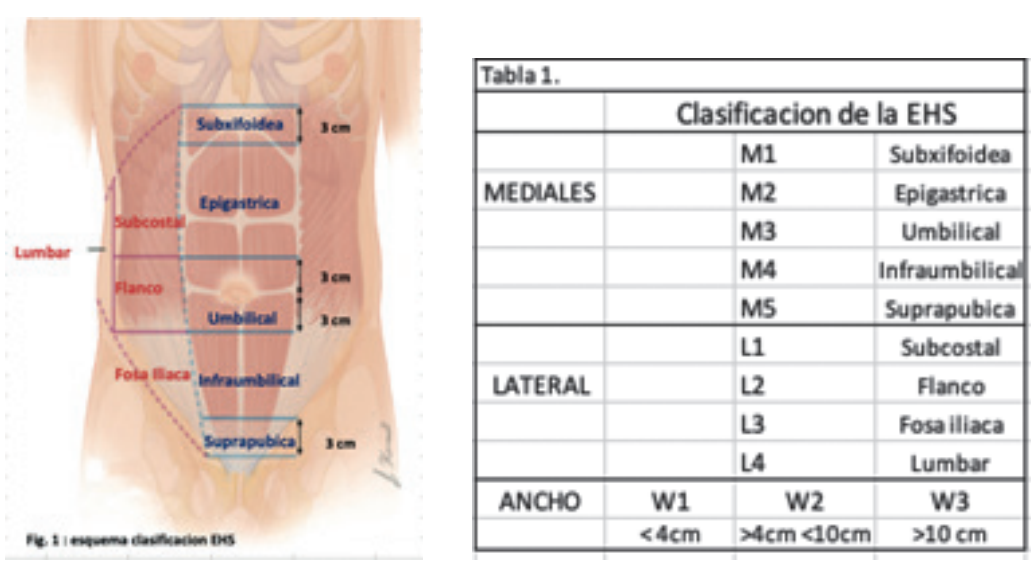

Fig 2. Esquema clasificación EHS

\section{TRATAMIENTO}

EL tratamiento de las HVP es quirúrgico, eso es indiscutible. El cierre del defecto y el refuerzo de la pared abdominal son los pilares del tratamiento de las HVP. Estos pueden ser realizados por vía abierta tradicional o por abordaje mini invasivo (AMI): hibridas, laparo-endoscópicas y robóticas.

Recordemos que en este capitulo nos referiremos a las HV primarias mediales(HVP) de tamaño pequeño y mediano. Dejamos de lado las hernias ventrales incisionales (HVI), que serán tratadas en otro capitulo y aquellos defectos que por su complejidad y tamaño requieran de técnicas de separación de componentes, o tratamientos adyuvantes (NPP + TBA).

EL abordaje quirúrgico de las HVP puede ser abierto, endoscópico, laparoscópico o técnicas hibridas, es decir, mediante la combinación de estas modalidades, englobadas en el abordaje mini invasivo de la pared abdominal (AMI). Como mencionamos antes, hasta $2 / 3$ partes de estos procedimientos se siguen practicando mediante un abordaje abierto ${ }^{(1)}$ respondiendo tal vez al desconocimiento o al no entrenamiento del cirujano general en estas técnicas.

En su trabajo Aly y col, ${ }^{(1)}$ evaluaron las tasas de complicaciones entre ambos abordajes, para una población de mayores e 65 años, N= 49.349 en el periodo de 2012 y 2016. Los pacientes fueron seleccionados de la base de datos del American College of Surgeons National Surgical Quality Improvement Project (NSQIP). En este trabajo, 5.079 (71,1\%) y $14.270(28,9 \%)$ pacientes fueron sometidos a reparaciones de hernias ventrales abiertas y laparoscópicas, respectivamente. La cirugía laparoscópica se asoció con una menor morbilidad general $(5,9 \%$ frente a $9,1 \% ; p<0,001)$ en comparación con la reparación abierta. La incidencia de infecciones del sitio quirúrgico $(1,1 \%$ frente a 3,5\%; p <0,001), infecciones posoperatorias $(2,7 \%$ frente a $3,6 \% ; \mathrm{p}<0,001)$ y reoperación $(1,7 \%$ frente a $2,1 \% ; \mathrm{p}=0,009)$ fueron todos más bajos después de la reparación laparoscópica (Tabla2). Todos los demás resultados quirúrgicos fueron mejores con la laparoscopia o comparables entre ambos grupos de tratamiento, excepto por el tiempo operatorio.

Si bien no se trata de un trabajo randomizado, del mismo puede desprenderse que el abordaje laparoscópico de las HV y de estas las HVP, parece ser mas seguro en la población mayor de 65 años, generalmente considerada mas vulnerable.

\begin{tabular}{|c|c|c|c|c|c|c|}
\hline & \multicolumn{3}{|l|}{ Unmakshed } & \multicolumn{3}{|l|}{ Matached } \\
\hline & $\begin{array}{l}\text { Open } \\
(n=35,09 y)\end{array}$ & $\begin{array}{l}\text { Lapuroscopic } \\
(n=14,270)\end{array}$ & pvaloe & $\begin{array}{l}\text { Open } \\
(n=14,270)\end{array}$ & $\begin{array}{l}\text { Lapuencopopic } \\
(n=14,270)\end{array}$ & p value \\
\hline Mortaling, n (\%) & $172(05 \%)$ & $51(0.45)$ & 0.065 & $n$ (0.5\%) & $51(0.45)$ & 0.021 \\
\hline Overall morbidity, $n$ (5) & 2981 (8.58) & 842 (5.9\%) & $<0.001$ & $1297(9.15)$ & $842(5.9 \%)$ & $<0.001$ \\
\hline Mince moetidity, $n(\%)$ & $1100(3.2 \%)$ & $281(2.05)$ & $<0.001$ & $494(355)$ & $281(2.05)$ & $<0.001$ \\
\hline Major morbidigy, $n$ (\%) & 2155 (6.1\%) & $618(4.3 \%)$ & $<0.001$ & $934(6.6 \%)$ & $618(4.3 \%)$ & $<0.001$ \\
\hline Cardiac coemplication, $n$ (\$) & $172(0.5 \%)$ & $79(0.65)$ & 0.370 & $20(0.5 \mathrm{~s})$ & $79(0.65)$ & 0.460 \\
\hline Throemboembolic events, $n$ ( $\%$ ) & $229(0.7 \%)$ & $74(05 \%)$ & 0.084 & $102(0.7 \%)$ & $24(0.5 \%)$ & 0.044 \\
\hline Renul inuafficiency, $n(5)$ & $150(0.4 \%)$ & $34(0.25)$ & 0.002 & $20(0.5 \%)$ & $34(0.2 \%)$ & $<0.001$ \\
\hline Pontoperative infectios, $n$ (S) & $1157(3.3 \%)$ & $358(2.75)$ & $<0.001$ & $515(3.68)$ & $388(2.75)$ & $<0.001$ \\
\hline Surgical site infection, $n$ (s) & 1093 (9.15) & $159(1.1 \%)$ & $<0.001$ & $500(35 \%)$ & $159(1.1 \%)$ & $<0.001$ \\
\hline Reoperaboe, $n(\boldsymbol{\Phi})$ & $755(2.2 \%)$ & $239(1.7 \%)$ & $<0.001$ & $299(2.19)$ & $239(1.75)$ & 0.009 \\
\hline Operative time, median (IQR) & $57(35-99)$ & $79(53-116)$ & $<0.004$ & $59(05-103)$ & $79(53-116)$ & $<0.001$ \\
\hline Lenget of stay, media (OQR) & $0(0-3)$ & $1(0-2)$ & $<0.001$ & $1(0-3)$ & $1(0-2)$ & 0.342 \\
\hline
\end{tabular}


La obesidad es un factor relevante en el desarrollo de HVP y en la aparicion de complicaciones locales, sistemicas y de recurrencia. Las urgencias con obstruccion y estrangulacion son mas frecuentes en este grupo de pacientes, ${ }^{(2)}$ por lo que no se recomienda el "watch and wait", postulados por algunos trabajos, independientemente del tamaño del defecto. En una revisión realizada por F. Köckerling, P. Chowbey y R. Khullar, publicada en el Update de las guias de la IEHS $(2019),{ }^{(10)}$ se demostro en varios trabajos una reduccion estadisticamente significativa en tasas de complicaciones en la herida operatoria, entre el abordaje abierto y el laparoscopico para los pacientes obesos (IMC > a $30 \mathrm{Kg} / \mathrm{cm} 2$ ) asi como tambien, una reduccion en tasas de infeccion del sitio quirugico (ISQ) de entre un 70 a $80 \% .{ }^{(12)(13)}$ En relacion a este ultimopunto, la ISQ duplica el riesgo de recurrencia, por lo tanto minimizar el desarrollo de ISQ es primordial para cortar con el "ciclo vicioso" de reparacion, complicacion, recurrencia, reoperacion. Otros factores viculados a la obesidad y que influyen de manera negativa en los resultados son la diabetes mellitus, el tabaquismo, y el uso cronico de corticoesteriodes.

La diabetes mellitus interfiere en la microcirculacion, lo que a su vez interfiere en los procesos normales de cicatrizacion. Esto aumenta el riesgo de ISQ asi como de recidiva temprana. Una hemoglobina glicosilada > a 6 o $7 \%$ se acompaña de un aumento de complicaciones relacionadas a la herida, mayor en diabeticos insulinodependientes. ${ }^{(5)} \mathrm{El}$ abordaje miniinvasivo en estos pacientes, reduce las alteraciones sobre los tejidos y con esto el desarrollo de complcaciones.

Son bien conocidos los efectos del tabaquismo en la aparicion de complicaciones postoperatorias en cirugia general. En la cirugia electiva de las HVP el tabaquismo aumenta el riesgo de ISQ asi como de alteraciones pulmonares postoperatorias. Al igual que la diabetes, el efecto nocivo esta en la microcirculacion asi como en los procesos de cicatrizacion. Se recomienda abandono del habito tabaquico al menos 4 semanas previas a la cirugia (tabla3). ${ }^{(10)(20)}$

El uso de corticoesteroides al actuar sobre los procesos inflamatorios se relacionan con aumenteo en las ISQ al igual que el uso de inmunosupresores. ${ }^{(5)}$ No se ha demostraso que guarden relacion con la recidiva.

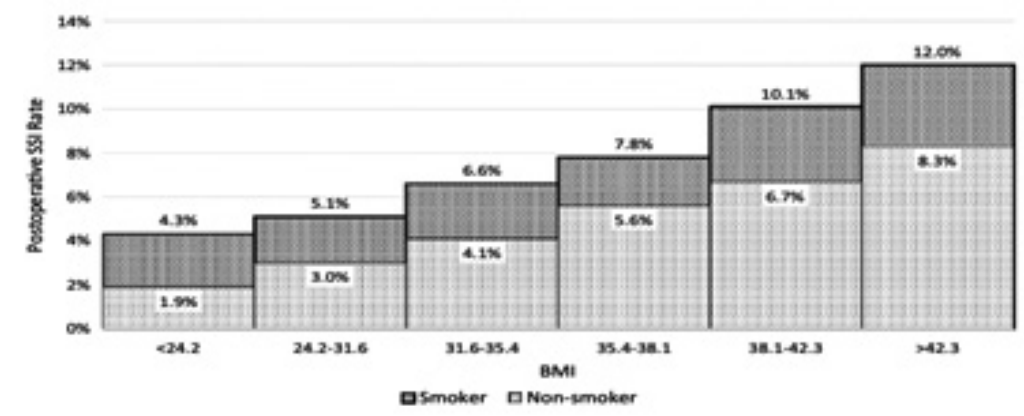

Tabla 3. ISQ en fumadores y no fumadores. Extraido de: H. Park, C. de Virgilio,D. Y. Kim, A. L. Shover, A. Moazzez Effects of smoking and different BMI cutoff points on surgical site infection after elective open ventral hernia repair. Hernia (2021) 25:337-343

\section{¿Debemos colocar malla? ¿Donde: en que plano?}

En general, la reparacion libre de tension con la colocacion de malla se considera como el gold standard para el tratamiento de las HVP ya que esto reduce el riesgo de recurrencias incluso en hernias pequeñas. Algunos cirujanos y publicaciones, promueven la reparacion mediante sutura primaria (herniorrafia) en caso de hernias pequeñas $(<2 \mathrm{~cm})$ ya que consideran que la colocacion de una malla de mayor tamaño puede resultar en un ensanchamiento iatrogenico del defecto y tener riesgo de complicacones propias del uso de una protesis (infeccion, dolor cronico). ${ }^{(5)}$ Otro argumento "en contra" es el costo que acarrrea el uso de protesis, que si bien puede tener relevancia en el caso del uso de mallas intraperitoneales, no es comparable al costo de la recidiva. Habiendo comentado esto, nosotros creemos que la reparacion de toda HVP debe ser reforzada con la colocacion de una malla independientemente del tamaño del defecto. El lugar donde colocamos la protesis, es decir, en que plano de la pared lo hacemos puede llegar a ser todo un dilema. Independientemente de ello, el fin es el mismo, reforzar la pared con la menor tasa de recurrencia y minimas complicaciones, sabiendo que cada plano tiene sus propiedades mecanicas especificas y que muchas veces escogeremos entre uno u otro de acuerdo a cada situacion particular.

Recientemente en las guias publicadas por la American Hernia Society (AHS) en conjunto con la EHS ${ }^{(11)}$ se recomienda la reparacion primaria para hernias umbilicales con defecto $<$ a $1 \mathrm{~cm}$. Para el resto se recomienda la colocacion de una protesis holgada sobrepasando al menos 3 a $5 \mathrm{~cm}$ el defecto en todas direcciones. En el caso de procedimientos laparoendoscopicos la medida del defecto puede ser estimada por estudios de imagen si es necesario, o medidos in vivo. 
Para ello se deben de utilizar reglas flexibles y realizar la medicion del mismo a 6 u $8 \mathrm{mmHg}$ de presion Las recomendaciones actuales de 1 sa guias internacionales son realizar estas medidas de forma dinamica. ${ }^{(2)}$

A efectos precticos y para evitar confusiones repasaremos las diferentes nomenclaturas vinculadas a los planos de la pared abdominal. De esta manera nos resultara mas facil comprender las diferentes tecnicas que desarrollaremos, ya que en lo que se diferencian basicamente es en el tipo o via de abordaje de un plano en particular.

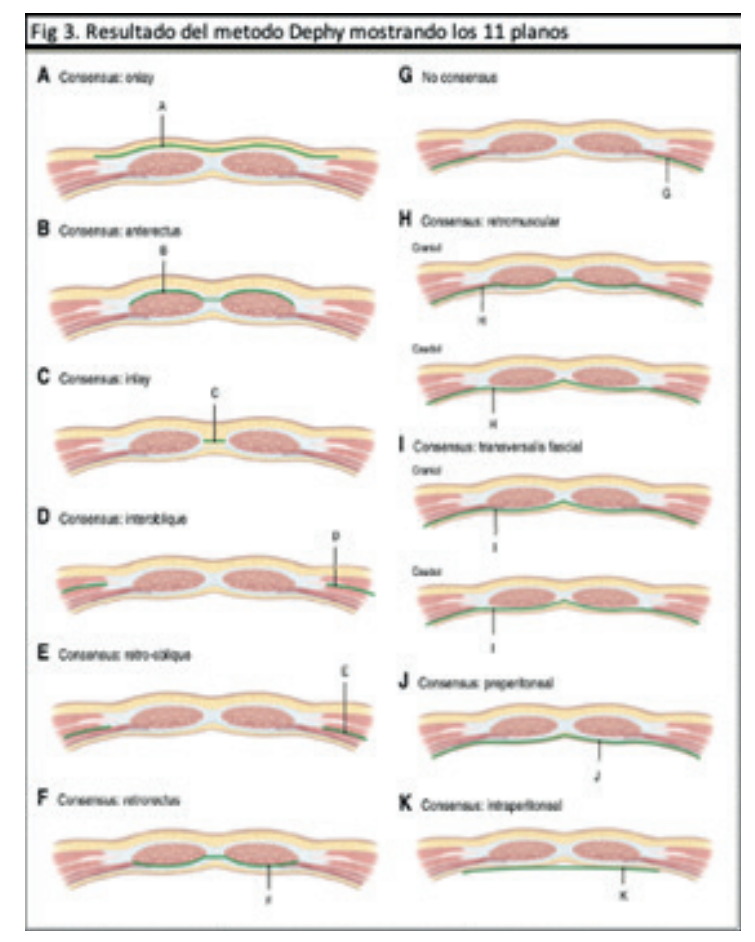

En 2019, se publica la nueva clasificacion internacional de planos de la pared abdominal, ${ }^{(6)}$ esta. surge con el fin crear una clasificacion globalmente aceptada y asi homogeneizar resultados de estudios futuros. Para ello participaron 20 expertos en cirugia parietal reconocidos internacionalmente y se les aplico un formulario con el metodo Delphi. De este estudio se desprenden por consenso la existencia de 11 planos musculares (ver Fig. 3). A continuacion describiremos de forma esquematica los 4 planos que mas frecuentemente son utilizados por los cirujanos generales:

ONLAY: en este plano la malla es suturada a la fascia anterior expuesta (Fig. 3 A). Por lo general requiere de decolamientos dermograsos extensos y en ocasiones de incisiones de descarga sobre los musculos laterales para lograr un cierre primario sin tension. La realizacion de estos decolamientos lo hace propenso a complicaciones como son la formacion de seroma y la infeccion de la protesis. Se describe mayor tasa de recurrencia comparado con los planos mas profundos. Es el que se utliliza durante la tecnica REPA.

INLAY: en este caso la malla es suturada a los bordes del defecto, sin cierre primario del mismo (fig 3.C). Tambien denominada "Bridge" o reparacion en puente. Este es el plano que se asocia a mayor tasa de recurrencia $(50 \%),{ }^{(5)}$ ya que precticamente no hay integracion de la malla y de ISQ debido a que la malla queda cubierta unicamente por piel. Como no se restituye la línea media, esta reparacion es propensa al "bulging" o pseudorecurrencia, lo que muchas veces trae desconformidad por parte de los pacientes.

SUBLAY: este es el plano ideal o "gold standard" para la reparacion de las HV, en este caso la malla se coloca en el espacio retro muscular (prefascial) preperitoneal en el denominado espacio de Rives- Stoppa. Para mayor comprension de este debemos recordar la disposicion y entrecruzamiento de las fascias muculares por encima y por debajo del la línea arcuata. Es asi que por encima de esta, el plano puede ser retromuscular o prefascial (fig3. F) o sobre la transversalis (fig.3 I) y preperitoneal por debajo (fig3. J). Es el que se describe con menor tasa de recurrencia y de complicaciones infecciosas. Tiene como desventaja que al realizar la diseccion sobre el vientre muscular tiene mayor riesgo de sangrado $\mathrm{y}$ de lesion del pediculo neurovascular del musculo recto. Ademas requeire de entrenamiento y mayor curva de aprendizaje. Este plano es el utilizado p ej. en el TEP/eTEP, en el ventral TAPP y en el ventral TARM

UNDERLAY: en este la malla es colocada en el plano intraperitoneal y asegurada sobre el peritoneo parietal anterior (fig3. K), es el plano tecnicamente mas accesible y permite la colocacion de mallas de gran tamaño con minima diseccion. Este es el plano utilizado en el IPOM. 
Estos dos ultimos planos son los planos preferidos por sus caracteristicas mecanicas. Al colocar la malla en posicion retromuscular/preperitoneal o intraperitoneal, las mismas fuerzas que aumentan la presion intra abdominal tienden a expandirse y repartirse en cada centimetro cuadrado de la protesis y no en la línea de sutura. Esto tiende a fijar la malla en su lugar, por el contrario en el plano supraaponeurotico y en al inlay, las fuerzas tienden a "empujar" la malla lo que es responsable de las mayores tasas de recidivas.

\section{Técnicas de Hernioplastia para HVP mediales}

Múltiples técnicas mini invasivas han sido desarrolladas para el abordaje de estos espacios (tabla 4), laparoscópicas, endoscópicas, hibridas e incluso muchas con su versión robótica. Estas ultimas, actualmente en desarrollo exponencial a nivel mundial, lamentablemente no planteables por el momento en nuestro medio debido a sus elevadísimos costos operativos.

A continuación, daremos una breve descripción de estas principales técnicas, las que se desarrollaran en profundidad en el capitulo del tratamiento laparoscópico de las hernias incisionales y de la diastasis de los rectos.

Como fue expuesto anteriormente, en el tratamiento laparoendoscópico de las HVP mediales pueden utilizarse 4 planos para colocar la malla, siendo los planos ideales el retromuscular/ preperitoneal (SUBLAY) y el intraperitoneal (UNDERLAY).

\begin{tabular}{|l|l|}
\hline Tabla 4. Principales tecnclas de acuerdo al plano: \\
\hline ONLAY & $\begin{array}{l}\text { REPA / SCOLA } \\
\text { LARDA } \\
\text { Ventral TEP } \\
\text { Ventral TAPP } \\
\text { Ventral TARM }\end{array}$ \\
\hline SUBLAY & $\begin{array}{l}\text { IPOM/ IPOM plus } \\
\text { URA }\end{array}$ \\
\hline INTRAPERITONEAL & MILOS/ eMILOS \\
\hline HIBRIDA & \\
\hline & Ventral TEP \\
\hline
\end{tabular}

El abordaje totalmente extraperitoneal (TEP) y su versión extendida (eTEP) son considerados como los ideales para los procedimientos endoscópicos de abordaje retromuscular (retrorectal).

Introducido por Jorge Daes en principio para el tratamiento de las hernias inguinales, el abordaje TEP/eTEP, demostró ser una técnica aplicable y efectiva para el tratamiento de las HVP (ventral TEP).

Sin intención de confundir, destacamos que en la literatura internacional veremos términos como e-Rives/Stoppa y totally extraperitoneal surgery (TES) para referirse a variantes técnicas del abordaje endoscópico de este mismo espacio. A diferencia del abordaje abierto clásico, en este se realiza el abordaje endoscópico del espacio retromuscular evitando las grandes incisiones cutáneas, y las potenciales complicaciones derivadas de estas como pueden ser el seroma, las ISQ y el dolor postoperatorio.

En comparación con las técnicas intraperitoneales (IPOM) la colocación retromuscular (retrorectal) de la prótesis tiene beneficios tanto a nivel mecánico como molecular. ${ }^{(15)}$ Evita el contacto de la malla con el contenido abdominal disminuyendo así la posibilidad de adhesión y fistulización visceral. Tiene la ventaja de colocar la malla en un plano que no requiere fijación por lo que evita las complicaciones de los dispositivos destinados para ello (tackers). Es un plano ricamente vascularizado lo que favorece la producción de colágeno tipo I y con ello se mejora la integración de la prótesis y la resistencia a la tensión. ${ }^{(15)} \mathrm{Al}$ no entrar en la cavidad peritoneal se reduce a un mínimo el riesgo de lesión visceral. ${ }^{(5)}$

Es un procedimiento que no requiere de insumos materiales específicos, basta con el material común de laparoscopia (endocamara de 30, trocares de 5 y $10 \mathrm{~mm}$ ).

La malla que utiliza es de polipropileno (macro o micro porosa) de 15x15 o 30x $30 \mathrm{~cm}$, menos costosas que las utilizadas en el IPOM. No requiere fijación por lo que el uso de mecanismos comerciales para ese fin no es necesario (siendo que muchas veces son el elemento de mayor costo), y una vez que se esta entrenado en el abordaje TEP tampoco es necesario el uso del balón disector. 
En cuanto a la ergonomía de la técnica, la colocación de los trocares es variable y dependiendo de estos la disección de la línea media podrá ser realizada Up/down, es decir de cefálico a caudal (sobre todo para las HVP), down/up o de caudal a cefálico, dependiendo del tamaño del defecto y de la preferencia del cirujano. Fig 4

Como contraparte debemos decir que es técnicamente compleja, requiere de entrenamiento y curva de aprendizaje. Son procedimientos que insumen mucho tiempo en comparación con las técnicas abiertas siendo en el entorno de los 120 min. $^{(1)}$

\section{Ventral TAPP - Ventral TARM}

Las técnicas laparoscópicas realizan el abordaje del espacio preperitoneal (ventral TAPP) o retromuscular (ventral TARM) a través de la cavidad abdominal, realizando una incisión a nivel peritoneal sobre el borde lateral del musculo recto. ${ }^{(16)}$ En estos el plano de colocación de la prótesis y las características de este son idénticas que para el TEP/ETEP. Una vez colocada la prótesis, requieren el cierre peritoneal mediante una sutura continua, generalmente con hilos barbados de reabsorción lenta. En estos casos habitualmente los trocares se colocan a nivel del flanco izquierdo (fig4) realizando así una disección lateral del defecto, aunque la disposición, al igual que para el TEP/eTEP dependerá de la preferencia del cirujano.

Las ventajas en general son las mismas que las descritas para el TEP/ eTEP en cuanto a las características del espacio retromuscular/ preperitoneal. Podemos agregar que al ser un abordaje transabdominal permite realizar una viscerolisis y reducción segura del contenido del saco. Además, permite valorar completamente el defecto y el resto de la línea media, diagnosticando así otros defectos asociados.

Similar a lo que ocurre con las otras técnicas endoscópicas, estas pueden resultar complejas en su realización, por un lado, la flacidez propia del peritoneo puede resultar difícil y a esto debemos sumarle una sutura continua para su cierre. Son técnicas que insumen tiempo y que claramente son de mayor riesgo de lesión visceral.

\section{IPOM - IPOM- plus}

Las técnicas intraperitoneales tienen al IPOM (IntraPeritoneal Onlay Mesh) (Fig 5) como la técnica de reparación de las HVP mas extendida a nivel mundial. Es una técnica fácil de realizar y con buenos resultados a corto y largo plazo. Presentada en la década del 90 por Le Blanc y Booth, quienes desarrollaron una técnica que permitía la colocación de una malla intraperitoneal que se fijaba a la pared anterior, y que excedía ampliamente el defecto con mínimas incisiones cutáneas. ${ }^{(5)}$ Sin embargo, la colocación de una malla intraperitoneal y su fijación conllevan cierto riesgo que debe ser considerado.

En este tipo de reparación el contacto entre la malla y las vísceras es inevitable lo que hace que el uso de las mallas de polipropileno, sea riesgoso. Si bien estas tienen bajo costo y logran una buena integración a la pared, generan una intensa reacción inflamatoria, que podría llevar a la formación de adherencias intraperitoneales y fistulas. Para ello se han desarrollado mallas doble capa (dual-layer) que por una de sus caras ofrecen materiales convencionales (poliéster, polipropileno) que entran en contacto con la pared abdominal y favorecen su integración, y por el otro, materiales inertes (colágeno, celulosa, PTFE) en contacto con las vísceras. Estas ventajas tienen su contraparte en los elevados costos, lo que ha hecho que muchos cirujanos opten por técnicas como el ventral TAPP o TARM que utilizan las mallas de polipropileno más baratas. ${ }^{(16)}$

Como sucede en el resto de las técnicas de reparación de la pared abdominal, la prótesis debe sobrepasar al menos $5 \mathrm{~cm}$ el defecto o para ser mas precisos, debe de tener una relación de radio malla/defecto de 4:1. ${ }^{(19)}$

La fijación de la malla a la pared anterior del abdomen, comúnmente se realiza de forma invasiva, ya sea con dispositivos comerciales de fijación laparoscópicos o con puntos transfasciales, si bien disminuyen el riesgo de recidiva herniaria, aumentan el riesgo de hematoma y dolor postoperatorio agudo y crónico. La utilización de colas y/o pegamentos se acompañan de mayores tasas de recidiva por lo que su uso en este tipo de reparación parietal no este recomendado. ${ }^{(10)}$

Estas posibles consecuencias negativas de los métodos de fijación no están totalmente relacionadas al tipo de material que utilicen, sino que guarda relación tanto a la cantidad como a la disposición de los tackers. La mayoría de los cirujanos que utilizan el IPOM- Plus realizan la fijación mediante la colocación de tackers cada 1 o $3 \mathrm{~cm}$ en doble corona. Uno pensaría que a mayor cantidad de tackers utilizados, mayor probabilidad de complicaciones como sangrado, hematoma, dolor y adhesiones. 


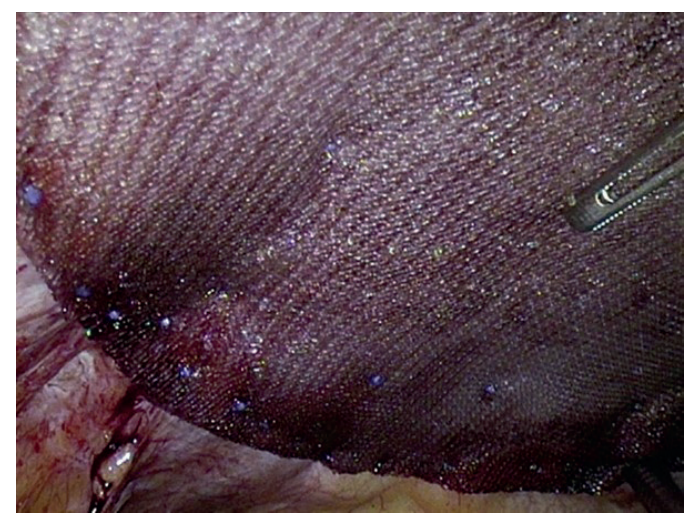

Para ello se describe una relación ideal entre el área de malla y el numero de tackers utilizados, es el denominado Mesh Tacker Ratio (MTR) tomando como relación ideal un MTR $<=$ a 4:1, es decir que cada $4 \mathrm{~cm} 2$ de malla debe existir un tacker fijándola. Chan Y. y col. (Hernia,2021)(19) en su estudio concluyen que a mayor cantidad de tackers utilizados (MTR <=4:1) se reduce la tasa global de recurrencia en pacientes con riesgo para esta. Por lo contrario, en relación al impacto del numero de tackers sobre el dolor postoperatorio y la calidad de vida, se observo una correlación positiva entre el numero de tackers (mas de 30) y la aparición del dolor.

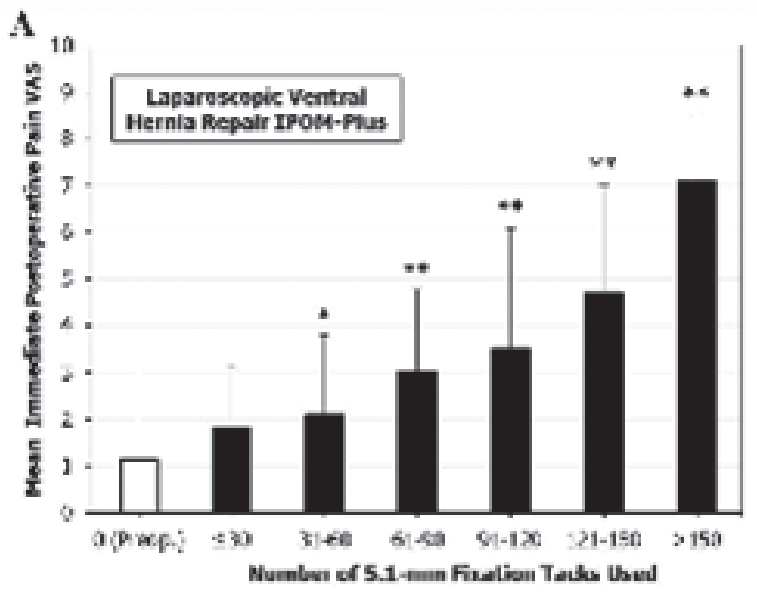

B

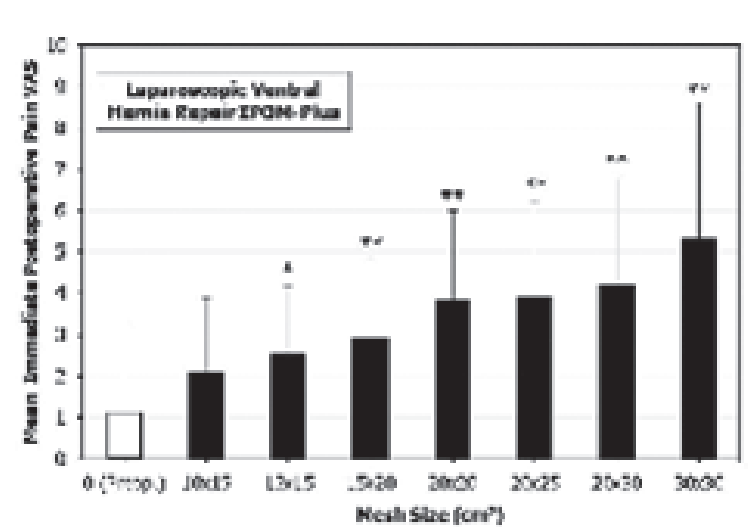

La fijación de la malla debe ser proporcional al tamaño de esta y a los factores de riesgo de recidiva que presente el paciente. Para pacientes con defectos grandes y factores de riesgo para recidiva (obesidad, Diastasis) se recomienda una relación $<=$ a 4:1, es decir colocar tackers cada $1 \mathrm{~cm}$ en 3 filas. En cambio, para pacientes sin factores de riesgo una relación de 4:1 o 5:1, es decir cada 2 o $3 \mathrm{~cm}$ en dos filas, parecería resultar suficiente.

Para los defectos muy grandes (mayores de $10 \mathrm{~cm}$ ), en los que por el tamaño de la malla $(20 \times 20 \mathrm{~cm})$ sean necesarios mas de 100 tackers, se recomienda optar por un procedimiento retromuscular o hibrido (TEP, eTEP o MILOS). ${ }^{(19)}$

Un tercer factor a tener en cuenta es que en el IPOM clásico, los autores no cerraban la brecha del defecto, esto llevo a que inicialmente tuvieran mayores tasas de recidiva herniaria temprana, de pseudo recidivas (bulging) y de complicaciones vinculadas el procedimiento quirúrgico. ${ }^{(5)}$

El uso de una malla sola (bridge repair), sin el cierre del defecto tiene como consecuencia la creación de un espacio muerto con la subsecuente formación de seromas. Mientras la mayoría estos seromas permanecerán asintomáticos, hasta un 30\% de ellos desarrollarán algún síntoma (18). Estos seromas pueden ser reducidos al mínimo si se realiza el cierre del defecto.

A.Martin del Campo, H. Miller, H. Elliott Y Y. Novitsky en $2018^{(19)}$ publican una revisión retrospectiva de casos en un mismo centro. Analizaron 783 casos operados, en 222 de ellos se efectuó cierre del defecto, en los 561 restantes no. Si bien se trata de una revisión de casos, estos pudieron mostrar diferencias significativas en cuanto a la aparición de seromas ( 0,4 vs $11,5 \%, \mathrm{p}<0.001)$ y de complicaciones vinculadas a la cirugía $(3,6$ vs $14,9 \%, \mathrm{p}<0.001)$ en favor de los del grupo de reparación con cierre del defecto. En cuanto a las recidivas herniarias al año, vieron cierto beneficio del cierre del defecto $(5,4$ vs $14,2 \%, \mathrm{p}=0.003)$ si bien esto no esta del todo demostrado por estudios prospectivos. 


\begin{tabular}{lllc}
\hline & $\begin{array}{l}\text { Defect closure } \\
(n=222)\end{array}$ & Non-closure $(n=561)$ & $p$ \\
\hline Intra-operative & & & \\
$\quad$ Hernia width $\left(\mathrm{cm}^{2}\right)$ & $5.0 \pm 2.2$ & $5.5 \pm 2.8$ & 0.12 \\
Hernia defect area $\left(\mathrm{cm}^{2}\right)$ & $54.5 \pm 45.2$ & $60.0 \pm 67.3$ & 0.20 \\
Mesh used area $\left(\mathrm{cm}^{2}\right)$ & $287 \pm 150$ & $289 \pm 158$ & 0.87 \\
$\quad$ Operative Time $(\mathrm{min})$ & $109 \pm 52$ & $104 \pm 57$ & 0.60 \\
Post-operative & & & $<0.0001$ \\
$\quad$ Surgical site events & $8(3.6 \%)$ & $84(14.9 \%)$ & $<0.0001$ \\
Seroma & $1(0.4 \%)$ & $65(11.5 \%)$ & 0.902 \\
Surgical site infection & $1(0.4 \%)$ & $3(0.5 \%)$ & 0.06 \\
Length of stay (days) (mean $\pm \mathrm{SD})$ & $2.1 \pm 2.6$ & $2.9 \pm 2.1$ & 0.003 \\
Hernia recurrence & $12(5.4 \%)$ & $80(14.2 \%)$ & \\
\hline
\end{tabular}

Actualmente, la restauración de la anatomía normal de la pared abdominal con la reconstrucción de la línea blanca es uno de los pilares actuales del tratamiento laparoscópico de las HVP (IPOM - Plus) y es lo recomendado en las guías de la EHS. ${ }^{(10)}$ Se recomienda realizar el cierre en todo defecto, y si este sobrepasa los $10 \mathrm{~cm}$ o la reparación queda a tensión, puede estar indicara la realización de algún procedimiento de liberación miofascial.

¿Entonces, cuando elegir realizar un IPOM?

El grupo de Bonheiden, Bélgica ${ }^{(5)}$ propone un algoritmo en base a:

- El tamaño de la hernia: para defectos menores a 2 o $3 \mathrm{~cm}$ proponen un abordaje abierto con cierre primario y refuerzo con malla protésica, en plano preperitoneal, sobrepasando los bordes del defecto, teniendo en cuenta la retracción de hasta un 30\% en la prótesis. Dejan la realización del IPOM laparoscópico para defectos mayores a $3 \mathrm{~cm}$.

- Pacientes con múltiples hernias de la línea media en la valoración preoperatoria (hernias en queso suizo) independientemente del tamaño del defecto.

- Pacientes que por su profesión estén sometidos a esfuerzos parietales mayores pej. trabajadores de la construcción, deportistas, etc.

- Pacientes con comorbilidades como obesos, diabéticos, fumadores o en tratamiento con corticoides. En ellos están alterados los procesos normales de cicatrización, por lo que tienen mayor riesgo de recidiva.

En la tabla 5 se muestra un resumen de los meta análisis publicados comparando resultados entre IPOM y otras técnicas de abordaje mini invasivo.

Tabla 5. Overview of comparative studies comparing IPOM to other approaches

\begin{tabular}{|c|c|c|c|c|c|c|c|c|c|c|}
\hline & & Patients & Recurrence (\%) & $p$ value & $\begin{array}{l}\text { Seroma } \\
\text { formation } \\
\text { (\%) }\end{array}$ & $p$ value & LOS (days) & $p$ value & $\begin{array}{l}\text { Opera- } \\
\text { tion time } \\
\text { (mins) }\end{array}$ & $P$ value \\
\hline \multirow{2}{*}{$\begin{array}{l}\text { Prassad et al. } \\
\text { (Pooled data) }\end{array}$} & Lap IPOM & 211 & 2.90 & NS & 8.5 & 0.05 & 1.4 & 0.35 & 87.4 & 0.001 \\
\hline & Lap TAPP & 68 & 3.30 & & 5.8 & & 1.5 & & 96.7 & \\
\hline \multirow{2}{*}{$\begin{array}{l}\text { Schroeder et al. } \\
\text { (Pooled data) }\end{array}$} & Open retromuscular & so & 0 & 1 & 2.20 & 1 & 4 & 0.295 & 115 & 0.13 \\
\hline & Lap sublay & 43 & $\mathbf{0}$ & & 0 & & 3.4 & & 125 & \\
\hline \multirow{2}{*}{$\begin{array}{l}\text { Kockerling et al. } \\
\text { (Incisional bernia) }\end{array}$} & Open sublay & 5797 & 4.2 & 0.783 & 5.12 & 0.0001 & 6.14 & 0.001 & NR & \\
\hline & Lap IPOM & 4110 & 4.1 & & 1.94 & & 4.35 & & NR & \\
\hline \multirow{2}{*}{$\begin{array}{l}\text { Liang et al. } \\
\text { (Primary hernia) }\end{array}$} & Open (pre-peritoneal) & 79 & 13.90 & 0.8 & 8.9 & 0.1 & $\mathbf{0}$ & 0.001 & NR & \\
\hline & Lap IPOM & 79 & 11.40 & & 20.3 & & 1 & & NR & \\
\hline \multirow{2}{*}{$\begin{array}{l}\text { Lomanto et al. } \\
\text { (Pooled data) }\end{array}$} & Open sublay & 50 & 10 & & 6 & & 4.7 & 0.044 & 93.3 & 0.796 \\
\hline & Lap IPOM & 50 & 2 & & 10 & & 2.47 & & 90.6 & \\
\hline \multirow{2}{*}{$\begin{array}{l}\text { Penchev et al. } \\
\text { (Pooled data) }\end{array}$} & cTEP & 27 & 0 & NS & 14.80 & NS & 2.9 & NS & 186 & $\mathbf{s}$ \\
\hline & Lap IPOM & 27 & 3.70 & & 11 & & 3,4 & & 90 & \\
\hline \multirow{2}{*}{$\begin{array}{l}\text { Reinpold et al. } \\
\text { (Incisional bernia) }\end{array}$} & eMILOS & 615 & 2.16 & 0.0001 & 0.55 & 0.001 & NR & & 103 & \\
\hline & Lap IPOM & 5865 & 7.34 & & 3.33 & & NR & & 82 & \\
\hline
\end{tabular}

$S$ significant, $N S$ non-significant, NR not recorded

Extraido de: Van Hoef S, Tollens T. Primary non-complicated midline ventral hernia: is laparoscopic IPOM still a reasonable approach? Hernia (2019)

23:915-925

\section{MILOS / EMILOS}

La técnica MILOS (Mini/less Open Sublay) es un concepto de tecnica hibrida para el abordaje laparoscópico de las HVP. Desarrollada por Reinpold y col esta técnica aprovecha las ventajas del abordaje mini invasivo, evitando así las complicaciones de las técnicas tradicionales. ${ }^{(21)}$ Decimos que es una técnica hibrida porque combina el abordaje abierto 
y el endoscópico, en ella se accede al espacio retromuscular, a través del propio defecto, sin abordar a la cavidad abdominal y sin grandes incisiones cutáneas. Esta disección del espacio retromuscular puede ser realizada de forma abierta (MILOS) o por endoscopia (EMILOS).

EL procedimiento de MILOS es un abordaje abierto que utiliza instrumentos endoscópicos para realizar la disección del espacio retromuscular, Reinpold diseña un instrumento específicamente para esta tarea, llamado Endotorch ${ }^{\circledR}$ (Fig. 6 y y) el cual trata de un tubo con fibra de luz que facilita la exposición, visualización y retracción. Mediante esta técnica se logra disecar un espacio de unos 8 a $10 \mathrm{~cm}$ de diámetro, y tiene la posibilidad de seguir como técnica endoscópica (EMILOS) colocando un puerto único de trabajo, o los trocares habituales como en el ventral TEP.

Esta técnica será descrita en detalle en el capitulo de hernias incisionales. Pero a forma de resumen podemos decir que el abordaje abierto (MILOS) implica incisión mínima, de hasta $1 / 4$ del diámetro de la malla a utilizar. ${ }^{(22)}$ Se realiza la disección del saco hasta el anillo herniario, desde ahí, $1 \mathrm{~cm}$ lateral al borde medial del musculo recto de cada lado, se aborda el espacio retromuscular. Desde entonces se libera circunferencialmente el saco herniario quedando libre el espacio retromuscular. Es entonces que se prosigue con el endotorch ampliando esta disección, la que de ser necesario puede extenderse desde el apéndice xifoides y el pubis en sentido cefalocaudal, y lateralmente asociar un procedimiento de liberación del musculo transverso (TAR) si así fuera necesario. Como se dijo antes, se puede continuar con un EMILOS, colocando un puerto de trabajo único o trocares de 5 y $10 \mathrm{~mm}$ como en el TEP. Se coloca una malla sobrepasando $5 \mathrm{~cm}$ el defecto en el plano retromuscular, que no requiere fijación. Se realiza el cierre del defecto mediante sutura con hilos de reabsorción lenta. El saco remanente se reseca para disminuir la formación de seroma y de ser necesario se coloca drenaje aspirativo.

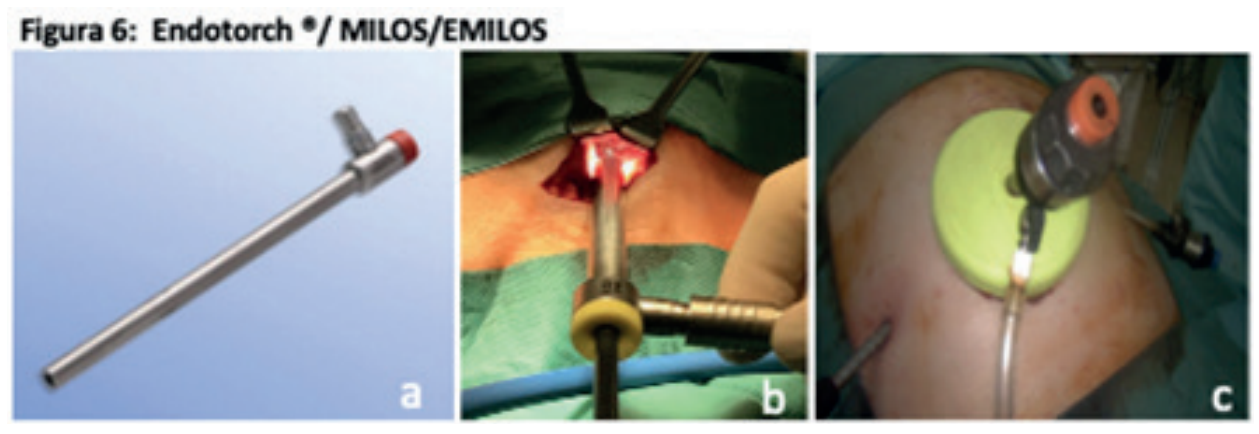

En 2019, en la revista hernia, ${ }^{(22)}$ Reinpold publica un articulo en el que muestra su experiencia con el abordaje EMILOS para el tratamiento de las HVP, umbilicales (HU) y epigástricas (HE). Estas fueron documentadas de forma prospectiva en el registro alemán de hernias "Herniamed" y se realizo un seguimiento a 1 año. Un total de 520 HU y $554 \mathrm{HE}$ fueron incluidas y seguidas durante el año. Las tasas de complicaciones perioperatorias así como de reoperaciones fueron del 1,2 y $0.9 \%$ en ambas, $\mathrm{HU}$ y He respectivamente. Las tasas de infección fueron del 0,0 y 0,2\% para las HU y HE respectivamente. La tasa de recurrencia al año, fue del 0,0 y 0,5\% respectivamente. La tasa de dolor crónico y de dolor crónico que requirió intervención fue del 1,5 y 2,7\% y del 0,6 y 1,8\% respectivamente. Reinpold concluye que el concepto EMILOS es una técnica reproducible, con buena relación costo/beneficio, fácil de estandarizar, y con bajas tasas de complicaciones.

\section{CONCLUSION}

Como conclusión podemos afirmar que el abordaje mini invasivo (AMI) de la reparación de las HVP ha demostrado ser seguro y factible en relación a los abordajes abiertos tradicionales. Los eventos adversos vinculados a la cirugía (hematoma, seroma) se reducen, así como las tasas de ISQ, debido al mínimo trauma sobre los tejidos. Como vimos cada técnica tiene sus ventajas y desventajas, pero en general, son varias las publicaciones que muestran los beneficios del AMI en cuanto a menores tasas de infección, de dehiscencia en la reparación, menor estancia hospitalaria y menor tasa de recurrencia. Por el contrario, dependiendo de la técnica que se utilice, pueden resultar técnicamente complejas, de costos elevados y de acuerdo al tipo de fijación que se utilice, pueden verse incrementadas las tasas de dolor postoperatorio. También se demostró que son técnicas que insumen mayor tiempo operatorio y requieren curva de aprendizaje mas larga. 


\section{BIBLIOGRAFIA:}

1) Aly S, L. de Geus S.W., Carter C.O., Hess D. T., Tseng J. F., Pernar L. I. M. Laparoscopic versus open ventral hernia repair in the elderly- a propensity score-matched analysis. Hernia (2021) 25:673-677.

2) González L., Lora A., Varela E., Vergara G., Vega Peña V., Ayala J. C., Martínez J. D.,Hanssen A., Gómez J. P., Ruiz J. P. Guía para el tratamiento laparoscópico de la hernia ventral e incisional. Rev Hispanoam Hernia. 2021;9(2):105-117.

3) Roca Domínguez B.,Gutiérrez Ferreras A., Mayagoitia C. Guía para el manejo de la hernia ventral e incisional medial. Rev Hispanoam Hernia. 2021;9(2):80-87

4) Alisa M. Coker and Gina L. Adrales. Laparoscopic Ventral Hernia Repair. The SAGES Manual of Hernia Surgery (2019) 11-22.

5) Van Hoef S., Tollens T. Primary non-complicated midline ventral hernia: is laparoscopic IPOM still a reasonable approach? Hernia (2019) 23:915-925

6) Parker S. G., Halligan S., Liang M. K., Muysoms F. E., Adrales G. L., Boutall A., de Beaux A. C., Dietz U. Adivino C. M., Hawn M. T., Heniford T. B., Hong J. P., Ibrahim N., Itani K. M. F., Jorgensen L. N., Montgomery A., Morales-Conde S., Renard Y., Sanders D. L., Smart N. J, Torkington J. J., Windsor A. C. J. International classification of abdominal wall planes (ICAP) to describe mesh insertion for ventral hernia repair. 2019 Wiley Online Library (www.bjs.co.uk). DOI: 10.1002/bjs.11400

7) Bittner R., Bain k., Bansal V.K., Berrevoet F., Bingener-Casey J., Chen D.,Chen J., Chowbey P., Dietz U.A., de Beaux A., Ferzlil G., Fortelny R., Hoffmann H., Iskander M., Ji Z., Jorgensen L. N., Khullar R., Kirchhoff P. Köckerling F., Kukleta J., LeBlanc K., Li J., Lomanto D., Mayer F., Meytes V., Misra M., Morales-Conde S., Niebuhr H., · Radvinsky D., Ramshaw B., Ranev D., Reinpold W., Sharma A., Schrittwieser R., Stechemesser B., Sutedja B., Tang J., Warren J. , Weyhe D., Wiegering A., Woeste G., Yao Q. B. Update of Guidelines for laparoscopic treatment of ventraland incisional abdominal wall hernias (International Endohernia Society (IEHS)): Part B. Surgical Endoscopy (2019) doi.org/10.1007/s00464-019-06908-6

8) Afaque M. Y., Assessing the complexity of ventral hernia by methods of Tanaka, Sabbagh, Carbonell, and Love. Hernia (2021) 25:557-558

9) Love M.W., Warren J. A., Davis S., Ewing J. A., Hall A.M., Cobb W. S., Carbonell A. M. Computed tomography imaging in ventral hernia repair: can we predict the need for myofascial release?. Hernia. Pulished on line april 2020. doi.org/10.1007/s10029-020-02181-y

10) Bittner R., Bain k., Bansal V.K., Berrevoet F., Bingener-Casey J., Chen D.,Chen J., Chowbey P., Dietz U.A., de Beaux A., Ferzlil G., Fortelny R., Hoffmann H., Iskander M., Ji Z., Jorgensen L. N., Khullar R., Kirchhoff P. Köckerling F., Kukleta J., LeBlanc K., Li J., Lomanto D., Mayer F., Meytes V., Misra M., Morales-Conde S., Niebuhr H., · Radvinsky D., Ramshaw B., Ranev D., Reinpold W., Sharma A., Schrittwieser R., Stechemesser B., Sutedja B., Tang J., Warren J. , Weyhe D., Wiegering A., Woeste G., Yao Q. B. Update of Guidelines for laparoscopic treatment of ventral and incisional abdominal wall hernias (International Endohernia Society (IEHS))-Part A. . Surgical Endoscopy (2019) doi.org/10.1007/s00464-019-06908-6

11) Köckerling F. Brunner W. Fortelny R. Mayer F. Adolf D. Niebuhr H. Lorenz R. Reinpold W. Zarras K. Weyhe D. Treatment of small $(<2 \mathrm{~cm})$ umbilical hernias: guidelines and current trends from the Herniamed Registry. Hernia (2021) 25:605-617

12) Shabanzadeh D.; Sørensen L. T.; Laparoscopic Surgery Compared With Open Surgery Decreases Surgical Site Infection in Obese Patients. A Systematic Review and Meta-Analysis. Annals of Surgery. 2012; Volume 256, Number 6,

13) Lee J.; Mabardy A.;Kermani R.,;Lopez M.;Pecquex N.; McCluney A. Laparoscopic vs Open Ventral Hernia Repair in the Era of Obesity. JAMA Surgery August 2013 Volume 148, Number 8

14) Sharma A.; Endolaparoscopic retromuscular repair of smaller midline ventral hernias-too much for too little?. Hernia (2021) 25:561-562

15) Li B.; Qin Ch.; Bittner R. Totally endoscopic sublay (TES) repair for midline ventral hernia: surgical technique and preliminary results. Surgical Endoscopy (2020) 34:1543-1550

16) Prasad P.; Tantia O.; Patle N.; i Khanna S.; Sen B. Laparoscopic Ventral Hernia Repair: A Comparative Study of Transabdominal Preperitoneal Versus Intraperitoneal Onlay Mesh Repair. Journal Of Laparoendoscopic \& Advanced Surgical Techniques; 2011: Volume 21, Number 6.

17) Appleby P.; Martin T.A.; Hope W. W.; Umbilical Hernia Repair Overview of Approaches and Review of Literature. Surg Clin N Am. 2018: 39: 6109/18.

18) Martin-del-Campo L. A.; Miller H. J.; Elliott H. L.; Novitsky Y. Laparoscopic ventral hernia repair with and without defect closure: comparative analysis of a single-institution experience with 783 patients. Hernia (2018) 22:1061-1065 
19) Chan Y.; Fischer W.; Pauzenberger Ch.; Dinnewitzer A.; Hollinsky Ch. Assessment of ideal ratio of mesh area to number of fixation tacks in laparoscopic ventral and incisional IPOM Plus hernia repair. Surgical Endoscopy (2021) 35:1230-1237

20) Park H.; de Virgilio C.; Kim D.Y.; Shover A. L.; Moazzez A. Effects of smoking and different BMI cutoff points on surgical site infection after elective open ventral hernia repair. Hernia (2021) 25:337-343

21) Schwarz J.; Reinpold W.; Reinhard Bittner R. Endoscopic mini/less open sublay technique (EMILOS)—a new technique for ventral hernia repair. Langenbecks Arch Surg (2017) 402:173-180

22) Reinpold W.; Schröder M.; Berger C.; Stoltenberg W.; Köckerling F. MILOS and EMILOS repair of primary umbilical and epigastric hernias. Hernia (2019) 23:935-944 


\title{
TRATAMIENTO ENDOSCÓPICO DE LA DIASTASIS DE LOS MÚSCULOS RECTOS
}

\author{
Dr. Nicolás Ramos
}

\section{INTRODUCCION}

La pared abdominal se puede considerar como una unidad anatomo-funcional compleja que tiene funciones importantes y precisas: participa en la respiración, en el sostén y contención visceral; en la bipedestación y en la correcta postura; en la continencia urinaria y defecatoria; en el embarazo y trabajo de parto. La diastasis de los músculos rectos (DMR) ha sido considerada como una anormalidad de la pared, con consecuencias mas bien estéticas. Su fuerte asociación con defectos herniarios y con síntomas propios ha hecho que la comunidad quirúrgica especializada esté constantemente investigando y desarrollando nuevas estrategias terapéuticas.

Con el resultado prometedor de los actuales tratamientos endoscópicos, la cirugía de la DMR, asociada o no a hernia ventral, tiene cada vez mejores resultados y con esto mas aceptación tanto por los pacientes, así como los cirujanos generales.

\section{DEFINICION}

La Diastasis de los Músculos Rectos (DMR) es una condición adquirida en la que existe una separación anormal entre los bordes internos de ambos músculos rectos (2). No implica un defecto en la pared, no tiene anillo por lo que los eventos obstructivos como estrangulación o atascamiento son muy poco probables. ${ }^{(4)}$

Si bien siempre se considero un problema mas bien estético, hoy sabemos que las DMR puede estar vinculada síntomas como dolor dorso lumbar, alteraciones del transito digestivo (sobre todo constipación), incontinencia urinaria, etc.

La DMR se caracteriza como la protrusión de la línea media debido al aumento de la presión intra abdominal que se hace mas evidente con la contracción muscular.

Podría decirse que existe una insuficiencia de la línea blanca, que es extremadamente fina y frágil, lo que junto a la laxitud de la pared abdominal actúan en conjunto como factores de riesgo para el desarrollo de hernias ventrales (umbilical, epigástrica, incisional, trocares). ${ }^{(9)}$

\section{PREVALENCIA}

Aparece en ambos sexos incluso en la infancia. Es mas frecuente en las mujeres luego del embarazo, entre un 30 y $70 \%{ }^{(1)} \mathrm{y}$ puede ser voluminosa hasta en un $15 \% \cdot{ }^{(13)}$

La prevalencia de distribución en ambos sexos es variada y muchas veces subestimada, esto se explicaría fundamentalmente por el punto de corte en la medida $(2 \mathrm{~cm})$, la altura a la que se realiza y el método de diagnostico utilizado. ${ }^{(14)} \mathrm{La}$ medición utilizando el ancho de los dedos del examinador es uno de los métodos mas ampliamente utilizado. Si bien resulta el mas económico de los métodos, el grado de subjetividad del mismo lo hace poco confiable.

\section{DIAGNOSTICO}

El mismo es fundamentalmente clínico, basado en la historia clínica y el examen físico. La mayoría de las veces estos pacientes son referidos al cirujano por una tumoración de la línea media, de forma piramidal, que puede extenderse desde el xifoides hasta el ombligo en hombres y mujeres. En aquellas que tienen DMR debido al embarazo esta puede estar limitada a la región peri umbilical o al abdomen inferior. En posición erguida la mayoría de los pacientes con DMR no evidencian tumoración, la que si se hace mas evidente en posición supina y al hacer contraer los músculos rectos (abdominal, flexión de miembro inferior). 
Es capital que el cirujano logre valorar adecuadamente la indemnidad de la línea media, para distinguir si se trata de una DMR o una hernia de la línea blanca.

La sintomatología de estos pacientes es variada y muchas veces no se piensa vinculada a la DMR. En su serie de casos Cuccomarino ( $\mathrm{N}=104)$ describe el dolor lumbar sin otra causa aparente, presente hasta en el $70 \%$ de los casos. Trastornos vinculados al contenido abdominal como son dolor abdominal, meteorismo y constipación presentes en el 90\%. Sensibilidad abdominal a los traumas, así como incontinencia urinaria (44\%).(1)

Una de las consecuencias principales y mas precoces de la DMR es la alteración en la contracción efectiva de los músculos laterales, sobre todo en el oblicuo externo y transverso. Esto lleva a una insuficiente tracción de la fascia toracolumbar. Esta ultima participa en un complejo mecanismo de regulación entre la pared anterolateral y los músculos paravertebrales que mantienen la cifosis dorsal y la lordosis lumbar para una correcta postura durante la bipedestación. La DMR interfiere con este mecanismo provocando un aumento en los ángulos de lordosis y cifosis con la aparición de dolor lumbar (fig. 2). La plicatura de los músculos tiene como fin reconstruir la geometría vectorial de los músculos. ${ }^{(1)}$ Lo mismo ocurriria con la incontinencia urinaria, en 2001 Bush y Sapsford vieron que en mujeres con dolor lumbar cronico, debido a una menor actividad muscular abdomial, se advertia una menor tonicidad de los musculos pelvicos. Esto relacionaba los musculos del tronco con los del piso pelvico para mantener una correcta postura y continencia.

Los métodos de imagen son los mas exactos para confirmar, medir y clasificar la DMR, estos incluyen la ecografía de partes blandas, la tomografía computada (TC) y la resonancia magnética (RM) (17). Como veremos mas adelante, los esquemas de clasificación toman en cuenta la distancia entre ambos rectos y la topografía del defecto. Dejemos en claro, para el diagnostico de DMR no son necesarios los estudios de imagen, estos cobran importancia en cuanto a dudas diagnosticas con otros defectos parietales o la asociación de ellos y de esta manera colaboran con la planificación del tratamiento quirúrgico.

Dentro de estos estudios, la ecografía de partes blandas (fig. 1) es el mas utilizado, es un método accesible, no radiante y de bajo costo. La medición se realiza con el paciente erguido y en decúbito dorsal. De acuerdo a la clasificación de Beer (ver tabla 1) la DMR se defina como la separación de los músculos rectos de al menos $2.2 \mathrm{~cm}$ medidos, $3 \mathrm{~cm}$ por encima del ombligo, con los músculos de la pared abdominal relajados. ${ }^{(12)}$ Otros toman la media en tres niveles, $2 \mathrm{~cm}$ por debajo del xifoides, $2 \mathrm{~cm}$ por encima y $3 \mathrm{~cm}$ por debajo de la cicatriz umbilical.

La TC, es uno de los métodos mas utilizados, sobre todo en USA para el diagnostico y valoración de defectos ventrales asociados. No necesita la adición de contraste oral o intravenoso. Su mayor utilidad, además de valorar completamente la línea blanca, es que permite valorar el tamaño y espesor de los músculos rectos fundamental en la planificación de la reparación quirúrgica. ${ }^{(17)}$

\section{ETIOPATOGENIA}

La DMR se produce como consecuencia del aumento mantenido de la presión intra abdominal. Este aumento hace que la línea media este expuesta a fuerzas que determinaran su afinamiento y estiramiento resultando en la separación de los músculos rectos. ${ }^{(3)}$ En algunos estudios se ha postulado un defecto congénito en la síntesis de colágeno I y III, pero estos datos están a la espera de evidencias científicas solidas.

Es mas frecuente secundaria al embarazo, si bien no hay consenso en cuanto a otros factores de riesgo vinculados al desarrollo de la DMR.

EL embarazo esta considerado como un factor de riesgo y guarda relación directa con su numero. Cuantas mas gestas tenga la mujer, mas posibilidades de desarrollarla tendrá. ${ }^{(9)}$ Aquellas cesareadas el riesgo se eleva luego de un segundo embarazo. ${ }^{(14)}$

El aumento de presión intra abdominal mantenido, producto de un feto y útero en crecimiento, combinado con los cambios hormonales propios del periodo (secreción de relaxina, progesterona y estrógenos) tienen su efecto en el tejido conectivo. Estos crean un ensanchamiento "normal" de la línea blanca, creando una DMR durante el embarazo. Hacia la semana 38 de gestación el musculo recto ve incrementado su largo en un 115\% comparado con las etapas iniciales. ${ }^{(9)}$ La región infraumbilical de la línea media se enriquece en fibras transversales, lo que hace sea mas resistente a la tensión en preparación al parto. 
En un estudio se comparo la distancia entre los rectos en mujeres nulíparas vrs multíparas. En este se vio que las mujeres postparto duplicaban la distancia entre los rectos medidos por ecografía $0.5 \mathrm{~cm}$ a $1.0 \mathrm{~cm}$ y de $1.2 \mathrm{~cm}$ a $2.4 \mathrm{~cm}$. En la mayoría de las mujeres la pared vuelve a la normalidad entre los 6 y 12 meses postparto, pero en un 30 a $40 \%$ de los casos la DMR permanece luego de dicho periodo y ya es considerada permanente. ${ }^{(5)}$

La prevalencia general de la DMR en hombres no es del todo conocida, esta oscila entre el 5.5\% y $9.8 \%$ según las revisiones realizadas por Mommers y Jessen. ${ }^{(18)}$

De acuerdo con $\mathrm{Wu}$, la obesidad es otro factor vinculado al desarrollo de DMR, ${ }^{(15)}$ esto se debe, por un lado: a que la acumulación de grasa en la cavidad abdominal (mesenterio y epiplón) determina un aumento de la presión intraabdominal y con ello a una separación de los músculos rectos; por el otro la propia infiltración grasa de la pared lleva a una perdida en la masa muscular. La diabetes mellitus puede causar perdida de masa y función muscular generando sarcopenia. Hay un cambio de las fibras musculares de acción rápida por las lentas.

El consumo de tabaco se causa debilidad el tejido conectivo con lo que favorece el desarrollo no solo de DMR sino también de hernias inguinales e incisionales.

La laxitud miofascial vinculada a la DMR se da tanto en un plano vertical como horizontal y en los casos mas severos puede involucrar toda la pared anterolateral, incluyendo la línea semilunar.

\section{CLASIFICACION}

Se han descrito varios sistemas de clasificacion para la DMR. La clasificacion de Nahas se basa en la deformidad miofascial y la etiologia (ver tabla 2 ). La clasificacion de Rath (tabla 3), que se basa en el ancho de la linea blanca en relacion al ombligo y la edad. La clasificacion de Beer basada en la medida normal de la line blanca en 150 mujeres nulipras. ${ }^{(3)}$ Estas clasificaciones son bastante dispares en las variables que representan, lo que las hace poca utilidad en la practica clinica.

Tabla 1.

\begin{tabular}{|l|l|}
\hline \multicolumn{2}{|l|}{ Beer classification } \\
\hline Normal width of the linea alba $(\mathrm{mm})$ \\
\hline Level & Width \\
\hline At Xiphoid & 15 \\
\hline $3 \mathrm{~cm}$ above umbilicus & 22 \\
\hline $2 \mathrm{~cm}$ below umbilicus & 16 \\
\hline
\end{tabular}

Tabla 3.

\begin{tabular}{|l|l|l|}
\hline \multicolumn{2}{|l|}{ Rath classification } \\
\hline Level & Age $<45$ & Age $>45$ \\
\hline Above umbilicus & $10 \mathrm{~mm}$ & $15 \mathrm{~mm}$ \\
\hline At umbilicus & $27 \mathrm{~mm}$ & $27 \mathrm{~mm}$ \\
\hline Below umbilicus & $9 \mathrm{~mm}$ & $14 \mathrm{~mm}$ \\
\hline
\end{tabular}

Tabla 2.

\begin{tabular}{|l|l|l|}
\hline \multicolumn{3}{|l|}{ Nahas classification } \\
\hline Deformity & Etiology & Correction \\
\hline Type A & Pregnancy & Anterior sheath plication \\
\hline Type B & $\begin{array}{l}\text { Myoaponeurotic } \\
\text { laxity }\end{array}$ & External oblique plication \\
\hline Type C & Congenital & $\begin{array}{l}\text { Rectus abdominis } \\
\text { advancement }\end{array}$ \\
\hline Type D & Obesity & $\begin{array}{l}\text { Anterior sheath plication } \\
\text { and rectus abdominis } \\
\text { advancement }\end{array}$ \\
\hline
\end{tabular}

En 2019, Reinpold junto a la sociedad alemana de hernias (DHG) y la sociedad internacional de endohernia (IEHS), viendo este problema y en vistas al desarrollo de la tecnicas de reparacion de la DMR, proponen una nueva clasificacion (2). Estos combinan lo descrito por Ranney en cuanto al ancho (W) (ver tabla 4) y en la existente de la Sociedad Europea de Hernia (EHS) para las hernias ventrales en cuanto a la longitud (M). Entonces proponen que la DMR debe clasificarse en relacion al largo como: subxifoiea, epigastrica, umbilica, infraumbilical y suprpubica. En cuanto al ancho en: leve <a $3 \mathrm{~cm}$, moderada entre 3 y $5 \mathrm{~cm}$ y severa cuando la distancia supera los $5 \mathrm{~cm}$ (fig.4).

Otros datos de importancia terapéutica que se deben dejar consignado son: la presencia de hernias de la línea media frecuentemente asociadas, así como cirugías previas sean abiertas o laparoscópicas. Si ya presento algún tipo de procedimiento de reparación parietal y relación con la DMR. Numero de embarazos previos, ya fue comentada la relación directa entre estos y el desarrollo de la diastasis. En vistas a la corrección se deberá hablar con la paciente en cuanto a los deseos gestacionales futuros, siendo una paridad satisfecha lo mas recomendado. 
La condición de la piel y tejido celular es particularmente importante, sobre todo en mujeres ya que tiene implicancias en cuanto al tratamiento quirúrgico. En estos casos la reparación de la diastasis debe ser asociada a una dermolipectomia.

Teniendo en cuanta lo anterior, en octubre de 2020 la EHS propone una nueva clasificación para la DMR que se muestra en la tabla 4. Todavía resta que esta clasificación sea universalizada y aplicada por el resto de las sociedades internacionales dedicadas a la cirugía de pared.

\begin{tabular}{|c|c|c|}
\hline $\begin{array}{c}T \\
\text { Type }\end{array}$ & $\underset{\text { Inter-rectus distance }}{\text { D }}$ & $\frac{\mathrm{H}}{\begin{array}{c}\text { Concomitant umbilical and/or } \\
\text { epigastric hernia }\end{array}}$ \\
\hline $\mathrm{T} 1=$ after pregnancy & $D 1=>2-3 \mathrm{~cm}$ & $\mathrm{HO}=$ without \\
\hline \multirow{2}{*}{$\mathrm{T} 2$ = with adiposity } & $\mathrm{D} 2=>3-5 \mathrm{~cm}$ & \multirow{2}{*}{$\mathrm{H} 1=$ present } \\
\hline & $\mathrm{D} 3=>5 \mathrm{~cm}$ & \\
\hline
\end{tabular}

\section{TRATAMIENTO}

La mayoría de los pacientes asintomáticos son tratados de forma conservadora. El beneficio del ejercicio físico para prevenir o corregir la DMR es controvertido y se ha asociado a resultados mixtos. ${ }^{(3)}$ Los protocolos preventivos incluyen caminar y fortalecer los músculos del abdomen. Los correctivos incluyen fortalecimiento muscular, ejercicio aeróbico y re educación neuromuscular. Aunque hubo cierto beneficio en términos de reducción en la distancia entre los rectos, no hubo pruebas suficientes para recomendar programas de ejercicio o la fisioterapia como técnicas para prevenir o corregir la DMR. Se consideran mas bien con una utilidad adyuvante al tratamiento quirúrgico. La asociación de ejercicio con técnicas de electro estimulación neuromuscular podrían tener algún beneficio y están en fase de desarrollo. ${ }^{(16)}$

La cirugía tiene indicación formal en aquellos casos que sean sintomáticos o que asocien otros defectos herniarios. ${ }^{(12)(23)}$ En esta ultima situación, muchas veces los cirujanos no tienen en cuenta las condiciones locales, asociadas a mayor debilidad de la pared debido a la propia etiopatogenia de la DMR. Este hecho, junto a la no utilización de mallas en los procedimientos de reparación parecen ser unos de los principales causantes de las altas recidivas de las hernias ${ }^{(12)}$ y por eso se justifica la reparación de ambas entidades.

El tratamiento de la DMR asociada o no a hernias requiere la restitución normal de la línea media; para ello las técnicas de plicatura son las mas utilizadas, sean estas asociadas o no a la colocación de mallas de refuerzo.

Se podría decir que existen dos grandes grupos de pacientes: aquellos en los que existe un exceso de piel, en los que a la reparación de la diastasis se asocia una dermolipectomia, generalmente realizada por una incisión transversal infraumbilical. Y por el otro, un grupo de pacientes, en los que no existe un exceso de piel y que tendría que ser abordados por una incisión mediana. Estos procedimientos abiertos requieren la realización de grandes decolamiento dermocutáneos que aumenta el riesgo de complicaciones ${ }^{(12)(23)(24)}$ y muchas veces no es aceptada desde el punto de vista estético. Es por esto que en la década del 90 se comienzan a desarrollar técnicas de reparación endoscópica de la DMR, buscando los mismos resultados con incisiones mas pequeñas.

No existe consenso en cuanto al tratamiento quirúrgico ideal para abordar la DMR. Es por esto que se siguen desarrollando técnicas diferentes e innovadoras, Se describen al menos 45 procedimientos quirúrgicos ${ }^{(18)}$ con diferencias en las vías de acceso, así como en las diferentes formas en la utilización de capas musculares y fascia de la pared abdominal para reparar el defecto y cubrirlo con una malla.

Como ya mencionamos antes, las técnicas de plicatura, sean por cirugía abierta o laparo/endoscopica han demostrado su efectividad con el paso del tiempo ${ }^{(20)} y$ han sufrido muchas modificaciones. Entre estas: la sutura en una o dos capas, el uso de suturas permanentes o absorbibles, uso de suturas interrumpidas o continuas y con o sin colocación de malla como refuerzo.

A continuación, mencionaremos algunas de las técnicas laparoscópicas que se han desarrollado y publicado en los últimos tiempos (tabla 5) muchas de estas se explican en detalle en el capitulo de hernias incisionales. 


\begin{tabular}{|l|l|}
\hline TABLA 5. & Tecnicas endoscopicas para el tratamiento de la DMR asociada o no a hernia ventral. \\
\hline TECNICA & Descripcion \\
\hline IPOM/ IPOM+ & malla recubierta intraperitoneal. Asociado o no al cierre del defecto parietal \\
\hline LARDA & puntos transfasciales totales \\
\hline MILOS/ eMILOS & plicatura y colocacion de malla en plano preperitneal.abordaje a traves de la hernia. \\
\hline LRA & Seccion longitudinal de la vaina POSTERIOR de ambos musculos rectos. Sutura y colocacion de malla recubierta (ONLAY) \\
\hline ELAR / ELAR + & Seccion longitudinal de la vaina ANTERIOR de ambos musculos rectos y sutra en la linea media y colocacion de malla \\
\hline eTEP & Abordaje del espacio preperitoneal con plicatura de la linea blanca y colocacion de malla (RIVES) \\
\hline LASAIM & abordaje hibrido, diseccion preaponeurotica y plicatura. Colocacion de malla intraperitoneal \\
\hline THT & Abordaje del espacio retromuscular, seccion de la linea media con maquina lineal cortante y colocacion de malla en ese plano \\
\hline
\end{tabular}

En este capitulo nos centraremos fundamentalmente en la técnica de reparación endoscópica preaponeurótica REPA, ya que creemos que es una técnica accesible desde el punto de vista técnico y económico, ya que no requiere de materiales especiales, fundamental en nuestro medio.

Esta técnica fue descrita inicialmente en el 2016 por el cirujano argentino Derlin Juares Muas ${ }^{(17)}$ y publicada en el 2017 en la revista Hispanoamericana de Hernia. En el año 2018 Claus publica en los archivos brasileros de cirugía una técnica similar a la que denomina SCOLA. ${ }^{(12)}$

En esta se realiza la disección endoscópica del espacio prefascial resolviendo el defecto de la línea media con la colocación de una prótesis preaponeurótica de refuerzo, asegurando así la reparación e intentando disminuir la tasa de recidiva. Todo esto sin entrar en la cavidad abdominal y con buenos resultados estéticos y funcionales. ${ }^{(13)}$

\section{DESCRIPCION DE LA TÉCNICA}

- EL procedimiento se realiza bajo anestesia general e intubación endotraqueal. Previo a la inducción anestésica se realiza antibioticoterapia profiláctica en base a Cefazolina 1 gramo i/v en dosis única.

- Paciente en decúbito dorsal, con las piernas separadas. La torre de laparoscopia se coloca hacia la cabecera. El cirujano se ubica entre las piernas, con el ayudante a un lado de acuerdo a preferencias y comodidad (fig. 4).

Se realiza el marcado el borde de los músculos rectos, el apéndice xifoides y reborde costal, el defecto herniario, así como el lugar donde se emplazarán de los trocares a nivel infraumbilical. Para esto es conveniente comparar el largo de las pinzas, para asegurarnos que la distancia hasta el xifoides sea acorde entre ellas (fig.5).(25)

La realización del bloqueo subcostal bilateral del plano del musculo transverso abdominal (SCATP- Block) puede ser efectuado bajo ecografía. Esta es una estrategia que ha demostrado su utilidad permitiendo una analgesia de buena calidad, bajos requerimientos de opioides, menor incidencia de nauseas y vómitos postoperatorios. ${ }^{(26)}$

Se emplaza una incisión de $10 \mathrm{~mm}$ en la línea media, a nivel suprapúbico. Inicialmente de forma digital y luego con ayuda de un separador de Farabef o pinza de Foerster realizamos la disección del plano pre aponeurótico hacia ambas fosas iliacas, hasta lograr el espacio suficiente para la colocación de el trocar óptico de $10 \mathrm{~mm}$ y dos trocares de trabajo de $5 \mathrm{~mm}$ en cada una de ellas (fig. 6). Se insufla la cavidad con Co2 a una presión de entre 8 y 10 mm Hg. Puede ser de utilidad colocar al paciente con ligero Trendelemburg, esto mejorara la ergonomía y evitara el enfisema subcutáneo hacia el tórax.

Se procede a la disección del espacio preaponeurótico hasta sobrepasar unos $3 \mathrm{~cm}$ el reborde costal bilateral en sentido cefálico, y lateralmente hasta alcanzar ambas líneas axilares anteriores no menos de $12-15 \mathrm{~cm}^{(12)}$ En el sector medial de la disección procederemos a desinsertar la cicatriz umbilical, a veces ayudados con un dedo desde afuera, para no cometer una lesión térmica (fig. 7). De existir un defecto herniario, se procederá a la disección del saco y tratamiento de su contenido, habitualmente grasa preperitoneal. En este momento puede abrirse el peritoneo, situación leve e intrascendente que no influye ni modifica la ejecución de la plastia reparadora. Los vasos perforantes son coagulados con energía monopolar, bipolar o ultrasónica.

Se realiza la plicatura de la vaina de los rectos mediante sutura continua desde el apéndice xifoides hasta $5 \mathrm{~cm}$ por debajo de la cicatriz umbilical, de ser necesario (DMR M4-5) se extenderá hasta el pubis (fig. 8) 
El uso de suturas barbadas podría facilitar este paso y lograría un mejor cierre de la línea media. ${ }^{(12)} \mathrm{El}$ tipo de material de sutura (polipropileno o polidoxanona) no influyo en las complicaciones ni produjo recurrencia de la DMR al año.(13)

En casos de DMR superiores a $7 \mathrm{~cm}$, para lograr una reparación sin tensión de la línea media, puede ser necesario la realización de una incisión de descarga sobre el musculo oblicuo mayor. Para ello se incide sobre la vaina del musculo ya sea de forma uni o bilateral y por fuera de su inserción en el musculo recto. ${ }^{(17)}$ EL calibre de la sutura si podría influenciar en esto ultimo, ya que se realizan menos incisiones de descarga cuando se utilizan hilos del calibre 0 o superiores.

Una vez finalizada la reparación de la línea media realizaremos un correcto y minucioso control de la hemostasis, así como un lavado de la cavidad.

En este momento se coloca una malla de polipropileno de al menos unos $22 \times 15 \mathrm{~cm}$, que iremos adaptando de manera que quede cubierta toda el área de reparación, incluyendo las incisiones de descarga si fueron realizadas (fig. 9).

La fijaremos con grampas (Tackers o helicoidales) puntos de sutura reabsorbibles o adhesivos de acuerdo a la disponibilidad.

Para la elección de la prótesis se deberá tener en cuenta: el tamaño de la DMR, el grado de debilidad parietal, el IMC y el grado de actividad física diaria. Para DMR de tamaño pequeño $(<5 \mathrm{~cm})$ e intermedio $(5<8 \mathrm{~cm})$ podremos usar mallas de polipropileno de peso ligero o intermedio. Cuando la diastasis supera los $8 \mathrm{~cm}$, el paciente tiene sobrepeso u obesidad, realiza actividad física exigente, se recomienda el uso de malla de polipropileno pesadas. ${ }^{(13)}$

Se reinserta la cicatriz umbilical con una sutura interna o externa transcutánea, puede ser de utilidad descender la presión del insuflador para ver la ubicación natural del ombligo.

Se dejarán uno o dos drenajes de tipo aspirativo exteriorizados por las incisiones de los trocares de $5 \mathrm{~mm}$. Se retirarán cuando tengan un gasto inferior a $30 \mathrm{cc} / \mathrm{dia}$, habitualmente no antes del 7 día. Si contamos con un adecuado servicio de internación domiciliaria o nurse especializada, el paciente poder ser dado de alta con los drenajes con total seguridad. Se coloca faja elástica tubular desde el postoperatorio inmediato, y si se indica su utilización permanente al menos por un mes. Se considera es el gesto más efectivo en la prevención de seromas y hematomas subcutáneos. Otras recomendaciones como medicaciones multivitamínicas y tensores tens ayudan a prevenir estas complicaciones.

EL seguimiento se hará semanal durante el primer mes, a los tres y seis meses, luego de forma anual. Durante este periodo se pesquisará la aparición de seromas, hematomas y/o infección de herida operatoria.

\section{COMPLICACIONES}

Las complicaciones luego de la reparación endoscópica de la DMR son infrecuentes estas incluyen: infección, seroma, rechazo de la prótesis, necrosis cutánea, recidiva, lesión nerviosa y dolor crónico. En las series de casos analizadas ${ }^{(8)(13)}$ estas son inferiores al 10\% y en general son tratadas de forma conservadora y sin mayor rechazo por parte del paciente. Es por esto que podemos considerar a la REPA como un procedimiento seguro.

El seroma, que se define como la acumulación de liquido serolinfohematico en espacio de decolamiento preaponeurótico, es una de las complicaciones mas frecuentes, podría considerase como algo "esperable" y no como una complicación en si. Este se determina mediante el examen clínico o mediante la ecografía. La tasa de aparición ronda el 10 y el 25\% (8) (13) en diferentes series publicadas y habitualmente es de manejo conservador, suele reabsorberse entre las 6 u 8 semanas. El uso de drenajes aspirativos, faja y frio local podrían disminuir su tasa de formación. ${ }^{(10)}$ También se recomienda la fisioterapia y el drenaje linfático como terapia adyuvante en el postoperatorio. ${ }^{(13)}$

La hipostesia es una manifestación que ocurre de forma casi inevitable y en la inmensa mayoría de los pacientes. La sensibilidad normal de la piel tiende a volver de la periferia hacia la línea media, entre el segundo y sexto mes del postoperatorio.

Hansenn y Palmisano ${ }^{(14)}$ describen una alteración cutánea luego de la realización de un REPA. Estos notaron enrojecimiento y aumento de la temperatura de la piel cuando es expuesta al calor (luz solar directa por 20') o actividad física. Este fenómeno desaparecía luego de unos minutos al colocar el paciente en un ambiente frio, o luego del cese de la actividad física. SI bien el mecanismo se cree vinculado a la lesión térmica de ramos nerviosos del sistema autónomo 
encargados de la termorregulación cutánea durante la disección y sección de los vasos perforantes, la causa real todavía sigue en investigación. Si bien este fenómeno tiende a desaparecer de forma espontanea y sin tratamiento especifico, puede verse hasta pasados 120 meses de la cirugía, pero en general es bien tolerado y aceptado por la mayoría de los pacientes (fig. 10).(14)

En la serie de casos presentada por Juares Muas en la descripción de la técnica ${ }^{(10)}$ reporta una mejora del dolor lumbar en el 100\% de los casos tratados entre los 7 y 30 días de postoperatorio. La incontinencia urinaria mejoraría en hasta un $70 \%$ en el mismo reporte.

Se considera que existe una recurrencia cuando la distancia entre los músculos rectos, medida por ecografía es superior a $15 \mathrm{~mm}$ a nivel supraumbilical o de $25 \mathrm{~mm}$ a nivel infraumbilical. En su serie de casos Juares Muas y Palmisano ${ }^{(13)}$ con un N de 216 procedimientos realizados entre el 2016 y 2018, no reportan recidivas al año con un 100\% de satisfacción con los resultados por parte de los pacientes.

\section{CONCLUSIÓN}

Podemos concluir que la diastasis de los músculos rectos es una condición frecuente que no debe ser solamente vinculada a un fenómeno estético. Hoy sabemos que es responsable de síntomas variados y que su fuerte asociación con defectos de la pared abdominal, hacen que deban ser abordados en conjunto.

La técnica REPA, así como otras técnicas endoscópicas preaponeuróticas, han demostrado su seguridad y reproducibilidad con bajas tasa de complicaciones y excelentes tasas de satisfacción tanto de los cirujanos que las utilizan, así como por parte de los pacientes. 


\section{IMAGENES}

Fig. 1: imagen ecografica de DMR.

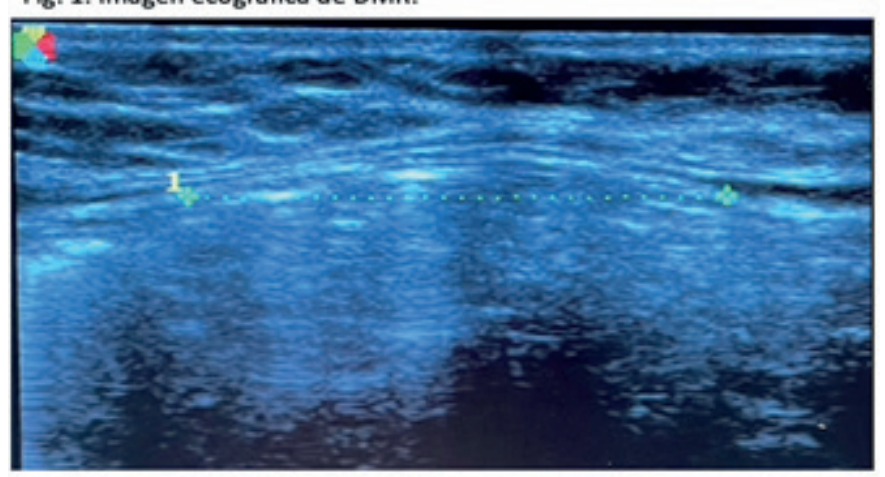

Fig 2: a: ángulo de la cifosis torácica, b: ángulo de la lordosis lumbar

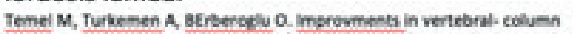

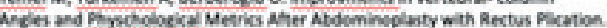
Aesthet Sorg 1. 2016:-35577.87?

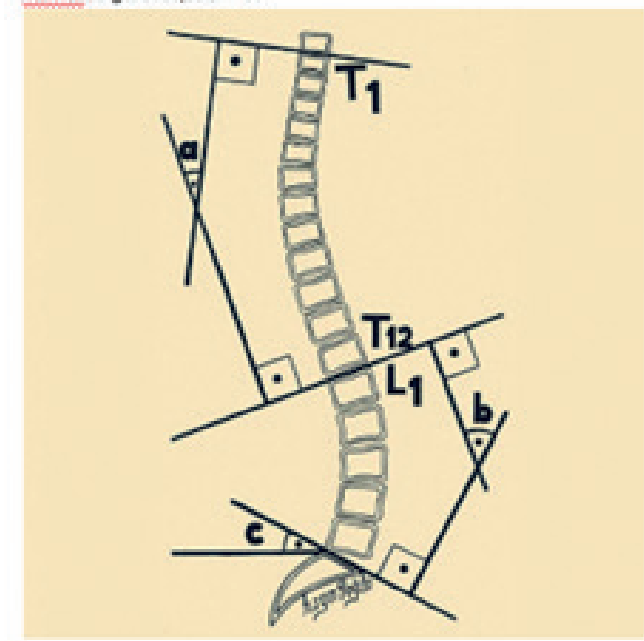

Fig.3: Clasificacion de la EHS

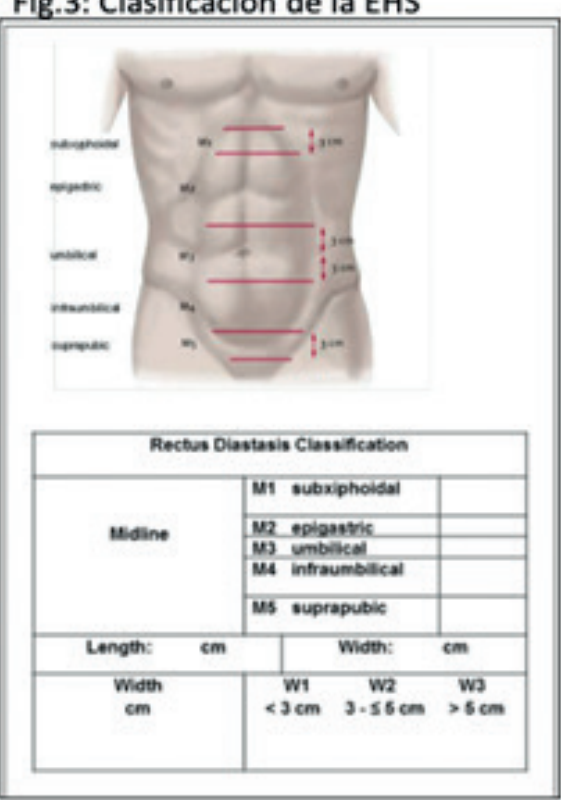

Fig. 5: marcado previo de defecto, reperes anatomicos y posicion de trocares

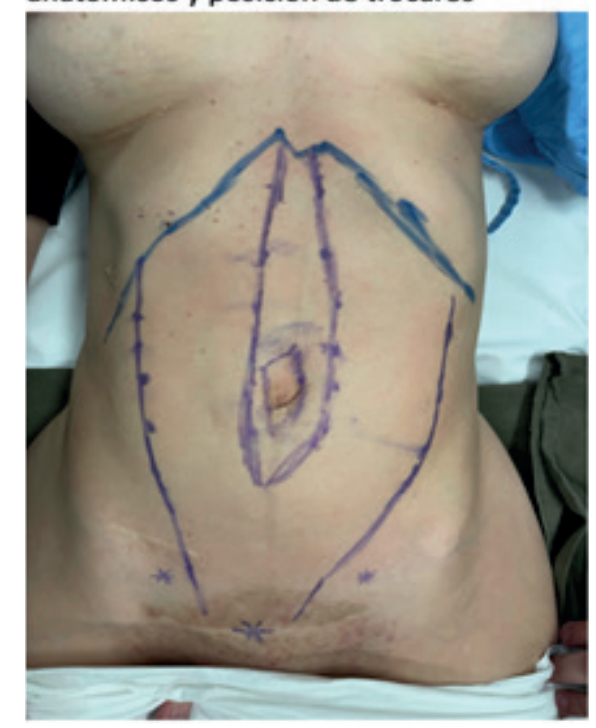

Fig. 4: Posicionamiento del paciente e instrumentos en REPA.

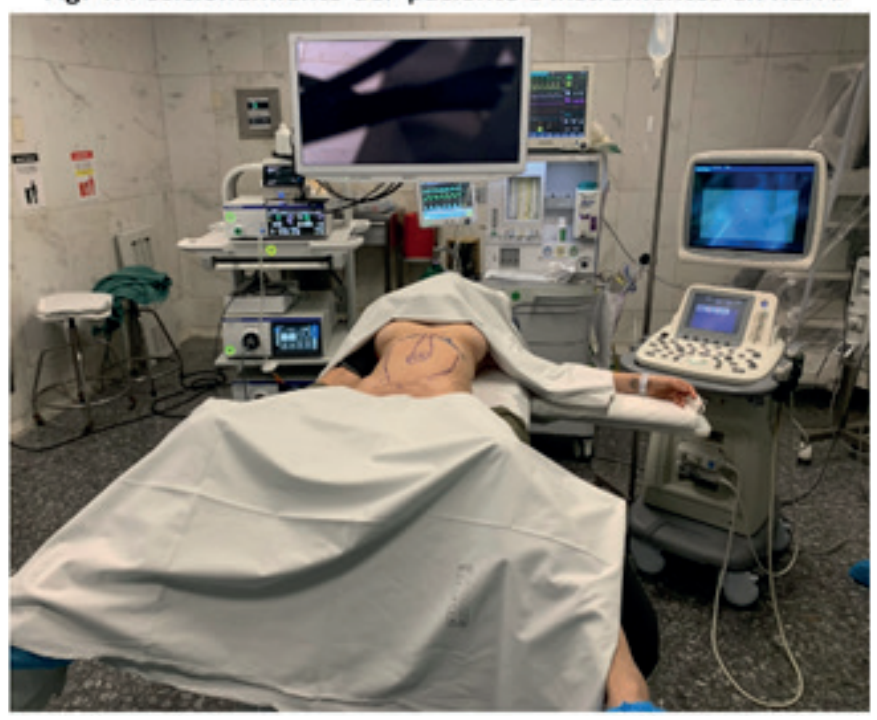




\section{Fig 6: posicion de trocares}

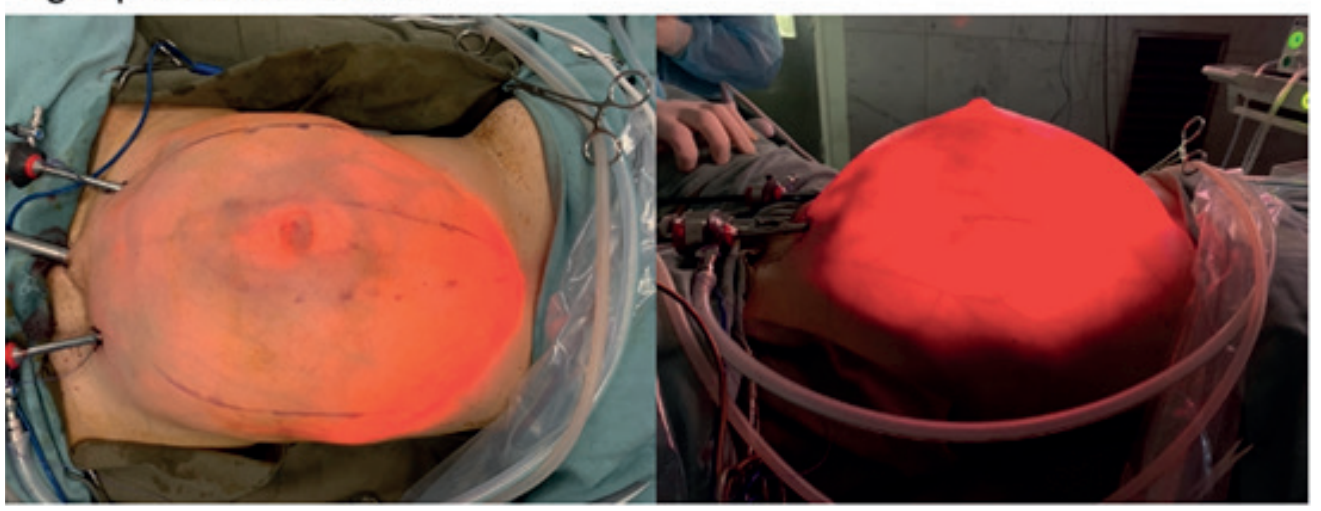

Fig. 7: tiempo de desinserción del ombligo.

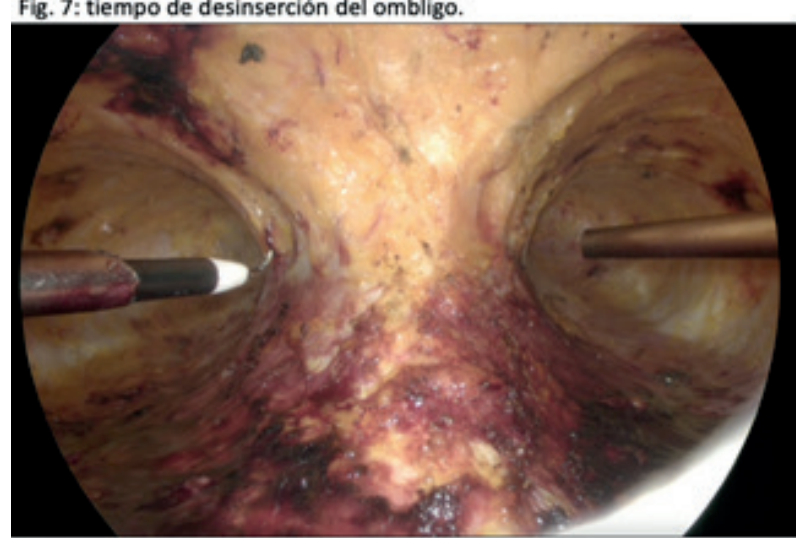

Fig. 8: plicatura de la diastasis.
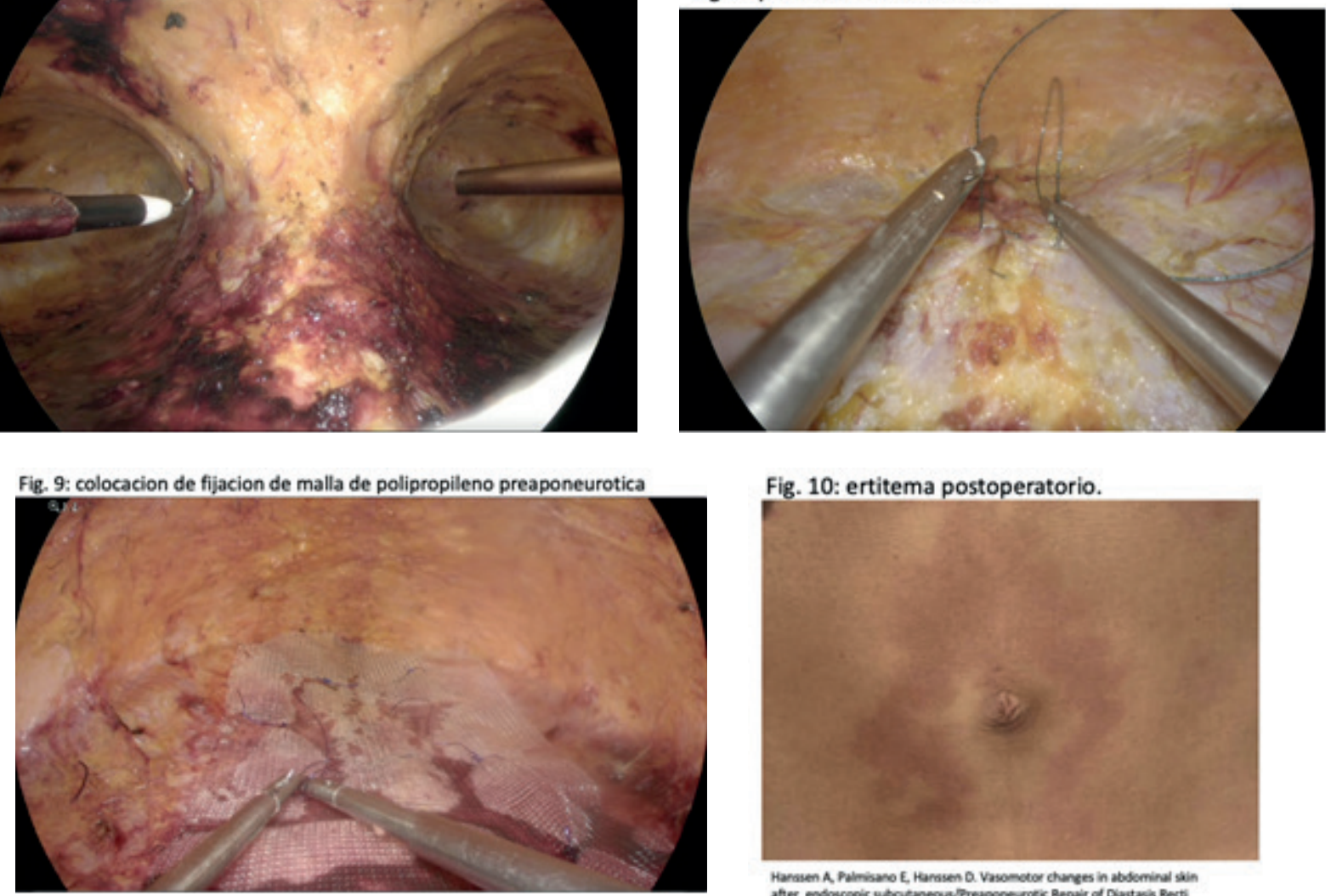

Fig. 10: ertitema postoperatorio.

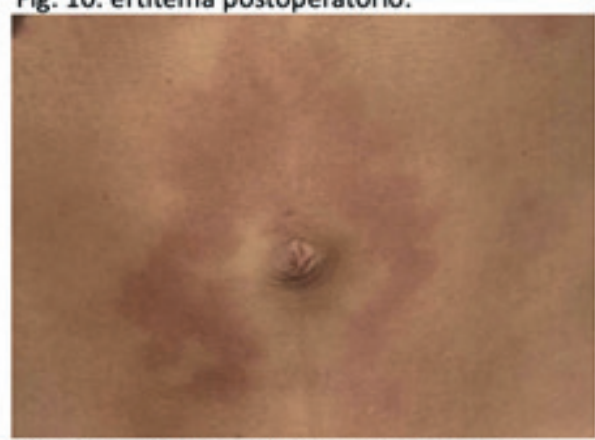

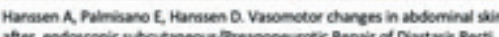

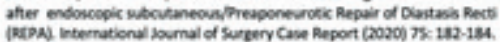

\section{BIBLIOGRAFIA}

1) Cuccomarino S. Why abdominal Wall surgeron should operate a diastasis recti? Rev. Hispanoam Hernia. 2019; 7(2): 43-46.

2) Reinpold W, Kockerling F, Bittner R. Classification of Rectus Diastasis - A proposal by The German Hernia Society (DHG) and the International Endohernia Society (IEHS).Front. Surg. 2019; 6:1.

3) Nahabedian M. Management Strategies for Diastasis Recti. Semin Plast Surg 2018; 32:147-154.

4) Bezana J, Debandi A. Diastasis de los Rectos. Tecnica Quiruigca Original. Rev Chilena de Cirugia 2009; 61 (1);97-100.

5) Olsson A, Kiwanuka O. Evaluation of functional outcomes following rectus diastasis repair - an up-to- date literature review. Hernia 2021; 25; 905-914

6) Dumanian G.A, Moradian S. Mesh abdominoplasty for Rectus Abdominus Diastasis in women and men. Hernia $2021 ; 25 ; 863-870$.

7) Reinpold W, Schroeder M, Schroeder F. Minimally invasive sublay mesh repair of incisional and primary abdominal wall hernias using the MILOS technique.EurSurg 2017; 49:59-64. 
8) Bellido Luque J, Bellido Luque A, Suarez Grau JM. Totally endoscopic surgery on diastasis recti asociated with midline hernias. The advantages of a minimally invasive approach. Prospective cohort study. Hernia 2015; 19; 493501

9) Cavalli M, Aiolfi A. Prevalence and risk factors for diastasis recti abdominis: a review and proposal of a new anatomical variation. Hernia 2021; 25; 883-890

10) Juarez Muas D. Preaponeurotic endoscopic repair (REPA) of diastasis recti associated or not to midline hernias. Surg Endosc. 2019; 33; 1777-1782.

11) Bezama J. Tecnica quirugica para reprar la diastasis de los rectos asociada a hernia umbilical. Diez años de experiencia. Rev Hispanoamer Hernia 2017;5(2):52-56.

12) Clauss Ch, Malcher F, Cavazzola L. Subcutaneous onlay laparoscopic approach (scola) for ventral hernia and rectus abdominis diastasis repair: technical description and initial results. Arq Bras Cir Dig 2018;31(4):e1399.

13) Juarez Muas D, Palmisano E, Pou Santoja G. Reparacion endoscopica preaponeurotica (REPA) como tratamiento de la diastasis de los musculos rectos asociados o no a hernia de la linea media. Estudio multicentrico. Rev Hispaonam Hernia 2019;7(2):59-65.

14) Hanssen A, Palmisano E, Hanssen D. Vasomotor changes in abdominal skin after endoscopic subcutaneous/ Preaponeurotic Repair of Diastasis Recti (REPA). International Journal of Surgery Case Report 2020; 75: 182184.

15) Ormsbee MJ, Prado CM, Ilich JZ, Purcell S, Siervo M, Folsom A, Panton L (2014) Osteosarcopenic obesity: the role of bone, and fat on health. J Cachexia Sarcopenia Muscle 5(3):183-192

16) KamelDM,YousifAM.Neuromuscularelectricalstimulationand strength recovery of postnatal diastasis recti abdominis muscles. Ann Rehabil Med 2017;41(03):465-474

17) Juárez Muas D, Verasay F, Martín García W. Reparación endoscópica prefascial de la diástasis de los rectos: descripción de una nueva técnica. Rev Hispanoam Hernia. 2017;5(2):47-51

18) Nienhuijs S, Berkvens E, de Vries Reilingh T , Mommers E, Bouvy N. Wegdam J. The male rectus diastasis: a different concept?. Hernia (2021) 25:951-956

19) Ross D, Nahabedian M. How to bridge the gap: understanding and optimising management of rectus diastasis. Hernia (2021) 25:825-826

20) Dey A. Abbreviations and synonyms of various surgical techniquesin management of rectal diastasis with primary ventral hernias. Hernia (2021) 25:1103-1104

21) ElHawary H, Barone N, Zammit D, Janis J. E. Closing the gap: evidence-based surgical treatment of rectus diastasis associated with abdominal wall hernias. Hernia (2021) 25:827-853

22) Lourdes E, Wijerathne S, Hu J, Tan WB, Davide L (2016) Lapa- roscopic assisted recti diastasis aapproximation (LARDA), expe- rience and outcome of a novel technique, SAGES 2016.

23) Köckerling F, Botsinis M, Rohde Ch, Reinpold W, Schug-Pass CH. Endoscopic-assisted linea alba reconstruction. New technique for treatment of symptomatic umbilical, trocar, and/or epigastric hernias with concomitant rectus abdominis diastasis. Eur Surg (2017) 49:71-75

24) Cimpean S, Gloire a Dieu B, Pau L, Cadiere G. Laparoscopic Aponeuroplasty by Subcutaneous and IntraAbdominal Approach with Inlay Mesh (LASAIM). ejbps, 2019, Volume 6, Issue 13

25) Palmisano E. Reparacion Endoscopica Pre Aponeurotica (REPA). Manual Practico Cirugia Endoscopica Pared Abdominal. 2020: 153-164. ISBN: 978-987-87-1035-8

26) Toscano, A., Cuccomarino, S., Capuano, P., Bonomo, L. D., Forcella, K., Aprà, F., Jannaci, A., \& Brazzi, L. (2021). Effectiveness of Subcostal Transversus Abdominis Plane Block in Subcutaneous Onlay Laparoscopic Approach (SCOLA) Surgery: A Retrospective Observational Study. Surgical laparoscopy, endoscopy \& percutaneous techniques, 10.1097/SLE.0000000000000988. 


\section{TRATAMIENTO ENDOSCÓPICO DE LAS HERNIAS VENTRALES LATERALES}

\section{Dr. Nicolás Ramos}

Como vimos al inicio del trabajo dentro de las hernias ventrales primarias de la pared abdominal se reconocen las de la línea media o mediales (Hernia Umbilical y Hernia Epigástrica) y las hernias laterales primarias (HLP).

Este segundo grupo menos frecuente, incluye las hernias que aparecen el área delimitada arriba por el reborde costal, abajo por la región inguinal, medialmente por el borde lateral de la vaina del musculo recto y lateralmente por el músculo erector de la espina. De acuerdo a la clasificación de la EHS (fig.2) esta área se divide en 4 zonas: subcostal (L1), Flanco (L2), Ilíaca (L3) y Lumbar (L4).

Este grupo de HLP incluyen las hernias de la línea semilunar o de Spiegel y las hernias lumbares. A continuación, describiremos brevemente el abordaje laparoscópico de estas, haciendo hincapié sobre todo en la hernia de Spiegel.

\section{HERNIA DE SPIEGEL}

Si bien lleva su nombre, la hernia de Spiegel en realidad fue descrita por primera vez en 1764 por Klinkosch (1). Adriaan van den Spiegel (1578-1625) describe la línea semilunar, como una línea curva lateral convexa que se extiende desde la punta del $9^{\circ}$ cartílago costal hasta espina del pubis, lateral a ambos músculos rectos y donde se hace la transición del musculo a la aponeurosis del transverso abdominal (Fig.7.4).

La hernia de Spiegel se define como el defecto que aparece en la aponeurosis del musculo transverso (fascia de Spiegel) entre el borde lateral del musculo recto abdominal y la línea semilunar.

Estas hernias aparecen mas frecuentemente en los que se denomina el "cinturón de hernia de Spiegel" (Spiegelian hernia belt), sector de la pared anterolateral del abdomen extendido de 0 a $6 \mathrm{~cm}$ craneal, a la línea que se extiende entre ambas espinas iliacas anterosuperiores (Fig. 7.6), en este sector la fascia de Spiegel es mas ancha llegando a medir hasta $2 \mathrm{~cm}$.

Por encima del ombligo, estas hernias son menos frecuentes, esto debido a, por un lado, a la disposición de las fibras entrecruzadas de los músculos oblicuo menor y transverso, y por el otro que a nivel mas cefálico la línea semilunar se dispone por detrás del musculo recto y no hay fascia de Spiegel a dicho nivel (Fig. 7.4).

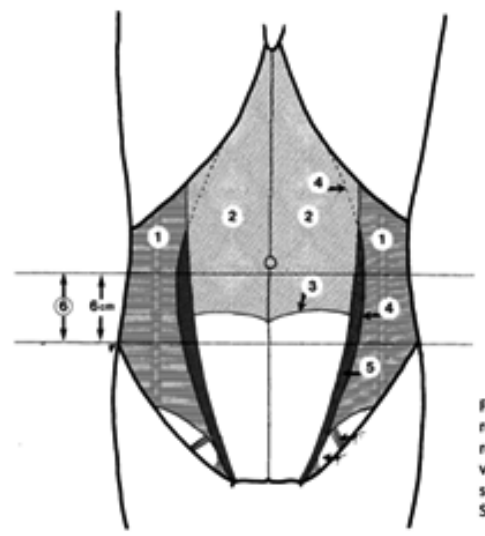

is 7: vista de lo pared anterolateral del abdomen: reverevertacion anatomica sin los musculos colicuos y recto anterior. 1. musculo transverso abdominal. 2 . vaina posterior de la fascia del musculo recta. 3. linea Spiegel 6. Cinturaon de la hernia de Spiegel.

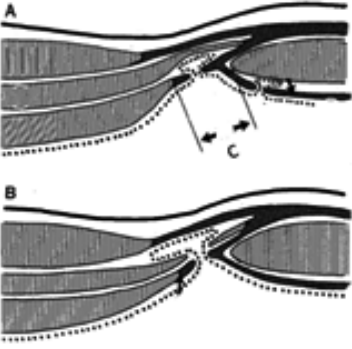

Fig. 8: esquema hernia de Spiegel: A. orificio sobre fascia de Spiegel. 8: hernia atravesando fascias de Spiegel yolbicuo menor. spiegel. 6. Cinturaon de la hernia de Spiegel.

C: Fascia de SpiegeL

El anillo herniario habitualmente de unos 0.5 a $2 \mathrm{~cm}$ de diámetro, tiene forma circular o ligeramente ovalada. En hernias de tamaño pequeño, el anillo se limita generalmente a la fascia de Spiegel. En las hernias de mayor tamaño, el crecimiento del anillo, así como del saco se ven detenidos por la presencia de la fascia del musculo recto en su sector medial lo que hace que el crecimiento sea fundamentalmente lateral, involucrando el vientre del musculo transverso. (fig. 8A).

Cuando estas hernias atraviesan las fascias de los músculos transverso y oblicuo menor, el crecimiento se puede dar en el plano interoblicuo (fig. 8B). Este plano, laxo sirve como guía a la expansión del saco y hace que adopten la típica 
forma en "T" o en "hongo", lo que hace que el saco habitualmente sea mas lateral que el anillo herniario. Por debajo del ombligo, la fascia del oblicuo mayor es habitualmente gruesa por lo que difícilmente sea atravesada por esta hernia, esto hace que no sean hernias que se logren palpar en el tejido celular subcutáneo.

Esta forma de disposición y crecimiento entre los planos musculares hace que sea mas difícil su diagnostico clínico, y es por esto que se le suele denominar hernia intermuscular/ intramural u intraparietal. ${ }^{(2)}$

Las hernias de Spiegel, son raras, representan el 0.12 y $2 \%$ de las hernias de la pared abdominal. Pueden ser congénitas, pero lo mas frecuente es que sean adquiridas. Ocurre mas frecuentemente entre la $4^{a}$ y $7^{a}$ décadas de vida, con una relación mujer/hombre de 1.18:1. Y son mas frecuentes del lado izquierdo. ${ }^{(5)}$

El diagnostico no es sencillo, solo en el 50\% de los casos se logra un diagnostico preoperatorio. ${ }^{(2)}$ En los casos en los que existe tumoración visible o palpable, el diagnostico clínico es mas evidente, puede existir historia de estrangulación herniaria con o sin obstrucción intestinal.

Como mencionamos anteriormente, por su localización intermuscular es poco probable que exista una masa palpable, hecho que se ve dificultado aun mas en pacientes obesos, debido a que el grosor del panículo puede enmascarar la palpación. ${ }^{(3)}$ En estos casos el síntoma mas frecuente es el dolor abdominal de carácter inespecífico. El examen clínico presenta una sensibilidad del $100 \%$ y un valor predictivo positivo (VPP) del 36\%.(5) Los estudios de imagen como ecografía dinámica, TC o RNM pueden ayudar en el diagnostico en estos casos. La ecografía de partes blandas tiene una sensibilidad del 90\% y un VPP del 100\%, para la TC se reportan valores del 100\% de sensibilidad y 100\% de VPP. Las guías de la EHS recomiendan la realización de una laparoscopia exploradora en casos de dudas fundadas, esta a la vez de ser diagnostica puede ser también terapéutica. ${ }^{(5)}$

La cirugía esta indicada en todos los casos de hernia de Spiegel debido al alto riesgo de atascamiento y estrangulación del contenido del saco que poseen, $24 \%$ según algunas series. ${ }^{(3)}$ Generalmente el anillo es pequeño y los bordes en la fascia de Spiegel son fibrosos y filosos, lo que los hace muy propensos a las complicaciones.

Debido a que la hernia de Spiegel es una entidad poco frecuente, tanto el abordaje como la técnica quirúrgica optimas no están del todo establecidas.

Tradicionalmente las hernias de Spiegel han sido tratadas mediante abordaje abierto, realizando el cierre primario del defecto y colocación de mallas en los planos preaponeurótico (ONLAY) o intramuscular (SUBLAY).

El desarrollo actual de las técnicas mini invasivas (TMI) para la reparación herniaria, hacen que estas sean mas atractivas para la mayoría de los cirujanos. Como vimos en el apartado de HVP, son claras las ventajas de estas técnicas, menor índice de complicaciones vinculadas a la herida operatoria, menor tasa de ISQ menor estancia hospitalaria, recuperación y reintegro laboral mas rápido. Recordemos que las tasas de dolor postoperatorio y de recurrencia son comparables a las técnicas abiertas, dependiendo sobre todo del tamaño del defecto y el método de fijación de la malla utilizado.

Las TMI que se recomiendan para el tratamiento de la hernia de Spiegel son prácticamente las mismas que para el tratamiento de las HVP. E1 IPOM clásico como abordaje laparoscópico con colocación de malla intraperitoneal y IPOM - plus si se le agrega el cierre del defecto herniario, esto ultimo recomendado por las guías de la EHS. ${ }^{(5)}$ Técnicas de abordaje del espacio retromuscular, totalmente extraperitoneal como el TEP y su versión extendida e-TEP y técnicas laparoendoscópicas de abordaje del espacio preperitoneal, como el ventral TAPP. Estas técnicas se describen en detalle en el capitulo hernias incisionales. En este apartado describiremos las variantes que presentan, cuando son utilizadas para el tratamiento de las HLP.

En general el abordaje y la colocación de los trocares son laterales y en el lado contralateral al de la hernia. El paciente se coloca en decúbito dorsal con ligera inclinación hacia el cirujano para la mayoría de las hernias. Puede ser necesario ligero Trendelemburg o anti-Trendelenburg $\left(15\right.$ y $\left.30^{\circ}\right)$ en casos de hernias L3 y L1 respectivamente. Para las hernias L4 se prefiere colocar al paciente en decúbito lateral con ligera inclinación hacia el lado opuesto al cirujano.

Una vez abordada la cavidad abdominal (IPOM/ IPOM - plus/ventral TAPP) se realiza la laparoscopía diagnostica, que permitirá confirmar el defecto a tratar, y descartar otros defectos asociados, de ser necesario se realiza la adherenciolisis (fig.9). 
Fig. 9: vista laparoscopica de hernia de Spiegel.

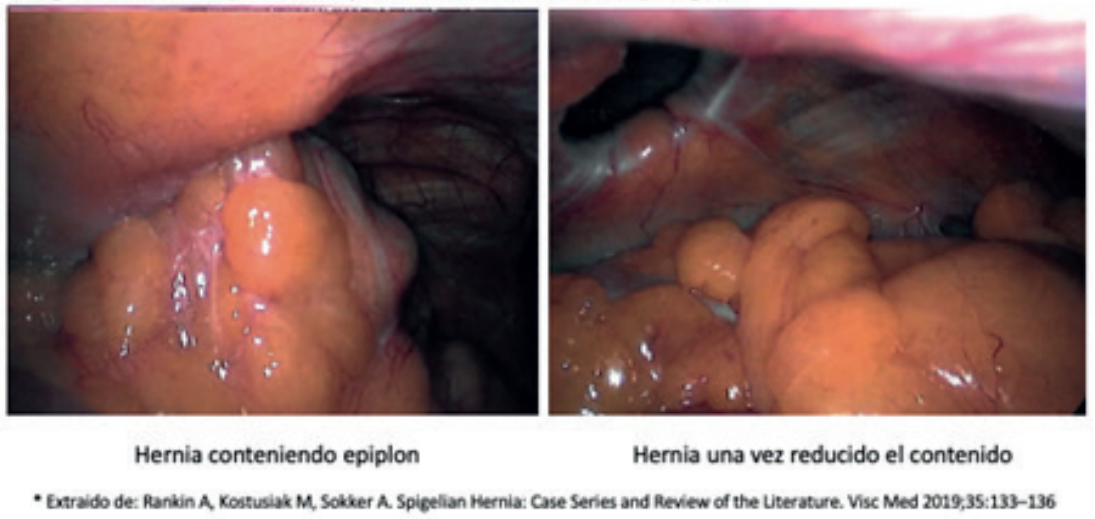

La técnica de IPOM/ IPOM- plus es similar a la descrita para el tratamiento de las HVP. Para las HLP se coloca un trocar óptico de $10-12 \mathrm{~mm}$ en el lado opuesto a la hernia, a una distancia suficiente que permita que la malla sobrepase unos $5 \mathrm{~cm}$ el defecto. Luego se colocan dos trocares de trabajo de $5 \mathrm{~mm}$, a $6-8 \mathrm{~cm}$ a cada lado del primero, logrando una adecuada triangulación. Una vez liberado y disecado el anillo se realiza el cierre del defecto, sea con puntos transfasciales de hilo irreabsorbible, con sutura continua de hilo barbado irreabsorbible o con ambos a la vez. Se coloca una malla compuesta (dual layer) que se fija de forma invasiva con una doble corona de grampas.

En estos casos debemos ser cuidadosos y no realizar la fijación sobre estructuras óseas como la espina iliaca anterosuperior.

La mayoría de los autores prefieren esta técnica cuando se espera una viscerolisis extensa, o cuando por esta ultima se producen daños a nivel del flap peritoneal. Es la técnica de elección para los defectos L1 en los que la disección mas allá del reborde costal suele ser dificultosa. ${ }^{(4)}$

Durante el abordaje totalmente extraperitoneal, TEP/eTEP, se coloca un trocar óptico de 10-12 mm a nivel infraumbilical o paraumbilical, medial a la línea semilunar del lado opuesto. SE aborda el espacio extraperitoneal extendiendo su disección en sentido distal y lateral a la hernia. Se colocan puertos de trabajo de $5 \mathrm{~mm}$ por debajo de la cámara, permitiendo una adecuada triangulación (fig.5). Puede ser necesario la sección de la línea arcuata (Douglas) para exponer el plano extraperitoneal lateral del lado de la hernia. Una vez en plano, se realiza la disección del saco y anillo herniario de forma amplia, se cierra el defecto y se coloca la malla en dicho plano, sobrepasando al menos $5 \mathrm{~cm}$ hacia cada lado tomando en cuenta el tamaño del defecto original. En todos los casos se prefiere realizar la fijación de la prótesis para esto podemos utilizar puntos de material de reabsorción lenta o irreabsorbibles, o fijarla mediante la utilización de grampas, absorbibles o irreabsorbibles o adhesivos. Otra posibilidad que puede abaratar costos y reducir complicaciones es utilizar mallas auto fijantes, sobre todo si estamos cerca de estructuras óseas que pueden resultar peligrosas para las grampas. Se recomienda este tipo de abordaje para las hernias tipo L2 y L3 de la clasificación de la EHS. ${ }^{(4)}$

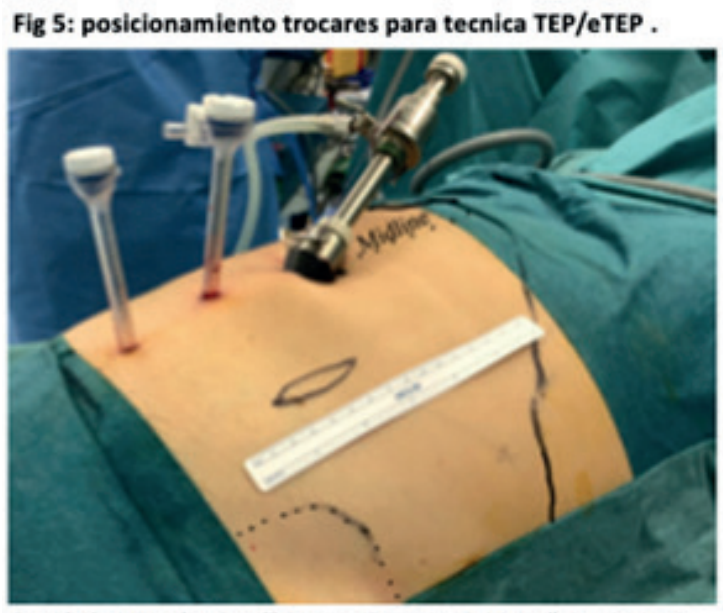

Extraido de : Wijerathe S, Malik S, Usmani F, Lomanto D; Minimally invasive repair for lateral ventral hernia: tailored approach from a hernia centre at a tertiary care institution Hernia (2021) 25:399-410

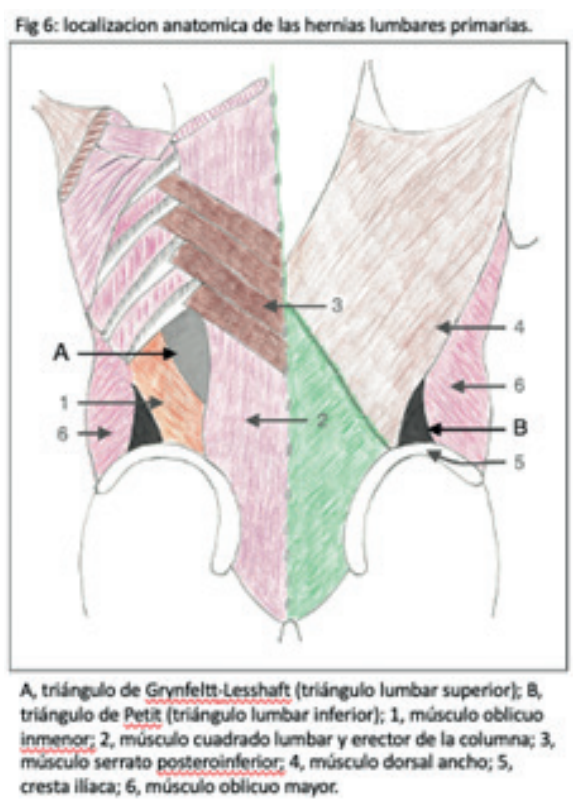


Para la técnica ventral TAPP se toma en cuenta el mismo abordaje lateral que para el tratamiento de la HVP. También como en el IPOM/IPOM plus se debe de tener en cuenta dejar suficiente distancia entre los trocares de trabajo y el defecto, para poder realizar el flap peritoneal, y que este sea lo suficientemente ancho como para cubrir por completo la prótesis. Se recomienda iniciar el flap a unos $8 \mathrm{~cm}$ del borde del defecto ${ }^{(4)}$ para defectos de entre $2-3 \mathrm{~cm}$, para defectos mas grandes esta distancia debería ser mayor. El cierre del flap peritoneal se realiza con sutura continua de hilo barbado de reabsorción lenta. Se recomienda esta técnica para defectos L2 de hasta $4-5 \mathrm{~cm}$ para facilitar una adecuada cobertura por malla y que esta queda correctamente cubierta por el flap peritoneal.

\section{HERNIAS LUMBARES}

Las hernias lumbares primarias son aquellas que aparecen en la zona lumbar, ya sea sobre el triangulo superior (triangulo de Grynfeltt - Lesshaft) o en el inferior (triangulo de Petit). EL primero se delimita medialmente por el musculo cuadrado lumbar, lateralmente por el musculo oblicuo menor y arriba por la 12a costilla. El triangulo inferior queda delimitado medial y superior por el musculo dorsal ancho, lateralmente por el musculo oblicuo mayor y la cresta iliaca por debajo (fig. 6).

Estas hernias al igual que las de Spiegel son raras que aparezcan de forma espontanea o primaria, generalmente se asocian a traumatismos o cirugías retroperitoneales. La incidencia global reportada es de 1,5\% de todas las hernias. ${ }^{(6)}$

No existe ninguna clasificación especifica para estas, si bien se recomienda utilizar la de la EHS como L4. ${ }^{(27)}$ La TC o la RNM son estudios útiles para diagnostico en casos de dudas, permiten determinar topografía y relaciones anatómicas necesario en vistas al abordaje terapéutico.

Los pacientes pueden presentar simplemente con una tumoración palpable y crecimiento progresivo o con una tumoración palpable y dolorosa cuya evolución puede dar lugar a la aparición de complicaciones mayores como el atascamiento (25\%) o estrangulación (8\%). Dicho esto, estaría recomendado el tratamiento temprano de estas hernias, pero, debido a la insuficiente evidencia y literatura internacional, las pautas de tratamiento no estas del todo estandarizadas. $\mathrm{El}$ abordaje quirúrgico de estas hernias puede representar todo un reto para el cirujano esto debido a que la presencia de estructuras óseas puede dificultar la disección del defecto, la colocación de la prótesis (ovelap) y la fijación de esta. En estos casos, como para la hernia de Spiegel, se aceptan tanto el abordaje abierto tradicional como el laparoscópico, este ultimo además de las ventajas ya mencionadas permite una vista anatómica excelente, evita lesiones en el contenido abdominal (bazo, uréter, vasos y nervios, etc.) y evita la exploración y / o disecciones extensas de la región lumbar.

Además de las técnicas laparoendoscópicas ya mencionadas para el tratamiento de la hernia de Spiegel (IPOM/ IPOM plus, TEP/eTEP, ventral TAPP) y que podrían aplicarse a alguno de estos pacientes, se describe una técnica especifica para el tratamiento de las hernias lumbares denominada transabdominal parcialmente extraperitoneal, TAPE (transabdominal partial extra-peritoneal).(6)

En estos pacientes habitualmente el defecto lumbar se encuentra por detrás del colon, por lo que esta técnica surge como una especie de modificación del clásico IPOM, incidiendo la fascia de Toldt, movilizando el colon y fijando la malla en el plano extraperitoneal en el sector posterior e inferior para posteriormente reconstituir anatómicamente la fascia de Toldt, suturando el colon a la misma malla.

En esta el paciente se coloca en decúbito lateral, con ligera inclinación hacia el cirujano y cambrado lumbar. Esto permite la apertura el espacio entre el reborde costal y la cresta iliaca. Se coloca un trocar de $12 \mathrm{~mm}$ generalmente a nivel umbilical y dos puertos de trabajo de $5 \mathrm{~mm}$ a cada lado, a unos 5-6 cm. Si el defecto es grande, los trocares podrán colocarse de forma que atraviesen el recto del lado opuesto. Realizada la inspección y adherenciolisis se libera el colon, seccionado la fascia de Toldt correspondiente. Esta movilización del colon permitirá la exploración y disección del espacio retroperitoneal. Posteriormente se continua la disección hasta el borde del musculo Psoas cuidando de no lesionas estructuras propias del retroperitoneo (uréteres, vasos y nervios). Hacia abajo la disección se extiende hasta el hueso iliaco y hacia arriba generalmente hasta unos 4 o $5 \mathrm{~cm}$ sobre e borde del defecto.

Una vez lograda una adecuada disección del defecto, se despliega una malla tipo doble cara (politetrafluroetileno) intraperitoneal con el suficiente solapamiento. La malla se fija de manera invasiva con grampas en "doble corona parcial", adelante hacia el musculo transverso, arriba a la cara ventral de la parrilla costal abajo al hueso iliaco. Otra fila de grampas se coloca sobre la malla en los bordes del defecto. EL borde posterior de la malla se fija en el plano extraperitoneal sobre el borde del musculo psoas, esta se realiza con puntos de hilo de reabsorción lenta o colas bilógicas, en este paso 
se evita la fijar la malla con grampas debido al peligro potencial de lesión de estructuras del retroperitoneo. Si el defecto se extendiera muy próximo al hueso iliaco, el margen inferior de la malla puede fijarse de forma preperitoneal a nivel del ligamento de Cooper. Si, por el contrario, el limite del defecto esta próximo a la costilla, se coloca la malla con un solapamiento (ovelap) de al menos $5 \mathrm{~cm}$ sobre el diafragma, sin fijación, de esta forma evitaremos complicaciones cardiovasculares y respiratorias graves. Una vez fijada la malla esta puede considerarse como parte del peritoneo y el colon que fuera movilizado, puede restituirse a su posición normal mediante sutura de la fascia del Toldt a la misma malla. Esto tendrá como beneficio que el propio colon estabilizará la malla en el postoperatorio.

Finalizada la reparación, la malla quedara en posición extraperitoneal hace atrás e intraperitoneal hacia adelante es decir de forma parcialmente extraperitoneal.

En su serie de 14 casos tratados con esta técnica, los autores ${ }^{(28)}$ muestran excelentes números en cuando a tasas de complicaciones postoperatorias y de dolor postoperatorio, sin lesiones viscerales y con $0 \%$ de tasa de conversión. El seguimiento a 33 meses no demostró complicaciones alejadas ni recidivas. Si bien el numero absoluto de casos registrados es bajo, dado lo infrecuente de esta patología, los resultados expresados podrían marcar alguna tendencia.

\section{BIBLIOGRAFIA}

1) Spangen L.; Spigelian Hernia. World J. Surg. 1989: Vol. 13, No. 5, 573/80

2) Filip S.; Dragomirescu C.; Copãescu C. Laparoscopic Treatment of Spiegel Hernia by Total Extraperitoneal (TEP) Approach. Chirirgia (2014); 3: 109: 325/29.

3) Rankin A.; Kostusiak M.; Sokker A. Spigelian Hernia: Case Series and Review of the Literature. Visc Med 2019; 35: $133-136$

4) Wijerathne S.; Malik S.; Usmani F.; Lomanto D. Minimally invasive repair for lateral ventral hernia: tailored approach from a hernia centre at a tertiary care institution. Hernia (2021) 25:399-410

5) Henriksen N. A., Kaufmann R., Simons M. P. ; Berrevoet F.; East B.; Fischer J.; Hope W.; Klassen D.; Lorenz R.; Renard Y.;. Garcia Urena M. A.; Montgomery A.; EHS and AHS guidelines for treatment of primary ventral hernias in rare locations or special circumstances. Published online in Wiley Online Library . 2019. DOI: 10.1002/ bjs5.50252

6) Sun J.; Chen X.; Li J.; Zhang Y.; Dong F.; Zheng M. Implementation of the trans-abdominal partial extraperitoneal (TAPE) technique in laparoscopic lumbar hernia repair. Sun et al. BMC Surgery (2015) 15:118 


\section{EXPERIENCIA DE LA UNIDAD DE CIRUGÍA DE PARED ABDOMINAL DEL HOSPITAL PASTEUR}

\section{Dr. Gonzalo Estapé}

Expondremos la experiencia inicial en cirugía parietal laparoscópica de la Unidad de Patred Abdominal y Cirugía Endócrina del Hospital Pasteur de Montevideo. Integramos esta Unidad, tres cirujanos estables (G.Estapé, C.Barreiro y G.Rodríguez), un asistente de la Clínica Quirúrgica 1 en forma esporádica (N.Ramos: 3/19-2/20) y tres Residentes de Cirugía, habitualmente dos R1 y un R3-4, que rotan cada 3 meses. Tratamos la mayoría de los pacientes con patologías parietales de coordinación y también de cirugía endócrina (tiroides, paratiroides y suprarrenales). Contamos con un horario de block quirúrgico promedio de 12 horas semanales. Por estos motivos, es muy variable el número de casos de cirugía laparoscópica parietal que operamos semanalmente, dependiendo de la entidad de la patología de los pacientes en espera (tumores, hiperparatiroidismo, grandes eventraciones, etc).

Así en nuestra planificación quirúrgica coexisten el tratamiento de patologías oncológicas, endocrinológicas y parietales complejas, curva de aprendizaje de algunos de los cirujanos de la Unidad, formación inicial de Residentes (1-2) en cirugía abierta y la introducción al la cirugía laparoscópica de los mismos y primeros casos como cirujano de los Residentes mayores.

Como mencionamos al inicio del Relato, la experiencia de nuestra Unidad en el Hospital Pasteur en el abordaje laparoscópico de los defectos de la pared abdominal, comenzó en junio del 2019, siendo hasta esa fecha, anecdóticas las hernioplastias laparoscópicas realizadas.

Si bien el inicio de la experiencia fue alentador por el número de casos y el progreso en el aprendizaje sin complicaciones, la llegada de la pandemia por SARS COV-2 en Marzo de 2020 detuvo completamente la cirugía de coordinación. Recién en Julio de 2021, con la estabilización de la pandemia en Uruguay, se reinició la cirugía parietal electiva en nuestro Hospital, solo para pacientes que cumplieran los requisitos de la cirugía ambulatoria. Así se retomó el programa establecido de desarrollo de la hernioplastia laparoscópica (TAPP), para la formación de cirujanos tutores y la experiencia inicial como cirujanos, de los Residentes mayores. En esta etapa, logramos un proceso seguro, progresivo $\mathrm{y} \sin$ interrupciones.

Expondremos esta muy breve experiencia en número de pacientes y corto seguimiento.

Pacientes operados: 46

Pacientes con hernias inguinales: 44 (46 hernias: TAPP)

Eventroplastias laterales: 2

\section{Operan cirujanos en formación y Residentes R3-4:}

$42(91 \%)$

Tiempos quirúrgicos:

entre 40-85 minutos (100 minutos en bilaterales)

\section{Internación:}

39 (84.7\%) ambulatorias (menos de 8hs);

7 (15.3\%) 24hs (edad, problema social y dolor).

\section{Complicación intraoperatoria:}

1 lesion de vena epigastrica (clipado)

\section{Complicaciones postoperatorias:}

2 seromas (4.3\%) ( 1 se puncionó a los 20 días)

2 equímosis extensas regionales( $4.3 \%)$

\section{Dolor postoperatorio:}

2 dolor 1 mes (solo AINEs) (4.3\%)

No dolor crónico 


\section{Reintegro:}

Actividad habitual: 15 días (65.2\%) y 30 días (91.3\%)

Tareas de esfuerzo y deportes: 21 días (69.5\%) y 30 días (74\%)

\section{Seguimiento (entre 1 y 15 meses):}

Recidivas: 0

Eventraciones de puertos: 0

Conformidad del paciente sobre el procedimiento (dolor, reintegro y estética), escala 1 al 3

3 (muy conforme): $69.5 \%$

2 (conforme): $24 \%$

1 (desconforme): $6.5 \%$ 


\section{RESULTADOS DE ENCUESTA: CIRUGÍA PARIETAL LAPAROSCÓPICA}

\section{Dr. Alejandro Soumastre}

\section{Dr. Gonzalo Estapé}

\section{Dr. Nicolás Ramos}

En el marco del Relato Oficial del 70o Congreso Uruguayo de Cirugía, se llevó a cabo esta encuesta referida a diferentes tópicos tratados en el mismo.

Como es tradicional, estas encuestas buscan conocer la realidad en nuestro medio, a sabiendas de los sesgos que pueden presentar las mismas. Sumamos a nuestra encuesta, participantes fuera de frontera. Esto último, lejos de representar un sesgo, enriquece el análisis de los resultados.

Nuestra encuesta logró un número de participantes considerablemente superior al de años anteriores. 131 cirujanos nacionales, sumado a 23 cirujanos extranjeros.

La misma fue difundida a través de una aplicación de mensajería instantánea, a dos grupos: Uno que agrupa a los asociados a la Sociedad de Cirugía del Uruguay (incluye Cirujanos recibidos y residentes), y otro que aglomera a Cirujanos y Cirujanas Nacionales e Internacionales.

Tal nivel de participación seguramente se deba, en parte, al tema tratado que tiene un reciente desarrollo en nuestro medio y que, además, hace partícipe hasta los cirujanos menos experimentados y residentes.

Apoyando lo anteriormente dicho, el 100\% de los residentes encuestados declararon haber participado de hernias laparoscópicas. Por último, y no menos importante, la disponibilidad y desarrollo de aplicaciones en dispositivos móviles, cuestionarios con auto llenado rápido, amigable a cualquier usuario, permitía completar nuestra encuesta, desde cualquier dispositivo, en menos de 3 - 4 minutos.

Respondieron un total de 154 Cirujanos, de los cuales el grupo mayoritario se dió entre los 36 a 45 años.

\section{Edad}

154 respuestas
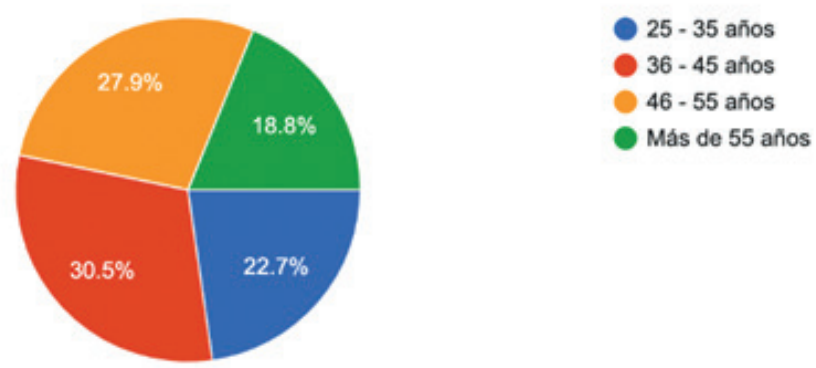

Más de la mitad de los participantes tenía más de 10 años de recibido como cirujano.

Años que finalizó su residencia

154 respuestas

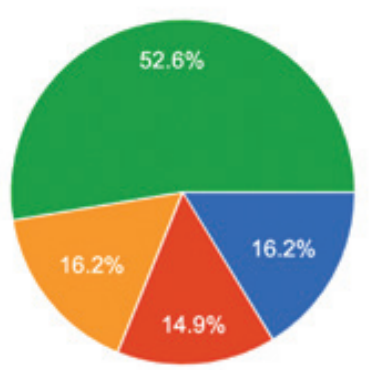


Unos de los aspectos que creemos de interés, fue conocer cómo valoran los cirujanos su formación en laparoscopía durante su residencia. Cerca de la mitad de los encuestados (46\%), la consideró escasa.

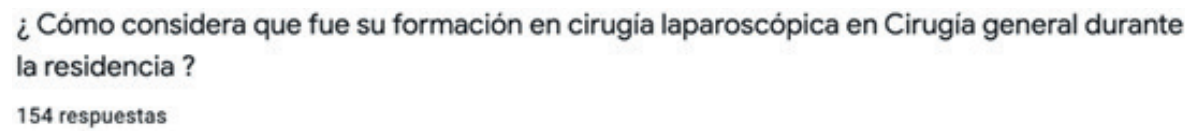

154 respuestas
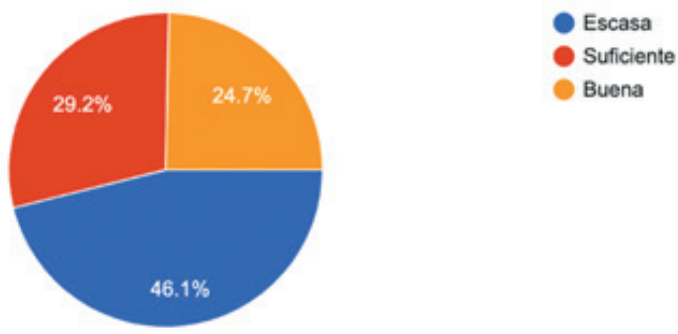

Cuando se indaga específicamente sobre hernias parietales laparoscópicas, la consideración es peor. Solo el 19\% considera que fue aceptable. Dentro de estos, el 45\% tenía menos de 5 años de recibido o residencia en curso.

E1 54\% de los encuestados participó en hernias laparoscópicas. Por último, el 19\% de los encuestados operó más de 10 hernias laparoscópicas.

\section{En cuanto a su formación en hernias parietales laparoscópicas}

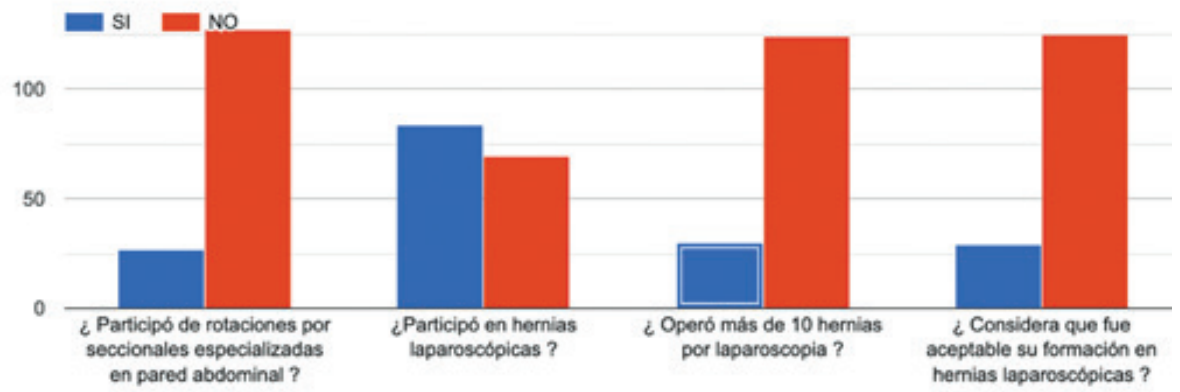

En cuanto al lugar de trabajo, el $46 \%$ realiza su práctica mayoritariamente en Montevideo.

El 14\% de los encuestados desarrolla su actividad en el exterior.

\section{Lugar de trabajo}

154 respuestas

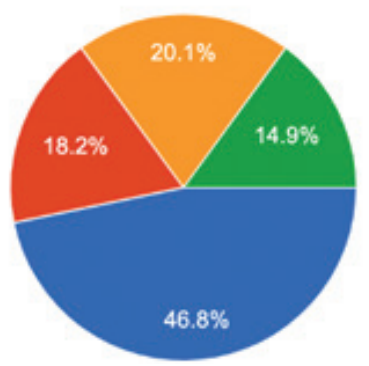

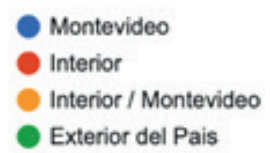

- Exterior del Pais

En cuanto a la dedicación principal dentro de la Cirugía, la gran mayoría declaró dedicarse a la Cirugía General. Solo 8 encuestados $(5,2 \%)$ se dedican principalmente a Cirugía de pared abdominal. Destacando que dentro de estos 8 encuestados, 7 corresponden a cirujanos que se desarrollan en el exterior del país. 


\section{Dedicación principal}

154 respuestas

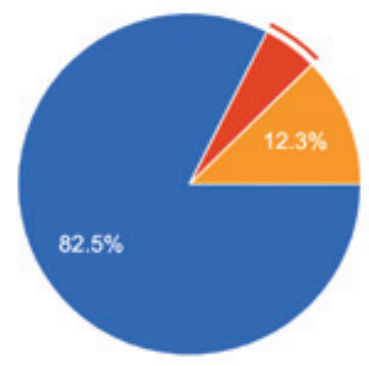

Cirugia general

- Especialidad en cirugia de pared abdominal

- Otra especialidad diferente

E1 65\% de los encuestados realiza Cirugía Laparoscópica avanzada. Al mismo tiempo, el 50,6\% realiza más de 15 procedimientos laparoscópicos mensuales.

\section{Cirugia laparoscópica en General}

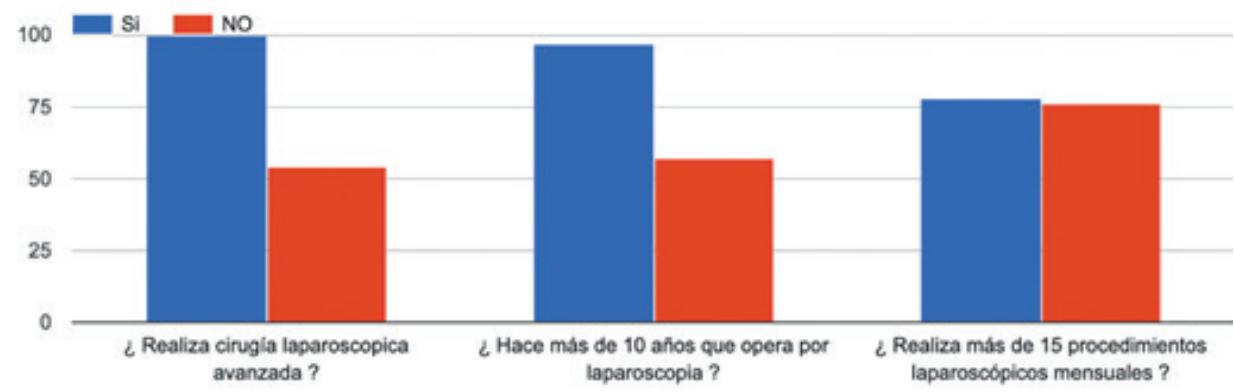

E1 60\% de los encuestados manifestó tener interés especial en la Cirugía de la pared abdominal.

\section{Con respecto a la cirugía de pared abdominal}

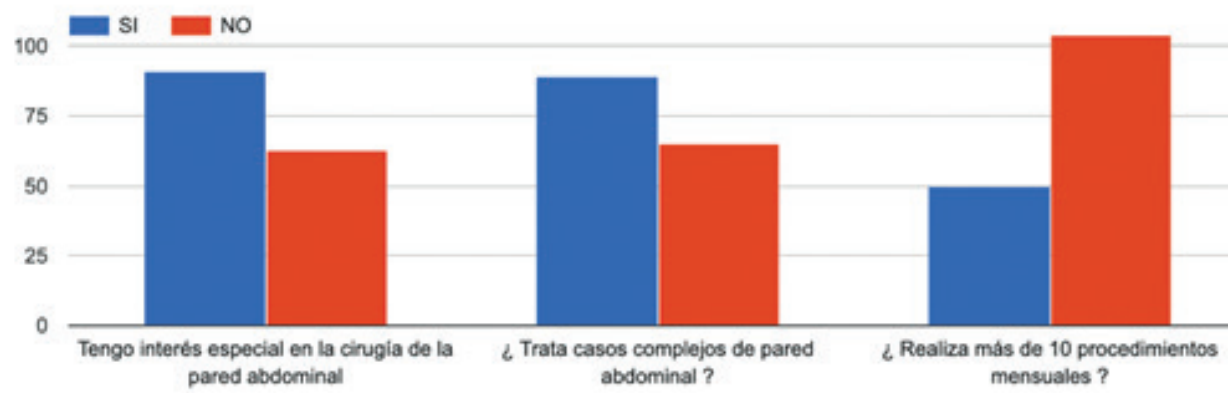

Solo 22 participantes (14,2\%), se especializaron en Cirugía parietal Laparoscópica. Nuevamente, dentro de estos 22, 11 de ellos (50\%) son Cirujanos del exterior del País. E1 32\% de los encuestados realizó cursos específicos de Cirugía parietal laparoscópica. Solo el 17,5\% integra grupos especializados en Cirugía Laparoscópica.

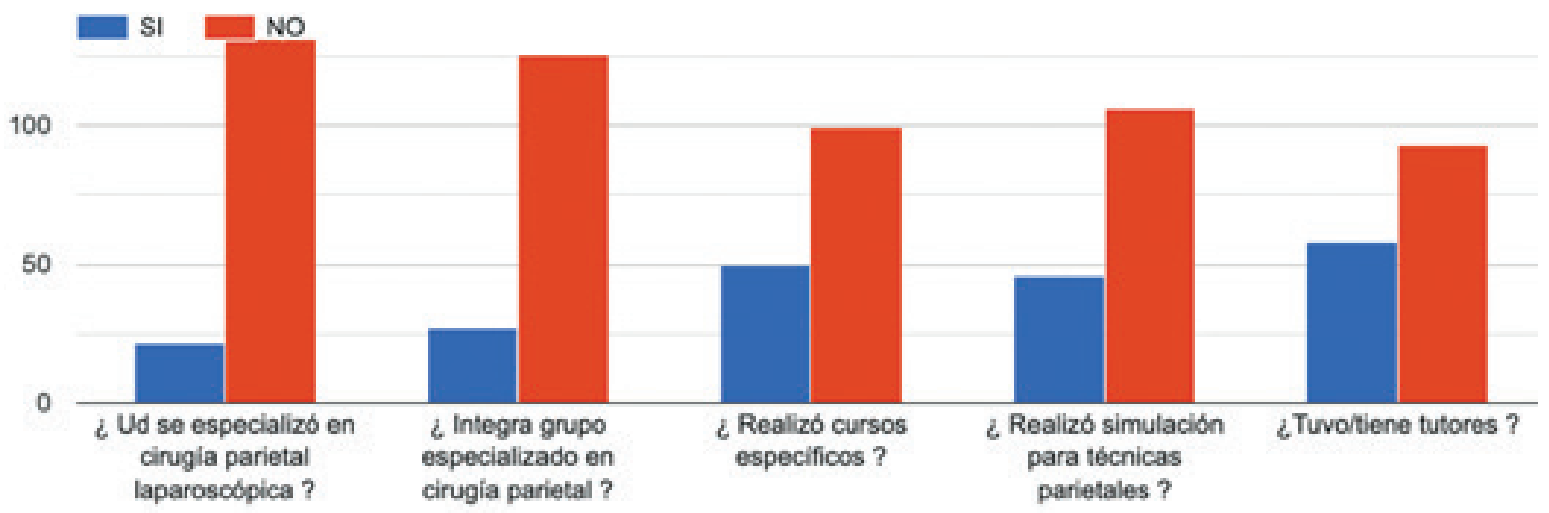


E1 56,5\% realiza Cirugía de pared abdominal por laparoscopia, incluyendo a cirujanos nacionales e internacionales. Si tomamos en cuenta sólo los nacionales, el porcentaje baja a 50\%.

\section{¿Usted realiza cirugia de pared abdominal por laparoscopia ? \\ 154 respuestas}

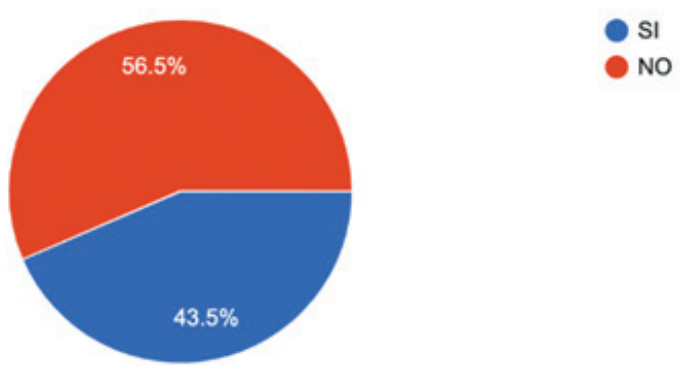

17 encuestados (11\%) realiza más de 10 procedimientos parietales laparoscópicos mensualmente. Dentro de estos, solo 5 corresponden a Cirujanos Nacionales.

E1 37\% de los encuestados ofrece al paciente Cirugía parietal Laparoscópica. Al mismo tiempo el 28,5\% refiere que el paciente pregunta por la opción laparoscópica. El 46\% manifestó que los pacientes deben pagar un ticket por la opción laparoscópica, y el 75\% consideró que el ticket condiciona el número de procedimientos.

cirugia de pared abdominal por laparoscopia
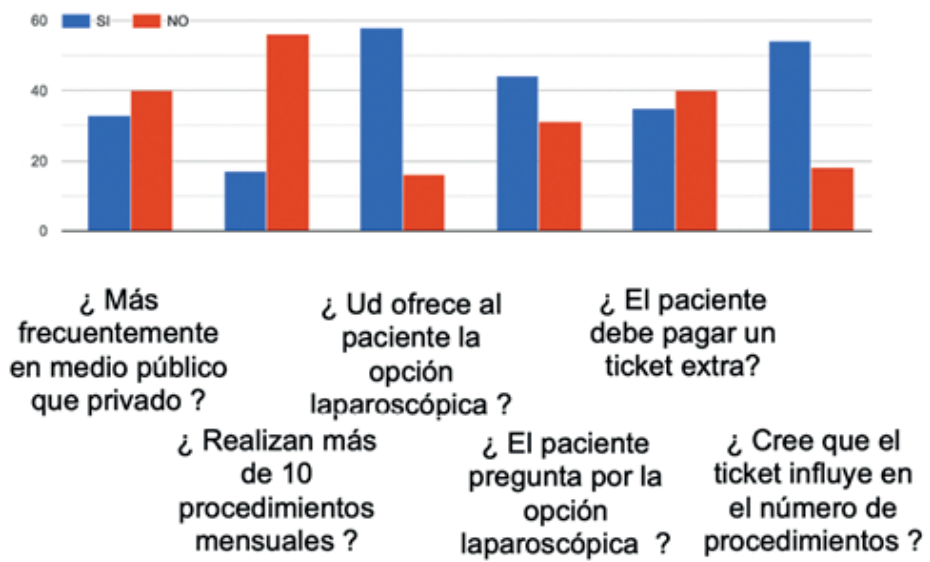

Con respecto a los aspectos técnicos: De los encuestados que realizan cirugía parietal laparoscópica, cerca de la mitad (46\%) manifestó tener problemas de ergometría. El mismo porcentaje refiere cansarse más en comparación con la cirugía abierta.

Cuando usted opera cirugia parietal laparoscópica (comparado con cirugia abierta)

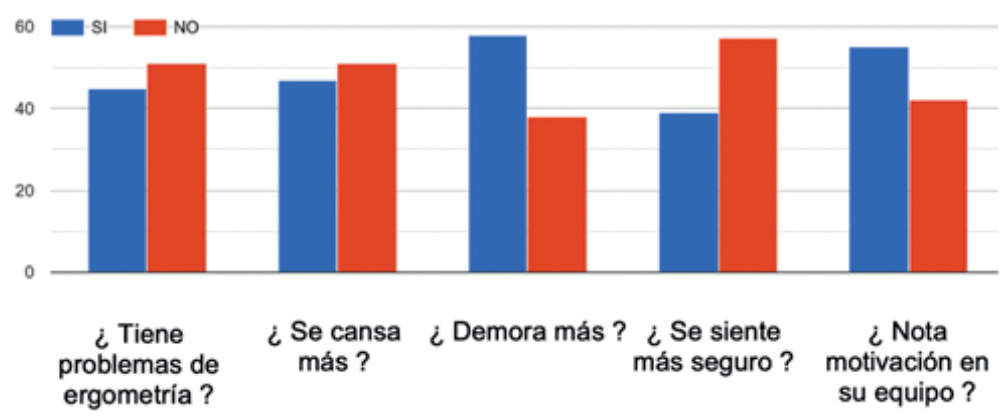

Dentro de la sección de la encuesta, relacionada exclusivamente a las hernias inguinales primarias. Cuando se les preguntó a los encuestados, que porcentaje de hernias inguinales primarias operan por laparoscopia (considerando paciente y medio ideal, sin pago extra), la gran mayoría (59\%) estima el mismo entre el 1 al 10\%. 


\section{¿Qué porcentaje de hernias opera por laparoscopia?}

100 respuestas

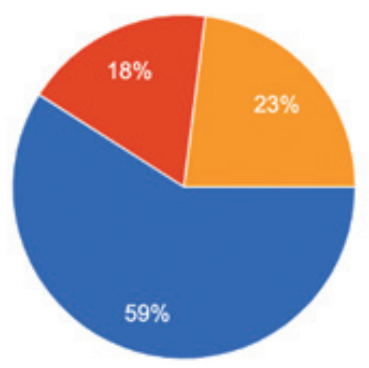

$1-10 \%$

$10-30 \%$

Más del $30 \%$

En cuanto a la indicación del procedimiento, surgieron tres datos de interés. El 68\% de los encuestados, de tener una hernia, se operaría por laparoscopia. Al mismo tiempo, el 40,4\% de los encuestados lo consideran el abordaje de elección. Por último, el 83,2\% selecciona el paciente por tipo de hernia para el abordaje laparoscópico.

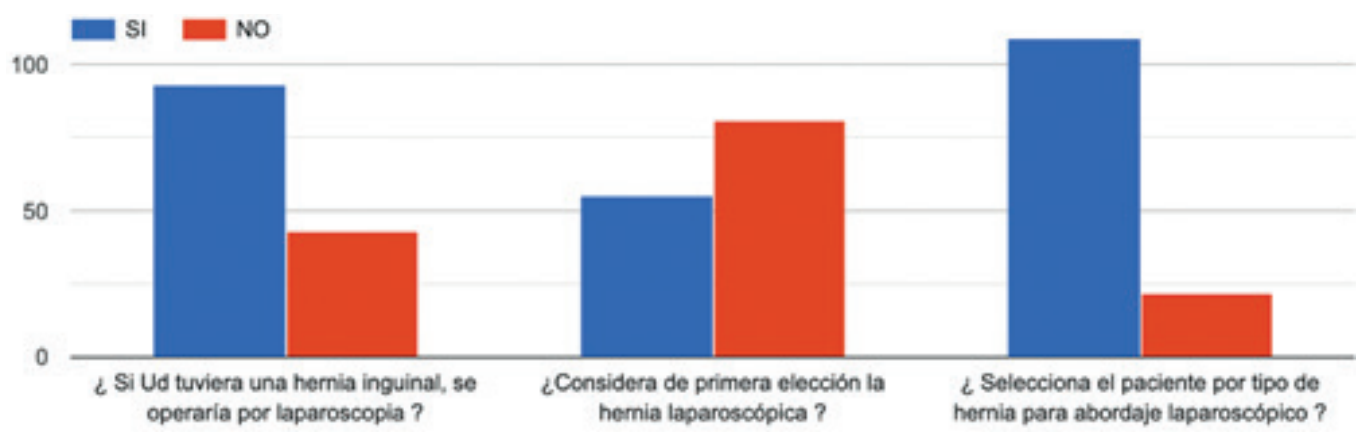

Solo 14 encuestados refirieron manejar con seguridad la técnica TEP solamente o TEP y TAPP, dentro de los cuales solo 4 son Cirujanos Nacionales.

\section{Maneja con seguridad técnicas}

87 respuestas
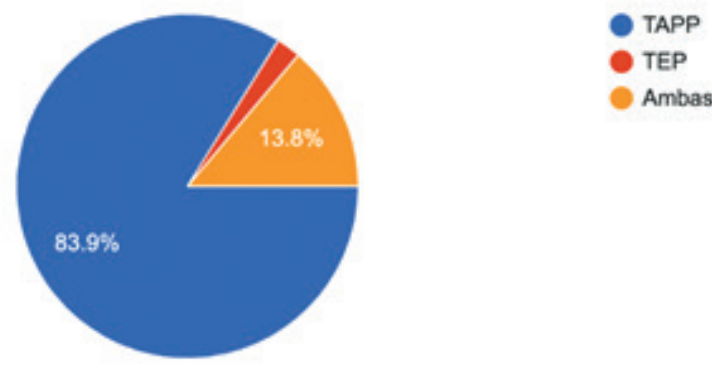

La gran mayoría de los cirujanos (90,7\%), que refirieron realizar hernias inguinales primarias por laparoscopia, utilizan preferentemente TAPP.

\section{Realiza preferentemente}

86 respuestas

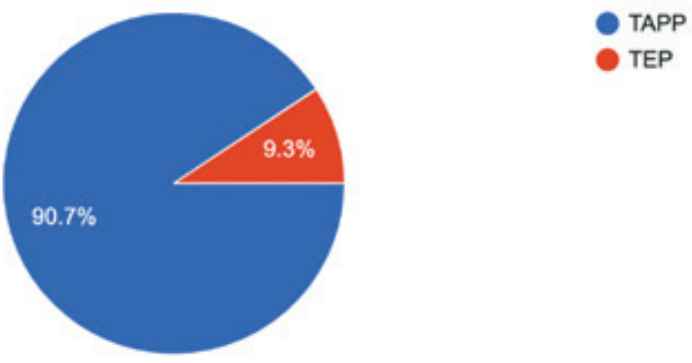


En cuanto a la especificaciones técnicas del TAPP, un 72\% refirió fijar la malla en todos los casos, los restantes lo realizan de forma selectiva. E1 83,2\% de los casos fijan la malla de forma invasiva. E1 84,9\% de los casos cierra el peritoneo con sutura. Solo el 3,2\% tuvo complicaciones mayores (3 casos). Si analizamos el perfil de estos entrevistados, los 3 se trataban de Cirujanos con más de 10 años en laparoscopia avanzada y realizaban más de 10 procedimientos parietales laparoscópicos mensuales.

\section{¿Fija la malla?}

95 respuestas

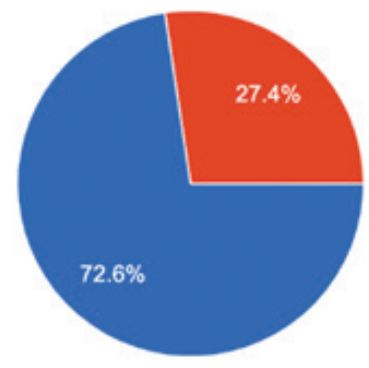

Siempre

Selectivo

\section{Técnica de fijación que usa}

95 respuestas

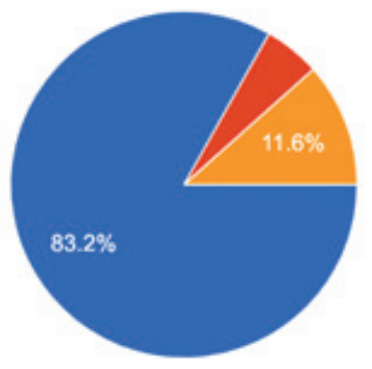

- Invasivo

- Pegamento

Ambos

\section{¿Tuvo complicaciones mayores?}

95 respuestas

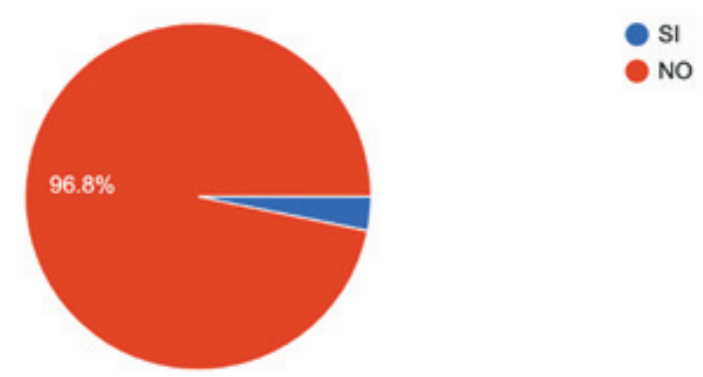

En referencia a la certificación médica, el 62,5\% realiza certificación médica menos de 15 días.

\section{En cuanto a la licencia médica}

96 respuestas

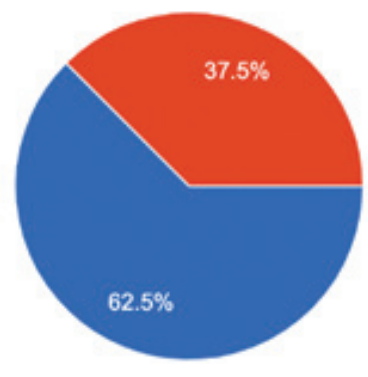


E1 40,2\% declaró reparar una eventual hernia contralateral incidental, solamente si figura en el consentimiento informado. Solo un $25,8 \%$ de los casos declaró repararlas, frente a dicha eventualidad.

\section{¿ Repara las hernias contralaterales incidentales? \\ 97 respuestas}

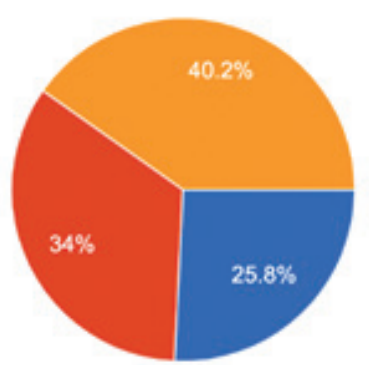

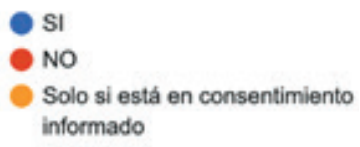

informado

En referencia a la comparación del TAPP vs Lichtenstein, el dato más sobresaliente es la relación costo beneficio. Aproximadamente la mitad de los encuestados declaró que no considera que tenga una mejor relación costo - beneficio en comparación al Lichtenstein.

\section{En su experiencia, la hernia laparoscópica en comparación con Litchenstein}

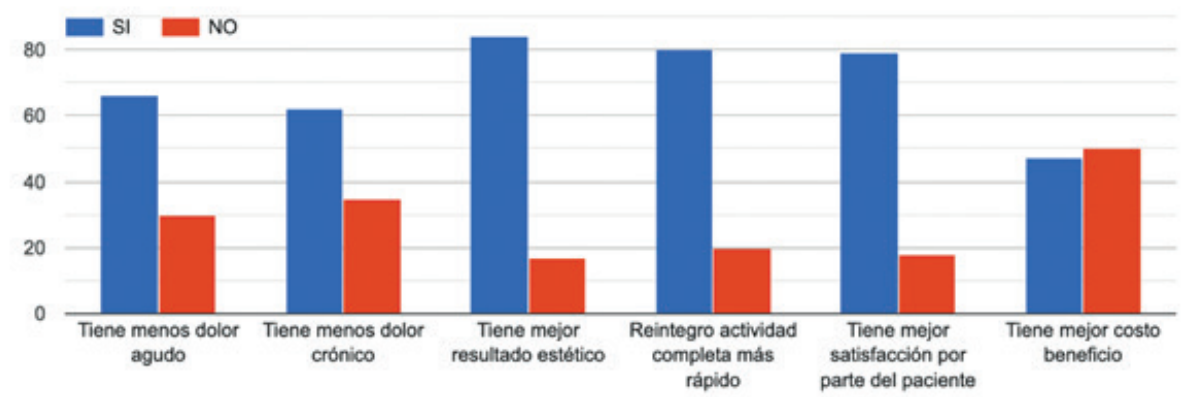

En cuanto a la preferencia de abordaje en determinadas situaciones especiales.

Existió una marcada preferencia del TAPP en hernias dudosas, hernias en deportistas, recidiva de Lichtenstein, hernias bilaterales no gigantes, y pacientes obesos. Por otro lado, hubo una fuerte tendencia al abordaje abierto en hernias estranguladas, con cirugía previa subumbilical o recidiva de TAPP.

\section{PREFERENCIA DE ABORDAJE EN SITUACIONES ESPECIALES}

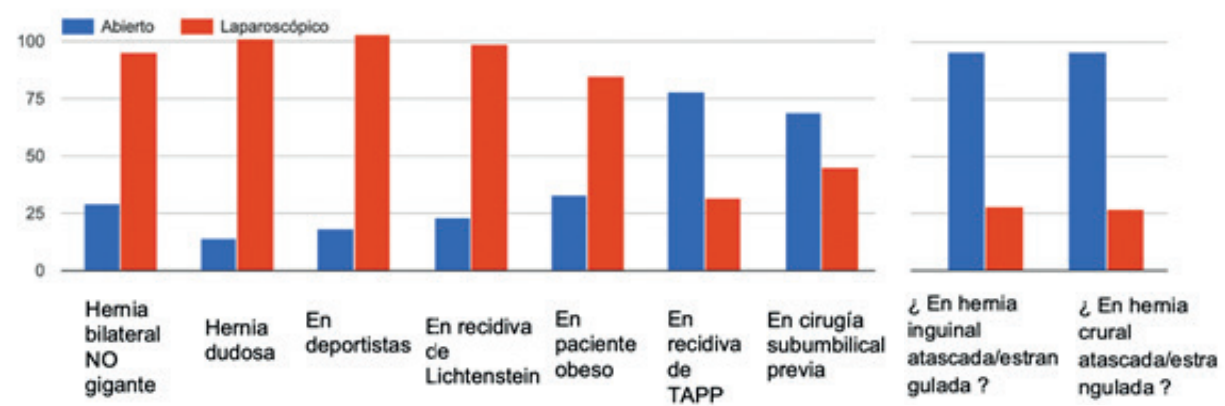

En cuanto a la reparación de las hernias de línea media y diástasis de los rectos, el 78\% cree que la cirugía mini invasiva tiene un lugar en esta patología. Sin embargo, el 34\% de los encuestados cree que es la técnica de elección. Muy similar es el sentir con referencia a las eventraciones laparoscópicas, donde la mayoría cree que la Cirugía mini invasiva tiene un lugar, pero no la considera el abordaje de elección. 


\section{REPA/SCOLA PARA HERNIAS DE LINEA MEDIA Y DIASTASIS DE LOS RECTOS}

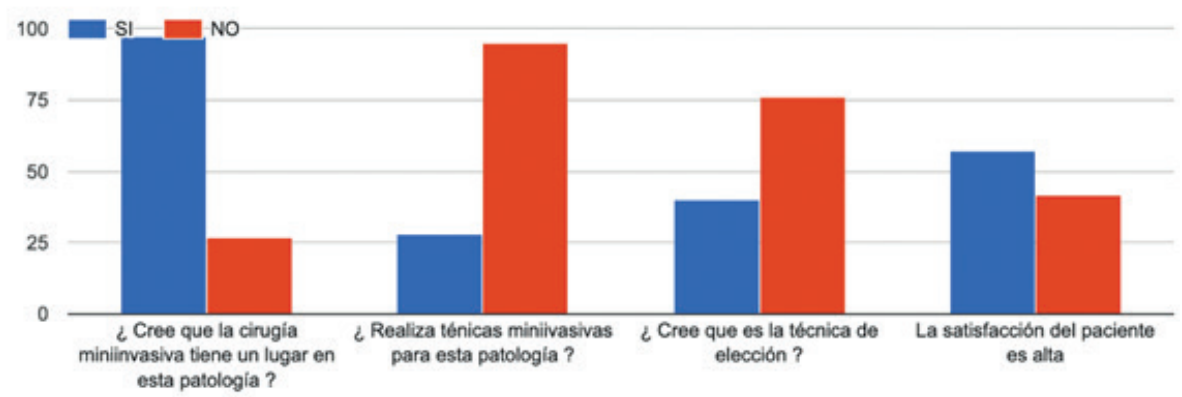

Eventraciones mediales, eventroplastia laparoscópicas (EL)

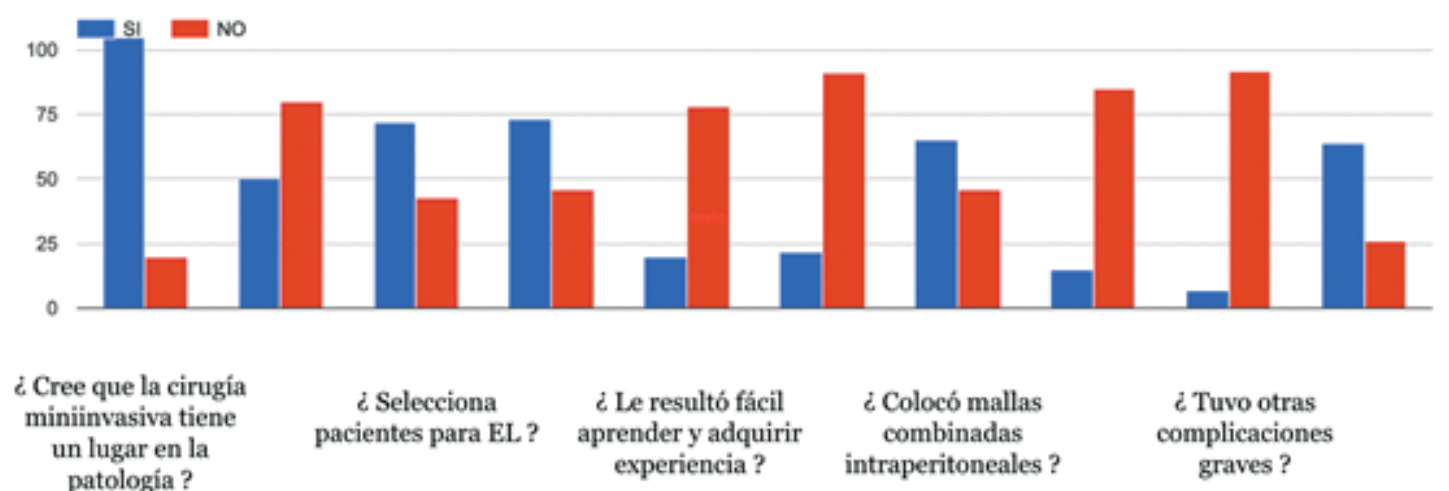

¿ Realizó eventroplastias laparoscópicas?

\author{
¿Solicita una TC de rutina ¿ Cree es la técnica \\ en preopoperatorio? \\ de elección?
}

¿Tuvo enterotomias en abordaje MI ?

\section{COMENTARIOS SOBRE LA ENCUESTA}

\section{Dr. Gonzalo Estapé}

Como datos de importancia, que definen las características de los encuestados, tenemos que el $83 \%$ selecciona los pacientes para la vía de abordaje; el 40\% considera que la laparoscopía es la via de elección; y el 68\% se operaría por laparoscopía si tuviera una hernia inguinal.

\section{Sobre la Formación durante la Residencia}

Formación en laparoscopía durante la residencia: 46\% escasa.

Formación hernias laparoscópicas: $81 \%$ escasa.

Participó en hernias laparoscópicas durante la Residencia: 54\%

Operó más de 10 hernias laparoscópicas: 19\%.

Participó en rotaciones por unidades especializadas pared abdominal: $18 \%$.

Tiene interés especial en la cirugía de la pared abdominal: $60 \%$.

Estos datos revelan la escasa formación durante la Residencia en cirugía laparoscópica parietal, tanto por la cantidad de procedimientos como en las sensación de una formación adecuada. A pesar de estos números y las escasas rotaciones por unidades especializadas, el 60\% tiene interés especial por la temática, lo que estimula a jerarquizar la formación en esta etapa, como semilla para el desarrollo de la especialidad. 


\section{Sobre la Formación luego de la Residencia}

Solo el 14\% se especializaron en cirugía parietal laparoscópica.

Menos del 30\% de los encuestados realizó cursos específicos sobre el tema, integra grupos especializados, tiene tutores o realizó simulación para técnicas laparoscópicas parietales.

La escasa formación en la Residencia, tampoco se compensa luego de recibidos, con actividades teóricas, prácticas o de intercambio grupal, para lograr la experiencia personal ni un desarrollo adecuado de estas técnicas.

\section{Sobre la Actividad Actual de los encuestados}

Si bien es aceptable la cantidad de cirujanos que realizan cirugía de avanzada, solo el 50\% operan más de 15 cirugías laparoscópicas mensuales. Es evidente que la baja escala de procedimientos en nuestro medio, hace dificultosa la curva de aprendizaje de técnicas complejas como la cirugía endoscópica parietal.

Lo mismo ocurre si vemos específicamente la frecuencia de cirugías parietales mensuales, considerando hernias y eventraciones; abiertas o endoscópicas, solo el 50\% opera más de 10 casos mensuales.

Sólo el 11\% ( 5 de estos 17 cirujanos, son Uruguayos) operan más de 10 cirugías mensuales de pared abdominal por laparoscopía.

Considerando situaciones ideales, el 59\% de los encuestados, estima que opera menos del 10\% de las hernias iguinales por laparoscopía.

Si bien es mayoritario el número de cirujanos que ofrecen la cirugía laparoscópica parietal, y de pacientes que preguntan por este abordaje, el cobro del prepago, aún frecuente en Uruguay, influye negativamente en el número de pacientes que finalmente se operan por laparoscopía.

\section{Sobre aspectos técnicos}

E1 90,7\% de los cirujanos que realizan hernias inguinales por laparoscopia, utilizan preferentemente TAPP, el 14\% maneja también la técnica TEP.

E1 72\% refirió fijar la malla en todos los casos, los restantes lo realizan de forma selectiva. E1 83,2\% de los casos fijan la malla de forma invasiva. Esta práctica de fijación es la recomendada durante la curva de aprendizaje, donde nos encontramos seguramente la mayoría de los encuestados de nuestro medio.

\section{Sobre la comparación de abordaje laparoscópico vs Lichtenstein}

Existió una marcada preferencia del TAPP en hernias dudosas, hernias en deportistas, recidiva de Lichtenstein, hernias bilaterales no gigantes, y pacientes obesos. Por otro lado, hubo una fuerte tendencia al abordaje abierto en hernias estranguladas, con cirugía previa subumbilical o recidiva de TAPP. Este patrón de preferencias, sigue las recomendaciones de las guías internacionales, y con selección de los casos, sugeridos para centros sin alta especialización

Fue francamente mayoritaria la impresión de los encuestados que la técnica laparoscópica tiene beneficios sobre la técnica de Lichtenstein en cuanto a: dolor agudo y crónico, reintegro completo, resultado estétio y satisfacción del paciente. No hubo, sin embargo, diferencias sobre la impresión de mejor costo beneficio entre ambas técnicas. Si bien estas consideraciones deben ser sustentadas por datos estadísticos, refleja globalmente buenos resultados del abordaje laparoscópico, estímulo principal para su mayor desarrollo. 


\section{Sobre las técnias REPA y Eventroplastia Laparoscópica}

Los encuestados coinciden en que tienen lugar en el tratamiento de diastasis de rectos y eventraciones abdominales en casos seleccionados, pero pocos las realizan y no las consideran el abordaje de elección, a pesar de lograr una satisfacción del paciente alta.

Seguramente la difícil curva de aprendizaje, la ausencia de tutores y los altos costos de mallas bilaminares y tackers, influyen en el bajo desarrollo de estas técnicas en nuestro medio. 


\section{EL FUTURO EN LA CIRUGÍA ENDOSCÓPICA DE LA PARED ABDOMINAL}

\section{Dr. Gonzalo Estapé}

El progreso de las técnicas endoscópicas de la pared abdominal fue amplio y vertiginoso en los últimos 10 años, por lo que esperamos nuevos avances en el corto plazo. Estos son notorios en los procesos preoperatorios (estudio, clasificaciones y optimización del paciente), biomateriales para cirugía parietal y nuevas técnicas quirúrgicas o modificaciones de las ya utilizadas. Dada la gran diferencia en el desarrollo de estas técnicas a nivel mundial, regional y local, nos es difícil analizar los futuros avances en forma global.

Analizaremos y daremos nuestra vision, sobre el futuro de la cirugía endoscópica parietal en :

1) Nuestro Hospital

2) Uruguay

3) El mundo

\section{1) Cirugía endoscópica parietal en el Hospital Pasteur de Montevideo}

A pesar del escaso desarrollo de estas técnicas en Uruguay, reconocemos nuestra situación de atraso con respecto a varios centros públicos y privados Nacionales. Iniciamos hace menos de 2 años uno proceso ambicioso, retrasado por la pandemia COVID 19, que estamos retomando progresivamente. Nos centramos inicialmente en la formación de cirujanos jóvenes y Residentes y en el desarrollo seguro de la hernioplastia inguinal TAPP.

Objetivos a corto plazo (2 años):

- Completar la formación de los cirujanos tutores en hernioplastia inguinal TAPP

- Asegurar a cada Residente, un número mínimo de 15 hernioplastias inguinales TAPP de coordinación, actuando como cirujano y tutorizado

- Familiarizar a los Residentes de inicio (R1-2) con las técnicas endoscópicas

- Iniciar la experiencia con hernioplastia inguinal TEP

- Iniciar la experiencia en tratamiento endoscópico de hernias ventrales y diastasis de los rectos (REPA)

- Avanzar en las indicaciones de eventroplastias laparoscópicas: TAPP, IPOM Plus

- Presentar nuestros resultados con seguimiento mínimo de 2 años.

Requerimientos:

- Mantener estabilidad del equipo quirúrgico, que funciona dentro de la Unidad de Cirugía Parietal y Endócrina del H. Pasteur

- Estimular la formación de los cirujanos de este equipo mediante cursos específicos, pasantías a centros especializados y cursos hands on.

- Estímulo al desarrollo de estas técnicas por parte de las autoridades académicas y gerenciales Hospitalarias

- Aumentar cupos horarios de block quirúrgico

- Asegurar el correcto flujo y actualización de biomateriales para cirugía parietal endoscópica y equipamiento necesario de videocirugía

Objetivos a mediano plazo (5 años):

- Asegurar a cada Residente, un número mínimo de 30 hernioplastias inguinales TAPP de coordinación, actuando como cirujano y tutorizado, acercándonos al ideal planteado de la curva de aprendizaje de 50 procedimientos.

- Formación de cirujanos en el exterior en técnicas endoscópicas: eTep, eTEP Rives Stoppa, separación endoscópica de componentes y eTAR

- Iniciar experiencia en estas técnicas endoscópicas

- Extender indicaciones de eventroplastia laparoscópica y hernias ventrales

- Formación de cirujanos en el exterior en técnicas robóticas para hernias y eventraciones

- Presentar nuestros resultados con seguimiento mínimo de 3 años.

\section{2) Cirugía endoscópica parietal en Uruguay}

La incidencia mundial global de las técnicas endoscópicas en cirugía parietal son bajas: menos del 30\% en hernias inguinales y menos de $15 \%$ en eventraciones, por lo que reconocemos la difícil tarea de extenderlas tambíen en nuestro medio. 
Para lograr la extensión de estas técnicas en Uruguay, debemos plantearnos como objetivos iniciales: evolucionar en la especialización de la cirugía parietal y lograr la misma accesibilidad a dichas técnicas en todo el País (y a nivel público y privado).

Para lograr estos objetivos, planteamos:

- Formación de Unidades de Cirugía Parietal en todos los servicios de cirugía públicos y privados, o al menos que las cirugías parietales estén realizadas por un grupo de cirujanos dedicados y especializados en el tema. Será la forma de: mejorar los resultados, lograr estandarización de las técnicas con la posiblidad de comparar estudios y avanzar en las técnicas endoscópicas más complejas.

- Incluir en el Programa de Residencia en Cirugía, los procesos formativos y número de procedimientos endoscópicos en cirugía parietal, recomendados para obtener el Título de Cirujano.

- Estimular la formación de cirujanos generales en técnicas endoscópicas parietales, a través de becas y pasantías en centros especializados internacionales. Estas pueden gestionarse desde de los centros asistenciales, Clínicas de la Facultad de Medicina, Sociedad de Cirugía del Uruguay y su Capítulo de Cirugía Mini-invasiva.

- Demostrar a los Gestores de Salud y Jefaturas Quirúrgicas de los centros públicos y privados de todo el País y con cifras locales, la eficiencia, seguridad para el paciente y buena relación costo-beneficio de las técnicas endoscópicas. Esta evidencia debe sustentarse en trabajos bien conducidos, con número de casos y seguimiento adecuados, que avalen esta recomendación técnica.

- Eliminar el ticket regulador prepago que cobran algunas instituciones privadas (30-40\% de la población) para acceder a la cirugía endoscópica parietal, al menos en la hernia inguinal. En el medio público (con dificultades de insumos), las instituciones de FEMI (interior del país) y algunas de Montevideo, ya no se cobra este prepago. Este hecho, como ya sucedió con otras técnicas como la colecistectomía y la apendicectomía laparoscópicas, permitirá habituar a todo el equipo de block quirúrgico a estos procedimientos y a los pacientes: conocerlos y pedirlos/aceptarlos con naturalidad. Para la eventroplastia laparoscópica, con tiempos quirúrgicos más prolongados y eventual alto costo de malla bilaminar y de al menos una máquina de tackers (no incluídos en las prestaciones básicas que deben brindar los centros de salud), debe individualizarse que caso debería tener un copago por el paciente.

- Colaborar con los Gestores en Salud, en lograr convenios con los provedores de biomateriales, intentando mejorar la accesibilidad y los costos de los mismos.

\section{3) Cirugía endoscópica parietal en el Mundo}

- El manejo de estas técnicas por Unidades Especializadas en Cirugía Parietal ya no se discute a nivel mundial.E1 concepto de restaurar el complejo anatomo-funcional parietal, con el procedimeinto más adecuado a cada caso, da la jerarquía requerida por los defectos parietales.

- Biomateriales. Avance en la biocompatibiliad de las mallas. Lograr barreras anti adherenciales más efectivas y reabsorbibles. Mayor elasticidad de las mallas reticulares, adaptadas a la fisiología parietal abdominal. Mejorar la resistencia a la infección de las mallas irreabsorbibles. Accesibilidad y menores costos de las mallas biológicas. Seguridad y mayor resistencia de las adhesivos tisulares para fijación no invasiva de mallas.

- Estandarización de las técnicas quirúrgicas. Difícil en este momento dada la constante aparición de nuevos procedimientos, insumos y tecnología, no permitiendo su evaluación adecuada, ni la comparación de resultados.

- Tácnicas endoscópicas extraperitoneales. Extender el desarrollo y enseñanza de estas técnias sobre las laparoscópicas, cuando estén indicadas, disminiyendo las complicaciones viscerales intraabdominales y las vinculadas a la malla intraperitoneal.

- Técnicas Robóticas. Como en otras patologías, lograr la mayor accesibilidad y menores costos de la cirugía robótica, puede permitir un notorio avance técnico en la cirugía miniinvasiva parietal. Dadas sus ventajas en visualización, articulación, precisión y ergonomía, con respercto a las técnicas laparoscópicas, presenta claros beneficios en procedimientos difíciles: rIPOM Plus, rTAPP, rTAR y r-eTEP. Aún está limitado a contados centros a nivel mundial.

- Confección de trabajos científicos prospectivos y a largo plazo, con situaciones clínicas y técnicas comparables. Darán la evidencia requerida en todos los metaanálisis para recomendar cada procedimiento según su efectividad, seguridad y relación costo-beneficio. La documentación de la experiencia, la evaluación de los procesos y la mejoría clínica continua, son las variables que tienen mayor influencia para cumplir este objetivo.

- La insistencia en la formación de cirujanos jóvenes y residentes, el entrenamiento, la simulación y la presencia de mentores (in situ o en forma remota), parecen ser los caminos a seguir para extender estas técnicas, aún limitadas en número, tipo de patologías y centros especializados. 


\section{AGRADECIMIENTOS}

\section{Dr. Gonzalo Estapé Viana}

Durante el desarrollo de este Relato, pasaron por mi mente, todos aquellos que influyeron en mi formación personal y médica. A ellos, el eterno agradecimiento y la dedicación de este trabajo.

- A mis padres, María Clara y Gonzalo Estapé Carriquiry. Faro en mi vida por su calidad humana y dedicación a los pacientes y a la formación médica hasta sus últimos días. Apasionado por la patología herniaria, seguramente hubiera disfrutado este Relato.

- A Daniel Montano, mi profesor y referente, por el ofrecimiento del Relato.

- A mis maestros en la cirugía de urgencia: Pepe Maggiolo, cirujano de guardia durante toda mi Residencia con su calidez y paciencia digna de los grandes, y Carlitos Ferreira, amigo y referente hasta el día de hoy.

- A Vartan Tchekmedyian, cuyos consejos y enseñanzas aplico día a día. El más grande cirujano que conocí, ejemplo de aplomo, tranquilidad y excelencia técnica en todas las ramas de la cirugía.

- A mis profesores y amigos de la Clínica Quirúrgica 1 del Hospital Pasteur, donde transcurrió toda mi vida académica. Mi segunda casa durante 20 años.

- A Claudia y Gabriela, con quienes comparto y disfruto la cirugía parietal y endócrina desde hace 4 años, el agradecimiento por su invalorable participación el este relato.

- Finalmente, a Beatriz, Santiago y Matías, verdaderos motivos y motores der mi vida, testigos del esfuerzo y estrés que genera un emprendimiento como este y víctimas de mis ausencias y desatenciones. Espero poder compensarlos algún día.

\section{Dr. Nicolás Ramos Serena}

En cirugía, muchas veces puede resultar difícil el intentar cambiar algo que esta bien y que tiene excelentes resultados por algo que puede resultar desconocido para muchos o que implique un cambio de paradigma.

La idea de lo expuesto en los capítulos que me fueron asignados, es dar las herramientas básicas y actualizadas para tratar de motivar a realizar una la lectura crítica, mantener al lector interesado y motivado a seguir investigando para poder aplicar estas técnicas quirúrgicas que sabemos son el presente y futuro de la patología parietal.

Quiero agradecer en primer lugar al Dr. Gonzalo Estapé por la invitación a participar en este trabajo, lo considero un reconocimiento y una gran oportunidad para realizar un trabajo responsable de investigación, lectura y desarrollo.

Quiero agradecer a quienes han participado activamente en mi formación como cirujano, a los doctores José Campos, Aníbal Vázquez, Jorge Curi y Justino Zeballos.

A los doctores Enrique Folle y Rubens Neirotti por su apoyo y motivación permanente.

A los doctores Guillermo Laviña y Eduardo Voliovici, colegas y hermanos, con quienes tengo el enorme placer de trabajar y de seguir aprendiendo día a día.

Al profesor Dr. Fernando González por sus enseñanzas y a todos y cada uno de los integrantes de la Clínica Quirúrgica 1 del Hospital Pasteur por su apoyo y colaboración. A mis compañeros de guardia por tantas horas robadas en la elaboración de este relato.

A Virginia, Renata y Delfina, mi hermosa familia, por su amor y apoyo incondicional, pilares fundamentales en mi vida y mi razón principal de ser. 
